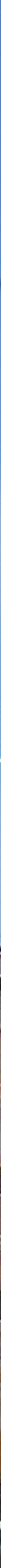


Band 119

Kommission für Neuere Geschichte Österreichs

Vorsitzende: Brigitte Mazohl

Stellvertretende Vorsitzende: Reinhard Stauber, Kurt Scharr

Mitglieder:

Franz Adlgasser

Gunda Barth-Scalmani

Peter Becker

Ernst Bruckmüller

Laurence Cole

Werner Drobesch

Margret Friedrich

Elisabeth Garms-Cornides

Michael Gehler

Andreas Gottsmann

Margarete Grandner

Hanns Haas

Wolfgang Häusler

Ernst Hanisch

Gabriele Haug-Moritz

Lothar Höbelt

Thomas Just

Katrin Keller
Grete Klingenstein

Alfred Kohler

Christopher Laferl

Wolfgang Maderthaner

Stefan Malfèr

Lorenz Mikoletzky

Gernot Obersteiner

Hans Petschar

Helmut Rumpler $\dagger$

Martin Scheutz

Arno Strohmeyer

Arnold Suppan

Werner Telesko

Thomas Winkelbauer

Sekretär:

Christof Aichner 
KURT SCHARR

\section{Der griechisch-orientalische Religionsfonds der Bukowina 1783-1949}

Kontinuitäten und Brüche einer prägenden Institution des Josephinismus 


\section{口 universität innsbruck}

Die in den Veröffentlichungen der Kommission für Neuere Geschichte Österreichs gemachten Aussagen sind die der jeweiligen Verfasser, nicht die der Kommission.

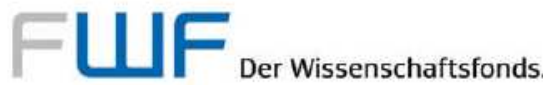

\section{Veröffentlicht mit der Unterstützung des Austrian Science Fund (FWF): PUB 622-G28}

Open Access: Wo nicht anders festgehalten, ist diese Publikation lizenziert unter der Creative-CommonsLizenz Namensnennung 4.0; siehe http://creativecommons.org/licenses/by/4.0/

Die Publikation wurde einem anonymen, internationalen Peer-Review-Verfahren unterzogen

Bibliografische Information der Deutschen Nationalbibliothek:

Die Deutsche Nationalbibliothek verzeichnet diese Publikation in der

Deutschen Nationalbibliografie; detaillierte bibliografische Daten sind im Internet über http://dnb.d-nb.de abrufbar.

(C) 2020 by Böhlau Verlag Ges.m.b.H \& Co. KG, Wien, Kölblgasse 8-10, A-1030 Wien

Umschlagabbildung: Ursprüngliche Hauptverwaltung des gr--orient. Religionsfonds in Czernowitz, heute landeskundliches Museum, Aufnahme K. Scharr 2009.

Korrektorat: Markus Winkler

Einbandgestaltung: Michael Haderer, Wien

Satz: Michael Rauscher, Wien

Druck und Bindung: Hubert \& Co., Göttingen

Gedruckt auf chlor- und säurefrei gebleichtem Papier

Printed in the EU

Vandenhoeck \& Ruprecht Verlage | www.vandenhoeck-ruprecht-verlage.com

ISBN 978-3-205-20927-0 
Allen meinen über die Jahre hin gewonnenen

Bukowiner Kollegen und Freunden! 


\section{Inhaltsverzeichnis}

Zum Geleit! . . . . . . . . . . . . . . . . . . . . . . . . . 11

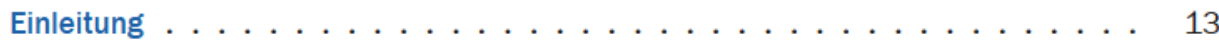

1. Vorwort . . . . . . . . . . . . . . . 13

2. Institutionen als Forschungsgegenstand: Analyse \& Methodik . . . . . . . . . 18

Soziologische Institutionenforschung . . . . . . . . . . . . . . . . 18

Institutionen in den Geschichtswissenschaften . . . . . . . . . . . . . . . . 22

Institution Religionsfonds . . . . . . . . . . . . . . . . . . . . . . . . . . . . . . . . . . . . .

Analyseeinheiten und Thesen . . . . . . . . . . . . . 28

Die Organisation: Von der Gründung zur Konsolidierung . . . . . . . . . . . . . 33

3. Aspekte des Josephinismus. Der katholische Religionsfonds . . . . . . . . . . 34

4. Gründung des griechisch-orientalischen Religionsfonds . . . . . . . . . . . . 43

Kirchliche Ausgangssituation . . . . . . . . . . . . . . . . . . 43

Diözesanregulierung \& Einrichtung des Fonds . . . . . . . . . . . . . . 46

Exkurs: Die Klostergüter um 1785 . . . . . . . . . . . . . . . . 60

Verpachtung oder Verkauf? . . . . . . . . . . . . . . . . . . . 71

Zusammenfassung . . . . . . . . . . . . . 86

5. Die wirtschaftliche Situation des Religionsfonds Mitte des 19. Jahrhunderts . . 89

Wirtschaftsreformen \& Religionsfonds . . . . . . . . . . . . . . . . 93

Das Religionsfondsvermögen . . . . . . . . . . . . . . . . . 100

Zusammenfassung . . . . . . . . . . . . . 112

Die Institution: Struktur \& Werte . . . . . . . . . . . . . . . . . . . . . . . . . . . 114

6. Nationsidee, Kirche \& Religionsfonds . . . . . . . . . . . . . . . . . . 116

Die Ära Eugen Hackmann $(1835-1873) \quad \ldots . . . . . . .116$

Im Sog nationaler Politik: Silvester Morariu-Andriewicz (1880-1895) . . . . . 151

Zusammenfassung . . . . . . . . . . . . . . . . . . 171

Ausgleichsversuche - Arkadius Czuperkowicz \& Wladimir v. Repta

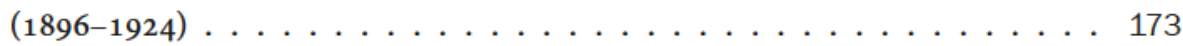

Zusammenfassung . . . . . . . . . . . . . . . 211

7. Die wirtschaftliche Situation des Religionsfonds bis 1914 . . . . . . . . . 215

Die Institution in Bilanzdaten: die Jahre 1864 bis 1913 . . . . . . . . . . . . 217

... als Quelle von Förderungen . . . . . . . . . . . . . . . . . . . 222 
... als Unternehmer: die Forstwirtschaft . . . . . . . . . . . . . . . . . . 227

... als Kriegsverlierer nach 1918 ? . . . . . . . . . . . . . . . . . . . . . 240

Zusammenfassung . . . . . . . . . . . . . . . . 242

8. Fondul Bisericesc Ortodox Român 1918-1948 . . . . . . . . . . . . . . . . 246

Zwischen Autonomie und Zentralregierung . . . . . . . . . . . . . . . . 249

Rumänische Kirche - Rumänischer Fonds? . . . . . . . . . . . . . . . . 256

,În biserică nu e politicăı. Konsolidierungsversuche versus Dauerkrise . . . . 267

Î̂n caz de evacuare`. Der Krieg und seine Folgen . . . . . . . . . . . . . . . 282

Zusammenfassung . . . . . . . . . . . . . . 286

9. Die wirtschaftliche Situation um $1938 \ldots \ldots$. . . . . . . . . . . . . . 289

Agrarreform und Religionsfonds . . . . . . . . . . . . . . . . . . 289

Kulturpalast Czernowitz . . . . . . . . . . . . . . . . . . . . . 294

Kriegswirtschaft und Religionsfonds . . . . . . . . . . . . . . . . . . . . 297

Zusammenfassung . . . . . . . . . . . . . . . . . . . . . 304

10. Hebel strukturellen Wandels: Jakobeny - Dornawatra (1784-1949) . . . . . 306

Jakobeny und seine Bodenschätze . . . . . . . . . . . . . . . . . . 307

Die Manzschen Werke . . . . . . . . . . . . . . . . . . . . . . . . . . . 310

Übernahme durch den Religionsfonds . . . . . . . . . . . . . . . . . . . 314

Von Heilquellen zum Kurort: Dornawatra . . . . . . . . . . . . . . . . . . . 328

Umbruchszeiten: 1918 bis $1948 \ldots \ldots 333$

Zusammenfassung . . . . . . . . . . . . . 338

11. Zusammenfassungen . . . . . . . . . . . . . . . . . 340

Der Bukowiner Religionsfonds: Kontinuität einer Institution? . . . . . . . . 340

The Bukovina Religious Fund: continuity of an institution? . . . . . . . . . 348

Fondul religionar bucovinean: continuitatea unei instituții ? . . . . . . . . . 355

Буковинський Релігійний фонд: безперервна діяльність інституції? .. 363

I. Verzeichnis ungedruckter Quellen . . . . . . . . . . . . . . . . . . . . 371

II. Abbildungsverzeichnis . . . . . . . . . . . . . . . . . . . . . . . . . 377

III. Abkürzungsverzeichnis . . . . . . . . . . . . . . . . . . . . . . 380

IV. Literaturverzeichnis . . . . . . . . . . . . . . . . . . . . . . . 381

V. Personenregister . . . . . . . . . . . . . . . . . . . . 433

VI. Synoptische Ortsnamenkonkordanz _ . . . . . . . . . . . . . . . . . . 439 
O Mutter unser, Bukowina, preisen

Darf Kindeslieb, denn ihre Weisen

Vom Herzen sind

Moses Rosenkranz ${ }^{1}$

( ${ }^{*} 1904$ Berhomet a. P., $\dagger 2003$ Lenzkirch-Kappel, Schwarzwald)

1 Aus dem Gedicht `Preis der Heimat‘, abgedruckt in RYchlo \& Liub 150. 


\section{Zum Geleit!}

Aus einer langen Beschäftigung mit Geschichte und Geographie der östlichsten Region der Habsburgermonarchie - der Bukowina - erschloss sich die Einsicht, dass dem Religionsfonds dieser Provinz wesentlich mehr Bedeutung zukam, als man gemeinhin von Einrichtungen dieser Art erwartet hätte. Hinter der Fassade einer zunächst vordergründig nur als unscheinbare Struktur zur Verwaltung der Kirchengüter wahrgenommenen Organisation eröffnete sich alsbald das komplexe Geflecht einer Institution und ihrer Akteure, das über Jahrzehnte hin weit über die Ränder seines engeren Aufgabenbereiches Einfluss auf die Gestaltung und das gesellschaftspolitische Feld des Kronlandes ausübte. Zudem bestand der griechisch-orientalische Religionsfonds als Institution über einen Zeitraum von mehr als 150 Jahren, und das systemübergreifend von der Habsburgermonarchie (1783-) über das Königreich (1918-) bis zur Volksrepublik Rumänien $(-1949)$.

Der Wissenschaftsfonds der Republik Österreich (FWF) ermöglichte schließlich durch eine großzügige Projektförderung ${ }^{1}$ die vertiefende Auseinandersetzung mit diesem Thema. Die Ergebnisse des Projektes können hiermit der Öffentlichkeit vorgelegt werden.

Für das Zustandekommen dieser Studie gilt mein erster Dank zunächst jenen fleißigen professionellen Archivmitarbeitern - allen voran in Czernowitz/Чернівці und Suceava aber auch in Lemberg/Львів, Bukarest und Wien - die mir stets hilfsbereit neue Wege im Dickicht der Überlieferung erschlossen und zugänglich gemacht haben. Ein gleichermaßen nicht unwesentlicher Anteil gebührt den Bibliotheken, die mir freundlicherweise ihre Sammlungen zur Lektüre und fallweise als Illustrationen zur Verfügung gestellt haben. Verpflichtet fühle ich mich auch meinen Kolleginnen und Kollegen, die mich in diesem Vorhaben in der Diskussion immer wieder mit Hinweisen unterstützten, hier für alle stellvertretend und namentlich den Teilnehmern des Workshops (Herrn Ao. Univ.-Prof. i. R. Dr. Harald Heppner, Graz; Priv.-Doz. DDr. Thomas M. Németh, Würzburg; Dr. Niels Grüne, Innsbruck und Priv.-Doz. Dr. Norbert Spannenberger, Leipzig), der in Innsbruck vom 27. bis 28. November 2014 unter dem Thema "Imperium - Kirche(n) - Institution(en). Verflechtungen und Lange Dauer « stattfand und dabei viele wichtige Impulse für die Ausarbeitung beisteuerte. Schließlich möchte ich mich noch ganz herzlich bei Herrn Dr. Markus Winkler für die ebenso geduldig-umsichtige

1 Arbeitstitel: Der Bukowinaer griechisch-orientalische Religionsfonds 1783-1949, Projektnummer P 24661, Kuratoriumssitzung vom 7.V.2012. 
wie inhaltlich-kritische wissenschaftliche Lektorierung des Manuskripts, sowie bei der Kommission für Neuere Geschichte Österreichs für die ehrenvolle Aufnahme in ihre Reihe bedanken! 


\section{Einleitung}

\section{Vorwort}

[...] nehmt das Reich in Besitz, das seit der Erschaffung der Welt für euch bestimmt ist. Denn ich war hungrig und ihr habt mir zu essen gegeben; ich war durstig und ihr habt mir zu trinken gegeben; ich war fremd und obdachlos und ihr habt mich aufgenommen [...]

Mt 25, 34-46, hier 34-35

Warum in der Einleitung zur Geschichte einer Institution wie der des gr.-orient. Religionsfonds der Bukowina ein Bibelzitat? Oberflächlich gesehen mag das durchaus naheliegend sein, doch hier hat das im Wesentlichen zwei tiefer reichende Gründe, die - für sich genommen - wiederum im Fortwirken dieser Institution eine Verbindung zwischen der Gegenwart und der Vergangenheit der historischen Region herstellen. Etwas paraphrasiert stellt der amtierende Erzbischof von Suceava und Rădăuţi (Arhiepiscop Sucevei și Rădăuților) Pimen diese Verse aus dem Matthäusevangelium bewusst seinem Vorwort zu einer 2010 publizierten Broschüre über den Religionsfonds voran. ${ }^{1}$ Dieser wurde von Kaiser Joseph II. im Jahr 1783 gegründet, wenige Jahre nachdem sich das Habsburgerreich die Bukowina einverleibt hatte und nunmehr vor der Aufgabe stand, die Provinz auch entsprechend den Wiener Vorstellungen einzurichten. Seine Auflösung erfolgte 1949 durch die Organe der Volksrepublik Rumänien im Zuge der kommunistischen Machtübernahme und der Sequestrierung des Privateigentums. Etwas mehr als ein Jahrzehnt nach dem Ende des sozialistischen Staates kam es im Jahr 2001 auf Initiative der Erzdiözese der Bukowina zur Neugründung dieser Institution als Stiftung privaten Rechts, geleitet von Erzbischof Pimen² ; allerdings mit der leicht abgeänderten Bezeichnung Fondul Bisericesc Ortodox Român al Bucovinei. ${ }^{3}$ Mithin ein zentrales Ziel dieser Gründung bestand für die Kirche darin, >ihr` Eigentum, das 1949 der entschädigungslosen Zwangsenteignung durch den autoritären Staat zum Opfer fiel, jetzt vom

1 Arhiepiscopa (Hg.) 2010, Fondul, Cuvânt înainte (Vorwort).

2 Der neue Religionsfonds konstituierte sich am 15. März 2000 unter der Präsidentschaft des Erzbischofs sowie weiteren 27 Mitgliedern; Anonymus 2009, Justiția, În Loc de Prefaţă (Anstelle des Vorwortes), If.; ebenda findet sich auch eine detaillierte Aufzählung der z.T. strittigen Mitglieder sowie der beanspruchten Gebäude.

ARHiepiscopa (Hg.) 2008, Fondul, 5. 
demokratischen Rumänien (bzw. der zuständigen Forstbehörde, Romsilva) restituiert zu bekommen. ${ }^{4}$ Dabei handelt es sich im heute rumänischen Anteil der ehemals österreichischen Bukowina - und nur der ist davon betroffen, da der Norden zur Ukraine gehört - immerhin um etwa 166.00o Hektar Wald (also ein Fünftel der Gesamtfläche des Kreises Suceava), an die 150 Gebäude und mehr als 1000 Kilometer an Wegen. ${ }^{5} \mathrm{Im}$ Februar 2017 wurde dieser langwierige Prozess in letzter Instanz schließlich durch den Kassationsgerichtshof in Bukarest zugunsten von Romsilva entschieden. Die Kirche besitzt damit auf Restitution keinen weiteren rechtlichen Anspruch mehr. ${ }^{6}$ Das Pressebüro des Erzbischofs reagierte unmittelbar darauf mit einem Communiqué, indem erneut auf die Zwangsenteignung Bezug genommen und in einem umfassenden historischen Rückblick darlegt wird, dass der Religionsfonds zu keinem Zeitpunkt seit seiner Gründung bis zur Auflösung Eigentum des Staates gewesen sei. ${ }^{7}$ Die Regierung in Bukarest hatte bereits zuvor unter Victor Ponta (Premierminister Rumäniens von 2012 bis 2015) ebenfalls anlässlich eines Gerichtsurteils der vorangegangenen Instanz vorgeschlagen, dass die Erträge aus den Wäldern der Südbukowina doch für die Erhaltung der Kulturgüter in der Region eingesetzt werden sollten. ${ }^{8}$ Soweit die gegenwärtige Situation.

Die vorliegende Studie beschäftigt sich nicht oder nur ganz am Rande mit der aktuellen Situation der Rumänisch-Orthodoxen Kirche und ihrem Verhältnis zur Regierung in Bukarest, aber - wie eingangs angedeutet - lassen diese Ereignisse deutlich institutionelle Persistenzen des Religionsfonds erkennen: da ist zum einen die enge wechselseitige Beziehung zwischen Fonds und Staat sowie sein Gestaltungspotential für die Region seit seiner Gründung und zum anderen die - selbst während der österreichischen Zeit eigentlich ungeklärt gebliebene sehr konkrete Frage nach dem letztlichen Eigentum der betroffenen Güter. Den Hinweis auf diesen Aspekt bleibt das Erzbistum in seiner Argumentationslinie schuldig, obwohl gerade hier ein zentraler Punkt im Gesamtverständnis der Thematik ruht. Vielmehr leitet der Erzbischof, aus seinem Selbstverständnis heraus, den Eigentumsanspruch an diesen Gütern ganz klar aus der Bibel ab. Allerdings verhält sich die Sachlage wesentlich komplizierter. Die über den gr-orient. Religionsfonds verwalteten Güter stammten zwar aus klösterlichem bzw. kirchlichem Besitz, den die Klöster zuvor als religiöse Stiftungen zum Dank und für das Seelenheil wiederum von den moldauischen Landesfürsten überantwortet bekommen hatten. Allerdings waren

4 Zur Situation der Wälder im Județ Suceava zwischen 1945-2002, inklusive einer genaueren Aufgliederung der jeweiligen Besitzer nach Bezirken und ihrer Erträgnisse vgl. MARCEAN 2002, Pădurile.

5 Manolache 2014, Fondul.

6 Anonymus 2017, Romsilva.

7 Biroul (Hg.) 2017, Comunicat.

8 Anonymus 2014, Fondul. 
vor wie nach 1783 weder die Kirche noch ihre Gremien befugt, völlig frei darüber zu verfügen. Die Kirche musste alle Entscheidungen, die den Fonds betrafen, in steter Abstimmung mit dem Staat als vorgeordneter Kontrollinstanz sowie mit dem Landesfürsten als oberstem Organ akkordieren. Insofern ist die Argumentation des rumänischen Gerichtes korrekt, der neu gegründete Religionsfonds ist im Gegensatz zu seinem Vorgänger eine Stiftung nach privatem Recht. ${ }^{9}$ Zum anderen - und das deutet die seitens der Regierung formulierte Kompromissformel an - sollten die Erträgnisse des Fonds im Sinne seiner ursprünglichen Bestimmung vorwiegend der Region zukommen und nicht in ein Zentralbudget des Staates oder der Kirche einfließen.

Im »Denn ich war hungrig und ihr habt mir zu essen gegeben" werden für die Institution gr--orient. Religionsfonds charakteristische Facetten greifbar: als Hülle zur Organisation der Kirchengüter und deren effizienter Verwaltung; als Ort, wo Einzelpersonen als Akteure sichtbar werden; und schließlich insgesamt als Institution, die auf dem politischen Feld selbst den Charakter eines Akteurs annimmt, der dem Staat zwar nahe steht, in und mit ihm existiert, aber nicht unmittelbar Teil davon ist. Das Bibelzitat wirft abseits kirchlicher Legitimitätsbegründungen zudem die Frage auf, wer und auf welche Weise damit als Nutznießer gewissermaßen angesprochen wird. Stehen die betroffenen Güter sowie ihre Erträge nun dem Staat, der Kirche, der (Erz-)Diözese, der Region, der Nation oder vielleicht gar Einzelnen zu? Auf dem Weg zu einer Antwort entwickelte sich zwischen den Begünstigten ein kontinuierlicher und immer wieder neu zu verhandelnder Prozess. Er speist das eigentliche Substrat des Religionsfonds. In Wechselwirkung wiederum bietet der Fonds umgekehrt die nötige Plattform für die dabei ausgetragenen Diskurse. Kirche, Region und Staat sowie ihre jeweiligen Akteure treffen in der Institution Religionsfonds aufeinander und gehen gleichzeitig eine enge Beziehung ein. Eben diese Beziehung rückt die Studie für den Zeitraum von 1783 bis 1949 ins Zentrum. Die Habsburgermonarchie und das angestammte Herrscherhaus verstanden sich ohne Zweifel als ein katholischer Staat, als eine katholische Macht in Europa. Andererseits definierte sich dieser Staat selbst in idealiter spätestens seit der Mitte des 19. Jahrhunderts als multikonfessionell, multireligiös und supranational. Auf einer übergeordneten Ebene begibt sich daher die vorliegende Monographie im Konkreten am Beispiel des Religionsfonds der Bukowina auf die Suche nach den Mechanismen und Ausgestaltungsformen in der Bewältigung dieser ideologisch verordneten Koexistenz im Alltag der `Provinz $\prec$.

9 Die Ansicht der Regierungsseite allerdings, die den österreichischen Staat seit 1783 (der rechtlich gesehen damals nicht existierte) bzw. nach 1918 Rumänien als jeweilige Eigentümer (Proprietar) bezeichnet, ist nicht korrekt; ANONYMUS 2009, Justiția, Istoricul Proceselor, 5-7. 
In zwölf Kapiteln - untergliedert in drei Abschnitte (Einleitung, Organisation, Institution) - werden nach der Analyse und Methodik (Kap. 2) zunächst der allgemeine und in der Folge der spezielle Gründungskontext im Zeitalter des Josephinismus erläutert (Kapitel 3 u. 4). Breiter Raum kommt darin der institutionellen Facette des Bukowiner Religionsfonds zu. Die Kapitel 6 und 8 blicken hingegen besonders auf die Interaktion von Institution, Akteuren und Öffentlichkeit auf dem politisch-gesellschaftlichen Feld. Im Spannungsdreieck Kirche-Fonds-Staat treffen hier in wechselnder Priorität Fragen nach dem Stellenwert nationaler Ideen, nach dem Träger der letztlichen Verfügungsgewalt über die Güter, nach dem Spielraum der Kirche und ihrer Autonomie und nach Formung, Umfang wie Vermittlung von Werten durch die Institution des Fonds aufeinander. Methodisch gesehen gibt hier die Quellenlage eine stärker indirekte Perspektive auf den Religionsfonds vor. Der Fonds erhält seine Konturen erst aus der Schnittmenge von Korrespondenzen, Berichten und Akten zwischen Bischof, Konsistorium (und seinen Mitgliedern), österreichischen Behörden sowie der Öffentlichkeit, letztere vorwiegend abgebildet durch die Medien. Um ein Gesamtbild des gr-orient. Religionsfonds bzw. der gr.-orient. Landeskirche der Bukowina über diesen vergleichsweise langen Zeitraum gewinnen zu können, musste daher eine entsprechende Bandbreite an unterschiedlichen Quellen eingesehen werden. Diese reicht von Archivalien auf zentralstaatlicher Ebene über solche auf Landesebene (staatliche wie kirchliche Behörden), vereinzelte Nachlässe und private Korrespondenzen hin zu gedruckten zeitgenössischen Publikationen aller Art. Als überaus wichtig für die Sichtbarmachung des für diesen Abschnitt maßgeblichen öffentlichen Diskurses um die Jahrhundertwende hat sich die Presselandschaft der Bukowina (eigentlich der Stadt Czernowitz) herausgestellt. Erst über sie war es für die Jahre vor dem Ersten Weltkrieg möglich, einen konziseren Einblick in die Entwicklung der "gr.-or. Kirchenfrage" (so eine zeitgenössische Zeitungsrubrik) zu gewinnen. Eine Schwierigkeit barg dabei die rumänische Periode nach 1918. $\mathrm{Da}$ für die Bukowina die Dokumentation der Periodika an der Österreichischen Nationalbibliothek mit Ende des Ersten Weltkrieges abrupt abbricht und ähnlich digitalisierte Zugänge zu Beständen (ANNO ${ }^{10}$ vergleichbar) in Rumänien (etwa in Cluj-Napoca oder Bukarest) erst im Aufbau sind, öffnet sich hier in der vorliegenden Darstellung eine Lücke. Letztere konnte über Einzelsichtungen vor Ort freilich nur teilweise überbrückt werden, zumal sich manche Fragen erst während des Schreibens stellten.

Drei methodisch auf zeitliche Querschnitte hin angelegte Kapitel zur wirtschaftlichen Situation des Religionsfonds (Kapitel 5, 7 und 9) erschließen seine jeweilige ökonomische Dimension, vorwiegend mit Fokus auf die Bukowina, immer aber auch in den nötigen Kontext des Staates eingebettet. In ihrer Abfolge ermöglichen diese Kapitel einen im

1o ANNO, AustriaN Newspapers Online, ein Suchportal der Osterreichischen Nationalbibliothek. 
Detail zwar nur losen, aber in den hauptsächlichen Punkten kontinuierlichen Einblick in die Entwicklung der wirtschaftlichen Ausgestaltung dieser Institution. Das Kapitel 10 unternimmt schließlich den Versuch eines ausgewählten Längsschnittes über den gesamten Zeitraum hinweg. Dabei fließen am Beispiel der Montanwerke von Jakobeny und des Kurortes Dornawatra ökonomische wie politisch-gesellschaftliche Aspekte des Fonds in Form einer gemeinsamen Betrachtung von regionaler Wirkung und Bedeutung wie staatlichem Dirigismus ineinander. Hier stützt sich die Analyse hauptsächlich auf die Akten der Güterdirektion des Religionsfonds, wo der Fonds gewissermaßen unmittelbar greifbar wird. Vergleicht man allein auf der Ebene des Staatsarchivs von Czernowitz den Bestand der Metropolie Bukowina (inkl. des Konsistoriums, Fond 320) mit fast 17.000 Akten und jenen der Güterdirektion (Fond 321) mit knapp 1300 Akten, so wird die bereits angesprochene Bedeutung der Verschneidung einzelner Blickwinkel, um den Fonds überhaupt fassen zu können, klar.

Jedes Kapitel bietet außerdem eine resümierende Diskussion, um trotz der Fülle an Details den Überblick zu erleichtern. Darauf aufbauend wird in einer Schlussbetrachtung (Kapitel 11) der Bogen zurück zu den Ausgangsfragen und Thesen (Kap. 2 und 3) geschlagen. Die Übersetzungen, soweit dies nicht anders angegeben wurde, stammen vom Autor.

Hinsichtlich deutscher, rumänischer, ukrainischer und fallweise russischer Schreibweisen von Ortsnamen, wie sie vielfach in der Bukowina vorkommen, wurde eine pragmatische Lösung angestrebt, da selbst innerhalb einer Sprache (besonders vor 1918) die Varianten mitunter beträchtlich abweichen können. Im Anhang der Arbeit findet sich daher eine synoptische Ortsnamenkonkordanz mit entsprechenden Seitenverweisen. Etwas einfacher gestaltet sich die Schreibung von Personennamen. Diese richtet sich weitgehend nach amtlichen Quellen bzw. gedruckt vorliegenden Publikationen. Auch deren Varianten werden in einem eigenen Personenindex wiedergegeben. 


\section{Institutionen als Forschungsgegenstand: Analyse \& Methodik}

Als kurze Einführung in den hier als Instrument gewählten methodisch-analytischen Ansatz soll zunächst ein Überblick zum Gegenstand der Institution in der Soziologie geboten werden, um daraus schließlich jenen relevanten Teil herauszufiltern, der für die getroffene Fragestellung der vorliegenden Studie von zentraler Bedeutung erscheint. Ein daran anknüpfender Blick auf Institution(en) als Forschungsobjekt in der Geschichtswissenschaft leitet den Versuch ein, das dargelegte soziologische Modellverständnis als theoretisches Grundgerüst auf die (hier vorab als solche postulierte) Institution des gr.-orient. Religionsfonds umzusetzen. Darauf aufbauend werden schließlich analytische Einheiten formuliert. Vier davon abgeleitete Leitthesen bilden die methodische Grundlage der Arbeit.

\section{Soziologische Institutionenforschung}

Im Hinblick auf ihre schwerpunktmäßige theoretische Fundierung ist die Institutionenforschung in den Bereich der Organisationssoziologie einzuordnen. Bereits in den 1960er Jahren erkannte man in diesem aus den USA stammenden Konzept für die Soziologie einen Zentralbegriff zur Analyse der modernen Gesellschaft. ${ }^{1}$ Hatten die damit in Verbindung stehenden modernisierungstheoretischen Konzepte den - am Ende - erfolgreichen Wandel (gewissermaßen als Aufholprozess gegenüber der 'westlichen Welt) im Visier, so dominiert hier gegenwärtig in den Geschichtswissenschaften, aus der Osteuropaforschung kommend, eine davon grundsätzlich abweichende Sichtweise. Im Mittelpunkt steht dabei nicht mehr so sehr das Transferergebnis - also die erreichte Modernisierung, das Gleichziehen mit dem zumeist `westlichen Vorbild -, sondern der Übertragungsprozess als solcher. ${ }^{2}$ Aus fachlicher Sicht soll hier jedoch vorerst der Blickwinkel der Soziologie beibehalten werden.

Mittlerweile charakterisiert sich dieser Forschungsbereich insgesamt durch eine weitgehende Ausdifferenzierung, die als Folge von zahlreichen Überschneidungen mit Nachbarfächern zu einer gewissen Unübersichtlichkeit führt. ${ }^{3}$ Der darin einzuordnende, allerdings inhaltlich spezifischere handlungstheoretische Institutionenbegriff schlägt in seinem Grundverständnis die Brücke zurück zu einem der zentralen Ausgangspunkte der Organisationssoziologie: die Analyse der Bürokratie als Organisation rationaler Ordnung von Max Weber. ${ }^{4}$

\footnotetext{
BERNSDORF (Hg.) 1969, Wörterbuch, 762, Schlagwort Organisation.

Vgl. dazu die Zusammenschau bei vanMeURS \& MÜLLER 2014, Institutionen, 12.

TACKE 2010, Organisationssoziologie, 341.

4 WeBer 1922, Wirtschaft; TACKE 2010, Organisationssoziologie, 343 u. 355; SELZNICK 1996, Institutionalizm, 276 .
} 
Vor allem US-amerikanische Soziologen wie Philip Selznick dachten die Weberschen Ideen rationaler Ordnung nach 1945 weiter. Sie konzentrierten sich dabei jedoch nicht ausschließlich auf die rationalen Dimensionen organisatorischen Verhaltens. Letztere so Selznick - "remain at once indispensable to the continued existence of the system of coordination and at the same time the source of friction, dilemma, doubt, and ruin ". ${ }^{5}$ Damit verweist Selznick bereits auf eine prozessuale Entwicklung von Institutionen, die er zunächst noch als adaptive social structures umschreibt. Gleichzeitig lässt sich hierin eine Annäherung an Emil Durkheims struktural-funktionalistischen Institutionenansatz (Glaubensvorstellungen und Verhaltensvorstellungen als Institution, die über Berufskooperationen in der Gesellschaft wirksam werden) erkennen. ${ }^{6}$ Später konkretisiert Selznick die Auffassung der schrittweisen Institutionalisierung ursprünglicher Organisationen als einen vorwiegend durch soziale Kräfte (social forces) gesteuerten Prozess. Allerdings gilt es dabei zu berücksichtigen, dass Institutionen in ihrer Genese nicht immer zwangsläufig einer zeitlich vorausgehenden Organisation bedürfen. ${ }^{7}$ Der zentrale Sinngehalt dieses Institutionalisierungsprozesses erschließt sich für Selznick in der allmählichen Durchdringung einer Organisation mit Werten (infuse with value). ${ }^{8}$ Dementsprechend nehmen in der von ihm weithin grundgelegten (älteren) Institutionentheorie values einen zentralen Platz ein. Die Analyse dieser Werte setzt einen Schwerpunkt auf deren jeweilige Verankerung sowie Wirkmächtigkeit in der Organisationskultur und in deren sozialer Struktur. ${ }^{9}$ Mit der Verinnerlichung von Werten erwächst innerhalb der Institution das Gefühl einer eigenständigen Persönlichkeit mit einer abgrenzbaren Identität ("as an organization acquires a self, a distinctive identity, it becomes an institution «). ${ }^{10} \mathrm{Im}$ Gegensatz zu den nach Weber rational administrativen, auf Effizienz hinzielenden Aufgaben einer Organisation gleicht sich im Zuge dieses Institutionalisierungsprozesses die Organisation an das Streben interner Akteure und an die values der sie umgebenden Gesellschaft an. ${ }^{11}$ Der schwedische Soziologe Nils Brunsson hat Ende der 1980er Jahre bereits provokant darauf hingewiesen, dass unter Umständen

\footnotetext{
5 SELZNICK 1948, Foundations, 25.

6 Durkheim 1992/1930, Arbeitsteilung, 55, 69-75.

7 REHBERG 2002, Institutionalismus, 42.

8 SELZNICK 1957, Leadership, $16 \mathrm{f}$.

9 SELZNICK 1996, Institutionalizm, 271.

10 SELZNICK 1957, Leadership, 21; ähnlich argumentiert Charles Perrow in seinen Überlegungen zur Theorie der Institutionen, »that at least some organizations do take on a life of their own ", PERROw 1979, Organizations, 184.

11 "The process of institutionalization is the process of organic growth, wherein the organization adapts to the strivings of internal groups and the values of the external society«, PERROW 1979, Organizations, 186 .
} 
propagierte Werte für eine Institution wichtiger sein können als tatsächlich gesetzte Handlungen. ${ }^{12}$ Hier versucht die neuere Institutionenforschung anzusetzen. Obwohl sie sich selbst wenig im Klaren über die Kohärenz des eigenen Ansatzes ist, so will diese Richtung innerhalb der Soziologie, in der Wahl der Ausgangsfragestellung sowie Untersuchungsebene differenzieren. ${ }^{13}$ Dabei soll die lokale Ebene sowie die der eigentlichen Institution verlassen werden und ein weiteres Umfeld ins Blickfeld gerückt werden, was argumentativ wenig überzeugt und sich in der Realität letztlich kaum von der älteren Richtung abhebt. Die vorliegende Studie orientiert sich daher methodisch weitgehend am Ansatz der älteren Institutionenforschung, wie er von Selznick vertreten wird.

Der kaum noch einzugrenzende, übergeordnete Sammelbegriff von Institution als die Summe der Spielregeln einer Gesellschaft (nach Durkheim), wie er vereinzelt in der Wirtschaftssoziologie Verwendung findet (und nicht zwangsläufig an eine konkrete Organisation gebunden ist), soll hier nicht weiter verfolgt werden. Wohl ist jedoch der von da ausgehende Impuls eines in der Analyse zu betonenden zeitlichen Aspektes zu berücksichtigen, der Gegenwart und Zukunft mit der Vergangenheit über die Kontinuität der Institutionen (und ihren Wandel) einer Gesellschaft verknüpft. ${ }^{14}$ So werden auch in der Theorie des Kultur-Ansatzes Institutionen häufig als ,Vermittlungsinstanzen kultureller Sinnproduktion ${ }^{15}$ und in einer erweiterten Perspektive als Steuerungs- wie Integrationsinstrumente ${ }^{16}$ bzw. »als Vermittlungsmechanismen zwischen Individuen und sozialen Strukturen ${ }^{17}{ }^{17}$ gesehen. Vereinfacht formuliert differenziert die Soziologie dabei zwischen politischen und sozialen Institutionen, betont aber gleichzeitig deren immanente Verwobenheit, wobei die soziale Institution ist als Begriff hingegen weiter zu fassen sei. Eine (politische) Institution kann zwar durch normative Satzungen einen formellen Charakter annehmen (etwa als rechtlich definierte juristische Person), sie kann andererseits aber auch über ihre indirekte - zunächst nicht `kodifizierte - Wirkung informeller Natur sein. Den informellen Existenzsinn, die Intention, erfährt die Institution über ihre maßgeblichen Akteure und die von ihnen eingebrachten Ideen ${ }^{18}$, was in reduzierter Form dem Ansatz von Selznick entspricht. Das kann weitestgehend ebenso für die soziale Institution geltend gemacht werden.

12 BrUnsson 1989, Organization. Den freundlichen Hinweis verdanke ich Niels Grüne anlässlich einer Diskussion zum Thema in Innsbruck am 28. Nov. 2014.

13 LoWndes 1996, Varieties, 184 u. 195; MAURer \& SChmid (Hg.) 2002, Institutionalismus, 15.

14 NoRTH 1991, Institutions, VII u. 3.

15 REHBERg 1994, Institutionen, 57.

16 GÖHLER 1994, Institutionen, 39.

17 MAURer \& Schmid 2002, Institutionalismus, 11.

18 BÉLAND \& Cox 2011, Introduction, 9-10. 
Institutionen sind somit als Schlüsselelemente in der politischen Umsetzung von Ideen bzw. gesellschaftspolitischen Wandels anzusprechen. ${ }^{19}$ Dementsprechend definierte etwa auch das Schwerpunktprogramm der Deutschen Forschungsgemeinschaft ,Theorie politischer Institutionen ‘ an der Freien Universität Berlin (1989-1995) soziale Institutionen als »relativ auf Dauer gestellte, durch Internalisierung verfestigte Verhaltensmuster und Sinngebilde mit regulierender und orientierender Funktion $*{ }^{20}$ Der Sonderforschungsbereich Institutionaliltät und Geschichtlichkeit an der Technischen Universität Dresden ${ }^{21}$ setzte - darauf aufbauend - in der Analyse den Fokus auf institutionelle Mechanismen bzw. deren Beitrag zur Stabilisierung sozialer Beziehungen. Dabei betrachtete man nicht die alleinige Dauer bzw. Existenz einer Institution an sich, sondern vor allem die durch sie selbst symbolisierten und repräsentierten verschiedenen »Formen zeitlicher Kontinuitätsherstellung ${ }^{22}{ }^{22}$ Eine die Tiefe einer konkreten >Institution ‘ (abseits der Analyse von gesellschaftlichen Makroeinheiten wie der Verfassung etc.) auslotende Auseinandersetzung lässt die Soziologie indes insgesamt weitgehend vermissen, obwohl theoretische Studien gerne exemplarisch auf empirisch allerdings nicht selten nur oberflächlich bearbeitete Beispiele zurückgreifen. ${ }^{23}$ Zudem geht die gegenwärtige sozialwissenschaftliche Literatur beim Forschungsgegenstand /Institution zumeist von großen und komplexen systemischen Einheiten wie etwa der Demokratie ${ }^{24}$ oder - wie schon angesprochen - der Gesellschaft als Ganzes aus. ${ }^{25}$ Seltener widmet man sich maßstäblich kleineren öffentlichen oder privaten Einrichtungen am anderen Ende des Spektrums wie Krankenhäusern, Schulen etc. ${ }^{26}$ Für die gewählte Fragestellung erscheint im Hinblick auf den gr.-orient. Religionsfonds der Bukowina daher der breit angelegte, auf drei Ebenen greifende und sowohl politische als auch soziale Institutionen umfassende Definitionsansatz von Vivien Lowndes sinnvoll anwendbar:

Institution is a middle-level (or >meso ) concept. Institutions are devised by individuals, but in turn constrain their action. They are part of the broad social fabric, but also the medium through which day-to-day decisions and actions are taken. Institutions shape human action,

19 BÉLAND 2009, Ideas, 707.

20 GöHLER 1994, Institutionen, 22-24; Göhler leitete den Schwerpunkt, ein Abschlussbericht liegt für 2001 vor.

21 SFB 537; [http://gepris.dfg.de/gepris/projekt/5481378].

22 ReHBERG 2001, Institutionalität, 4 u. 10.

23 Stinchсомве 1997, Virtues; 1968, Demography; Perrow 1961, Analysis; Perrow 1979, Organizations, bes. 174-182.

24 BÉLAND \& CoX 2011, Introduction; CAPOCCIA \& ZIBLATT 2010, Turn.

25 NORTH 1991, Institutions.

26 Stinchсомве 1968, Demography; Perrow 1961, Analysis. 
imposing constraints whilst also providing opportunities. Institutions have formal and informal aspects [...] Institutions have a legitimacy and show stability over time. Institutions have a legitimacy beyond the preferences of individual actors. They are valued in themselves and not simply for their immediate purposes and outputs. Institutions may gain their legitimacy because of their relative stability over time, or because of their link with a sense of place ${ }^{27}$

Verdichtet und zusammengefasst auf eine strukturell-funktionale Betrachtung werden daher Institutionen in ihrer Aktivität und Wirkung von drei zentralen Aspekten getragen, einem relational-normativen (soziale Beziehungen und Werte), einem regulativen (Machtpositionen, Bedingungen) und einem kulturell-kognitiven (Ideologie und Sinnstiftung). ${ }^{28}$ Soziale Beziehungen erfahren mitunter durch die von Institutionen gesteuerten Mechanismen (hier in Form der Aspekte angesprochen) ihre Stabilisierung. ${ }^{29}$

\section{Institutionen in den Geschichtswissenschaften}

Innerhalb der deutschsprachigen Geschichtswissenschaft hat die Institution als Forschungsobjekt vor allem im Rahmen der Verfassungs- und Verwaltungsgeschichte eine gewisse Tradition aufzuweisen. Zwar lieferten hier die Arbeiten der Historiker Otto Brunner und Otto Hintze wichtige Impulse, die sich daran anschließende Diskussion wurde jedoch nicht in der gleichen Intensität fortgesetzt und weiter vertieft. ${ }^{30} \mathrm{Zudem}$ konzentrierte Brunner seine Schwerpunkte vorrangig auf eine weitgehend statische Analyse von Verfassung und Struktur, wohingegen Hintze Wandel und steten Entwicklungsprozess betonte. ${ }^{31}$ Die zusammengezogene Frage nach dem institutionellen Wandel bzw. der >Langen Dauer institutioneller Zeit ` bzw. auch der erwähnten zeitlichen Kontinuitätsherstellung durch die Institution und ihrer räumlichen Dimension (wie sie im vorliegenden Fall der Bukowina eine entscheidende Bedeutung besitzt) bleibt selbst in den nachfolgenden Studien zumeist nur von untergeordneter Natur. ${ }^{32}$ Aber auch im weiteren Feld geht die Institutionengeschichtsschreibung kaum auf deren umfassendere Dimensionen

\footnotetext{
27 Lowndes 1996, Varieties, 182.

28 BÜHL ${ }^{4} 2007$, Institution, 299; ScOTT 2014, Institutions, 59-67.

29 REHBERG 2002, Institutionalismus, 4.

30 Brunner ${ }^{4} 1959$, Land; ${ }^{2} 1968$, Wege; auch Regele 1949, Hofkriegsrat.

31 DIPPER 1987, Brunner; zur Kritik an Brunner vgl. zusammenfassende Aspekte bei BoldT 2003, Brunner, besonders 205f.; HINTZE 1911, Entstehung; BüsCH \& ERBE (Hg.) 1983, Hinze.

32 Giddens fordert eine Wiedergewinnung von Raum und Zeit; die Brennpunkte der Forschung sollten dabei auf Theoretisierung von Handlung, Struktur und Kontextualität gelegt werden; GIDDENS 1988, Konstitution, 413-427, hier 421; einen Úberblick zur Diskussion um den Spatial Turn bietet Döring \& ThielmanN (Hg.) 2008, Turn.
} 
wie ihr kultureller Einfluss oder ihre regionale Bedeutung - bei synchroner Betrachtung des jeweiligen Herrschaftszentrums und der von dort ausgehenden Ideen - ein. ${ }^{33}$ Das Zusammenwirken von Institution und Modernisierung wird in diesem Rahmen vielfach nach wie vor gerne von den Feldherrenhügeln der Staatsverfassung aus beobachtet, wenngleich die Analyse der Auswirkungen selbst wiederum in einer breiten gesellschaftlichen Basis stattfindet. ${ }^{34}$ Das Feld der Institutionenforschung erscheint, basierend auf diesem verdichteten Befund, weitgehend der Soziologie ${ }^{35}$ und der Politikwissenschaft ${ }^{36}$ überlassen worden zu sein. ${ }^{37}$ Letztere haben in den vergangenen beiden Jahrzehnten eine Reihe von Ideen und möglichen analytischen Ansätzen vorgelegt ${ }^{38}$, deren angepasste Umsetzung für historische Fragestellungen neue Ergebnisse versprechen.

Zusammenfassend bleibt zu erwähnen, dass zwar aus der soziologischen Perspektive herrührende theoretische Impulse durch die Geschichtswissenschaft aufgegriffen worden sind, eine breite praktische Umsetzung anhand konkreter Studien jedoch bislang nicht festzustellen ist. Lediglich im Rahmen jüngerer historischer Forschung zum Institutionenwandel und Rechtstransfer während des 20. Jahrhunderts findet die erwähnte, aus der Soziologie kommende strukturell-funktionelle Betrachtung von Institutionen eine sichtlich fruchtbare Anwendung. Das zeigt etwa der Schwerpunkt am Geisteswissenschaftlichen Zentrum Geschichte und Kultur Ostmitteleuropas (GWZO) in Leipzig, wo Institutionenforschung am Beispiel des Eigentumsbegriffes an der Schnittstelle von Verfassung, Verfassungsrealität und Reformpolitik in Ostmittel- und Südosteuropa der Zwischenkriegszeit einen zentralen Stellenwert einnimmt. ${ }^{39}$

33 Eine Ausnahme dazu bildet in Teilen die Studie von SchindLER, die explizit zentrale Institutionen und deren Einfluss bzw. Auswirkungen auf die Verwaltung der Peripherie diskutiert; SchINDLER 1998, Bedeutung; auf der Ebene landwirtschaftlicher Organisationen hat sich besonders BRUCKMÜLLER aus sozialhistorischer Sicht mit Fragestellungen der Modernisierung auseinandergesetzt; BRUCKMÜLLeR 1977, Organisationen; ders. (Hg.) 2002/2003, Geschichte.

34 VogT 2008, Erneuerung; die anderen Beiträge in diesem Sammelband, die unter Kapitel V mit dem Titel >Modernisierung: Akteure und Institutionen ‘ zusammengefasst sind, beziehen einen vorwiegend staatlich zentralen Standpunkt am Ausgang ihrer Überlegungen zur institutionellen Modernisierung.

35 Zum Begriff `Institution « in den Sozialwissenschaften vgl. LANE \& Ersson 2000, Politics.

36 CZada 1995, Theorien.

37 Bezieht man sich auf die Bedeutung von Institutionen wie Schulen und der Kirche für die Herausbildung bzw. Bewahrung von Identitäten (ein ohnedies weites Feld), so liegen dafür zahlreiche neuere Studien vor, die allerdings in ihrer fachlichen Zuordnung wie inhaltlichen Qualität als sehr heterogen zu betrachten sind und kaum (methodisch) aufeinander Bezug nehmen; stellvertretend für die Bandbreite sind hier zu erwähnen: PACHOLKIV 2002, Emanzipation; GAFU \& NUBERT-CHEŢAN 2009, Institutions.

38 Etwa Rehberg 1994, Institutionen, 47-84; Dauss \& Rehberg 2009, Raumsymbolik.

39 Vgl. die Webseite des GWZO [https://www.uni-leipzig.de/ gwzo/index.php?option=com_content 


\section{Institution Religionsfonds}

Die neuere Kulturgeschichte versucht die angesprochenen Institutionsformen ter Betonung der zeitlichen Dimension stärker miteinander zu verknüpfen und sieht in "sozialen und politischen Institutionen zentrale Medien und Orte menschlichen Handelns ${ }^{4}{ }^{40}$ Dabei konzentriert sich der erkenntnisleitende Fokus auf drei markante Aspekte (Institutionalisierung, Institutionen und Gruppen und institutionelle Mechanismen), die inhaltlich in der vorliegenden Studie auf den Bukowiner gr--orient. Religionsfonds als analytische Kategorien Anwendung finden und zunächst in vier Thesen formuliert werden. Über die Betrachtung der langen Dauer institutioneller Zeit steht der Wandel dieser Aspekte, bezogen auf den Religionsfonds, in ihrer jeweils unterschiedlich intensiven Konfiguration zwischen 1848 und 1949 im Blickfeld (siehe Abb. 1). Institutionelle Neuerungen bzw. Wandel ergeben sich dabei in der Regel nicht ausschließlich aus dem zielgerichteten Streben Einzelner, sondern aus "akkumulierten Nebenwirkungen der Tätigkeit von Akteuren «. ${ }^{41}$ Aus dem eingangs ausgebreiteten ersten Übersichtsbefund zur institutionellen Entwicklung des Religionsfonds lässt sich dem folgend und mit Blick auf die nationale Frage ein Bogen zwischen supranationaler und nationaler Leitidee spannen. Ihre Umsetzung im Alltag ist anhand der Wirkungs- und Funktionsweise institutioneller Reproduktionsmechanismen (Schule, Universität, Pfarren etc.), des Zusammenspiels von politischem Ausgleichsversuch 1910 und nationalem Kirchenkampf zwischen der sich in steigendem Maße als rumänisch verstehenden Orthodoxie des Kronlandes, den ruthenischen Gläubigen und den (ebenfalls ruthenischen) Unierten (die in ihrer absoluten Zahl in der Bukowina vergleichsweise unbedeutend waren) zu bewerten. Daraus resultiert - parallel zu seinem organisatorischen Feld - ein auch zeitgenössisch sichtbarer immanenter Öffentlichkeitsbezug des Fonds. Dieser mit Werten aufgeladene Bezug wurzelt einerseits in seinem eigenen Geltungsanspruch als Institution sowie andererseits in seiner Nähe bzw. seinem diskursiven Verhältnis zur staatlichen Ideologie (i.e. der Leitidee des Herrschaftszentrums). ${ }^{42}$ Die zuvor schon angerissene Stabilisierungsleistung durch eine Institution wirkt in die Gesellschaft vor

\&view=article\&id=941\&Itemid=1534]; MüLLER 2012, Bodeneigentum, 338f. sowie SIEGRIST 2007, Propertisierung; Siegrist \& Troebst (Hg.) 2012, Institutionenwandel; vanMeUrs \& MÜlleR (Hg.), Institutionen.

40 BLÄNKNER 1994, Überlegungen, 85; zu den institutionellen Mechanismen vgl. im Besonderen ReHBERG 2001, Institutionalität.

41 OFFE 2003, Institutionen, 180; BÉLAND 2009, Ideas, 702.

42 Dauss \& Rehberg 2009, Raumsymbolik, 110. Zum Problem der `österreichischen Identität vgl. BELLER 2001, Kraus. 
allem durch ihre »symbolische Darstellung von Ordnungsprinzipien « - den erwähnten Leitideen - hinein. ${ }^{43}$

Ohne die Kritik an der Modernisierungstheorie hier außer Acht lassen zu wollen ${ }^{44}$, erscheint im Fall der Bukowina der zunächst wertfreie zeitlich-räumliche Kontext jener mit Ende des 18. Jahrhunderts einsetzenden Neuerungen und Umbrüche von Bedeutung. ${ }^{45}$ Die Region geriet dergestalt durch die serfolgreicher Umorientierung ihrer staatlichen Zugehörigkeit bis in die Zwischenkriegszeit hinein aus zeitgenössischer Wahrnehmung zum Vor- bzw. Gegenbild eigener Entwicklung (etwa in Bezug auf das rumänische Altreich/Regatul vechi vor 1918 oder die Nachbarländer der Bukowina wie Galizien-Lodomerien bis 1918). Die Modernisierung der Bukowina während des 19. Jahrhunderts verlief asynchron, auf verschiedenen Ebenen, $z$. T. erheblich segmentiert. Sie unterscheidet sich damit kaum von anderen peripheren Teilräumen des Habsburgerreiches. Während in administrativer Hinsicht mit der von Wien aus kontrollierten Zentralverwaltung der ersten Periode österreichischer Herrschaft (1774-1786) entscheidende Grundsteine für die spätere Entwicklung gelegt wurden (u.a. gerade eben in der Schaffung des Religionsfonds), leitete die Eingliederung dieser Provinz ins habsburgische Königreich Galizien-Lodomerien (1786-1849) zunächst eine hauptsächlich politisch verursachte Stagnationsphase ein. ${ }^{46}$ Erst mit der Erhebung der Bukowina zum Kronland 1849 und der neuerlich einsetzenden inneren Ausgestaltung einer gewissen Selbstverwaltung beschleunigte sich die Modernisierung. Parallel dazu gewann die wachsende Intensität der Bindung dieses Raumes gegenüber Wien an prägendem Einfluss. ${ }^{47}$ Technische Innovationen wie die Verbindung mit dem europäischen Eisenbahnnetz lösten zusätzlich Peripherisierungsprozesse aus, verstärkten bestehende, oder wie im Falle der Forstwirtschaft in Jakobeni - schwächten diese durch nunmehr über die Infrastruktur erschlossene Marktzugänge entscheidend ab. Sie zeitigten dabei nicht selten erhebliche Auswirkungen auf die nur wenig konkurrenzfähigen regionalen sozioökonomischen Strukturen. ${ }^{48}$ Der weitgehende Zusammenbruch der kleinstrukturierten privaten Bergbauindustrie von Jakobeni im südlichen Landesteil der Bukowina belegt dies eindrücklich. Nur der finanziell gut ausgestattete Großgrundbesitz - und dazu ist auch der Religionsfonds zu zählen - mit seinem erheblichen politischen Einfluss und

\footnotetext{
43 ReHBERG 2002, Institutionalismus, 47.

44 Berger 1996, Modernisierungstheorie; ders. 1986, Moderne. Sundhaussen 1993, Modernisierung. 45 Zum Epochenbegriff und zur Moderne vgl. Osterhammel 2009, Verwandlung, $88 \mathrm{f}$. 46 SCHARR 2010, Landschaft.

47 Lemberg unterstreicht diese wechselseitige Verknüpfung besonders; LEMBERG 2005, Imperien, 30; auch SUPPAN 2005, Imperien.

48 KAPS 2009, Peripherisierung.
} 
innovativen Potential war schließlich in der Lage, entsprechende Investitionen zu tätigen und die Vorteile der Modernisierung für sich gezielt zu nutzen. ${ }^{49}$

Der gr--orient. Religionsfonds der Bukowina als sparastaatliche`, jedoch kirchlich kontrollierte und als eine in ihrer Anlage ständische` Institution vereinte in sich über mehr als ein Jahrhundert lang die gesamtgesellschaftlichen Aspekte regionaler Modernisierung. Mehr noch, die Institution des Fonds selbst war einer ihrer wesentlichen Motoren. Der Fonds gehörte zu jenen institutionellen Mechanismen, derer sich das Habsburgerreich zur Stabilisierung seiner Herrschaft konsequent bediente. ${ }^{50}$ Mit der Nationalisierung dieser Institution begannen indes die zentrifugalen Kräfte an Gewicht zu gewinnen. Die ursprüngliche auch über den Fonds gesellschaftlich implementierte Integrationsidee wandelte sich über sozial und national konnotierte Exklusion in der Politik des Religionsfonds in einen gegenteilig gesetzten Eckstein aufdämmernder Desintegration des Imperiums. ${ }^{51}$

Dementsprechend umschreibt die ältere Institutionentheorie in einer ihrer auf Weber zurückgehenden Grundaussagen die rationale Ordnung des Staates bzw. seiner Bürokratie..$^{52}$ Das gilt in der Grundintention und in einem anderen Maßstabe im Allgemeinen freilich ebenso für den Josephinischen Religionsfonds (als quasi Verlängerung des Staates). Im gr.-orient. Religionsfonds der Bukowina gerinnt während des 19. Jahrhunderts allmählich im Zusammenwirken von ursprünglich organisatorischer Bürokratie, zunehmender Personalität (Akteure) und sich festigender sozialer Strukturen über die schrittweise Aufladung mit Werten eine für die gesamte Region formende, wenn nicht gar in weiten Bereichen bestimmende Institution. Anfänglich gesetzte technische Ziele zur Ausführung der Verwaltung bzw. der weiteren Landesorganisation, an der sich auch der Fonds zu beteiligen hatte, verloren ihre zunächst dominante Stellung innerhalb der Institution. Sie teilten diese in steigendem Maße mit value und einer moralischen Integrität, die sowohl vom Staat als auch den Akteuren innerhalb der Institution des Fonds (wenn auch nicht immer im Gleichklang) eingefordert wurde. Der politischen

49 SchaRr 2013, Religionsfonds.

50 Vgl. das Forschungsprojekt )Empires` (Fachbereich Geschichte Universität Hamburg, 2006-2008, Leitung: Hirschhausen/Leonhard) [http://www1.geschichte.uni-hamburg.de/de/forschung/for schungsprojekte/empires.html].

51 In der jüngeren Imperienforschung vgl. LeONHARD (Hg.) 2011, Empires.

52 "The chief merit of bureaucracy is its technical efficiency, with a premium placed on precision, speed, expert control, continuity, discretion, and optimal returns on input $[\ldots]$ through sentiment formation, emotional dependence upon bureaucratic symbols and status, and affective involvement in spheres of competence and authority, there develop prerogatives involving attitudes of moral legitimacy which are established as values in their own right, and are no longer viewed as merely technical means for expanding administration«; MERTON 1940, Structure, 561 u. 565. 


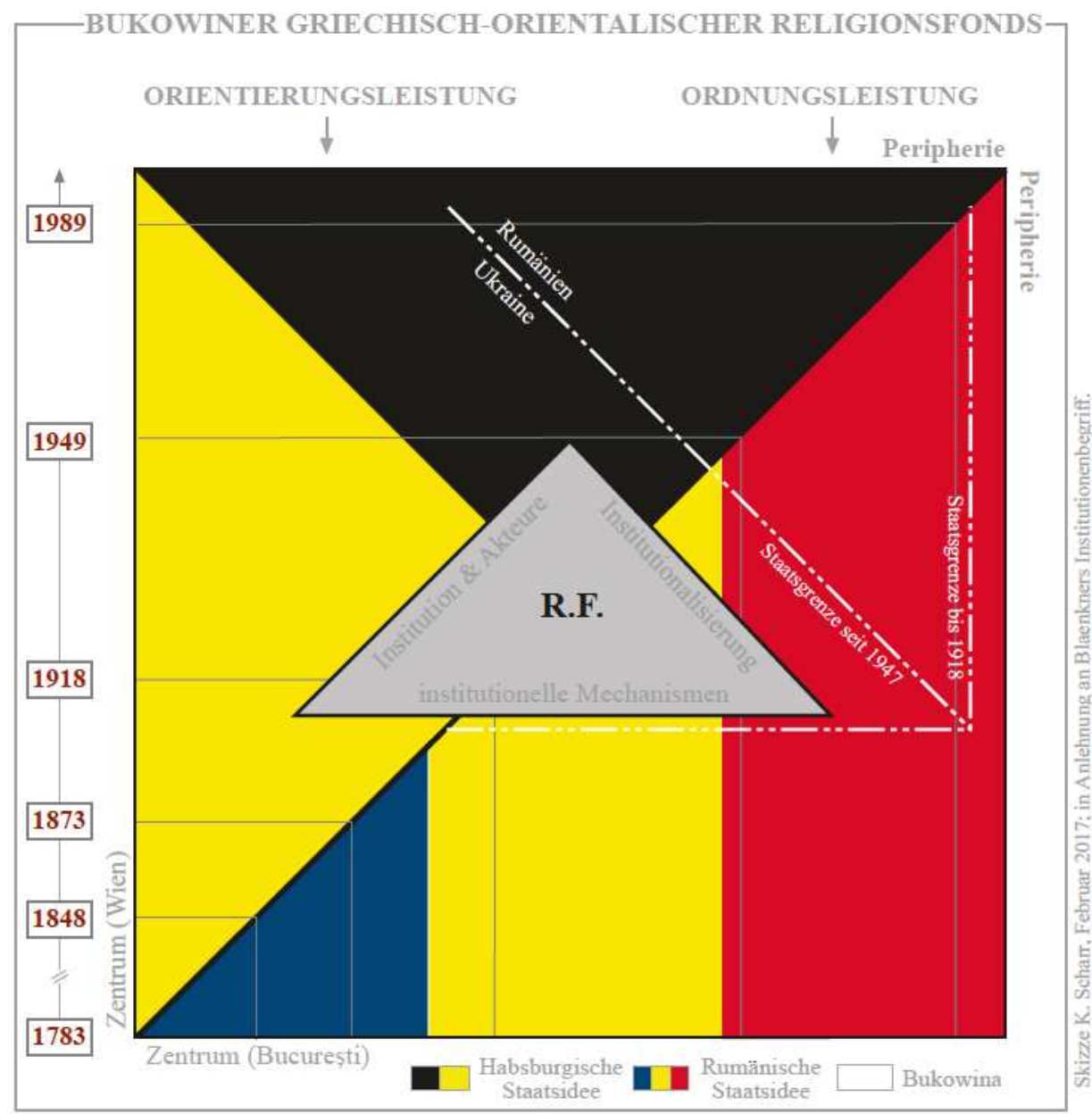

Abb. 1: Der Bukowiner griechisch-orientalische Religionsfonds als Institution.

wie gesellschaftlichen Rolle einer Institution, wie sie im Religionsfonds der Bukowina mit seiner über die Region hinausgehenden Wirkung typischerweise Gestalt annahm, kam daher vergleichsweise zu den (katholischen) Religionsfonds der Habsburgermonarchie eine ausgesprochene Sonderstellung zu. Die nicht orthodoxen Religionsfonds schienen aus verschiedenen Gründen (worunter im Fall der Bukowina die territoriale Geschlossenheit, die weitgehende konfessionelle Homogenität und die später an Schärfe gewinnende nationale Frage sicherlich zu den zentralen gehören) den Sprung von der Organisation zur Institution nicht durchgemacht zu haben. Die aktuelle Forschungslage dazu lässt das allerdings vorerst nur vermuten. 
Analyseeinheiten und Thesen

Aus den vorangestellten Überlegungen können daher zusammenfassend nachstehende analytische Einheiten zur Institution des Religionsfonds formuliert werden. Sie formen die drei zentralen Teile der vorliegenden Arbeit. Der Aspekt Institutionalisierung ist weitgehend chronologisch orientiert. Er widmet sich der Entstehung des Fonds, den Prozessen seiner physischen Strukturierung als Organisation und - über die schrittweise Einbindung in die sich herausbildende Gesellschaft der Bukowina als Region seiner fortschreitenden Institutionalisierung. Institution \& Akteure: Hier stehen die (Erz-)Bischöfe sowie das Konsistorium als Entscheidungsträger und Vermittler der jeweils zentralen Leitidee im Zentrum der Betrachtung, aber auch der Staat bzw. seine unmittelbaren Vertreter in ihrem Einfluss auf den Fonds. Die Abhängigkeit des Fonds als Institution einerseits vom Zentrum und andererseits von der regionalen Alltagsrealität bilden einen weiteren Fokus der Analyse, ebenso wie die Frage nach der persönlichen Rolle des jeweiligen (Erz-)Bischofs sowie einzelner Vertreter der regionalen Kirchenhierarchie und ihrer religiös wie politisch motivierten Beweggründe in der Entscheidungsfindung für die Ausrichtung des Fonds. Schließlich ist auf die institutionellen Mechanismen einzugehen. Dabei ist die Frage nach der Reproduktion eigener Eliten ebenso zu stellen wie nach den Steuerungsmöglichkeiten des regionalen politischen Diskurses über den Fonds. Auch ist dessen spezifischer Beitrag zum überregionalen, nationalen Diskurs - angesiedelt im Spannungsfeld Zentrum-Peripherie - zu überprüfen. Hieraus sind vorab vier für diese Studie zentrale Thesen zu formulieren:

\section{These 1: Gründung der Institution und Aufgabe}

Die Gründung des griechisch-orientalischen Religionsfonds der Bukowina durch Joseph II. hatte ein klares Ziel, das mit der Neuordnung des modernen Territorialstaates in enger Beziehung stand: Die Schaffung einer regionalen, wirtschaftlich verlässlichen Basis für die neugewonnene Provinz und die Möglichkeit zentralstaatlichen Durchgriffs auf einen wesentlichen Teil der untersten Verwaltungsebene bei gleichzeitig kontrollierter Einbindung wie Instrumentalisierung des geistlichen Standes. Der Kaiser legte damit den Grundstein für eine zentrumsloyale Organisation, deren primärer Schwerpunkt auf der erwarteten Ordnungsleistung bestand. Im Verbund mit der neu arrondierten (orthodoxen) Kirchenprovinz lag aber bereits der Kern einer zweigeteilten Orientierungsleistung als latenter Auftrag einer werdenden Institution: die Schaffung einer neuen Provinz mit ihrem eigenen Bewusstsein und deren gleichzeitige ideelle Ausrichtung auf das Zentrum Wien. Der Religionsfonds spiegelte somit in regional basierter, verkleinerter Form die Idee des modernisierten Habsburgerstaates wider. Als kirchliche Institu- 
tion trug der Fonds zunächst noch den äußeren Charakter einer ständischen Vertretung, der sich davon allerdings nicht zuletzt durch die zentrale und maßgebende Mitsprache Wiens abzuheben begann.

\section{These 2: Institutioneller Wandel und nationale Frage}

Während der zweiten Hälfte des 19. Jahrhunderts geriet der Religionsfonds in steigendem Maße zum Instrument nationaler Interessen, wobei das orientierende Element regionaler Identitätsschaffung nach wie vor Bedeutung hatte. Die wechselnden politischen Haltungen seiner regionalen Entscheidungsträger von Eugen Hackmann über Silvester Morariu-Andriewicz bis hin zu Wladimir Repta spiegeln diesen Wandel wider, aber auch den persönlichen Glaubenskonflikt über die gefährdete Kircheneinheit. Innerregional wird der Religionsfonds zur Stellschraube der gr--orient. Kirche, die sich zunehmend als rumänisch-orthodoxe Kirche versteht und die wirtschaftlich mächtige Institution des Fonds gezielt zur Mobilisierung und Elitenreproduktion in ihrem Sinne einsetzt. Die ebenso orthodoxen, jedoch ruthenischen Gläubigen der Bukowina profitieren nur mehr in geringem Maße von den Möglichkeiten des Fonds.

Parallel zur wachsenden wirtschaftlichen Machtbasis (These 3 ) verläuft eine (zunächst auf das Habsburgerreich beschränkte) Konfliktlinie an Begehrlichkeiten zwischen den conationalen rumänischen Bistümern der Monarchie (Czernowitz, Hermannstadt), die sich in ihrer strukturellen Basis erheblich unterscheiden. Die starke regionale Verankerung des Religionsfonds in der Bukowina setzt in der Frage der Vereinigung der orthodoxen rumänischen Bistümer beidseits der Karpaten mit Sitz in Czernowitz (Cisleithanien) und Hermannstadt (Transleithanien) wirtschaftliche wie regional basierte Interessen vor nationale Ideen. Der Religionsfonds und der Bukowiner Bischof bremsen damit die nationalrumänische Bewegung der Habsburgermonarchie zum Nachteil der in der ungarischen Reichshälfte lebenden Rumänen aus.

\section{These 3: Institutioneller Wandel und regionale Modernisierung}

Die ursprüngliche Intention Wiens, den Religionsfonds zur wirtschaftlichen Basis einer regionalen, aber vom Zentrum aus kontrollierten Entwicklung zu machen, greift verstärkt erst seit der zweiten Hälfte des 19. Jahrhunderts. Der Fonds beteiligt sich an tragender Stelle an der Modernisierung des Kronlandes und versucht Krisenerscheinungen durch Umstrukturierungsmaßnahmen abzufangen (z. B. das Eisenwerk in Jakobeny). Die voranschreitende Erschließung der Bukowina ermöglicht ihm dabei gleichzeitig, seine enormen (Wald-)Ressourcen erstmals gewinnbringend in ein internationales Wirtschaftssystem einzuspeisen. Teil dieses Wandels ist indes auch eine allge- 
meine gesellschaftliche Demokratisierung. So liegt die angedeutete Differenz zwischen Hackmann und Andrei Schaguna einerseits in der unterschiedlichen innerkirchlichen Struktur beider Bistümer begründet, deutet aber auch bereits die schrittweise Demokratisierung der cisleithanischen Kronländer an und damit einen schleichenden Verlust elitärer Exklusivität der Kirchenhierarchen. ${ }^{53}$

In der Erweiterung der Überlegungen zum institutionellen Wandel des Religionsfonds über den Ausgang des Ersten Weltkrieges hinaus liefert ein Gedankenspiel von H. Bude zur Implosion der DDR und dem darauffolgenden sallmählichen inneren Ableben der Bundesrepublik^ einen Mehrwert für die Formulierung der letzten These, der hier Erwähnung finden soll. Bude konstatiert darin einen gesellschaftlichen Systemwechsel bei politischer Regimekontinuität, der letztlich zu einer Festigung der deutschen Verfassung führt. ${ }^{54}$ Mit Einschränkung trifft das zunächst auch auf die Situation der Bukowina und den parallel damit einhergehenden Wertewandel nach $1918 \mathrm{zu}$. Großrumänien hatte die nationale Vereinigung erreicht. Es kam innerhalb des Religionsfonds durch die gesamtstaatliche Neuorientierung zu einer beträchtlichen Verschiebung der values in ihrem jeweiligen Stellenwert. Der Bukowiner Religionsfonds und seine Akteure fühlten sich in ihrer national ausgerichteten Politik bestätigt. Und doch stellte sich eine schleichende Krise dieser Institution mit diesem Ereignis ein, wenngleich seine sichtbaren Auswirkungen erst über ein Jahrzehnt später an die Oberfläche traten. Aus dieser Perspektive scheint die weltweite Wirtschaftslage am Ende der 1920er Jahre nur der Auslöser, nicht aber die tiefere Ursache für die Krise des Fonds zu sein. Der institutionelle Wandel hatte sich im Sinne der Akteure in einer nunmehr erfüllten nationalen Leitidee und einer erreichten Deckungsgleichheit des eigenen mit dem staatlichen Orientierungsmuster vollzogen. Er war jedoch ab diesem Zeitpunkt mit der überaus heterogenen politischen Realität Rumäniens konfrontiert, in der sich seit dem letzten Drittel des 19. Jahrhunderts ein erheblicher Reformstau aufgebaut hatte. Fragen des nation building und nach der eigenen Identität spielten dabei eine zentrale Rolle. ${ }^{55}$ Auf organisatorischer Ebene ergaben sich durch die rumänischen Sprachgesetze Anfang der 1930er Jahre ebenso bald Probleme, etwa fachlich versierten Nachwuchs für die Forstwirtschaft zu rekrutieren. In beiden Fällen, sowohl vor, als auch nach 1918, zeigt sich deutlich, dass ökonomische Strukturen wie die Institution des Religionsfonds zwar (staats-)kapitalistische Grundsätze in einem Raum installieren, bewahren oder erweitern helfen sollen, jedoch ei-

53 SELZNick 1951, Vulnerability, 321.

54 BUDE 2003, Altern, 221f.

55 Mareci \& PUrici 2007, Pressure; Barbu \& PReda 2006, Building, bes. 371; auch Harre 2009, Wege. 
gentlich weitgehend in ihrem Verhalten von anderen Werten als jenen des Kapitalismus geleitet werden. ${ }^{56}$ Allerdings, und das unterstreicht der Ansatz der älteren Institutionenforschung in der Soziologie, werden Institutionen trotzdem zu einem entscheidenden Teil von ihren ursprünglichen organisatorischen Aufgaben zusammengehalten. ${ }^{57}$ Für den Religionsfonds der Bukowina war das vor 1918 der österreichische Staat bzw. sein Vertreter vor Ort, der Landespräsident. Nach 1918, nunmehr auf einer anderen Ebene und unter geänderten staatlichen Rahmenbedingungen, waren es die Bukowiner Metropoliten selbst. Sie bezogen eine bewusste Verteidigungshaltung gegen die ansteigende wie regelmäßige politische Einflussnahme von außen und versuchten regionale Identität sowie Autonomie der durch sie repräsentierten Institution zu bewahren. Letzteres zeigte sich besonders in der divergierenden Haltung des neuen national-rumänischen Zentralstaates, der regionale Strukturen, wie sie der Religionsfonds an entscheidender Stelle in der Bukowina mitbegründet hatte, mit wachsender Skepsis betrachtete und sukzessive zurückzudrängen suchte. Zudem wirkte die systemimmanente zentralisierende Grundtendenz der orthodoxen Kirche mit ihrem jungen, seit 1925 bestehenden Patriarchat in Bukarest zusätzlich gegengerichtet auf die regionale Institution des Religionsfonds ein.

Im Rückblick und aus dem Wissen rund um die Restitutionsbemühungen der kirchlichen Religionsfondsgüter nach 1989 gelangt hier eine konträre Bewegung an die Oberfläche. Die Metropolie der Moldau und der Bukowina stellt in diesem Prozess und in der (in seinen Aufgaben wie Zielen im Vergleich zum historischen Vorgänger allerdings sehr selektiv wahrgenommenen) Wiedererrichtung des Religionsfonds nach 1989 vor allem dessen regionale, von Bukarest - auch in kirchlicher Hinsicht - unabhängige Bedeutung klar in den Vordergrund. Zusammenfassend lässt sich daraus wie folgt die vierte These ableiten:

\section{These 4: Institutioneller Wandel, persistente Strukturen und Lange Dauer}

Der Ausgang des Ersten Weltkrieges und die damit verbundene Eingliederung der Bukowina nach Großrumänien verstärkten den schleichenden funktionalen Wandel ${ }^{58}$ innerhalb des Religionsfonds, der - ausgedrückt in der nationalen Diskussion - spätestens seit der Jahrhundertwende zur bestimmenden ökonomischen Kraft geworden war. Durch den Zusammenbruch der Habsburgermonarchie und das Entstehen Großrumäniens vollzog sich ein struktureller Wandel auf übergeordneter Ebene (Leitidee staatli-

\footnotetext{
56 STINCHсомве 1997, Virtues, 12; Stinchcombe bezieht sich hier auf Joseph Schumpeter.

57 "The guts of institutions is that somebody somewhere really cares to hold an organization to the standards«; STINCHCOMBE 1997, Virtues, 18.

58 GöHLER (Hg.) 1997, Eigenart, $38 \mathrm{f}$.
} 
chen Daseins) vom (zumindest im Grundanliegen) supranationalen Vielvölkerstaat hin zu einem klar definierten wie exklusiv handelnden Nationalstaat. Die bewusst wie unbewusst integrative Leistung (Orientierungsleistung) des Religionsfonds für die Schaffung und Ausgestaltung einer Region (der Bukowina) ging durch die zunehmende Nationalisierung und wachsende Ausrichtung nach Bukarest ab 1918 schrittweise verloren, um letztlich auf wirtschaftliche wie gesamtnationale Aspekte reduziert zu werden. Mit der Hinwendung zur neuen staatlichen Leitidee geriet ein wesentlicher Teil der institutionellen Orientierungsleistung des Religionsfonds - die Schaffung regionalen Bewusstseins - in steigendem Maße in Konflikt mit dem Zentrum. Die Wiederbegründung des Religionsfonds als juristische Person nach 1989 verschuf hingegen dem über die Zeit persistent gebliebenen regionalen Bewusstsein neuerlich institutionelle Öffentlichkeit. 


\section{Die Organisation: Von der Gründung zur Konsolidierung}

Dieser Abschnitt will sich auf jene Phase in der Geschichte des Religionsfonds der Bukowina konzentrieren, die dessen Entwicklung von seiner Gründung bis hin zum sinstitutionellen Sprung` umfasst. Dabei ist zunächst von der politischen Situation auf gesamtstaatlicher Ebene auszugehen. Letztere erfuhr während der Regierungszeit Joseph II. wesentliche Impulse. Eine zentrale Rolle spielten hierin die bislang kaum beachteten und wenig untersuchten Langzeitwirkungen der unter der Herrschaft des Reformkaisers angestoßenen Neuerungen und Umbaumaßnahmen des allmählich sichtbar werdenden, modernen Staates. Mit der Gründung des gr-orient. Religionsfonds der Bukowina stellten sich jetzt - über diese allgemeinen Reformabsichten hinaus - ganz praktische Fragen der konkreten Umsetzung. Die im Rahmen der josephinischen Kirchenpolitik angestrebte Diözesanregulierung im Inneren wie nach außen, entlang territorialstaatlicher Grenzen, oder der Umgang des Staates mit den orientalischen (i. e. orthodoxen) Klöstern respektive deren Besitz jenseits der Landesgrenzen, formten dabei durchaus ein hoch diskursives Vorhaben. Unter anderem entspannten sich daraus zum Teil langwierige Aushandlungsprozesse zwischen regionalen Akteuren mit ihren Interessen und den Wiener Behörden bzw. ihren Vertretern vor Ort. Diese Prozesse mündeten, ungeachtet lokaler wie zentralstaatlicher Schwierigkeiten, schließlich in eine allmähliche Konsolidierung, also Festigung und Etablierung der Organisationsstrukturen des Fonds während des ersten Drittels des 19. Jahrhunderts. Die konkrete ökonomische Situation des Fonds hingegen wird in einem eigenen Abschnitt thematisiert (Kapitel 5). Damit soll die Ausgangsbasis für den späteren wirtschaftlichen wie gesellschaftspolitischen Aufschwung - mithin den Sprung zur Institution - näher analysiert werden. 


\section{Aspekte des Josephinismus. Der katholische Religionsfonds}

Um die Rolle der Orthodoxie als Konfession in ihrer speziellen Verfasstheit, wie sie sich in der österreichischen Bukowina darstellte, in das Gefüge des Habsburgerreiches einordnen zu können und um einen Ausgangspunkt für die Bewertung der Gründungsphase des gr.-orient. Religionsfonds im ausgehenden 18. Jahrhundert zu setzen, ist es zunächst nötig, den Kontext zum politisch-gesellschaftlichen Leitbild dieser Epoche dem Josephinismus ${ }^{1}$ - herzustellen. Der Josephinismus als eine bedeutende jedoch durchaus spezifische Variante des aufgeklärten Absolutismus gilt in der historischen Forschung unbestritten als eine gesamtgesellschaftliche Reformbewegung ${ }^{2}$, deren deklariertes Ziel in der Durchsetzung des modernen Staates gegenüber der tradierten, ständisch geprägten Verfasstheit von Gesellschaft sowie Territorium lag. Zu den Charakteristika des Josephinismus in den habsburgischen Ländern zählt, dass dieser Reformansatz weniger von einem übergeordneten philosophisch begründeten Ideengebäude, denn vielmehr von der eigentlichen Praxis der Aufklärung selbst ausging. ${ }^{3} \mathrm{Zu}$ dem war mit den über diese Politik gesetzten Maßnahmen auch die Frage des weiteren Landesausbaues verbunden. ${ }^{4}$ Die dadurch angestoßenen prozesshaften Veränderungsbewegungen, die Periodizität des Josephinismus (mit den vorauslaufenden Reformen während der Regierungszeit Maria Theresias) sind als Faktum weitgehend anerkannt, wohingegen die Langzeitwirkungen in ihrer beträchtlichen Tiefe bislang noch viel zu wenig ausgeleuchtet wurden. ${ }^{5}$ Das spiegelt sich auch in der von Anton Schindling vorgeschlagenen Pluralbezeichnung des Phänomens (Josephinismen`) wider. Damit wird zwar aus dem Blickwinkel der Geschichtswissenschaften auf die nicht immer konsequent und oftmals in sich widersprüchlich durchgesetzten Reformvorhaben seitens Kaiser Josephs II. Bezug genommen, die regional z.T. sehr differenzierte Wirkung - mithin also auch Teil dieser `Josephinismen`, gewissermaßen am anderen Ende des Spektrums

1 Zur Begrifflichkeit und zur periodischen Eingrenzung des \Josephinismus im Überblick vgl. MAURER 1999, Kirche; Kovács $\left({ }^{2} 1980\right.$, Josephinismus, 24$)$ spricht sich gegen die Verengung des Josephinismus auf die staatskirchliche Gesetzgebung aus, zumal sie bereits bei Zeitgenossen den Begriff als eine »Weltanschauung und eine Philosophie mit unabänderlichen Prinzipien « feststellt.

2 Aretin 1985, Josephinismus, 518; ReINALter 2008, Josephinismus, 32; zusammenfassend bei ReINALter 2011, Joseph II., 7f.; damit bezieht sich die Forschung klar auf Fritz Valjavec, der den Josephinismus vor allem hinsichtlich seiner Wirkmächtigkeit in einen längeren Betrachtungszeitraum stellt; VALJAVEC ${ }^{2} 1945$, Josephinismus, IX u. XII.

REINALTER 2010, 1790, 153.

4 Bendel \& SPANnenberger 2015, Aufklärung, 15.

5 MaURer 1999, Kirche, 84; Ogris 1983, Joseph II., 151; SchindLING 1997, Aspekte, 690. 
zentralstaatlichen Machtdurchgriffes - deckt Schindling damit freilich nicht ab. ${ }^{6}$ Neuerdings greift die historische Forschung »das Elend der Kategorien « in Bezug auf Aufklärung und Josephinismus in den Geschichtswissenschaften wieder vermehrt auf. ${ }^{7}$ Nur wenige Studien widmeten sich bis dato den Langzeitwirkungen des Josephinismus auf der Ebene der österreichischen bzw. habsburgischen Länder. ${ }^{8}$ An Zahl noch geringer ist in dieser Hinsicht die Auseinandersetzung auf breiter Basis über das durch den Josephinismus begründete Verhältnis von Kirche und Staat innerhalb der verschiedenen Regionen. ${ }^{9}$ Und das, obwohl schon 1945 Fritz Valjavec auf die zu wenig beachtete lange Dauer des Josephinismus als Gesamterscheinung hingewiesen hat. ${ }^{10}$ Zudem diskutieren die Geschichtswissenschaften die Kirche-Staat-Beziehung des Josephinismus bis heute nahezu ausschließlich in Bezug auf die katholische Kirche. ${ }^{11}$ Gerade in der Haltung Josephs II. gegenüber den nicht katholischen Konfessionen zeigte sich jedoch die angesprochene Praxis der Aufklärung. "Ohne Begeisterung, doch entschlossen « - so sein Biograph François Fejtö - trieb den Kaiser hier allen voran das Staatsinteresse und nicht der Gedanke an Glaubens- oder gar politische Freiheit. ${ }^{12}$ In paralleler Betrachtung und die katholische Kirche blieb ja im Habsburgerreich bis zuletzt in konfessioneller Hinsicht tonangebend - stellt sich allein aus diesem qualitativen Unterschied heraus innerhalb der allgemeinen Kirchenreform für die (in der Bukowina besonders betroffene) Orthodoxie die Frage nach einem weiteren `Josephinismus،. Daher wäre es wohl auch gerechtfertigt im Rahmen der josephinischen Kirchenpolitik in Betreff der Konfessionen nicht nur von einer Pluralität der Wirkungen, sondern unter Umständen auch von einem heterogenen Reformansatz in der durch den Kaiser angestrengten Sache an sich zu sprechen.

Es sind vor allem vergleichende Studien, die bislang fehlen und die vorhandenen Ergebnisse zur Wirkmächtigkeit dieses Reformphänomens zusammenführen könnten, um damit ein räumliches Bild des Josephinismus für alle Territorien der Habsburgermon-

\footnotetext{
6 SChindling 1997, Aspekte, 683.

7 Fillafer 2016, Elend.

8 Reinalter 1993, Josephinismus, 8; Reinalter (Hg.) 2008, Josephinismus; für Rumänien (respektive den Teilraum Siebenbürgen) vgl. etwa zuletzt BUD 2015, Limitele; Bud geht darin vor allem auf die Wirkungsgeschichte und die Imagination(en) zu Joseph II. aus rumänisch-siebenbürgischer Perspektive nach dessen Tod 1790 bis zum Zerfall der Habsburgermonarchie ein.

9 Dazu beispielhaft die Arbeiten von Franz 1908, Studien; Bernhauer 1989, Kirche sowie Rajsp 2002, Religionsfonds.

10 VALJAVeC ${ }^{2} 1945$, Josephinismus, IX u. XII.

11 LeISCHING ${ }^{2} 1995$, Kirche.

12 Fејтӧ 1956, Joseph II., 272 f.
} 
archie zu schaffen. ${ }^{13}$ Es ist mehr als wahrscheinlich, dass dieses Bild fast erwartungsgemäß eine ziemliche Heterogenität im Sinne der erwähnten 'Josephinismen` offenlegen würde. Daraus ließe sich denn auch in der Folge das ungleichmäßige Eindringen sowie die hier nur postulierte unterschiedlich lange Dauer dieser Reformen sichtbar machen. Inwiefern das Ergebnis dann auf die strukturelle Heterogenität der jeweiligen Region zurückzuführen ist, gilt es zu überprüfen. Erst damit aber ergäbe sich die grundsätzliche Möglichkeit, das Wesen des Josephinismus auch auf der Wirkungsebene in einem längeren Zeitrahmen als bisher fassbar zu machen.

Das hier anschließende Kapitel kann freilich in keiner Weise den Anspruch erheben, diese doch beträchtliche Lücke schließen zu wollen. Sehr wohl wird aber versucht, die Genese des bis dato kaum in der Forschung beachteten gr-orient. Religionsfonds nachzuzeichnen und - vor allem, was dessen Gründungsphase betrifft - die Folgen der josephinischen Reformen am regionalen Beispiel der Bukowina aufzuzeigen und diese in den zeitgenössischen Kontext einzubetten. Daher erscheint es auch nötig, diesem Kapitel einen kürzeren Abschnitt über einen zentralen Teilaspekt des Josephinismus, d.i. der katholische Religionsfonds, voranzustellen. Darauf aufbauend lässt sich denn auch, obgleich etwas vorauseilend, die Frage ableiten, inwieweit und wenn ja, aus welchen Gründen die Reformbestrebungen unter Kaiser Joseph II. gerade in der peripheren (konfessionell weitestgehend orthodox-ostkirchlich geprägten) Bukowina weit nachhaltiger gegriffen bzw. gewirkt haben, als dies vergleichsweise in den (katholischen) deutschen Erblanden der Fall war; und das, obwohl das primär intendierte Ziel der angestoßenen staatlichen Umgestaltungsmaßnahmen sich in erster Linie eigentlich auf diese zentralen Räume richtete.

Mit Rationalität und größtmöglicher Effizienz einer aufzubauenden zentralstaatlichen Bureaucratie sollte die Stabilisierung des durch die Reformen in Bewegung geratenen Herrschaftssystems garantieren. Am Ende sollte in der Vorstellung der modernisierte Staat stehen. Die völlige Überwindung tradierter Strukturen, wozu vor allem die ständischen Einrichtungen zu zählen waren, blieb jedoch zweitrangig. Der Platz letzterer

13 Einen Ansatz dazu bot die niederösterreichische Landesausstellung über Joseph II. 1980; GUTKAS (Hg.) 1980, Osterreich; ein kürzlich erschienener Sammelband zur katholischen Aufklärung setzt hier einen wichtigen Schritt zur Überbrückung dieser Forschungslücke; BENDEL \& SPANNENBERGER (Hg.) 2015, Aufklärung; in Bezug auf Einkünfte und Mittel der (katholischen und unierten) Religionsfonds sowie die Anzahl ihrer Kleriker liegt eine vergleichende, kleinere Ubberblicksstudie für die Jahre 1781-1790 vor; DICKsON 1993, Joseph; für eine kritische historiographische Betrachtung des Josephinismus liefern FILlafer \& WALlNig [(Hg.) 2016, Josephinismus] neue Perspektiven des Vergleichs. 
pendelte im Reformgebäude zwischen Entmachtung, Zerschlagung und Integration. ${ }^{14}$ Man hatte alsbald erkannt, dass "verwaltungstechnische Vereinfachung", wie sie durch diese Reformen unternommen wurden, nicht ausreichten, einen auf Dauer stabilen und modernisierten Staat zu schaffen. ${ }^{15}$ Innerhalb dieses nur schwer in seiner Tiefe und Tragweite gänzlich zu überblickenden Facettenreichtums an Reformen ist daher das Augenmerk hier primär auf das Staatskirchentum ${ }^{16} \mathrm{zu}$ lenken, also jenen maßgeblichen Teil der Umgestaltung, "ohne den alles andere nicht gelingen konnte « ${ }^{17}$ Sie entpuppte sich als eine der tragenden Säulen der josephinischen Reformperiode. Betrachtet man den Josephinismus als gesamtgesellschaftliches Phänomen, so gehört die Beaufsichtigung der Kirche durch den Staat zu seinem Fundament, womit zugleich auch jener Bereich des Josephinismus angesprochen ist, dessen unmittelbare Nachwirkungen sich am längsten verfolgen lassen. ${ }^{18}$

Schon seit den ersten Reformansätzen unter Maria Theresia kristallisierte sich immer mehr die Kirche als ein "störendes Element für den absolutistischen Verwaltungs- und Wirtschaftsstaat « heraus. ${ }^{19}$ Einerseits standen die Klöster für eine im Sinne des Josephinismus nicht mehr zeitgemäße Feudalordnung. Sie verhinderten in ihrem Machtbereich den unmittelbaren Durchgriff des Staatsapparates auf sseine ' Untertanen. Die autonomen Bereiche, etwa in Form der (vor allem durch die Kirche maßgeblich ausgeübten) Grundherrschaft, sollten im Zusammenwirken mehrerer Reformschritte (z.B. Urbarialregulierung, Grundsteuer etc.) sukzessive zu Gunsten des Staates zurückgedrängt werden. ${ }^{20}$ Zum anderen sah die Staatsverwaltung in der Kirche (hier und besonders wiederum in den Klöstern) als größtem Grundbesitzer eine weitgehend stote Hand`, in der sich beachtliche Vermögenswerte angehäuft hatten, die nach den zeitgenössischen Vorstellungen keine effiziente Nutzung mehr erkennen ließen. ${ }^{21}$ Nicht nur in unmittelbar wirtschaftlicher Hinsicht, sondern auch an der staatsloyalen Erziehung der Untertanen hatte die Kirche ihren Beitrag zu leisten. Zielte das Maria-Theresianische Volksschulwesen noch hauptsächlich auf die tiefere Verwurzelung des Katholizimus in den unteren Volksschichten $\mathrm{ab}^{22}$, so sollte die Kirche unter Joseph II. in dieser Beziehung als loyale

14 Reinalter 2008, Josephinismus, 25; KovÁcs ${ }^{2}$ 1980, Josephinismus, 27.

15 Heindl 1990, Bürokratie, 39.

16 Als Uberblick zum Staatskirchentum vgl. RiTTER 1954, Vermögensverwaltung, $77 \mathrm{f}$.

17 ARETIN 1985, Josephinismus, 519.

18 VALJAVEC ${ }^{2} 1945$, Josephinismus, 50 u. 53; ARETIN 1983, Josephinismus, 524; OgRIS 1981, Joseph II., 151.

19 Schindling 1997, Aspekte, 688.

20 OGRIS 1981, Joseph II., 122 u. 136.

21 ARETIN 1985, Josephinismus, 515.

22 Schinding 1997, Aspekte, 688. 
Dienerin am Staat fungieren und eine möglichst breite wie direkte Kontaktmöglichkeit mit dem Staatsvolk herstellen helfen. ${ }^{23}$ Dafür musste allerdings die einheitliche Ausbildung der Priester (außerhalb der bischöflichen Seminare) und deren regelmäßiges, standesgemäßes Einkommen garantiert werden. Ebenso bedurfte die Pfarr- und Diözesanregulierung - die unter anderem eine annähernde Deckungsgleichheit politischer und kirchlicher Verwaltungsgrenzen im Staatsinneren herbeiführen sollte - einer stabilen wie dauerhaften Finanzierung. Dergestalt war klar, dass das sfiskale Element ‘, die Finanzierung des Staates und seiner neuen Aufgaben, zum Dreh- und Angelpunkt seit den Reformen Maria Theresias geriet. ${ }^{24}$ Eine dafür vermeintlich ausreichend gut sprudelnde Quelle glaubten der Staat und sein oberster Repräsentant, der Kaiser, im Kirchenvermögen entdeckt zu haben.

Erste Ansätze - die jedoch nicht realisiert wurden - den Regularklerus der Habsburgermonarchie zur Gänze einer staatlichen Verwaltung zu unterstellen bzw. zumindest die Überschüsse aus den geistlichen Stiftungen abzuschöpfen, tauchen bereits in den 1750er Jahren auf. ${ }^{25}$ Die lombardische Guinta economale von 1765 - sie säkularisierte 80 Klöster und leitete dabei ihr Vermögen einer eigenen Verwaltungsbehörde, dem Regio economato, $\mathrm{zu}$ - gilt hingegen als frühes auch tatsächlich umgesetztes Beispiel dieser Politik $^{26}$, auf das Joseph II. zur Finanzierung seiner Staatskirchenreform später zurückgreifen sollte. Ein anderer Vorläufer, der strukturelle Ähnlichkeiten mit dem späteren Religionsfonds aufwies, war der 1773 aus dem Vermögen des auch im Habsburgerreich aufgehobenen Jesuitenordens angelegte `Exjesuitenfonds $\triangleleft$ bzw. `Studienfonds $\triangleleft{ }^{27}$ Bereits 1781 ließ der Kaiser bestehende Religionsfundi, die Maria-Theresia zur Mission der Protestanten geschaffen hatte, zur Finanzierung von Seelsorgestellen und Schulen umwidmen. Schließlich folgten dem Patent vom 12. Jänner 1781 zur Aufhebung der Klöster am 28. Februar 1782 und am 23. Mai 1783 weitere Verordnungen Joseph II., die den Umgang mit dem durch die Säkularisierung frei gewordenen Vermögen regeln sollten. Das daraus zu erlösende Kapital war zweckgebunden und einer zu errichtenden Religions- bzw. Pfarrkasse zuzuführen. ${ }^{28}$ Mit dieser ersten Phase der Klosteraufhebungen war die Gründung des katholischen Religionsfonds eingeleitet worden. Wenig später,

23 VALJAVEC ${ }^{2} 1945$, Josephinismus, 62 u. 65 .

24 HOLZKNECHT 1914, Ursprung, 66 u. 79.

25 ReInHARDT 1966, Kirchenreform, 110 u. 117.

26 Hock \& BidermanN 1879, Staatsrath, 394.

27 MAČEK 2002, Religionsfond, 416.

28 Verwendung des Vermögens der aufgehobenen Klöster, КRоратsCHeK, Handbuch II, 272; abgedruckt in KLUeting (Hg.) 1995, Josephinismus, 295 (Nr. 121); im Überblick HussAReK 1909, Religionsfonds, 92. 
am 26. Juli 1782, gründete Joseph II. die Geistliche Hofkommission und bestimmte sie zur zentralen Administration des frei gewordenen Kirchenvermögens. ${ }^{29}$ Eine gänzliche Abhängigkeit der Kirche von der Staatsgewalt war in den katholischen Ländern kaum durchsetzbar ${ }^{30}$, wohl aber eine unter anderem auch über den Religionsfonds ausgeübte zentrale Kontrolle. Über die Institution des Religionsfonds gelang es dem Staat letztlich, sowohl die Bischöfe als auch die Klöster nahezu zur Gänze aus der Verwaltung des Kirchenvermögens hinauszudrängen. ${ }^{31}$ Spätere Novellen des Religionsfonds ermöglichten indes eine gewisse, wenngleich immer noch durch das letztliche Entscheidungsrecht der staatlichen Behörden nach wie vor maßgeblich kontrollierte Mitsprache kirchlicher Institutionen wie etwa der Konsistorien bei der Mittelverwendung. ${ }^{32}$

Die theoretischen Grundlagen dafür aus staatskirchenrechtlicher Sicht hatte Paul Joseph Riegger (1705-1775) aufbereitet. Demnach war mit diesem Schritt, die Kirchengüter einer staatlichen Aufsicht zu unterstellen, die "Freiheit des Staates von der Kirche « wieder hergestellt. Die Rechte und die Pflichten des Herrschers wurden sinngemäß durch den Staat wahrgenommen. ${ }^{33}$ Der zeitweise aus Kirchenkreisen geäußerte Vorwurf, damit lediglich Kapital »auf kirchlicher Seite aufzulösen [...] um [es] auf staatlicher Seite in großen Fonds anzuhäufen oder auf kirchlicher Seite zu atomisieren ${ }^{34}$, ist in dieser Form kaum haltbar. Selbst gegenüber dem Josephinismus kritische Stimmen verweisen darauf, dass mit dem Religionsfonds das Kirchengut keineswegs der Kirche entfremdet wurde, im Gegenteil, die Mittelverwendung streng zweckgebunden "ganz allein zur Beförderung der Religion, und des damit so eng verknüpften und so schuldigen Besten des Nächsten verwendet werden «. ${ }^{35}$ Das erlöste und dem Religionsfonds zugewiesene Kapital $^{36}$ war in seiner rechtlichen Natur als ‘fideikommissarisch ¿ zu sehen, wonach »das ganze geistliche Vermögen nach dessen echtem Ursprung und Endzweck, auch nach dem wahren Geist der Kirche als ein für das Beste des Seelenheils und der Armuth bestimmtes Patrimonium anzusehen sei, wovon die geistlichen Individuen und

29 Errichtung des ,geistlichen Okonomats،, Österreichische Zentralverwaltung II/4, 74-79; abgedruckt in KLUeting (Hg.) 1995, Josephinismus, 298 (Nr. 124).

30 Rieser 1963, Geist, XI; Aretin 1985, Josephinismus, 521.

31 HörtNagl 1950, Stellung, 106.

32 Im Zuge der Reformen nach 1848 und des Konkordats von 1855 wurde den Bischöfen ein Recht auf Einsicht in das Gebaren des Fonds gewährt jedoch kein unmittelbarer Einfluss darauf. Huss AREK 1909, Religionsfonds, 94.

33 SeIfert 1973, Riegger, 274 u. 345 f.

34 Rieser 1963, Geist, 43; in der Argumentation ähnlich Zenker 1909, Kirche, 47.

35 BRUnNeR 1874, Joseph II., 200 u. 225; a. d. Kabinettschreiben Joseph II. a. Graf Blümegen 27.II.1782, zit. nach HUSSAREK 1909, Religionsfonds, 92.

36 Im Detail vgl. die Auflistung der ursprünglichen Religionsfondszuflüsse mit den entsprechenden Hofdekreten bei HeLFerT $1825^{2}$, Kirchenvermögen, $₫ 105$. 
Gemeinden nur für ihre standesgemäße Nothdurft Fruchtnießer sind und die sichere Verwendung des Ueberschusses für ersterwähnte Hauptbestimmung dem Landesfürsten als obersten Kirchenvogte und Wächter der Canonen gebührt «. ${ }^{37}$ Diese Formulierung ließ freilich einen gewissen Spielraum in der Mittelverwendung offen, wie am Beispiel der Bukowina noch zu zeigen sein wird. ${ }^{38}$ Die Rechtsverhältnisse, also die Frage wem nun letztlich das Eigentum an diesem im katholischen Religionsfonds gelagerten Kirchenvermögen zustand, blieben de facto ungeklärt. So befand sich im zeitgenössischen Rechtsverständnis der Religionsfonds doch weder "im Eigentum des Staates, eben so wenig aber in dem der Gesamtkirche oder kirchlicher Institute ${ }^{39}$, und das, obwohl das Konkordat von 1855 (Artikel 21) theoretisch das Eigentumsrecht der katholischen Kirche an diesem Vermögen anerkannte. Der Staat übte jedoch weiterhin die Verwaltung aus, so blieb als kleinster gemeinsamer Nenner das - juristisch etwas verklausulierte Verständnis vom »eigentümlichen Rechtsstatus des Fonds als selbständiges Zweckvermögen mit stiftungsartigem Charakter " weiterhin existent. ${ }^{40}$

Der katholische Religionsfonds in den deutschen Erblanden ${ }^{41}$ stellte sich in seiner Umsetzung als ein praktisch schwer handzuhabendes Kompositum aus 14 verschiedenen Provinzialfonds jedoch - zumindest theoretisch - unter einheitlicher Disposition durch den Staat dar. ${ }^{42}$ Die von Joseph II. anfänglich strikt eingeforderte Universalität

37 Hock \& BidermanN 1879, Staatsrath, 418.

38 Für den katholischen Religionsfonds bis in die Mitte des 19. Jahrhunderts bietet Helfert $\left({ }^{2} 1825\right.$, Kirchenvermögen, $\$ \$ 116-127)$ eine Ubersicht zur zweckgebundenen Mittelverwendung.

39 HUSSAREK 1909, Religionsfonds, 95; RAJŠp 2002, Religionsfonds, 434; auch für die Republik Österreich nach 1918 blieb diese Rechtsfrage im Grunde unbeantwortet; Gross ${ }^{8} 1922$, Lehrbuch, 350 u. 36 off.; RitTter 1954, Vermögensverwaltung, 8off. Faktisch war das Vermögen des Fonds durch den Krieg und die Inflation arg geschädigt. Die Finanzierung der Kirche musste daher durch das Konkordat von 1933 neu geregelt werden. Der Religionsfonds selbst wurde 1939 mit der Einführung der Kirchensteuer durch das Deutsche Reich kassiert, womit auch die Aufhebung der staatlichen Patronatsverpflichtung verbunden und der Fonds 1940 de facto aufgelöst worden war; ScHWARZ 2007, Verhältnis, 485f.; BANDHAUER-SchöFFMANN 2004, Entzug, $39 \mathrm{ff}$; de jure jedoch kommt der katholische Religionsfonds in Österreich (nach der formalen Wiedereinsetzung durch den Staatsvertrag 1955, Art. 26) erst 1988 zur Auflösung; vgl. Bundesgesetz v. 22.I.1988 betreffend die Auflösung der Religionsfonds-Treuhandstelle, BGBl. Nr. 98/1988. Damit verpflichtete sich jedoch die Republik Österreich zu regelmäßigen Zahlungen an die Kirche(n) aus dem laufenden Budget.

40 BINDER 1999, Religionsfonds, Spalte 1049.

41 In Ungarn mussten die diesbezüglichen Reformgesetze noch durch Joseph II. aus innenpolitischer Rücksichtnahme weitestgehend zurückgenommen werden; FrANZ 1908, Studien, 123.

42 Hock \& Bidermann 1879, Staatsrath, 416; vgl. die Detailstudie von Franz (1908, Studien) am Beispiel des Breisgaus. Böhmen, Mähren, Oesterreich Ob der Enns / Unter der Enns, Steuermarkt, Kärnthen, Krain, Görz und Gradiska, Tyrol, Vorarlberg, Vorderösterreich, Ost- / West-Galizien; Summarium. Uiber den reinen Ertrag aller mit Ende Oktober 1801 in der eigenen Verwaltung sowohl, als 
des Religionsfonds, dem Prinzip der staatsweiten Vereinheitlichung folgend, nahm in keiner Weise Rücksicht auf die "so bunt gewürfelten Bestandteile« der deutsch-österreichisch-böhmischen Länder dieser Zeit. ${ }^{43}$ Das führte in Konsequenz für den Fonds zu einer kaum mehr überblickbaren Verwaltungsstruktur. Ein interner Finanzausgleich, das heißt, die wechselseitige Unterstützung der Provinzialreligionsfonds, förderte zudem die Zentralisierung. Im Jahr 1794 kam es folglich zur Gründung einer Zentralreligionsfondskasse, die allerdings nur bis 1802 Bestand hatte. ${ }^{44} \mathrm{Im}$ gleichen Jahr übertrug Wien die katholischen Religionsfonds in die Verantwortung der Behörden auf Landesebene. Die Defizite deckte die Staatskasse. Damit waren in erster und zweiter Instanz die Kreisämter sowie Landesbehörden für die katholischen Religionsfonds zuständig, was in Konsequenz zu deren politischer Marginalisierung auf Landesebene beitrug. ${ }^{45}$

Den mit der in umfassender Weise aufgenommenen Kirchenreform wachsenden Finanzbedarf - so stellte sich alsbald heraus - war dieser Fonds allerdings nur leidlich in der Lage zu decken, sodass innerhalb weniger Jahre eine zweite Welle von Klosteraufhebungen und Gesetzen zur Besteuerung geistlichen Vermögens folgten. Unter anderem sollten nunmehr mit der seit 1787 eingehobenen Religionsfondssteuer neben den zentralen Aufgaben des Fonds im Hinblick auf die Kirche endgültig auch die langfristige Finanzierung der Schulen sowie der Pfarr- und Diözesanregulierung sichergestellt sein. ${ }^{46}$ Die dadurch regelmäßig eingeforderten Zahlungen an den Religionsfonds empfanden besonders die Bischöfe als einen "drückenden Beytrag « ${ }^{47}$ Wenn der Fonds auch der hohen Geistlichkeit als ein persönlicher Nachteil und Machtverlust erschien, so stand nunmehr doch der Staat durch die mit dem Fonds an sich gezogenen Aufgaben der Kirche gegenüber in der Pflicht. Der mit dem Religionsfonds geschaffene Modus war besser in der Lage diese zu erfüllen, als es die regional unterschiedlichen Partikularinteressen kirchlicher Institutionen ermöglicht hätten. Eine gänzliche Sequestrierung der kirchlichen Institute hingegen hätte hier wahrscheinlich ein für die Kirche in Konsequenz wesentlich ungünstigeres Verhältnis hergestellt. ${ }^{48}$ Von Seiten der Weltpriesterschaft, die

in der Verpachtung befindlichen sämmtlichen Fonds Güter in den deutsch erbländischen Staaten, dann in der Buccowina, und in Ost- und Westgallizien; OSTA-HHSTA Faßbender Karton 6 Fasz. XII/MS/ $\mathrm{XIII} / 1$.

43 FranZ 1908, Studien, 261.

44 HussareK 1909, Religionsfonds, 93.

45 Die Religionsfondskasse unterstand dem Cameral-Zahlamt. Die Zahlungsabwicklungen hatten jedoch nach 1802 die jeweiligen Kreisämter zu tätigen; HELFERT ${ }^{2} 1825$, Kirchenvermögen, $\$ 107$ u. $\$$ 180; Gross ${ }^{8} 1922$, Lehrbuch, $361 \mathrm{f}$.

46 FranZ 1908, Studien, 119 f. u. 254.

47 Bernhauer 1989, Kirche, 646.

48 FranZ 1908, Studien, 252. 
jetzt über ein geregeltes Einkommen und eine einheitliche Ausbildung verfügte, wurden die Reformen des Staatskirchentums im Hinblick auf das Kirchenvermögen wenn schon nicht in allem zur Gänze goutiert so doch immerhin weitgehend akzeptiert. ${ }^{49}$ In Summe blieb die Finanzgebarung des katholischen Religionsfonds jedoch weitgehend passiv. Seine durch die vielfältigen Aufgaben zumeist negativen Bilanzen mussten regelmäßig aus Staatszuschüssen abgedeckt werden..$^{50}$

Der Vorwurf einer im Allgemeinen inkonsequenten wie sprunghaft agierenden Politik Josephs II.$^{51}$ bestätigte sich im Besonderen am Beispiel des katholischen Religionsfonds. Die vorwiegend kirchliche Kritik an den vermeintlich aus der Finanznot für die Reform heraus gesteuerten Klosterauflösungen ${ }^{52}$ ist freilich nicht gänzlich von der Hand zu weisen. Insgesamt wäre es indes verfehlt, den Josephinismus ähnlich der französischen Aufklärung als von vornherein kirchenfeindlich zu deuten. Die Kompromisshaltung stand hier deutlich im Vordergrund und war weithin entscheidungsbestimmend. ${ }^{53}$ Die verdichtet formulierte Einschätzung von Hermann Franz über den Religionsfonds als einer zentralen, den Josephinismus verkörpernden Idee ist von diesem Standpunkt aus sicherlich weitgehend zuzustimmen: "Die josephinischen Reformen entbehren vielfach des geschlossenen, festen Aufbaues. Sie stellten eine Verbindung von finanzpolitischen, sozialreformerischen und reformkirchlichen Absichten dar. Sie können fast alle als einzelne, selbständige Reformwerke angesehen werden, aber auch mit manchem Recht als Teil der großen, umfassenden, im Religionsfonds verkörperten Idee. $\aleph^{54}$ Dass sich hingegen mit dem Religionsfonds auch die "Idee von der Einheit [... des] Landes« verband und "diese Idee im josephinischen Staate zur Rechtsauffassung geworden ist " $"$, trifft aus verschiedenen Gründen für den katholischen Religionsfonds weit weniger zu - wie noch eingehend darzulegen sein wird - als für den einzigen ostkirchlichen, den gr-orient. Religionsfonds der Bukowina.

\footnotetext{
49 VAlJavec ${ }^{2} 1945$, Josephinismus, 66.

50 HUSSAREK 1909, Religionsfonds, 94; zur gleichen Einschätzung gelangen schon zuvor RIEHL \& REINÖHL 1881, Kaiser, 98: „Der Religionsfond reichte auch in der Folgezeit niemals für die kirchlichen Zwecke aus, so daß der Staat immer wachsende Zuschüsse leisten mußte.«

51 SCHINDLING 1997, Aspekte, 690.

52 BenEDikT 1947, Kaiser, 160.

53 ARETIN 1985, Josephinismus, 519.

54 Franz 1908, Studien, VI.

55 Franz 1908, Studien, 240.
} 


\section{Gründung des griechisch-orientalischen Religionsfonds}

Hatten die im Zentrum des Reiches gesetzten Reformschritte Kaiser Joseph II. zunächst lediglich den Rahmen für umfassende Veränderungen in der Verwaltung der habsburgischen Territorien definiert, so stand jetzt die schwierige Umsetzung dieser Vorhaben in den Regionen bevor.

So wurde etwa ein markanter Eckstein für die Entwicklung der Orthodoxie innerhalb des Habsburgerreiches im letzten Drittel des 18. Jahrhunderts gesetzt. Das Jahr 1774 leitete dabei das allmähliche Hereinnehmen der Oberen Moldau bzw. der Bukowina wie das Gebiet von österreichischer Seite wenig später offiziell tituliert wurde ${ }^{1}$ - in den unmittelbaren habsburgischen Herrschaftsbereich ein. ${ }^{2}$ Im Gegensatz zu Siebenbürgen und dem Banat, die beide zu diesem Zeitpunkt bereits seit Jahrzehnten unter Wiener Einfluss standen, wies die Bukowina in ihrer gesellschaftlich-konfessionellen Verfasstheit eine gänzlich andere Struktur auf. Die kurzzeitige Herrschaft der Habsburger über Teile Serbiens und der kleinen Walachei besitzt in dieser Hinsicht kaum eine eigene Bedeutung und ist hier daher nicht näher zu erörtern. ${ }^{3}$ Während der siebenbürgische Raum und (mit Einschränkung) auch das Banat vor allem auch durch ihre konfessionelle Struktur nach Westen hin orientiert waren, gehörte die Bukowina als Teil der Moldau in einen Kulturkreis, dessen Quellen spirituell gesellschaftlicher Entwicklung weitestgehend in Kiew und vor allem in Byzanz bzw. im Patriarchat von Konstantinopel lagen. Daran änderte die Ausbreitung des Osmanischen Reiches nur wenig. In seiner inneren Verfasstheit blieb die Moldau gegenüber der Hohen Pforte zwar ein tributpflichtiges, jedoch im Inneren suzeränes Fürstentum mit einer mehrheitlich orthodoxen Bevölkerung. ${ }^{4}$

\section{Kirchliche Ausgangssituation}

Mit der Aussteckung habsburgischer Adler entlang der äußeren Grenzen der Bukowina zum Osmanischen Reich hin ${ }^{5}$ richtete sich einerseits die politische Valenz der Oberen

1 SCHARR 2010, Landschaft, 121-142.

2 Obwohl sich im 18. Jahrhundert im Allgemeinen die Bezeichnung orthodoxe Kirche allmählich durchsetzte, bestand in der Habsburgermonarchie die offizielle Benennung griechische bzw. griechisch-orientalische Kirche bis zu deren Auflösung 1918 fort; in Dokumenten des ausgehenden 18. Jahrhunderts trifft man vereinzelt auf griechisch-schismatische Kirche oder in Unterscheidung zu den Unierten auch die lateinische Variante graeci ritus non unitorum.

3 BRUNNER 1930, Osterreich.

4 Im Überblick MURgeSCU 2006, Länder.

5 SCHARR 2010, Landschaft, $132 \mathrm{f}$. 
Moldau erstmals eindeutig nach Westen aus. Andererseits geriet damit eine vergleichsweise homogen strukturierte, in Zahl und Verbreitung weitgehend orthodox gläubige Bevölkerung zu Untertanen eines katholischen Fürsten, des Kaisers, in Wien. ${ }^{6}$ Die nationale Differenz zwischen orthodoxen Ruthenen und Rumänen der Bukowina ist ein erst Jahrzehnte später während der zweiten Hälfte des 19. Jahrhunderts zum Tragen kommendes Phänomen. Zunächst spielte dieses im Bewusstsein wie Handeln der Gläubigen, die für die Kirche als Einheit galten, keine Rolle. ${ }^{7}$ Das sich in der Bukowina mit der österreichischen Verwaltung josephinischer Prägung etablierende normative Rechtsverständnis eines direkten Abhängigkeitsverhältnisses zwischen dem Staat - vertreten durch den Landesfürsten bzw. Kaiser - und der Kirche ${ }^{8}$ war der Orthodoxie im Gegensatz zur katholischen Kirche zu diesem Zeitpunkt in Form der traditionellen Symphonia keinesfalls fremd. ${ }^{9}$ Dieses Verhältnis ermöglichte staatlichen Behörden ein weitreichendes Mitwirken innerhalb der orthodoxen Kirche. ${ }^{10}$ Das Fehlen eines christlichen Herrschers seit der Eroberung Konstantinopels hinterließ im byzantinischen Raum eine entsprechende Lücke, in die regionale Landesfürsten drängten. Der Patriarch, der sich nach wie vor in Istanbul befand, hatte hierauf keinen wesentlichen Einfluss. ${ }^{11}$

Hinsichtlich der Religionsausübung verfügten die orthodoxen Christen auf dem Gebiet der Habsburgermonarchie schon seit 1761 über weitgehende Freiheiten in der Öffentlichkeit. ${ }^{12}$ Die Toleranzgesetzgebung unter Joseph II. wandte sich dabei dementsprechend weniger der Orthodoxie bzw. der Kirchennation als Einheit selbst zu, sondern vielmehr den einzelnen Gläubigen. Das Patent vom 13. Oktober 1781 beseitigte die

6 Die Huldigung und Eidesleistung der Bukowiner Stände, als auch der Geistlichkeit fand am 12.X.1777 statt, ANR-B HKR III/12/1777 Eines an nach Comandirenden Generalen Feldzeugmeister Grafen von Siskovics [...] Rittmeisters von Linken dato Zallesczyki den 15. October 777 erstatteten Berichts.

7 TURCZYNSKI ${ }^{2} 1995$, Orthodoxe, 402.

8 VALJAVEC 1945, Josephinismus, 38.

9 Innerhalb des Patriarchates von Konstantinopel und der osmanisch verwalteten wie dirigierten Gebiete galten die Bischöfe der griechischen Kirchen durch das Millet-System als staatsrechtliche Institution « mit eigenem Jurisdiktionsbereich. Das begründete für die Hohe Pforte ein selbstverständliches Entscheidungsrecht etwa bei der Einsetzung von Kirchenhierarchen, aber umgekehrt ebenso eine nicht unerhebliche Einschränkung kirchlicher Autonomie; SUTTNER 2007, Staaten, $181 \mathrm{f}$.

10 SUTTNER 1989, Staat, 347.

11 "Was die äusserliche Aufsicht über die Kirche in der Moldau anlangt, so kömmt diese allein dem Fürsten zu, welcher fleissig und sorgfältig darauf Acht hat, daß der Wandel und die Lehre der Geistlichen mit den Grundsätzen des wahren Glaubens überein kommen«; CANTEMIR 1771/1973, Beschreibung, 320 u. 324 ; IORGA 2011, Istoria, 8 of.

12 PRокschi 2007, Kirche, 78. 
Beschränkungen des persönlichen Karriereaufstiegs, der bislang in erheblichem Maße von der religiösen Zugehörigkeit abhängig gewesen war. ${ }^{13}$ Das bedeutete in der Folge auch einen freien Zugang orthodoxer Christen zur höheren Bildung, was andererseits wiederum im Sinne der Staatsraison den Reformvorhaben in der Bukowina in die Hand spielte, wie das persönliche Beispiel des Bojaren Basilius Balsch unterstreicht. ${ }^{14}$ Die Veröffentlichung des Patentes hielt der kommandierende General der Bukowina indes fast ein halbes Jahr bis zum 7. April 1782 zurück. General Karl Freiherr von Enzenberg befürchtete, dass dies in einer Provinz »ungleiche Eindrücke« hervorrufen musste. Einerseits liefen zur gleichen Zeit Verhandlungen über die Diözesanregulierung. Zum anderen musste Enzenberg unbedingt den Verdacht entkräften, mit dem Toleranzpatent seitens des Staates auch in der Bukowina eine Kirchenunion herstellen zu wollen. Zudem waren hier die allermeisten Ruthenen des Landes ganz im Gegensatz zum benachbarten Galizien-Lodomerien nicht-uniert. ${ }^{15}$

Der mit der Pfarr- und Diözesanregulierung von Joseph II. im Habsburgerreich in Gang gebrachte Prozess zielte hauptsächlich auf eine starke zentralstaatliche Durchdringung des Raumes und der Gesellschaft auf allen Ebenen ab. ${ }^{16}$ Hier griff die Wiener Verwaltung bewusst auf frühere Erfahrungen zurück, die gezeigt hatten, dass gerade die Pfarrämter einigermaßen erfolgreich als Institutionen des Konsolidierungsprozesses durch den Staat herangezogen werden konnten. ${ }^{17}$ Aus diesem Blickwinkel wirkt es umso verständlicher, dass die Reorganisation der kirchlichen Verhältnisse als Fundament staatlicher Ordnung gerade in der Bukowina von ebenso zentraler wie primärer Bedeutung war, mehr vielleicht als in den alten Kron- und Erbländern, die auf einer weitgehend gefestigten ständischen wie staatlichen Grundstruktur ruhten.

Auf das ordnende Potential der Kirche für die Bukowina hatte bereits der erste Landesadministrator der Bukowina, Gabriel Freiherr Splény von Miháldy, in seiner Beschreibung des Bukowiner Distrikts verwiesen, deren Anregungen wegweisend für die fortschreitende Landeseinrichtung werden sollten. ${ }^{18}$ Enzenberg, der Splény als militä-

13 SUTTNER 1981, Toleranzgesetzgebung, 100; ders. 2009, Kirche, 160.

14 Zur Person Balschs vgl. Ceaușu 2007, Iluminist.

15 »[...] man müsse bei dem ohnehin finsteren Volke jeden Schein einer irrigen Auffassung des erst in diesem Jahr publicierten Toleranzpatentes vermeiden «; Ministerium f. Cultus u. Unterricht 1782, ad. Nr. 19.IV.a.3., Enzenberg, Czernowitz v. 13.VII.1782, zit. nach ZIeglaUeR 1896, Bilder III, 103.

16 OTRUBA 1985, Staatshaushalt, 198.

17 Göszy bezieht sich hier auf das frühe 18. Jahrhundert unmittelbar nach dem Ende der osmanischen Herrschaft in den Gebieten südlich der Donau; GöszY 2014, Konsolidierung, 210.

18 "Alle diese Clerisey ist ohne aller Wissenschaft und die Unwißenheit erstrecket bey denen mehresten auch auf die Glaubenssachen. Ihr Privat-Lebenswandel will eben auch nicht allerdings belobet werden, doch wißen sie durch die Hypokrisie des allzustrengen Fastens die Einfalt des Pöbels in 
rischer Verwalter der Bukowina nachgefolgt war, hob denn auch diesen josephinischen Grundsatz der Reform von Kirche und Religion als den zentralen Ansatzpunkt für eine tiefgreifende Umgestaltung dieser Provinz im Sinne des Staates besonders hervor, nicht ohne gleichzeitig auf drängende Verbesserungsschritte aufmerksam zu machen: „So nöthig eine gute Polizei, das Justizwesen, die gute Bestellung des Ackerbauers und der Landwirtschaft und die Ordnung überhaupt einem gesittet werdenden Lande ist, ebenso nöthig ist die gute Bestellung der Geistlichkeit, der Kirche und die strenge Darobhaltung einer Religion, ohne welche der Pöbel als der mehrste Haufen der Menschen nicht wohl in Furcht, Gehorsam und gehörigen Schranken weder zum Nutzen des Staates noch des Gemeinwesens selbst gehalten werden kann [...]. Leider nur zu weit ist die Bukowiner und die Moldauer Geistlichkeit aller Klassen von dieser Grundlage entfernt. « ${ }^{19}$

\section{Diözesanregulierung \& Einrichtung des Fonds}

In kirchlicher Hinsicht war die Bukowina zu diesem Zeitpunkt zweigeteilt. Der größere, südliche Landesteil unterstand in ecclesiasticis der Metropolie von Jassy, wohingegen der Norden in die Diözese des Bischofs von Radautz fiel. Die gesamte Provinz gehörte in die Jurisdiktion des Metropoliten von Jassy, Gavril Callimachi, von dem gleichzeitig auch alle orthodoxen Klöster der Oberen Moldau abhängig waren. ${ }^{20}$ Das Eigentum an Grund und Boden der angesprochenen Diözese und Metropolie in der Oberen Moldau erstreckte sich zudem über die neu gezogene Grenze - sowohl im Fürstentum Moldau wie umgekehrt - hinweg, was abseits der ohnehin komplizierten kirchlichen Situation zusätzlich für erhebliche Schwierigkeiten bei der Landeseinrichtung durch Wien sorgte.

Obwohl Enzenberg in seiner Beschreibung der orthodoxen Geistlichkeit des Landes insgesamt ein wenig schmeichelhaftes, dennoch kritisch differenziertes Zeugnis ausstellte, so fand er indes für den Bischof von Radautz durchaus lobende Worte. Aus seiner Sicht führte der Geistliche einen "gerechten und auferbauenden, stillen und eingeschränkten Lebenswandel «. ${ }^{21}$ Diese im Vergleich zum Metropoliten von Jassy ungleich positivere Charakteristik mag wohl ebenso bewusst platziert wie ausschlaggebend gewesen sein für den aus Wiener Perspektive letztlich günstigen Ausgang der Verhandlungen hinsichtlich der anstehenden Diözesanregulierung.

engen Feßeln zu erhalten«; PoleK (Hg.) 1893, General; zit. nach Grigorovici 1998, Bucovina, Absatz 147, 76.

19 Denkschrift Enzenberg v. 30.X.1779 Das Geistlich- und Kirchenwesen; zit. nach Zieglauer 1893, Bilder I, 51 .

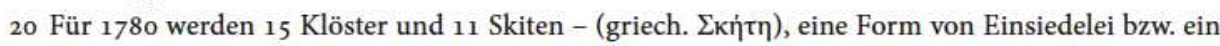
kleineres Kloster - angegeben; DACZ 29/1/8 Ausweiß Über die Buckoviner Orthschaften 1780.

21 Enzenberg (s. Anm. 19); zit. nach ZIEGLAUeR 1893, Bilder I, 54. 
Wien war über die Situation der Klöster in der Bukowina durch die seit 1774 regelmäßig eingehenden Berichte und Beschreibungen von Friedrich $\mathrm{Mieg}^{22}$, Splény ${ }^{23}$, Enzenberg und Basilius Balsch bestens informiert. ${ }^{24}$ Für die Administration bot nicht nur der Umstand, dass die meisten Basilianerklöster überaus vermögend waren, einen Anreiz, gerade hier mit der Reform anzusetzen und deren weitere Schritte aus diesem Kapital zu finanzieren. ${ }^{25}$ Die Tatsache, dass allein der jeweilige Igumen ${ }^{26}$ in Abstimmung mit dem noch dazu außerhalb der Bukowina im Fürstentum Moldau residierenden Metropoliten über die Vermögensgebarung der Klöster bestimmen konnte, widersprach den zentralstaatlich orientierten Vorstellungen josephinischer Politik. ${ }^{27}$ Darüber hinaus gestaltete sich als Folge der in den westlichen Ländern der Krone bereits eingeleiteten Kirchenreformen die Stimmung jener vor Ort eingesetzten Beamtenschaft gegenüber der in ihren Augen unzumutbar bremsend wirkenden Kirche ohnedies mit massiven Vorbehalten. Die in der Bukowina angetroffene, zumeist wesentlich ärmlichere und mit den katholischen Klöstern nicht zu vergleichende Situation der Basilianer verstärkte diese negative Grundhaltung nur. Entsprechend wiederholen sich diese stereotypen Bilder in den diversen Berichten. Viele Weltgeistliche vermochten weder zu lesen noch zu schreiben und hatten damit nur einen äußerst eingeschränkten Zugang zu den Neuerungen ihrer Zeit. ${ }^{28}$ Das durch die Reformen verunsicherte »Mönchen-Volck « erschien den zumeist zugezogenen oder in Wien ausgebildeten Beamten als »ungesittet, abergläubisch, und ohne in das innere eines Gegenstandes zu dringen, [als] halsstarrig «. ${ }^{29}$ Ausgesprochen kompromisslose Josephinisten wie der Lemberger Universitätsprofessor Balthasar Hacquet konnten in der Existenz von Geistlichen im Allgemeinen und

22 Major Friedrich v. Mieg führte um 1774 eine erste Rekognoszierung der Bukowina durch, worin der beträchtliche Klosterbesitz erstmals systematisch aufgenommen wurde; POLEK (Hg.) 1897, Beschreibung, 12.

23 Splény verfasste als Militäradministrator zwischen 1774 und 1778 insgesamt drei Denkschriften über die Bukowina; Polek (Hg.) 1893, General.

24 Einen Uberblick zur Ausgangssituation der Bukowina am Beginn der österreichischen Herrschaft bietet Polek (1894, Reisen, 34-37); SCHARR 2010, Landschaft, v.a. Kapitel 6 (Innere Verwaltungsentwicklung).

25 "Der geistl. Stand in der Buccovina [... ] machet den ersten Stand aus, und übersteiget weit den weltlichen am Vermögen und am Bestand der Güter«; ANR-B HKR VI/48/1781 Protokoll 14. Sitzungd. Staatsrates v. 12.VI.1781, fol. 25.

26 Auch Hegumen, Klostervorsteher in orthodoxen Klöstern.

27 "Die Macht des Radaunczer Bischofs war bisher nicht weiter, als auf die zu seiner Dioces gehörigen Popen gegangen «; ANR-B HKR VI/48/1781 Protokoll 14. Sitzung d. Staatsrates v. 12.VI.1781, sowie Enzenberg (s. Anm. 19); zit. nach ZIEGLAUER 1893, Bilder I, 55.

28 Enzenberg (s. Anm. 19); zit. nach Zieglauer 1893, Bilder I, 53.

29 Balsch nach PoLeK 1895, Reisen, 107. 
von Klostergeistlichen im Besonderen ohnedies kaum einen Nutzen für den modernen Staat erkennen. Aus seiner Sicht führten die Mönche ein »lockeres, säuisch, mäßig und müßiges Leben $[\ldots]$ in der größten Unwissenheit«, zudem würden sie ihre Untertanen "unmenschlich « behandeln. ${ }^{30}$

Splény hatte in seiner Landescharakteristik bereits den Nachteil einer "Vermischung der geistlichen Jurisdiction des dies- und jenseithigen Cordons « für den Staat hervorgehoben. In Hinsicht auf das Klostervermögen der Bukowina trat Splény für eine Konfiszierung desselben ein. ${ }^{31}$ Sein Nachfolger Enzenberg schlug daher vor, das formelle Einverständnis des Patriarchen von Konstantinopel vorausgesetzt, eine von Jassy unabhängige Diözese der Bukowina zu gründen. Dem Bischof von Radautz war dabei die Jurisdiktion in ecclesiasticis vollständig zu überlassen. Im Gegenzug sollte ihm jedoch "alle Gelegenheit benommen werden, auf dass er sich mit weltlichen Dingen und ökonomischen Gegenständen, die sich mit dem heiligen Wesen unmöglich vereinbaren können, abzugeben nicht gemüßigt wäre «. Klostergüter wie bischöflichen Besitzungen wären allerdings einzuziehen und eine Erstattung $a b$ arario zu leisten ${ }^{32}$ Der in österreichischen Diensten stehende und bereits in Wien ausgebildete Basilius Balsch riet zur Einrichtung eines Konsistoriums, das sich - finanziert durch die zusammengeführten Klostereinkünfte - um die innere Kirchenverwaltung kümmern sollte. ${ }^{33}$ Unter dem Vorsitz des Bischofs von Radautz, dem Mitwirken der Klostervorsteher sowie zweier weltlicher Räte hätte dieses Gremium seiner Meinung nach der kirchlichen Zersplitterung entgegenzuwirken, aber ebenso die Wirtschaftsagenden zusammenzuziehen. ${ }^{34}$ Damit war die Grundidee des gr.-orient. Religionsfonds für die Bukowina zeitlich noch vor der Einrichtung des katholischen Fonds formuliert worden.

Die Umsetzung des Vorhabens musste indes aus verschiedenen Gründen aufgeschoben werden. Auf mehrfaches Drängen der Wiener Stellen, besonders des Staatskanzlers Kaunitz, hatte die Bukowiner Distriktseinrichtung außenpolitisch in dieser Angelegenheit auf die Pforte und den Fürsten der Moldau Rücksicht zu nehmen. Dort wollte man angesichts der kritischen Lage, in der sich das Osmanische Reich seit 1774 befand, allen Neuerungen, welche auch die eigenen Untertanen betroffen hätten (und dazu gehörte

30 SCHARR 2004, Karpaten, 67; die Originalarbeiten von Hacquet sind online unter Austrian Literature online [http://www.literature.at/default.alo] zugänglich.

31 »Meiner Meinung nach könnte bei der Klostergeistlichkeit füglich alles fiscalisch angesehen werden, was selbe über erste Fundation an Einkünften besitzen «; zit. nach Grigorovici (Hg.) 1998, Bucovina, 78 u. $182 \mathrm{f}$.

32 Enzenberg (s. Anm. 19); zit. nach Zieglauer 1893, Bilder I, $146 f$.

33 Balsch geriet durch seine Tätigkeit und Eigeninitiative in eine Konfliktlage zum Landesverwalter und dem Bischof; vgl. SCHARR 2010, Landschaft, 154; CEAUșu 2007, Iluminist, 122-130.

34 Balsch nach PoLeK 1895, Reisen, 107. 
die ebenso weitreichende wie grenzübergreifende Arrondierungspolitik in der Bukowina), aus dem Weg gehen. ${ }^{35}$ Von einem Austausch der Klostergüter in der Moldau nahm Wien auch aus innenpolitischen Bedenken gegenüber der Bevölkerung vorerst Abstand. ${ }^{36}$ Eine offensichtlich an die erste Welle der katholischen Klostersäkularisierungen angelegte Resolution des Kaisers, auch in der Bukowina Aufhebungen zu veranlassen und »die Einkünfte den Religionsgenossen in der Provinz zu Nutzen kommen « zu lassen, war zudem angesichts der allgemeinen Situation im Inneren des Landes realistischer Weise vorerst nicht umsetzbar. ${ }^{37}$ Dementsprechend berief Wien für diesen Schritt eine eigene Kommission ein, der auch Balsch angehörte, um letztlich Gewissheit über die tatsächlichen Verhältnisse der Klöster zu erlangen. ${ }^{38}$ Das anvisierte Ergebnis dieses Auftrages, nämlich »vom Vergangenen einen Abschnitt zu machen«, d.h. vor allem die Güteradministration der Klöster auf einen neuen Fuß zu stellen, hatten die Wiener Stellen jedoch eindeutig vorgegeben. ${ }^{39}$ Damit wurde parallel zur ebenfalls erst im Aufbau begriffenen politischen Verwaltung ein zweiter Prozess, jener der geistlichen Landeseinrichtung in Gang gesetzt. Beide Prozesse verlangsamten sich zeitweilig - abseits der politischen Verwicklungen - durch die gelegentliche Überforderung des eigenen Verwaltungssystems gegenseitig, musste sich doch »jeder wichtige Fall zumeist durch die Stufenreihe der Behörden abhandlungsmäßig durchwinden «. ${ }^{40}$

Als ersten Schritt der Diözesanregulierung leitete die Verwaltung im Frühjahr 1781 die Entflechtung der beiden Kirchenprovinzen in der Bukowina ein. Die Jurisdiktion des Erzbischofs und Metropoliten von Jassy wurde gänzlich aufgehoben und dem Bischof von Radautz zugewiesen. Dositheus Hereskul ( $\uparrow 1789$ ), blieb amtierender Bischof

35 Protocollum commissionis sub 4 ta Aprilis 1780 Viennae habitae in Angelegenheit der Buccowiner Districts-Einrichtung, Punkt 23, abgedruckt in PoleK 1895, Reisen, 83; auch BIDermanN 1875, Bukowina, 16; OSTA-AVA Karton 230 Mappe 62 ex dic 1780.

$36 »[\ldots]$ dermalen aber hiemit vorzugehen, scheint um so weniger räthlich, da nach Aufhebung der Geistlichen Jurisdiction gleich hierauf eine solche Neuerung zu veranlassen einen allzu unrichtigen Eindruck unter der Nazion machen könnte«; ANR-B HKR VI/40/1781 Kaunitz a. HKR, Wien v. 2.VI.1781.

$37 \mathrm{DACZ}_{320 / 1 / 26}$ Allerhöchste Resolution in Betreff der Aufhebung einiger Klöster und der Verwendung ihres Vermögens $\mathrm{Nr}$. 2239, Wien v. 27.XI.1781.

38 "Von dem weiteren Vorschlage, alle Einkünfte der Klöster zusammen zu ziehen und durch das Consistorium und die Administration verwalten zu lassen, kann dermahlen noch kein Gebrauch gemacht werden, da es vorerst noch auf die Erhebung des Vermögensstandes der Klöster und Geistlichen $[\ldots]$ ankommt «; DACZ 320/1/26 HKR a. galizisches Generalkommando Nr. 3837, Wien v. 27.III.1782.

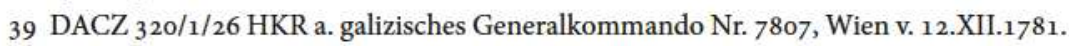

40 WiCkenhauser 1890 , Molda IV, 54 u. 57 f; z.T. finden sich die bei Wickenhauser verwendeten wie in der Folge zitierten Quellenstellen auch bei ZIEGLAUER (1893-1904, Bilder I-X) abgedruckt. 
(vgl. Abb. 18). Er war seit 1750 Igumen des Klosters Putna gewesen. ${ }^{41}$ Ebenso unterstellte Wien dem damit exemten Bischof der Bukowina alle Klöster des Landes. ${ }^{42}$ Noch im gleichen Jahr ordnete der Hofkriegsrat an, den Sitz der Diözese nach Czernowitz zu verlegen und »die Installation des Bischofs durch die Distrikts-Administration in der Hauptkirche von Czernowitz vorzunehmen ${ }^{43}{ }^{43}$ Der Metropolit konnte dem kaum etwas entgegensetzen. ${ }^{44} \mathrm{Ganz}$ im Sinne der damit geschaffenen neuen Verhältnisse überreichte Enzenberg im Rahmen der Einsetzungsfeierlichkeiten dem Bischof, nach dessen in Lateinisch (sic!) vorgetragenen Treueschwur, im Namen des Kaisers ein Goldkreuz. ${ }^{45}$ Die Verlagerung des Bischofssitzes fand während des Jahres 1782 statt. Bis zur Fertigstellung eines geeigneten Amtsgebäudes in Czernowitz durch die Militäradministration 1783 musste Hereskul allerdings bei seinem Bruder Ilie in beengten Verhältnissen Quartier nehmen. ${ }^{46}$ Als Diözesanhauptkirche stand vorerst lediglich die kleine Holzkirche zur Heiligen Dreifaltigkeit zur Verfügung, die Nistor im Rumänischen so bildhaft mit $o$ mică bisericuță din lemn beschreibt. ${ }^{47}$

Ebenfalls 1781 konstituierte sich in Czernowitz weitgehend nach den ursprünglichen Vorschlägen Balschs das Konsistorium, eine Einrichtung, die in der orthodoxen Kirche

41 Rum. Dosoftei Herescul, vgl. Zieglauer 1893, Bilder, 50, Anm. 28; Nicolae Iorga bezeichnete Hereskul als "Metropolit ohne Patent" und Anerkennung, als einen »orientalischen Kirchenfunktionär « der österreichischen Regierung: „Era un fel de Mitropolit cu patentă de la Viena, fără titlu și fără recunoaștere în cuprinsul lumii ortodoxe, un funționar bisericesc de nuanţă răsăriteană al guvernului statelor austriece"; IORGA 2011, Istoria vol. 2, 179.

42 DACZ $_{320 / 1 / 26}$ HKR a. galizisches Generalkommando Nr. 3753, Wien v. 13.VI.1781; Nr. 6963, Wien v. 3.XI.1781.

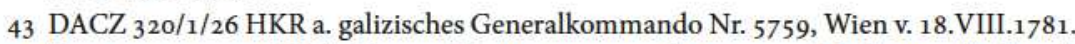

44 Zieglauer 1895, Bilder II, 156; Nistor unterstreicht in seiner Kirchengeschichte, dass die österreichische Historiographie diesen kanonisch fragwürdigen Vorgang der Einschränkung kirchlicher Freiheit beschönigt hätte; NisToR 2003, Istoria, 4 u. 7. Zieglauer stellte diese Umstände jedoch keineswegs in Abrede; allerdings fehlte auf der moldauischen Seite mit Ausnahme des Grundsatzes der Symphonia - wo dem Metropolit eine Stellvertreterrolle des Fürsten zukam, letzterer jedoch in allen Dingen bestimmend war - eine zeitgenössisch vergleichbare Kirchenordnung; vgl. BRUSANOWSKI 2011, Kirchenordnungen, 12; dem Metropoliten von Jassy verblieb als einzige kirchenrechtliche Verbindung zur Bukowina danach nur noch das Patronat über die St. Georgs-Kirche in Suceava; Nistor 2003, Istoria, 15; seit 1873 bildete die Bukowina eine Metropolie. Erst mit 1990 konnte die rumänische Kirche diese Aufteilung (zumindest für den südlichen rumänischen Landesteil) rückgängig machen. Die Südbukowina als Erzbistum mit Sitz in Suceava (Arhiepiscopia Sucevei şi Rădăuților) wurde dabei neuerlich der Metropolie der Moldau mit Sitz in Jassy zugeordnet (Mitropolia Moldovei şi Bucovinei), vgl. [http://patriarhia.ro/].

45 Enzenberg a. HKR Czernowitz v. 16.II.1782; zit. nach ZIEGLAUER 1896, Bilder III, 35.

46 Zieglauer 1895, Bilder II, 163.

47 "Ein kleines Kirchlein aus Holz«. NISTOR 2003, Istoria, 4. 
bislang unbekannt war. ${ }^{48}$ Die Sitzungen jedoch mussten mangels probater Unterbringungsmöglichkeiten noch im Administrationsgebäude der Landesverwaltung stattfinden. ${ }^{49} \mathrm{Um}$ die an sich positive Haltung Hereskuls gegenüber Wien nicht zu untergraben, forderte der Hofkriegsrat von der Landesverwaltung ausdrücklich ein, dass »alles mit Wißen, Einwilligung und Zuthun des Bischofs von Radauncz (sic!) eingeleitet" werden müsse. ${ }^{50}$ Letztlich hatte sich aber der gesamte Klerus der Bukowina nolens volens allen Entscheidungen des Kaisers zu fügen, auch wenn sie zunächst noch formal durch den Bischof und das Konsistorium angenommen werden mussten. ${ }^{51}$

Basierend auf den von Enzenberg eingereichten Vorschlägen trat Wien über die Bukowiner Administration zunächst mit Hereskul in Verhandlungen ein. Ihm sollte - ganz im Sinne der auf ähnliche Weise später zu regelnden Einkünfte der Weltgeistlichen durch die Abtretung seiner persönlichen Güter ein jährlich fixiertes Gehalt zugesichert werden $^{52}$, von dem »er und seine Nachfolger für ihren Charakter ganz anständig leben können «. Zusätzlich wäre der Bischof - so die Wiener Argumentationslinie- der leidigen »Verwicklung mit den Pächtern«, die sich aus zahlreichen Grund- und Rechtsstreitigkeiten ergab, entledigt. ${ }^{53}$ Lediglich sein Gut in Radautz sollte dem Bischof, nachdem dieser ausdrücklich darauf bestanden hatte, auf Lebenszeit bleiben. ${ }^{54}$ Mehrfach geäußerte Befürchtungen seitens Hereskuls, dass die Güter der Kirche an Private verkauft werden könnten, bemühte sich der Hofkriegsrat hingegen tunlichst zu entkräften,

48 IORGA 2011, Istoria vol. 2, 179.

49 In diesem Gremium war außer dem Bischof und zwei weltlichen Beisitzern nur noch ein Igumen vorgesehen; DACZ $320 / 1 / 26$ HKR a. galizisches Generalkommando Nr. 5373, Wien v. 21.VIII.1781 (ksl. Handbillet v. 18.VIII.) u. Nr. 7807, Wien v. 12.XII.1781.

50 ANR-B HKR VI/48/1781 Protokoll 14. Sitzung d. Staatsrates 12.VI.1781, fol. 26.

51 ANR-S Colecţia Documente, pach. VI/19/1782; zit. nach CEAUȘU 2007, Iluminist, 121.

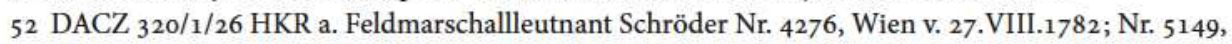
Wien v. 12.X.1782; OSTA-HHSTA Kabinettskanzlei Bd. 27 (1783), 451f., Nr. 506 Joseph II. an Feldmarschallleutnant Schröder, Lemberg v. 25.VI.1783; dem Bischof wurde ein jährliches Salaire von 6000 sowie zusätzlich durch den Kaiser ad personam 2000 Gulden verfügt.

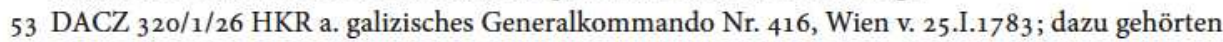
auch die häufigen Grund- und Grenzstreitigkeiten der Klöster untereinander, für die der Bukowiner Bischof nunmehr auch zuständig war; WICKENHAUSER 1890, Molda IV, 55.

54 Landesverwaltung a. galizisches Generalkommando v. 26./27.II. bzw. galizisches Generalkommando a. HKR v. 2.III.1783; zit. nach WICKENHAUSER 189o, Molda IV 78; DACZ $320 / 1 / 26$ HKR a. Enzenberg Nr. 1913/1914, Wien v. 19.IV.1783; nach dem Tod Hereskuls erfolgte die Verwaltung der Herrschaft Radautz zunächst durch die Staatsgüteradministration in Eigenregie, 1792 ging die Herrschaft in das Eigentum des Religionsfonds über, wurde jedoch an die k.k. Gestütsanstalt des HKR und ab 1818 auf Basis einer kaiserlichen Entscheidung an die Gestüts-Remontierungs-Anstalt des Militärs gegen einen jährlichen Pachtzins vergeben; OSTA-KA VIIh 127-3 Beschreibung der Herrschaft Radautz $1833,13 \mathrm{ff}$. 
wusste man doch um die Vorbildwirkung eines einvernehmlichen Abkommens mit dem Bischof für die Klöster. An der Verwaltung der betroffenen Güter sowie ihrer Einkünfte sollten sowohl der Bischof als auch das Konsistorium Anteil nehmen. ${ }^{55}$ Die bischöfliche Herrschaft über das Gut Kotzmann (mit den Dörfern Kotzmann, Suchowerchow, Kliwodyn, Dawidestie, alt und neu Lastiowka [Sadowa] sowie die zwei moldauischen Dörfer Haworna und Nowosielitza) gingen im Frühjahr 1783 zunächst in den Staatsschatz ein und ab 1785 schrittweise in den Religionsfonds über. ${ }^{56}$ Nicht nur Wien, sondern vor allem auch die Landesverwaltung hatten zu diesem Schritt gedrängt, da man für den Raum zwischen Pruth und Dnister die Unterbringung von Kolonisten vorgesehen hatte, wofür de facto erst damit geeignete und eben - wohl mithin auch aus diesem Grund bereits ausgemessene Güter für den Ackerbau zur Verfügung standen. ${ }^{57}$ In ähnlicher Weise sollte sich Wien wenig später der Religionsfondsgüter bedienen. So gelangten nach Entschluss des Kaisers 1784 etwa auf den Religionsfondsherrschaften Kuczurmare und St. Illie Lippowaner (russische Altgläubige) zur Ansiedlung. ${ }^{58}$

Erst die im Frühsommer 1783 von Joseph II. unternommene Reise in die Bukowina brachte durch die persönliche Anwesenheit des Kaisers auch für den weiteren Reformprozess einen maßgeblichen Schub mit sich. Obwohl die Gespräche mit Hereskul zur Abtretung seiner Güter als auch die Angelegenheiten um die Klosterkapitalien weitgehend von der Landesadministration vorangetrieben worden und im Sommer $1783 \mathrm{ab}$ schlussreif waren, so konnte doch die von Joseph II. eingeforderte Kirchenregulierung der Bukowina nicht gänzlich ohne Rücksichtnahme auf den Fürsten der Moldau und die

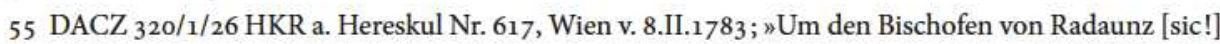
auf eine ganz unmerkbbare Art in eine gewisse Verbindlichkeit von der stetshinigen Erfüllung der diesseitigen Absichten zu bringen, muss derselbe vördrist das Allerhöchste Wohlgefallen über sein zeitheriges Betragen und dessen zur werkthätigen Vollziehung Sr. Majestät Gesinnung bereits zu vernehmen geweste Äusserungen und ausserdeme noch weiter zu empfinden bekommen«; HKR a. galizisches Generalkommando, Wien v. 21.VIII.1781; abgedruckt bei PoLEK 1895, Reisen, 118.

56 Enzenberg a. galizisches Generalkommando v. 12.IV.1783; zit. nach WICKENHAUSER 189o, Molda IV, 65; ein genaues Übergangsdatum lässt sich jedoch nicht ermitteln; 1801 werden etwa die Güter Kotzmann (Bischof), Kimpolung (kaiserlich) und Zuczka (einem auswärtigen Kloster gehörig) in den Religionsfonds eingelöst, OSTA-FHKA Domänenakten 1801/o75 Exp. 17/1288, fol. 82, VI.1801; zu den Orten vgl. Tab. 1.

57 ANR-B HKR XI/21/1783 Enzenberg a. galizisches Generalkommando (bzw. HKR) v. 20.I.1783; das erklärt die im Wesentlichen nur im Raum zwischen Pruth und Dnister zwischen 1782 und 1783 durchgeführte Josephinische Katasteraufnahme (Oberst Metzger); PALDUs 1916, Einverleibung, 446 U. 449 SOWie SCHARR 2010, Landschaft, 107 U. 182.

58 Rumpler \& Scharr (Hg.) 2015, Kataster; KAINDL 1896, Entstehen, 25 (257) ff. u. 96 (328); Staatsarchiv L'viv 146/4/911 (auch ANR-B Inv. 3117 Colecţia Consiliul de Miniștri, 13) Relation des Hofrates Hochkirchen über Zustände in Bukowina 1804, fol. 19. 
Hohe Pforte umgesetzt werden. Der Kaiser sah sich daher schon am zweiten Tag nach seiner Ankunft in Czernowitz - am 19. Juni - veranlasst, gegenüber Kaunitz in einem Schreiben die ihm offensichtlich lästigen »differentes insinuations de la part de plusieurs Bojars de la Moldavie et particulierement de Canti-Cuzene« dezidiert anzumerken. Der Adel erwartete sich zwar einen gewissen Schutz gegenüber der Pforte, brachte in der Situation des Neuverhandelns der Macht zugleich jedoch eine Reihe von Forderungen vor. ${ }^{59}$ Die Bojaren und mit ihnen Teile der Bevölkerung hatten dabei - begünstigt durch die dominierende Wirtschaftsweise der Transhumanz - stets die Möglichkeit, sich vergleichsweise schnell dem kaiserlichen Zugriff zu entziehen, indem sie sich in die Moldau absetzten. ${ }^{60}$ Diese diplomatisch zum Teil heikle Situation sollte sich noch in extenso bei den kommenden Verhandlungen um die außerhalb der Bukowina in der Moldau gelegenen Religionsfondsgüter auswirken.

Den Schlussstein für die kirchenrechtliche Neuaufstellung des Bistums Bukowina hingegen setzte der Kaiser bereits nach der schon erwähnten Loslösung vom Metropolitanverband Jassy (1781) im Juli 1783 durch die Zuordnung der Diözese in dogmaticis et mere spiritualibus als Suffraganbistum der Metropolie von Karlowitz. ${ }^{61}$ Eine kirchenpolitische Einmischung des Metropoliten von Jassy in innere Angelegenheiten der Bukowina war damit nicht mehr möglich. Dieser den Reformgedanken der Deckungsgleichheit von Staats- sowie Kirchengrenzen entspringende Akt begründete in der Bukowina (im Verband mit der Reorganisation der Provinz insgesamt) weit mehr als in anderen Kronländern letztlich jene Autonomie und jenes Selbstbewusstsein für die gr.-orient. Landeskirche, die für die Identität dieser Provinz am Ende des 19. Jahrhunderts zur entscheidenden Größe heranwachsen sollte. ${ }^{62}$ Zunächst schlug Wien noch den Religions-

59 OSTA-HHSTA Kabinettskanzlei Bd. 27 (1783), 435, Joseph II. a. Kaunitz, Czernowitz v. 19.VI.1783. 60 SCHARR 2010, Landschaft, 184; Enzenberg forderte eine schnelle Einziehung des Klostervermögens, da es seiner Meinung nach "keinen [sic!] Zweifel unterliegt, dass bei einer Regulirung der Klöster die Kaluger nicht mit ihrer Barschaft, mit Vieh und Habe in die Moldau hinüber gehen «; der Igumen von Woronetz konnte "mit Habschaften, Vieh und Geld in die Moldau entweichen"; Bericht Enzenberg, 27.IV.1781 und Bericht der Landesverwaltung sowie Verständigung d. Bischofs, v. 10.VII. bzW. 24.VIII.1782, zit. nach WICKENHAUSER 1890, Molda IV, 52 u. 60.

61 OSTA-HHSTA Kabinettskanzlei Bd. 27 (1783), 44of., Joseph II. a. Hadik, Czernowitz v. 19.VI.1783 sowie DACZ $302 / 1 / 26$ HKR a. galizisches Generalkommando Nr. 3469 v. 4 .VII.1783, auch bei PoLEK 1895, Reisen, 134.

62 Die um die Wende vom 19. zum 20. Jh. geäußerte (und bis in die Gegenwart vielfach für die rumänische Historiographie prägende) Sichtweise des rumänischen Historikers Nicolae Iorga, dass `Österreich ‘ das "Prestige, den kulturellen und nationalen Wert der rumänischen Kirche der Bukowina" damit ruiniert hätte, ist zwar aus dem Blickwinkel des zeitgenössischen nationalstaatlichen Denkens nachvollziehbar, sie blendet jedoch einseitig die in dieser Zeit erreichte Autonomie der Bukowiner orthodoxen Kirche und den davon nicht zu trennenden wirtschaftlichen Erfolg des gr-orient. Reli- 
lehrer Daniel Wlachowicz aus Suczawa - der sich zu diesem Zeitpunkt bereits seit drei Jahren in der Bukowina befand und auch die Landessprache ausreichend beherrschte zum Bischofsamt vor. In der Folge bemühte sich Wien bei den Bischofsernennungen um geeignete Persönlichkeiten, die aus der Provinz selbst stammten. ${ }^{63}$

Die zwischenzeitlich vom Konsistorium eingeleitete Untersuchung der Klöster gestaltete sich indes als "voller Mühe und Verdriesslichkeit", da von mehreren Igumen überhaupt keine Angaben zu erhalten waren, sodass den Vorstehern von vornherein eine weltliche Aufsicht zur Seite gestellt werden musste. ${ }^{64}$ Das konnte allerdings nicht verhindern, dass Klostervorsteher in einzelnen Fällen trotzdem abgesetzt und zur Rechenschaft gezogen wurden. ${ }^{65}$

Durch die Umorientierung der Diözese und die gleichzeitige Einschränkung des nunmehr zuständigen Metropoliten von Karlowitz auf dogmatische und geistliche Angelegenheiten, hatte Wien freie Hand in der weiteren Vorgehensweise bezüglich der Klöster und ihres Vermögens. Noch in Czernowitz veranlasste daher Joseph II. »in Ansehung des geistlichen Fachs [...] daß die Verminderung, und Zusammenziehung der Callugier Klöster ohne weiteres vor sich gehe, daß ihre Gebäude und Fonds alle in die Administration genommen [...] und aus dem hieraus entstehenden ganzen Fundo der gesammte griechische Clerus unterhalten, und wenigsten eine Schule es sey zu Suczava oder zu Czernowitz errichtet werde«. ${ }^{66}$ Die Auflösung betraf bis auf Putna (als Grablege Stefan des Großen), Suczawitza und Dragomirna, dem als Grenzbefestigung eine gewisse militärische Bedeutung zukam, alle Klöster der Provinz. ${ }^{67}$ Lediglich das

gionsfonds gänzlich aus; IoRG A 2011, Istoria vol. 2, 183. Ceauşu unterstreicht mehrfach im schroffen Gegensatz zu Iorga die positiven Folgen des durch den Josephinismus mit den Reformen in der Bukowina begründeten und im Vergleich zur Moldau günstigeren Klimas von Gleichheit und Freiheit; Ceauşu 1993, Aspecte, 402; 1996, Politica, 156 und 2008, Reformen, 64.

63 OSTA-AVA Kultus AK gr--or. Karton 2, Nr. 1354 v. 11.IV.1789 (Nachfolge Hereskul); Nr. 3659 v. 14.VII.1823 und $26469 / 1362$ ad 14.VII.1823 (Isaias Balescheskul); Wlachowitz war am 7.IX.1822 in Dorna Watra verstorben, detto Nr. $3085 / 1835$.

64 "[...] ohne dessen Mitwissen kein Klostervorsteher über Empfang und Verwendung der Einkünfte eine Disposition treffen möge"; ANR-B HKR VI/48/1781 Protokoll 14. Sitzung d. Staatsrates v. 12.VI.1781, fol. 27.

65 WiCKenHAUSER 1890, Molda IV, $55 \mathrm{ff}$.

66 OSTA-HHSTA Kabinettskanzlei Bd. 27 (1783), 44of., Joseph II. a. Hadik, Czernowitz v. 19.VI.1783 sowie HKR a. galizisches Generalkommando Nr. 3469, Wien v. 4.VII.1783; auch bei PoLEK 1895 , Reisen, $133 \mathrm{f}$.

67 Die Angaben über die Gesamtanzahl der in der Bukowina befindlichen Klöster schwanken. Das mag z.T. damit begründet sein, dass die im Vergleich zu den Klöstern kleineren Skiten schlechter oder kaum dotiert waren und oftmals (abhängig von den dort lebenden Mönchen) nur eine unsichere 
Nonnenkloster Petroutz erwirkte einen vorläufigen Aufschub und wurde zu Lasten des Religionsfonds auf einen Aussterbeetat gesetzt. ${ }^{68}$ Dieser Entscheidung waren zum Teil heftig geführte Verhandlungen zwischen den betroffenen Parteien vorangegangen. Im März 1784 legten die Igumen der Klöster Putna, Suczawica, Dragomirna, Solka und Woronetz bei der Landesverwaltung Protest gegen das Vorhaben der Klosterauflösung wie Kirchenregulierung ein und baten gleichzeitig um die Erlaubnis, geschlossen in die Moldau auswandern zu dürfen. Gegen den Willen Enzenbergs betrieb der Hofkriegsrat zunächst eine Politik des Lavierens, die darauf hinauslief, die swiderspenstigen Igumen von ihrem Dienst zu suspendieren. Joseph II. konnte dieser Haltung zwar nichts abgewinnen, wollte aber einmal eingeleitete Maßnahmen nicht mehr rückgängig machen, um weitere Verstimmungen hintanzuhalten. ${ }^{69}$ Dennoch merkte er in seiner Resolution kritisch gegenüber seiner Behörde an, dass mit »einem solchen Volke keine Umwege gesucht werden müssen, sondern man muß dem klar und deutlich sagen, was man haben will, um bei demselben nicht Mißtrauen, Widerwillen und endlich wohl gar Widerspenstigkeit entstehen zu machen ${ }^{70}{ }^{70}$ Obwohl ein Massenabzug der Mönche aus der Bukowina letztlich ausblieb, entschieden sich doch einige mit der Auflösung der Klöster und Beschränkung der Anzahl von Mönchen, sofern sie sich nicht der Weltgeistlichkeit zuwandten, in moldauische Klöster jenseits des Cordons einzutreten. ${ }^{71}$

In der Umsetzung der weitreichenden Klosterauflösung war Wien von Beginn an auf eine peinliche Trennung der Religionskasse - die unbedingt vor Ort bleiben sollte - von

Existenz besaßen. Zum anderen wurden schon vor 1783 Klöster aufgehoben und in den Quellen nicht immer klar zwischen beiden Klosterformen unterschieden. 1780: 26 (DACZ 29/1/8 Ausweiß; s. Anm. 20); Balsch: 26 Basilianerklöster (ANR-B HKR V/20/1780 Vortrag a. Kaiser); ebenso viele nennt eine zeitgenössische Statistik; ANONY MUS 1779, Karte; Enzenberg: 21 (zit. nach ZIEGLAUER 1893, Bilder I, 52); ein späterer Bericht des HKR zählt neun Männer- und ein Frauenkloster, von denen drei beibehalten wurden, alle Skiten kamen zur Auflösung; ANR-B HKR XXII/94/1786; KAINDL gibt 31 Klöster vor der Regulierung an (1896, Kaiser, 12), ONCIUL kommt auf 25 (13 davon Skiten, plus das in Galizien gelegene Groß-Skit; (1891, Fondul, 4f.); Onciul folgt den Angaben von Pumnul (1865, Privire, 9f.); Ceaușu zählt 20 (2008, Reformen, 59) und bezieht sich darin vermutlich auf Nistor, der neun große und elf kleinere Klöster erwähnt (2003, Istoria, 12); letztere Angabe dürfte wiederum dem zitierten Bericht des HKR entsprechen. Веі РАномг werden - allerdings für 1775 und ohne nähere Quellenangabe - 17 Klöster, 15 Skiten und vier Einsiedeleien (sowie 247 Kirchen) ausgewiesen (1998, Reforma, 67).

68 Zieglauer (1893) Bilder I, 152.1785 lebten in Petroutz noch 14 Nonnen, DACZ 29/1/42 Copia Einer Hof Kriegs Räthl. Verordnung Wien v. 15.X.1785, fol. 1 of.

69 ANR-B HKR XIII/18/1784, ausführlich dargestellt bei ZIEGLAUER 1897, Bilder IV, 157-205, bes. $174 \mathrm{ff}$.

70 Zit. nach Zieg LAUER 1897, Bilder IV, 191.

71 WiCKenhaUSER 189o, Molda IV, 107; IORGA 2011, Istoria vol. 2, 182. 
den anderen Landeseinnahmen bedacht, "um vorzüglich dem Volke in der Bukowina einen offenbaren Beweis zu geben «. Zudem versicherte der Hofkriegsrat, dass "alle Dispositionen hierüber [...] unter der Aufsicht und respective [dem] Vorwissen des Bischofs und des Konsistoriums" getroffen werden würden. ${ }^{72}$ Das geschah einerseits, um den nach wie vor bischöflicherseits eingebrachten Sorgen über die korrekte Mittelverwendung entgegenzuarbeiten. ${ }^{73}$ Zum anderen versuchte man damit, letzte Bedenken der Klostervorsteher zu zerstreuen, dass die Güter dem ursprünglichen Stifterwillen zweckentfremdet Verwendung finden könnten. ${ }^{74}$ Ende 1784 fand Wien zu einem Kompromiss mit der Kirche. ${ }^{75}$ J.J. Beck, der bisher Enzenberg in der Landesverwaltung zur Hand gegangen war, bekam die Verwaltung der Religionsfondsgüter mit den Wirtschaftsämtern in Kotzman, Zuczka, Kuczurmare, St. Onufri, Fratautz, St. Ilie, Ilischestie und Kimpolung überantwortet. Die reale Übertragung der Klostergüter in den Fonds und die Aufnahme der Arbeit folgten im Frühjahr 1785. ${ }^{76}$ Die Administration der Fondsgüter blieb vorerst beim Staat (Kameralärar). Der Fonds war in die Staatsgüterverwaltung eingegliedert und stand unter der Aufsicht der Kreisadministration sowie einer eigenen Kameralverwaltung mit Sitz im ostgalizischen Peczeniżyn unweit von Kolomea. ${ }^{77}$ Der Besitz des in Galizien gelegenen, jedoch zur Bukowina gehörenden bereits aufgehobenen orthodoxen Klosters Groß-Skit gelangte zur Aufteilung. Dabei musste ursprünglich von Bukowiner Klöstern übertragenes Eigentum restituiert werden, hingegen waren jene in der Bukowina und in der Moldau befindlichen reigentümlichen` Güter von Skit durch den Religionsfonds zugunsten des galizischen Normalschulfonds abzulösen. ${ }^{78}$ Mit der admi-

$72 \mathrm{DACZ}_{320 / 1 / 26} \mathrm{HKR}$ a. Enzenberg Nr. 151, Wien v. 10.I.1784, HKR a. galizisches Generalkommando Nr. 2484, Wien v. 8.V.1784.

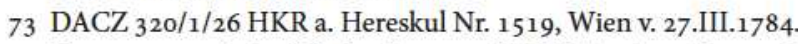

74 Bidermann (1875) Bukowina, 17; ANR-S Fond 11, Inv. 296 Diverse, 54/1784, HKR a. Konsistorium Czernowitz v. 29.IV.1784.

75 Nistor 2003, Istoria, 9.

76 Vortrag u. Entscheidung Joseph II. v. 26./27.XI., Erlass HKR v. 7.XII. a. galizisches Generalkommando a. Bukowiner Landesverwaltung v. 18.XII. a. Bischof u. Konsistorium v. 28.XII.1784; zit. nach Wickenhauser 1890, Molda IV, $118 \mathrm{ff}$.; einen detaillierten Überblick zu den Besitzungen der Klöster bzw. ihrer historischen Rechte sowie Stifter und Schenkungen bieten PumnuL (1865, Privire) u. Onciul (1891, Fondul); Pumnul gibt darin auch an, welche der ursprünglichen Güter sich 1865 noch im Besitz des Religionsfonds befanden; als Staatsgüteradministrations-Direktionen werden 1788 Fratautz, Kotzman und St. Illie ausgewiesen; OSTA-HHSTA Nr. 80 Fasz. 8 179o, Finalisierungsoperat, fol. 846; zu Struktur und zum Stand der Herrschaften 1801 vgl. Tab. 4.

77 OSTA-KA VIIh127-3 Beschreibung der Herrschaft Radautz 1833; HHSTA Faßbender Karton 4 X/4$\mathrm{XI} / 2$.

78 Oncivl 1891, Fondul, 122; DACZ 29/1/42 Copia Einer Hof Kriegs Räthl. Verordnung Wien 15.X.1785, fol. $11 \mathrm{f}$. 
nistrativen Eingliederung der Bukowina in das Königreich Galizien-Lodomerien 1786, d.h. dem Ende der Militäradministration, endete auch die Direktverwaltung der Provinz durch Wien. Beck erhielt die Stelle des Kreishauptmannes, ihm bzw. dem Kreisamt unterstand im Weiteren die Güterverwaltung des gr.-orient. Religionsfonds (im Rahmen der schon erwähnten allgemeinen Kameralverwaltung). Lemberg fungierte in diesen Belangen als nächst höhere Instanz. ${ }^{79}$ In der Realität freilich ließ die ausreichende Versorgung von Priestern und Bischof aus den Mitteln des Religionsfonds noch geraume Zeit auf sich warten und stellte sich keineswegs als ausreichend dar. So waren die Popen noch zu Beginn des 19. Jahrhunderts gezwungen, ihren Lebensunterhalt weitgehend aus dem ihnen zur eigenen Bearbeitung zugeteilten Grund und Boden zu bestreiten. Selbst der Bischof musste in "schmutzigen und zerfezten Meßgewändern pontifizieren « und die "Gemeinde auf dem Lande zur Begehung der Sontagmessen « die Kerzen selbst mitbringen, wie das etwas drastisch ein zeitgenössischer Bericht zum Ausdruck bringt. ${ }^{80}$

Der Hofkriegsrat, der schon knapp zwei Jahre zuvor den zentralen Stellenwert der Regulierung der Geistlichkeit für die Einrichtung der Provinz und den zentralstaatlichen Einfluss erkannt hatte, setzte sich letztlich in seiner Ansicht durch. ${ }^{81}$ Unter dem administrativen Dach des Religionsfonds vereinigten sich nunmehr alle eingezogenen Liegenschaften der aufgelösten sowie noch bestehenden Klöster. Die Kapitalien waren zur >Aufrechterhaltung der Religion` streng zweckgewidmet. Vor den Umstrukturierungen durch die Grundentlastung im Gefolge des Jahres 1848 gehörten allein 105 von 190

79 SChARR 2010, Landschaft, 162. Die gr.-orient. Kirche erinnerte - wie auch die Bukowiner Eliten die Zeit der galizischen Verwaltung und den Einfluss Lembergs weitgehend negativ: "Fondul religionariu se supuse Guvernului din Leov. Cum se vor fi administrat averile fondului pe timpul a cela nu pute dice nimica hotărât, dară de bună samă că aceasta nu s’a facut totdeauna în favorul bisericii ortodoxe.« [Der Religionsfonds wurde dem Gubernium in Lemberg unterordnet. Wir können nichts Konkretes darüber aussagen, wie das Vermögen des Fonds zu der Zeit verwaltet wurde, aber offensichtlich ist das nicht immer zugunsten der orthodoxen Kirche geschehen; Ubersetzung L. Madly]; NeșCIUC 1893, Istoria, 20.

80 Staatsarchiv L'viv 146/4/911 Relation, fol. 51 ff. u. 78 (s. Anm. 58); "während alle dortigen Pfarrer zum großten Scandal und Abwürdigung ihres Standes das Feld mit eigenen Händen bauen müssen, um sich kümmerlich zu ernähren!!!«; OSTA-HHSTA Faßbender Karton 4 X/4, fol. 729, Bericht der k.k. Peczenijczijner (Galizien) Kameralverwaltung v. 9.XII.1802.

81 "In den Händen der Geistlichkeit sind die meisten besitzungen, und in dieser ihrer Gewalt steht auch das Volk, es findet mithin der Hofkriegsrath für nothwendig, den anfang von einer dauerhaften nutzbaren Einrichtung der Bucowina dadurch zu machen, daß die Geistlichkeit auf eine solche Art, die beim Volk kein Ärgerniß, und nicht einmal eine besorgniß ein absehen auf die Religion wirken kan, auf ihren standsmäßigen Beruf zurückgesetzet, und eingeschränket, der Geistlichkeit ihre Gütter, und Wirtschaften [...] pro cassio eingelöset [...] und [...] denen Herzen des Volkes die noch völlig ermangelnde Bildung nach, und nach eingeflößet, und $\mathrm{d}$. Volk zu gehorsam gegen die weltliche Obrigkeit herbeygebracht werde«; ANR-B HKR VI/51, HKR a. Graf Hatzfeld Wien v. 16.VI.1781. 
Quadratmeilen der Bukowina in den Religionsfonds. Das waren mehr als zwei Drittel der Landesfläche. ${ }^{82}$ Von der 1837 laut Katastralerhebung ausgewiesenen produktiven bzw. landwirtschaftlich nutzbaren Fläche der Provinz mit knapp mehr als 1,7 Millionen niederösterreichischen Joch zählten 1854 immerhin noch etwas mehr als 505.000 in den dominikalen Besitz des gr.-orient. Religionsfonds. Die Dominien des Kameralärars als zweitgrößtem Grundbesitzer der Bukowina erreichten davon, weit abgeschlagen, nur knapp 142.000 Joch. ${ }^{83}$ Berücksichtigt man zudem die mit der Gründung des Fonds schon erwähnten rechtlichen Zugriffsmöglichkeiten Wiens, so ergaben sich daraus für den Zentralstaat in der Bukowina beträchtliche und direkt einsetzbare Machtmittel zur Gestaltung der Provinz.

Die praktische Implementierung vor Ort, „die Berichtigung des geistlichen Wesens und ihres Vermögensstandes « durch die Landesverwaltung zog sich indes noch Monate nach der Entscheidung Josephs II. hin und verlangsamte nicht unerheblich die weitere Landeseinrichtung insgesamt. ${ }^{84}$ Das erklärt mithin die vergleichsweise späte Vorlage des geistlichen Regulierungsplanes der Bukowina. Die Verzögerungen in der Einsetzung des Religionsfonds durch die mannigfachen Bedenken des Bischofs und des Konsistoriums, die vielfach in einem anderen Rechtsverständnis gründeten, hatten letztlich Wien von der dringenden Notwendigkeit einer grundlegenden Regulierung des Klerus und seiner Ausbildung überzeugt. ${ }^{85}$ Ein wesentlicher Anteil am Zustandekommen des Planes kam dabei, nach Einschätzung des rumänischen Historikers Mihai Şt. Ceauşu, dem Bukowiner Bojar Basilius Balsch zu. Joseph II. war während der Bereisung der Bukowina auf den jungen Balsch aufmerksam geworden und hatte ihn als Konzipist zur weiteren Ausbildung in den Hofkriegsrat geholt. ${ }^{86}$

Minutiös werden im geistlichen Regulierungsplan unter anderem die Größen sowie die Anzahl der neu zu ordnenden Pfarrgemeinden (jeweils abhängig von der Anzahl der dort siedelnden Familien), Ausbildung sowie Aufgaben der Popen, ihre Rechte bis hin zu den benötigten Kleidungsstücken, deren Kosten und deren Finanzierung gere-

82 KaINDL 1896, Kaiser, 14.

83 FiCKer (Hg.) 1854, Darstellung, 11 u. 13.

84 Enzenberg a. Hadik, Czernowitz v. 12.XI.1783, zit. nach WICKENHAUSER 1890, Molda IV, $96 \mathrm{ff}$.

85 Der Kaiser hatte nicht nur eine gediegene Religionsausbildung verlangt: „Auch muß von Karlowitz folglich ein geschickter, wohldenkender, der wallachischen Sprache gut kundiger, und in dem griechischen Religionsunterricht wohl erfahrener Mann hierher geschickt werden um sowohl dem Bischofe [...] als auch dem Consistorio und den Landes-Einwohnern die ächten Begriffe derselben beyzubringen«; OSTA-HHSTA Kabinettskanzlei Bd. 27 (1783), 440, a. Hadik Czernowitz v. 19.VI.1783.

86 ANR-B HKR XII/89/1783, zit. nach CEAUşU 2007, Iluminist, 133 u. 144f.; zuvor CEAUşU 1998, Bucovina, 109. 
gelt. ${ }^{87}$ Die Homogenisierung der Pfarrverteilung über die ganze Bukowina sollte nicht nur die Seelsorge und Bildung für alle Untertanen garantieren bzw. ihre jeweilige ökonomische Rechtfertigung vor Ort stärken, sondern wohl auch die staatliche Präsenz in allen Winkeln der Provinz, vertreten durch die orthodoxe Geistlichkeit. Noch vor dem endgültigen Abschluss des Regulierungsplanes war der Hofkriegsrat intensiv darum bemüht, in der Diskussion mit der Militärverwaltung der Bukowina (und dem Konsistorium), diesen Stellen die zentralen Inhalte einzuschärfen und damit mithin deren letztliche Umsetzung auch zu garantieren. Der 1786 vom Hofkriegsrat erlassene Plan für die Bukowina legte nunmehr - gleich in der Präambel - die Mittelverwendung aus dem Religionsfonds zum »ausgemessenen Unterhalt für die Geistlichen Personen, und für die Schulen blos, und allein zum wahren Besten des Klerus, der Religion und der Menschheit « definitiv fest. Als oberster Schutzherr fungierte der Kaiser. Ihm stand als Letztinstanz auch die jeweilige Befürwortung oder Ablehnung über den Mitteleinsatz zu. Dem Konsistorium hingegen fiel als zentrale Aufgabe im Wesentlichen die Verantwortung über die Ausbildung und die Aufsicht der Religionspflichten der Geistlichkeit (spiritualia und disciplinaria) zu. ${ }^{88}$ Neben dem Bischof, der den Vorsitz führte, bestand das Konsistorium aus einem Archimandriten, einem Igumen, vier weiteren Geistlichen und fünf weltlichen Kanzleikräften (davon zwei moldauische und zwei deutsche) sowie einer entsprechenden Dienerschaft zur Erledigung der Tagesgeschäfte ${ }^{89}$ Damit wich die Umsetzung nur geringfügig von den ursprünglichen Vorschlägen Balschs ab. Die letztliche Entscheidungsgewalt über die Mittel des Fonds wie ihre Verwendung waren dem Konsistorium damit de facto allerdings entzogen worden.

87 Dazu zählte besonders die Ausbildung sowohl von Klerus als auch der Bevölkerung, die mit Nachdruck anzuhalten war, ihre Kinder in die Schulen zu entsenden: »nach der bereits gegebenen Anleitung theils denen Eltern die Aufmunterung zum Schiken ihrer Kinder in die Schulen beyzubringen, theils deren Kindern die Lust zum Lernen einzuflößen und überhaupts alles mögliche anzuwenden ist, durch Ertheillung vom unterricht welcher vom Bischofen denen Pfarern aufgetragen, und in Gelegenheiten von ihm selbst gegeben werden soll«; DACZ 29/1/42 Copia Einer Hof Kriegs Räthl. Verordnung Wien v. 15.X.1785, fol. 5 f.

88 Der Regulierungsplan v. 29.IV.1786 ist in mehreren Abschriften in Archiven vorhanden (etwa DACZ 321/1/326), abgedruckt findet er sich erstmals bei CALINESCU (Hg.) 1887, Normalien 1, 28135; zuletzt nach Calinescu bei BRUSA NOWSKI 2011, Kirchenordnungen, 208-259.

89 DACZ $_{321 / 1 / 326}$ Regulierungsplan $\$ 69$, fol. 69v, bei BRUSANOW KSI 2011, Kirchenordnungen, 251. 


\section{Exkurs: Die Klostergüter um 1785}

Da eine lückenlose Darstellung aller in den Fonds eingebrachten Kloster- und Kirchengüter für das Jahr 1785 in den Archivbeständen nicht vorliegt, wird die Rekonstruktion über eine zeitnahe Aufstellung von 1780 versucht. Eine zeitgenössische, von der Militärverwaltung der Bukowina in Auftrag gegebene Karte der den "Klöstern eigenthümlich zugehörigen Ortschaften « bestätigt diese Liste und zeigt kaum Abweichungen dazu (vgl. Tab. 2). ${ }^{90}$

Vorerst verwaltete der Staat die Güter des Religionsfonds noch direkt. Von den 1780 mehr als 80 ausgewiesenen Klostergütern in der Bukowina war annähernd ein Drittel verpachtet und wurde entsprechend extensiv bewirtschaftet. Aus Sicht der zuständigen galizischen Staatsgüteradministration trug diese Wirtschaftsform zwei wesentliche negative Aspekte in sich. Einerseits befanden sich die Pächter nicht selten mit ihren Zahlungen im Rückstand, woraus wiederum langwierige Prozesse resultierten, auf die man schon im Zuge des Vergleichs mit dem Bischof von Radautz aufmerksam geworden war. Andererseits führte das landesübliche Pachtsystem zu einer regelrechten Ausbeutung der Güter wie Unterpächter selbst, bei einer gleichzeitig entsprechend geringen Bereitschaft zu investieren oder überhaupt Neuerungen einzuführen. Darüber hinaus fanden sich die Subpächter, ständig am Rande ihrer eigenen Existenz. Sie sahen oftmals nur noch in der Auswanderung die einzig ihnen verbliebene Möglichkeit, den drückenden Lasten zu entfliehen, wie das ein zusammenfassender Bericht an den Wiener Hofkriegsrat festhält: "Je länger die Pachtung also noch dauert, je sicherer ist es, daß der Religionsfond nebst ruinierten Waldungen, auch verarmte Unterthanen erhält. Die Bedruckung der Unterthanen auf Gütern, die in der 3 ten und 4ten Hand in Unterpacht stehen, ist unvermeidlich, auf wirkliche Verbesserungen sieht aber Niemand. ${ }^{91}$

Die zuständigen Behörden betrieben folglich eine schrittweise Auflösung der für die Landesentwicklung letztlich äußerst ungünstigen Pachtverhältnisse und zogen die Güter allmählich in die eigene Verwaltung und Bewirtschaftung. Dieser Prozess beanspruchte jedoch Jahrzehnte. Das zeigt sich etwa am Beispiel des Pächters Baron von Lezzeny, der Religionsfondsgüter der Herrschaft Kuczurmare und St. Onuphri seit 1789 in Erbpacht besaß. Trotz der 1791 auf eine kaiserliche Entschließung hin erfolgten Umwandlung in ein Zeitpachtverhältnis lassen sich die Prozesse um die von Lezzeny mehrfach einge-

90 AdLer 1784 , Karte.

91 OSTA-HHSTA Faßbender Karton 4 X/4, fol. 675 u. 727, Berichtsauszug Inspektor Paulj, Radautz v. 13.V.1802 sowie Bericht der k.k. Peczenijczijner Kameralverwaltung v. 9.XII.1802. 
klagte Güternutzung bis ins Jahr 1802 verfolgen. ${ }^{92}$ Das Pachtdilemma in der Bukowina wird noch 1804 ausführlich als ein grundlegendes Gebrechen der Bukowina geschildert, „denn die Pächter, dessen (sic!) Gewinnsucht der Bukowiner Unterthan nach dem allgemeinen Loose dieses Ländchens geopfert ist, finden ihr ganzes Interesse in dem größtmöglichen Vortheile des Augenblickes, und ganz und gar kein Interesse in der künftigen Wohlfahrt ihres momentanen Unterthans! $«{ }^{93}$ Die allgemeine wirtschaftliche wie politisch prekäre Situation des Habsburgerreiches begünstigte zudem - vor allem während der ersten beiden Jahrzehnte des 19. Jahrhunderts - kaum die dringend nötigen Reformschritte.

Ein eigenes Problem stellten die Herrschaften der moldauischen Geistlichkeit bzw. Kirche in der Bukowina dar. Ein erster Versuch Enzenbergs, über den Bischof von Radautz beim Metropoliten in Jassy einzuwirken und »demselben die Billigkeit begreiflich zu machen, damit der Hr. Metropolit diese Güter, da selbe zur Kirche in Sucawa gehören, anher abtrete«, musste schon allein wegen der von Wien politisch unabhängigen Stellung des Metropoliten erfolglos bleiben und offenbarte die Komplexität dieser Verhandlungen, zu denen eine gewichtige außenpolitische Komponente hinzukam. ${ }^{94}$ Auch die von Joseph II. geforderte Einziehung von Gütern, die Geistlichen gehörten, welche im Fürstentum Moldau lebten, konnte in dieser Form nicht durchgesetzt werden. ${ }^{95}$ Die von Wiens eingebrachte Unterscheidung zwischen in der Bukowina gelegenen Gütern des Adels und solchen der Kirche, die in der Moldau ihren Sitz hatten - erstere sollten ihren Besitz behalten, wohingegen jener der Kirche einzuziehen war - sowie der Stand ihrer letztlichen Realisierung, lassen sich in ihrer tatsächlichen Wirkung jedoch nicht mehr eindeutig rekonstruieren. Dementsprechend unklar bleibt das Schicksal des Besitzes der Metropolie von Jassy. Dieser wäre - so nicht der Metropolit als adliger Grundherr auftrat - nach Meinung des Hofkriegsrates »in das Eigentum des Landesfürsten « zu ziehen gewesen. ${ }^{96}$ Die Beantwortung dieser Frage muss hier allerdings offen gelassen werden.

92 OSTA-HHSTA Faßbender Karton 4 X/4, fol. 648, 683, 712 u. 723; auch KAINDL weist die Nutzungsstreitigkeiten zwischen Ansiedlern und dem Pächter Lezzeny nach; KAINDL 1896, Entstehen, 56 (288).

93 Staatsarchiv L'viv 146/4/911 Relation, fol. 14, 22ff. u. bes. 26ff., (s. Anm. 58).

94 Enzenberg a. Bischof v. 23.IX.1782, zit. nach WICKENHAUSER 1890, Molda IV, $6{ }_{3} f$.

95 OSTA-HHSTA Kabinettskanzlei Bd. 27 (1783), 440, a. Hadik Czernowitz v. 19.VI.1783.

96 ANR-B HKR VI/48/1781 Protokoll 14. Sitzungd. Staatsrates v. 12.VI.1781, fol. 29. 
Tab. 1: Grundbesitzverteilung in der Bukowina um $1780^{97}$

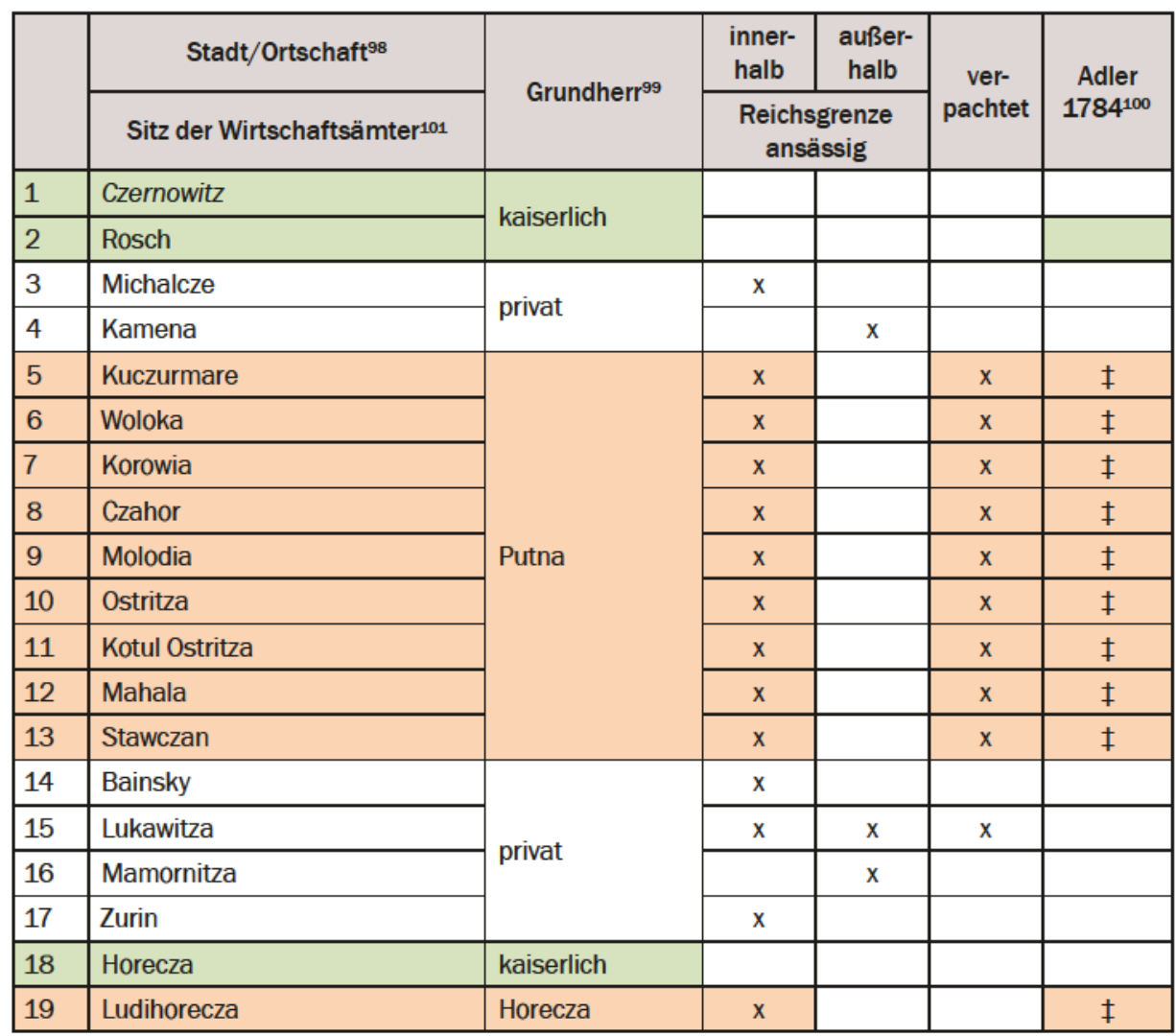

97 DACZ 29/1/8 Ausweiß Über die Buckoviner Orthschaften. Die Aufstellung findet sich in abgeänderter Form auch in SchaRR (2010) Landschaft, Tab. 9, 276ff. Die Nummerierung ist der Vergleichbarkeit mit den dort bereits publizierten Karten beibehalten worden.

98 Die Schreibweise der Ortschaften richtet sich nach der in der Volkszählung von 1910 üblichen. Wo sich die Toponyme der Quelle nicht jenen Ortsnamen von 1910 eindeutig zuordnen lassen, ist dies mit einem Fragezeichen und der in Klammer nachgestellten Form von 1780 kenntlich gemacht worden; vgl. Landesamt (1913) Ergebnisse.

99 Als Grundherr werden hier namentlich lediglich der Kaiser (späterer der Kameralfonds) bzw. die Kirche (Klöster, Bischof, Metropolie, Geistliche; späterer der Religionsfonds) ausgewiesen, alle anderen sind mit sprivat` bezeichnet.

100 Angegeben sind nur die 1784 noch als solche verzeichneten Kirchengüter nach Adler (1784) Auszug. 101 Fett gesetzte Ortschaften bezeichnen die Sitze der jeweiligen Güterverwaltungen um 1800 lt. OSTA-HHSTA Faßbender Karton 5 XI/3-XII MS XII, Ertragsausweis der Buccowiner Staats- und Fondsgüter 1801-1803. 


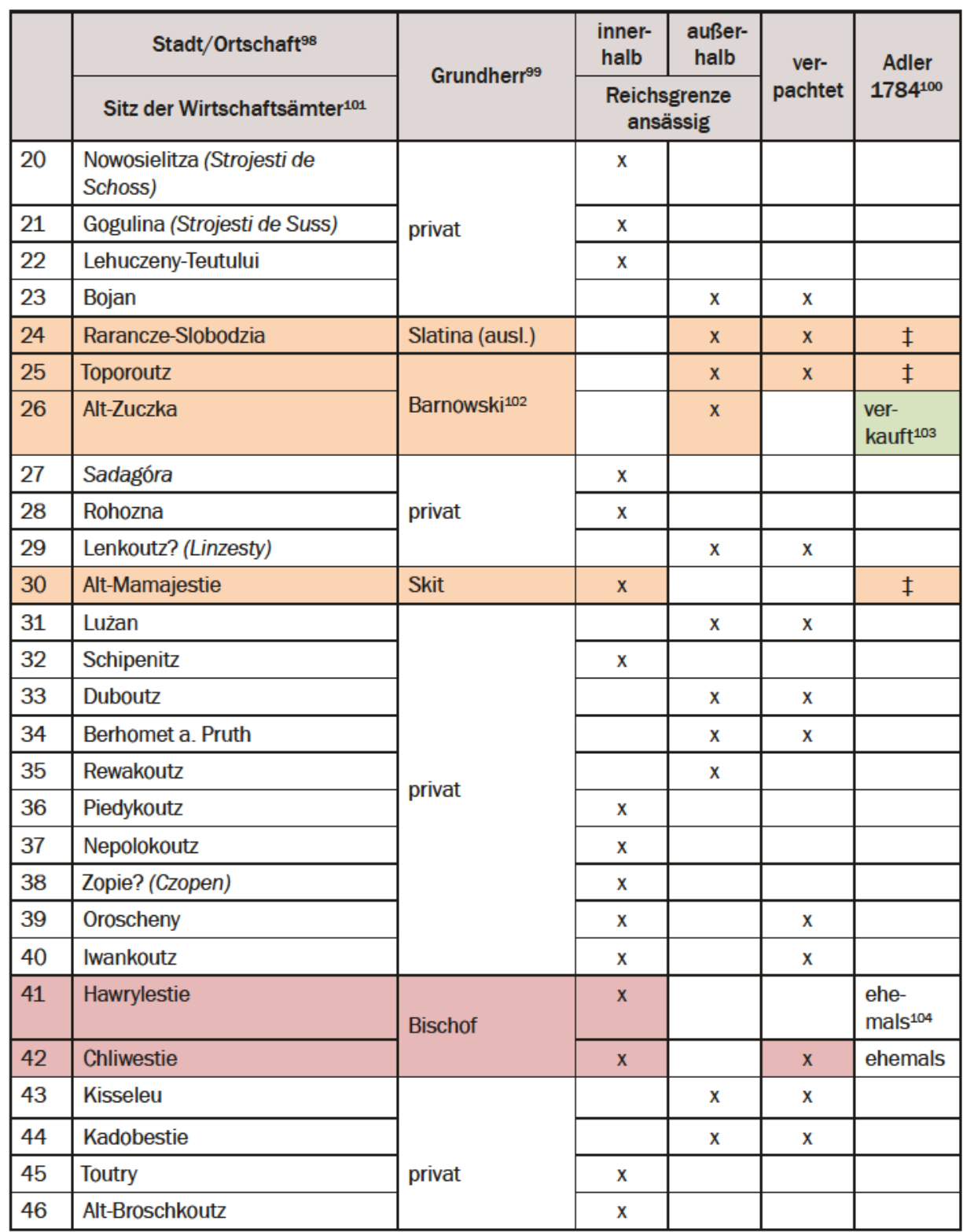

102 Heute Bănești?

103 Die Herrschaft Zuczka ging 1784 durch Kauf (1783) an den Kameralfonds über; vgl. Kaindl (1900)

Zuczka, 5 .

104 Dorfschaft ehemals bischöfliches Gut. 


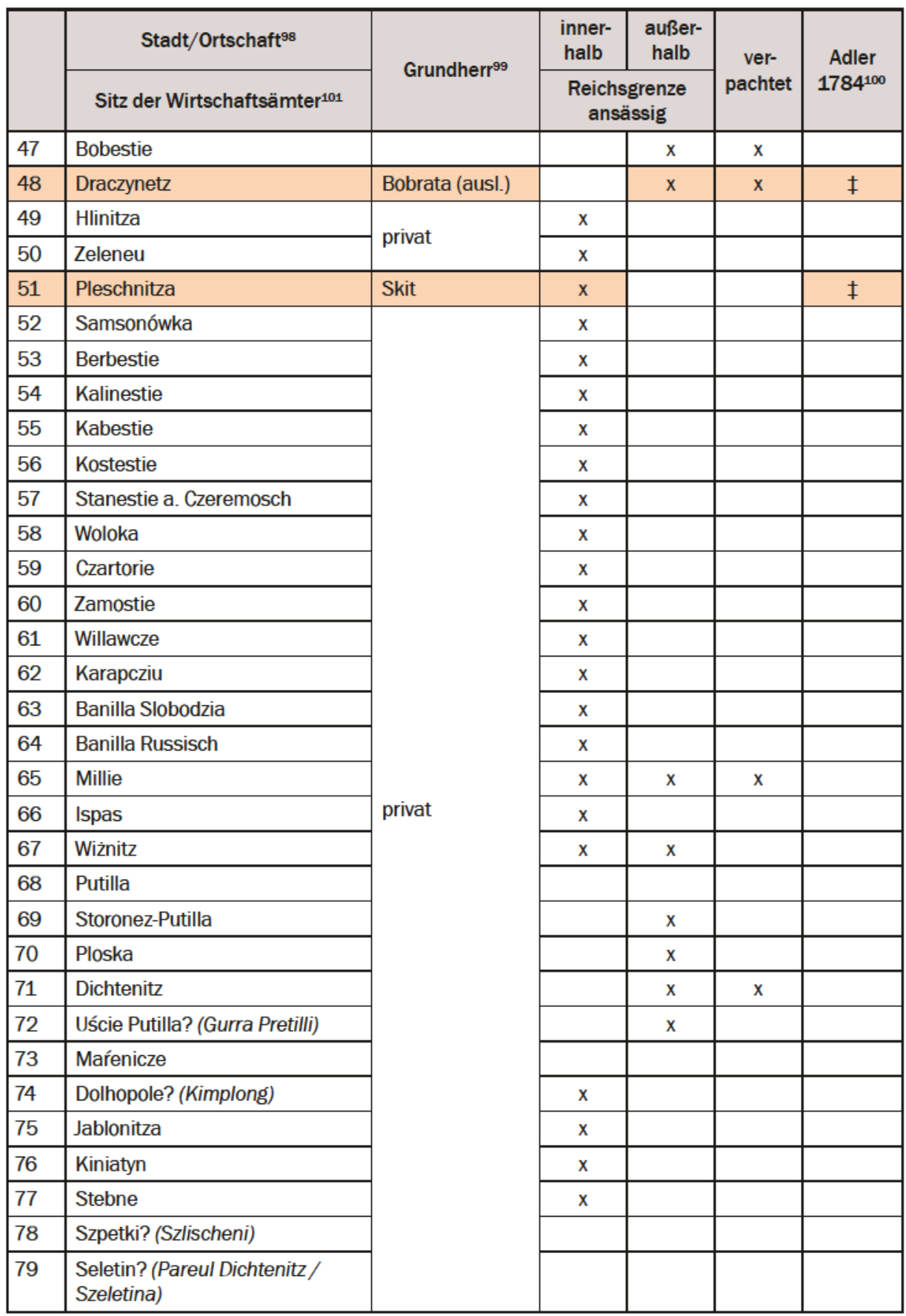




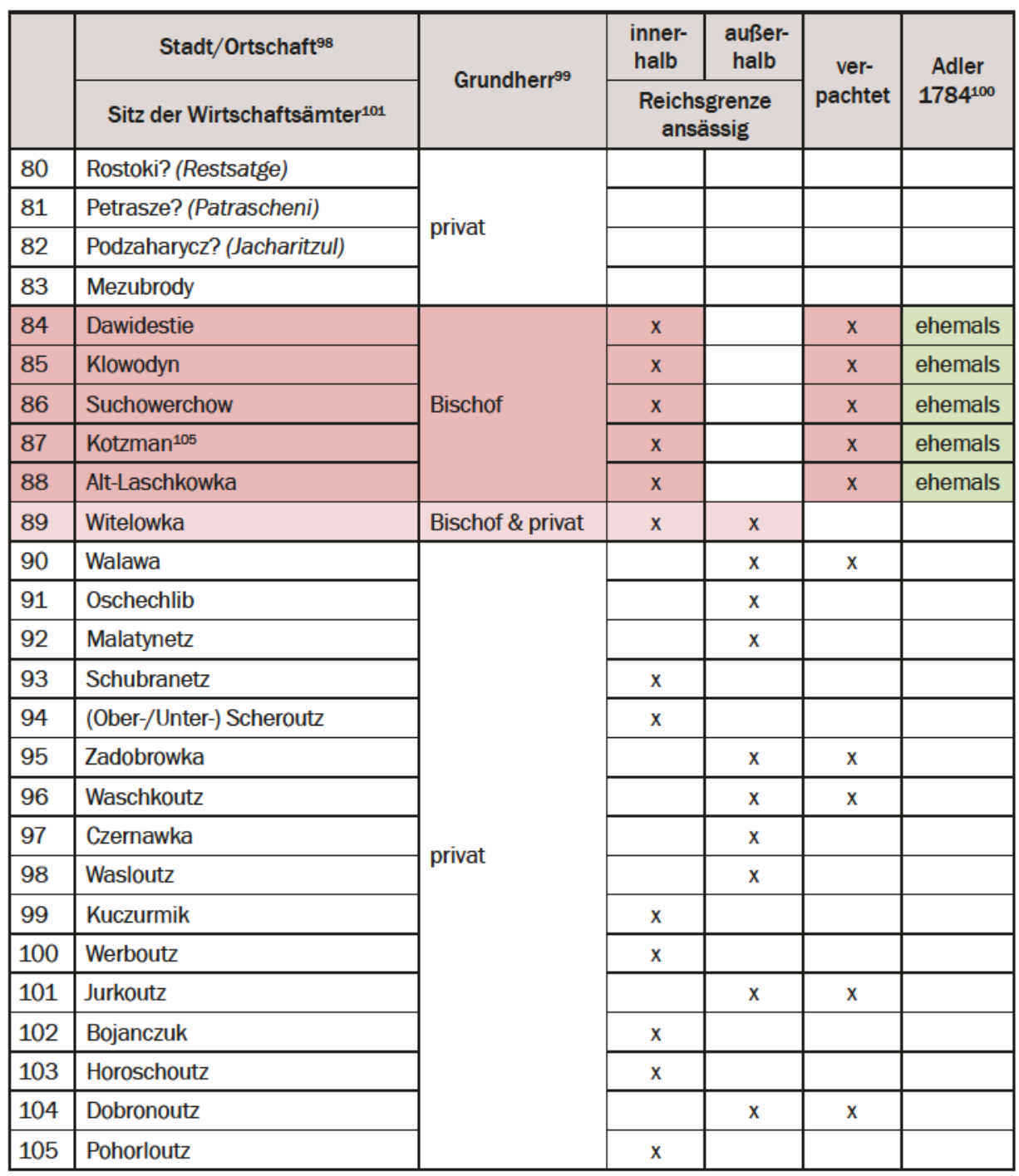

105 Zugleich Direktionssitz der Staatsgüterverwaltung; OSTA-FHKA Nr. 80 Fasz. 8 179o Finalisierungsoperat, fol. 846v. Das Staatsgut Kotzmann setzte sich 1797 aus den Dörfern Kotzmann, Altund Neu-Laszkowka, Suchowerka, Dawidestie, Chliwestie, Hawrylestie und Stawczan zusammen; OSTA-FHKA-NHK Dom. Staatsgüterbeschreibung Kotzmann im Bukowiner Kreis 1797 958.34 (die Schreibweise entspricht den Angaben in der Quelle!). Zur Herrschaft Kotzmann/Kuczurmare und St. Onufri 1862 vgl. die statistische Darstellung im Nachlass Kaindl, Universitätsarchiv Graz, Karton 5. (s. Quellenverzeichnis im Anhang). 


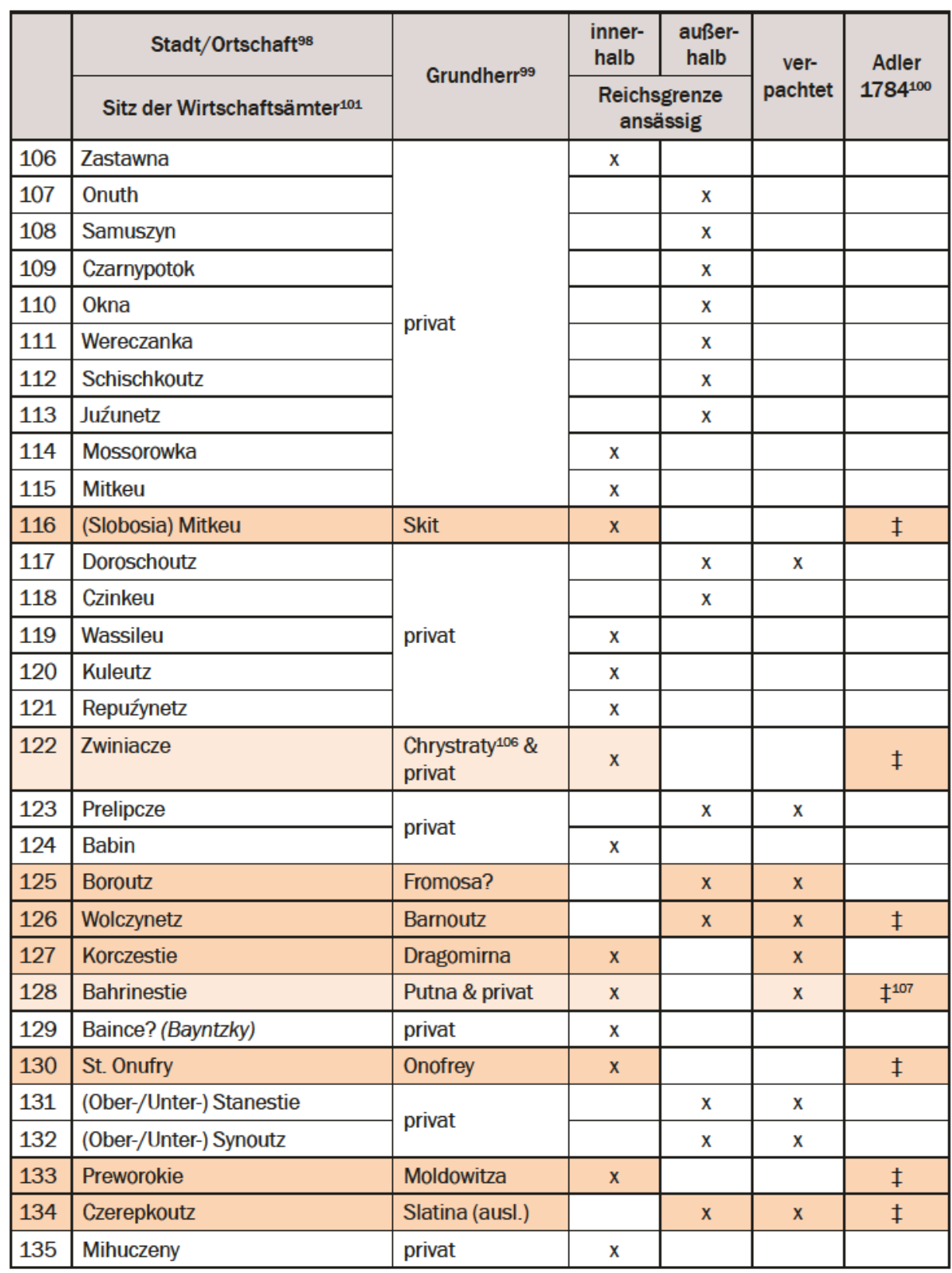

106 Bei Pumnul (1865) Privire, 10: Crișceátecul.

107 Dorfschaft einem ausländischen Kloster gehörig. 


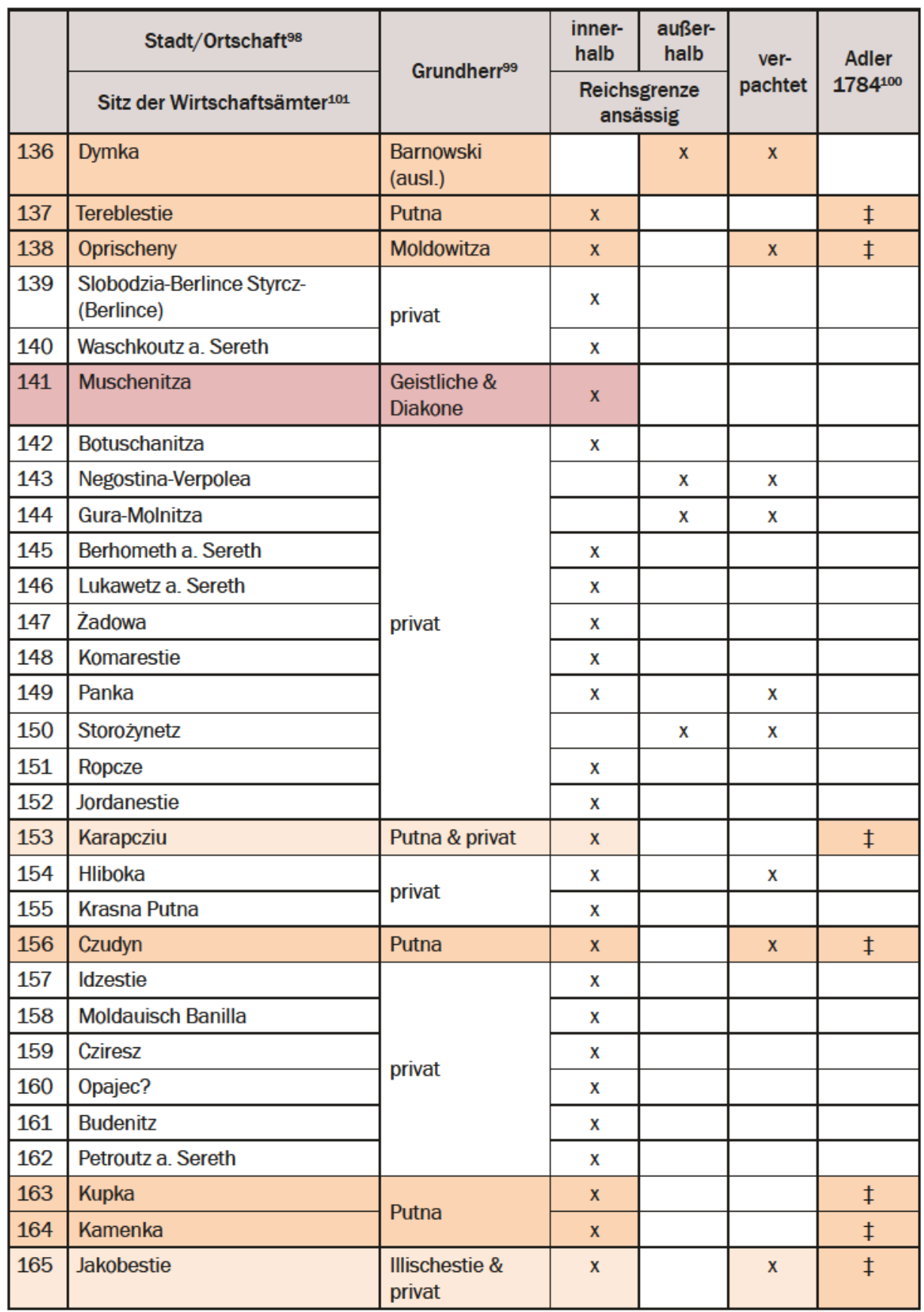




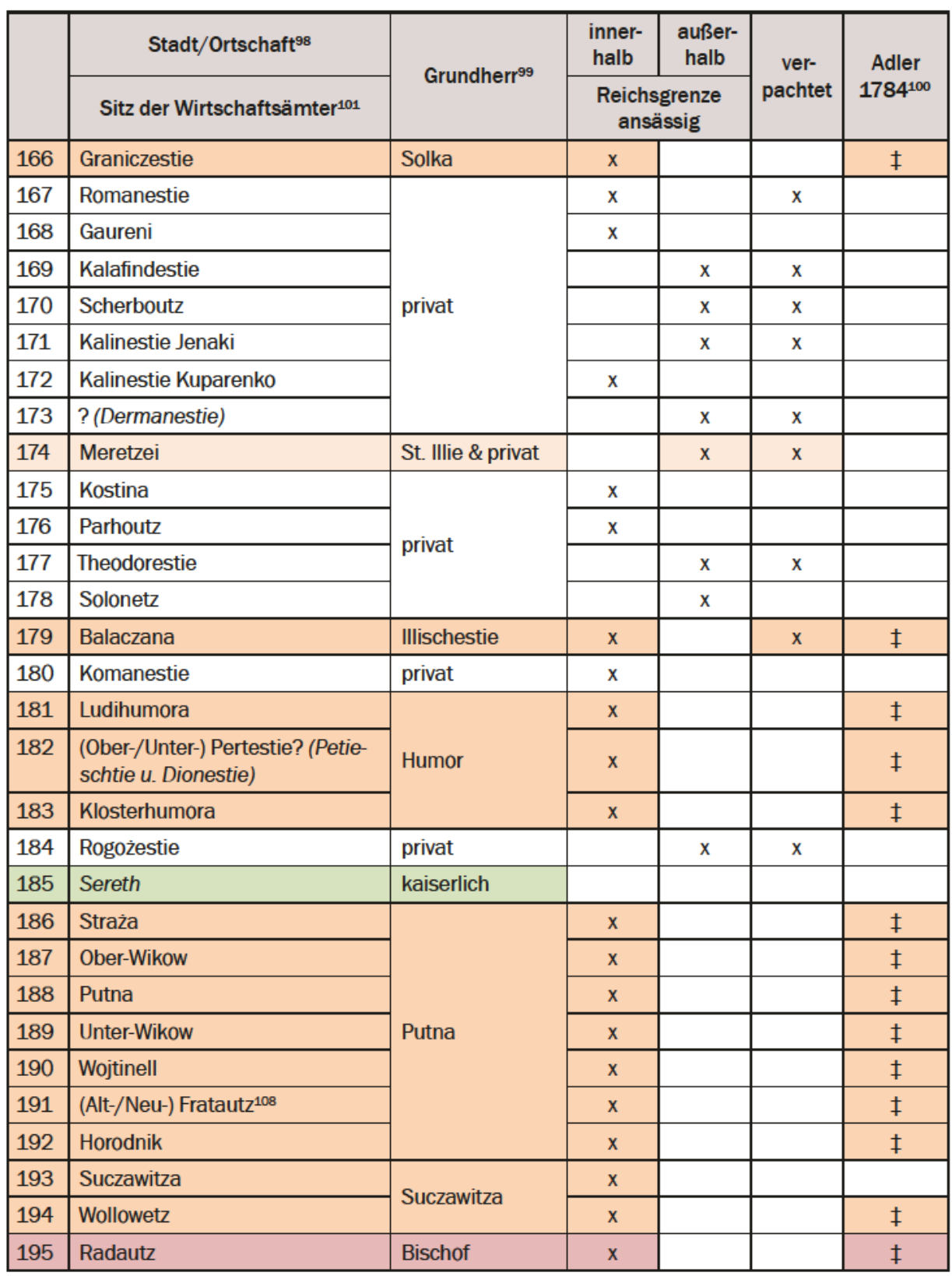

108 Direktionssitz der Staatsgüterverwaltung; OSTA-FHKA Nr. 8o Fasz. 81790 Finalisierungsoperat, fol. $846 \mathrm{v}$. 


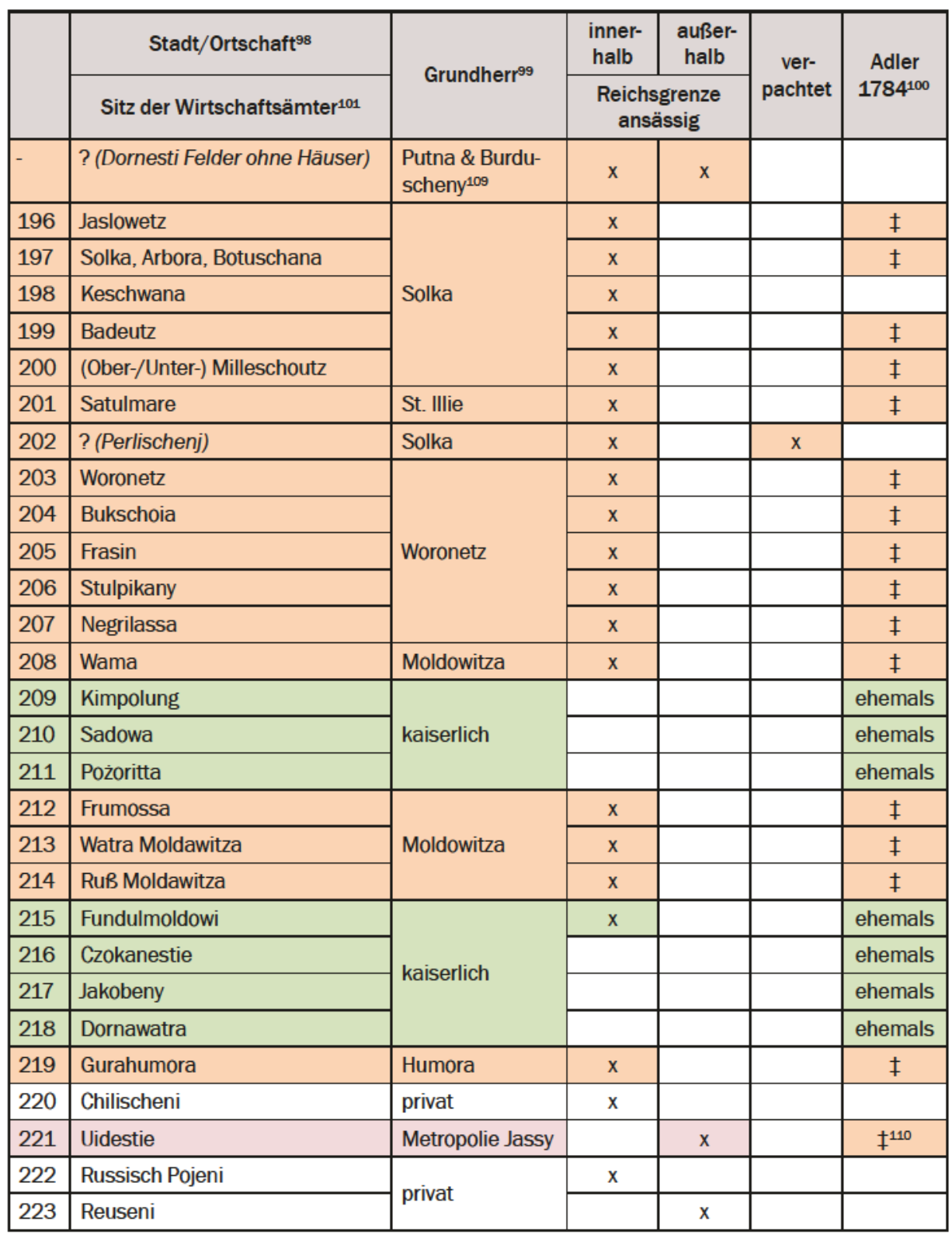

109 Heute Kloster Teodoreni/Todireni in Burdujeni.

110 Dorfschaften Nr. 221, 224, 225 u. 228 einem ausländischen Kloster gehörig. 


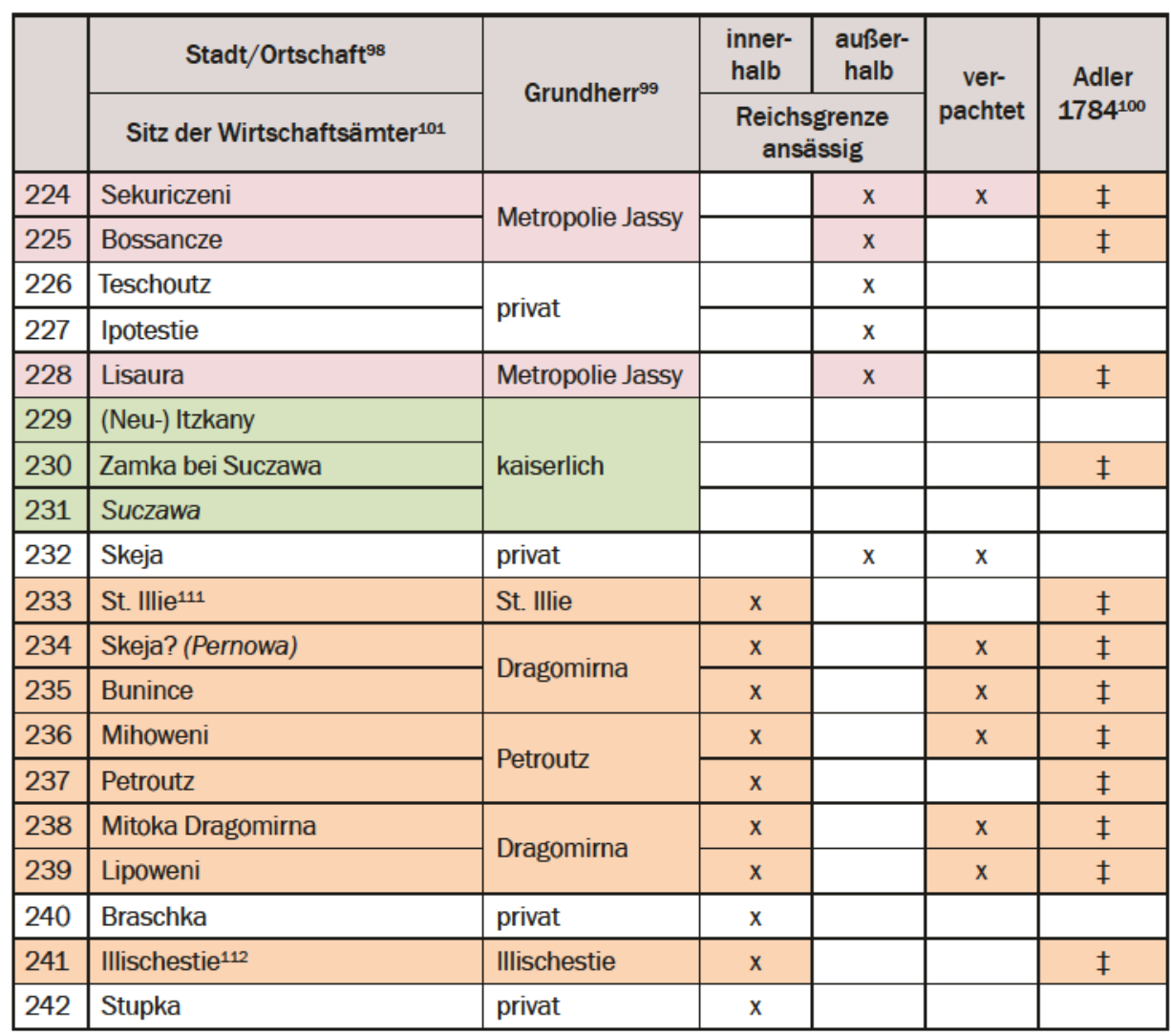

111 Zugleich Direktionssitz der Staatsgüterverwaltung; ÖTA-FHKA Nr. 8o Fasz. 8 179o Finalisierungsoperat, fol. 846v. Zur Herrschaft St. Illie zählten 1785 das Kloster Dragomirna (Dorf Mittoka, Dragomizna mit Lippowan, Bunincze); Kloster St. Illie (St. Illie mit dem Anteil Kostina, Dorf Millescheuz oder Fogotisten); Kloster Illischestie (ein ganz geringer Anteil von Jacobestie, welches mit dem Dorf Danilla vereinbart war); Nonnenkloster Petroutz (das Dorf Petroutz, Mowoweni); OSTA-FHKA-NHK Dom. Staatsgüterbeschreibung 958.35, Staatsherrschaft St. Illie im Bukowiner Kreis 1797, per 1.III.1785 (die Schreibweise entspricht den Angaben in der Quelle!).

1121801 ging die Verwaltung an St. Ilie über. OSTA-HHSTA Faßbender Karton 5 XI/3-XII MS XII, Ertragsausweis der Buccowiner Staats- und Fondsgüter 1801-1803. In die Herrschaft Illischestie gehörten per 1. V.1785 folgende Güter: Kloster Illischestie (Dorf Illischestie, Ballaczana und Praedium Schestiora); Kloster Solka (Dörfer Bottoschana und Keszvana); Kloster Woronecz (Dragoestie, Stulpikani, Woronecz und Bunschoja, Frasin, Schemini, Slatiora und Ostra, Praedium Lukaschestie); Kloster Homora (Dörfer Perlestie, Anteil Komarestie, das halbe Dorf Bajaschestie, Kapukodruluij, Gora Humora, Ludi Humora, und Monaster Homora); Kloster Moldowicza (Dorf Wama, Berkischestie, Formosa, Watra Moldawicza, Rus Moldawicza und Rus pe Boul); OSTA-FHKA-NHK Dom. Staatsgüterbeschreibung 958.35 (die Schreibweise entspricht den Angaben in der Quelle!). 


\begin{tabular}{|c|c|c|c|c|c|c|}
\hline & Stadt/Ortschaft ${ }^{98}$ & \multirow{2}{*}{ Grundherr ${ }^{99}$} & $\begin{array}{l}\text { inner- } \\
\text { halb }\end{array}$ & $\begin{array}{l}\text { außer- } \\
\text { halb }\end{array}$ & \multirow{3}{*}{$\begin{array}{c}\text { ver- } \\
\text { pachtet }\end{array}$} & \multirow{3}{*}{$\begin{array}{c}\begin{array}{c}\text { Adler } \\
1784^{100}\end{array} \\
\ddagger\end{array}$} \\
\hline & Sitz der Wirtschaftsämter ${ }^{101}$ & & \multicolumn{2}{|c|}{$\begin{array}{c}\text { Reichsgrenze } \\
\text { ansässig }\end{array}$} & & \\
\hline 243 & Dragojestie & Woronez & $x$ & & & \\
\hline 244 & Mazanajestie & Slatina (ausl.) & & $x$ & $x$ & $\ddagger$ \\
\hline 245 & Kapukodrului & Woronetz & $\mathrm{x}$ & & & $\ddagger$ \\
\hline 246 & Walesaka & Slatina (ausl.) & & $\mathrm{x}$ & & $\ddagger$ \\
\hline 247 & Korlata & \multirow{2}{*}{ privat } & & $x$ & $x$ & \\
\hline 248 & $?$ (Korlazelile) & & $\mathrm{x}$ & & & \\
\hline 249 & ? (Korlazelile Slatini) & Slatina (ausl.) & & $\mathrm{x}$ & & \\
\hline 250 & Bajaschestie & Humora \& privat & $\mathrm{x}$ & & $\mathrm{x}$ & $\ddagger$ \\
\hline 251 & Berkischestie & Moldowitza & $\mathrm{x}$ & & & $\ddagger$ \\
\hline 252 & Liteni & \multirow{3}{*}{ privat } & & $\mathrm{x}$ & $\mathrm{x}$ & \\
\hline 253 & Zaharestie & & & $\mathrm{x}$ & & \\
\hline 254 & Strojestie & & & $\mathrm{x}$ & $x$ & \\
\hline
\end{tabular}

Verpachtung oder Verkauf?

Die außerhalb der Bukowina gelegenen Güter oder der Fall Mustazza

In der Sache wesentlich schwieriger gestaltete sich die Arrondierung des über die neu gezogenen Grenzen hinweg verstreuten kirchlichen Güterbesitzes der nunmehr vom moldauischen Jassy unabhängigen Bukowiner Diözese. Ein nicht ganz unbeträchtlicher Teil der in den Religionsfonds eingezogenen Liegenschaften der Bukowiner Klöster lag nunmehr außerhalb dieser Provinz in der Moldau. Die tatsächliche Verteilung und der Umfang dieser Liegenschaften waren 1781 selbst dem Hofkriegsrat weitgehend unbekannt. ${ }^{113}$ Der Großteil davon im Fürstentum Moldau, ein kleinerer in der Chotyner Raya, die zu diesem Zeitpunkt direkt in der Verwaltung der Hohen Pforte stand. Allerdings besetzten Reichstruppen die Raya zwischen 1788 und 1793 und die Verwaltung des Gebietes erfolgte über die Bukowina, sodass der Austausch der 1791 (vgl. Tab. 2) gezählten acht Religionsfondsgüter vorerst nicht überaus dringend erschien. ${ }^{114}$ Mit dem Jahr 1802 änderte sich die politische Situation neuerlich und die Raya wurde von der Pforte aus der Istanbuler Direktverwaltung dem Fürstentum Moldau übertragen. ${ }^{115}$ Trotzdem scheint es, dass die Güter in der Raya auch 1810 noch immer nicht zur Gänze

113 ANR-B HKR VI/48/1781 Protokoll 14. Sitzung d. Staatsrates v. 12.VI.1781, fol. 30.

114 SCHARR 2010, Landschaft, 131 u. 150.

115 Wiener Zeitung v. 15.XII.1802, Nr. 100, Ausländische Begebenheiten Türkey, 4503. 


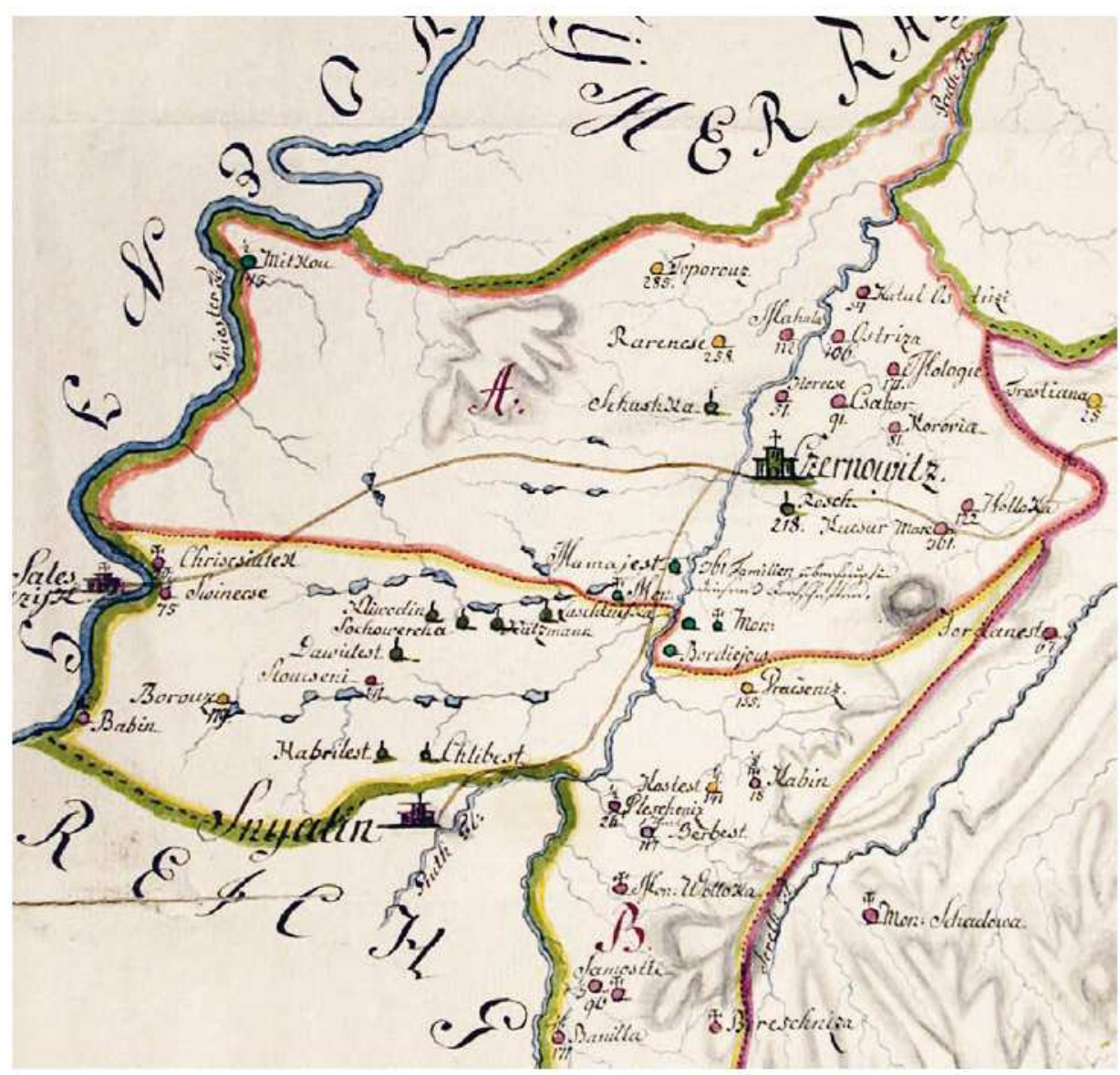

Abb. 2: Auszug aller in dem kk Buvvoviner district befindlichen und denen Klöstern eigenthümlich zugehörigen Ortschaften, Ausschnitt (AdLER 1784; @ OOSTA-KA Wien, ALB Port 207,9). Die Bruchzahlen oberhalb der Ortssignaturen zeigen an, wie viele Teile der Ortschaft der Kirche gehören, die Zahlangaben unterhalb verweisen auf die dort sesshaften Familien.

Legende

- große und kleine Monasteri oder Kloster

Dorfschaften welche denen Buccoviner Klöstern gehören

- die denen ausländischen Klöstern zugehörig

- welche der groß Skit aus Gallizien in der Buccovina besitzet

borhin bischöflich und Kameral Dorfschaften samt den verkauften Gütl Schuska 


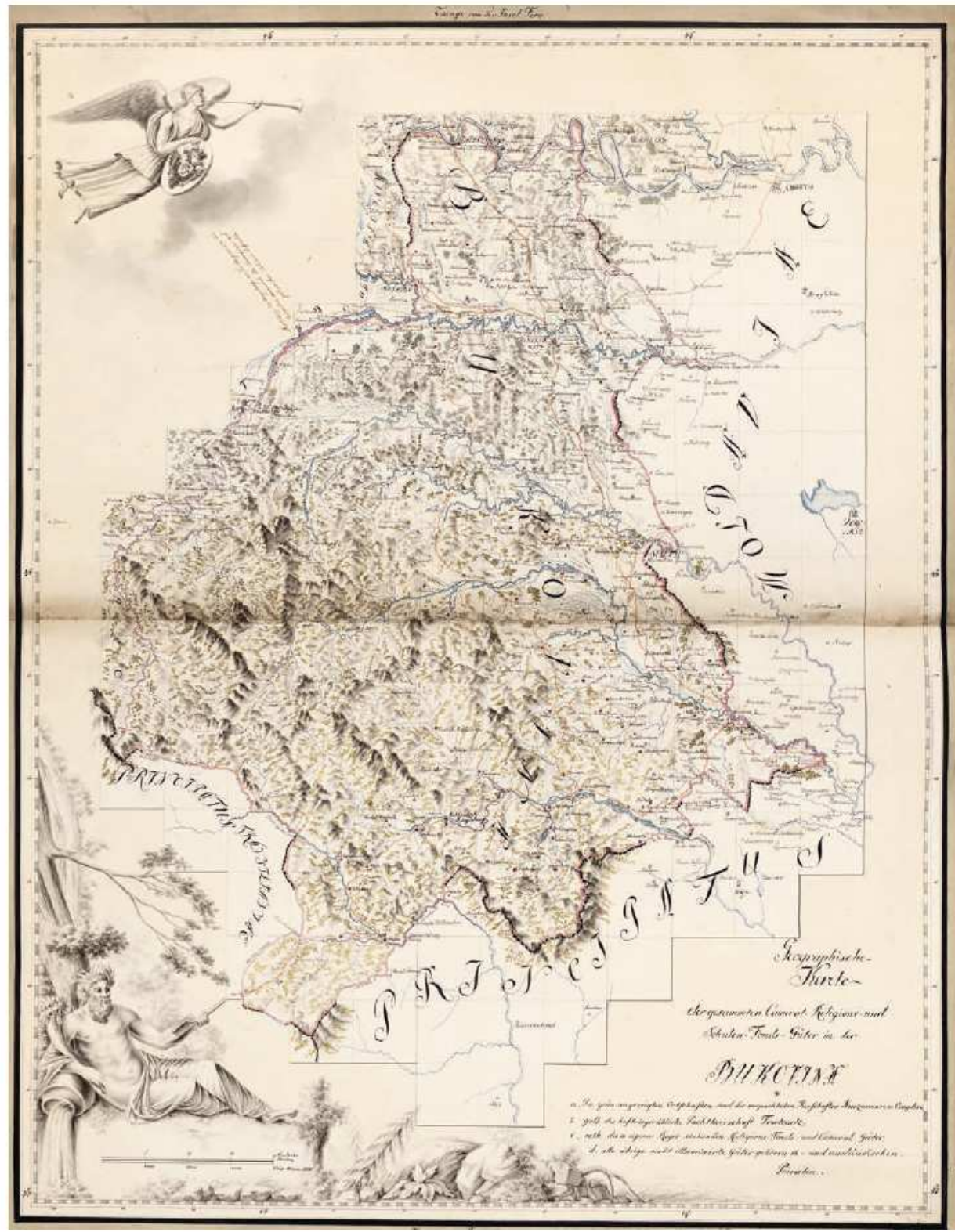

Abb. 3-5: (Gesamtkarte u. Ausschnitte) - Geographische Karte der gesammten Cameral-Religionsund Schulen-Fonds-Güter in der Bukovina. (Anonymus um 1805; ( OeNB-Wien). Ortschaften in grün: verpachtete Herrschaften Kuczurmare u. Onuyphre; gelb: hofkriegsrätliche Pachtherrschaft Fratautz; rot: in eigener Regie stehende Religions-Fonds- und Cammeral Güter, nicht illuminirte Güter gehören in- und ausländischen Privaten. 


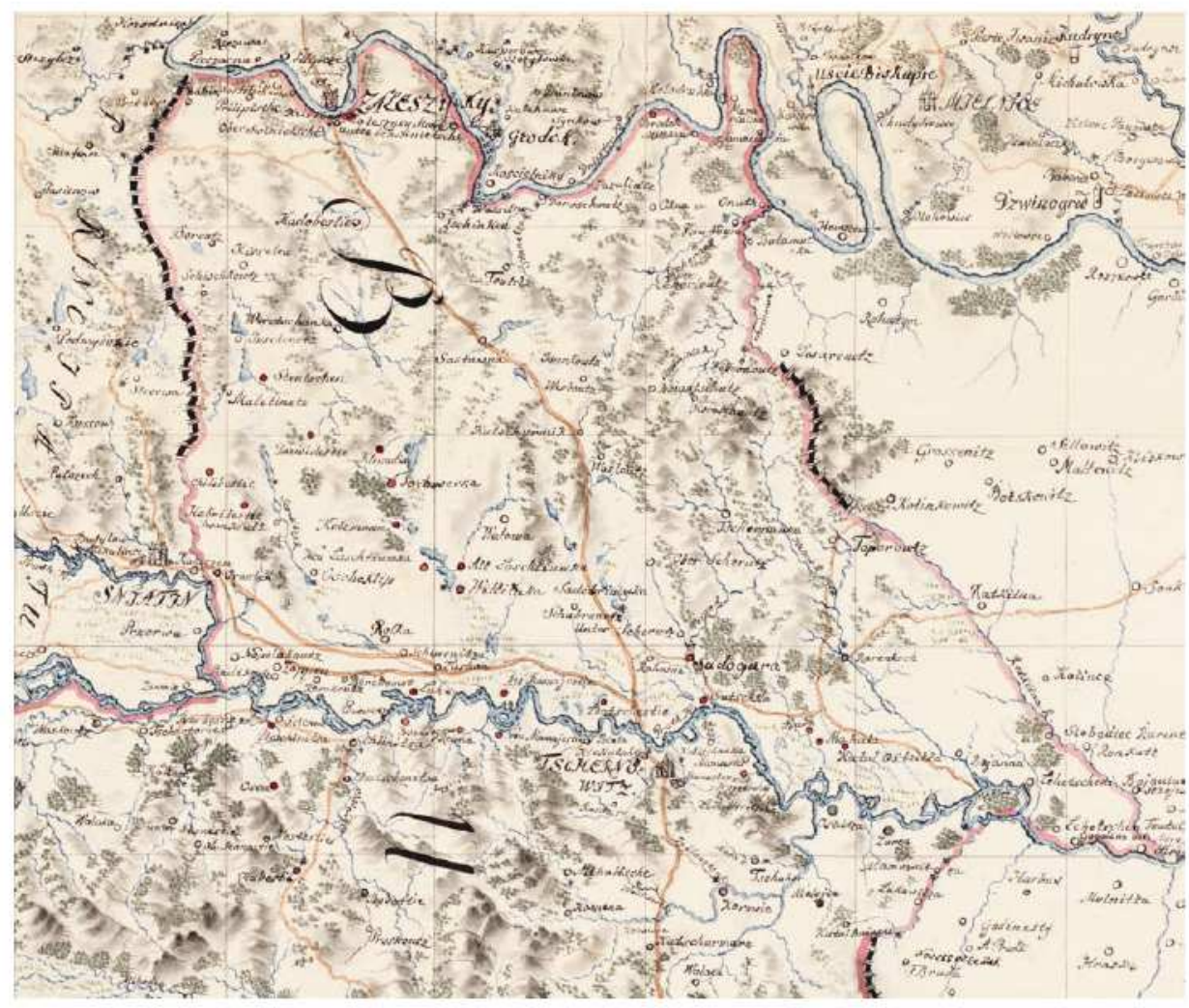

veräußert werden konnten. Balsch bekam den Auftrag, sich darum zu kümmern. Einige Monate später fiel die Entscheidung, die verbliebenen Liegenschaften der Raya nochmals für ein Jahr in Pacht zu geben. ${ }^{116}$

116 OSTA-FHKA Domänen Nr. 084 10-28068/2326 v. 19.IX.1810; Nr. 085 10-136/15307, v. 30.V.1811. 


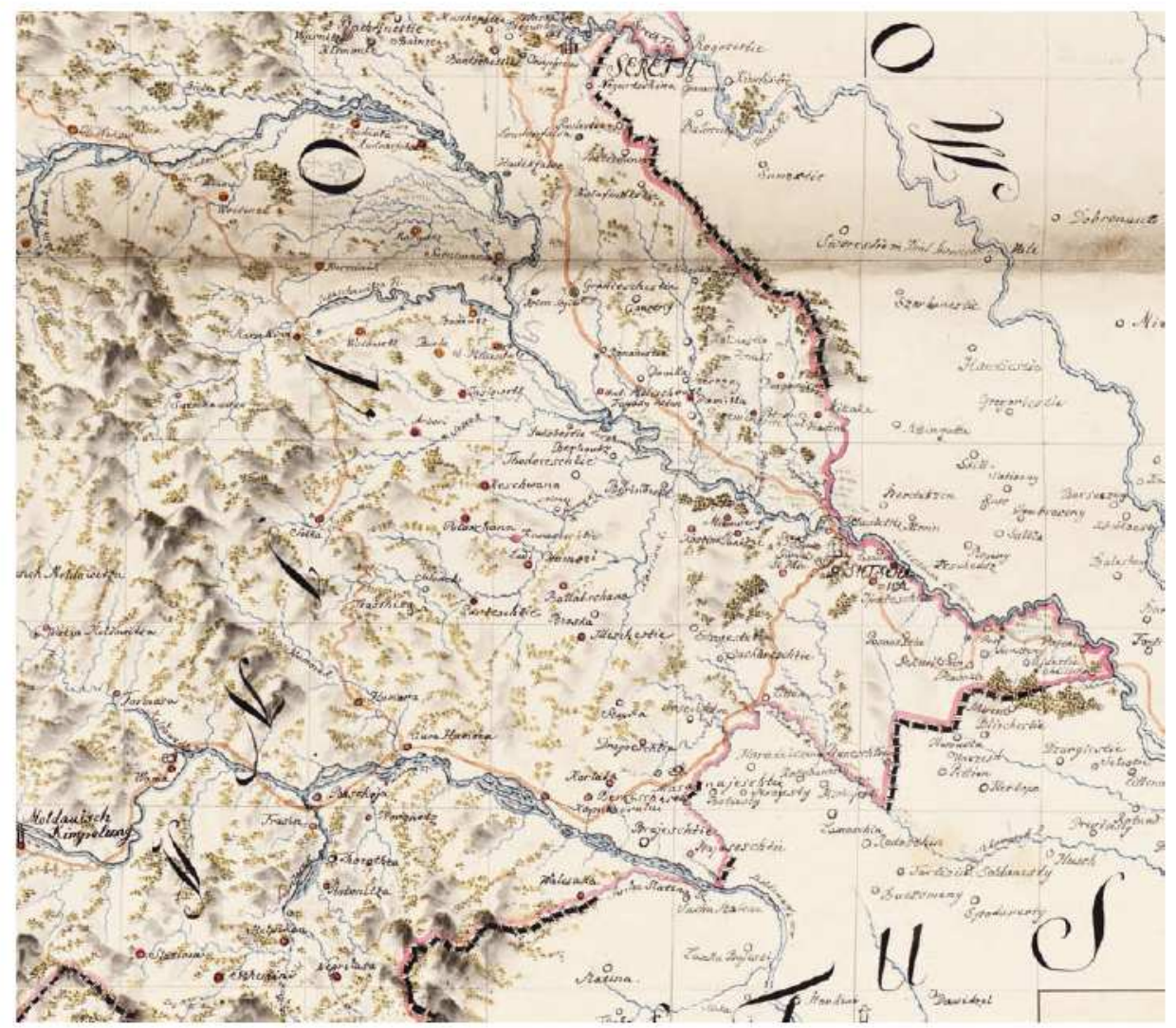

Tab. 2: Religionsfondsgüter in der Chotyner Raya $1791^{117}$

\begin{tabular}{|c|c|}
\hline Namen der Güter (heutiges Toponym) & Kloster \\
\hline Dorf Scheroutz (Шировцы - UA) & Putna \\
\hline Dorf Kerestenȳ (Керстенцы - UA) & Moldowitza \\
\hline Dorf Drepkeutz (Арепкэуць/Drepcăuți - MD) & \multirow{6}{*}{ Suczawitza } \\
\hline Dorf Stanilestỹ (Стальновцы? - UA) & \\
\hline Linkeutz und Makarota (Ленковцы/Макаровка? - UA) & \\
\hline Wahoren (Вороновица? - UA) & \\
\hline $1 / 2$ Hruschenitz (Трушевцы? - UA) & \\
\hline 1/22 (P)Ruschintze (Ружница/Rujnița? - MD) & \\
\hline
\end{tabular}

117 OSTA-HHSTA Staatskanzlei Provinzen Bukowina alt 1 (Karton) Verzeichnis der in der Chotiner 
Tab. 3: Religionsfondsgüter im Fürstentum Moldau 1799

\begin{tabular}{|c|c|c|c|}
\hline & Distrikt & Güter/Prädien/Weingärten ${ }^{118}$ & heutiger Name $e^{119}$ \\
\hline 1 & Botoschaner (Botoşani) & Stauczenÿ mit Bradinestie & Stăuceni (R0) \\
\hline 2 & & Oretczenÿ & Orăşeni (R0) \\
\hline 3 & & Horodestie & Horodiştea (R0) \\
\hline 4 & & Worniczenȳ mit Pomerlenỹ & Vorniceni (R0) \\
\hline 5 & & Monastireny̆ & Mânăstireni (R0) \\
\hline 6 & & Nikschenÿ & Niçseni (R0) \\
\hline 7 & & Praedium Balinze & Balinți? (RO) \\
\hline 8 & & Mundrestie & $\begin{array}{l}\text { Mândreşti (R0, westl. v. } \\
\text { Botuşani) }\end{array}$ \\
\hline 9 & & Serafinestie mit Mitestie & Sarafineşti (R0) Mesteacăn? \\
\hline 10 & Dorohoÿer (Dorohoi) & $\begin{array}{l}\text { Stubienȳ, Petrikanỹ, und } \\
\text { Pustien? }\end{array}$ & $\begin{array}{l}\text { Ştiubieni / Petricani / Bozi- } \\
\text { eni? (RO) }\end{array}$ \\
\hline 11 & & Preedium Podraga & Podriga (RO) \\
\hline 12 & & $\begin{array}{l}\text { Ibanestie, Kertinestie, mit } \\
\text { Mogura }\end{array}$ & Ibăneşti / Criştineşti? / ?(R0) \\
\hline 13 & Herleuer (Hârlău) & Weikulestie & Văculeşti (R0) \\
\hline 14 & & Preedium Strahotȳn & Strahotin (R0) \\
\hline 15 & & Preedium Feredeu & Fereden (R0) \\
\hline 16 & & \begin{tabular}{|l|} 
Flamindze, Uriczenÿ, \\
Dogmaczenỹ, Dragodestie
\end{tabular} & $\begin{array}{l}\text { Flămânzi / Nicolae } \\
\text { Bălcescu? (RO) }\end{array}$ \\
\hline 17 & & Dorf Slatunoje & $?$ \\
\hline 18 & & Dorf Werbie & $?$ \\
\hline 19 & & Preedium Hadora & Hodora (R0) \\
\hline 20 & & Preedium Monestie & $?$ \\
\hline 21 & & Preedium Oroszenÿ & Orăşeni (R0) \\
\hline 22 & Faltscheuer (Fălciu) & Preedium Tschorsatzi & Chersăcosu? (R0) \\
\hline 23 & & Fischerey Baltaluzzÿ & $?$ \\
\hline 24 & Olatul Gretschenita & Frumosa & $?$ \\
\hline 25 & $\begin{array}{l}\text { Putnaer und Fokschana } \\
\text { (Putna \& Focşan) }\end{array}$ & $\begin{array}{l}\text { 36. Pogon } 2 \text { Weingärten zu } \\
\text { Odobestie und Krucze }\end{array}$ & Odobeşti / Crucea (R0) \\
\hline 26 & Falticzener (Fălticeni) & Faltyczenỹ und Reczuleny & Fălticeni (RO) \\
\hline
\end{tabular}

Raja gelegenen, und dem Buccowiner Religionsfonds nach den aufgehobenen Klöster zugefallenen Gütern vermög hier erliegenden Urkunden, Radautz 19.I.1791; detto Faßbender Karton 4 X/4-XI/2, fol. 822, Copia, An die Domainen Administration i. Lemberg.

118 Die Schreibweise laut den Angaben in der zitierten Quelle.

119 Die mit einem Fragezeichen versehenen Orte ließen sich nicht eindeutig zuordnen bzw. auffinden. 


\begin{tabular}{|c|c|c|c|}
\hline & Distrikt & Güter/Prädien/Weingärten 118 & heutiger Name ${ }^{119}$ \\
\hline 27 & & Derska & Dersca (R0) \\
\hline 28 & & Dobronoutz & $?$ \\
\hline 29 & & Ruschiera & $?$ \\
\hline 30 & & Potestie & Boteşti (RO) \\
\hline 31 & & Balestie mit Schimenitza & $?$ \\
\hline 32 & Bakauer (Bacău) & Faracenȳ & $?$ \\
\hline 33 & Galatzer (Galați) & Seligestie & $?$ \\
\hline 34 & Piatraer (Piatra-Neamț) & Holda mit Krucze & Holda / Crucea (RO) \\
\hline 35 & Sorokaer & $\begin{array}{l}\text { Neipeidowa, Sufflinze, Gisdita, } \\
\text { Nerskowa }\end{array}$ & \\
\hline 36 & Hertzer (Герца) & Philippeutz & Великосімя / Pilipăuți (UA) \\
\hline 37 & & $\begin{array}{l}\text { Magoschestie, Glihoreny, No- } \\
\text { woselitza }\end{array}$ & Новоселица (UA) \\
\hline 38 & Jassyer (laşi) & $\begin{array}{l}\text { Kowasna, Ruschenica, } \\
\text { Bohatȳn }\end{array}$ & Covasna /?/Bohotin (RO) \\
\hline
\end{tabular}

Auf der anderen Seite des Cordons, im Fürstentum Moldau, befanden sich immerhin 38 "ansehnliche " Güter mit mehr als 213.000 Joch "der besten und fruchtbarsten Acker, Wiesen, Teiche «. ${ }^{120}$ Eine anfängliche Überlegung, diese Liegenschaften teilweise zumindest vorerst weiter in der landesüblichen Weise zu verpachten (vgl. Tab. 1), erschien daher als Verlegenheitslösung wohl naheliegend, wenngleich in Summe ökonomisch wenig reizvoll. ${ }^{121}$ Die daraus für die in der Moldau gelegenen Güter resultierende Rechtslage gestaltete sich für die österreichischen Beamten jedoch ebenso wenig klar wie deren wirtschaftliche Situation. ${ }^{122}$ Damit hatte sich Wien auf ein administrativ auf-

120 OSTA-HHSTA Staatskanzlei Bukowina alt 1 (Karton), geheime Hof- und Staatskanzlei, Wien v. 22.III.1802; für 1803 weist eine Ertragsaufstellung der Bukowiner Fondsgüter für die moldauischen Besitzungen knapp 24.00o Gulden (bei einer Gesamtsumme von annähernd $160.000 \mathrm{fl}$.) aus. Unklar bleibt darin freilich, inwieweit diese Summe auch tatsächlich von den Pächtern zur Gänze eingebracht werden konnte; ders. Faßbender Karton 5 XI/3-XII MS XII, Ertragsausweis der Buccowiner Staats- und Fondsgüter 1801-1803.

121 OSTA-FHKA Domänen 1801 Fasz. 10 8-28824/2794, fol. 163 v. 11.XI.1801 sowie 12-32061/3003, fol. 181 v. 2.XII.1801; Pachtverlängerung, betreffend die Moldauer Religionsfondsgüter Nikscheni, Stubieni mit Petrikani und Pastuil, Rusziora, Pharanoni mit Holda und Krucza, Hodora, Feredui, Slatunoje, Jubanestie, Czorsacźy, Pilipeuz und Jezura Fischerey sowie Jubanestie, Slatunoje, Pelipeutz, Czornzawy und Feredeu; vgl. dazu die Listen bei OSTA-HHSTA Faßbender Karton 3 Faszikel IX-2 Zahl 14 sowie Staatskanzlei Provinzen Bukowina alt 1 (Karton).

122 Landesverwaltung Bukowina a. Konsistorium v. 21.VI.1784, zit. nach WICKENHAUSER 1890, Molda IV, 111. 
wendiges sowie diplomatisch überaus heikles Unterfangen eingelassen, die »äußerst laue Rechtspflege des moldauer Divanes « begünstigte zudem die Pächter, gegenüber denen man vor Ort praktisch keine Handhabe bei Nichteinhaltung des Vertrages besaß. ${ }^{123}$ Die Idee eines "vortheilhaften Austausches « mit Moldauern diesseits des Cordons hingegen bedurfte geschickter Verhandlungen mit dem Fürsten der Moldau, für man zeitweise einen eigenen Hofagenten nach Jassy beorderte. ${ }^{124}$ Letztlich versprachen die sich seit 1785 bereits über Jahre hinziehenden Gespräche und Interventionen nur wenig Aussicht auf Erfolg. Ungeachtet dessen blieb der Gütertausch bei momentaner Beibehaltung des Pachtsystems als provisorische Lösung im Blickfeld der Wiener Behörden. Man erhoffte sich durch den Frieden von Sistowa und dem Ende des (letzten) österreichisch-türkischen Krieges 1791 einen positiven Ausgang der in Jassy noch offenen Anliegen. ${ }^{125}$

Dieser zögerlichen Haltung - die wohl in einem nicht geringen Maße den geo- wie innenpolitischen Umständen, in denen sich das Habsburgerreich um die Jahrhundertwende befand, geschuldet war - trachtete Kaiser Franz II. ein Ende zu setzen. Aus seiner Sicht hatte die zuständige Behörde diese Liegenschaften des Religionsfonds zum "möglich vorteilhaftesten Kaufschilling « abzugeben. ${ }^{126}$ Diesem Entschluss folgend leitete Wien Verhandlungen und diplomatische Gespräche mit dem für die Außenbeziehungen der Pforte beauftragten Reis Effendi ein. ${ }^{127}$ In Baron Theodor von Mustazza, dessen Ansitz in Sadagóra lag und der als vormaliger Bojar seit 1794 zum anerkannten Adelsstand der Bukowina gehörte ${ }^{128}$, hatte sich alsbald ein Interessent gefunden, der die Liegenschaften geschlossen zu erwerben trachtete. Ein erstes 1797 ausgesprochenes Kaufvorhaben des Barons wurde umgehend auf allerhöchsten Befehl wieder rückgängig gemacht. ${ }^{129}$ Es stand die Option offen, dass eventuell in Gesprächen über den Internuntius Baron von Herbert und den Reis Effendi alle Güter direkt an die Pforte gehen könnten. Istanbul hatte dazu dem Fürsten der Moldau bereits Vollmachten erteilt. ${ }^{130}$ Der Internuntius hatte Mustazza zudem ein schlechtes Zeugnis ausgestellt und ihn als we-

123 OSTA-FHKA Domänen Fasz. 10/1.830 Gutachten Copia a. Erzherzog Karl v. 24.III.1803.

124 DACZ 29/1/42 Copia einer HKR Verordnung, Wien v. 15.X.1785, fol. 12.

125 OSTA-HHSTA Staatskanzlei Bukowina alt 1 (Karton), geheime Hof- und Staatskanzlei, Wien v. 22.III.1802.

126 OSTA-FHKA Domänen Nr. 073 Fol. 6-Exp. 1/1 Veräußerung der in der Moldau gelegenen Staatsgüter des Bukowiner Religionsfonds, Vortrag u. Resolution v. 29.XII.1797.

127 OSTA-FHKA Domänen Nr. 075 Fasz. 10-28/78, geheime Hof- und Staatskanzlei, Wien 8.I.1801; Fasz. 10 Exp. 91-10058/1489 geheime Hof- und Staatskanzlei, Wien v. 12.VI.1801.

128 ANonymus 1857 , Poczet, 310.

129 OSTA-FHKA Domänen Fasz. 10/1.816 Gutachten Copia a. Erzherzog Karl v. 24.III.1803.

130 OSTA-FHKA Domänen Fasz. 10/1.816 Nr. 028, ostgalizisches Gubernium a. Hofkammer 5.XII.180o; Note Hof- und Staatsvizekanzler a. Hofkammer v. 5.I.1801; Nr. 18, Sitzung v. 24.II.1801; Nr. 91, Sitzung v. 17.VI.1801. 
nig vertrauenswürdig eingestuft, zweifelte man doch an seiner Bonität. ${ }^{131}$ Offenbar hatte Mustazza spätestens zu Beginn des Jahres 1802 neuerlich einen Antrag eingereicht und bat, die Pacht der betreffenden Güter nicht mehr zu verlängern, damit sie zum Kauf freigestellt werden könnten. Mit Mai 1802 hatte sich der Bukowiner Adelige für einen Betrag von 331.000 Gulden bereit erklärt, die Liegenschaften zu erwerben. ${ }^{132}$ Daraufhin war Wien sichtlich bemüht, den »wahren Werth « dieser Güter zu ermitteln. ${ }^{133}$ Mit der Sicherstellung der Kaufsumme und dem Verzicht von Entschädigungsklagen aus früheren Abmachungen sollten Mustazza per 1. Mai 1802 die Liegenschaften endlich übertragen bekommen, "weil andurch allen bisherigen Weitläufigkeiten und Einstrengungen auf einmal ein Ende gemacht [...] werden würde «. ${ }^{134}$

Fühlte man sich von Mustazza übervorteilt oder hatte die Verwaltung vor Ort in der Person des Staatsgüterinspektors Franz Pauli ${ }^{135}$ bereits begonnen, das Anliegen aus eigenen Überlegungen zu bremsen? Seitens der Hofkanzlei und der vereinigten politischen Hofstelle als dem Religionsfonds vorgeordneter Behörde gab es indes keine Einwände. Zudem lief die Pachtfrist per 1. April 1802 ohnedies aus und die Eingaben an die moldauische Regierung, ausständige Pachtzinse einzutreiben, blieben weiterhin »fruchtlos «. Aus der Perspektive der Wiener Zentralbehörden wollte man daher »diese Güter je eher je lieber los werden «. ${ }^{136}$ Im Februar 1802 erging folglich per kaiserlichem Handbillet der Auftrag an das galizische Landesgubernium, die betreffenden Liegenschaften an Mustazza zu veräußern. Wiederholte Einwände Paulis gegen diesen Verkauf blieben offenbar unberücksichtigt. Sie warfen allerdings ein bezeichnendes Licht auf den weiteren Verkaufsprozess, der zunehmend ins Stocken geraten sollte. ${ }^{137}$ Noch im Juni desselben Jahres ließ das ostgalizische Gubernium - offenbar parallel zu den Verkaufsgesprächen einen neuen Pachtschilling für die meisten der moldauischen Liegenschaften auf die Dauer von zwei bis drei Jahren festsetzen, zur Einbringung der Rückstände betraute

131 "[...] schlechterdings für unfähig halte, neue und zwar so betrachtliche Guter, als die Bukowiner Religionsfondsgüter in der Moldau sind, an sich zu kaufen «; ÖSTA-FHKA Domänen Fasz. 10/1.816 Nr. 93, Sitzung v. 16.VII.1801.

132 ÖSTA-FHKA galiz. Domänen Fasz. $1057-1615 / 111$, Sitzung Hofrat v. Erben v. 13./20.I.1802.

133 OSTA-HHKA Faßbender Karton 3 Fasz. IX/18 v. 22.II.1802, Handschreiben a. Hofrat v. Holzmeister.

134 OSTA-FHKA galiz. Domänen Fasz. 10/1.816 Nr. 41, Sitzung v. 16.XII.1801.

135 Pauli war zunächst Wirtschaftsdirektor der Herrschaft Radautz und seit 1801 Direktor der gesamten Staatsgüter in der Bukowina; OSTA-FHKA galiz. Domänen Nr. 108 Fasz. 10 Juli-Dez. 1801, Bericht des ostgalizischen Landesguberniums a.d. Kaiser, Lemberg v. 17.IV.1801.

136 OSTA-FHKA galiz. Domänen Fasz 10 36-4275/279, Note geheime Hof- und Staatskanzlei, Wien 27.I.1802; Fasz. 10 130-10642/708, Hofrat v. Erben, Wien v. 24.III.1801.

137 OSTA-FHKA galiz. Domänen Fasz. 10 2-5306/346, Präsidialschreiben a. ostgalizisches Gubernium v. 6.II.1802; Abschrift Handbillet v. 1.II.1802. 
man wiederum Pauli. ${ }^{138}$ Mustazza hatte in der Zwischenzeit einen Advokaten in Lemberg eingeschaltet, fühlte er sich doch durch die Rückgängigmachung eines aus seiner Sicht bereits abgeschlossenen Geschäftes geschädigt. ${ }^{139}$ Baron Balsch, der Mustazza in dieser Sache in Wien unterstützte, geriet gleichfalls in die Anfeindungen von Bojaren aus der Bukowina, die jedoch von den höchsten Stellen als Verleumder in die Schranken gewiesen wurden. ${ }^{140}$ Allem Anschein nach war es, neben den Eigeninteressen der Bojaren, hauptsächlich der Domäneninspektor Pauli, der dem Verkauf an den, wie Pauli ihn nennt, »verschmitzten Griechen « Mustazza von Beginn an skeptisch gegenüberstand. Er hegte die Befürchtung, der Baron könnte die Liegenschaften einzeln mit einem erheblichen Aufschlag weiter veräußern, sodass der Preis für die Religionsfondgüter in der Moldau mindestens 500.000 Gulden betragen müsse. ${ }^{141}$ Zusätzlich stellte sich für die Behörden heraus - oder man warf Mustazza dies jetzt bewusst vor -, dass er selbst den Pachtschilling schuldig geblieben wäre. ${ }^{142}$ Baron Mustazza hingegen war eingedenk der eigenen Situation im Fürstentum sichtlich bemüht, jeden Eklat mit den moldauischen Bojaren zu vermeiden. ${ }^{143}$ Gleichzeitig warteten die österreichischen Behörden vergeblich auf die erhoffte Bestätigung der Abgrenzung der Religionsfondsgüter in der Moldau durch die Pforte, wofür es dort allerdings weitgehend sowohl der nötigen rechtlichen als auch der technischen Mittel mangelte. Mittlerweile bemühte Wien neuerlich den Internuntius, da die Interessen der moldauischen Bojaren und des Landesfürsten in Jassy immer wieder zu Verzögerungen führten. ${ }^{144}$ Mustazza ließ sich von seinem Ansinnen, die Güter zu erwerben, indes keinen Jota abbringen und suchte ebenfalls um Fürsprache in der Sache bei der Pforte an. ${ }^{145}$ Ein detailliertes Gutachten der Hofkammer wies schließlich die Einwände des Domäneninspektors endgültig ab und empfahl als günstigste Lösung nun doch den Verkauf der moldauischen Güter des Bukowiner Religions-

138 OSTA-FHKA galiz. Domänen Fasz. 10 v. 16.VI.1802.

139 OSTA-FHKA galiz. Domänen Nr. 075 Fasz. 10 Exp. 93-13588/1722 v.16.VII.1801; HHKA Faßbenderakten Karton 4 X/4-XI/2, fol. 817, Wien v. 17.XII.1802.

140 ÖSTA-FHKA galiz. Domänen Nr. 073, Vortrag u. Resolution v. 15.VIII.1799 Beschwerde Bukowiner Edelleute gegen Kreishauptmann Freiherr v. Balsch.

141 OSTA-HHSTA Faßbender Karton 3 Fasz. IX/2, Auszug aus dem Schreiben Pauly, Radautz 2.I.1802.

142 OSTA-HHSTA Faßbender Karton 4 X/4-XI/2 fol. 821, Wien v. 17.XII.1802; FHKA galiz. Domänen Nr. 081 Fasz. 10 Nr. 2445 Präsidialschreiben a. galizisches Gubernium v. 27.I.1802.

143 "[...] pour obtenir une indemnisation sans laquelle Moustaza est ruiné«; OSTA-FHKA galiz. Domänen Fasz. 10, Raport Mr. Timoni, Jassy 5.VIII.1803.

144 OSTA-FHKA galiz. Domänen Fasz. 10, Bericht a. d. Staatskonferenz u. Kabinettsminister Colloredo, Wien 9.VII.1803.

145 OSTA-HHSTA Faßbender 5 XI/3-XII, Auszug a.d. Schreiben des k.k. Buccowiner Domainen Inspectors Pauly, Radautz v. 17.XII.1803. 
fonds an Baron Mustazza, der im April 1804 nach mehr als sieben Jahren vom Kaiser auch bewilligt wurde. ${ }^{146}$

Insgesamt dokumentiert dieser über die vorhandenen Quellen einigermaßen detailliert nachzuverfolgende 'Fall Mustazza ‘ mehrere Aspekte der Bukowiner Landeseinrichtung, auf die zum Teil schon in einer früheren Studie hingewiesen wurde. ${ }^{147}$ Nicht nur dass es gelegentlich auf Grund der unterschiedlichen Landeskenntnis bei Entscheidungen zwischen den Wiener Zentral- und den Bukowiner Lokalbehörden zu divergierenden Auffassungen kam; auch mit dem nicht selten erheblich abweichenden Rechtsvorstellungen - in dem Fall jener des Fürstentums Moldau - musste man aus österreichischer Sicht erst lernen umzugehen. Abseits der ohnedies drückenden außenpolitischen Umstände und der steten finanziellen Nöte des habsburgischen Staates um die Wende vom 18. zum 19. Jahrhundert fanden sich die österreichischen Behörden auf der Suche nach einer Lösung für die Religionsfondsgüter in der Moldau nur schwer mit den politischen Strukturen des benachbarten Fürstentums zurecht. Zudem bedurfte jeder Schritt in den Verhandlungen mit Jassy einer Abstimmung mit den entscheidenden Instanzen in Istanbul, von den jeweiligen Eigeninteressen lokal einflussreicher Bojaren und des moldauischen Fürsten einmal ganz abgesehen. Weder Verpachtung noch Gütertausch oder Einzelversteigerung stellten sich am Ende als zielführend heraus. Erst in dem 1804 vorgelegten abschließenden Gutachten hatte man die Einsicht gewonnen, dass letztlich nur ein geschlossener Verkauf dieser Güter geeignet war, unter diesen mit der Systemisierung der Klöster wie der Kirche in der Bukowina 1783 eingeleiteten komplizierten territorialen Arrondierungsprozess endgültig einen vertretbaren Schlussstrich zu ziehen.

146 OSTA-FHKA galiz. Domänen Fasz. 10/1.830 Vortrag des Bukowiner Staatsgüterinspectors Pauli 30.XII.1802; Gutachten Copia a. Erzherzog Karl v. 24.III.1803; 12148/(970-974) Hofkammer Vortrag a. d. Kaiser u. Genehmigung v. 13.IV.1804; Nr. 78 Fasz. 10 101/35905/2831 v. 9.XI.1804, womit der Verkauf sämtlicher Religionsfondsgüter in der Moldau an Theodor Mustazza bestätigt wird.

147 SCHARR 2010, Landschaft. 


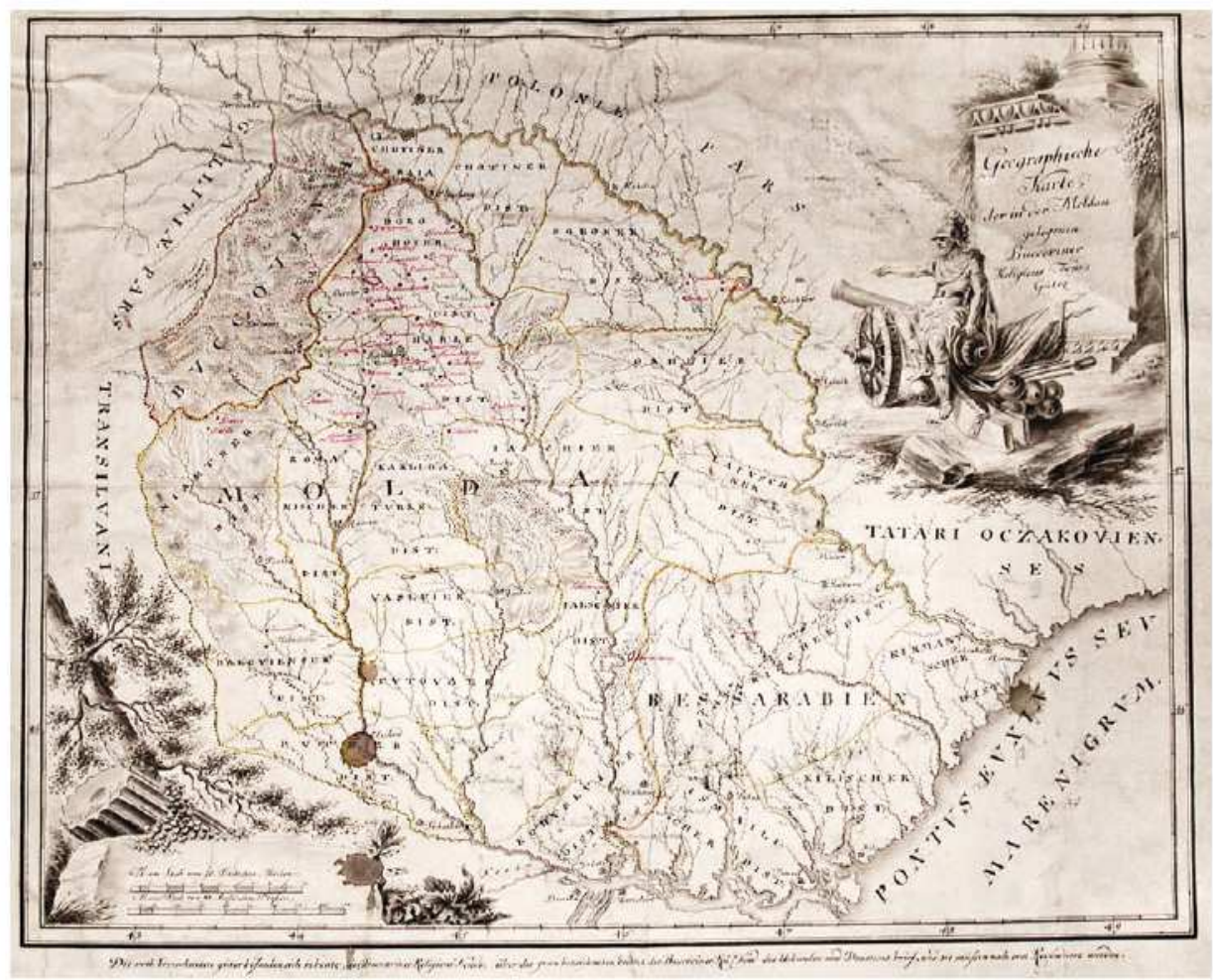

Abb. 6 und 7 Geographische Karte der in der Moldau gelegenen Buccoviner Religions-Fonds-Güter, Gesamtkarte und vergrößerter Ausschnitt (Anonymus um 1802; @ ÖSTA-Wien); Die Dorfschaften in der Karte sind oftmals lagefalsch verzeichnet, was wohl auch das zeitgenössisch unsichere Wissen der österreichischen Behörden widerspiegelt. Die in der Karte rot unterstrichenen (und dort nicht vollständig eingetragenen) Orte entsprechen weitgehend der Aufstellung in Tab. 4. 


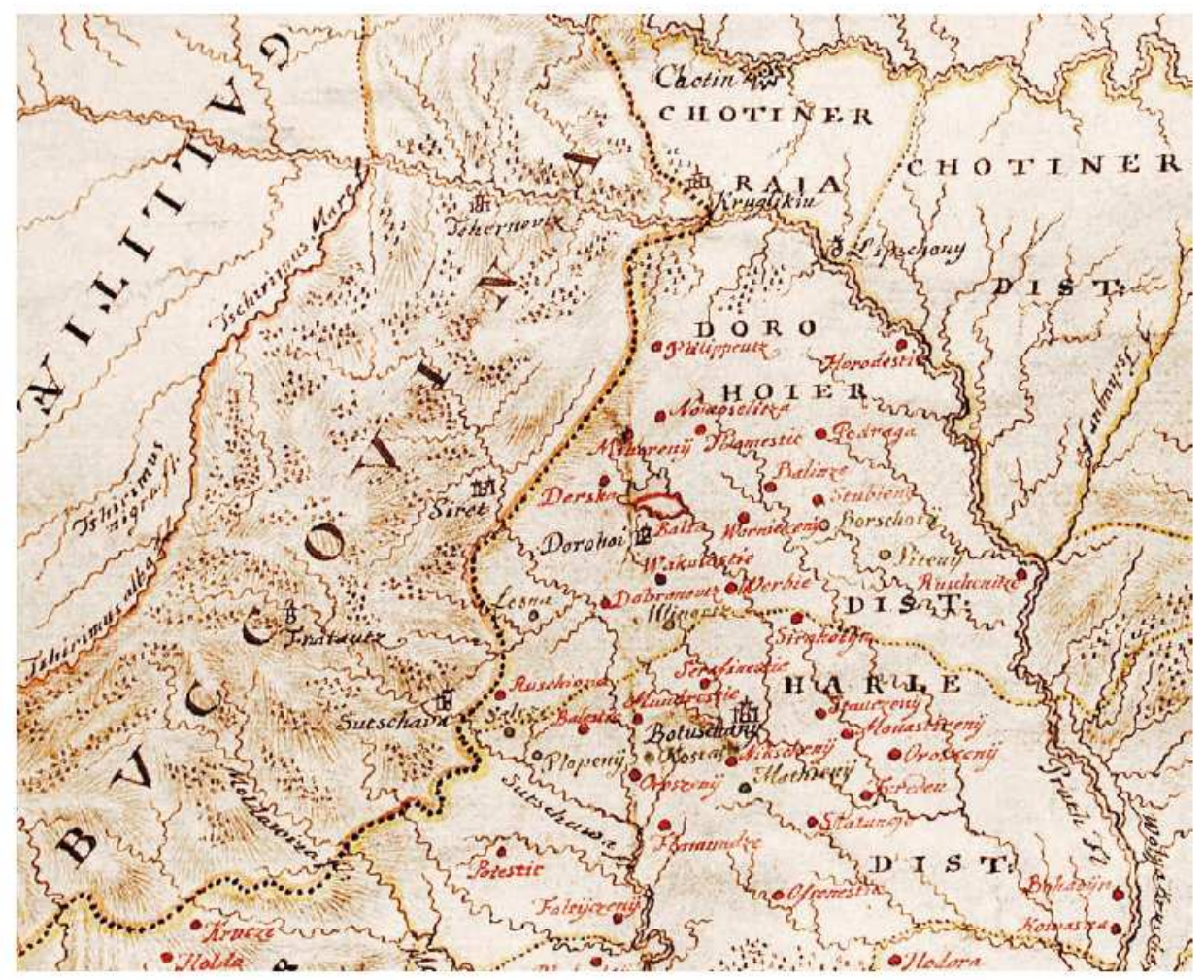

Tab. 4: Verwaltungsstruktur und Dörfer der Staatsgüter in der Bukowina $1801^{148}$

\begin{tabular}{|c|c|c|c|c|c|}
\hline & Herrschaft & Dorf & ganz & anteilig & vormals ${ }^{145}$ \\
\hline 87 & \multirow{7}{*}{ Kotzman } & Kotzman & $x$ & & $\ddagger$ \\
\hline 88 & & Laschkowka & $\mathrm{x}$ & & $\ddagger$ \\
\hline 89 & & Witelowka & & $\mathrm{x}$ & $\pm / P$ \\
\hline 85 & & Klowodyn & $\mathrm{x}$ & & $\ddagger$ \\
\hline 86 & & Suchowerchow & $\mathrm{x}$ & & $\ddagger$ \\
\hline 13 & & Stawczan & $\mathrm{x}$ & & $\ddagger$ \\
\hline 42 & & Chliwestie & $\mathrm{x}$ & & $\ddagger$ \\
\hline
\end{tabular}

148 OSTA-FHKA galiz. Domänen Nr. 108 Fasz. 10 Juli-Dez. 1801, Personal und Besoldungs Standes Entwurf für die Bukowiner Staatsgüter, Lemberg 10.IV.1801.

$149 \ddagger$ kirchlich (rot: Bischof, orange: Kloster), P - privat, K - kaiserlich/kameral (grün). 


\begin{tabular}{|c|c|c|c|c|c|}
\hline & Herrschaft & Dorf & ganz & anteilig & vormals ${ }^{149}$ \\
\hline 41 & \multirow{16}{*}{ Kotzman } & Hawrylestie & $\mathrm{x}$ & & $\ddagger$ \\
\hline \multirow[t]{6}{*}{30} & & Alt-Mamajestie & $x$ & & $\ddagger$ \\
\hline & & Neu-Mamajestie & $\mathrm{x}$ & & $\ddagger$ \\
\hline & & Bordiejew (Burdej?) & $\mathrm{x}$ & & \\
\hline & & Rewna & $\mathrm{x}$ & & \\
\hline & & Brodok & $x$ & & \\
\hline & & Krysczatek & $x$ & & \\
\hline 12 & & Mahala & $x$ & & $\ddagger$ \\
\hline 11 & & Kotul Ostritza & $x$ & & $\ddagger$ \\
\hline \multirow[t]{2}{*}{26} & & Zuczka & $\mathrm{x}$ & & $\ddagger$ \\
\hline & & Buda & $\mathrm{x}$ & & \\
\hline 29 & & Lenkoutz & & $x$ & $P$ \\
\hline \multirow[t]{2}{*}{51} & & Pleschnitza & & $\mathrm{x}$ & $\ddagger$ \\
\hline & & Ostra & & $\mathrm{x}$ & \\
\hline 64 & & Banilla & & $x$ & $\mathrm{P}$ \\
\hline 60 & & Zamostie & & $x$ & $\mathrm{P}$ \\
\hline \multirow{2}{*}{197} & \multirow{10}{*}{ Solka } & Solka & $x$ & & \multirow{2}{*}{$\ddagger$} \\
\hline & & Arbora & $\mathrm{x}$ & & \\
\hline \multirow[t]{2}{*}{196} & & Jaslowetz & $x$ & & $\ddagger$ \\
\hline & & Mardzina & $\mathrm{x}$ & & \\
\hline 193 & & Suczawitza & $\mathrm{x}$ & & $\ddagger$ \\
\hline 198 & & Keschwana & $x$ & & $\ddagger$ \\
\hline 142 & & Botuschanitza & $\mathrm{x}$ & & $\mathrm{P}$ \\
\hline 182 & & Pertestie & $\mathrm{x}$ & & $\ddagger$ \\
\hline 181 & & Ludihumora & $\mathrm{x}$ & & $\ddagger$ \\
\hline 180 & & Komanestie & $\mathrm{x}$ & & $\mathrm{P}$ \\
\hline 233 & \multirow{9}{*}{ St. Illie } & St. Illie & $\mathrm{x}$ & & $\ddagger$ \\
\hline 158 & & Moldauisch Banilla & & $x$ & $\mathrm{P}$ \\
\hline 237 & & Petroutz & $\mathrm{x}$ & & $\ddagger$ \\
\hline 238 & & Mitoka Dragomirna & $\mathrm{x}$ & & $\ddagger$ \\
\hline 229 & & Itzkany & $\mathrm{x}$ & & $\mathrm{K}$ \\
\hline 226 & & Teschoutz & $x$ & & $\mathrm{P}$ \\
\hline 227 & & Ipotestie & $\mathrm{x}$ & & $P$ \\
\hline 235 & & Bunince & $\mathrm{x}$ & & $\ddagger$ \\
\hline 236 & & Mihoweni & $\mathrm{x}$ & & $\ddagger$ \\
\hline
\end{tabular}




\begin{tabular}{|c|c|c|c|c|c|}
\hline & Herrschaft & Dorf & ganz & anteilig & vormals $^{149}$ \\
\hline 175 & & Kostina & & $\mathrm{x}$ & $P$ \\
\hline 200 & & (Unter-)Milleschoutz & & $\mathrm{x}$ & $\ddagger$ \\
\hline 241 & \multirow{19}{*}{ Illischestie } & Illischestie & $x$ & & $\ddagger$ \\
\hline 243 & & Dragojestie & $\mathrm{x}$ & & $\ddagger$ \\
\hline 247 & & Korlata & $x$ & & $P$ \\
\hline 251 & & Berkischestie & $\mathrm{x}$ & & $\ddagger$ \\
\hline 250 & & Bajaschestie & $x$ & & $\ddagger / P$ \\
\hline 245 & & Kapukodrului & $\mathrm{x}$ & & $\ddagger$ \\
\hline 219 & & Gurahumora & $x$ & & $\ddagger$ \\
\hline 183 & & Klosterhumora & $\mathrm{x}$ & & $\ddagger$ \\
\hline 203 & & Woronetz & $x$ & & $\ddagger$ \\
\hline 204 & & Bukschoia & $\mathrm{x}$ & & $\ddagger$ \\
\hline 206 & & Stulpikany & $x$ & & $\ddagger$ \\
\hline & & Schemini (Ozemine?) & $x$ & & \\
\hline & & Slatiora mit Ostra & $\mathrm{x}$ & & \\
\hline 207 & & Negrilassa & $x$ & & $\ddagger$ \\
\hline 212 & & Frumossa & $x$ & & $\ddagger$ \\
\hline 208 & & Wama & $x$ & & $\ddagger$ \\
\hline 213 & & Watra Moldawitza & $x$ & & $\ddagger$ \\
\hline 214 & & Ruß Moldawitza & $\mathrm{x}$ & & $\ddagger$ \\
\hline & & Rußpeboul & $\mathrm{x}$ & & \\
\hline 209 & \multirow{5}{*}{ Kimpolung } & Kimpolung & $x$ & & \\
\hline 210 & & Sadowa & $x$ & & \\
\hline 211 & & Pożoritta & $x$ & & \\
\hline 215 & & Fundulmoldovi & $\mathrm{x}$ & & K \\
\hline & & Waleputna & $x$ & & \\
\hline 216 & \multirow{5}{*}{ Kimpolung } & Czokanestie & $x$ & & $\mathrm{~K}$ \\
\hline 217 & & Jakobeny & $x$ & & K \\
\hline \multirow[t]{3}{*}{218} & & Dornawatra & $x$ & & $\mathrm{~K}$ \\
\hline & & Dorna Kandreny & $x$ & & \\
\hline & & Dorna ?peschernelue? & & $\mathrm{x}$ & \\
\hline
\end{tabular}

unklar, ob das nunmehr nur Staatsgüter sind? Die sich zum Großteil aus ehemaligen Fondsgütern/Bischofsgütern zusammensetzen?

Staats- und Fondsgüter wurden vorerst gemeinsam verwaltet, vgl. Kap. 4. Die in der Tab. 4 ausgewiesenen Dorfschaften sind offenbar nur Güter-bzw. die Verwaltungssitze der Staatsdomänen, die sich jedoch zu einem wesentlichen Teil aus vormaligem Eigen der Kirche zusammensetzen. 


\section{Zusammenfassung}

Wenn gegen Ende des 19. Jahrhunderts der Czernowitzer Historiker Raimund Friedrich Kaindl die Kirchenreform und die Gründung des gr--orient. Religionsfonds der Bukowina bewusst aus der Schusslinie der zeitgenössischen Kritiker des Josephinismus nahm ${ }^{150}$, so war diese Äußerung nicht nur einer gewissen Loyalität seiner Person Wien gegenüber geschuldet, sondern wahrscheinlich auch einer real nachvollziehbaren Wahrnehmung. Die anfänglichen Schwierigkeiten bei der Einrichtung waren zu diesem Zeitpunkt bereits seit langem überwunden, und die Ende des 18. Jahrhunderts grundgelegten Strukturen begannen sich allmählich positiv auf die weitere Entwicklung des Kronlandes auszuwirken. Zu Beginn dieses Jahrhunderts schien man davon allerdings noch weit entfernt, wie die Analyse der Schwierigkeiten und innerbehördlichen Uneinigkeiten bei der Gründung des Fonds zeigen. Im Jahr 1832, also knapp 50 Jahre nach der Begründung des Fonds, wird diese Einrichtung als einer der "reichsten Religionsfonde in den österreichischen Provinzen « beschrieben, die zudem einen kontinuierlichen Überschuss erwirtschaftete. ${ }^{151}$ Dass der Staat - nicht ganz selbstlos - bereits in diesem frühen Stadium für sich aus dieser Quelle Profit zu schöpfen wusste, bleibt dabei unbestritten. So erwarb 1811 das Militär nach jahrelanger Pacht im Austausch mit anderen Staatsgütern die dem Religionsfonds gehörende wirtschaftlich nicht unbeträchtliche Domäne Fratautz, und nutzte sie für die Remontierung mit Pferden und den Aufbau eines Gestüts. Die Domäne war ursprünglich aus einem Teil der vormals bischöflichen Güter von Radautz hervorgegangen. ${ }^{152}$ Fratautz wies für das Jahr 1803 immerhin einen Ertrag von 12.000 Gulden (bei einer Gesamtertragssumme der Fondsgüter in der Bukowina von knapp $160.000 \mathrm{fl}$.) aus. ${ }^{153}$ Dank dieser Fondsgüter in der Bukowina verfügte der Staat nunmehr für die Ansiedlung von deutschsprachigen Kolonisten aus dem Heiligen Römischen Reich - wie schon bei den erwähnten bischöflichen Liegenschaften nördlich des Pruth - auch im südlichen Landesteil über dringend benötigten Grund und Boden. Allein auf den Herrschaften Fratautz, Kuczurmare und St. Illie - alle vor-

150 "Durch die Uebernahme der kirchlichen Güter in die Verwaltung des Staates hat also der Kaiser sicher nicht, wie es manchen beschränkten oder übelwollenden Gemüthern schien, die Kirche geschädigt, sondern dieselbe in der Bukowina ganz besonders gefördert«; KAINDL 1896, Kaiser, 15.

151 STÖGER 1832, Übersicht, 90 (Nr. 23 v. 23. II. 1832).

152 PoleK 1894, Anfänge, 42; sowie ÖSTA-FHKA galiz. Domänen Nr. 85 Fasz. 10 139/1340 Entschädigung für die Herrschaft Radautz v. 17.I.1811; FHKA Domänen Nr. 72 Fasz. 7, Vortrag und Resolution v. 17.I.1795 Verpachtung der Bukowiner Religionsfondsgüter der Herrschaft Fratautz nebst Ober- und Unterwikow dann Strascha.

${ }_{153}$ OSTA-HHSTA Faßbender Karton 5 XI/3-XII MS XII, Ertragsausweis der Buccowiner Staats- und Fondsgüter 1801-1803. 
maliges Kirchengut - kamen 179075 Familien, verteilt auf acht Kolonien zur Ansiedlung. ${ }^{154}$ Zur Finanzierung der desolaten Staatsfinanzen ließ Wien 1811/12 Teile der Religionsfondsbesitzungen, vorwiegend in den fruchtbareren und landwirtschaftlich ertragreichen Gebieten der nordöstlichen Bukowina ${ }^{155}$, veräußern. Das führte mithin zur später so deutlichen Dominanz der Forstwirtschaft innerhalb des Religionsfonds.

Bis zur Regulierung der Fondsmittelverwendung durch einen allerhöchsten Beschluss von Kaiser Franz I. (Troppau 12.XII.1820) betrachtete die Lemberger Verwaltung den Fonds - was den Aspekt des Eigentums angeht - als öffentliches Gut. ${ }^{156}$ Letztlich setzte erst mit der Märzverfassung von 1849 jener Prozess ein, der das durch den Religionsfonds administrierte Kircheneigentum (das es theoretisch auch immer geblieben war) wieder schrittweise in dessen Verfügungsgewalt - wenngleich mit Einschränkungen - zurückführte. Wie allerdings noch zu zeigen sein wird, war damit die Eigentumsfrage bzw. vor allem die Frage der Verfügungsgewalt darüber keineswegs geklärt. Sie sollte bis zum Ausbruch des Ersten Weltkrieges noch Gegenstand von zum Teil heftig geführten Diskussionen in der Bukowina werden.

Einmal abgesehen von der lobenden Einschätzung des Zeitgenossen Raimund F. Kaindl formten die Diözesanregulierung, der Güteraustausch mit der Moldau und die Einrichtung des gr--orient. Religionsfonds einerseits eine hochkomplexe Thematik. Letztere ermöglicht einen Einblick in das diskursive Verhältnis von Reformwillen, Verwaltungspraxis und realem Umsetzungsspielraum vor Ort. Hier waren die Wiener Behörden in ihren Entscheidungsprozessen nicht nur vom eigenen Wollen (und zeitweilig wohl auch Unvermögen) abhängig; ganz im Gegenteil, sie mussten diese jeweils in Einklang mit einer sich stetig ändernden Außenpolitik, den wechselnden Befindlichkeiten an der Hohen Pforte oder am Hof des Fürsten der Moldau in Jassy bringen. Dass dabei praktisches Wissen und Verständnis um andere Herrschaftsformen jenseits der Grenze nach wie vor gering waren, zeigen nicht nur die langwierigen und ebenso widersprüchlichen Verhandlungen um den Verkauf der betroffenen in der Moldau gelegenen Bukowiner Klostergüter an Baron Mustazza. Andererseits war es gerade der Einsicht lokaler, aus der Bukowina selbst stammender, jedoch bereits in Wien ausgebildeter loyaler Beamter, wie wir in der Person Basilius Balsch ein Paradebeispiel dafür finden, zu

154 Fratautz (Nr. 191) 16, Satulmare (Nr. 201) / Itzkany (Nr. 229) / St. Onufry (Nr. 130) / Arbori (Nr. 197) u. Milleschoutz (Nr. 200) jeweils 8, Tereblestie (Nr. 137) 7 u. Illischestie (Nr. 241) 12 Familien; Bericht der k. Domainen Zentral Hofbuchhaltung, Wien v. 1.X.179o, OSTA-FHKA galiz. Domänen Nr. 108 Fasz. 10 Juli-Dez. 1801, fol. 864-871v; vgl. dazu SCHARR 2010, Landschaft, v.a. Kapitel 7.3.2. (Kolonisation aus dem Reich).

155 Ostra, Banilla, Zamostie, Cabeștie, Pleschnitza, Crișeiatec, Luca și Banin; die Schreibweise der Ortschaften entspricht, soweit dort vorhanden, jener in Tab. 4;

156 NeșCIUC 1893, Istoria, 20. 
verdanken, dass eine so wesentliche Reform wie der geistliche Regulierungsplan und die Begründung des gr.-orient. Religionsfonds letztlich doch einigermaßen erfolgsversprechend auf den Weg gebracht werden konnten.

In Summe bedingten die von Joseph II. in der Bukowina aufgenommenen Reformen auf lange Sicht jedoch nicht nur eine schrittweise Heranführung an die übrigen Länder des Habsburgerreiches, sondern sie verliehen dieser Provinz - als einem in zeitgenössischer Sicht vergleichsweise leicht zu beackernden Experimentierfeld - in der rückblickenden Einschätzung ebenso einen gewissen "Vorbildcharakter für die angestrebte josephinische Staatsordnung « im Allgemeinen. Diese `Experimente staatlicher Neuordnung ließen sich hier offensichtlich in weiten Bereichen weit mehr auf den Grund bringen als in den Erbländern. ${ }^{157}$ Für die Provinz selbst legten diese Kirchenreformen im weiteren Sinne schließlich die nötige Basis, aus der sich gegen Ende des 19. Jahrhunderts in Abgrenzung zur Moldau Identität und Selbstbewusstsein der Bukowina nicht zu einem geringen Anteil speisen sollten.

157 Ceaușu 2008, Reformen, 64. 
Innerhalb der Habsburgermonarchie herrschte zwischen den einzelnen Ländern zur Mitte des 19. Jahrhunderts ein beträchtliches sozio-ökonomisches Entwicklungsgefälle, dessen Grundcharakter sich - trotz zum Teil erheblicher Verbesserungen - bis zur Auflösung des Reiches auch nicht mehr wesentlich ändern sollte. ${ }^{1}$ Hinter dem oberflächlich politisch geordneten Länderkonglomerat verbarg sich noch weit über die 1848 eingeleitete Grundentlastung hinaus eine nahezu unüberschaubare Vielzahl struktureller Eigenheiten (insbesondere mit Blick auf die vorangegangene individuelle Agrarverfassung der in concreto betroffenen Region), welche auf die ökonomische Situation des jeweiligen Kronlandes und ihre weitere Gestaltung einen entscheidenden Einfluss ausübten. ${ }^{2} \mathrm{Um}$ - ohne diese Details völlig auszublenden - trotzdem eine handhabbare Vergleichsübersicht der allgemeinen Situation zu gewinnen, versuchte etwa David F. Good in seiner Wirtschaftsgeschichte des Habsburgerreiches jeweils mehrere Kronländer in ihren strukturellen Ähnlichkeit zu gruppieren (vier Regionen für die österreichische Reichshälfte und drei für die Länder der Stephanskrone). Galizien und die Bukowina werden dabei unter dem Begriff ,Karpatenländer ‘ als Makroregion subsummiert. ${ }^{3} \mathrm{Da}$ mit entspricht Good weitgehend einer Gliederung, die auch zeitgenössische Autoren bereits vorgeschlagen hatten. ${ }^{4}$ Der wirtschaftliche Schwerpunkt dieser Region lag auf der Erzeugung von Nahrungsmitteln, im Wesentlichen in Form von Vieh und Getreide. ${ }^{5}$ Charakteristisch für die im Vergleich zu den westlichen Regionen sichtbare ökonomische Rückständigkeit war eine dementsprechend geringe Agrarproduktivität, ein schwach ausgebildeter sekundärer wie tertiärer Sektor sowie eine auffällige Dichotomie von urbanen Zentren und ländlichem Raum. ${ }^{6}$ Damit glich die Situation in der Bukowina im Großen und Ganzen einem Bild, das auf weiten Strecken für die ökonomische Lage Osteuropas zu diesem Zeitpunkt typisch war. ${ }^{7}$

Zusammen mit Galizien und Dalmatien gehörte die Bukowina also zu jenen Teilräumen der Monarchie, deren "rückständige Form der Wirtschaftsführung" (eine Ein-

1 Rumpler \& Seger (Hg.) 2010, Gesellschaft.

2 GrüNBeRG 1899, Grundentlastung, 2; im Úberblick Vilfan 1973, Agrarsozialpolitik.

3 GOOD 1986, Aufstieg, 23,

4 Umlauft 1897, Monarchie; Zeehe et al. (Hg.) ${ }^{6} 1919$, Vaterlandskunde.

5 Good 1986, Aufstieg, 27.

6 Vgl. dazu u.a. die Betriebsgrößenangaben bei BRUскмüller 2010, Arbeitswelten, 298; die augenfällige Dichotomie der Karpatenländer Galizien und Bukowina wurde auch in der Reiseliteratur immer wieder thematisiert, etwa bei K. E. Franzos, zit. nach SCHARR 2010, Landschaft, 82; oder SöLCH 1911/12, Tschernowitz.

7 MÜlleR 2004, Nachzügler, 12. 
schätzung, die sich auf den dominierenden Landwirtschaftssektor bezog) selbst über die Jahrhundertmitte hinaus bestimmend blieb. ${ }^{8}$ Wirkten sich die Reformen im Umfeld der Grundentlastung in den meisten westlichen Kronländern kaum merkbar auf deren Wirtschaft aus ${ }^{9}$, so bot sich in der Bukowina ein anderes Bild. Einerseits fand sich der produktivere Großgrundbesitz (in der vorherrschenden Form der Gutswirtschaft), zu dem auch der Religionsfonds gehörte, mit dem Wegfall billiger Arbeitskräfte in einer prekären wirtschaftlichen Situation wieder. Andererseits konnten die aus der Grundentlastung erlösten Kapitalien die notwendige Modernisierung nicht decken und nötige Investitionen blieben vielfach aus. Die Entschädigung der Dominien in der Bukowina hätte eigentlich aus Staatsgeldern erfolgen müssen, allerdings sah das entsprechende Reichsgesetz dafür keine konkreten Maßnahmen vor, sodass die Zahlungen zunächst in gleichen Teilen vom Kronland und den Grundherrschaften zu tragen waren. Schließlich hatte die Bukowina die ganze Last allein zu schultern. ${ }^{10}$ Um die daraus resultierende "notorische Capitalarmut « im Lande zu überbrücken, hatte selbst der Landespräsident der Bukowina Rudolf Graf Amadei im Landtag den Vorschlag eingebracht, das Religionsfondskapital als vorübergehendes Darlehen zu verwenden, was Wien allerdings ablehnte. ${ }^{11}$ Hinter dieser Entscheidung der Zentralregierung verbarg sich wohl auch die drohende Absicht der vormaligen Grundherrschaften, die ihnen übertragenen Lasten der Kirchenpatronate ebenso auf Kosten des gr.-orient. Religionsfonds zu bestreiten. ${ }^{12}$ Dem wollte man offensichtlich von Seiten Wiens einen Riegel vorschieben. ${ }^{13}$ Der struk-

8 SANDGRUBER 1978, Agrarstatistik, 197.

9 Good 1986, Aufstieg, 88.

10 Officielle stenographische Berichte über die Verhandlungen des österr. Reichstages, 36 . Sitzung des constituierenden Reichstages v. 7.IX.1848, S. 291 Punkt 8d, sowie Patent zur Aufhebung des Unterthänigkeitsbandes und Entlastung des bäuerlichen Besitzes v. 7.IX.1848; Patent v. 4.III.1849, wodurch die Durchführung der Aufhebung des Unterthans-Verbandes und der Entlastung des Grund und Bodens angeordnet wird; das Patent stellte für das Königreich Galizien zum Patent v. 7.IX.1848 noch eine eigene Durchführungsverordnung in Aussicht; Erlaß des Ministers des Innern vom 25. September 1849 an den Herrn Kreischef der Bukowina wegen Anweisung einstweiliger Vorschüsse auf Rechnung der für die aufgehobenen unterthänigen Leistungen in dem Herzogthume Bukowina zugesicherten Vergütung Nr. 397; der Erlass sah eine teilweise Gegenrechnung der Vergütungsbeträge mit der anfallenden Grundsteuer vor.

11 Stenographische Protokolle des Bukowinaer Landtages 1864, 20. Sitzung III. Session 9.V.1864, 316f.; 21. Sitzung III. Session v. 11.V.1864, 329f. sowie 4. Sitzung IV. Session, 20.II.1865, 30.

12 Das Konsistorium hatte bereits 1859 in einer ausführlichen Stellungnahme die Übernahme privater Kirchenpatronate bzw. die Gewährung von Krediten zur Herstellung der Kirchen etc. für / durch den Religionsfonds angeregt; OSTA-AVA, Neuer Kultus NK Akath. gr.-or. K 22, Entwurf ex 1859; vgl. Kapitel 8 (wirtschaftliche Situation um 1914).

13 GrünBERg 1901, Studien, 97. 
turelle Kapitalmangel verstärkte sich in der Folge indes noch mehr, zudem fehlte es vorerst an nötigen wie geeigneten rechtsstaatlichen Instrumentarien. Grundbücher etwa wurden in Cisleithanien erst 1871 eingeführt. ${ }^{14}$ Immerhin bot die 1856 flächendeckend abgeschlossene (seit 1819 mit Unterbrechungen gelaufene) Katastralvermessung eine solide Grundlage für weitere Reformschritte in diese Richtung. ${ }^{15}$ Erst 1863 - die für die Grundentlastung in der Bukowina zuständigen Organe hatten ohnedies spät ihre Tätigkeit aufgenommen ${ }^{16}$ - griff der Staat ein und stellte die dafür dringend benötigten Finanzmittel bereit. ${ }^{17}$

Die wachsende Belastung der früheren Grundobrigkeit resultierte zunächst in einer extensiven Bewirtschaftungsform vieler Gründe, zumeist auf Basis von Pachtverhältnissen bei gleichzeitig äußerst geringer Investitionsbereitschaft. Auch die Bauern vermochten ihre gewonnenen Freiheiten ebenso wenig zu nutzen und konnten sich kaum in der zur Verfügung stehenden Zeit den geänderten Verhältnissen anpassen. ${ }^{18}$ So gelang es der Bukowina nur teilweise, an den sgoldenen Jahren ‘ der europäischen Landwirtschaft im letzten Viertel des Jahrhunderts, vor dem Einsetzen eines allgemeinen Preisverfalls durch die überseeische Konkurrenz, zu partizipieren. Auf Bedeutung wie Folgen derartig hemmender Tendenzen und institutioneller Schwächen der vormaligen Agrarverfassung als auch auf die latente Persistenz vorherrschender Mentalitäten, die letztlich ein vollständiges Ausschöpfen der Modernisierungsressourcen - wie sie etwa die Grundentlastung bot - entscheidend verzögerte, wird auch in anderen Teilen der Monarchie verwiesen. ${ }^{19}$ Vielfach benötigte die reale Verbesserung dieser Verhältnisse Jahrzehnte. Den Zugang sowie die Möglichkeiten gewinnbringender Nutzung land- und fortwirtschaftlicher Innovationen vermochten sich in der Bukowina - aber auch hier nur unter erheblichen Schwierigkeiten - noch am ehesten Großgrundbesitzer wie der Religionsfonds zu erschließen, "während bei der Masse der Bevölkerung die Bodencultur [nur] einen geringen Grad von Entwicklung « aufwies. ${ }^{20}$ Eigens aus diesem Umstand heraus ins Leben gerufene Institutionen wie beispielsweise der 1851 gegründete Verein für Landescultur und Landeskunde im Herzogthume Bukowina arbeiteten hartnäckig an der systematischen Verbreitung neuer landwirtschaftlicher Kenntnisse. ${ }^{21}$ Auch hatte man

\footnotetext{
14 RGBl. Nr. 95 v. 25 .VII.1871 über die Einführung eines allgemeinen Grundbuchgesetzes.

15 Rumpler \& SCharr (Hg.) 2015, Kataster.

16 RGBI. Nr. 234 v. 23 .X.1853 betreffend die Durchführung der Grundentlastung im Herzogthume Bukowina.

17 GRÜNBERG 1901, Studien, 98.

18 ZACHAR et al. 1901, Entwickelung, 5off.; im Überblick DiNKLAGE 1973, Entwicklung, 41 off.

19 Für Kärnten vgl. Droвesch 2013, Agrarverfassung(en), 16.

20 Handels-Ministerium (Hg.) 1854, Mittheilungen, 24 und 69.

21 Handels-Ministerium (Hg.) 1854, Mittheilungen, 71.
} 
unter anderem im Fehlen von Fachschulen eine der zentralen Ursachen für die ökonomisch triste Situation des Kronlandes bereits folgerichtig erkannt. So forderte die 1850 eingerichtete Bukowinaer Handels- und Gewerbekammer dementsprechend seitens des gr--orient. Konsistoriums ein, dass der Religionsfonds hierfür im Sinne seines Auftrages Mittel bereitstellen sollte. Allerdings - und das ist wiederum ein Beispiel für die Persistenz politischer Strukturmängel, die noch aus dem administrativen Zusammenschluss der Bukowina und Galiziens zwischen 1786 und 1849 herrührten - sah sich dabei das einflussreiche lateinisch katholische Konsistorium in Lemberg im Nachteil, hätten doch die Schulen in diesem Fall dem gr.-orient. Bischof unterstanden. ${ }^{22}$ Der Zuständigkeitsbereich des Lemberger Konsistoriums als Schuloberbehörde erstreckte sich zu diesem Zeitpunkt immer noch auf die Bukowina, ungeachtet der seit 1849 erfolgten politischen Trennung von Galizien. ${ }^{23}$ Trotz der dadurch bedingten Verzögerungen konnte schließlich in den Jahren 1860 bis 1863 in Czernowitz eine Oberrealschule eingerichtet werden. ${ }^{24}$ Die Dotation dafür hatte der Bukowiner Religionsfonds geleistet.

Auf die gesamtwirtschaftliche Lage der Bukowina wirkten sich überdies nicht nur außenpolitische Ereignisse wie der Krimkrieg (die damit verbundenen Truppenkonzentrationen, Handelsbeschränkungen etc.) negativ aus, sondern auch die wiederholten Missernten dieser Jahre. Die Grundentlastung und das schon erwähnte Fehlen billiger Arbeitskräfte zogen für die in der Bukowina dominierende Gutsherrschaft den Verlust ursprünglicher Kostenvorteile gegenüber einer wachsenden Konkurrenz in der Moldau und Bessarabien nach sich. ${ }^{25}$ Zusammen mit der mangelhaften Strukturmodernisierung in der Landwirtschaft wurzelte darin ein weiterer sich gegenseitig aufschaukelnder Nachteil. ${ }^{26}$

In der Forstwirtschaft stellten sich die Probleme durchaus ähnlich dar. Den Wald als "Factor des Nationalreichthums ${ }^{27}$ hatte man in der Bukowina wohl erkannt. Immerhin beliefen sich die Waldungen des Kronlandes laut Katastralausweis für das Jahr 1847 auf

\footnotetext{
22 AnONymus 1862, Hauptbericht, 9 u. 11, Vorwort W. v. Alth u. A. Mikulitsch.

23 Die Trennung von Galizien-Lodomerien hinsichtlich der einzelnen Verwaltungsstränge erfolgte schrittweise in den auf 1849 folgenden Jahrzehnten; hinsichtlich der Justiz war etwa eine Loslösung zu Lemberg mit den Reformen von 1868 eingetreten; die Oberaufsicht über das Schulwesen für die Bukowina lag seit 1850 in den Händen des gr.-orient. Konsistoriums (nach wie vor davon ausgenommen waren allerdings katholische Schulen); mit 1869 fiel das gesamte Schulwesen in die Kompetenz des neu errichteten Landesschulrates; CATARGI (Hg.) 1899/2004, Bukowina, 444 u. 449 f. 24 KAINDL 1908/2005, Geschichte, 286; CATARGI (Hg.) 1899/2004, Bukowina, 452.

25 GRÜNBERG 1899, Gundentlastung, 3.

26 ANONYMUS 1862 , Hauptbericht, $4 \mathrm{f}$.

27 Handels-Ministerium (Hg.) 1854, Mittheilungen, 43.
} 
$45 \%$ der Gesamtbodenfläche (von 1.045.00o Hektar). ${ }^{28}$ Nach der Reambulierung von 1867 betraf das 478.000 Hektar. ${ }^{29}$ Allerdings mussten sich die Behörden eingestehen, dass (vor der Herstellung des Eisenbahnanschlusses und vor dem Bau der Waldbahnen) ein beträchtlicher Teil dieser Ressource aus Mangel an Beförderungsmöglichkeiten und ungenügender Erschließung nur äußerst unbefriedigend in Wert gesetzt werden konnte. ${ }^{30}$ Selbst die Landesverwaltung vor Ort bemängelte die chronisch fehlende "Zweckmäßige Benützung « der Wälder vor allem durch Private, da man "weder den Wert der Waldungen, noch die Vortheile, welche eine forstwissenschaftliche Behandlung derselben gewähren «, kenne. ${ }^{31}$

Daraus lässt sich für die ersten beiden Jahrzehnte nach 1848 in Summe ein in ökonomischer Hinsicht wenig dynamisches Bild der Bukowina nachzeichnen, das zu einem Teil auch für den Religionsfonds seine Gültigkeit besaß. Ausgehend von dieser Skizze ist daher die wirtschaftliche Situation des Fonds noch vor den Reformen, die mit dem neuen Organisationsstatut von 1870 einsetzten und auch hier nunmehr endgültig eine spürbare Dynamisierung einleiteten, näher zu analysieren.

\section{Wirtschaftsreformen \& Religionsfonds}

Mitte des 19. Jahrhunderts waren in der Bukowina drei Viertel aller Beschäftigten in Land- und Forstwirtschaft tätig bzw. im Erwerb ihres Lebensunterhaltes von diesem Sektor abhängig. ${ }^{32}$ Damit lag das Kronland über dem Durchschnitt der Monarchie, der für 1869 mit 70\% der Erwerbstätigen angegeben wird. ${ }^{33}$ Ungeachtet der statistischen Ungenauigkeit und Mängel dieser Daten deutet das Verhältnis doch den grundsätzlichen Stellenwert von Land- und Forstwirtschaft für weite Teile der Bevölkerung der Bukowina an, auch wenn dieser bis 1918 im Zuge der allgemeinen Entwicklung noch schrittweise abnehmen sollte.

28 Hinsichtlich der Waldfläche lag die Bukowina in Cisleithanien nach der Steiermark (48\%) und Kärnten/Krain (44\%) damit an dritter Stelle, gefolgt von Tirol (39\%); KoLoss A 1965, Untersuchung, 150f.; zit. nach BRUскмÜLLER 2010, Arbeitswelten, $292 \mathrm{f}$.

29 ZaCHAR et al. 1901, Entwickelung, $43 \mathrm{f}$.

30 Handels-Ministerium (Hg.) 1854, Mittheilungen, 46.

$31 \mathrm{DACZ}_{3} / 1 / 68$ Administrationsbericht an das Ministerium des Innern 1852.

32 In absoluten Zahlen betraf das ca. 298.00o von knapp 385.00o Einwohnern (der anwesenden erwerbsfähigen einheimischen Bevölkerung); ANONYMUS 1862, Hauptbericht, 106f.; Taglöhner sowie im Haushalt beschäftigte Frauen wurden der in Land- und Forstwirtschaft tätigen Bevölkerung hinzugezählt; zur Problematik der statistischen Erfassung agrarischer Arbeitswelten vgl. BRUCKMÜLLER 2010, Arbeitswelten, 256f. u. 277.

33 Kolossa 1965, Untersuchung, 141f.; zit. nach BRUCKMÜLleR 2010, Arbeitswelten, 253. 
Gilt die Frage der Grundentlastung von 1848 und ihre Folgen im Allgemeinen als »epochaler Wendepunkt in der Geschichte der österreichischen Volkswirtschaftspolitik«, so trifft das auf die Bukowina, obgleich aus längerfristiger Perspektive, im Speziellen umso mehr zu. ${ }^{34}$ Hatten etwa in den innerösterreichischen Ländern bereits im Vormärz einzelne entscheidende Entwicklungen zur Verbesserung der Agrarverhältnisse angehoben und hatten jetzt sichtbar zu greifen begonnen, so setzte in den Kronländern Bukowina und Galizien erst der mit der Grundentlastung eingeleitete Übergang von der feudalen zur liberalen Wirtschaftsordnung eine wirklich spürbare Zäsur. Langfristig gründete darin ein merklicher Modernisierungsschub. Insofern ist der positiv formulierten abschließenden Wertung dieses Prozesses durch den Wiener Wirtschaftshistoriker Karl Grünberg, wonach »mit dem Jahre 1848 die besondere Geschichte der Bukowiner ländlichen Bevölkerung in die allgemeine österreichische einmündet $\aleph^{35}$, durchaus zuzustimmen, wenngleich gerade in diesem Raum die angesprochenen strukturellen Lasten der älteren Agrarverfassung noch lange Zeit nachwirken sollten.

Früh aufgenommene, jedoch in der Bukowina bald wieder unterbrochene Reformvorhaben wie etwa die Franziszeische Katastralmappenaufnahme gewannen damit neuerlich an Fahrt und zudem eine klare Richtung, wenngleich diese - wie im Fall des Grundsteuerkatasters - von Anfang an so nicht unbedingt beabsichtigt gewesen waren. ${ }^{36}$ Der Kataster wirkte zweifellos beschleunigend auf den Prozess der Grundentlastung, allerdings bedingte der Widerstand der politisch einflussreichen Großgrundbesitzer auch hier Verzögerungen und mündete vielfach in Sonderregelungen. So behielten in der Bukowina wie in Galizien die Gutsgebiete - die vorerst nicht Teil der neu geschaffenen politischen Gemeinden waren - noch über Jahrzehnte hin ihre rechtliche Sonderstellung bei. ${ }^{37}$ Die vergleichsweise kleineren Staatsdomänen und der Religionsfonds sahen sich trotzdem von diesen Reformen in einen gewissen Nachteil gesetzt. ${ }^{38}$ Ihre rechtliche Situation bzw. die direkte Abhängigkeit vom Staat wiesen ihnen dabei eine Zwitterstellung zu, die Entscheidungsprozesse erschwerte.

34 SCHIFF 1898, Grundentlastung, 13.

35 GRÜ NBERG 1901, Studien, 95; Grünberg stammte aus dem rumänischen Focşani und hatte in Czernowitz das Gymnasium besucht. Er spricht im Zusammenhang mit der Bukowina auch von »unserem Kronlande«; ebd. S. 97.

36 RUMPler \& ScharR (Hg.) 2015, Kataster.

37 SCHIFF 1898, Grundentlastung, 22.

38 Dem widerspricht die zeitgenössische Fachliteratur deutlich, konstatierte diese doch gerade das Gegenteil; GRÜNBERG 1899, Grundentlastung, 66. 
Mit der Grundentlastung länderweise eingerichtete Fonds übernahmen de facto die Funktion von Kreditanstalten. ${ }^{39}$ Sie hatten das nötige Kapital zwischen Berechtigten und Belasteten in Form der Grundentlastungsobligationen zu vermitteln. Die berechtigten Grundherren bezogen daraus Entschädigungszahlungen, welche die verpflichteten Bauern im Verlauf von zwei Jahrzehnten (unter Wegfall aller anderen grundherrlichen Abgaben) gegen eine Verzinsung in den Entlastungsfonds einzubringen hatten. Mit der angestrebten und durchgeführten Grundentlastung gelang es zwar dem Staat, die über Jahrhunderte hin gewachsene Beziehung zwischen Bauer und Grundherren zu entflechten und auf eine neue - für alle gleiche - Rechtsgrundlage zu stellen, aber auf regionaler Ebene zeitigte dieses Vorhaben - wie in der chronischen Kapitalarmut der Bukowina bereits angesprochen - seine Schwächen.

In den meisten Ländern der Habsburgermonarchie (die Länder der Stephanskrone ausgenommen) galt der Prozess der Grundentlastung nach wenigen Jahren bereits als abgeschlossen. Nicht so in Galizien und der Bukowina. Während sich mehrheitlich die Verteilung der Belastungen zwischen Land und Verpflichteten entweder die Waage hielt oder hauptsächlich von den Verpflichteten getragen wurde, entfiel die Hauptlast in Galizien und der Bukowina auf die Kronländer selbst. Von mehr als 46 Millionen Gulden Grundentlastungskapital waren das über 44 Millionen, lediglich zwei Millionen steuerten die Verpflichteten selbst bei. ${ }^{40}$ So musste 14 Jahre nach der erfolgten Einleitung der Grundentlastung das damit beschäftigte Landtagskomitee der Bukowina in einer Denkschrift feststellen, dass trotz des vergleichsweise zu den anderen Kronländern hohen Grundentlastungszuschlages (einer Art Steuer zur Deckung des Entschädigungskapitals) die daraus erlösten Zahlungsmittel weder zur Amortisierung noch zur Bedienung der Zinslast ausreichten. ${ }^{41}$ Der Grundentlastungsfonds der Bukowina verfügte nicht über ausreichende Mittel, da - wie erwähnt ein Sonderfall - die Verpflichteten hier von der Zahlung einer Entschädigungsquote weitestgehend befreit waren. Die Tilgung und weitere Emission von Obligationen an die Berechtigten musste daher vorerst suspendiert werden, sodass die Liquidierung selbst 1899 noch nicht als vollständig beendet gelten konnte. ${ }^{42}$ Da die Kapitalisierung der Renten indes weiterlief, führte dies zum kontinuierlichen Anwachsen einer zunehmend als drückend empfundenen Schuldenlast. Die Landesvertretung betrachtete die »Kapitalisierung der Interessen [nicht nur] als

\footnotetext{
39 Die korrekte Bezeichnung der dafür in der Bukowina verantwortlichen Abwicklungseinrichtung der Landesverwaltung lautete Bukowinaer Grundlasten-Ablösungs- und Regulirungs-Landes-Komission. 40 SCHIFF 1898, Grundentlastung, $19 \mathrm{f}$.

$41 \mathrm{DACZ}_{320 / 3 / 3258}$ Denkschrift über den Stand der Grundentlastungsschuld in der Bucowina, Czernowitz v. 9.IX.1862.

42 GrünBerg 1899, Grundentlastung, Tabelle IV, 76.
} 
eine Besorgniß erregende Kallamität«, sondern in Anbetracht der allgemeinen Situation vielmehr als gefährlichen Ansatzpunkt schleichender Verarmung. Zur gesicherten Tilgung der Grundentlastungsschuld forderte das Komitee daher dringend vermehrt Deckungsmittel seitens des Staates ein. Indirekt betraf diese missliche Finanzlage auch die Grundherren und den gesamten Grundentlastungsprozess, da das erforderliche Kapitel nicht oder lediglich mit Verzögerungen an die Berechtigten floss. So waren allein für 1862 annähernd 250.000 Gulden an Zinsen fällig, worauf die Staatsdomänen selbst, der Religions- und der Studienfonds Brodok auf die Hälfte Anspruch hatten. ${ }^{43}$ Zudem erforderte die Umgestaltung der Wirtschaftsweise außer den Grundentlastungsentschädigungen zusätzliche Kapitalien, die auf Grund der strukturellen Mängel in der Bukowina ohnedies nur schwer aufzubringen waren. ${ }^{44}$ Von den 11.800 .000 Gulden an errechnetem Grundentlastungskapital für die Bukowina standen den Kameral- und Religionsfondsgütern etwas weniger als 4.200.00o Gulden zu. Das Konsistorium als Eigentümervertreter sah sich indes noch 1864 gegenüber der Statthalterei veranlasst, ausdrücklich darauf hinzuweisen, dass »der Religionsfonds bis zur Stunde weder an Vorschüßen noch an Obligationen oder Renten etwas von der Grundentlastungsentschädigung erhalten « habe. Man bat sich deshalb von der Finanzlandesdirektion (die gleichzeitig als gesetzlicher Vertreter des Religionsfonds agierte) die Anweisung von 40.000 Gulden aus, um zumindest für die abzulösenden Holznutzungsrechte der Gemeinden einen Ausgleich zu erhalten. ${ }^{45} \mathrm{Ob}$ dadurch die Auszahlung an private Grundherrschaften wirklich schneller - also letztlich ebenso auf Kosten des Fonds - vonstattenging, kann angesichts der Quellenlage nicht eindeutig rekonstruiert werden und erscheint auch im Hinblick auf die ablehnende Haltung gegenüber dem oben erwähnten Ansuchen das Landespräsidenten Graf Amadei eher unwahrscheinlich.

Eingedenk dieser Situation festigt sich der Eindruck, dass der Staat in der finanziell misslichen Lage der Bukowina seine Stellung gegenüber dem Religionsfonds nutzte, um auf diese Weise den Kapitalmangel zeitweise zu umgehen. Nachweisbar ist jedenfalls, dass sich Bischof und Konsistorium schon 1859 in einem Schreiben bereit erklärten, »als Beitrag zu den gegenwärtigen aussergewöhnlichen Staats-Auslagen « eine Million Gulden an Grundentlastungsobligationen aus Mitteln des Religionsfonds aufzukaufen. Im Gefolge des für Österreich überaus misslichen Kriegsausganges von 1866 mit Preußen stiftete der Fonds, verbunden mit einer "patriotischen Bitte", auf die gleiche Weise

$43 \mathrm{DACZ}_{320 / 3 / 3258}$ Denkschrift über den Stand der Grundentlastungsschuld in der Bucowina, Czernowitz v. 9.IX.1862.

44 Zachar et al. 1901, Entwickelung, 52.

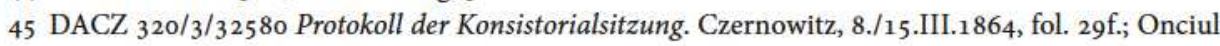
erwähnt in seiner Darstellung den Betrag von 4.143.476 fl., ONCIUL 1891, Fondul, 175. 
neuerlich 100.000 Gulden zu »Rüstungs- und Kriegszwecken«. Einen weiteren Antrag, dem der Landespräsident bereits zugestimmt hatte, auf zusätzliche 20.000 Gulden an Handgeldern, die für Freiwillige Soldaten aus der Bukowina gedacht waren, lehnte der Kaiser diesmal ab. Hingegen sollte die Hälfte des Betrages in die Anschaffung von Lebensmitteln für die Spitäler des Kronlandes fließen. ${ }^{46}$ Beide Male genehmigte der Kaiser als Landesfürst und oberster Schirmherr des Religionsfonds diese Förderungen ausdrücklich. Dabei lässt sich aus heutiger Sicht einerseits natürlich nur mehr schwer einschätzen, wie weit die >patriotischen ' Gesten von Konsistorium und Bischof auch als solche einzuschätzen und welche Absichten ihrerseits damit verbunden waren. Andererseits darf angenommen werden, dass dem >Patriotismus an Spendenfreude ein Aufruf von Wien vorausging.

In der Sache weitaus komplizierter stellte sich die Frage der Grundlastenablösung dar. Hier galt es in umgekehrter Form, die Leistungen der grundherrlichen Obrigkeit gegenüber den neu entstehenden politischen Gemeinden und den Bauern zu regeln. Eine Schwierigkeit trat dabei in der Ablöse von Nutzungsrechten in den Wäldern und Weidegründen zu Tage. Vielfach mündeten diese Lösungsversuche besonders im Alpenraum und in Galizien, aber auch in der Bukowina in ebenso erbittert geführten wie langwierigen Rechtstreitigkeiten, die schließlich doch die Großgrundbesitzer für sich entscheiden konnten. ${ }^{47}$ Mit dem 1853 erlassenen Patent zur Servitutsregulierung trachtete der Staat danach, diese Situation einer einheitlichen Lösung zuzuführen. ${ }^{48}$ Der Gesetzgeber erfüllte damit indes nicht die anfänglich aufgestellten Bedingungen einer gänzlichen Entlastung von Grund und Boden ${ }^{49}$, sondern wollte zumindest die Dienstbarkeiten (Servituten) einer überschaubaren Lösung zuführen. Die damit verbundene grundsätzliche Lastenablösung erforderte zunächst eine eindeutige Regulierung der rechtlichen Verhältnisse und Ansprüche; ein Faktum, das durch die bereits losgetretene Prozessflut erhebliche Verzögerungen mit sich brachte. Im Hinblick auf die dadurch in der Hauptsache betroffenen Wälder stand zudem zu befürchten, dass mit dem Gesetz von 1853 - das eine Abtretung an die Gesamtheit der Berechtigten (in der Regel die Ge-

46 Hackmann an Landespräsidenten v. 10./22.V.1859; sowie Landespräsident an Hackmann v. 12.VIII.1859; Staatsministerium 5761/G.U., Wien v. 7.VII.1866; zit. nach ONCIUL 1891, Fondul, 175 ff. u. 197-201.

47 SCHIFF 1898, Grundentlastung, 36f. u. $49 \mathrm{ff}$.

48 RGBl. Nr. 130, kaiserliches Patent v. 5.VII.1853 über die Regulirung und Ablösung der Holz-, Weideund Forstprodukten-Bezugsrechte, dann einiger Servituts- und gemeinschaftlichen Besitz- und Benützungsreche.

49 Zweitens. Grund und Boden ist zu entlasten; alle Unterschiede zwischen Dominical- und Rusticalgründen werden aufgehoben; Patent v. 7.IX.1848; abgedruckt in GRÜNBERG 1899, Grundentlastung, 49. 
meinden) vorsah - eine Schädigung dieser Ressource vorprogrammiert war, fehlten den betroffenen Gemeinden doch die für eine geregelte Bewirtschaftung oftmals sowohl die notwendigen Einrichtungen als auch die Erfahrung. Dem vermochte der Staat erst vergleichsweise spät 1873 durch die Schaffung von Forstbehörden als übergeordneten Aufsichtsorganen gegenzusteuern. ${ }^{50}$

Die Ablösung der Holznutzungsrechte in Geld oder Obligationen erachtete der Religionsfonds als nachteilig "in so lange nicht alle Ansprüche der Gemeinden auf das Eigenthum von Waldparzellen des Religionsfondes und alle anderen Waldservitutenansprüche dieser Gemeinden ausgetragen seien «. Man wollte daher die Entscheidungen der Bukowinaer Grundlasten-Ablösungs und Regulirungs-Landes-Kommission wie der Finanzlandesdirektion als gesetzlicher Vertreter des Religionsfonds abwarten. Grundsätzlich boten sich dafür drei Lösungsvarianten an, die auch das Patent von 1853 vorsah: die Ablöse in Geld oder Obligationen, in Grund und Boden oder durch einen servitutenmäßigen Naturalbezug. Zwischenzeitlich konnte das bischöfliche Konsistorium als Eigentumsvertreter des Fonds gegenüber den staatlichen Stellen nicht ganz kritiklos bleiben, hatten doch die Bevollmächtigen der Finanzlandesdirektion und die Servituten-Lokal-Kommissare, die "aus dem Religions-Fonde so bedeutende Bezüge als Pauschalien und als Reisekosten bezogen, seid (sic!) ihrer Einsetzung so wenig Ersprießliches geleistet . $^{51}$

Ursprünglich wiesen 300.690 Hektar der Religionsfondswaldungen Servitutslasten aus. ${ }^{52}$ Gegen die Ablösung der Holzbezugsrechte brachten die Konsistorialbeamten gleich mehrere aus ihrer Sicht schwerwiegende Einwände vor. Einerseits befürchteten sie auf Grund der Höhe des erforderlichen Ablösungskapitals (immerhin pro Jahr 366.00o Gulden, auf 20 Jahre!) eine Existenzgefährdung des Fonds. Andererseits wies das Konsistorium - freilich nicht ganz uneigennützig - auch auf soziale Aspekte hin. Wie sollten sich etwa bei steigenden Preisen die Armen der Gemeinden künftig ihren Holzbezug sichern? Dazu hält ein Bericht des Konsistoriums fest: „Religionsfonds und hohes Aerar würden diese immerhin enorme, die Holzungsberechtigten aber ruinierende Summe für ein Holzwerk hinauswerfen, welches, ohne zu dem geringsten Preise verwerthet werden zu können, in den ungeheueren Waldungen dieser Güter zu Hunderttausenden von Stämmen unnütz verfault.« Zudem zweifelte man seitens des Konsistoriums erheblich an der Fähigkeit der Gemeinden, eine »selbständige wie gemein-

50 Kundmachung Ackerbauministerium v. 3.IV.1873 in Betreff der künftigen Verwaltung der Staats- und Fondsforste und Domänen (RGBl. XVI. Stück, Kundmachung Nr. 44 ex 1873, S. 194ff.); die Güter des gr-orient. Religionsfonds waren davon ausgenommen.

51 DACZ $_{320 / 3 / 3258}$ Protokoll der Konsistorialsitzung. Czernowitz v. 3./15.III.1864.

52 GuZMan 1901, Forstwirtschaft, 103. 
sinnige « Verwaltung aufstellen zu können, die sowohl die Aufrechterhaltung der Forstkultur als auch eine langfristige Deckung des Holzbedarfes zu gewährleisten im Stande wäre. ${ }^{53}$ Obwohl das bischöfliche Konsistorium sich aus ebendiesen Gründen für eine Beibehaltung der Servitutspflichten des Fonds ausgesprochen hatte, setzte sich letztlich in der Bukowina eine vergleichsweise radikale und vom Staat forcierte Ablösung durch. Von den vor der Einleitung der Grundlastenablösung 16.983 servitutsberechtigten Personen in den Wäldern des gr.-orient. Religionsfonds verfügten 1881 nur mehr 395 (!) über entsprechende Einforstungen. ${ }^{54}$ Ein Jahr zuvor hatte in der Bukowina insgesamt immerhin noch eine mit Servituten belastete Waldfläche von nahezu 39.00o Hektar bestanden (bei in Summe 451.195 Hektar).$^{55}$ Fünf Jahre später galten die Forste des Religionsfonds als servitutsfrei. ${ }^{56}$ Dafür mussten jedoch rund 80.500 Hektar an Wald und anderen Gründen abgetreten sowie annähernd 230.000 Gulden an Zahlungen geleistet werden. Außerdem hatten sich dadurch in der Bukowina - neben den Fondsforsten (die Staatsforste waren wenige Jahre zuvor größtenteils durch Ankauf an den Fonds übergegangen) - ein Gemeinde- und kleiner Privatwaldbesitz gebildet, der vorher in dieser Form nicht existierte. ${ }^{57}$

Die enge, man möcht fast meinen dirigistische Beziehung Religionsfonds-Staat führte in der Bukowina letztlich zu einer langfristigen, für alle Beteiligten klaren Lösung. Sie beseitigte die ebenso unübersichtlichen wie auf Dauer in mehrfacher Hinsicht teuren Servitutslasten, obwohl das nicht immer - wie gezeigt werden konnte - mit der sofortigen Zustimmung des bischöflichen Konsistoriums als ursprünglichem Eigentumsvertreter geschah. Im benachbarten Galizien, wo der Staat über wesentlich weniger direkte Zugriffsmöglichkeiten auf die zumeist privaten Grundherrschaften verfügte, hatte 1895 nach wie vor knapp ein Viertel der Waldfläche Servitutslasten zu bedienen. ${ }^{58}$

53 DACZ 320/3/3258 Bericht Consistorial Actuar an bischöfliches Consistorium. Czernowitz v. 29.II./12. III.1864; " In der Bukowina hat der griechisch-orientalische Religionsfond allein - zum größeren Theile an Gemeinden oder Gemeinschaften ohne weitere Regelung 119.365 Joch Waldungen zur Ablösung von Servituten abgetreten; vergeblich bemüht man sich nunmehr die allenthalben fehlende pflegliche Behandlung derselben zu erreichen«; Österreichische Zeitschrift für Verwaltung IX. Jg. Nr. 30 v. 27 .VII. 1876,3 .

54 In Salzburg betrug der Anteil der 1895 noch mit Servituten belasteten Waldfläche vergleichsweise immer noch 62\% (sic!); SCHIFF 1899, Regulierung, 13 of.

55 Schiff weist allerdings auf die überaus ungenauen Angaben zu den bestehenden Servituten sowie ihrer Regulierung zur Zeit der Grundlastenablösung hin; SCHIFF 1898, Agrarpolitik, 38f. u. 162;

56 SCHINDLER 1885 , Forste, 462.

57 Guzmann 1901, Forstwirtschaft, 99 u. 104.

58 SCHIFF 1899, Regulierung, 130. 


\section{Das Religionsfondsvermögen}

Tab. 5: Güter des gr.-orient. Religionsfonds \& Cameralgüter nach dem ort. Diözesanschematismus $1856^{59}$

gegliedert nach Erzpriesterschaften in Reihenfolge des Schematismus: Czernowitzer; Serether; Suczawär; Radautzer; Homorer; Kimpolunger; Putillär; Wikowär; Storoschinetzer; Czeremoszer; Kotzmaner; Dnisterer; Cameralgut.

\begin{tabular}{|c|c|c|c|c|c|c|}
\hline & Klostergut & bischōflich & & & \multicolumn{2}{|c|}{ Stand 1780 (vgl. Tab. 1) } \\
\hline \multirow{2}{*}{ Nr. } & \multicolumn{3}{|c|}{ Ortschaft ${ }^{60}$} & \multirow{2}{*}{\multicolumn{2}{|c|}{$\begin{array}{l}\text { zugehörige } \\
\text { Erzpriesterschaft }\end{array}$}} & \multirow{2}{*}{$\begin{array}{l}\text { Religionsfonds } \\
1859^{61} \text { Kirchen- } \\
\text { patronatsrecht }\end{array}$} \\
\hline & \multicolumn{3}{|c|}{ Sitz der Wirtschaftsämter ${ }^{62}$} & & & \\
\hline 5 & \multicolumn{3}{|c|}{ Kuczurmare } & \multirow{7}{*}{\multicolumn{2}{|c|}{ C }} & $x$ \\
\hline 6 & \multicolumn{3}{|l|}{ Woloka } & & & $\mathrm{x}$ \\
\hline 7 & \multicolumn{3}{|l|}{ Korowia } & & & $x$ \\
\hline 8 & \multicolumn{3}{|l|}{ Czahor } & & & $\mathrm{x}$ \\
\hline 9 & \multicolumn{3}{|l|}{ Molodia } & & & $x$ \\
\hline 10 & \multicolumn{3}{|l|}{ Ostritza } & & & $\mathrm{x}$ \\
\hline 12 & \multicolumn{3}{|c|}{ Mahalla (mit Buda \& Kotul Ostritza) ${ }^{63} \mathrm{~s}$. Nr. 11} & & & $x$ \\
\hline
\end{tabular}

59 Nach ANONYMUS 1856, Schematismus; die durchlaufende Nummerierung ist der Vergleichbarkeit wegen mit den Karten in SCHARR 2010, Landschaft beibehalten worden, vgl. auch Tab. 4; die Tabellen basieren auf den Angaben in DACZ 29/1/8 Ausweiß Über die Buckoviner Orthschaften; Tab. 5 verzeichnet nur den unmittelbaren Grundbesitz des Fonds, keine anderen Rechte (wie etwa Propinationen); auch führt der Schematismus nur Orte mit einer gr.-orient. Pfarre an, daher sind die Angaben um Ortschaften (in Orange gesetzt) aus DACZ 320/3/21 Ortschafts-Verzeichniß des Herzogthums Bukowina mit Angabe [...] der landtäflichen Eigenthumer (ex 1860) ergänzt worden; PUMnUL 1865, Privire, 153.

6o Die Schreibweise der Toponyme richtet sich nach der in der Volkszählung von 1910 üblichen; LANDESAMT (Hg.) 1913, Ergebnisse.

61 OSTA-AVA, Neuer Kultus NK Akath. gr.-or. K 22, fol. 5; Ausweis Uiber die dem Bucccowiner gr. n. un. Religionsfonde angehörenden Ortschaften ex 1859; zu den Patronatskirchen des Religionsfonds sind noch Czernowitz, Sereth, Suczawa und Rohosch zu zählen, die als landesfürstliche Städte/Orte in der älteren Aufstellung nicht enthalten sind.

62 Fett gesetzte Ortschaften markieren den Sitz einer Güterverwaltung um 1800; laut ÖSTA-HHSTA Faßbender Karton 5 XI/3-XII MS XII Ertragsausweis der Buccowiner Staats- und Fondsgüter 18011803; diese Domänenverwaltungen (so die durch die Reformen seit 1848 übliche Bezeichnung) bestanden bis zur Auflösung der österreichischen Bukowina fort und wurden lediglich $1870 \mathrm{um} \mathrm{Ra-}$ dautz sowie Kimpolung erweitert oder - wie im Falle von Zuczka - an einem Ort zusammengezogen (s. Anm. 66); SCHINDLer 1885, Forste, 463.

63 Kursiv gesetzte Ortschaften geben die Schreibweise nach dem Schematismus von 1856 wieder; beide Orte werden nach DACZ $320 / 3 / 21$ (s. Anm. 59) als ärarisch ausgewiesen; dieser Ausweis scheint 


\begin{tabular}{|c|c|c|c|}
\hline \multirow{2}{*}{ Nr. } & Ortschaft $^{60}$ & \multirow{2}{*}{$\begin{array}{l}\text { zugehörige } \\
\text { Erzpriesterschaft }\end{array}$} & \multirow{2}{*}{$\begin{array}{l}\text { Religionsfonds } \\
1859^{61} \text { Kirchen- } \\
\text { patronatsrecht }\end{array}$} \\
\hline & Sitz der Wirtschaftsämter ${ }^{62}$ & & \\
\hline 11 & Kotul-Ostritza & & \\
\hline 19 & Ludihorecza & & $\mathrm{x}$ \\
\hline 26 & Alt-Zuczka & \multirow{2}{*}{ Cam } & \\
\hline- & Neu-Zuczka & & \\
\hline 29 & Lenkoutz (Lencestie mit Bila) ${ }^{64}$ & C & \\
\hline 138 & Oprischeny (oder Pancier) & \multirow{9}{*}{ s } & $\mathrm{x}$ \\
\hline 137 & Tereblestie (mit Styrcze oder Berlince) s. Nr. 139 & & $\mathrm{x}$ \\
\hline 139 & Slobodzia-Berlince Styrcz-(Berlince) & & \\
\hline 130 & $\begin{array}{l}\text { St. Onufry (oder Manastiora mit Banczestie \& } \\
\text { Draguschanka) }\end{array}$ & & $\mathrm{x}$ \\
\hline- & Balkoutz (Laudon-Falva) & & $\mathrm{x}$ \\
\hline 166 & Graniczestie (Krainiczestie) & & $\mathrm{x}$ \\
\hline- & Danila & & $\mathrm{x}$ \\
\hline- & Istensegits (oder Czibeni) & & \\
\hline- & Klimoutz & & \\
\hline 227 & Ipotestie & \multirow{11}{*}{ su } & $\mathrm{x}$ \\
\hline 226 & Teschoutz & & $\mathrm{x}$ \\
\hline 241 & Illischestie (mit Braschka) & & $\mathrm{x}$ \\
\hline 179 & Balaczana & & $\mathrm{x}$ \\
\hline 237 & Petroutz & & $\mathrm{x}$ \\
\hline 238 & Mitoka Dragomirna (inkl. Adrasfalva) & & $\mathrm{x}$ \\
\hline 235 & Bunince (mit Mivoveni) s. Nr. 236 & & $\mathrm{x}$ \\
\hline 236 & Mihoweni & & \\
\hline 233 & St. Illie & & $\mathrm{x}$ \\
\hline 229 & Neu Itzkany & & \\
\hline - & Kostina (mit Berindestie) & & \\
\hline
\end{tabular}

sich jedoch auf die zwischen 1803 bis 1866 praktizierte gemeinsame Verwaltung des Kameralgutes Zuczka sowie der Religionsfondsgüter Mahalla und Kotul-Ostritza zu beziehen; Verordnung des Finanzministeriums v. 14.I.1866 über deren Trennung, zit. nach KAINDL 1900, Zuczka, 7 u. 38 (Anhang Nr. 16).

64 Beide Orte werden nach DACZ $320 / 3 / 21$ (s. Anm. 59) als ärarisch ausgewiesen.

65 St. Onufry erscheint 1871 bereits nicht mehr als Domänensitz; GUZMAN 1901, Forstwirtschaft, 121; die Verwaltung der Fondsdomänen Kotzmann, Kuczurmare und St. Onufry war in Zuczka stationiert; OSTA-FHKA Präs. FM Beilagen ad zl. 19483 Protocoll aufgenommen zu Czernowitz am 1. November 1856. 


\begin{tabular}{|c|c|c|c|}
\hline \multirow{2}{*}{ Nr. } & Ortschaft $^{60}$ & \multirow{2}{*}{$\begin{array}{c}\text { zugehörige } \\
\text { Erzpriesterschaft }\end{array}$} & \multirow{2}{*}{$\begin{array}{l}\text { Religionsfonds } \\
1859^{61} \text { Kirchen- } \\
\text { patronatsrecht }\end{array}$} \\
\hline & Sitz der Wirtschaftsämter62 & & \\
\hline 195 & Radautz $^{66}$ & \multirow{19}{*}{$\mathrm{R}$} & $\mathrm{x}$ \\
\hline 191 & Alt-Fratautz & & $\mathrm{x}$ \\
\hline 192 & Horodnik (Unter-/Ober-) & & $\mathrm{x}$ \\
\hline 193 & Suczawitza & & $\mathrm{x}$ \\
\hline- & Mardzina & & $\mathrm{x}$ \\
\hline 197 & Solka (mit Klitt) & & $\mathrm{x}$ \\
\hline- & Pojenile & & $\mathrm{x}$ \\
\hline \multirow[t]{2}{*}{182} & Pertestie (Ober Partestie mit Kaczika) & & $\mathrm{x}$ \\
\hline & Pertestie (Unter Partestie) (\& Solonetz) & & $\mathrm{x}$ \\
\hline 181 & Ludihumora (Komanestie mit Ludi-Homora) & & $\mathrm{x}$ \\
\hline 198 & Keschwana & & $\mathrm{x}$ \\
\hline \multirow[t]{2}{*}{197} & Botuschana & & $\mathrm{x}$ \\
\hline & & & $\mathrm{x}$ \\
\hline 196 & Jaslowetz & & $\mathrm{x}$ \\
\hline- & Burla & & $\mathrm{x}$ \\
\hline- & Wollowetz & & $\mathrm{x}$ \\
\hline 200 & Milleschoutz (mit Badeutz) & & $\mathrm{x}$ \\
\hline 199 & Badeutz & & \\
\hline 201 & Satulmare (mit Hadikfalva) & & $\mathrm{x}$ \\
\hline- & Karlsberg & \multirow{10}{*}{$\mathrm{H}$} & \\
\hline- & Dzemine mit Slatiora \& Ostra & & $\mathrm{x}$ \\
\hline 206 & Stulpikany (\& Negrilassa) s. Nr. 207 & & $\mathrm{x}$ \\
\hline 207 & Negrilassa & & $\mathrm{x}$ \\
\hline 203 & $\begin{array}{l}\text { Woronetz (mit Bukshoia, Frassin, Dorothea \& Plo- } \\
\text { tonitza) s. Nr. 204/205 }\end{array}$ & & $x$ \\
\hline 204 & Bukschoia & & $\mathrm{x}$ \\
\hline 205 & Frasin & & \\
\hline 219 & Gurahumora & & $\mathrm{x}$ \\
\hline 183 & Klosterhumora (Homora oder Kloster Homora) & & $\mathrm{x}$ \\
\hline 245 & Kapukodrului (mit Paltinossa) & & $x$ \\
\hline
\end{tabular}

66 Die Forst-Domäne Radautz stand aufgrund ihrer besonderen Verwendung bis 1870 unter Militärverwaltung und war seit diesem Zeitpunkt Teil der Staats- bzw. Fondsforste und in Folge auch Sitz einer Domänenverwaltung, der Pachtvertrag mit dem Militär blieb jedoch bestehen; GuZMaN 1901, Forstwirtschaft, 113 sowie CATARGI (Hg.) 1899/2004, Bukowina, 406. 


\begin{tabular}{|c|c|c|c|}
\hline \multirow{2}{*}{ Nr. } & Ortschaft ${ }^{60}$ & \multirow{2}{*}{$\begin{array}{l}\text { zugehörige } \\
\text { Erzpriesterschaft }\end{array}$} & \multirow{2}{*}{$\begin{array}{l}\text { Religionsfonds } \\
1859^{61} \text { Kirchen- } \\
\text { patronatsrecht }\end{array}$} \\
\hline & Sitz der Wirtschaftsämter ${ }^{62}$ & & \\
\hline 251 & Berkischestie & \multirow{11}{*}{$\mathrm{H}$} & $\mathrm{x}$ \\
\hline 247 & Korlata & & $\mathrm{x}$ \\
\hline 243 & Dragojestie (\& Josephfalva) & & $\mathrm{x}$ \\
\hline 244 & Mazanajestie (mit Lukaczestie) & & $\mathrm{x}$ \\
\hline 250 & Bajaschestie (mit Kornulunczyl) & & $\mathrm{x}$ \\
\hline- & Kapukimpolui & & $\mathrm{x}$ \\
\hline 214 & Ruß Moldawitza (mit Ardziel) (mit Czumurna) & & $x$ \\
\hline- & Rußpeboul & & $\mathrm{x}$ \\
\hline 213 & Watra Moldawitza & & $\mathrm{x}$ \\
\hline 212 & Frumossa & & $\mathrm{x}$ \\
\hline 208 & Wama (Unter-/Ober-Wama) (mit Eisenau) & & $x$ \\
\hline 210 & Sadowa (Gura Sadowei \& Fundul Sadowei) & \multirow{12}{*}{ Cam } & \\
\hline 211 & Pożoritta & & \\
\hline 215 & Fundulmoldowi (Unter- \& Ober Fundul Moldowei) & & \\
\hline 216 & Czokanestie (mit Kirlibaba ${ }^{67} \&$ Ludwigsdorf) & & \\
\hline 209 & mold. Kimpolung (mit Gropa, Breaza \& ?) ${ }^{68}$ & & \\
\hline 217 & $\begin{array}{l}\text { Jakobeny (mit Waleputna \& Puczosu) (mit Marien- } \\
\text { see, Crotina) }\end{array}$ & & \\
\hline 218 & Dornawatra & & \\
\hline- & Dorna-Kandreny \& Pojana-Stampi & & \\
\hline 215 & Fundul-Moldowi (mit Louisenthal) & & \\
\hline- & Fürstenthal & & \\
\hline- & Lichtenberg & & \\
\hline 231 & Suczawa (mit Alt-ltzkani, Kutt, Scheptelitz und Zamka) & & $\mathrm{x}$ \\
\hline- & Schipot, Izwor \& Moldowa oder Sulitza & \multirow{2}{*}{$\mathrm{P}$} & $x$ \\
\hline 79 & Seletin & & $\mathrm{x}$ \\
\hline 190 & Wojtinell (mit Galinestie) & \multirow{5}{*}{ W } & $\mathrm{x}$ \\
\hline 189 & Unter-Wikow & & $x$ \\
\hline 188 & Putna & & $\mathrm{x}$ \\
\hline 186 & Straża & & $x$ \\
\hline 187 & Ober-Wikow & & $x$ \\
\hline
\end{tabular}

67 Kirlibaba wird nach DACZ $320 / 3 / 21$ (s. Anm. 59) als Religionsfondsgut ausgewiesen.

68 Moldauisch Kimpolung erwarb der Religionsfonds 1870 aus Staatsbesitz und war seither Sitz einer Verwaltung; GUZMAN 1901, Forstwirtschaft, 102; BRUSATTI 1958, Staatsgüterveräußerungen. 


\begin{tabular}{|c|c|c|c|}
\hline \multirow{2}{*}{ Nr. } & Ortschaft ${ }^{60}$ & \multirow{2}{*}{$\begin{array}{c}\text { zugehörige } \\
\text { Erzpriesterschaft }\end{array}$} & \multirow{2}{*}{$\begin{array}{l}\text { Religionsfonds } \\
1859^{61} \text { Kirchen- } \\
\text { patronatsrecht }\end{array}$} \\
\hline & Sitz der Wirtschaftsämter62 & & \\
\hline 155 & Krasna Putna (Krasna mit Alt- \& Neu-Hütte) $)^{69}$ & \multirow{8}{*}{ W } & \\
\hline 156 & Czudyn (Czudiul mit Neu-Hütte) & & $\mathrm{x}$ \\
\hline 127 & Korczestie & & $\mathrm{x}$ \\
\hline 163 & Kupka & & $x$ \\
\hline 164 & Kamen(k)a (mit Petriczanka) & & $\mathrm{x}$ \\
\hline- & Kostischa & & \\
\hline 191 & Neu-Fratautz & & $\mathrm{x}$ \\
\hline- & Bilka & & $\mathrm{x}$ \\
\hline- & Suczaweny & \multirow{2}{*}{ St } & \\
\hline 152 & Jordanestie (mit Slowodzia Robcze) & & $\mathrm{x}$ \\
\hline 87 & Kotzman (Ober \& Unter Kotzmann) & \multirow{8}{*}{ Ko } & $\mathrm{x}$ \\
\hline 86 & Suchowerchow & & $\mathrm{x}$ \\
\hline 85 & Klowodyn & & $\mathrm{x}$ \\
\hline 84 & Dawidestie & & $\mathrm{x}$ \\
\hline 30 & Alt-Mamajestie & & $\mathrm{x}$ \\
\hline- & Rewna mit Striletzki Kut & & $\mathrm{x}$ \\
\hline- & Burdey & & $\mathrm{x}$ \\
\hline 30 & Neu-Mamajestie & & $\mathrm{x}$ \\
\hline 89 & Witelowka & Ko/Privat & \\
\hline 88 & Laschkowka (Neu und Alt) & Ko & $\mathrm{x}$ \\
\hline 116 & (Slobosia) Mitkeu (Brodok?) & D & $\mathrm{x}$ \\
\hline- & Kirlibaba & - & \\
\hline
\end{tabular}

Die Güter des Religionsfonds behielten auch nach der Grundentlastung im Südwesten des Landes ihren eindeutigen Schwerpunkt bei. Überwiegend gehörte Grund und Boden dieser Ortschaften, der im Wesentlichen aus Waldungen bestand, in das Fondseigentum (vgl. Tab. 5). Landwirtschaftliche Gründe - nicht jedoch die Wälder - hatte man indes zumeist an Private verpachtet. ${ }^{70}$ Insgesamt verfügten Kameral- wie Fondsgüter der Bukowina zur Mitte des 19. Jahrhunderts aus pragmatischen Gründen über eine gemeinsame Verwaltung, nicht zuletzt auch deshalb, weil das ärarische Eigentum im Vergleich zum Fonds klein war. Als übergeordnete Kontrollinstanz für den Fonds fungierte die Finanzhofkammer bzw. in ihrer

69 Krasna Putna wird nach DACZ $320 / 3 / 21$ (s. Anm. 59) als ärarisch ausgewiesen.

70 KAINDL 1900, Zuczka, 6 u. 21; vgl. Stenographische Protokolle des Bukowinaer Landtages 1863, 364ff. sowie 1864,299 ff. 
Nachfolge das spätere Finanzministerium. Mit den Reformen im Umfeld der Grundentlastung stellte sich auch die Frage einer Eigentumsneustrukturierung. Dementsprechend legte eine Ministerialkommission dem Religionsfonds den Ankauf der Kameraldomäne Zuczka nahe, was zwar rechtlich eine Änderung darstellte, aber hinsichtlich der realen Verfügungsgewalt darüber keine Auswirkungen hatte. Bei der Domäne Kimpolung allerdings wollte sich der Staat offenbar den unmittelbaren Zugriff vorerst noch sichern. Hier argumentierte man vor allem mit notwendiger Sorgfalt, derer die Waldungen dieser Herrschaft bedurften, der anwachsenden wirtschaftlichen Bedeutung des Holzhandels und mit den fortdauernden Rechtsstreitigkeiten des dortigen Bergwerksbetreibers Manz. ${ }^{71}$ Im Falle von Kimpolung sollte es noch bis 1870 dauern, wo in der Folge des Übergangs der Bergwerke auch die ursprüngliche Kameralherrschaft an den Religionsfonds abgetreten wurde. ${ }^{72}$ Damit setzte eine Arrondierung ein, welche die Dominanz des Religionsfonds innerhalb der Bukowina zusätzlich bekräftigte. Dem Staat indes gelang es dergestalt, sich - zugunsten des Fiskus elegant der unmittelbaren Verwaltung zu entledigen, ohne dabei gänzlich auf seinen Einfluss verzichten zu müssen. Letzteren konnte Wien ja weiterhin indirekt über den Fonds geltend machen. Wie auch immer, die Kosten dafür hatte freilich der Religionsfonds zu bestreiten.

Die damit umgesetzte weitgehende Übertragung ursprünglicher Staatsforste (i.e. des moldauisch Kimpolunger Gebietes) führte im Südwesten des Kronlandes zu einem nahezu geschlossenen, fast flächendeckenden Besitzstand des Religionsfonds (vgl. Abb. 8). Noch deutlicher wird seine ökonomische Rolle für die Bukowina, wenn man etwa die kartographische Detailaufnahme der Religionsfondsherrschaften Illischestie und Solka näher betrachtet. Außerhalb der unmittelbaren Siedlungen und der sie umgebenden Flur dominierten hier in wirtschaftlicher Hinsicht - neben zumeist kleineren Wiesengründen, die auch in der Regel dem Religionsfonds zuzurechnen waren - die Waldungen. Von den knapp 291.000 Hektar an Gesamtfläche der beiden Herrschaften entfielen in Summe auf Grundstücke der darin miteingeschlossenen Gemeinden lediglich 82.000, auf die Fondswaldungen hingegen fast 190.000 Hektar. Der Anteil an Wiesen, Weiden und Gärten, die dem Dominikalgrund der Fondsherrschaften zugehörten, nahm sich indes mit knapp 19.000 Hektar vergleichsweise bescheiden aus (vgl. Abb. 9). In der Nordbukowina glich der Fondsbesitz damit mehr einer Streulage mit lokalen Schwerpunkten (etwa bei Krasna Putna oder Kuczurmare). Vereinzelt besaß der Religionsfonds hier auch kleinere landwirtschaftlich genutzte Gründe (vgl. Abb. 10).

71 OSTA-FHKA Präs. FM Beilagen ad Zl. 19483, Protocoll aufgenommen zu Kimpolung am 25. Oktober 1856; Protocoll aufgenommen zu Czernowitz am 1. November 1856; Protokoll aufgenommen über die bei der kk Finanz Landes Direction in Lemberg am 8. November 1856 gepflogene Berathung; Vorsitz Statthalter und Präsident der Finanzlandesdirektion A. Goluchowski.

$72 \mathrm{Zu} \mathrm{Manz} \mathrm{vgl.} \mathrm{Kap.} 10$ (Hebel strukturellen Wandels). 


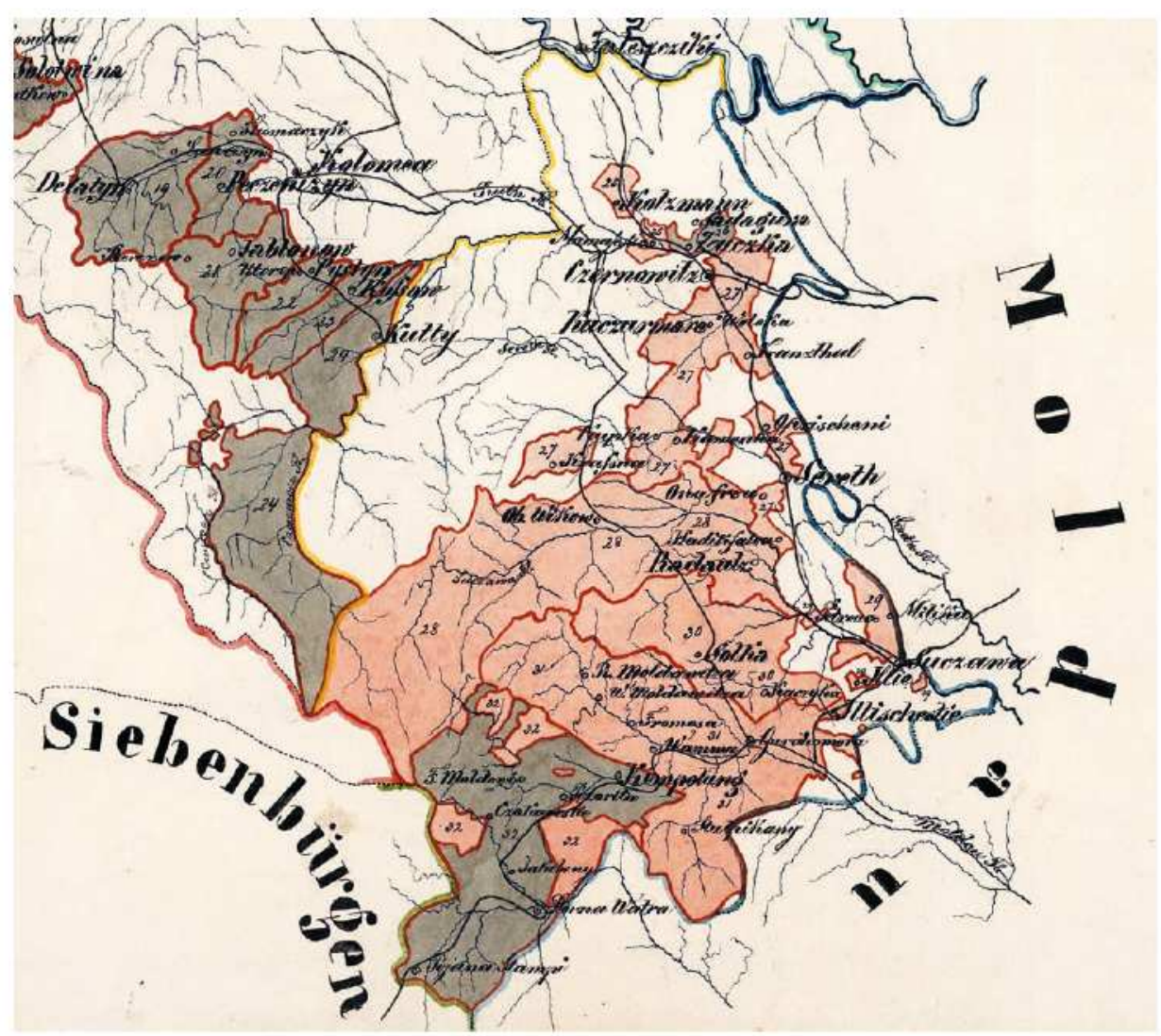

Abb. 8: Uibersichts-Karte Cameral- und Fonds Domaenen in Ostgalizien und der Bukowina 1855. (c) ÖSTA ${ }^{73}$

$25^{(87)}$ Kotzmann; $26^{(26)}$ Zuczka; $27^{(5)}$ Kuczurmare; $28^{(195)}$ Radautz; 29(233) St. Illie; 30(197) Solka; $31^{(241)}$ Illischestie; $32^{(209)}$ Kimpolung.

Fondsforste Kameralforste $\square$ landwirtschaftliche

73 OSTA-FHKA Präs. FM Beilagen ad Zl. 19483 (Kart. 165) Ausweis uiber den Stand sämmtlicher Obligationen Activ Capitalien und verzinslichen Vorschüsse des Buccovinaer gr. n. u. Religions Fondes mit Ende October 1855; die Nummerierung verweist auf die Angaben in der abgebildeten Karte (Abb. 8), die hochgestellten Nummern in Klammer beziehen sich auf die Gliederung in Tab. 5. 


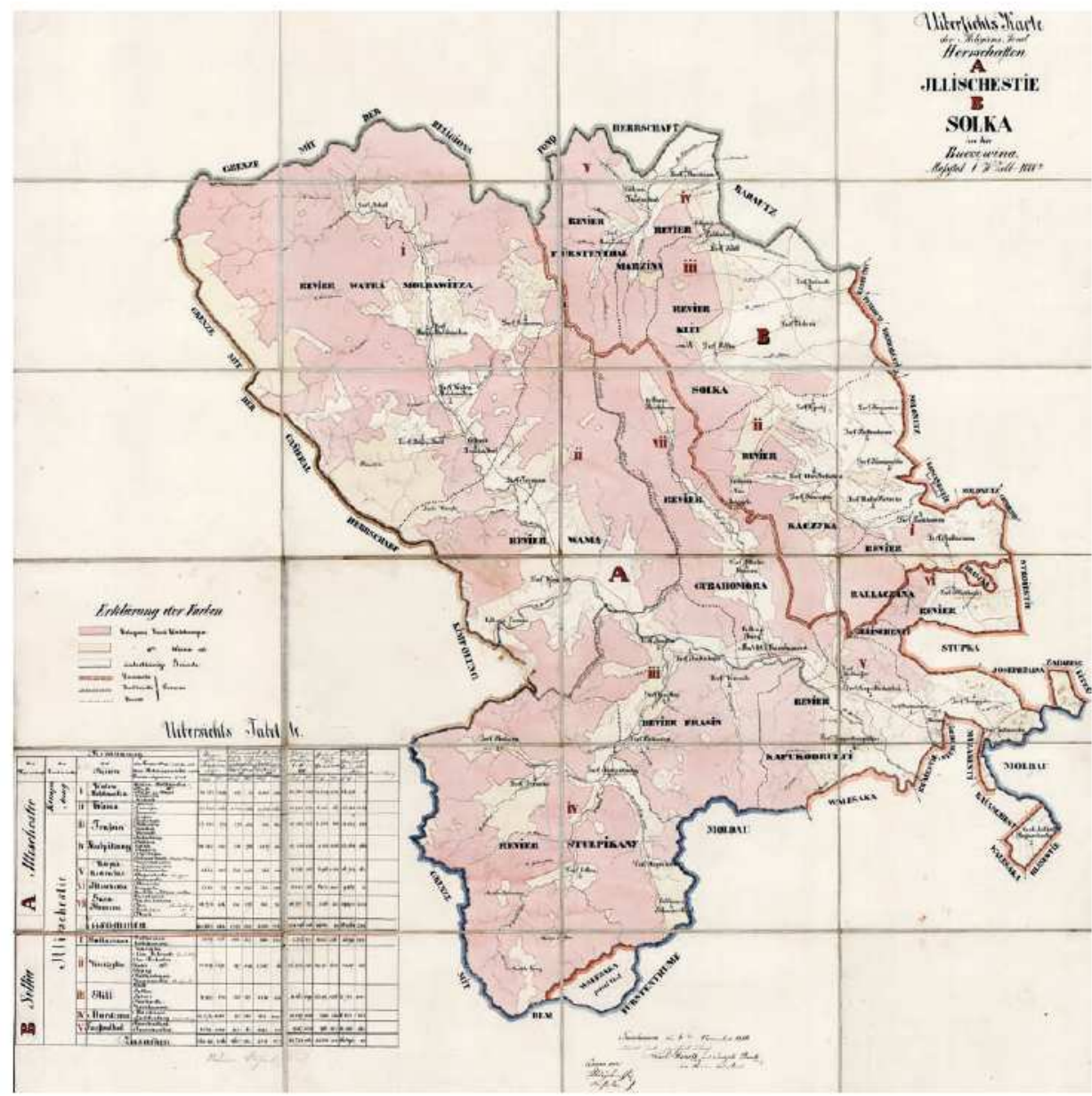

Abb. 9: Uibersichts-Karte der Religions Fond Herrschaften A Jllischestie B Solka in der Buccowina 1856. Zur Legende vgl. Abb. 8. (c) ÖSTA

74 OSTA-FHKA Präs. FM Beilagen ad Zl. 19483 (Kart. 165) Ausweis uiber den Stand... (wie Anm. 73). 


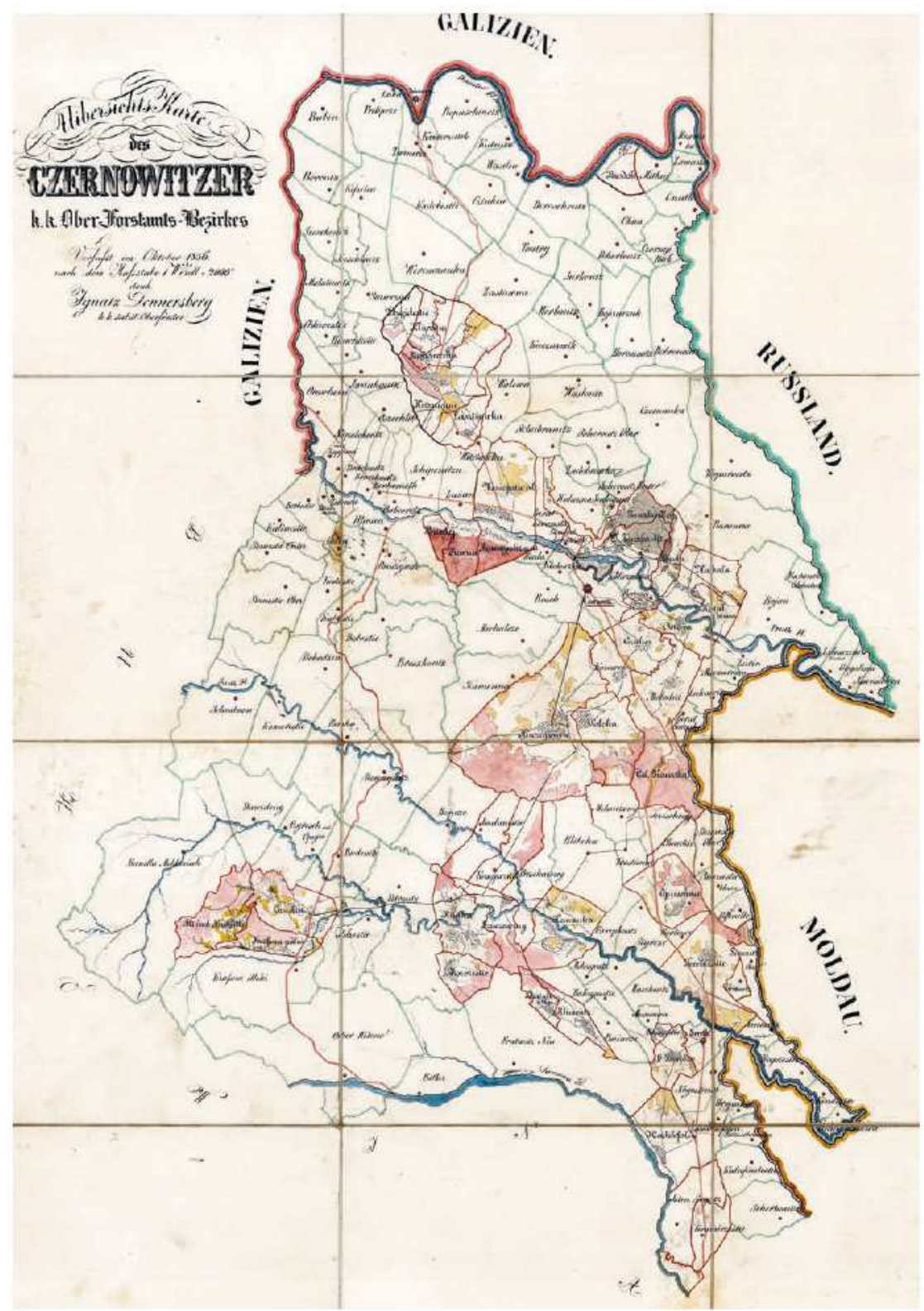

Abb. 10 Uibersichts-Karte des Czernowitzer k.k. Ober-Forstamts-Bezirkes 1856. Zur Legende vgl. Abb. 8. (C) ÖTA ${ }^{75}$

75 OSTA-FHKA Präs. FM Beilagen ad Zl. 19483 (Kart. 165) Ausweis uiber den Stand... (wie Anm. 73). 


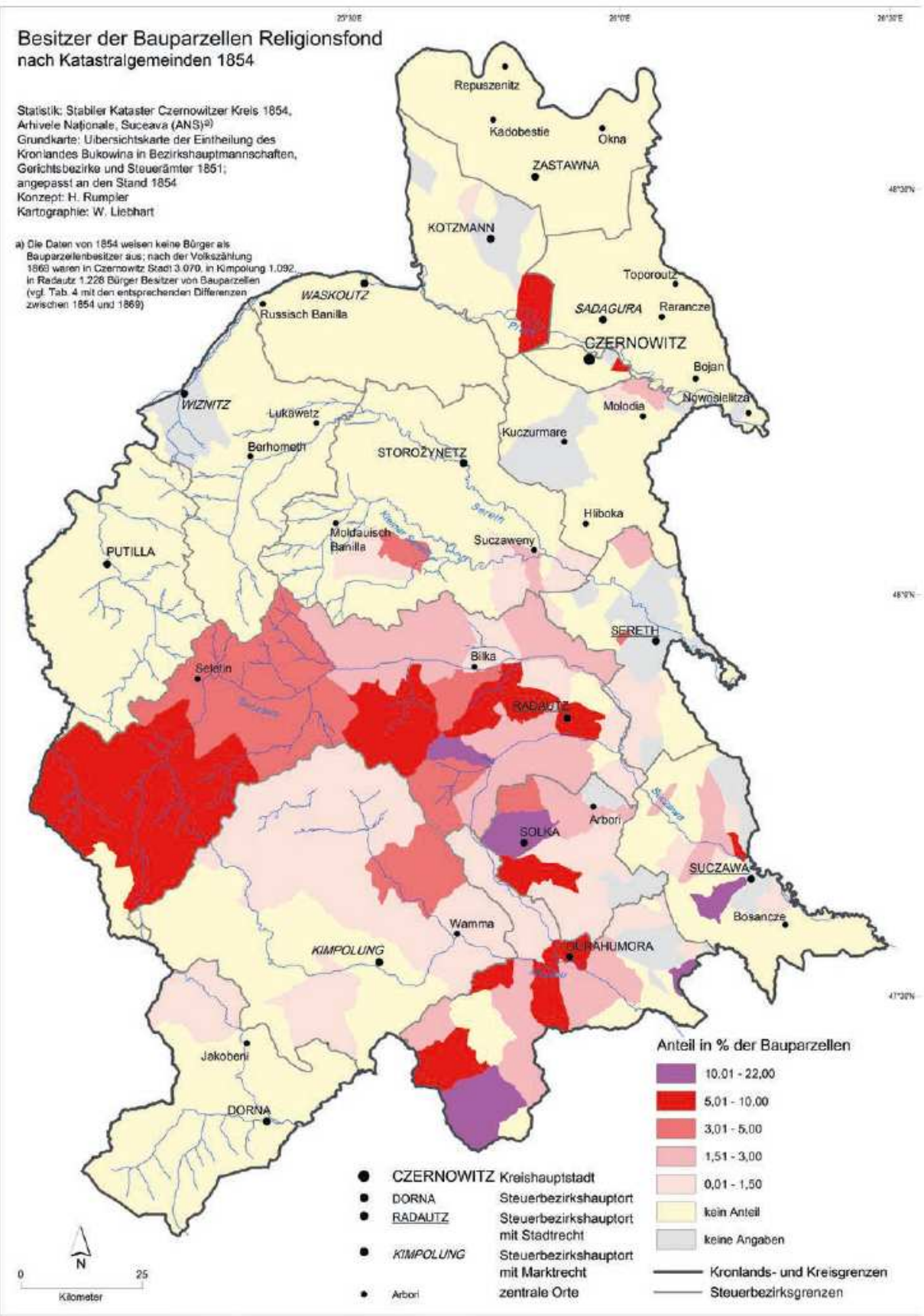

Abb. 11: Besitzer der Bauparzellen Religionsfonds nach Katastralgemeinden 1854. 
Eine absolute Darstellung der Vermögensverhältnisse des Religionsfonds für den hier relevanten Zeitraum ist auf Grund der Quellenlage kaum in befriedigender Weise möglich. Dennoch bieten fallweise greifbarer Eckdaten zumindest einen annähernden Einblick in die Finanzgebarung und damit auch in die Aufgaben des Fonds. So wies etwa der Rechnungsabschluss für das Jahr 1843 insgesamt Barausgaben von 576.000 gegenüber Einnahmen von 596.000 bei einem Vermögen von 4.000.000 Gulden an verzinslichen Obligationen aus. ${ }^{76}$ Die summierten Kultusausgaben, worunter unter anderem der Erhalt der Pfarreien und Klöster wie auch der Unterhalt der Klostergeistlichen fielen, beliefen sich für 1850 auf 151.000 Gulden, wohingegen die vom Fonds dotierten Hauptschulen in Czernowitz sowie Sereth ( $1.800 \mathrm{fl}$.) und die verschiedenen ländlichen Trivialschulen (2.900 fl.) vergleichsweise bescheidene Ausgabenposten besetzten. Allerdings stieg der Aufwand in Summe während der folgenden Jahre bis 1867 fast um das Doppelte auf 327.000 Gulden (bei Renteneinnahmen von $621.000 \mathrm{fl}$.) an. Insgesamt gilt es hier anzumerken, dass durch die Mittel des Religionsfonds erstmals auch für die orthodoxen Pfarrer regelmäßige Unterhaltszahlungen sowie Pensionsvorsorgen vorgesehen waren; letzteres ein Novum für die orthodoxe Priesterschaft. Zusätzlich erhielten die Pfarrstellen Brennholzservitute und kleinere Sozialleistungen. ${ }^{77}$

Für das mittlerweile hinzugekommene ebenfalls vom Fonds betriebene Gymnasium in Suczawa und die Oberrealschule in Czernowitz (seit 1860/63) fielen 35.000 an, Hauptund Trivialschulen schlugen im Verrechnungsjahr 1867 mit annähernd 13.000 Gulden zu Buche. ${ }^{78}$ Für die Mönche der drei noch aktiven - nicht aufgelösten, d.h. systemisierten - Klöster Suczewitza, Putna und Dragomirna standen aus Religionsfondsmitteln 1857 für Besoldung, Unterhalt und Kleidung 17.500 Gulden zur Verfügung ${ }^{79}$, annähernd zehn Prozent der Kultusausgaben dieses Jahres (von $178.000 \mathrm{fl}$.), wohingegen die Schulen (allerdings damals noch ohne das Gymnasium und die Oberrealschule) mit 3.600 Gulden an Dotation vergleichsweise wenig vom Kultusbudget des Fonds bekamen. ${ }^{80}$ Für das Jahr 1850 wird hingegen ein im Vergleich zu 1844 bereits erheblich geringeres Gesamtvermögen des Fonds von 1.200.000 Gulden ausgewiesen, mit dem Hinweis, dass

$76 \mathrm{DACZ}_{320 / 2 / 85}$ (3829) Bericht an das k.k. Landesgubernium Lemberg v. 27.I.1844.

77 VAlenCIUC 2011, Preotima, 19.

$78 \mathrm{DACZ}_{3 / 1 / 3442}$ Uibersicht über die Gebahrungs-Ergebnisse des gr.-or. Religions Fondes für die Jahre 1850 bis 1867 .

79 ANS F 11, Inv. 296 Diverse 110-1787 Entwurf Uiber die klösterlichen Unterhaltsgelder, welche den drei Buccovinaer sistemisierten Klöstern [...] aus dem Buccovinaer gr:n.u. [gr. nicht-unierten] Religionsfonde zu folge geistlichen Regulierungsplanes Cass. II \# 19 verbrieft worden sind.

80 DACZ $_{3} / 1 / 3442$ Uibersicht über die Gebahrungs-Ergebnisse des gr-or. Religions Fondes für die Jahre 1850 bis 1867 , hier 1857 . 
der Fonds über kein disponibles Geld verfüge bzw. dieses lediglich in Gütern und Staatspapieren bestünde. ${ }^{81}$

Im Hinblick auf die gesamtwirtschaftliche Bedeutung des Religionsfonds für das Kronland lässt sich über die Steuerleistung seiner Herrschaften und der dazugehörigen Gemeinden ebenso eine klare Aussage treffen. So betrug etwa das gesamte Grundsteueraufkommen der Bukowina für das Jahr 1865 gerundet 360.000 Gulden. ${ }^{82}$ Die allein über die Fondsherrschaften, inklusive der auf ihnen ansässigen Gemeinden, durch den Staat eingenommene Grundsteuer erreichte annähernd im selben Jahr immerhin ein gutes Drittel davon (vgl. Tab. 6).

Tab. 6: Grundsteuerleistung der Religionsfondherrschaften \& dazugehörigen Gemeinden in Gulden um $1860^{83}$

\begin{tabular}{|l|l|c|c|c|}
\hline Nr. ${ }^{1}$ & & Herrschaft & Gemeinden ${ }^{2}$ & $\Sigma$ Grundsteuerleistung \\
\hline 87 & Kotzmann & 2.204 & 11.510 & 13.714 \\
\hline- & Kuczurmare & 2.576 & 26.288 & 28.864 \\
\hline- & Radautz & 6.283 & 26.041 & 32.324 \\
\hline 197 & Solka & 2.388 & 12.478 & 14.866 \\
\hline 233 & St. Illie & 2.340 & 6.401 & 8.741 \\
\hline 241 & Illischestie & 2.917 & 9.219 & 12.136 \\
\hline 208 & Wama & 2.028 & 5.264 & 7.292 \\
\hline & Summe & 20.736 & 97.201 & 117.937 \\
\hline
\end{tabular}

81 Ministerratsprotokolle II/2, Ministerrat v. 17.IV.1850/V, Nr. 322 u. $18 . I V .1850 / V$, Nr. 323.

82 Statistische Central-Commission k.k. (Hg.) 1871, Tafeln, Tafel 7, Directe Steuern, $10-$ Zergliederung der Grundsteuer im Jahre 1865; die darin enthaltene, wesentlich geringere Haussteuer ist für den Gesamtbetrag weitgehend zu vernachlässigen.

$8_{3}$ OSTA-AVA, Neuer Kultus NK Akath. gr.-or. K22, Entwurf betreffend die Bedürfnisse der griech. orientalischen Kirchen- und Pfarrhausbaulichkeiten auf den Religionsfonds Gütern in der Buccowina (zu datieren nach 1859, spätestens jedoch 1866); Beilage zum Entwurf, Ausweis Uiber die direkten Steuer[n], welche die sämmtlichen Bucowinaer g. n. u. Religionsfonds Herrschaften, und die dahin gehörigen Gemeinden alljährig bezahlen; auf Gulden gerundet.

1 Die Nummerierung entspricht den Angaben in Tab. 4.

2 Grundsteuerleistung der auf den Gütern des Religionsfonds ansässigen Gemeinden. 


\section{Zusammenfassung}

Vergleicht man aus diesem Umfeld heraus die Situation der Bukowina mit jener in den innerösterreichischen Ländern, so zeigen sich dabei durchaus auf den ersten Blick Ähnlichkeiten. Die ältere Agrarverfassung wirkte in vielfach persistenten Strukturen trotz angestoßener Reformen fort und verhinderte bzw. bremste eine Modernisierung auf breiter Basis. Die von W. Drobesch für Innerösterreich überzeugend dargestellte Teilmodernisierung als eine Modernisierung ohne Industrialisierung` trifft allerdings auf die Bukowina nur mit gewisser Einschränkung zu. ${ }^{3}$ Während in den Jahrzehnten nach 1848 Kapitalarmut und eine anhaltend versorgungsorientierte Landwirtschaft auch in weiten Bereichen der Bukowina ungebrochen dominierten, lassen sich doch einige wichtige Unterschiede festhalten. Einerseits bestanden in der Bukowina größere private Gutsbetriebe weiter und es gelang einigen unter ihnen, wenngleich mit Verzögerung, den Kapitalmangel zu überwinden bzw. erfolgreich Investitionen zu tätigen. Dazu gehörten etwa die Besitzungen der Familie Wassilko in der Nordbukowina. Zudem profitierte die Bukowina von der steigenden Bedeutung der stark wachsenden Hauptstadt Czernowitz, die im Umfeld kaum Konkurrenz zu fürchten hatte. Vor allem jedoch profitierte das Kronland vom Markt benachbarter und weit weniger entwickelter Länder, der zugegeben ein instabiler war, wie die politischen Ereignisse bis zum Ausbruch des Ersten Weltkrieges in diesen Räumen zeigen.

Ein wesentlicher regionsinterner Faktor für die einigermaßen erfolgreiche Teilmodernisierung dieses Kronlandes scheint jedoch in der Existenz und im Wirken des gr.orient. Religionsfonds selbst zu liegen, der auf Drängen des Staates oder im eigenen Interesse notwendige Reformschritte setzte und damit zumindest sektoral (vor allem in der Forstwirtschaft) wie regional (zeitlich später in der Bergbauregion Jakobeni und im Kurort Dorna Watra) Innovationen bewirkte. Gerade die bei W. Drobesch als zentrale Schwachpunkte bezeichneten persistenten bäuerlich-grundherrschaftlichen Rechtsverhältnisse konnten in der Bukowina nicht zuletzt auf Grund der vorhandenen besonderen Eigentumsstruktur wie der Dominanz des Fonds (sowie der direkten staatlichen Eingriffsmöglichkeit) während dieser entscheidenden Periode der ersten beiden Jahrzehnte seit der Grundentlastung letztlich mit Erfolg überwunden werden. Damit war die Bukowina zwar immer noch kein Vorreiter unter den Kronländern der Monarchie,

3 DRовеSCH 2003, Grundherrschaft, 181ff.; die von Vilfan bereits früh in der Historiographie eingeforderte differenzierte Sichtweise (durch regionale Unterschiede der jeweiligen Agrarverfassung) bestätigt sich damit, ebenso wie die von ihm angebrachte (und von Drobesch später wieder aufgegriffene) Kritik an der These vom Reformstillstand während des Vormärz in der Habsburgermonarchie; Vilfan 1973, Agrarsozialpolitik, 31-39. 
schaffte es jedoch, sich in der intraregionalen Nachbarschaft (Galizien, Ungarn) wesentlich besser zu positionieren und seinen wenngleich bescheidenen Vorsprung entsprechend zu nutzen. 


\section{Die Institution: Struktur \& Werte}

Um die Mitte des 19. Jahrhunderts - nach mehr als fünfzig Jahren seit der Gründung des gr-orient. Religionsfonds der Bukowina - war die ursprünglich von Joseph II. geschaffene Organisationsform für die Verwaltung kirchlichen Vermögens in eine Phase schrittweiser 'Institutionalisierung`getreten. Über maßgebliche Akteure wie den Bischof erfuhr die sich herausbildende Institution Religionsfonds eine wachsende Aufladung mit Werten. Der Fonds bezog damit, über seine Organisationsexistenz hinaus, innerhalb einer sich Schritt für Schritt etablierenden Gesellschaft der Bukowina als >Akteur Position. Gewissermaßen pars pro toto für diesen prozesshaften wie vielschichtigen Übergang steht die Amtszeit des Bischofs Eugen Hackmann. Durch die mit der Loslösung von Galizien-Lodomerien swieder ' gewonnene relative Autonomie wurden aus der Struktur der gr--orient. Landeskirche heraus wie im Religionsfonds und seinen Vertretern zunehmend Fragen nach kirchlicher Selbstverwaltung bzw. vermehrter Mitbestimmung formuliert und in der Folge zum Teil heftig diskutiert. Das ständisch geprägte Denken eines Bischofs Hackmann war in seiner Ambivalenz geradezu beispielhaft dafür. Einerseits forderte der Bischof dem Staat gegenüber ein ausgeweitetes Verfügungsrecht über den Fonds ein, andererseits schürte sein Selbstverständnis als `Kirchenfürst‘ den internen Konflikt mit einer jüngeren Generation von nachrückenden Hierarchen, die für eine verstärkte institutionelle Beteiligung der Gläubigen eintraten. Zugleich fanden die allmählich einsetzenden zentrifugalen Wirkungen nationaler Gedanken gerade im Fonds, als einer der mittlerweile bedeutendsten Landesinstitutionen, ein fruchtbares Substrat zur Umsetzung vor.

Dass Werte für eine Institution wie den gr.-orient. Religionsfonds eine nicht zu unterschätzende Triebkraft in der gesellschaftlichen Positionierung und Dynamisierung darstellten, steht hingegen nur für eine von zwei Seiten dieses Entwicklungsprozesses. Der markante politische Bruch von 1918 brachte zwar eine weitgehende Deckungsgleichheit nationaler Wertvorstellungen mit dem neuen rumänischen Staat, die unter anderem seit der Jahrhundertwende den gesellschaftlichen Diskurs im ehemaligen österreichischen Kronland im Allgemeinen und im Fonds im Besonderen an zentraler Stelle bestimmt hatten; allerdings erwies sich dieser Wechsel à la longue durchaus als zweischneidig. Mit dem durch den Kriegsausgang bedingten Wechsel zum Königreich Rumänien sollte auch die für das bisherige Funktionieren der Institution Religionsfonds maßgeblich regulierende Komponente Staat eine grundsätzliche Neubewertung erfahren, die erheblich von den bisherigen Erfahrungen abwich. Die relative innere Autonomie der gr.- 
orient. Kirche und die regional stets eingeforderte Verfügungsgewalt über den Fonds standen jetzt grundsätzlich zur Disposition. Beide waren mit diesem Wechsel für die Landeskirche keineswegs als gegeben oder gar als endgültig erreicht zu verbuchen. Der Fondul Bisericesc Ortodox Român und mit ihm die dahinterstehende Kirchenhierarchie der Bukowina fanden sich mithin in einem aufreibenden dauerhaften Aushandlungsprozess wieder. In diesem zog Bukarest weit mehr als Wien die Agenden an sich und bestimmte ihn zugleich auf weiten Strecken. Die Kirche hingegen musste alsbald die Beschränktheit des eigenen Spielraumes erkennen.

In ökonomischer Hinsicht ist während dieser Periode die dominierende Stellung des Fonds für die Bukowina herauszustreichen. Vor wie nach 1918 verstand es der Staat, dieses wirksame Durchgriffsmittel geschickt für dringend nötige Strukturmaßnahmen in der Region oder schlicht eigene Interessen zu nutzen.

Insgesamt steht daher in diesem Abschnitt der institutionelle Wandel des Religionsfonds während einer vergleichsweise langen, über einhundertjährigen Zeitspanne als zentraler Betrachtungsaspekt im Vordergrund. 


\section{Nationsidee, Kirche \& Religionsfonds}

\section{Die Ära Eugen Hackmann (1835-1873)}

Als Kaiser Franz Joseph I. am 23. Jänner 1873 der Einrichtung einer selbständigen gr-orient. Metropolie für die Bukowina und Dalmatien zustimmte und damit die orthodoxe (nicht unierte) Kirche der Bukowina mit der Metropolitanwürde ausstattete, schienen die jahrzehntelangen Bemühungen Eugen Hackmanns ${ }^{1}$, der dadurch in den Rang eines Erzbischofes aufstieg, ihr Ziel erreicht zu haben. ${ }^{2}$ Hackmann erlebte - bereits schwer krank - noch seine Ernennung zum Metropoliten, allein starb er kurz darauf 78-jährig am Karsamstag, den 12. April 1873 in Wien. ${ }^{3}$ Nach einem feierlichen Leichenbegängnis in der gr--orient. Kirche am Wiener Fleischmarkt und unter »lebhafter Teilnahme der Bevölkerung « überführte man seine sterblichen Überreste in die Landeshauptstadt der Bukowina nach Czernowitz. ${ }^{4}$

Eugen Hackmann, geboren am 16. März 1793, stammte aus einer verarmten Bauernfamilie in Wasloutz (heute ukr. Васловівці, rum. Vaslăuți) in der Nordbukowina. Nach Absolvierung der Klerikalschule in Czernowitz inskribierte er an der r. k. theologischen Fakultät der Universität Wien. Mit dem Studienabschluss im Jahr 1823 legte der junge Theologe zugleich seine Gelübde als Mönch ab und trat eine Stelle als Katechet an der Trivialschule der Bukowiner Landeshauptstadt an. In den Jahren 1827 bis 1835 führte Hackmann die Professur für Bibelstudien am Czernowitzer theologischen Institut. 1835 empfing er die Weihen zum gr.-orient. Bischof der Bukowina, nachdem der Kaiser seiner Ernennung die Zustimmung erteilt hatte. ${ }^{5}$ Am Ende seines Lebens

1 Zur Schreibweise: dt. auch Eugen Hakmann, rum. Eugenie Настап, ukr. Євгеній Гакман, russ. Евгений Гакман; hier findet durchgehend die zeitgenössische häufiger vorkommende Form Eugen Hackmann Verwendung, auch wenn diese selbst in deutschsprachigen Quellen nicht immer konsequent einheitlich erscheint.

2 Wiener Zeitung Nr. 27 v. 2.II.1873, Amtlicher Theil, 1; vgl. dazu das Errichtungsdiplom für die grorient. Metropolie der Bukowina und von Dalmatien, Wien v. 30.III.1874; Foaea Ordinaecînilor Consistorîuluî Archiepiscopal în trebile bisericescî ale Archidiecesê̂ Bucovinê̂ 1874, 129-133; vollständig in NÉMETH 2012, Zhishman, 260-263.

3 Todesanzeige v. 31.III./12.IV.1873, um "11 1/2 Uhr Abends seelig in dem Herrn entschlafen «; DACZ 3/2/9498, Konsistorium an Landespräsidenten d. Bukowina v. 1./13.IV.1873.

4 Wiener Zeitung Nr. 88 v. 16.IV.1873, 4; Neue Freie Presse Nr. 3104 v. 15.IV.1873 (Politische Übersicht), 1.

5 OSTA-AVA, Kultus AK gr.-or. Karton 2, 3058-1835, allerhöchste Entschließung v. 8.V.1835; ein Vorschlagsrecht für Bischöfe in der Bukowina war weder durch den Klerus des Landes noch durch Karlowitz vorgesehen; detto 152 ex Nov. 1822 33019/1832, allerhöchster Vortrag vereinte Hofkammer v. 26.IX.1822 26888/1486. 
angelangt, resümierte Hackmann rückblickend: "Ich bin Bischof geworden, gerade in der Epoche des Übergangs meiner Diözese von ihrem alten traurigen Zustande zu einer besseren glücklicheren Periode. ${ }^{6}$ Tatsächlich verkörpert Hackmann in seiner Person eine ausgeprägte Phase der Transition für die gr.-orient. Kirche der Bukowina und den Religionsfonds.

Im Kontext gesamtgesellschaftlicher Veränderungen zur Mitte des 19. Jahrhunderts in der Habsburgermonarchie lässt sich diese Periode für die Bukowina in drei Schritten verdichten. Hatte noch wenige Jahrzehnte zuvor die josephinische Politik Religionsfreiheit mit administrativer Regulierung und Instrumentalisierung bzw. Loyalisierung der Kirchen für die Anliegen des Staates verbunden, so forderten die Reformkräfte der Revolution von 1848 - ungeachtet ihrer Heterogenität und ihrer teils sehr unterschiedlichen Beweggründe - bereits eine breitere Laienbeteiligung innerhalb der Kirchenorganisation ein. ${ }^{7}$ Letzteres Anliegen richtete sich, zweitens, indirekt gegen die zentralisierende Kraft des Staates und zielte offen gegen die weitgehende Macht der Bischöfe innerhalb der Kirchen. Das betraf vor allem die Orthodoxie, was besonders in der Diskussion um die Einberufung eines Kirchenkongresses in der Bukowina evident wird. In einem dritten Schritt, der weithin bis zum Ersten Weltkrieg bestimmend bleiben wird, geriet die Loyalität der Kirchen gegenüber dem Staat in der Habsburgermonarchie zunehmend seitens der wachsenden wie national geleiteten Forderungen ihrer Gläubigen unter Zugzwang. ${ }^{8}$ Zusätzlich bezogen die - sich mit 1848 auch in der Bukowina artikulierenden - nationalen Kräfte ihre Energie nicht nur aus der größer werdenden wirtschaftlichen Bedeutung des gr.-orient. Religionsfonds. Sie begannen vielfach auch, ihre Ansprüche auf das in dieser Institution vermeintlich (und aus ihrer Perspektive eindeutig rumänisch konnotierte) nationale Erbe als Eigentum auszuweiten. ${ }^{9}$

Auf den hierin bereits beispielhaft erkennbaren direkten Zusammenhang zwischen Nation und Ökonomie wurde allerdings seitens der Nationalismusforschung zu Beginn der $1980 e r$ Jahre für den Zeitraum vor 1918 nur vereinzelt Rücksicht genommen. Und das, obwohl beide Felder - Nation wie Ökonomie - durch »ein breites Zwischenfeld sozialer, politischer, kultureller und psychologischer Vermittlungsinstanzen miteinander verbunden « waren. Evident ist indes, dass die Ansätze der eingeleiteten kapitalistischen Transformation in diesem Kontext weitestgehend nur dafür ausreichten, »die alten Vielvölkerstaaten an ihren ethnischen Nahtstellen aufbrechen zu lassen $* .{ }^{10}$ Der Bukowiner

\footnotetext{
6 HAKMANN 1864/1899, Sendschreiben, 200.

7 Schulze-Wessel 1998, Religion, 340 u. 348.

8 Schulze-Wessel 1998, Religion, 354; SCHneIder 2005, Metropolit, 207.

9 TURCZYNSKI 1976, Konfession, 257.

10 JAWORSKI 1982, Nationalismus, 185, 194f. u. 200.
} 
Religionsfonds erschien als ein derartiger Hebel, der an diesen Nahtstellen von verschiedener Seite Einsatz fand.

Angelehnt an diese drei Aspekte und die damit verbundenen Überlegungen ist daher ausgehend von der Person Eugen Hackmann der Fokus auf das Beziehungsgeflecht Staat (Landesverwaltung) - Religionsfonds - Bischof/ Konsistorium zu richten. Wann und in welcher Form gerät der Fonds zum Gegenstand nationaler Ideologien? Auf welche Weise äußerten sich diese national formulierten Begehrlichkeiten in der Struktur des Bistums bzw. des Religionsfonds selbst? Im Weiterdenken darüber drängt sich außerdem die Frage nach den Folgen dieser Ideologisierung im Hinblick auf die Wirtschaftlichkeit des Fonds - als ein mithin zentrales Fundament für die Entwicklung der Bukowina - auf. Damit wäre gleichwohl auch die langfristige Perspektive über das Jahr 1918 hinaus eröffnet. Vorab soll jedoch ein kurzer Blick auf die Person des Bischofs Hackmann und damit auch auf die historiographische Einschätzung seiner Ära geworfen werden.

\section{Hackmann im Fokus der Historiographie}

In der Einschätzung Hackmanns orientiert sich die gegenwärtige (vorwiegend rumänische) Historiographie vielfach ohne die nötige Distanz an den Leitlinien älterer, aus zumeist problematischer und oftmals nach 1990 neu wie weitgehend unkommentiert aufgelegter Arbeiten. Diese bezichtigen den Bischof im Allgemeinen einer antinationalen Haltung. ${ }^{11}$ Seit der Wende von 1989 schärften sich zudem von Neuen die Konturen nationaler Verortung an der Person Hackmanns, gerade auch von kirchlicher Seite. So wird der Bukowiner Bischof heute sowohl vom Moskauer als auch vom Kiewer Patriarchat in jeweils spezifischer Weise vereinnahmt, instrumentalisiert und entsprechend den eigenen Anliegen als Ikone vorangetragen. ${ }^{12}$ Diese aktuelle Politisierung Hackmanns wurzelt freilich in der älteren, vor dem Ausbruch des Ersten Weltkrieges geführten Diskussion um die innenpolitische Position des österreichischen Bischofs. So ist jedenfalls das von dem Slawisten der Czernowitzer Universität Stefan Smal-Stocki ${ }^{13}$ 1899 in der Buchdruckerei Ruska-Rada herausgegebene Sendschreiben Hackmanns vor dem zeitgenössischen Hintergrund zu deuten. Das »autographierte Sendschreiben ", das Smal-Stocki in seinem Vorwort als "Seltenheit « bezeichnet, da er davon »sonst kein Exemplar mehr gesehen hätte«, lieferte in der zum Teil zu diesem Zeitpunkt öffentlich

11 Etwa NISTOR 1916/2003, Istoria; PUȘCARIU 1900, Metropolia.

12 SCHARR 2011, Religionsfonds.

13 Auch Smal-Stockyj (1859-1938), 1893 bis 1918 Lehrstuhlinhaber für ruthenische Sprache und Literatur an der Universität Czernowitz; Osterreichisch Biographisches Lexikon 1815-1950, Bd. 12 (Lieferung 58, 2005), 363 f. 
bereits heftig geführten Diskussion um die Stellung der Ruthenen innerhalb der Bukowiner Orthodoxie eine nicht ganz unbedeutende Argumentationsgrundlage gegen die Nationalisierungspolitik der Kirchenhierarchie, besonders unter dem Bischof Silvester Morariu-Andriewicz (1818-1895). Die Schrift, die Smal-Stocki seiner eigenen Schilderung nach von einem Priester aus Mamajestie (heute ukr. Мамаївці, rum. Mamaești) erhalten hatte, dürfte weitgehend authentisch sein, auch wenn der Anlass ihres konkretes Erscheinens wohl eher politisch motiviert war. ${ }^{14}$ Ihre Veröffentlichung und der entsprechende zeitgenössische Kontext haben wahrscheinlich nicht unwesentlich zum Bild Hackmanns in der rumänischen als auch ukrainischen Literatur beigetragen. ${ }^{15}$

In der nicht gerade reichhaltigen Historiographie zu seiner Person gehen einige wenige neuere Studien, die Hackmann zu allermeist nur am Rande erwähnen, einen kritischeren Weg und beginnen das lange Zeit zu eng abgesteckte Interpretationsfeld allmählich zu verlassen. ${ }^{16}$ Dabei kondensiert im, dem Bischof so angetragenen, autoritären Führungsstil - allerdings ohne eine ausreichende Berücksichtigung des nötigen zeitgenössischen Kontextes - ein zentraler Charakterzug des Bischofs. ${ }^{17}$ Vor allem im noch zu erörternden Vergleich zu seinem siebenbürgischen Amtsbruder Andrei Schaguna ${ }^{18}$ hebt sich Hackmann in der historiographischen Wertung deutlich ab. ${ }^{19}$ Dass der Bukowiner Hierarch indes etwa auf die Einführung der rumänischen Sprache anstatt des Lateinischen am theologischen Institut von Czernowitz gedrängt hatte, wird wohl erwähnt, aber in dieser Hinsicht nicht entsprechend in Rechnung gestellt. ${ }^{20}$ Der Begleitumstand

14 Die Ortschaft im Bezirk Kotzmann gehörte zu den zahlenmäßig von ruthenischer Bevölkerung dominierten Siedlungen. Es ist daher anzunehmen, dass der von Smal-Stocki erwähnte Priester Eusebius Andrijczuk ebenfalls Ruthene war.

15 НACKMANN 1864/1899, Sendschreiben, Vorwort Smal-Stocki.

16 Etwa Bocşan 2005, Șaguna; LuCEAC 2007, Discursurile; Németh 2012, Zhishman; A Brudan 2015, Ortodoxie, bes. S. $231 \mathrm{f}$.

17 SATCO 2004, Enciclopedia T. 2, 47 of.; im Vergleich zu Morariu-Andrievici: Satco, T. 1, 83 f.

18 Rum. auch Andrei(u) Şaguna (1809-1873); Bischof seit 1848, Erzbischof und Metropolit von Siebenbürgen, seit 1864 mit Sitz in Hermannstadt (heute rum. Sibiu).

19 STAN 2009, Şaguna, 211, 250, 297 u. 299; Stan überschreitet hier deutlich die Grenze von einer objektiven Analyse hin zur emotionalen Polemik: »Austria succeeded in cultivating for some time discord among the Romanians, following its old governing saying: divide et impera! This quarrelling policy led from Vienna found a docile supporter in the person of Bishop Eugeniu Hacman of Bukovina, who sheltered Șaguna's plan and caused a great affliction in the hearts of many Romanians of Bukovina " (211); »The establishment of a Metropolitanate in Bukovina, which would have been, in fact, on one hand the sprices paid by the Court to Bishop Eugeniu Hacman for his acceptance of the political plans $[\ldots]$ and on the other hand the 'Trojan Horse s through which the Court could penetrate in the internal affairs of the Orthodox Church in its attempt to imitate the Russian caesaropapism, was strongly opposed by Bishop Andrei Şaguna (297).

20 SATCO 2004, Enciclopedia, 470. 
hingegen, dass Hackmann sich für die Beibehaltung der kyrillischen Schreibweise des Rumänischen und gegen die Einführung der lateinischen Schrift aussprach, scheint mehr auf seine in diesen Fragen vorwiegend wertkonservative und weniger als national zu interpretierende Haltung hinzudeuten. Selbst in ihrer Anlage an sich hervorragende Studien sind nicht immer ganz bar derartiger schablonenhafter Kategorisierungen. ${ }^{21}$ Dabei vertraten sowohl Schaguna als auch Hackmann zeitlebens ein vormodernes Konzept von Nation. Beide Persönlichkeiten waren in ihrem Denken wie Handeln grundsätzlich gegen die Idee des modernen Staates und des Nationalismus eingestellt oder ihr gegenüber zumindest höchst skeptisch. ${ }^{22}$ Hackmann nannte den Nationalismus ein "Losungswort" und befürchtete daraus weitreichende Konsequenzen für eine multiethnische Region wie die Bukowina. ${ }^{23}$

Die Charakterisierung seiner Peron vorerst abschließend sei hier aus zeitgenössischer Perspektive die Einschätzung der Wiener Presse mit den wenigen Kommentaren und Nachrufen zu seiner Rangerhebung bzw. zu seinem Tod angeführt. Die deutschsprachigen Medien der Reichshauptstadt betonten dabei geradezu gegensätzlich die verfassungstreue (supranationale) Gesinnung des Bischofs im Sinne der Gesamtstaatsauffassung Wiens:

Zum Erzbischof und Metropoliten wurde der greise Bischof Hackmann in Czernowitz, bekannt durch seine in den Tagen Hohenwart'scher Bedrängniß mannhaft bewahrte verfassungstreue Gesinnung, ernannt [...] Die Maßnahme [...] ist eine Konsequenz des Dualismus [...] Das Karlowitzer Kirchenregiment war und ist der Brennpunkt der staatsfeindlichsten Agitationen, und die rumänische Geistlichkeit hat, obwohl sie nicht mehr dem Karlowitzer Commando zu gehorchen braucht, sondern unter dem Erzbischof Schaguna steht, die alte Wühllust ungebrochen bewahrt. Jetzt werden die Rumänen der Bukowina und die Morlachen Dalmatiens den verderblichen Einflüssen der Mileticseaner und Schaguniaten ${ }^{24}$ entzogen und der Einwirkung des verfassungstreuen Hackmann unterstellt. Die Wirkung dieser Consequenz wird sich bald in der Bukowina und mehr noch in Dalmatien erweisen. ${ }^{25}$

21 "Şaguna thought in terms of universals - empire and nation; Hacman's horizons did not extend beyond his own province«; Hitchins 1977, Orthodoxy, 192.

22 "In an age of nationalism he was not a nationalist. Rather he was the last of the great bishop national leaders"; Hitchens 1977, Orthodoxy, 284 (hier auf Schaguna bezogen).

23 НаскMANN 1864/1899, Sendschreiben, 204.

24 Morlachen (a), Mileticseaner (b), Schaguniaten (c) : zeitgenössische Bezeichnung für orthodoxe Gläubige bzw. deren spolitische` Richtungen in Dalmatien (a), in Bosnien-Hercegovina (b) bzw. in Siebenbürgen (c).

25 Neue Freue Presse Nr. 3034 v. 3. II.1873, S. 1 (Politische Uebersicht). Mit der »Hohenwart'schen Bedrängniß« spielte der Verfasser hier wahrscheinlich auf die liberale Regierung Hohenwart an, die - 
Die Verfassungspartei wurde von einem schweren Verluste betroffen: am 13. d. ist hier der griechisch-orientalische Erzbischof und Metropolit von Czernowitz, Se. Exzellenz Eugen Hackmann [...] gestorben. Der greise Kirchenfürst war einer der treuesten Anhänger der österreichischen Verfassungspartei [...] Dieses Verdienst ist dem Verstorbenen um so höher anzuschlagen, als er seine Reichstreue trotz der mannichfachen Anfeindungen der Petrinoten stets mannhaft offen bekundete. Auch unter dem Ministerium Hohenwart-Jirecek gab er glänzende Beweise von seiner Verfassungstreue. In der Debatte über die Wahlreform im Herrenhause hat sich Erzbischof Hackmann ebenfalls hervorgetan; seine bekannte Rede war ein glänzendes Plädoyer für die Verfassungspartei. ${ }^{26}$

\section{Metropolitanordnung \& Kirchenkongressfrage}

Auf gesamtstaatlicher Ebene war Wien während der Ära Hackmann hauptsächlich an einer stabilen Neuordnung bzw. Positionierung der orthodoxen (nicht unierten) Kirche(n) interessiert. Darin entzündeten sich kircheninnenpolitisch nicht nur bereits vorhandene Spannungen mit dem serbischen Patriarchen von Karlowitz (heute serb. Sremski Karlovci / Сремски Карловци) ${ }^{27}$ zur Frage einer gemeinsamen (zunächst noch serbisch-) rumänischen Metropolie. Es zeichnete sich außerdem die 1867 vollzogene Reichsteilung in ihren Konturen ab. In der Bukowina und bezogen auf die Amtsperiode Hackmanns betraf das im Kern die Anstrengungen zu einer generellen Modernisierung bzw. Neuordnung der Diözese. Diese lassen sich vor allem in den Diskussionen um die Einführung eines Kirchenkongresses, der Frage nach dem Verfügungsrecht über den Religionsfond sowie im Wunsch nach einer eigenen Metropolie greifen. Eine sichtbare Öffentlichkeit erfuhr dieser Prozess in den nicht selten gegenteilig laufenden Bestrebungen bzw. Motivationen der beiden srumänisch ^orthodoxen, nicht unierten Bischöfe der Monarchie dies- wie jenseits der Karpaten, Eugen Hackmann und Andrei Schaguna.

Im östlichen Europa stand zur Mitte des 19. Jahrhunderts - wie es sich hier am Beispiel der Bukowina zeigt - die Religion in einem konstanten Spannungsfeld zwischen Imperium (der Habsburgermonarchie) und nationalen Ideen (i.e. jeweils jener der Rumänen und Ruthenen). ${ }^{28}$ Hierbei handelte es sich um kein einseitiges Verhältnis. Nicht

über den Dualismus hinausgehend - durch eine Föderalisierung der Kronländer das Gesamtstaatsproblem der Monarchie zu lösen versucht hatte.

26 Neue Freie Presse Nr. 3104 v. 15.IV.1873, S. 1 (Politische Uebersicht). Alexander v. Petrino, Großgrundbesitzer aus der Bukowina, galt unter der Regierung Hohenwart bis zu seinem Ausscheiden als Reichsratsabgeordneter im Jahr 1873 als aktiver Verfechter einer föderalistischen Politik.

27 Seit 1848 führte der dortige Erzbischof den Titel eines Patriarchen; in dem bis 1918 zur Habsburgermonarchie gehörenden Syrmien bestand ein Erzbistum seit 1713 .

28 SChUlze-WeSSEL 2006, Nationalisierung, 12. 
nur, dass die Religion als Legitimationsressource seitens des Imperiums betrachtet und dass die Loyalität der Kirchenobrigkeit gegenüber dem Staat seit Joseph II. unbedingt eingefordert wurden. Vielmehr bezog auch die Kirchenhierarchie sowie ihre eigene Verfasstheit daraus in umgekehrter Weise Legitimität. So überrascht es wenig, wenn gerade eine führende Wiener Tageszeitung wie die Neue Freie Presse in ihrem Nachruf auf Hackmann die Verfassungstreue so pointiert herausstreicht. Zudem erlangte die nationale Bewegung in der Bukowina trotz erster Impulse unter den Eliten um 1848 vergleichsweise erst spät eine breitere Basis. Das war für eine vormodern agrarisch strukturierte Bevölkerung nicht außergewöhnlich. Emanuel Turczynski resümiert diese Situation folgendermaßen: "Unter dem Einfluß einer sozial differenzierten, nach Wien orientierten rumänischen Oberschicht, die mit Hilfe ihrer vorherrschenden Stellung in Kirche, öffentlichem Leben und Verwaltung die ruthenische Grundschicht überlagerte, wurde die Nationalisierung der Rumänen wie der Ruthenen weitgehend retardiert und durch das zu den außerösterreichischen Siedlungsgebieten der Rumänen und Ruthenen geschaffene Sozial- und Kulturgefälle beeinflußt. «"

Auch wenn die Revolution von 1848 der nationalen Frage der rumänischen Untertanen der Habsburgermonarchie Leben eingehaucht hatte, so blieb zunächst die nationale Renaissance doch noch weit entfernt von einer einigermaßen monolithischen Struktur, wie das in diesem Zusammenhang ansonsten gerne gegenteilig vermutet wird. ${ }^{30}$ Die nicht zur Union gehörenden orthodoxen Rumänen des Reiches formten dabei zwei räumlich definierte Lager, jenes in Siebenbürgen und jenes der Bukowina. In Siebenbürgen fanden sich die Rumänen außerhalb der anerkannten und damit rechtlich besser gestellten historischen Nationen, obwohl sie vielerorts die eigentliche Mehrheitsbevölkerung bildeten. Ihre Elitenstruktur war vergleichsweise klein. ${ }^{31}$ In der Bukowina verfügten die Rumänen indes nicht nur über eine Majorität unter den Bewohnern (wenngleich mit regionalen Differenzierungen), sondern ihnen stand auch eine ebenso anerkannte wie politisch aktive und einflussreiche Oberschicht zur Seite. ${ }^{32}$

Für die orthodoxe nicht-unierte Kirche Siebenbürgens und ihr Anliegen um rechtliche Gleichberechtigung der Rumänen als Nation stand vor allem der 1848 inthroni-

29 TurCZYNSKI 1976, Konfession, 163 ; auf die Außenwirkung bzw. die Bedeutung der Nationalstaatsbildung etwa am Beispiel Rumäniens ist hier nicht weiter einzugehen; dieser Aspekt spielte jedoch in der nationalen Entwicklung der Bukowina eine entscheidende Rolle. Turczynski hob darin das auch den Zeitgenossen bereits bewusste Gefälle jenseits der Grenze besonders hervor; SCHARR 2016, Anderen.

30 Hitchins 1977, Orthodoxy, 7; MAIOR 2006, Habsburgi, bes. 37-48 u. 59-62; Maior nimmt vorwiegend auf Siebenbürgen Bezug.

31 Im Überblick dazu Bolovan 2000, Transilvania.

32 TURCZYNSKI 1993, Geschichte, bes. 72-88. 
sierte Bischof Andrei Schaguna ein. ${ }^{33}$ Sein eigener Handlungsspielraum erstreckte sich aus Überzeugung klar zwischen einem konsequenten Streben um die Verbesserung der sozio-ökonomischen Situation der orthodoxen Kirche sowie ihrer Gläubigen in Siebenbürgen und einer gleichzeitig dazu ebenso unbedingten Loyalität gegenüber dem angestammten Herrscherhaus der Habsburger. Die Revolution als Aufstand gegen eine legitime Herrschaft musste daher aus seinem Blickwinkel - auch angesichts der von ihm persönlich wahrgenommenen Folgen - als "nichts weniger als eine Katastrophe erscheinen. ${ }^{34}$ Darin passte sich das vom Hermannstädter Oberhirten zeitlebens vertretene Konzept eines multinationalen, jedoch autonomen (von der ungarischen Stephanskrone unabhängigen) Kronlandes Siebenbürgen nahtlos ein. Unter diesen Prämissen verstand Schaguna wohl auch seine Idee der Einrichtung einer gesamtrumänischen Metropolie des (zu diesem Zeitpunkt noch) österreichischen Kaiserreiches, die er anlässlich einer am 15 . Oktober 1850 nach Wien einberufenen orthodoxen Synode vorbrachte. ${ }^{35}$ Konzeptionell für Schaguna, der die Laienbewegung innerhalb der Kirche massiv unterstützte, war seine kategorische Ablehnung einer sherrschenden orthodoxen Kirche. ${ }^{36}$ Beides waren Anliegen, die sich erst aus dem siebenbürgischen Kontext verstehen lassen.

Gerade daran entzündete sich indes der Gegensatz zu Eugen Hackmann. Hatte in der Grundsatzforderung nach einer Entflechtung von der Karlowitzer (von den Rumänen als serbisch dominiert empfundenen) Metropolie noch ein weitgehender Konsens bestanden, so erschien aus Czernowitzer Perspektive - wo die orthodoxe Kirche eine privilegierte Stellung besaß - die Errichtung einer gemeinsamen, die politischen Provinzen überschreitenden orthodoxen (rumänischen) Metropolie als unannehmbar, obgleich sich der Bukowiner Bischof damit in eine vehemente Opposition zu den national gesinnten rumänischen Kreisen seiner eigenen Diözese begab. Letztere bedachte Hackmann polemisch als Allegorie "menschlichen Ehrgeizes im Priestergewand mit dem Zwietrachtsapfel «. ${ }^{37}$ Hackmann, der seine Argumentationslinien vor allem aus dem Kirchenkanon heraus begründete ${ }^{38}$, führte gegen die von ihm geradezu in apodiktischer Weise betriebene Ablehnung einer gemeinsamen Metropolie im Wesentlichen vier

33 Dazu biographisch ausführlicher SCHNEIDER 2005, Metropolit.

34 Hitchins 1977, Orthodoxy, 46 u. 78.

35 Hitchins 1977, Orthodoxy, 100 u. 79; im Original: Adresa Episcopului Andreiu Şaguna cătră episcopul Bucovinei, Eugenie Hacman, prin care cere părerea acestuia și a clerului din Bucovina asupra unor puncte privitóre la independența ierarchică a Românilor; Olmütz 18.IV.1849; abgedruckt in PUȘCARIU 1900, Metropolia, 40-43; ausführlicher zu Schagunas Reformpoltitik in Siebenbürgen vgl. ABRudan 2015, Ortodoxie.

36 SCHNeIDER 2005, Metropolit, 14 u. 59.

37 STYRCZA et al. 1864, Einigkeitsruf, Vorwort.

38 Zusammenfassend dazu HACKMANN 1864/1899, Sendschreiben. 
Punkte an. Diese sind unbedingt vor dem Hintergrund der gesellschaftlichen Situation in der Bukowina zu sehen und stehen zudem untereinander in einem engen, sich gegenseitig beeinflussenden Verhältnis: erstens - eine unumstritten hierarchisch organisierte Kirchenführung ausgehend vom Bischof sowie eine den politischen Provinzgrenzen entsprechende Organisation der Diözesen; zweitens - eine klare Zuordnung des Religionsfonds, widmungsgemäß und ausschließlich für die Bedürfnisse der Bukowina; drittens - die Verfügungsgewalt des Bischofs darüber sowie - viertens - eine drohende Gefahr nationaler Spaltung des Kronlandes (im Hinblick auf den ruthenischen Bevölkerungsanteil innerhalb der orthodoxen nicht unierten Kirche der Bukowina).

Während die Demokratisierungsversuche innerhalb der nicht unierten Orthodoxie Siebenbürgens durch Andrei Schaguna zielgerichtet eine Stärkung aller Rumänen auf Basis nationaler Gleichberechtigung und gegen die voranschreitende Magyarisierung beabsichtigte, hätte aus der Sicht Hackmanns eine kirchliche Vereinigung und eine damit zusammenhängende Laisierung der Hierarchien "den sorgsam gehüteten Hausfrieden in der Bukowina " erheblich gestört. ${ }^{39}$ Ein Kirchenkongress, wie ihn Schaguna verstand, hätte die Beteiligung von Laien an entsprechender Stelle vorausgesetzt, jedoch gleichzeitig in einer polyethnisch verfassten Religionsgemeinschaft wie der orthodoxen Kirche der Bukowina unweigerlich zu einer Nationalisierung der Konfession und damit in Konsequenz schlimmstenfalls zur Spaltung geführt. Letzteres sollte sich Jahrzehnte später bestätigen. Zudem teilte sich die ruthenische Volksgruppe der Bukowina auf zwei - allerdings nicht in einem vergleichbaren Verhältnis wie die Rumänen Siebenbürgens - Bekenntnisse auf: in ihrer überwiegenden Mehrheit auf die gr.-orient. Kirche und in einer sehr viel kleineren Minderheit (vorwiegend aus Galizien-Lodomerien Zugewanderter) auf die gr.-kath. (unierte) Kirche Brester Union. Gleich mehrfach äußerte sich daher Hackmann, mitunter auch emotional, gegen die angestrebte Laienbeteiligung:

Näher angesehen, ist das keine constitutionelle Verfassung, wie sie heutzutage in Österreich besteht, denn wer wäre hier der andere gesetzgebende Factor, da der Bischof bloss Präses ist. Diese Verfassung ist nichts mehr, nichts weniger als Calvins republikanische. Und da die Laienvertretung um das doppelte grösser ist als die der Geistlichen, so wird bei dieser Verfassung die Herde die Hirten weiden. ${ }^{40}$

Die nationalen Reibungen und Kämpfe, welche seit vierzehn Jahren bereits die gr. orient. Kirche in Osterreich bewegen und das Band ihrer äußeren Einheit zu zerreisssen (sic!) drohen, sind nicht ohne aufregenden Eindruck auf die zwei verschiedenen nationalen Elemente der

39 TURCZYNSKI 1976, Konfession, 255-257.

40 HaCKMANn 1864/1899, Sendschreiben, 112, ebenso 4. 
Bukowiner Diöcese geblieben. Das nationale Selbstgefühl ist daselbst jetzt eben so lebhaft, als anderwärts, und dies eben so natürlich bei den Ruthenen, als Romanen [...] Bei dieser Gemüthsstimmung meiner national gemischten Diöcese würde der Bukowiner Romane höchst unzufrieden sein, wenn er einer ausschliesslich serbischen Hierarchie angehören müsste, und ebenso unzufrieden wäre der Bukowiner Ruthene unter einer ausschliesslich romanischen $\mathrm{Hi}$ erarchie. Jedenfalls würde die Unzufriedenheit wenigsten die Hälfte meiner Diöcese erbittern. ${ }^{41}$

Die in Personalunion 1859 vollzogene de facto Vereinigung der rumänischen Fürstentümer unter Ioan Cuza gerieten beide Bischöfe, wenngleich aus unterschiedlichen Gründen, gegenüber national-rumänischen Kreisen ihrer Diözesen in Zugzwang. Ein einflussreicher Teil der Bukowiner Eliten ${ }^{42}$, darunter Mitglieder der Familie Hormuzaki, unterstützte beispielsweise - nicht ganz uneigennützig - Schaguna. So erbat sich etwa Gheorghe Hormuzaki beim Hermannstädter Bischof im Sinne des nationalen Anliegens Fürsprache. Gh. Hormuzaki war in Hermannstadt kein Unbekannter, er hatte den >Anthorismus Schagunas ins Deutsche übersetzt. ${ }^{43}$ Mehrfach vermutete Hackmann in

41 Hackmann 1864/1899, Sendschreiben, 129

42 Hackmann adressiert diese in seinem Sendschreiben alle namentlich: "An die Hochwohlgeborenen, Wohlgeborenen, Geehrten Herrn P.T. [pleno titulo] Emanuel von Styrca, Dr. Alexander von Zotta, Nicolaus von Wassilko aus Slobodzia-Komarestie, Eudoxius von Hormuzaki, Theodor Ritter von Buchenthal, Gregor von Gojan, Demeter von Gojan, Georg Flondor, Eugen Styrcza, Georg von Hormuzaki, Alexander Hormuzaki, Nicolaus Hormuzaki, Georg Kostin, Alexander Kostin, Nicolaus von Wassilko aus Lukawetz, Victor Styrcza, Johann Czerniawski, Leon Rey, Chrisanft Mathiasiewicz, Georg Konstantinowicz, Nicolaus Jeremiewicz, Joanne Litwiniuk, Johann Zebaczinski, Orestes Renney de Herszeny, Leo Popeskul, Jon al lui G. Sbiera, Johann Karapetz, Ambrosius Dimitrovitza, Demeter von Daszkiewicz, Leon Isseczeskul, Basil Illasiewicz Official, Nicolaus Stefanowicz Official, Georg Woronka Official, Nicolaus Balmosch, Johann Reus, Konstantin Karadże, Alexander Humuika, Johann von Lupul, Arthenmius Czuntuliak Postofficial, Theodor Czuntuliak, Johann Dżosan, Nicolaus Jeremiewicz, Basil von Wolczinski, Leon von Manescul, Alexander Roskip, Basil Manescul, Nicolai Braha, Michael Manescul, Grigori Konstantinowicz, Georg Soroczan, Jordaki Dobrowolski, Theodor von Reus, Basil Boszniaga, Georg Dżurumia, Konstantin Tuszynski, Leo Czuperkovics und Emanuel Böndewski - zu Händen Sr. Hochwohlgeboren des Herrn Emanuel Ritters von Styrcza«; HACKMANN 1864/1899, Sendschreiben, 3 .

43 SChaguna 1863, Anthorismus; "Cu inima sângerândă însĕ împărtășesc Excelenţiei Vóstre, cum înţelege acum episcopia nóstră causa metropoliei române«; Schreiben Gh. Hurmuzachi an Schaguna 9./21.II.1861; abgedruckt in PUȘCARIU 1900, Metropolia, 182-185, hier 182; auch LUCEAC 2007, Discursurilele, 33. Das Frontispiz der Hermannstädter Ausgabe erwähnt allerdings, dass die Ubersetzung "von mehreren ortodoxen Christen romanischer Nationalität aus der Bukowina ins Deutsche angefertigt worden wäre. Damit ist wahrscheinlich auf Eudoxiu Hormuzaki, den Bruder von Gheorghe, verwiesen, der die deutsche Ubersetzung vor der Veröffentlichung überarbeitet hat; LUCEAC 2015, Hurmuzaki, $62 \mathrm{f}$. 
dieser Strömung, die er in seinem Sendschreiben personalisiert mit "Sie meine Herren, und ihre auswärtigen Freunde « ansprach ${ }^{44}$, illegitimes Handeln, sowohl gegen die gültige Verfassung des österreichischen Staates als auch gegen den Kanon der orthodoxen Kirche. ${ }^{45}$ Obwohl Hackmann vorerst noch das gemeinsame Anliegen einer Loslösung von der Karlowitzer Metropolie befürwortet hatte, distanzierte er sich 1861 nach dem Erscheinen des >Anthorismus deutlich von Schagunas Forderungen eines Kirchenkongresses sowie einer gemeinsamen (rumänischen) orthodoxen Diözese in Österreich. Hackmann vertrat nunmehr die Errichtung einer jeweils eigenen Metropolie für jede Kirchenprovinz. ${ }^{46}$ Der Hermannstädter Bischof hatte 1861 mit seinem - im Original in rumänischer Sprache und mit kyrillischem Schriftsatz - vorgelegten Text ausführlich zu den Befürchtungen Hackmanns bzw. des Bukowiner Klerus Stellung bezogen. Darin verteidigte er sein Vorhaben einer vereinten rumänischen wie, getrennt davon, einer serbischen Metropolie. ${ }^{47}$ Ebenso stand aus Hermannstädter Sicht das Laienwahlrecht - d.h. die freie Wahl des Bischofs durch eine Eparchialsynode - keineswegs im Widerspruch zum Kirchenkanon, wie das Hackmann so strikt vertrat. Die Synode selbst wäre dabei "von Seiten der gesamten Hierarchie « und nicht nur durch den Kaiser einzuberufen gewesen. ${ }^{48}$ Der Bukowiner Hierarch unterstrich dem entgegenhaltend, dass eine Einbeziehung seines Bistums unter eine wie auch immer zu errichtende gemeinsame Metropolie »keineswegs und nie der Wunsch des Landes oder des Bukovinaer Klerus gewesen sei«. Die dahingehend eingereichten Petitionen und Erklärungen erachtete Hackmann gegenüber der geltenden Verfassung nicht als legitim. ${ }^{49}$ Für Eugen Hackmann trug der aus dem Altgriechischen stammende Begriff `Ethnos` ( $\check{\varepsilon} \theta v \circ \varsigma)$ die Bedeutung >Land bzw. >Provinz in sich und begründete damit für ihn deutlich genug das Recht auf eine

44 Hackmann 1864/1899, Sendschreiben, 117.

45 Hackmann bezieht sich u.a. auf folgende Schriften: Petiţiunea generală a Naţiunei române, Olmütz 13./25. Febr. 1849 (abgedruckt in PUȘCARIU 1900, Metropolia, 10-13; dt. gekürzt in HaCKMANN 1864/1899, Sendschreiben, 154 u. 159ff.); STYRCZA et al. 1864, Einigkeitsruf (rum. abgedruckt in PușCariu 1900, Metropolia, 295-305).

46 Bocşan 2005, Corespondența, 55; zu Schagunas Ansichten vgl. Episcopul Șaguna cătră Hacman, episcopul Bucovinei, din sinodul diecesan ţinut în Sibiu in Otc. 1860; abgedruckt in PUșCARIU 1900 , Metropolia, 177-180; zur Polemik zwischen Hackmann und Schaguna vgl. BRUSANOWSKI 2006, Polemica.

47 Schaguna 1863, Anthorismus, 6, 15 u. 101. Bereits 1849 und 1851 hatte Schaguna in einem Promemoria sowie einer rumänisch-deutsch verfassten Denkschrift an das Kultusministerium seine Sicht einer rumänischen Metropolie dargelegt; letztere lag 1860 als Druck in Hermannstadt vor; ȘAGUNA 1849, Promemoria u. Schaguna 1860, Denkschrift.

48 Schaguna 1863, Anthorismus, 59 u. 74.

49 Propunerile episcopului Bucovinei Eugenie Hacman la sinodul din Carloviț, Karlovitz, 26.VIII./7. IX.1864, abgedruckt in PUȘCARIU 1900, Metropolia, 248-252, hier 294. 
eigene Metropolie für jede Provinz, d.h. eben auch für das Kronland Bukowina. ${ }^{50}$ Aus dieser Logik heraus betrachtet - so Hackmann weiter - bestünde de facto bereits eine Art von Metropolie, da Czernowitz die Hauptstadt (Metropolis) eines neuen Kronlandes sei. Mehr noch, eben weil der Bukowiner Klerus "seinem wahren Metropoliten, der in der Moldau wohnt, aus wohlbegreiflichen politischen Gründen nicht unterstehen darf [... und] die Bukowiner Diöcese bekanntlich eine Tochter der Metropolie Moldaus ist «, wäre diese Forderung logisch gerechtfertigt. ${ }^{51}$ Ein zugegebenermaßen ambivalentes Interpretationsmuster, dessen »wohlbegreifliche politischen Gründe« klar auf die josephinische Kirchenordnung ${ }^{52}$ verweisen, die Hackmann als Teil der gültigen Verfassung nicht nur akzeptierte, sondern loyal vertrat, wenngleich der Hinweis auf den "wahren Metropoliten « frühere - jedoch ebenfalls legitime - Loyalitäten damit nicht in Abrede stellte. Schaguna deutete allerdings Ethnos auf gegensätzliche und weniger an den Raum gebundene Weise mit >Volk`, >Nation` und `Stamm`, was wiederum ein Argument für eine vereinte rumänische Metropolie lieferte: „Wir Romanen aus Siebenbürgen, Banat und Ungarn wollen die Wiederherstellung unserer alten Metropolie. ${ }^{53}$ Den nicht ganz unberechtigten Einwand der Bukowiner Laien, wonach die "Creierung von zwei Metropolien auf Grund des Nationalitätenprinzips und einer dritten ohne jedwede Rücksicht auf Nationalität [also dreier Partikularkirchen: eine serbische, eine rumänische in Siebenbürgen und eine in der Bukowina; Anm. K.S.] aber schon von vornherein einen Widerspruch « in sich führe, ließ Hackmann unbeachtet. ${ }^{54}$ Die rumänischen Eliten der Bukowina fühlten sich mit der Entscheidung von Karlowitz, die Diözesen getrennt zu lassen, geradezu in ihrem ursprünglichen Vorhaben bestätigt: „Carlowicz ist theilweise ein kirchliches Frankfurt geworden, und das laute Zeugniß der Kirche, daß sie sich nicht aus und durch sich selbst regenerieren könne, ruft unwillkürlich die Laienwelt ihr zur Hilfe «. ${ }^{55}$ Noch 1866 berichtete der Ausschuss des Bukowiner Landtages zur Kirchenautonomie unter Bezug auf die Erhebung des Bistums Hermannstadt zur Metropolie: »Umso schmerzlicher muß es dieses stets getreue Kronland empfinden, daß seine Diöcese allein von der Wohlthat der Wiedergeburt der gr. or. Gesamtkirche nicht berührt sondern außerhalb der Bereiche der kanonischen Sazungen (sic!), in derselben vorgezeichneten Richtung belassen wurde«. Der Ausschuss sah darüber hinausgehend in die-

50 HACKMANN 1864/1899, Sendschreiben, 138f.; Motivarea propunerilor episcopului Bucovinei Eugenie Hacman la sinodul din Carloviţ, Karlovitz, 2./14.IX.1864, abgedruckt in PUșCARIU 1900, Metropolia, 252-285, hier 253; auch SchNeIDER 2005, Metropolit, 12 u. 169.

51 Hackmann 1864/1899, SendSChreiben, 109 u. 120, $138 \mathrm{f}$.

52 Vgl. Kap. 3 (Aspekte des Josephinismus).

53 Schaguna 1863, Anthorismus, 117.

54 StYrCZA et al. 1864, Einigkeitsruf, 15.

55 STYRCZA et al. 1864, Einigkeitsruf, Vorwort. 
ser Haltung eine systematische Behinderung der gr.-orient. Kirche »in ihrer natürlichen kanonischen Entwicklung " durch die Staatsverwaltung. ${ }^{56}$

Letztlich stand Hackmann mit seinen Ansichten auf der Seite Wiens. Der kaiserlichen Regierung selbst lag aus Gründen der inneren Machtverteilung wenig an der Errichtung einer geschlossenen orthodoxen und in der Mehrheit der Gläubigen rumänischen Diözese. Zudem hätte eine derartige Entscheidung - selbst noch vor dem Ausgleich mit Ungarn - eine erhebliche innenpolitische Verstimmung seitens der Ungarn nach sich gezogen. Das nachgewiesen freundschaftliche Verhältnis zwischen Eugen Hackmann und Josef von Zhishman als einer der ebenso zentralen wie einflussreichen Figuren, dem Berater der Wiener Regierung in Kirchenfragen der Orthodoxie, verdeutlicht diese Einschätzung nur, ebenso wie andererseits national-rumänische Kreise die Expertise Zhishmans weitgehend ablehnten. ${ }^{57}$ Für Wien musste die loyale Haltung Hackmanns gegenüber der Gesamtstaatsidee in Verbund mit seiner traditionell-konservativen Interpretation der Kirchenhierarchie unter ausdrücklicher Betonung der Gefahr, die vom nationalen Lager ausströmte, mehr als akzeptabel erscheinen. Auch wenn die Habsburgermonarchie seit der Gegenreformation und den Siegen über das Osmanische Reich von außen oftmals als katholische Macht wahrgenommen wurde, so darf das keineswegs über die der damaligen Verwaltung durchaus bewussten Realität eines nicht nur multiethnischen, sondern auch multikonfessionellen Reiches hinwegtäuschen. ${ }^{58}$ Hier ergänzen sich beide Ansichten, sodass die pragmatischen, der Staatsraison geschuldeten Entscheidungen Wiens, sowohl Hermannstadt (1864) als auch Czernowitz $(1873)^{59}$ zu jeweils eigenständigen Metropolien aufzuwerten, vor allem unter diesem Blickwinkel verstanden werden sollten. Ein abschließender, allerdings zentraler Punkt in der prinzipiellen (kirchen-)politischen Linie Hackmanns lag jedoch in der Frage des gr.-orient. Religionsfonds, der Verfügungsgewalt darüber und der Zweckgebundenheit seiner Mittel.

Die innerhalb der Habsburgermonarchie durch den Hackmann-Schaguna-Diskurs in der Öffentlichkeit aufgeworfene rumänische Frage blieb über die Ära des Bukowiner Bischofs hinaus bestehen, wenngleich sich der Schwerpunkt auf die ungarische Reichshälfte zu verlagern schien. Mithin ein Grund dafür mag die vergleichsweise größere konfessionelle und damit auch kirchenhierarchische Heterogenität der Rumänen in Siebenbürgen und im Banat gewesen sein (vgl. Abb. 14).

\footnotetext{
$56 \mathrm{DACZ}_{2} / 1 / 25$ Bericht des Ausschusses zur Vorberathung des Antrages in der Frage der Kirchenautonomie, Alexander v. Kostin (Obmann), Georg von Hormuzaki (Berichterstatter), 14.II.1866; sowie Adresse des Bukowiner Landtages an den Kaiser, 27.III.1863.

57 NÉmeth 2012, Zhishman, 27 u. 86.

58 AdANIR 2011, Commentary, 386.

591864 erfolgte die Herauslösung der beiden Diözesen aus der Metropolie von Karlowitz.
} 
Abb. 12 und 13:

Oppositionelle Kritik an Hackmann

Der unsichtbare, jedoch durch seinen Klobuk erkenntliche Hackmann hindert die allegorisch in Form einer Frau dargestellte Bukowina daran, in die gemeinsame rumänisch gr-orient. Metropolie (wie es die Inschrift auf dem Türrahmen verheißt) einzutreten, wo der Metropolitenstuhl von Hermannstadt noch unbesetzt im Raum steht. Darunter tanzen "Secretarienbach $\AA^{60}$ und "Rusneacovits ${ }^{61}$ im Verband mit den "Juden, Ruthenen, Deutschen und Polen $\alpha^{62}$ vor Freude um die verhinderte Vereinigung mit der Hermannstädter Metropolie eine Hora um die Eparchie der Bukowina, symbolisiert durch den Bischofshut, den Hirtenstab und den Religionsfond, auf dessen Kiste die Insignien liegen. ex: Revista Gura Satului ${ }^{63}$.
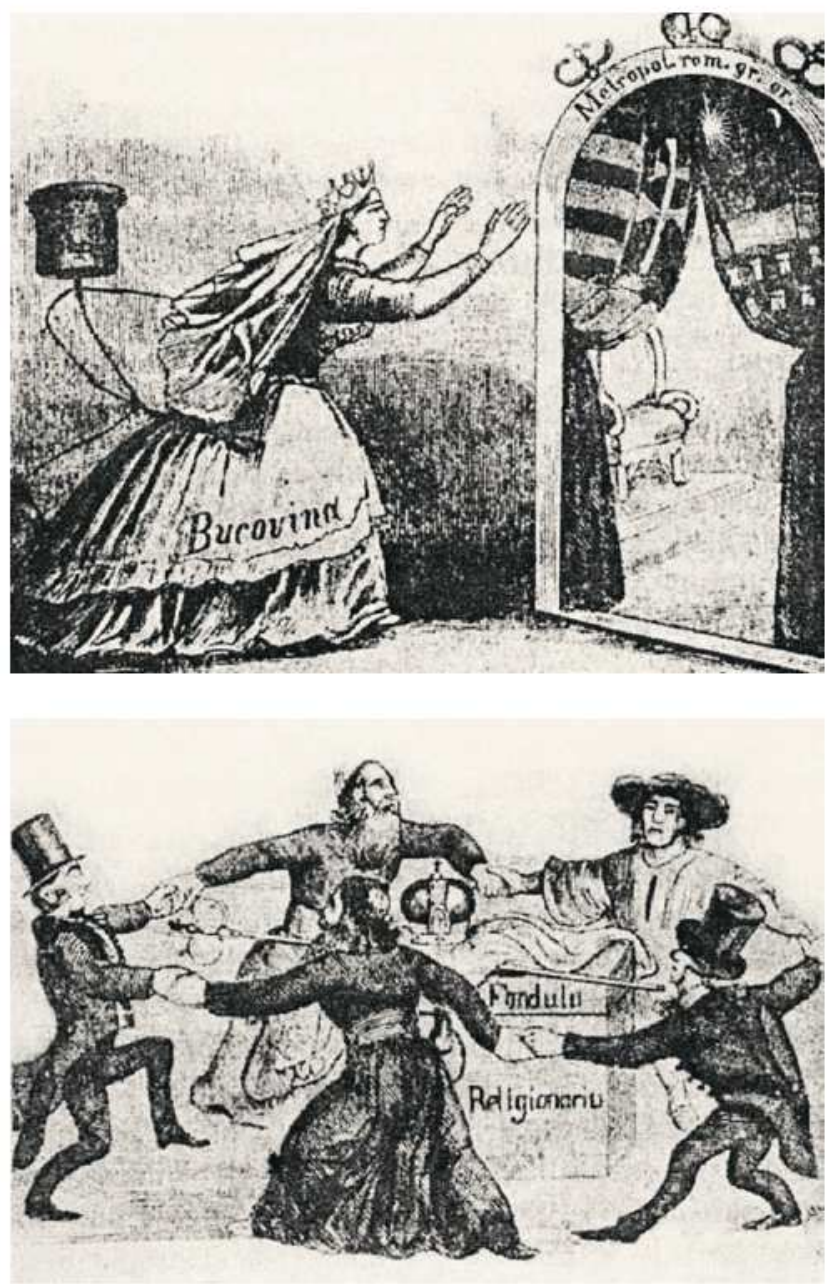

6o Gemeint ist Anton Schönbach, Sekretär und Kanzleidirektor des Konsistoriums; ANoNYMUS 1866, Schematismus, 7.

61 Einer der Konsistorialassessoren (oder symbolisch für alle vier Assessoren, deren Familiennamen alle auf --wicz (enden)?, ANONYMUS 1865, Schematismus, $6 \mathrm{f}$.

62 Nistor 1916/2003, Istoria, 73 .

63 Abbildung aus NisToR 1916/2000, Istoria, 74 u. 78; bei der hier nicht näher zitierten Revista Gura Satului dürfte es sich um eine Ausgabe des Jahres 1864 handeln; die Universitätsbibliothek der Babeș-Bolyai in Cluj-Napoca verfügt erst ab dem Jahr 1869 über Digitalisate der seit 1861 erscheinenden Zeitschrift; andere Ausgaben konnten nicht lokalisiert werden; [http://enciclopediaroma niei.ro/wiki/Iosif_Vulcan]; BCU-Cluj-Napoca [http://documente.bcucluj.ro/web/bibdigit/perio dice/gurasatului/]. 


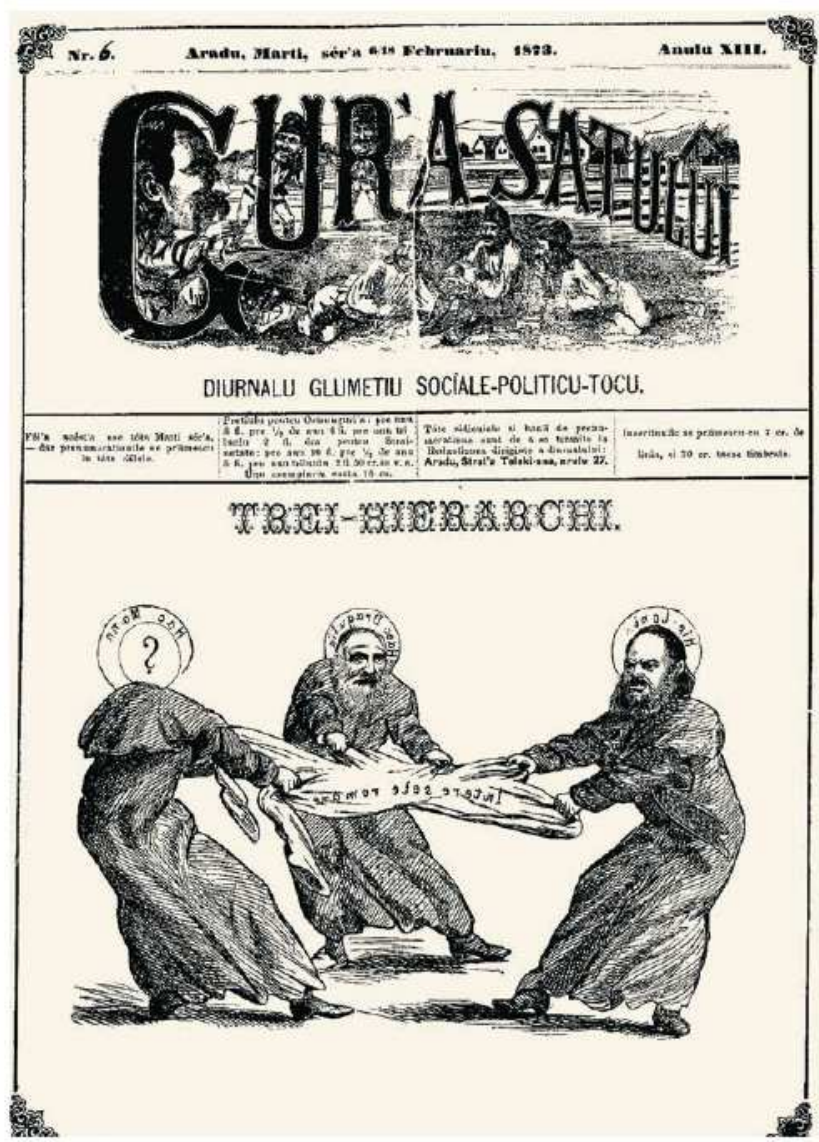

Abb. 14 - Zuständigkeit in der rumänischen Frage (Titelseite der Zeitung $u$. Text aus dem Innenteil s.u. $)^{64}$ In der Titelkarikatur des Arader Satirejournals Gura Satului streiten sich drei orthodoxe Kirchenhierarchen - wie die rōmischen Soldaten nach der Kreuzigung um die Kleider Christi - um die rumänischen Interessen (Interesele romane). Wenn man die (wegen der Zensur?) absichtlich spiegelbildliche Darstellung in ihre richtige Lage bringt, lassen sich nicht nur die Namen lesen, sondern die dargestellten Protagonisten nehmen auch geographisch ihren richtigen Platz ein, wobei die eindeutige persōnliche Zuordnung mit Unsicherheiten behaftet bleibt: Parintele Olténu (Hic loni) dürfte loan Oltean (unierter Bischof von Lugosch/Lugoj im Banat 1870-1873) sein; er geht 1873 nach Großwardein/Oradea und wird dort 1874 gr-kath. Bischof. Parintele Popasu (Haec Dragut'ia) ist wahrscheinlich loan Popazu (orthodoxer nicht unierter Bischof von Karansebesch/Caransebeş 1865-1889, dessen Bischofssitz 1865 neu eingerichtet wurde); Parintele Hakmann (Hoc-Mann) steht für den damals bereits schwerkranken Bukowiner Metropoliten, der als einziger ohne Gesicht bleibt. Ihn ersetzt der Landtagsabgeordnete der verfassungstreuen Partei seit 1871 Anton Schönbach, zuvor Sekretär des erzbischöflichen Konsistoriums ${ }^{65}$

64 Gura Satului Nr. 6 (Anul III) v. 6./18.II.1873; die Abbildung wurde freundlicher Weise von der Biblioteca Centrală Universitară "Lucian Blaga« Cluj-Napoca zur Verfügung gestellt.

65 Ceaușu 2000, Landtag, 2188 ; vgl. Anm. 59. 
Text

... Apoi da! -- Trei sfinti parinti Archierei -- si romani -- déca voimu ... Pentru ocasi’a santei dîle de "Trei-Hierarchi « n’am potutu sà presentàmu Onor. publicu romanu ceva mai potrivitu - decàtu acestu hierarchicescu trifoiu: parintele Olténu, parintele Popasu, sî parintele Hakmann, trei capi bisericesci, ce, in fórte multe privintie, sî-sémena. - Ilustratorulu nostru i-a suprinsu tocmai in momentulu, candu ei, asemena jidoviloru asupr’a vestmentului Mantuitoriului, voiescu sà se imparta asupra intereseloru romane, -deci tocmai in momentulu, candu ei voiescu sà hotarésca mesu'ra, in care fiacare d'intre dinsîi are sà dispuna asupra d'in intereseloru romane - pentru sine. Precum apare d'in ilustratiune, numai "Hic Ioni” este presentatu in genu barbatescu, pentru cà elu, alipitu catra barbatésc'a natìa magiara, mai multu domnesce pr'in frumuséti’a sà barbatésca. "Haec Dragutia" pare mai potrivitu in genulu femeiescu, de óre-ce blànd’a lui anima sî iubirea sa catra totu ce sclipesce, lu-apropia de acestu sesu. - "Hoc-Mann" firesce! - nu póte sà fia presentatu decàtu in genulu neutru, -- de óre-ce nu se scie, -- dèca este elu romanu, rusu, eroatu, némtiu ori jidanu - Lamu presentatu fara capu, càci - capului lui este Schönbach. - Fiindu Hakmann de càte-va dîle sî Metropolitu-cosmopolitu, ar' fi trebuitu sà-lu asîendiamu in medilocu: dar' noi, ne supusî usului bisericescu, amu pusu pre celu mai demnu de respect in medilocu. - Pre parintele Olténu l'amu pusu in drépta, pentru-cà dela elu totu-sî se póte asceptá mai multu bine decàtu dela - scimu dela cine! --

\section{Textübersetzung}

„Dann ja! Drei ehrwürdige hohe Geistliche - und Rumänen - wenn wir wollen ... zum Anlass des heiligen Tages zu den »drei Hierarchen « konnte man dem löblichen rumänischen Publikum nichts Angemesseneres vorzeigen - als dieses dreiteiliges Kleeblatt: der Pfarrer Olténu, der Pfarrer Popasu, und der Pfarrer Hakmann, drei führende Geistliche, welche sich in vielerlei Hinsicht ähneln. Unser Illustrator hat sie eben in dem Moment erwischt, als sie, ähnlich wie die Juden gegenüber den Gewändern Christi, sich die rumänischen Interessen aufteilen wollten, also in dem Moment, als sie das Maß beschließen wollten, in welchem jeder von ihnen über die rumänischen Interessen verfügen sollte für sich selbst. Wie es in der Abbildung erscheint, wird nur »Hic Ioni« als männliche Gestalt präsentiert, weil dieser, anhänglich gegenüber der mannhaften ungarischen Nation, eher durch seine männliche Schönheit leitet. „Haec Dragutia « erscheint angemessener als Frau, weil sein weiches Herz und die Liebe gegenüber allem was glänzt ihn diesem Geschlecht näher bringt. »Hoc-Mann«, natürlich, kann nicht anders geschildert werden als mit neutralem Geschlecht, weil man über ihn nicht weiß, ob er Rumäne, Russe, Kro- 
ate, Deutscher oder Jude ist - wir haben ihn ohne Kopf abgebildet, weil sein Kopf Schönbach ist. Da Hakmann seit ein paar Tagen Metropolit-Kosmopolit ist, hätten wir ihn in der Mitte abbilden sollen, aber wir, da wir die kirchlichen Gebräuche nicht kennen, haben den am meisten Respekt erheischenden in die Mitte gestellt. Den Pfarrer Olténu haben wir rechts gestellt, weil man von ihm viel Besseres erwarten kann als man weiß. ${ }^{66}$

\section{Metropolitanordnung \& Religionsfondsfrage}

Das siebenbürgische Bistum verfügte um 1855 über verschiedene Fonds mit einem Gesamtwert von etwa 130.000 Gulden, bis 1868 sollte dieser noch auf annähernd 300.000 Gulden anwachsen. ${ }^{67}$ Im Vergleich zu den fast neun Millionen Gulden des Bukowiner gr.-orient. Religionsfonds 1864 (bzw. mit mehr als zwölf Millionen im Jahr 1870) war das indes eine mehr als bescheidene Summe. ${ }^{68}$ Ein Zusammengehen der beiden orthodoxen Diözesen Hermannstadt und Czernowitz hätte unwillkürlich die Frage nach der Verfügungsgewalt über den gr.-orient. Religionsfonds nach sich gezogen. Eugen Hackmann hatte schon früher befürchtet, dass sich der serbische Patriarch - obwohl die Bukowina dieser Metropolie lediglich als Suffraganbistum in dogmaticis et mere spiritualibus unterstand - Zugriff zum Fonds verschaffen könnte ${ }^{69}$, ebenso wie sein Amtsbruder Schaguna:

Auch erklärte mir S. Heiligkeit, der verstorbene Patriarch Rajacic persönlich, als wir im Jahre 1860 in Wien zusammentrafen, die Absicht zu haben, aus allen Diöcesanfonden einen Zentralfond in Karlovitz zu begründen, aus welchem den materiellen Bedürfnissen aller in Osterreich befindlichen gr. or. Diöcesen gleichmässig Rechnung getragen werden sollte. Ganz dieselbe Absicht schimmert aus den romanischen Projekten und Statuten zu Hermannstadt hervor. ${ }^{70}$

Schaguna seinerseits wollte hingegen deeskalierend wirken und versicherte Hackmann im Anthorismus der »Unantastbarkeit des Religionsfondes«. An ihn diesbezüglich he-

66 Die Übersetzung hat dankenswerter Weise L.L. Madly (Cluj-Napoca) übernommen, Hervorhebungen im Original.

67 Popea 1879, Metropolie, 99; zit. nach BRUSAnOwSKI 2011, Kirchenordnungen, 202; ebenso PușCarIU 1900, Metropolia, 145 (Schreiben Schagunas an den Kaiser v. 1.XII.1855).

68 OnciUl 189o, Fondul, 677, sowie ders. 1891 Fondul, 193-204; zit. nach BrUSANOWSKI 2012 Kirchenordnungen, 202.

69 Eugen Hacman către Andrei Șaguna, Mânăstirea Putna v. 14./26.IX.1860; zit. nach BocşAN 2005, Corespondența, $53 \mathrm{f}$.

70 Motivarea propunerilor episcopului Bucovinei Eugenie Hacman la sinodul din Carloviţ, Karlovitz v. 2./14.IX.1864, abgedruckt in PUȘCA RIU 1900, Metropolia, 277. 
rangetragene politische Ansinnen dieser Art hätte er, Schaguna, darüber hinaus stets von sich gewiesen. ${ }^{71}$ Indes ließ sich jedoch Hackmanns Skepsis nicht leicht zerstreuen, "alsdann würde die Bukowiner Diöcese zusehen müssen, wie die Metropolitansynode mit ihrem Vermögen wirtschaften und welchen Theil davon sie der Bukowina zumessen würde. Alsdann würde die unmittelbare Verwaltung der zahlreichen Religionsfondsgüter in der Bukowina in die Hände einer Epitropie von 1/3 Geistlichen und 2/3 Laien fallen ${ }^{72}$

Hinter den >Laien `es Kirchenkongresses standen im Wesentlichen die rumänischen Eliten des Kronlandes, in ihrer Mehrheit Großgrundbesitzer. Die einflussreichen rumänischen Familien der Bukowina waren, wie gezeigt werden konnte, bereits durch ihren Einsatz für eine gemeinsame Metropolie und die Einrichtung einer derartigen Versammlung unter Laienbeteiligung hervorgetreten. Sie befürchteten ihrerseits eine allmähliche »Entnationalisierung « der Diözese. ${ }^{73}$ Gheorghe Hormuzaki als Berichterstatter des Landtagsausschusses zur Frage der Kirchenautonomie merkte dahingehend an, dass schon der josephinische Regulierungsplan der kanonischen Satzung weitgehend zuwiderlaufen würde, da die praktizierte Verwaltung de facto einem Entzug des Vermögens gleichkomme und Bedürfnisse oftmals erst nach Jahren an Verhandlungen wenn denn überhaupt - erfüllt werden würden. ${ }^{74}$ Ein Umstand, den der Bischof nicht gänzlich von der Hand weisen konnte, betraf ihn das doch in der Frage der baufälligen Residenz selbst. Im vorgebrachten Anliegen blieb indes, was den Religionsfonds angeht, ein ganz persönlicher Beweggrund dieser Eliten unausgesprochen. Da der Bukowiner Landtag 1861 mehrheitlich von ebendieser Gruppe dominiert war, musste der Bischof befürchten, dass dieser die Verfügungsgewalt - wenn auch im Sinne des Landes - an sich bringen könnte, woraufhin Eugen Hackmann selbst in Wien die Übertragung dieser Gewalt auf sein Amt beantragte. Das Ministerium beauftragte in der Folge den Landeschef der Bukowina mit einer Aufklärung des Sachverhaltes. Wien stellte von vornherein

71 Schaguna 1863 , Anthorismus, $14 \mathrm{f}$.

72 HaCKMANN 1864/1899, Sendschreiben, 106.

73 HormuZa KI 1870, Denkschrift, 7. Hier ist der Kontext zu den seit 1859 unter Ioan Alexandru Cuza vereinigten rumänischen Fürstentümern zu sehen. Die Reformen von 1863 führten zur Säkularisierung des Kircheneigentums (in Form von Staatsdomänen) zu Gunsten des Staates. Letztlich lief dieser Akt auf eine weitgehende Entmachtung der Kirche, zum Vorteil des Adels, hinaus. Damit stand vergleichsweise spolitisch günstiger` Grund und Boden zum Verteilen an die bäuerliche Bevölkerung für die gleichzeitig einsetzende Agrarreform zur Verfügung, ohne dass davon die Bojaren im Übermaße betroffen gewesen wären; IoRG A 2011, Vol. II, Istoria, 305-310.

74 DACZ $_{2} / 1 / 25$, Bericht des Ausschusses zur Vorberathung des Antrages in der Frage der Kirchenautonomie, Alexander von Kostin (Obmann), Georg von Hormuzaki (Berichterstatter) v. 14.II.1866; sowie Adresse des Bukowinaer Landtages an den Kaiser v. 27.III.1863. 
klar, dass die Verwaltung der Religionsfondsmittel zwar »im Namen der Kirche (nomine ecclesiae) also nicht von der Kirche« erfolgen müsse, "während die Bischöfe die ihnen gebührende Aufsicht « ausüben sollten. ${ }^{75}$ Ein Kirchenkongress in der diskutierten Form hätte diesen Kreisen zusätzlich von anderer Seite den Zugriff auf den Fonds gesichert, wie das der daraufhin erstellte Ministerialbericht zusammenfassend analysierte:

In der Bukowina herrschen in Bezug auf die Autonomie der griechisch-orientalischen Kirche zwei Parteien, deren eine aus griechisch-orientalischen Layen, die andere aus dem griechischorientalischen Clerus, der Bischof an der Spitze, besteht. Aber von jeder dieser Parteien wird die Autonomie anders verstanden. Die Layen wollen die unter ihrer Betheiligung berufene Synode vornemlich darum, um diese selbst als das zur Verwaltung des Kirchenvermögens kanonisch berufene Organ zu proklamiren, und dadurch den reichen griechisch-orientalischen Religionsfond in ihre Disposition zu bekommen. Darum hat der Großgrundbesitz insoferne ein allgemeines Interesse, als nahezu alle Mitglieder desselben und zwar mit sehr erheblichen Summen Schuldner des Religionsfonds sind. Unter dieser Partei bildet die Familienverbindung Hormuzaki eine eigene Fraktion, welche weiter geht, indem sie die innige Verbindung der Bukowina mit den übrigen Romanen und die Romanisierung des nur zur Hälfte slavischen Landes als ihr Endziel anstrebt, und die Hoffnung hegt, mittels der Synode die Vereinigung der bukowiner Romanen mit jenen Ungarns und Siebenbürgens vorläufig auf dem kirchlichen Gebiete durchzusetzen. Der griechisch-orientalische Clerus strebt aus Besorgnis vor dem der Geistlichkeit Bukowinas abholden Einflusse einer auch aus Layen zusammengesetzten Synode auf die Gebahrung des Religionsfonds und von des letzteren Ausbeutung durch die ungarischsiebenbürgische Metropolie die Selbständigkeit der Diöcese an und trachtet die entscheidende Einwirkung auf die Verwaltung des Kirchenvermögens sich selbst zu vindiciren. ${ }^{76}$

Gegenüber dem Bukowiner Oberhirten bemühte sich das Ministerium allerdings ebenso ausdrücklich festzuhalten, dass der Religionsfonds "nach den Bestimmungen des Grundgesetzes für die gr.n.u. [gr. nicht-unierte] Kirche in der Bukowina [...] jene Aufgaben zu erfüllen [habe], welche sonst den Religions-Studien- und Schulfonden zugewiesen wird. Die Verwaltung, Aufbewahrung und widmungsmäßige Verwendung desselben hängt, nach dem unzweifelhaften Wortlaute des Regulativs, blos von der

$75 \mathrm{DACZ}_{3 / 1 / 2142}$, fol. 1-2; Staatsministerium für Cultus und Unterricht an Landeschef der Bukowina Wenzel Ritter v. Martina v. 29.XII.1861; Unterstreichungen im Original.

76 OSTA-AVA, Unterricht und Kultus, Kultus Präsidium, Staatsministerium I Zl. 7267/1866; Bericht des Landeschefs der Bukowina v. 31.III.1866 Zl. 4611 Präs. nach der Zusammenfassung im Ministervortrag Belcredis v. 11.XI.1866 (Staatsministerium Zl. 2061, ad Kabinettszahl 3809); abgedruckt in NÉMETH 2012, Zhishman, 232. 
Anordnung des Landesfürsten ab [...] im Namen der Kirche [...] keineswegs aber von der Kirche«. Dem Landtag jedoch obliege darin lediglich die Sorge über Fonds aus dem eigenen Landesvermögen, nicht jedoch jenem der Kirche. Ein jeder anderslautender Beschluss - so das Ministerium warnend - wäre entsprechend eindeutig ein "Eingriff in die der Krone vorbehaltenen Rechte $«{ }^{77}$ Auf Landesebene stellte Eugen Hackmann dem Ansinnen der »Herren « das drastisch gezeichnete Bild einer überhaupt erst durch den geistlichen Regulierungsplan unter Joseph II. begründeten und darauf bis dato erblühenden Bukowina gegenüber, nicht ohne zugleich wiederholt auf die Folgen einer kirchlichen Vereinigung mit Siebenbürgen zu verweisen. Einen direkten Angriff auf die dahinterliegenden Absichten der rumänischen Großgrundbesitzer - wie sie im Ministerialbericht dezidiert geäußert worden waren und die wohl auch der Bischof kannte vermied Hackmann allerdings geschickt:

Se. Majestät weiland Kaiser Joseph II. begründete aus den bischöflichen und klösterlichen Gütern in der Bukowina, welche bis dahin brache lagen, und wobei nur einige wenige vollauf hatten, der ganze übrige Clerus aber im Elende und in der Unwissenheit, und das Volk in Finsternis, Aberglauben und in moralischer Versunkenheit verschmachtete, den heutigen Bukowiner Religionsfond und öffnete hiedurch einen reichen, unversiegbaren Born des materiellen, geistigen und religiös-moralischen Wohles für die ganze Diöcese. ${ }^{78}$

Der Bukowiner Religionsfond ist gross genug für die Bukowiner Diöcese, deren rechtmässiges Eigentum er ist. Sollte er aber auf alle Diöcesen oder nur auf die romanischen vertheilt werden, so verschwindet er und schrumpft zu einem unbedeutenden Unterstützungsbeitrage für jede derselben zusammen. Alsdann müsste die Diöcese bei ihrem großen Vermögen entweder darben oder es würde die last ihrer besseren Erhaltung grösstentheils auf das Volk fallen, wie dies in den übrigen romanischen und serbischen Diöcesen der Fall ist. Und das wünschen Sie, meine Herren, als gute Patrioten und getreue Söhne Ihrer Mutterkirche und Ihres Mutterlandes? ?9 $^{79}$

Nachdem die Adresse des Landtages von 1863 vorerst ohne Folgen geblieben war, drängte Hormuzaki drei Jahre später - ebenfalls im Landtag - auf deren neuerliche Vorlage. In geradezu drastischen Worten schilderte er nochmals die aus seiner Sicht wanormale, rechtlose Lage der Bukowinaer Landeskirche«, die eine "Befreiung der gr. or. Kir-

$77 \mathrm{DACZ}_{3 / 1 / 2142}$, fol. 29-31; Ministerium für Cultus und Unterricht an Landeschef der Bukowina Rudolf Graf Amadei v. 31.XII.1862.

78 HaCKMANn 1864/1899, Sendschreiben, 124.

79 НаскмаNN 1864/1899, Sendschreiben, 178 ; eine detaillierte Analyse aus kirchenrechtlicher Sicht zur Frage des Kirchenkongresses bietet NÉMETH 2012, Zhishman, 172-184. 
che dieser Diöcese aus der Zwangsstellung « erforderte. Der Regulierungsplan von 1786 sei nichts mehr als die "Zwangsjacke einer fremdartigen Organisation «. Zudem - so Hormuzaki weiter - würde die "Vorenthaltung ihrer Autonomie eine höchst traurige und beklagenswerthe Wirkung « zeigen, was sich in seiner Argumentation vor allem am Zustand zahlreicher Kirchen, der schlechten Versorgung der Seelsorger und der mangelnden Ausstattung der Volkschulen wie der weitgehend fehlenden Stipendien für Studierende ablesen ließe. ${ }^{80}$ Nebenbei war es dem Abgeordneten offenbar ein Anliegen, zumindest indirekt gegenüber Bischof Hackmann eine Spitze anzubringen, indem er in diesem Zusammenhang den Bau der neuen Residenz ansprach, und das nicht zuletzt auch, um damit seinerseits die vermeintlichen Ursachen der »beispiellosen Stagnation der Bukowinaer Diöcese« zu unterstreichen:

Ich muss jedoch bemerken, daß für alle diese Mängel unsere betrübte Kirche keinen Ersatz finden könne in dem Feenpallast, der als künftige bischöfliche Residenz mit einem Geldaufwande erbaut wird, der hinreichend sein würde, um alle jene baufälligen Landkirchen und nöthigen Pfarrwohnungen herzustellen. ${ }^{81}$

Mit Verweis auf das Patent vom 31. Dezember 1851 und das Diplom vom 20. Oktober 1860 erneuerte Hormuzaki - wiederum unterstützt vom Landtag - entsprechend die Forderung nach Wiederherstellung der Autonomie und der Einberufung einer Diözesanversammlung bei gleicher Beteiligung von Laien. Der damalige Landeschef Franz v. Myrbach entgegnete Hormuzaki indes, dass die ganze Angelegenheit noch in Verhandlung sei und dass der Bischof sich dazu erst vor kurzem geäußert habe. ${ }^{82}$ Die Gutachten Josef v. Zhishmans dürften die Wiener Regierung schließlich darin bestätigt haben, auf das - mit der Statutenreform bestätigte - Recht des Landesfürsten als oberster Entscheidungsinstanz in Fondangelegenheiten weiterhin zu insistieren. Mit klarem Bezug auf den zitierten Bericht des Landespräsidenten der Bukowina aus dem Jahre 1866 resümierte Zhishman in seinem Kommentar darüber an die kaiserliche Regierung:

Es wäre ein Zustand geschaffen, welchem die Regierung nicht Hand bieten könne, während andererseits die öffentliche Meinung sich gegen eine derartige Erweiterung des klerikalen Einflu-

8o StenoProt, XVI. Sitzung, IV. Session, Bukowinaer Landtag, 8.II.1866, 247-250.

81 StenoProt, XVI. Sitzung, IV. Session, Bukowinaer Landtag, 8.II.1866, 249.

82 StenoProt, XIX. Sitzung, IV. Session, Bukowinaer Landtag, 15.II.1866, 337 f.; vgl. auch DACZ 2/1/25 Bericht des Ausschusses zur Vorberathung des Antrages in der Frage der Kirchenautonomie, Alexander von Kostin (Obmann), Georg von Hormuzaki (Berichterstatter) v. 14.II.1866; Adresse des Bukowinaer Landtages an den Kaiser v. 27.III.1863. 
Bes mit Entschiedenheit aussprechen würde [...] Die weitere Voraussicht des hohen Ministeriums, daß dabei alsbald zwischen Laien (namentlich dem Großgrundbesitze, dessen Schulden an den Religionsfonds große Summen erreichen) und dem Consistorium ein Ringen um den Einfluß auf die Fondsverwaltung hervorrufen würde, dessen Fortwuchern der Regierung die mißlichsten Schwierigkeiten bereiten müßte, ist bereits bei der Feststellung der Wahlordnung eingetroffen. Schon in der ersten Sitzung vom 13. März 1871 entstand ein leidenschaftlicher Kampf zwischen den Laien und dem Klerus, weil die Ersteren zwei Drittel der Stimmen in Anspruch nahmen, während der Clerus die Hälfte derselben verlangte. ${ }^{\mathbf{8 3}}$

\section{Religionsfondsmittel \& ihre Verwendung}

Die Frage nach der Verfügungsgewalt über den Religionsfonds und seiner Mittel war indes nicht nur eine immanent landespolitische, sondern auch eine lebensweltliche, die Bischof Hackmann über die Jahrzehnte seiner Tätigkeit im Alltag begleitete. Von dieser persönlichen Ebene aus betrachtet, zeigen sich - abseits aller Debatten und Verordnungen - klar die realen Machtverhältnisse, die der Landtag nicht zu Unrecht im oben erwähnten Ausschuss kritisiert hatte. Mit der Verlegung des Bistumssitzes von Radautz nach Czernowitz mussten durch den Ärar entsprechende Gebäude in der Kreishauptstadt bereitgestellt werden. Das war keine leichte Aufgabe, da es gerade während der und durch die Landeseinrichtung in den ersten Jahrzehnten der österreichischen Herrschaft in der Bukowina an passablen, in Stein aufgeführten Bauten erklecklich mangelte, sodass selbst die höheren Behörden vielfach mit jahrelangen Provisorien auskommen mussten. Die erste bischöfliche Residenz in Czernowitz konnte trotz Verzögerungen der Baubewilligung im Amtsweg - damals noch auf Kosten des Ärars - 1783 fertiggestellt und schließlich bezogen werden. "Damit war aber « - so die nachträgliche Einschätzung des Landeshistorikers Ferdinand Zieglauer - »keine dauernde Schöpfung begründet. Es ist schwer zu sagen, ob unabwendbares Mißgeschick oder der durch allzuweit getriebene Sparsamkeit hervorgerufene geringe Kostenaufwand, oder Schleuderhaftigkeit bei der Ausführung die Schuld an dem raschen Verfalle dieses Baues trugen. Thatsache ist, daß schon fünf Jahre nach Vollendung desselben der ffliegende Schwamm « solche Verheerungen angerichtet hat, daß der, an der Nordseite gelegene hölzerne Theil der Residenz dem Einsturze nahe kam, und im Frühlinge des Jahres 1790 völlig zusammenbrach [...]. Man behalf sich Jahrzehnte lang mit einem kümmerlichen Flickwerke. ${ }^{84}$

83 Universitätsbibliothek Wien, Nachlass Zhishman, Manuskript III 786 germ. (III 354.815) Josef Zhishman, Bukowiner Kirchenkongress, Bl. 24-46 (1878); abgedruckt in NÉMETH 2012, Zhishman, 179.

84 ZIEGLAUER 1896, Bilder III, 57. Beim sfliegenden Schwamm ‘ dürfte es sich um Braun- oder Weiß- 
Da das alte Residenzgebäude seit 1842 endgültig nicht mehr bewohnbar war (vgl. Abb. 15), musste der Bischof und seine Konsistorialkanzlei in ein Privathaus verlegt werden. Dieses `dauerhafte` Provisorium schien sich nicht beheben zu lassen. Nicht nur, dass zur Mitte des 19. Jahrhunderts generell zu wenig Kubatur in Czernowitz existierte, selbst die vorhandenen Möglichkeiten waren oftmals zu teuer bzw. häufig aus hygienischen Gründen unzumutbar. Nach dem dritten Umzug innerhalb von acht Jahren sah Hackmann keine andere Möglichkeit mehr, als sich direkt mit einer drängenden Bitte an das Kultusministerium zu wenden, »damit die vor 50 Jahren zur Erbauung eines neuen, für die Würde des Bischofs angemessenen Wohngebäudes eingeleiteten Verhandlungen finalisiert « würden. ${ }^{85}$ Das Müllersche Haus, das Hackmann zu diesem Zeitpunkt bewohnte und das ihm die Behörde gegen seinen Willen zugewiesen hatte ${ }^{86}$, war als Quartier unhaltbar geworden, verbreiteten sich doch darin seiner eigenen Schilderung nach "wegen der schmalen und schlecht angebrachten Aborte solche übelriechenden Dünste, [die durch die] beinahe in allen Zimmern herrschende[n] Luftzüge für die Gesundheit gefährlich werden ${ }^{87}{ }^{87}$ Die Bukowiner Kreisadministration konnte daran jedoch vorerst nichts ändern, da das Amt bei allfälligen Reparaturen am alten Residenzgebäude mit »bedeutenden Kosten « für den Religionsfond rechnete; Kosten, die man offensichtlich dafür zu diesem Zeitpunkt nicht decken wollte. ${ }^{88}$ Auch das Angebot Hackmanns, die Miete für ein entsprechendes Gebäude, das Baron Mustazza zur Verfügung stellen würde, aus dem »für einen Bischof beschränkt bemessenen Gehalte« selbst finanzieren zu wollen, hatte keine Zustimmung der dafür zuständigen Instanz in der vorgeordneten galizischen Landesverwaltung zu erwarten. ${ }^{89}$ Der Vorschlag war durchaus nicht ungewöhnlich. Für die Einrichtungsgegenstände war der Bischof auch bereits selbst aufgekommen bzw. hatte aus Fondsmitteln dafür lediglich ein Darlehen (sic!) bewilligt bekommen. ${ }^{90}$

fäule handeln; beide Schwammarten greifen die Zellulose oder das Lignin der (in diesem Fall schon verbauten) Holzsubstanz an und vermindern damit ihre Tragfähigkeit bzw. Stabilität erheblich.

85 DACZ 1026/1/1225, fol. 1, Hackmann an Ministerium für Cultus und Unterricht v. 24.VIII./5. IX.1851.

86 DACZ 1026/1/1225, fol. 9, Gubernialverwaltung Lemberg an Hackmann v. 27.VIII.1851

87 DACZ 1026/1/1225, fol. 5, Hackmann an Landesstelle v. 30.VII./11.VIII.1851

88 DACZ 1026/1/1225, fol. 11, Kreisamt Czernowitz an Landesgubernium Lemberg v. 9.X.1851.

89 DACZ 1023/1/1225, fol. 56-61, Hackmann an Landeschef der Bukowina Baron Henninger v. 24.VIII./5.V.; sowie Kreisamt Czernowitz an Landesgouverneur Goluchowski v. 2.XII. und Hackmann an Landesgubernium Lemberg v. 2./14.XII.1851.

90 OSTA-AVA, Kultus AK gr.-or. Karton 2, 22737-1837, allerhöchster Vortrag der vereinten Hofkanzlei v. 21.IX.1837; Hackmann beantragte 3.000 fl. Gehaltsvorschuss, die ihm der Kaiser (v. 4.XI.1837) gegen Rückzahlung in 36 Monatsraten bewilligte. 


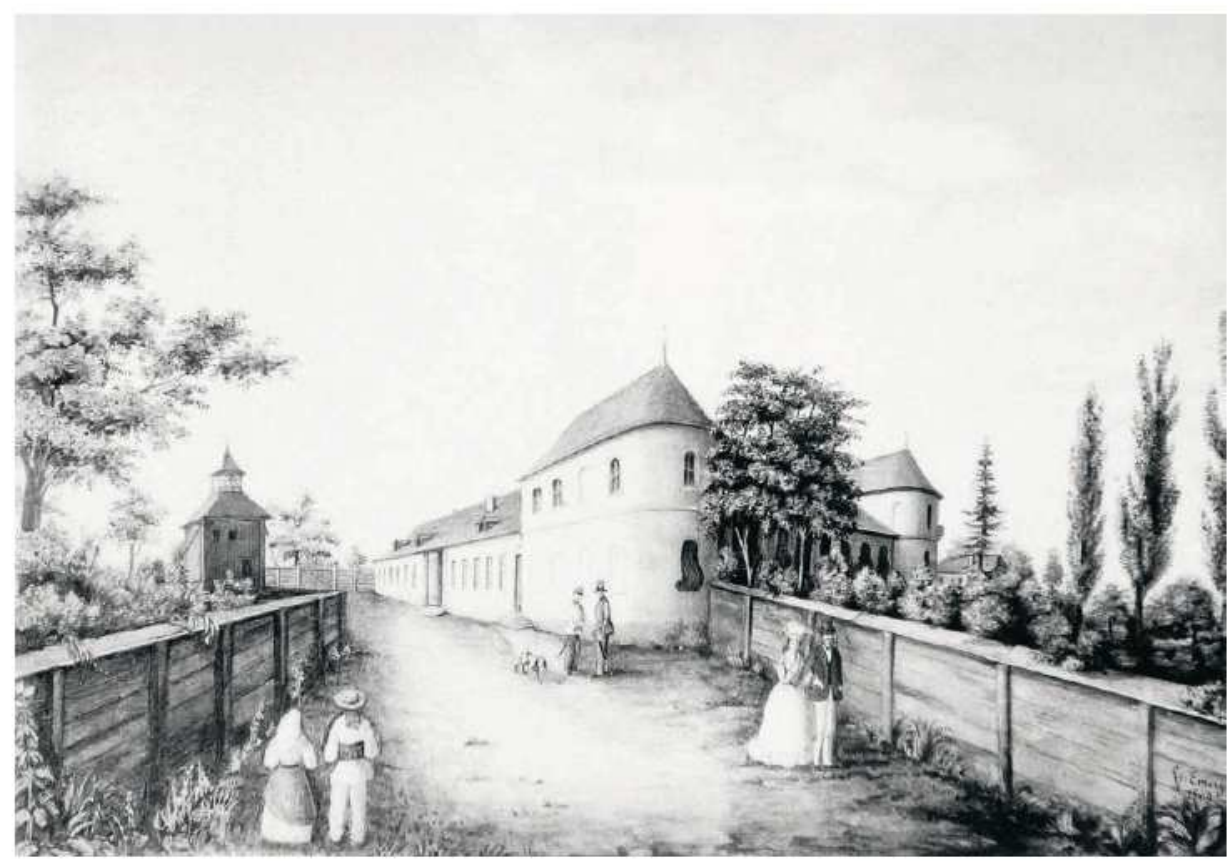

Abb. 15: Residenz des Bischofs der Bukowina in Czernowitz. Nach einer Zeichnung aus dem Jahre 1869, photographische Reproduktion L. Weinreb. (c) Universitätsarchiv Graz, Nachlass Kaindl, Karton 7.

Aus den Akten lässt sich zu diesem Sachverhalt nichts Weiteres erfahren. Es ist jedoch anzunehmen, dass sich an der für den Bischof verständlicherweise leidigen Situation bis zur Fertigstellung der neuen Residenz, dem heutigen Hauptsitz der Jurij-Fedkowitsch Nationaluniversität (seit 2011 Unesco-Weltkulturerbe), grundsätzlich in den kommenden Jahren wenig änderte; und das, obwohl das Landespräsidium bereits 1844 angesichts der Baufälligkeit der alten Residenz einem Neubau und den dafür veranschlagten Kosten von 81.000 Gulden positiv gegenübergestanden war. ${ }^{91}$ Die Grundsteinlegung für den Neubau der Residenz erfolgte erst 1864, die Finanzierung hatte der Religionsfonds zu bestreiten. Der Umstand allerdings, dass Hackmann persönlich als Bittsteller gegenüber den Behörden vorstellig werden musste, um eine Finanzierung der eigenen Residenz aus Fondsmitteln zu bewirken, dürfte ihn auch in dem Anliegen - abseits der erwähnten politischen Erwägungen -beeinflusst haben, auf eine baldige wie grundsätzliche Reform der Fondsverwaltung zu drängen. Die geschilderten Verzögerungen und

91 OSTA-AVA, Kultus AK gr.-or. Karton 2, N1023/186-1844 ad 18844-1844 Bericht an k.k. vereinte Hofkanzlei Wien v. 7.VIII.1844. 
die vergleichsweise erst spät durchgeführte Umstrukturierung sind mit einiger Wahrscheinlichkeit mit der generellen Lage der Bukowina als 19. Kreis Galizien-Lodomeriens zu erklären. Es ist anzunehmen, dass die in Lemberg residierende und der Bukowina seit dem ausgehenden 18. Jahrhundert vorgeschaltete Guberniumsverwaltung in Verbindung mit der dortigen Vorherrschaft der katholischen Kirche bzw. den polnischen Interessen auch im Bereich der gr.-orient. Landeskirche nachteilig wirkte. Erst die Aufwertung zu einem autonomen Kronland, die Trennung der Verwaltung sowie die Einrichtung eines eigenen Landtages eröffneten auch hier neue Möglichkeiten.

Die vom Landtagsabgeordneten Hormuzaki mehr oder weniger unverblümt an die Adresse der Landesregierung (und den Bischof?) gerichtete Kritik am Bau des ,Feenpalastes - der neuen Residenz - brachte indes eine innerhalb der Bukowina Eliten herrschende Uneinigkeit über die Mittelverwendung des Fonds zu diesem Zeitpunkte zu Tage. ${ }^{92}$ Ein ausführlicher Bericht des gr-orient. Konsistoriums argumentierte hingegen gegenüber den verantwortlichen Wiener Stellen minutiös die seitens des Fonds als dringend eingeforderten Investitionen. ${ }^{93}$ Mit der Pfarrregulierung von 1843 umfassten die in den Religionsfonds gehörigen Ortschaften der Bukowina in Summe 85 Pfarren sowie fünf Filialsprengel mit 84 Pfarr- und zwölf Filialkirchen. Betreut wurden diese Seelsorgestellen von 85 Pfarrern, fünf Hilfspriestern und 16 Kooperatoren. Allerdings verfügten nur 25 Pfarren über "aus hartem Materiale gemauerte Kirchengebäude«. Die überwiegende Mehrheit von 60 Kirchen bestand aus »weichem Holze« und war aus der Sicht des Konsistoriums höchst reparaturbedürftig. Ihre Errichtung lag in den $1860 e r$ Jahren bereits Jahrzehnte zurück. Die Kirchenbehörden schilderten den Zustand dieser Gotteshäuser als "hüttenartig und faßt durchgehends morsch und der Art zerüttet, daß darin besonders zu Winterszeit die Abhaltung des Gottesdienstes mit Gefahr verbunden ist, und sämmtliche nur durch Spreitzbalken gegen den gänzlichen Einsturz nothdürftig bewahret werden«. In einer ähnlich schlechten Verfassung zeichnet das Konsistorium die Unterkünfte der Seelsorger, letztere shausten` größtenteils mit ihren Familien in einfachen Bauernhütten. Wenig besser stand es mit der materiellen Ausstattung der Kirchen. Es fehlte an Büchern, liturgischen Gegenständen, Ikonen und anderem Kultusbedarf, sodass vielfach die Gemeinden in Eigenregie gezwungen waren hier auszuhelfen.

92 StenoProt, XVI. Sitzung, IV. Session, Bukowinaer Landtag am 8.II.1866, 249.

93 OSTA-AVA, Neuer Kultus NK Akath. gr-or. K22, Entwurf betreffend die Bedürfnisse der griech. orientalischen Kirchen- und Pfarrhausbaulichkeiten auf den Religionsfonds Gütern in der Buccowina (zu datieren nach 1859, spätestens jedoch 1866); die Angaben im Folgenden beziehen sich unmittelbar auf diesen Bericht, der von allen Konsistoriumsmitgliedern persönlich unterfertigt sowie von Hackmann vidiert wurde. 
Das Konsistorium sparte gegenüber Wien nicht mit Kritik, zumal sich viele der Bauvorhaben bereits geraume Zeit hinzogen und trotzdem »im Laufe so vieler Jahre die wenigsten Resultate gedihen «. Der Religionsfonds hätte demnach für die gesamte Bukowina seit 1786 für Neubau und Reparatur von Gebäuden, diverse Requisiten wie Sakristeiauslagen (Kerzenwachs, Öl etc.) lediglich knapp 244.00o Gulden aufgewendet (etwa 3.000 Gulden pro Jahr). Der durchschnittliche Bedarf pro Pfarre für die nötigsten Arbeiten bzw. Anschaffungen beliefe sich hingegen auf 31.000 Gulden, also in Summe auf über 1,8 Millionen Gulden. Argumentativ geschickt rechnete das Kirchengremium dem die jährlichen Steuereinnahmen aus den Religionsfondsherrschaften sowie den dazugehörigen Gemeinden in der Höhe von mehr als 97.00o Gulden gegen. ${ }^{94}$ Entsprechende Investitionen fehlten offensichtlich. So schließt der Bericht des Konsistoriums denn auch »mit der erfreulichen Hoffnung [...] da es dem Religionsfonde an Mitteln nicht gebricht, [dass] die baldige Beseitigung aller geschilderten Mängel erfolgen wird «.

Wie schon im Falle der den Bischof persönlich betreffenden Wohnungsfrage, zeigt sich auch bei den umfangreicheren Angelegenheiten der gr.-orient. Kirche, dass die Vorwürfe der Landtagsabgeordneten nicht gänzlich einer realen Grundlage entbehrten oder lediglich auf die Eigeninteressen der adeligen Grundherren, die vielfach wiederum dem Fonds in der Schuld standen, zurückzuführen waren. Die staatlichen Behörden agierten hier offensichtlich ebenso eigennützig. Galt ihnen die Kostenminimierung als Maxime, so schien das vorwiegend die regelmäßig wiederkehrenden Forderungen des Konsistoriums oder des Bischofs zu treffen, wohingegen Ausgaben wie der Bau der Universität in Czernowitz oder die Abgleichung von zusätzlichem, durch den Religionsfonds verursachten Verwaltungsaufwand geradezu selbstverständlich aus den Mitteln des Fonds zu finanzieren waren. Bereits früher hatte sich der Staat keineswegs gescheut, nicht unbeträchtliche Fondsmittel nach Maßgabe für politische Zwecke auch außerhalb der Bukowina einzusetzen. ${ }^{95}$ Wie schon $1811^{96}$ entrichtete der Fonds nach den verlorenen Kriegen von 1859 und 1866 neuerlich einen beträchtlichen Obolus in die leeren Staatskas-

94 OSTA-AVA, Neuer Kultus NK Akath. gr.-or. K22, Beilage zum Entwurf (vgl. Anm. 93), Ausweis Uiber die direkten Steuer[n], welche die sämmtlichen Bucowinaer g. n. u. Religionsfonds Herrschaften, und die dahin gehörigen Gemeinden alljährig bezahlen.

$95 \mathrm{Im}$ Jahr 1850 bewilligte der Ministerrat $50.000 \mathrm{fl}$. aus Mitteln des gr--orient. Religionsfonds für die dringendsten Anschaffungen von Paramenten der griechisch nicht-unierten Kirche in der Woiwodschaft Serbien und im Banat, die unter den Folgen der Revolution von 1848 besonders gelitten hatte. Dabei galt es offenbar unbedingt zu verhindern, dass Russland mit seiner Unterstützung (und damit seinem Einfluss) an (auf) den Patriarchen zuvorkomme. KLETEČKA 2005, Ministerratsprotokolle 2/2, Ministerrat v. 17.IV.1850/V, Nr. 322; 18.IV.1850/V, Nr. 323 u. 27.IV.185o/III, Nr. 331.

96 Vgl. Kap. 5 (Die wirtschaftliche Situation Mitte des 19. Jh.). 
sen. Die Initiative dazu ging allerdings in beiden Fällen von Bischof Hackmann aus. ${ }^{97}$ Dazu kam 1869 noch der Ankauf von Staatsdomänen und vormaliger Besitzungen des in die Krise geratenen Unternehmers Manz in der Südbukowina. ${ }^{98}$ Außerdem stellte das Kultusministerium dem Religionsfonds durch den Fond verursachte Mehrausgaben der Verwaltung in Rechnung. ${ }^{99}$ Ein jährlich angepasster Regiekostenausgleich "für die Agenden des Religionsfonds « war dem noch zuzuschlagen. ${ }^{100}$ Die Bukowiner Landesregierung ließ sich selbst kleinere Beträge, wie die Anschaffung eines Apparates zum "Zwecke von photographischen Aufnahmen von Kirchen und ähnlichen Objekten historischen und kunsthistorischen Wertes« aus Mitteln des Religionsfonds bezahlen, wenngleich der Verwendungszweck hier nicht ausschließlich der Kirche zugutegekommen sein dürfte. ${ }^{101} \mathrm{Im}$ Gegenzug vertraten die Wiener Behörden bei der »Bestreitung von Reisekosten und Diäten für Amtshandlungen rein kirchlicher Natur wie Kirchenwesen, Wallfahrtskosten « etc. die feste Ansicht, dass diese nicht aus Mitteln des Fonds zu bestreiten seien. ${ }^{102}$

97 NEşCIUC 1893, Istoricul, 25.

98 Vgl. Kap. 9 (Die wirtschaftliche Situation um 1938); Neșciuc gibt für 1859 eine Million Gulden an; NeşCiUC 1893, Istoricul, 22.

99 Das Ministerium bezifferte für 1899 auf drei Jahre gerechnet einen abzugeltenden Mehraufwand an Kanzleierfordernissen von 1.200 fl.; DACZ $320 / 1 / 4376$, fol. 12, k.k. Landesregierung Bukowina an Konsistorium v. 28.III.1899, Nr. 222 Präs.; fol. 17, k.k. Landespräsidium Bukowina an Konsistorium v. 6.XII.1901; sowie 320/1/4376, fol. 18, Geschäftseinlauf der k.k. Landesregierung in den Jahren 1890 bis 1901, Czernowitz 20.III.1902; fol. 19f., k.k. Landesregierung Bukowina an Konsistorium v. 20.III.1902 sowie Konsistorium an k.k. Landesregierung Bukowina v. 4.IV.1902.

100 Das Konsistorium ‘bewilligte` dafür dem Kultusministerium 18.00o Kronen (1910) p.a. und dem Ackerbauministerium 16.000 (1909); im Jahr 1902 hatte dieser über das letztere Ministerium indirekt in die Staatskassen fließende Pauschalbetrag noch 12.00o Kronen p.a. betragen; DACZ 320/1/4376, fol. 26, Direktion des Bukowiner Religionsfonds an Konsistorium, Czernowitz v. 8.XII.1902; fol. 29, dieselben, Czernowitz v. 30.III.1909 sowie k.k. Landespräsidium Bukowina an Konsistorium, Czernowitz 10.I.1910. Im Jahre 1903 scheint sich die Landesregierung auf Grund der steigenden gr--orient. Kultusagenden (die hauptsächlich mit den vielen Kirchenbauten begründet wurden) dazu entschlossen zu haben, diese Angelegenheiten aus dem Kultusdepartement auszugliedern und eine eigene Bezirkskommissarsstelle dafür einzurichten; ebenda fol. 25, k.k. Landesregierung an Konsistorium v. 4.XII.1902.

101 Dafür wurden insgesamt 1.200 Kronen und 1908 noch einmal $200 \mathrm{~K}$ an Kosten für Fotopapier etc. bewilligt; DACZ 320/1/4376, fol. 29, (Abschrift) k.k. Ministerium für Cultus und Unterricht an k.k. Landesregierung Bukowina v. 19.X.1909, Zl. 30302.

102 OSTA-AVA Kultus Neu, Akath. gr. or. K 30 , k.k. Ministerium für Cultus und Unterricht 1887, Nr. 19854 u. 17986, Ansuchen Morariu-Andrievici, Gutachten Zhishman. Dies gründet auf einer älteren Ansicht von Minister Thun, wonach der Religionsfonds dafür eigentlich nicht Verwendung finden sollte; KLETEČKA 2002, Ministerratsprotokolle II/1, Ministerrat v. 3.II.1849, Nr. 201. 


\section{Ein neues Statut für den Religionsfonds}

Die österreichischen Behörden waren - ohne indes die letztliche Verfügungsgewalt über die Mittel des Religionsfonds, die nach wie vor in den Händen des obersten Landesherren lag, abgeben zu wollen - von Beginn an daran interessiert, die anstehende wie eingeforderte Reform auf einen breiten Konsens innerhalb der Bukowina und ihrer Eliten zu begründen. So lud der Landespräsident der Bukowina als Vertreter der Wiener Zentralbehörden in Zusammenarbeit mit dem Ackerbauministerium zu einer Enquete ins Kultusministerium ein, um »über eine sach- und zeitgemäße Reform in der Verwaltung der Güter des Bucowinaer gr.or. Religionsfondes « zu beraten. ${ }^{103}$ Der Konnex zu den zeitgleich laufenden Übernahmeverhandlungen der Manzschen Bergwerke in Jakobeni (vgl. Kap. 10), die ebenfalls der Religionsfond zu tragen hatte und die wohl mithin zu dieser Enquete geführt haben, sind dabei kaum zu übersehen. An der Beratung beteiligten sich nachstehende Personen: Landespräsident Ritter v. Myrbach (Vorsitz), Eugen Hackmann (Bischof), Hugo Pramberger (k.k. Oberfinanzrat und Finanzdirektor), Dr. Albin Hammer (k.k. Oberfinanzrat und Finanzprokurator), Otto Baron Petrino (Gutseigentümer), Jakob Ritter von Petrowicz (Gutseigentümer) sowie der k.k. Regierungskonzipist Sparzistin(?) als Schriftführer. ${ }^{104}$ Der Bukowiner Landespräsident begründete die notwendig gewordene Reform damit, dass "die Resultate der bisherigen Administration der Religionsfondgüter [...] nicht die befriedigendsten gewesen « seien. Den Grund dafür ortete der Landeschef »nicht im Verschulden der kk. Finanzdirektion [...] sondern vielmehr im System « an sich. ${ }^{105}$ Petrowicz, der nach dem vorgelegten Bericht Prambergers sein Staunen über die niedrigen Wirtschaftsresultate kaum verbergen konnte, sah dafür hauptsächlich drei Ursachen. Einerseits erschien ihm die Besteuerung eines erheblichen Teils der Religionsfondsgüter, die im Gebirge gelegen waren, als »überspannt [..., so] daß viele der besteuerten Objekte nicht einmal so viel Erträgniß abwerfen als jährlich hievon an Steuern entrichtet werden muß«. Ebenso wäre der Pachtschilling zu hoch, die Dauer der Pacht zu kurz und das System der Pachtersteigerung nur dazu geeignet, »eine förmliche Raubwirtschaft « an den Gütern zu betreiben. Andererseits würden die Herrschaft Radautz und das Staatsgestüt "zu einem Spottpreis [an den Staat;

103 DACZ $_{3} / 1 / 3213$, Landespräsident der Bukowina an k.k. Oberfinanzrat Hugo Pramberger v. 10.VII.1869; sowie DACZ 320/3/2846 Landespräsident Myrbach an Hackmann 28.VII.1869, fol. 5.

$104 \mathrm{DACZ}_{321 / 1 / 13}$, Organisations-Statut für die Administration der Güter des bucowinaer gr.or. Religionsfondes (hektographierte Vorlage; fol. 1-2), Innere Einrichtung und Wirkungskreis der zur Verwaltung der Güter des bucowinaer gr.or. Religionsfondes berufenen Direction (handschriftliches Manuskript; fol. 16- 26), Protokoll über die am 9. August 1869 stattgefundene Enquette-Comission (handschriftliches Manuskript; fol. 29-38); hier fol. 29 (Protokoll).

105 DACZ $_{321 / 1 / 13}$ Protokoll, Myrbach, fol. $28 \mathrm{f}$. 
Anm. K.S.] verpachtet «. ${ }^{106}$ Pramberger räumte ein, dass die Steuerlast mit der Reform behoben und der Pachtvertrag in Radautz ohnedies aufgelöst werden würde. Auch sei ein neues Pachtsystem vorgesehen, das die bislang übliche Versteigerung der Pachtangebote, die zur unwirtschaftlichen Preistreiberei geführt hatte, nicht mehr vorsah. Zum Teil schob Pramberger die Schuld am herrschenden Pachtsystem in zeitgenössischer Manier auch den "zumeist jüdischen Gutspächtern « zu, die »ordentliche Wirtschaftsgebäude gar nicht dulden « würden. ${ }^{107}$

Das primäre Ziel von Enquete und beabsichtigter Statutenänderung lag in einer Hebung der Wirtschaftlichkeit des Fonds und damit seiner Erträgnisse, worüber alle Beteiligten wenig überraschend einer Meinung waren. Die österreichische Verwaltung vermied bei all dem ganz bewusst eine Junktimierung mit der politisch aufgeladenen Frage nach einer Kirchenautonomie. Myrbach strich in der Diskussion mehrfach diesen Aspekt heraus, vor allem als von Popowicz das Selbstverwaltungsrecht der gr--orient. Kirche als eigentlich rechtmäßigem Eigentümer der Fondsgüter beansprucht wurde. Dabei nahm der Gutsbesitzer auf das Patent von 1851 und das Staatsgrundgesetz von 1867 (RGBl. Nr. 142) Bezug, wonach jeder Religionsgemeinschaft das Recht auf Selbstverwaltung des Vermögens zu garantieren sei. ${ }^{108}$ Auch das von Bischof Hackmann vorgebrachte Ansinnen, zum Statut - vor einer abschließenden Äußerung seinerseits - zunächst die Stellungnahme des gr--orient. Konsistoriums einholen zu wollen, entkräftete Myrbach umgehend. Das Konsistorium hätte auch bisher keine Zuständigkeit gehabt und dem Bischof stünde in der Verwaltung des Religionsfonds nach wie vor ein »hervorragender Einfluß « zu, der von der Statutenänderung ohnedies nicht betroffen sei. ${ }^{109}$

Die Konsensmeinung der Enquete, »die Güter zu nachhaltig höherem Reinertrage zu bringen, um aus denselben die Zwecke des betreffenden Fonds ausgiebiger dotieren zu können «, teilte das Ackerbauministerium. Aus der Sicht ebendieser Zentralstelle wäre die oberste Leitung des Religionsfonds ohnedies zweckmäßiger im Ressort des Ackerbauministeriums anzusiedeln gewesen. Zudem sprach sich der Ackerbauminister gegen den designierten Güterdirektor Hugo Pramberger (der aus der Finanzverwaltung stammte) aus, fehlten ihm doch

106 DACZ $_{321 / 1 / 13}$ Protokoll, Pramberger/Petrowicz, fol. 32 ff.

$107 \mathrm{DACZ}_{321 / 1 / 13}$ Protokoll, Pramberger/Petrowicz, fol. 33 f.

108 DACZ 321/1/13 Protokoll, Myrbach auf Einwand Popowicz, fol. 3of.; der Bezug auf das Silvesterpatent ist zentral in der Argumentation um die Kirchenautonomie; Rede des Abgeordneten Andriewicz; StenoProt, 7. Sitzung, 1. Session, 5.VI.1867, 144.

109 DACZ $_{321 / 1 / 13}$ Protokoll, Hackmann/Myrbach, fol. 37f.; eine Weisung des Kultusministeriums versuchte hier, das Verhältnis Bischof-Konsistorium-Religionsfonds zu klären: „Nur dem Bischofe und nicht dem Konsistorium, der nur ein Beirath des Bischofs ist, und dessen Beschlüsse kanonisch für den Bischof nicht maßgebend sind, gebührt der Einfluß auf den Religionsfond, anläßlich der Vertretung der Relig. Fonds Güter am Landtage«; OSTA-AVA Kultus NK akath. gr.-or. Karton 6, Nr. 2111 C.U. 1867. 
seiner Meinung nach »alle Nachweise landwirtschaftlicher Bildung «, zudem sollte in dieser Funktion nicht eine »kameralistisch-juristische, sondern eine national-ökonomische Capacität « stehen. ${ }^{110}$ Die Wahl war zu diesem Zeitpunkt allerdings schon auf Pramberger gefallen. ${ }^{111}$ Mit kaiserlicher Entschließung vom 18. März 1870 wurde das neue Statut auch offiziell angenommen, die Entflechtung vom bisher zuständigen Finanzministerium hatte per 1. Juli d.J. zu erfolgen. ${ }^{112}$ Landespräsident Myrbach regte noch vor der Beratung den designierten Güterdirektor Pramberger dazu an, die als vorbildlich geltende Teschener (heute poln. Cieszyn) Gutswirtschaf Erzherzog Albrechts in dienstlichem Auftrag zu bereisen und zu studieren, um demensprechend Vorschläge für die nunmehr anstehende Reform der Güterverwaltung des Fonds ausarbeiten zu können. ${ }^{113}$ Die Grundlage für diese Reform bildete mit Hinweis auf den Regulierungsplan ein kaiserliches Dekret, womit ssich zugleich auch die kaiserliche Entscheidungsinstanz als solche bestätigte und außer Frage stellte:

Wenn sohin weiland Se. Majestät Kaiser Josef II. diese Güter und Fonds zur Bildung eines Religionsfondes bestimmte, so wurde damit eine Verfügung vollzogen, welche gänzlich von der Willensmeinung des Landesfürsten abhieng und deren Modalitäten auch Niemand anderer, als einzig und allein der Landesfürst festzustellen berechtigt war [...] Es ist mein Wille, dass die von Meinem Vorfahren, weiland Kaiser Joseph (sic!) II. dem Landesfürsten vorbehaltene Schutzherrschaft über den von ihm für gr.-or. Cultus und für Schulzwecke gewidmeten Bukowinaer Religionsfond, so wie auch der Grundsatz, dass bei genauer Festhaltung der widmungsmässigen Zwecke dieses Fondes, die Verwaltung, Aufbewahrung und Verwendung desselben bloss von der Anordnung des Landesfürsten abzuhängen habe, auch fortan aufrecht erhalten werde. Hiedurch soll jedoch der Fortbestand des bisher eingehaltenen Grundsatzes, vermöge dessen dem Consistorium die Einsichtnahme in die Gebahrung der Fondsverwaltung offengehalten und dasselbe über Fragen von grösserer Tragweite vor deren Entscheidung einvernommen werde, durchaus nicht alteriert werden. ${ }^{114}$

$110 \mathrm{DACZ}_{3} / 1 / 3369$ Bemerkungen des Herrn kk Ackerbauministers zur Zl. 671/präs. 1869; Ministerium für Cultus und Unterricht an Landespräsident Myrbach mit der Bitte um Berücksichtigung, bevor das neue Statut dem Kaiser vorgelegt wird, 29.XII.1869.

111 Pramberger erhielt seine Bestellung zum Finanzdirektor der Güterdirektion mit kaiserlicher Ernennung durch das kk. Ministerium für Cultus und Unterricht per 3.IV.1870 Zl. 158. DACZ 320/3/3260 Landespräsidium Bukowina an Hackmann v. 22.IV.1870, fol. 17.

$112 \mathrm{DACZ}_{3} / 1 / 3369$ Ministerium für Cultus und Unterricht an Landespräsident Myrbach v. 26.III.1870.

113 DACZ $321 / 1 / 13$ Protokoll, Myrbach, fol. 30; DACZ $3 / 1 / 3213$ Landespräsident Myrbach an Pramberger v. 10. VII.1869.

114 Allerhöchste Resolution v. 10.XII.1869 sowie Verordnung des Ministeriums für Cultus und Unterricht v. 11.I.1870, Nr. 11742; abgedruckt in ONCIUL 1891, Fondul, 208-213; StenoProt, 15. Sitzung, 5. Session, 28.I.1870, 298 (vorgelesen v. Abgeordneten Andriewicz, späterer Metropolit der Bukowina). 
Das neue Statut sah demnach vor, die oberste Leitung des Religionsfonds mit 1. Jänner 1870 in die Zuständigkeit des k.k. Ministeriums für Kultus und Unterricht zu überführen und das bisher verantwortliche Finanzministerium darin abzulösen (vgl. Statut §I). Für die selbständige Verwaltung der Güter war unter dem Titel `K.K. Direktion der Güter des bucovinaer gr. or. Religionsfondes` ein eigenes Amt in Czernowitz zu errichten $(\S I V)^{115}$, wobei dem jeweiligen Landespräsidenten der Bukowina die Funktion eines Vorstandes der Direktion zugewiesen wurde $(\$ V)$. Schließlich erhielten die in der Direktion tätigen Funktionäre ( 24 Personen, verteilt auf verschiedene Diätenklassen; vgl. Tab. 7) eine völlige rechtliche Gleichstellung mit den Staatsbeamten (\$VI). ${ }^{116}$ Der Kaiser stellte als Landesherr die oberste Verfügungsinstanz des Fonds (\$III). Der Landesfürst behielt sich das endgültige Ernennungsrecht des Güterdirektors (nach Vorschlag des Landespräsidenten und in konsultierender Rücksprache mit dem Bischof) vor (\$VIII). Damit war der staatliche Kontrollmechanismus über einen breit ausgelegten selbständigen Wirkungskreis ${ }^{117}$ der Direktion verlässlich sichergestellt. Als innere Geschäftssprache galt Deutsch. ${ }^{118}$ Dem Bischof und seinem Konsistorium gestand das Statut bei der Administration der Güter des Fonds lediglich eine in realiter beschränkt zu verstehende »normierte Mitwirkung « ein $(\$ \mathrm{XII}) .{ }^{119}$ Die Grenzen möglicher Einflussnahme, die beiden kirchlichen Institutionen dadurch sichtbar ausgesteckt wurden, erstreckten sich auf die unten angeführten Bereiche. In grundsätzlichen Entscheidungen - finanzieller wie struktureller Natur - stand sowohl dem Bischof als auch dem Konsistorium ausschließlich eine beratende Tätigkeit zu:

1. Die Übersicht über das Vermögen des Religionsfondes, die Wahrung der Interessen desselben, die Begutachtung beabsichtigter Verminderung der Substanz durch Verkauf, Tausch, Belastung, die Wahrnehmung von Gefahren und Schäden, welche den Religionsfond treffen könnten; die Äusserung über Voranschläge und Rechnungsabschlüsse des Fondes.

2. Die Erstattung von Gutachten über die Gewährung von Darlehen und Vorschüssen aus dem

115 Die Direktion wurde laut allerhöchstem Beschluss per 18.III.1870 eingerichtet; DACZ 320/3/326o, fol. 17, Landespräsidium an Hackmann v. 22.IV.1870.

116 Sowohl Konsistorialbeamte als auch Angestellte der Güterverwaltung hatten - ähnlich Staatsbeamten - einen Eid auf Kaiser, Kirche und Konsistorium abzulegen, womit sie gelobten, ihren Dienst "gewissenhaft und genau zu erfüllen, dabei stets nicht nur das Beste des Dienstes, Seiner kk Apostolischen Majestät, der gr. or. Kirche und der Bukowiner gr. or. Diözese, so wie des kk österreichischen Staates vor Augen zu haben [... und] sich stets die thunlichste Schonung des Bukowinaer gr. or. Religionsfondes angelegen sein zu lassen «; DACZ 320/3/2846, fol. 69, Diensteid 1865 .

$117 \mathrm{DACZ}_{321 / 1} / 13$, Innere Einrichtung, fol. $21 \mathrm{ff}$.

$118 \mathrm{DACZ}_{321 / 1 / 13}$, Innere Einrichtung, fol. 19.

119 DACZ $_{321 / 1 / 13}$, Organisations-Statut, fol. 1f. 
Religionsfonde, über die Verwaltungsart der Religionsfondsgüter, über die Systemisirung von bleibenden Ausgabeposten und über nicht systemisierte Ausgaben aus dem Religionsfonde.

3. Schenkungen, Vermächtnisse, Stiftungen.

4. Die Aufsicht und die Überwachung des Vermögens der einzelnen Kirchen, Klöster und Pfarren.

5. Die gesetzliche Einflussnahme auf die Regelung der Einkünfte der Geistlichen und der Stollgebühren.

6. Die Erstattung von Anträgen in Betreff der Aktivbezüge und Ruhegenüsse der im Kirchendienste stehenden Personen, so wie in Betreff der Unterstützungen und Personalzulagen für dieselben. ${ }^{120}$

Tab. 7: Personalschema der Güterdirektion nach dem Statut von $1869^{121}$

\begin{tabular}{|l|c|c|l|c|}
\hline Dienstkategorie & Anzahl & Diätklasse & \multicolumn{1}{|c|}{ Gehalt p.a. in fl. } & Wohnung \\
\hline Güterdirektor & 1 & VI. & 6000 & $\mathrm{x}$ \\
\hline Amtsverwalter & 1 & VII. & 3000 & $\mathrm{x}$ \\
\hline Forstinspektor & 1 & VII. & 3000 & $\mathrm{x}$ \\
\hline Wirtschaftsinspektor & 1 & VII. & 3000 & $\mathrm{x}$ \\
\hline Bauinspektor & 1 & VII. & 3000 & $\mathrm{x}$ \\
\hline Sekretär & 1 & VIII. & 2500 & $\mathrm{x}$ \\
\hline Bauadjunkt & 1 & $\mathrm{IX}$ & 1600 & $\mathrm{x}$ \\
\hline Forstkonzipist & 1 & $\mathrm{IX}$ & 1200 & $\mathrm{x}$ \\
\hline Konzipisten & 3 & $\mathrm{IX}$ & $1200(1000 / 800)$ & $\mathrm{x}$ \\
\hline Buchhalter & 1 & VIII. & 1600 & $\mathrm{x}$ \\
\hline Revidenten & 3 & $\mathrm{IX}$ & $1000(800 / 600)$ & $\mathrm{x}$ \\
\hline Calculanten & 3 & - & $1 f 1.50 \mathrm{x} / 1 \mathrm{fl} .20 \mathrm{x} / 1 \mathrm{fl} . / \mathrm{Tag}$ & \\
\hline Hilfsämtervorsteher & 1 & $\mathrm{IX}$ & 1000 & $\mathrm{x}$ \\
\hline Kanzleioffizial & 1 & $\mathrm{IX}$ & 700 & $\mathrm{x}$ \\
\hline Schreibgehilfe & - & - & 800 & - \\
\hline Bauzeichner & 1 & - & $1 f 1.50 \mathrm{x} /$ Tag & - \\
\hline Kanzleidiener & 2 & - & $350 / 300$ & $\mathrm{x}$ \\
\hline Kanzleidienersgehilfe & 1 & - & 250 & $\mathrm{x}$ \\
\hline
\end{tabular}

120 Allerhöchste Resolution v. 2.II.1869 (Geschäftsordnung gr--orient. Konsistorium der Bukowina); Erlass Ministerium für Cultus und Unterricht v. 5.II.1869 Nr. 924; zit. nach ONCIUL 1891, Fondul, 205 f. 121 Vereinfacht nach DACZ $321 / 1 / 13$, Innere Einrichtung, fol. 25; neben der Wohnung erhielten die Beamten mit der höchsten Diätklasse (VI. und VII.) zusätzlich diverse Real- (Brennholz) wie Pauschalvergütungen für Reisekosten sowie Mittel zur Pferde- und Wagenhaltung zugesprochen; dem Amtsverwalter standen in diesem Schema keine Pauschalvergütungen zu. 
Tab. 8 - Forstverwaltung und Forstpersonal der Religionsfondsgüter $1869^{122}$

\begin{tabular}{|c|c|c|c|c|c|c|c|}
\hline \multirow{2}{*}{$\begin{array}{l}\text { Oberforstamt } \\
\text { Sitz }\end{array}$} & \multicolumn{7}{|c|}{ Forstpersonal } \\
\hline & Förster & $\begin{array}{l}\text { Unter- } \\
\text { förster }\end{array}$ & Sitz & Reviere & $\begin{array}{l}\text { Prak- } \\
\text { tikant }\end{array}$ & Wart & Heger \\
\hline Czernowitz & 1 & - & Zuczka & Zuczka/Toporoutz & $\begin{array}{l}1 \\
-\end{array}$ & $\begin{array}{l}- \\
1\end{array}$ & $\begin{array}{l}9 \\
7\end{array}$ \\
\hline \multirow{7}{*}{$\begin{array}{l}\text { f.d. Herrschaft } \\
\text { Zuczka, } \\
\text { Kotzmann, } \\
\text { Kuczurmare, } \\
\text { Toporoutz }\end{array}$} & 1 & - & Mamajestie & $\begin{array}{l}\text { Mamajestie/ } \\
\text { Kotzmann }\end{array}$ & $\begin{array}{l}- \\
-\end{array}$ & $\begin{array}{l}- \\
1\end{array}$ & $\begin{array}{l}8 \\
5\end{array}$ \\
\hline & 1 & - & Kuczurmare & Kuczurmare & - & 1 & 7 \\
\hline & 1 & - & Franzthal & $\begin{array}{l}\text { Franzthal/ } \\
\text { Woloka }\end{array}$ & $\begin{array}{l}- \\
-\end{array}$ & $\begin{array}{l}- \\
1\end{array}$ & $\begin{array}{l}9 \\
4\end{array}$ \\
\hline & - & 1 & Tereblestie & Tereblestie & - & - & 12 \\
\hline & - & 1 & Kamenka & Kamenka & - & - & 5 \\
\hline & - & 1 & Kupka & Kupka & - & - & 7 \\
\hline & - & 1 & Krasna & Krasna & - & - & 8 \\
\hline Gurahumora & 1 & - & Frassin & Frassin & 1 & - & 7 \\
\hline \multirow{5}{*}{$\begin{array}{l}\text { f.d. Herrschaft } \\
\text { Illischestie }\end{array}$} & - & 1 & Stulpikany & Stulpikany & - & - & 8 \\
\hline & 1 & - & Kapukodruluj & $\begin{array}{l}\text { Kapukodruluj } \\
\text { Gurahumor }\end{array}$ & - & $\begin{array}{l}- \\
1\end{array}$ & $\begin{array}{l}6 \\
6\end{array}$ \\
\hline & - & 1 & Illischestie & Illischestie & - & - & 5 \\
\hline & 1 & - & Wama & Wama & - & - & 9 \\
\hline & - & 1 & Moldawica & Moldawica & - & - & 10 \\
\hline Solka & 1 & - & Mittoka & $\begin{array}{l}\text { Mittoka } \\
\text { Petroutz }\end{array}$ & $\begin{array}{l}1 \\
-\end{array}$ & $\begin{array}{l}- \\
1\end{array}$ & $\begin{array}{l}6 \\
8\end{array}$ \\
\hline \multirow[t]{3}{*}{$\begin{array}{l}\text { f.d. Herrschaft } \\
\text { Solka, St. Jllie }\end{array}$} & 1 & - & Mardzina & $\begin{array}{l}\text { Mardzina } \\
\text { Fürstenthal }\end{array}$ & - & $\begin{array}{l}- \\
1\end{array}$ & $\begin{array}{l}6 \\
7\end{array}$ \\
\hline & - & 1 & Glitt & Glitt & - & - & 8 \\
\hline & 1 & - & Ballaczana & $\begin{array}{l}\text { Ballaczana } \\
\text { Kaczyka }\end{array}$ & $\begin{array}{l}- \\
-\end{array}$ & $\begin{array}{l}- \\
1\end{array}$ & $\begin{array}{l}6 \\
7\end{array}$ \\
\hline Kimpolung & - & 1 & Kimpolung & Kimpolung & 1 & - & 8 \\
\hline \multirow[t]{3}{*}{$\begin{array}{l}\text { f.d. Herrschaft } \\
\text { Kimpolung, } \\
\text { Jakobeny }\end{array}$} & 1 & - & Pozoritta & $\begin{array}{l}\text { Pozoritta } \\
\text { Vale Putna } \\
\text { Fundule Moldowi }\end{array}$ & - & $\begin{array}{l}- \\
1 \\
1\end{array}$ & $\begin{array}{l}6 \\
4 \\
9\end{array}$ \\
\hline & 1 & - & Czokanestie & Czokanestie & - & - & 6 \\
\hline & 1 & - & Dorna & $\begin{array}{l}\text { Dorna } \\
\text { Georgiczeny }\end{array}$ & - & $\begin{array}{l}- \\
1\end{array}$ & $\begin{array}{l}5 \\
5\end{array}$ \\
\hline
\end{tabular}

$122 \mathrm{DACZ}_{3} / 1 / 3213$, fol. 12; die Schreibweise entspricht den Angaben in der Quelle. 


\begin{tabular}{|l|c|c|l|l|c|r|r|}
\hline \multirow{2}{*}{$\begin{array}{l}\text { Oberforstamt } \\
\text { Sitz }\end{array}$} & \multicolumn{7}{|c|}{ Forstpersonal } \\
\cline { 2 - 8 } & Förster & $\begin{array}{c}\text { Unter- } \\
\text { förster }\end{array}$ & \multicolumn{1}{|c|}{ Sitz } & Reviere & $\begin{array}{c}\text { Prak- } \\
\text { tikant }\end{array}$ & Wart & Heger \\
\hline \multirow{3}{*}{} & 1 & - & Pojana stampi & Pojana stampi & - & - & 5 \\
\cline { 2 - 9 } & - & 1 & Kandreny & Kandreny & - & - & 6 \\
\cline { 2 - 9 } & - & - & Jakobeny & Jakobeny & - & 1 & 5 \\
\hline & 1 & - & Czernowitz & & & & \\
\hline Summe & 15 & 10 & & & 4 & 12 & 239 \\
\hline
\end{tabular}

Der von Wien ausgesteckte Rahmen, innerhalb dessen sich mit der Reform der Statuten für den gr.-orient. Religionsfonds der Einfluss des Bischofs bzw. des Konsistoriums manifestieren konnte, war nach wie vor sehr eng gezogen. Das zeigt das Beispiel der ,Verstaatlichung der Manzschen Werke in Jakobeni, die letztlich auf Kosten des Religionsfonds stattfand, in aller Deutlichkeit (vgl. Kap. 10). Auch hatte Wien - wohl in Verbindung mit diesem Paket - die Verpflichtung des Fonds "zur Unterstützung der gr. orient. Volksschulen« erneuert. Das Konsistorium selbst konnte darüber im Grundsatz nicht bestimmen. ${ }^{123}$ Mit der gleichzeitig durchgeführten Erneuerung der Geschäftsordnung des Konsistoriums steckte der Staat klar jene Angelegenheiten ab, welche sich auf Verwaltung und Verwendung des Kirchenvermögens sowie dessen Gebarung bezogen. Letztlich war die Reform 1870 nicht zu einem Abschluss gelangt, sondern markierte lediglich einen weiteren Schritt in einem längeren Prozess der Neustrukturierung. So setzte sich etwa schon zwei Jahre später im Zuge der durch die Insolvenz der Bergwerke in Jakobeni das Ackerbauministerium mit seinem bereits früher geäußerten Wunsch durch. Die ministerielle Zuständigkeit für die Güterverwaltung des gr.-orient. Religionsfonds wanderte neuerlich, diesmal vom Kultus- ins Ackerbauministerium. Allerdings vermochte sich das Kultusministerium auch weiterhin einen Zugang in die Fondgebarung offen zu halten, soweit »dieselbe dem Wirkungskreise der Güter-Direktion entrückt und nicht rein wirtschaftlicher Natur war «. ${ }^{124}$ Größere Finanz- und Strukturentscheidungen des Fonds im Sinne des Regulierungsplanes traf damit ausschließlich Wien, und zwar im Amtswege auf Antrag des Konsistoriums oder Bischofs bzw. anderer

$123 \mathrm{DACZ}_{3} / 1 / 3442$, allerhöchste Entschließung v. 18.V.1844, sowie auf Basis des Reichsvolksschulgesetzes v. 14.V.1869, RGBl. 362 allerhöchste Entschließung v. 10.XII.1869, Widmung von Religionsfondsmitteln für Schulzwecke.

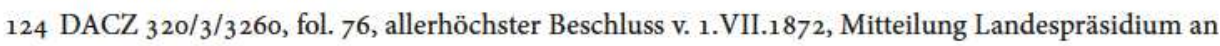
Konsistorium v. 21.VI.1872. 
Stellen, beispielsweise von Landesausschüssen, im Dreischritt Landespräsident - Ministerium - Kaiser. ${ }^{125}$

Die Übergangsphase, wie Bischof Hackmann die - einleitend zum Kapitel - mehr als zwei Jahrzehnte dauernde Periode seit den $1848 \mathrm{er}$ Jahren bezeichnete, brachte eine Reihe von richtungsweisenden Neuerungen für die gr--orient. Kirche der Bukowina mit sich. Es hat sich dabei deutlich aufzeigen lassen, dass eine klare Trennung der grundsätzlichen Fragen zur innerkirchlichen Organisation - wie sie zum einen in der Diskussion um den Kirchenkongress angeklungen ist - und der zunächst oberflächlich betrachteten Frage nach der Verwaltungsstruktur des Religionsfonds zum anderen wenig sinnvoll erscheint. Die von Hackmann gegen eine gemeinsame Metropolie mit Siebenbürgen angeführten Argumente kreisen - abseits rein kanonischer Aspekte - einerseits immer wieder um die eigentliche Machtbasis der gr-orient. Kirche der Bukowina, den Religionsfonds. Andererseits jedoch ebenso um die hier erstmals auch für Zeitgenossen wie den Bischof spürbare Sprengkraft nationaler Aspirationen, die auf diesen Fonds nicht nur seiner primär wirtschaftlichen Bedeutung wegen schielten, sondern darin folgerichtig auch eine zentrale Stellschraube für die Geschicke der Provinz und damit deren machtpolitischen Verhältnisse erkannten. Hatte Hackmann hier noch versucht, den aufdämmernden Problemen durch seine dezidierte Verfassungstreue von oben her den Nährboden zu entziehen und damit freilich gleichzeitig seine hierarchische Stellung zu konservieren, so bot sich seinen Amtsnachfolgern bereits ein gänzlich verschobener Handlungsspielraum. Die allmähliche nationale Aufladung der ökonomischen Basis der gr.-orient. Landeskirche als srumänisches` Erbe und gleichzeitig der andererseits konfessionell begründete Anspruch der orthodoxen ruthenischen Bevölkerung auf Mittel dieses Fonds blieben bis zum Zusammenbruch der Monarchie für die Bukowina bestimmend. Gleichwohl versuchte die Staatsverwaltung aus wirtschaftlichen wie aus ideellen Gründen der - zumindest in Cisleithanien im Sinne der hier nach 1867 weiterlebenden Gesamtstaatsidee einen Ausgleich zwischen den Gegensatzpaaren zu bewerkstelligen. Kirchliche Strukturen und mit ihnen die (Erz-)Bischöfe des Kronlandes unterstützen dieses Anliegen jeweils oder arbeiteten dem entgegen. Der Übergang blieb allerdings auch hier ein fließender.

125 DACZ $_{3} / 1 / 3865$, fol. 1, Landesausschuß Herzogthum Bukowina, E. Hormuzaki an Landespräsidenten v. 22.V.1873; Ministerium für Cultus und Unterricht an Landespräsidenten v. 18.VII.1873; im vorliegenden Fall betraf die Anfrage des Ausschusses ein Darlehen aus Religionsfondsmitteln (in Summe $42.500 \mathrm{fl}$. zu $3 \%$ ) zum Ankauf von Realitäten für die landwirtschaftliche Lehranstalt in Czernowitz, das mit allerhöchster Entscheidung auch bewilligt wurde. 

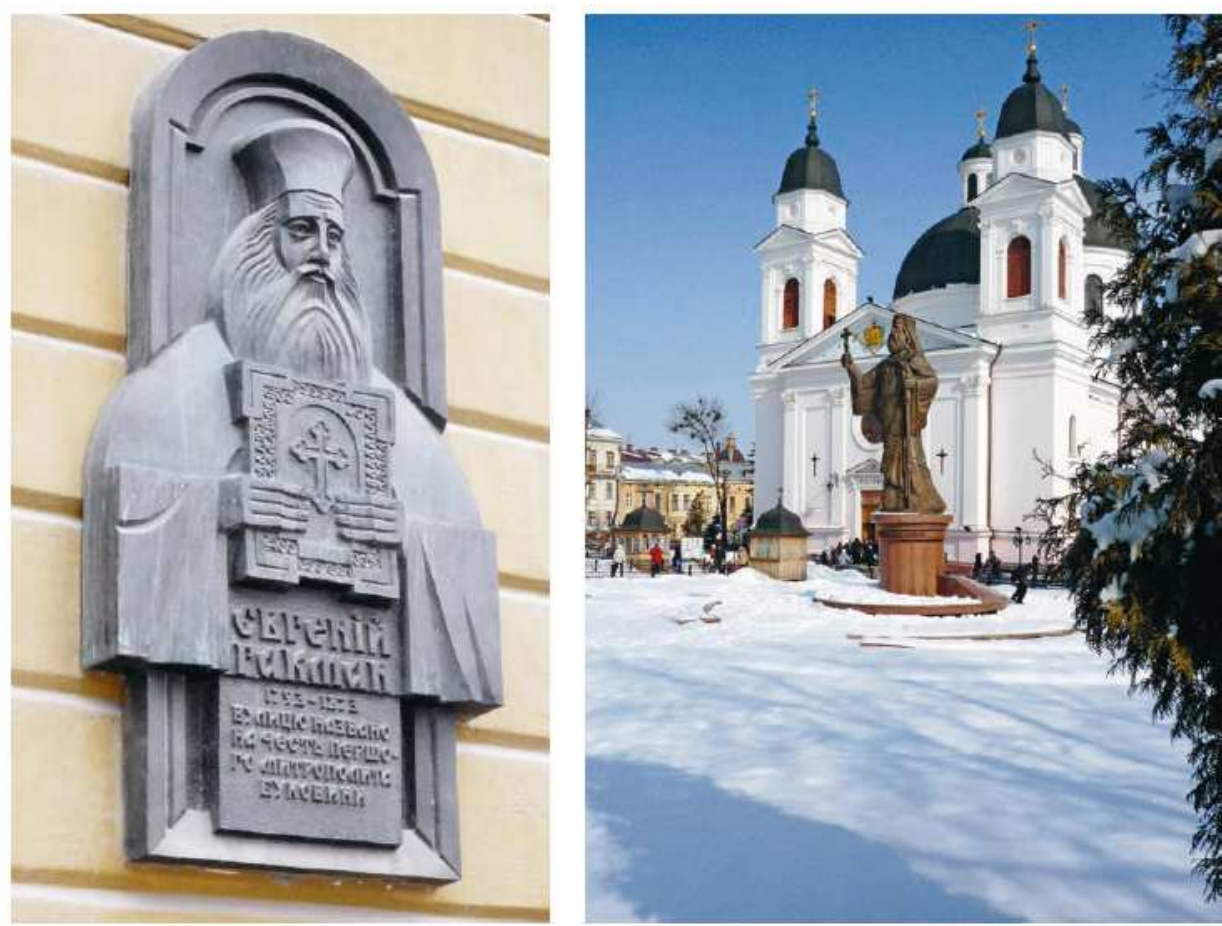

Abb. 16: Halbplastik v. E. Hackmann; Hausfassade gegenüber der heutigen (russ-orth.) Kathedrale von Czernowitz, angebracht von der ukr-orth. Kirche Kiewer Patriarchat; Aufnahme K. Scharr 2017.

Abb. 17: Bronzestatue für E. Hackmann; Hauptkirche des Moskauer Patriarchates in Czernowitz; Aufnahme K. Scharr 2017.

Im Sog nationaler Politik: Silvester Morariu-Andriewicz (1880-1895)

Obwohl Silvester Morariu-Andriewicz ${ }^{126}$ erst 1880 , sieben Jahre nach dem Tod Eugen Hackmanns, auf den Stuhl des Metropoliten nachrückte, erscheint das Hineinwirken seiner Person in die Angelegenheiten der gr.-orient. Kirche der Bukowina von wesentlich längerer, über die reine Amtszeit als Bischof hinausreichender Dauer. Für die im Lande an Virulenz gewinnende nationale Frage zwischen Rumänen und Ruthenen setzte er über die Kirche wie ihre Institutionen entscheidende Impulse, die bis zum Ausbruch des Ersten Weltkrieges für das Kronland weitgehend die politische Tagesordnung

126 Rum. Samuil Morariu-Andrievici; hier wird die Schreibweise, wie sie in den österreichischen amtlichen Quellen weitgehend Verwendung fand, herangezogen. 
der Bukowina bestimmten. Morariu-Andriewicz besetzt schon in den beiden Jahrzehnten vor seiner Berufung ins Hirtenamt, noch unter Hackmann, eine gewichtige Rolle in der Diskussion um die Frage kirchlicher Autonomiebestrebungen, des Kirchenkongresses und der Verfügungsgewalt über den Religionsfonds. Die beiden ihm vorangehenden Bischöfe, seit 1873 auch Metropoliten (der Bukowina und Dalmatiens), Theophil Bendella (1873-1875) sowie Theoctist Blazewicz (1877-1879), hatten vergleichsweise wenig bleibenden Einfluss, was zum Teil auch in der Kürze ihrer Amtszeiten begründet sein mag. ${ }^{127}$ Beide sollen hier daher lediglich im weiteren Kontext von Morariu-Andriewicz behandelt werden, auf dessen Wirken hingegen genauer eingegangen wird. ${ }^{128}$ In seiner Beziehung zu Hackmann, vor allem im Hinblick auf die Kirchenkongressfrage, ist dabei ein Fokus zu setzen, da gerade dieser Lebensabschnitt die spätere politische Agenda des künftigen Hierarchen vorzeichnete.

Der spätere Erzbischof und Metropolit stammte aus der Bukowina. Er wurde 1818 in Mitoka-Dragomirna (heute rum. Mitoca-Dragomirnei) als Sohn der gr--orient. Pfarrerfamilie Gherasim und Zamfira Morariu geboren. Der Junge bekam den Taufnamen Samuel (Samuil). Mit der Einschreibung in die Volksschule von Suczawa erhielt er den Familiennamen Andriewicz. ${ }^{129}$ Die Slawisierung seines Namens dürfte auf den Einfluss des zu dieser Zeit meist aus Galizien stammenden polnisch-sprachigen Lehrkörpers und der bis 1848 üblichen Politik der Lemberger Schulaufsicht zurück zuführen sein. ${ }^{130}$ Erst ein 1871 erlassenes Dekret der Landesverwaltung berechtigte ihn, wieder offiziell den (Doppel-)Namen Morariu(-Andriewicz) zu tragen. ${ }^{131}$ Nach seiner Schulausbildung am Gymnasium und dem theologischen Seminar in Czernowitz, wo er ab 1839 studierte, schlug Andriewicz mit der Priesterweihe 1843 die geistliche Laufbahn ein. Die erste Pfarrstelle erhielt der junge Priester 1845 in Czahor unweit der Landes-

127 Bendella hatte über Jahre hinweg gesundheitliche Probleme und konnte seine Stelle als Konsistorialarchimandrit nur bedingt ausfüllen; OSTA-AVA Kultus, NK akath. gr--or. Karton 6 ad 10322.1865 C.U.

128 Bendella (rum. Bendela) (* $\left.{ }^{*} 814\right)$, am 13.XI.1873 in das Amt des Erzbischofes sowie Metropoliten der Bukowina und Dalmatiens eingesetzt, verstorben in Franzensbad am 2.VIII.1875; Blazewicz (rum. Blajevici) $\left({ }^{*} 1807\right)$, Metropolit vom 22.III.1877 bis zum 9.VII.1879; die (Erz-)Bischöfe der Bukowina wurden in der am 7.VI.1884 fertiggestellten und aus Mitteln des gr.-orient. Religionsfonds errichteten Gruftkapelle auf dem allgemeinen Czernowitzer Friedhof bestattet bzw. nachträglich dorthin umgebettet; darunter befindet sich auch Dositheus Cherescul (rum. Dosofteiu Herescul); Bukowinaer Post Nr. 218 v. 18.IV.1895, 1-3.

129 NeșciUC 1893, Istoricul, 26; SATCO 2004, Enciclopedia, 83; Angaben aus dem Nachruf der Neuen Freien Presse Nr. 11006 v. 16.IV.1895, Morgenblatt, kleine Chronik, Titelseite.

$130 \mathrm{Zu}$ Namen, Biographie sowie zum Schaffen von Morariu-Andriewicz vgl. JACOBESCU 1995, Silvestru, 149 .

131 Dekret Nr. 1751 v. 10.V.1871; nach NeşCıUC 1893, Istoricul, 26. 

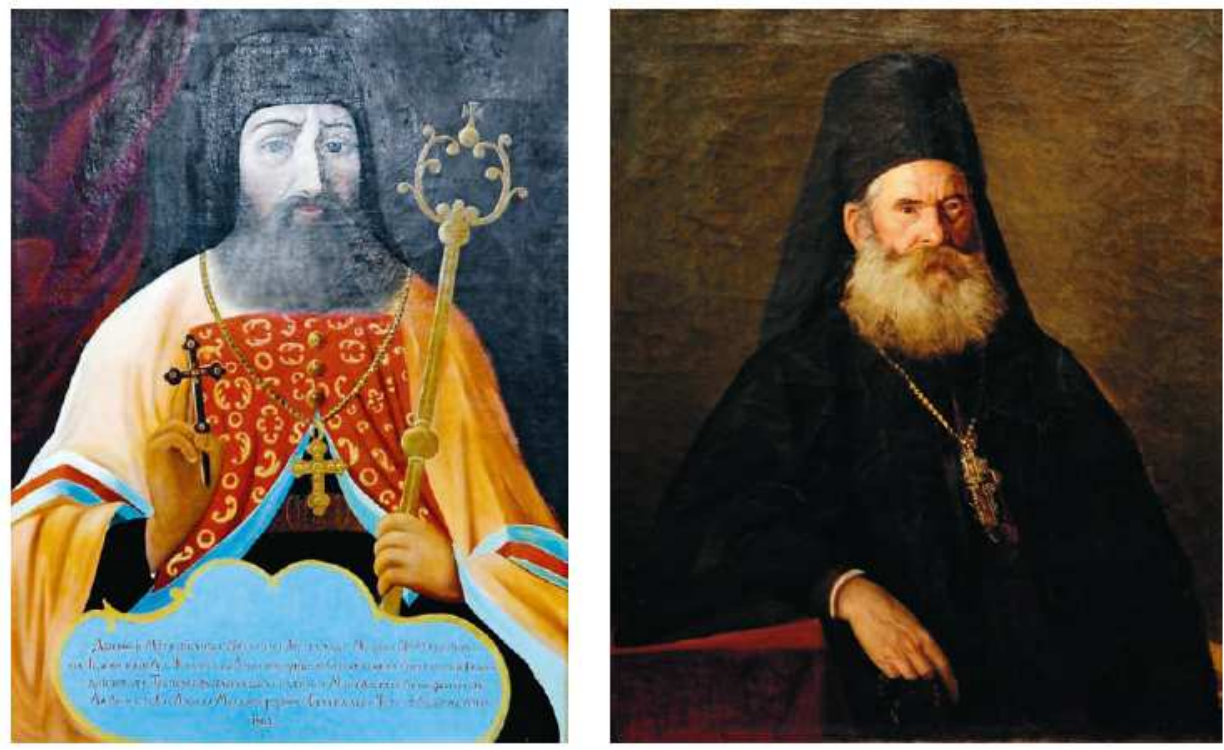

Abb. 18: Dositheus Cherescul (1710-1789), Bischof von Radautz und Hotin, erster Bischof der Bukowina (1750/1781-1789). In seine Amtszeit fällt 1783 die Rūckführung des HI. Johannes von Novi aus dem galizischen Schowkwa nach Suzcawa, darauf nimmt auch die Bildunterschrift Bezug. @ Kunstmuseum Czernowitz (KB-2446, Ж-252; mit freundlicher Abdruckgenehmigung v. 10.X.2017)

Abb. 19: Archimandrit Theoctist Blazewicz (1807-1879), Metropolit der Bukowina und Dalmatiens (1877-1879). Portrait von Epaminonda Butschewskij. @ Kunstmuseum Czernowitz (KB-2442, K-248; mit freundlicher Abdruckgenehmigung v. 10.X.2017).

hauptstadt. Mit der Ernennung zum Erzpriester 1861 und fünf Jahre später zum Mitglied des bischöflichen Konsistoriums (Konsistorialrat) übernahm Andriewicz mehr und mehr einflussreiche Positionen innerhalb der Kirchenhierarchie des Landes. Nach dem Tod seiner Gattin (1873) trat Morariu-Andriewicz 1874 als Titulararchimandrit mit dem Namen Silvester in den Regularklerus über. ${ }^{132}$ Drei Jahre später erfolgte die Ernennung zum Diözesanarchimandriten und Generalvikar der Metropolie, eine Position, aus der heraus traditionell der Bischof bestimmt wurde. Parallel dazu hatte sich der spätere Metropolit bereits einen Namen als Pädagoge erarbeitet und unter anderem zahlreiche (Schul-)Lehrbücher in deutscher wie rumänischer Sprache verfasst, deren breit gestreute Inhalte von Mathematik über Sprache bis zu katechetischen Manualen reichen. ${ }^{133}$ Als Erzbischof rief Morariu-Andriewicz 1884 die Academia Ortodoxă, eine

132 ReLI 1935, Mitropolitul, 8.

133 Aufzählung seiner Schriften bei NEșciUc 1893, Istoricul. 
Czernowitzer theologische Einrichtung, ins Leben. Die Academia widmete sich dem Unterricht des Kirchengesangs. Sie hatte ihre Wurzeln teilweise in der seit 1881 bestehenden, ebenfalls von Morariu-Andriewicz initiierten Gesellschaft Armonia. Als Dorfpfarrer in Czahor war ihm der Mangel an Schulbüchern in rumänischer Sprache und der seitens der Priesterschaft nur wenig ausgeprägte Hang, neben ihren religiösen Aufgaben auch solche der breiteren Volksbildung zu übernehmen, bewusst geworden. ${ }^{134}$ In seine Amtszeit fällt daher auch die Gründung der Candela (1882-1946), einer bilingual rumänisch-ruthenischen Zeitschrift - geführt von den Professoren der theologischen Fakultät der Universität Czernowitz - und die Einrichtung einer eigenen Druckerei 1883 mit seinem Namen. ${ }^{135}$ Beides sollte zu einer verbesserten Volksbildung beitragen.

Zugleich verfolgte der s self made man « - wie ihn ein zeitgenössischer Biograph charakterisierte $^{136}$ - mit Vehemenz seine eigenen politischen Ziele, zunächst als Vertreter des geistlichen Großgrundbesitzes mit einer Virilstimme im Bukowiner Landtag (1867) und von 1867 bis 1870 auch als Abgeordneter im Wiener Reichsrat. Mit der Ernennung bzw. Weihe zum Erzbischof und Metropoliten $1880^{137}$ war schließlich die Mitgliedschaft im Herrenhaus verbunden. Sein unablässiges Streben nach einer Verfassung und sein Eintreten für das Recht nach Selbstbestimmung der Kirche der Bukowina gehörten lebenslang zu den zentralen Anliegen des Geistlichen. Nach fünfzehn Jahren an der Spitze der gr--orient. Landeskirche verstarb Morariu-Andriewicz in seiner Residenz in Czernowitz.

Zum Ableben des Erzbischofs am 15. April 1895 erschien eine Reihe von Nachrufen in der Bukowiner Presse aber auch in anderen Zeitungen der Doppelmonarchie. Ihr Grundtenor ist, wie in solchen Texten üblich, pietätvoll und positiv. So schreibt etwa die Bukowinaer Post: "Der verblichene Kirchenfürst war ein fester Charakter, der eigene Schmied seines Glückes, der Alles was er erreichte, hauptsächlich nur sich selbst zu danken hatte. ${ }^{138}$ Das auflagenstarke und liberale Neue Wiener Tagblatt geht in seinem

134 ReLI 1935, Mitropolitul, 6.

135 Die erste Nummer der Candela [Das Ewiglicht] erschien am 1.VII.1882; GĂINA 1907, Arhiepiscopul, 14; mit dieser Zeitschrift sollte ein Kommunikationsorgan zwischen Klerikern unterschiedlicher Muttersprache geschaffen werden; TURCZYNSKI 1993, Geschichte, 173.

136 »El a fost un self made man în toată puterea cuvântului « [Er war ein self made man im vollsten Sinne des Wortes]; ein anderer Zeitgenosse, GÃINA (1907, Arhiepiscopul, 28; zum 50. Priesterjubiläum), beschreibt ihn als »un bărbat foarte erudit drept și energic « [eine Persönlichkeit hoch gelehrt, gerecht und tatkräftig]; VoRовCHIEVICI 1893, Privire, 15.

137 Ernennung am 17.III.1880; Weihe in der Dreifaltigkeitskirche (heutige Griechenkirche zur Hl. Dreifaltigkeit), Wien am 6.IV., Aufnahme in das Herrenhaus am 3.V., Inauguration Czernowitz am 8.V.1880.

138 Bukowinaer Post Nr. 218 v. 18.IV.1895, 1ff. 
Rückblick noch weiter und streicht vor allem die Toleranz des Metropoliten gegenüber der israelitischen Kultusgemeinde hervor:

Hier in Wien war der verblichene Kirchenfürst eine wohlbekannte Persönlichkeit. Er nahm stets im Hotel `Oesterreichischer Hof`Absteigequartier und Aller Blicke wandten sich nach der ehrwürdigen Priestergestalt [...] Metropolit Dr. Sylvester Morariu-Andrievici war eine durchaus vornehm angelegte Natur. Besonders ehrendes Lob sei seiner Toleranz gewidmet [...] unvergessen ist es in Czernowitz, daß, als vor einigen Jahren der Landesrabbiner Dr. Igel zu Grabe getragen wurde, Dr. Morariu-Andriewicz als Leidtragender dem Sarge zu Fuß gefolgt ist. $^{139}$

Die konservative Neue Freie Presse übernahm zwar den Großteil ihres Nachrufes aus dem offiziellen Partezettel und anderen Bukowiner Quellen ${ }^{140}$, lässt dabei indes doch durchblicken, dass Morariu-Andriewicz eine wesentlich differenzierter zu sehende Persönlichkeit war, an der sichtbar auch Konflikte ihren Angelpunkt fanden. ${ }^{141}$ Im Inhalt wesentlich deutlicher zeigt sich der Nachruf der in der ungarischen Reichshälfte erscheinenden rumänisch-sprachigen Wochenzeitung Familia, deren Titel mit einem ganzseitigen Portrait des Erzbischofs aufwartet. Hier liegt der Grundton mehr als deutlich auf der Wahrnehmung einer dezidiert national rumänischen Facette des Erzbischofs. ${ }^{142}$ Worin gründet also folglich dieser Konflikt mit Eugen Hackmann, der einerseits die Berufung von Morariu-Andriewicz auf den Sitz des Erzbischofes auf Jahre hinaus verzögerte und ihm andererseits die Achtung der rumänisch nationalen Fraktion in der Bukowina wie darüber hinaus auch in Siebenbürgen eintrug?

139 Neues Wiener Tagblatt v. 16.IV.1895, zit. nach Bukowinaer Post Nr. 219 v. 21.IV.1895, 2.

140 Darauf weist ein Druck- oder Lesefehler eines Ortes hin, Szabor statt Czahor.

141 "Die prononcierte politische Haltung war später der Grund, daß Morariu zweimal bei der Besetzung der Metropolie übergangen und erst unter dem Ministerium Taaffe zum Metropoliten ernannt wurde"; Neue Freie Presse Nr. 11006, Morgenblatt v. 16.IV.1895, kleine Chronik, Titelseite.

$142 "[\ldots]$ la 1866 reorganisându-se consistoriul [...] apoi i se deschise un teren mai larg de activitate și suş̦inênd in consistoriu o luptă desperată in contra episcopului Hackmann; îşi atrase increderea și stima tuturor românilor; dar Hackmann îl destitui $[\ldots]$ şi [...] indurară multe persecuţiuni« [1866 wurde das Konsistorium neu organisiert [...], danach eröffnete sich ein breiteres Betätigungsfeld und im Konsistorium führte man einen verzweifelten Kampf gegen Bischof Hackmann; er (i.e. Morariu-Andriewicz; Anm. K.S.) hat das Vertrauen und den Respekt aller Rumänen erworben; aber Hackmann hat ihn abgesetzt $[\ldots]$ und $[\ldots]$ er hat mehrfach Verfolgungen erleiden müssen; Übersetzung L. Madly]; Familia. Fo’ia enciclopedica si beletristica cu ilustratiuni, [Oradia-Mare/ Großwardein], Hg. v. Iosif Vulcan. Familia Anul XXXI, Nr. 15, 9./21.IV.1895, 17; für die Hilfe bei der Übersetzung der hier zitierten Texte aus dem Rumänischen ins Deutsche danke ich besonders Herrn Univ.-Prof. Dr. Rudolf Gräf (Cluj-Napoca). 


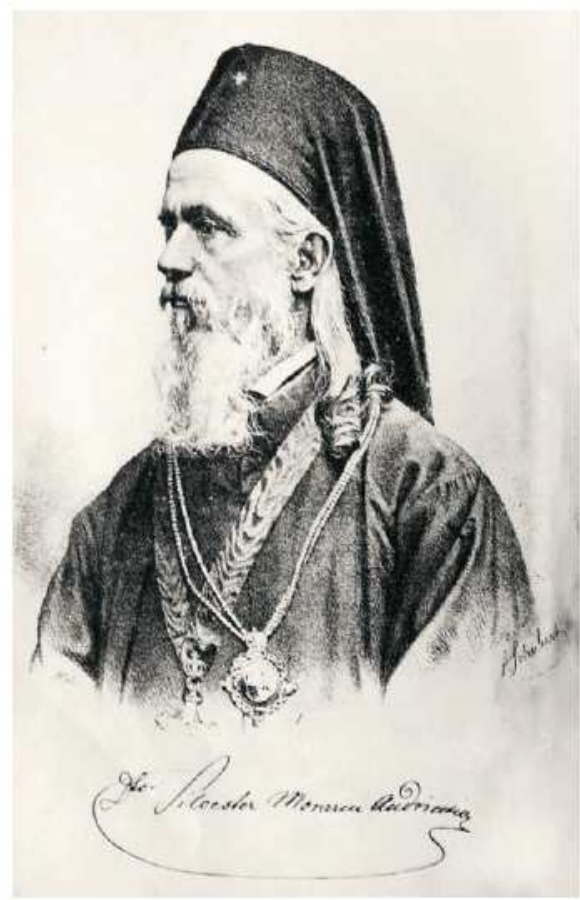

Abb. 20: Morariu-Andriewicz als Erzbischof und Metropolit der Bukowina; entnommen aus Neşciuc 1893, Istoricul.

\section{Der Konflikt mit Eugen Hackmann}

Eugen Hackmann hatte sich von Beginn seines Ordinariates an einerseits strikt gegen jedwede Nationalisierung der Diözese ausgesprochen und alle Versuche einer breiteren Mitbestimmung seitens der Gläubigen unterbunden. Andererseits erforderten die geänderten Verhältnisse sowohl das Konsistorium in seiner Struktur als auch die Kirche insgesamt neu zu regeln. Darin waren sich Kirche und Staat durchaus einig. ${ }^{143}$ Gleichwohl und das sei hier vorweggenommen - blieb letztlich die endgültige Normierung der gr.orient. Kirche in Österreich eben auch aufgrund der innerkirchlichen Differenzen in der Bukowina über das Ordinariat Morariu-Andriewicz hinaus bis 1918 eine Baustelle. ${ }^{144}$

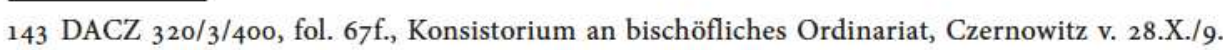
XI.1859.

144 DACZ $_{320 / 3} / 83$, fol. 17 ff. Ministerium f. Cultus und Unterricht an Morariu-Andriewicz, Wien v. 19.IX.1892; zum Verlauf der Kirchenkongressfrage vgl. BRUSANOWSKI 2011, Kirchenordnungen, 204-207. 
Die Spannung zwischen notwendiger Reform und konservativer Haltung lässt sich an einem konkreten Konflikt nachzeichnen. So hatte beispielsweise 1852 das Konsistorium versucht, national motivierte Versetzungen bzw. Einsetzungen von Pfarrern vorzunehmen, die nicht ohne Widerspruch blieben. ${ }^{145}$ Die daraus resultierenden "Spaltungen und Zerwürfnisse über der Geistlichkeit « kamen auch dem Kultusministerium zu Ohren. Wien bemühte sich um eine klare Regelung der kirchlichen Verhältnisse in der Bukowina, musste allerdings aus der Sachlage heraus in diesem Vorfall "ganz jenen Geist der Collegialität und des einträchtigen Zusammenwirkens « vermissen. Die Frage eines erneuerten Statuts, d.h. einer Kirchenordnung, war ohnedies seit Jahren anhängig. Johann Kalinczuk (1812-1875), zu diesem Zeitpunkt Professor für Dogmatik am theologischen Seminar in Czernowitz und Konsistorialassessor, hatte sich zuvor gegenüber dem Ministerium in Wien darüber beschwert, »daß sich das gr.[iechisch] n. [icht] u. [unierte] Consistorium in Czernowitz von seiner ursprünglichen Bestimmung wesentlich entferne « und daraufhin eine dringende Behebung der Übelstände verlangt. ${ }^{146}$ Daraufhin reagierte Bischof Hackmann rasch. Er ließ zunächst die Ministerialmeinung in einer Zusammenfassung allen Mitgliedern des Konsistoriums zur Kenntnis bringen. In einem zweiten Schritt nahm der Bischof zu den geäußerten Vorwürfen gegenüber dem Ministerium Stellung. Er bat in Konsequenz den Minister, ihn "von einem Hülfsarbeiter [i.e. Kalinczuk] zu befreien, zu dem ich, durch vierjährige Erfahrung überzeugt, seiner Grundsätze und seines kirchenwidrigen Wirkens wegen, [k] ein Vertrauen faßen kann, der mir in allen meinen Verfügungen entgegenarbeitet, und mir in meinem redlichen Streben, ein guter Oberhirt der Diözese zu seyn, immer ein Stein des Anstoßes ist «. ${ }^{147}$ Obwohl der eigentliche Sachverhalt aus der Quellenlage nicht mehr mit gänzlicher Klarheit herzustellen ist, bleibt anzunehmen, dass sich Kalinczuk, der später zu den führenden Mitgliedern der rumänischen Kulturgesellschaft der Bukowina zählte, zuvor gegen die Einsetzung ruthenischer Pfarrer bzw. für die Besetzung ruthenischer Pfarren mit rumänischen Priestern ausgesprochen hatte. Sowohl das eigenmächtige Handeln Kalinczuks als auch sein hier vermutet nationales Ansinnen mussten das Misstrauen des Bischofs erregt haben. In ähnlicher Weise sollte Hackmann mehr als ein Jahrzehnt später auf das, seinem Dafürhalten nach, zu eigenständige Denken und Agieren des jungen Konsistorialrates Andriewicz reagieren. Kalinczuk trat

145 DACZ $_{320 / 3 / 400}$, fol. 65, Statthalterei Lemberg an Hackmann v. 7.I.1853.

146 DACZ $320 / 3 / 400$, fol. 33, Bericht Konsistorialassessor Dimitrowicz über Ministerialerlass an Hackmann, Czernowitz v. 9.I.1852.

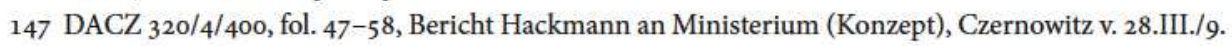
IV. 1852 , hier fol. 58 . 
später - ganz im Sinne von Andriewicz - durch ein ausführliches Gutachten über die Kirchenautonomiefrage hervor. ${ }^{148}$

Am 9. Februar 1869 kam es schließlich während einer Konsistorialsitzung zum Eklat. Der Erzpriester Constantin Popowicz hatte versucht, den notwendigen geistlichen >Mitkommissars` für eine durch das Landespräsidium eingesetzte Disziplinarkommission vorzuschlagen, um anderen zuvorzukommen. Popowicz, der im Rang niedriger stand als die anwesenden Konsistorialräte, wurde jedoch vom Vorsitzenden, dem Archimandriten Theophil Bendella, mit dem Hinweis abzuwarten, zurechtgewiesen. Daraufhin fühlte sich Popowicz »nicht als Rath, sondern als fünftes Rad « des Konsistoriums behandelt und wandte sich mit mehreren ausführlichen Begründungsschreiben für sein ihm von dritter Seite als >Ausschreitung vorgehaltenes Verhalten während der Sitzung direkt an den Bischof. ${ }^{149}$ Die eigentliche Ursache dafür findet sich in einem zu diesem Zeitpunkt schon länger schwelendem Konflikt zwischen Morariu, der seit $1866 \mathrm{dem}$ Konsistorium angehörte, und dem Bischof selbst. Die geforderte Disziplinarkommission, an der sich die Emotionen von Popowicz entzündeten, hätte eine Untersuchung der Vorwürfe gegen Morariu und ein weiteres geistliches Mitglied des Konsistoriums, Johann Zurkanowicz ${ }^{150}$, einleiten sollen. Popowicz, der sich in der »Rolle des Advokaten für Andriewicz und Zurkanowicz« sah, beschuldigte den Konsistorialsekretär Schönbach $^{151}$, „ein Laie fremder Confession «, einer Meinung mit Bendella zu sein und eigentlich auf die Absetzung zweier Mitglieder des Konsistoriums hinzuarbeiten. Gleichzeitig drohte er gegenüber dem Bischof mit der großen Popularität der beiden betroffenen Räte, für sie stünden seiner Ansicht nach »eine weit ausgebreitete und verzweigte Verwandtschaft, der größere Teil des Klerus, der ganze Adel und die romanische Intelligenz « ein. Auch - so Popowicz im selben Schreiben weiter - sei es "Andriewicz unbeschieden, daß er sich in den Reichsrath wählen ließ gegen den Willen Eurer Excellenz, daß er sich daselbst durch seine Reden und Thätigkeit hervor zu thun sucht und daß er im Bewußtsein alles dessen und seiner sonstigen auch literarischen Verdienste [...] die er aufweisen kann, lüsterne Augen auf das Bisthum wirft, während ein Anderer da ist, der ein Erbrecht darauf zu haben glaubt $« .{ }^{152}$ Damit griff Popowicz direkt den amtierenden Archimandriten Bendella an.

$148 \mathrm{DACZ}_{320 / 3 / 70}$, fol. 91-123; Joan Kalinczuk, Gutachten Kirchenautonomie, Czernowitz v. 18./30. IV.1864.

149 DACZ $_{320 / 3 / 2901}$, fol. 153f., Popowicz an Hackmann, Czernowitz v. 6./18.II.1869, sowie fol. 163f./169-172, Popowicz an Hackmann, Czernowitz v. 14./26.II.1869.

150 Konsistorialrat und Pfarrer in Alt-Mamajestie sowie Mitglied des Vereins für Landeskultur.

151 Vgl. Abb. 13.

$152 \mathrm{DACZ}_{320 / 3 / 2901}$, fol. 153 f. (s. Anm. 24). 
Andriewicz, der seit 1867 ein Reichsratsmandat in Wien hielt, hatte in dieser Eigenschaft mehrfach mit Hinweis auf den Artikel 15 des Staatsgrundgesetzes von 1867 und das Silvesterpatent von 1851 auf die Umsetzung einer selbständigen Verwaltung der gr.orient. Kirche in der Bukowina und ihrer Angelegenheiten - mithin auch des Religionsfonds - gedrängt. ${ }^{153}$ Noch im Jänner 1870 argumentierte Andriewicz in seiner Rede vor dem Reichsrat erfolglos, dass allein der jährliche Aufwand der vom Kultusministerium angestrebten Einrichtung einer Güterverwaltung des gr--orient. Religionsfond der Bukowina »in kurzer Zeit die Kräfte dieses Kirchenvermögens aufzehren müßte«. Zudem ließ Andriewicz als Abgeordneter eine Spitze gegenüber der Staatsverwaltung fallen, dass die "Verwaltung der Staatsdomainen im Allgemeinen und auch der Religionsfondgüter in der Bukowina ja erwiesenermaßen nicht die beste « sei. Der Bukowiner Geistliche appellierte geradezu an das versammelte Abgeordnetenhaus, für die $>$ Befreiung der orientalischen Kirche einzutreten:

Die orientalische Kirche braucht daher nichts, als die Befreiung von der aus der Zeit der absoluten Herrschaft herstammenden Bevormundung durch die administrativen Organe der Regierung, welche die Kirche in Allem und Jedem festhalten; sie braucht nichts, als die Lösung derjenigen Fesseln und Banden, mit welchen ihre Lebensadern unterbunden sind; sie braucht nichts als die Ermöglichung, jene Luft der constitutionellen Freiheiten einathmen zu können, welche durch die Staatsgrundgesetze gewährleistet sind. ${ }^{154}$

Das neue Statut wurde dessen ungeachtet am 18. März 1870 angenommen. Andriewicz war an den vorangegangenen, in Wien und in Czernowitz stattgefundenen Verhandlungen nicht beteiligt gewesen. Auch wenn er in manchen Teilen für ein ähnliches Ziel eintrat wie sein Bischof, so blieben gleichwohl die erheblichen Differenzen in der Ansicht der Kirchenführung gegenüber Hackmann bestehen. Um trotz allem doch die Idee einer erweiterten kirchlichen Selbstverwaltung, soweit dies das neue Statut vorsah, und die Einberufung eines Kirchenkongresses voranzutreiben, veranstaltete die rumänische Fraktion im Czernowitzer Volksgarten am 23. Juni 1870 nach einer feierlichen Messe in der Kathedrale eine öffentliche Versammlung zu diesem Thema. Die Leitung hatte Gheorghe v. Hormuzaki (1817-1882) ${ }^{155}$ übernommen. Berichten zufolge nahmen an dieser

153 StenoProt, II. Legislaturperiode, 7. Sitzung, 1. Session, 5.VI.1867, 144; StenoProt; 15. Sitzung, 5. Session, 28.I.1870, 295-300; sowie 29. Sitzung, 5. Session, 8.III.1870, 630-633.

154 StenoProt; 15. Sitzung, 5. Session, 28.I.1870, 297 u. 300.

155 Gheorghe v. Hormuzaki (rum. Hurmuzachi) war der erste Präsident der Gesellschaft für rumänische Kultur und Literatur in der Bukowina (Societatea pentru Cultura şi Literatura Română în Bucovina), gegründet 1862/1865. 
Manifestation mehrere tausend Personen teil. ${ }^{156}$ Die Rede Hormuzakis wurde bewusst ins Ruthenische gedolmetscht. Ion Sbiera - zu diesem Zeitpunkt Gymnasialprofessor in Czernowitz - sprach über die Rechte der Kirche, sich nicht nur selbst zu verwalten, sondern ebenso autonom über ihr Eigentum, den Religionsfonds, verfügen zu dürfen. ${ }^{157}$

Insgesamt müssen diese Aktionen vor dem Hintergrund der für den Sommer angesetzten Landtagswahlen verstanden werden. Insbesondere der Wahlkampf hatte Ängste der ruthenischen Bevölkerung artikuliert und zugleich geschürt. ${ }^{158}$ Dem »reichen Religionsfonde « warf man eine Vernachlässigung der Ausbildung und Versorgung Geistlicher vor, die sich ihrerseits wieder auf die Landbevölkerung übertrug. ${ }^{159}$ Die rumänische Fraktion sah sich einem Zusammenschluss von Deutschen, Polen und Ruthenen der Bukowina gegenüber und befürchtete durch deren Mehrheit politisch ausgebootet zu werden. ${ }^{160}$

Die Episode um den Kathedralprediger in Czernowitz Wasile Prodan, den der Konsistorialrat Morariu-Andriewicz ruthenischer Interessen beschuldigt hatte, war bezeich-

156 Die Albina [Die Biene] berichtet von 3000 bis 4000 Teilnehmern; Albina, V/51 21.VI./3.VII.1870, Foisiora, 1f., sowie Primulu meting in Bucovina, [Cernăuţi] 25.VI.1870, 2f.; Nistor gibt dafür 2000 Personen an, bezieht sich allerdings auch auf Angaben aus der Albina; NISTOR 1916/2003 Istoria, 89 ; bei Găina: „Prima adunare poporală în causa autonomiei bisericei dreptcredincioase din Bucovina " [Erste Volksversammlung in Sachen der Autonomie der orthodoxen Kirche der Bukowina]; GăINA 1907, Arhiepiscopul, 15.

157 Albina/Foisiora, wie Anm. 31. Die Teilnahme von Morariu-Andriewicz wird nicht explizit erwähnt, obwohl ca. 18o Pfarrer bei diesem Treffen zugegen waren. Ein Nachruf auf den späteren Metropoliten spricht nicht nur von der Gefahr, in der sich der Religionsfonds 1870 befunden hätte, sondern auch von Morariu-Andriewicz als dem Kopf dieser Versammlung: "La 1870, pe când bogatul fond religionar ajunse in pericol d'a fi inghiţt, dênsul a fost capul meetingului de protestare ţinut la Cernăuţi.« [Im Jahr 1870, als der reiche Religionsfonds in Gefahr geriet, verschlungen zu werden, war er (i.e. Morariu-Andriewicz; Anm. K.S.) es, der die Protestversammlung in Czernowitz anführte]; Familia. Fo'ia enciclopedica si beletristica cu ilustratiuni [Oradea-Mare], Anul XXXI, Nr. 15 v. 9./21.IV.1895, 177.

158 Vielfach fühlten sich die Ruthenen in ihrer Sprache gegenüber dem Rumänischen in der Kirche zurückgesetzt; " [...] die Pfarrer betrachten eben ihre Gemeinde als Melkkuh, die sie berauben und plündern können nach Herzenslust [...] Unsere geistlichen und weltlichen Behörden halten es für Recht und Pflicht, die russinische Sprache nicht bloß zu vernachlässigen, sondern geradezu zu unterdrücken [...]. Dann ist's kein Wunder, wenn unser russinische [sic!] Bauer, nach der Nationalität gefragt, antwortet: Er sei ein Russine, aber >romanischer Religion!«; Der russinische Klerus in der Bukowina. Von einem Eingeborenen; in: Zukunft. Organ für nationale konstitutionelle und volkswirthschaftliche Interessen VII. Jg. Nr. 166 [Wien] v. 23.VII.1870, 1 f.; DACZ 320/3/4, fol. 14 .

159 Flugblatt, Vordruck "Euer Wohlgeboren!«, Russisches Comitè 1870; DACZ 320/3/4, fol. 7 .

160 Die Neue Freie Presse berichtete darüber, bezieht allerdings gegen die Rumänen Stellung; Deutsche, Polen und Ruthenen »bilden eine imposante Majorität im ganzen Kronlande gegenüber den durch ihre eigenen Machinationen nunmehr isolirt [sic!] dastehenden Rumänen«; Neue Freie Presse Nr. 2095 v. 29.VI.1870, 5. 
nend für die gegenseitigen Ängste in dieser aufgeladenen Stimmung. Als Vorstand der Czernowitzer Rus'ka Besida - eines ruthenischen Kulturvereins - hätte der Kathedralprediger eine "Gefahr für die gr.-or. Kirche heraufbeschworen«. Darin bahnte sich aus der Sicht von Morariu-Andriewicz ein Zusammengehen mit den Unierten an. Diese Anschuldigungen wies das Konsistorium jedoch als gegenstandslos zurück. ${ }^{161}$

Damit hatte Morariu-Andriewicz schließlich in mehrfacher Weise klar den historischen Führungs- und Verfügungsanspruch der rumänischen Bevölkerungsgruppe in der Bukowina formuliert, jedenfalls aber innerhalb der gr.-orient. Landeskirche dafür sichtbar einen politischen Raum geschaffen. Die Forderung nach Einführung des Rumänischen als gleichberechtigte Debattensprache im Bukowiner Landtag hatte MorariuAndriewicz schon im Jahr zuvor erhoben. ${ }^{162}$ Zugleich bekräftigte diese Haltung seine Fundamentalopposition zu Hackmann:

Man sagt, die Bukowina sei ein Oesterreich in Miniatur. Ich gebe dies vollständig zu. Da sind neben der Stammbevölkerung des Landes romanischer Nationalität und griechisch-orientalischen Cultus mehrere Zungen und Confessionen des Reiches vertreten. Es wäre aber, meine Herren, zu wünschen, daß die Romanen und die griechisch-orientalische Kirche als nationale und confessionelle Minorität im Reiche so betrachtet werden und sich so wohl befinden mögen, wie die nationalen und confessionellen Minoritäten in der Bukowina, einem mit dem Glanze der Civilisation nicht prunkenden Lande sich befinden [...]. Und wie kränkend dieses für eine Kirche ist, welche den größten Theil der Bevölkerung des Landes, einen selbstbewußten Clerus, den Kern der Intelligenz und die Familen [sic!] des Adels in ihrem Schoße zählt, das läßt sich, meine Herren, leicht denken, aber nicht so leicht aussprechen. ${ }^{163}$

Sowohl dieses eigenständige politische Agieren von Morariu-Andriewicz als auch seine deklariert national-rumänische Position verschärften den ohnedies bereits seit Jahren anhängigen Konflikt mit dem Bischof, der sich ausdrücklich gegen einen Kirchenkongress positioniert hatte. Hackmann musste als Kirchenoberhaupt in einer erweiterten Autonomie und den damit unweigerlich einhergehenden Forderungen nach Laienbeteiligung seine umfassenden Rechte als Hierarch gefährdet sehen. Aus der bischöflichen Perspektive hätte die Nationalisierung der Kirche dadurch zusätzlich an Fahrt aufge-

161 DACZ $_{320 / 3 / 4}$, fol. 52-95 u. 101; Wasile Prodan an Konsistorium v. 10./22.II.1871; sowie Beschlussfassung Konsistorium v. 10./22.V.1873

162 Sitzung des Bukowiner Landtages v. 21.X.1869; nach GĂINA 1907, Arhiepiscopul, 11.

163 StenoProt, Abgeordnetenhaus, 15. Sitzung, 5. Session, 28.I.1870, 299 (Rede Abgeordneter Andriewicz). 
nommen und in Konsequenz dessen wäre für ihn eine Spaltung der Diözese und ihrer Gläubigen zunehmend unausweichlich geworden.

Noch vor der entscheidenden Konsistorialsitzung, die auf einen offenen Streit hinauslief, hatte Morariu-Andriewicz das Gespräch mit seinem Bischof gesucht und gezielt danach getrachtet, Hackmann im Sinne der "Eintracht und Ordnungsmäßigkeit « der Diözesanbehörde von der Einsetzung einer Disziplinarkommission abzubringen. Da sich Morariu-Andriewicz zuvor gegen die Wahl des amtierenden Konsistorialsekretärs gestellt hatte, vermutete er als Antrieb hinter der Eskalation der momentanen Situation Schönbachs "Aufstachelungen " und einen durch denselben "künstlich geschürrten [sic!] Ingrimm des hochwürdigen Herrn Bischofs«. Deutlich gab Andriewicz, der sich in die Enge getrieben fühlte, seinem Bischof indes zu verstehen, dass er gezwungenermaßen durchaus dazu bereit sei, »das Bild unserer kirchlichen Administration seit dem Jahre $1835^{164}$ bis jetzt zu entrollen und daran all' die schwarzen wie wohlbekannten Punkte zum Vorschein zu bringen«. Darüber hinaus verwehrte sich Morariu-Andriewicz aufs Entschiedenste gegen eine Mitsprache der eigenen Diözesanbehörde auf die Zusammensetzung der Disziplinarkommission. Gegebenenfalls müsse er »die Sache vor die Öffentlichkeit im Reichsrathe « bringen. ${ }^{165}$

Der Konflikt selbst war zu diesem Zeitpunkt allerdings bereits in der Öffentlichkeit angelangt. Die mehrmals wöchentlich erscheinende Albina ${ }^{166}$ - eine Zeitschrift der siebenbürgischen Rumänen - wohl schon durch den vorangegangenen Diskurs zwischen Schaguna und Hackmann auf diese Situation aufmerksam geworden - berichtete darüber. Auch die Albina vertrat unter Bezug auf das Silvesterpatent die Ansicht, dass die Kirche sich und ihr Vermögen selbst verwalten sollte. Ungeachtet dessen existiere im »todten Buchstaben « der Verfassung - wie es Andriewicz bezeichnete ${ }^{167}$ - immer noch eine »unnatürliche Abhängigkeit« der Kirche und des Fonds, dessen Hauptaufgabe eigentlich in der Unterstützung des "unglücklichen Volkes« bestünde - so die Albina im weiteren Wortlaut. ${ }^{168}$ Ebenso artikulierte die Zeitschrift vor allem den als >selbst-

1641835 war das Jahr der Inthronisation Hackmanns als Bischof der Bukowina.

165 DACZ $_{320 / 3 / 2901}$, fol. 157 f., Andriewicz an Hackmann, Wien v. 1./13.II.1869 [Abschrift].

166 Albina. Ziar al românilor din Transilvania [Zeitung der Rumänen Siebenbürgens]; erschien zunächst (27.III.1866 bis 14.VII.1869) dreimal wöchentlich in Wien und danach zweimal pro Woche in Pest (16.VII.1869 bis 31.XII.1876), redigiert wurde das Journal von Georgiu Popp (1866-1869) und Vincențiu Babeș (1870-1876), als Herausgeber fungierte Vasile Grigoroviță; Angaben nach Biblioteca Digitala BCU-Cluj.

167 Andriewicz, StenoProt; 15. Sitzung, 5. Session, 28.I.1870, 295-300.

168 »Fondulu relegiunariu alu Bucovinei ar fi fostu de unu deplinu si destulu te tempuriu ajutoriu nenoricitului poporu, alu carnia-a buni si strabuni parinti, ha si generatiunea de fatia, acestu fondu 
verständlich vertretenen rumänisch nationalen Charakter der gesamten Bukowiner gr.-orient. Diözese und ihrer Institutionen, den Kampf gegen den "absolutistischen Hierarchen « sowie den »Versuch der Slawisierung « ${ }^{169}$ Die Pester Satirezeitschrift Gura Satului widmete dem innerkirchlichen Konflikt der Bukowina gar einen komödiantischen Einakter - bewusst in einem rumänisch-deutschen Kauderwelsch gehalten - mit dem polemischen Titel »Bukowinaer Kriechertum«. Die beiden Hauptfiguren Pechentiuk (Bischof von Radautz) und Secretarienbach (Sekretär des berühmten Pechentiuk) spielen darin, ohne ein Blatt vor den Mund zu nehmen, ganz offen auf Hackmann und Schönbach an. Schönbach habe sich - so der Einakter - zum Dank für seine Treue vom Bischof ein Haus mit Ziegeln von der erzbischöflichen Residenz sowie aus Religionsfondsmitteln erbauen lassen. ${ }^{170}$

Das Landespräsidium der Bukowina listete schließlich die gegen Morariu-Andriewicz in Anschlag gebrachten Vorwürfe auf: Unterschlagung von Amtsschriften, Aufhetzung schuldbarer Priester, Überschreitung des Wirkungskreise und Veruntreuung von Gemeinde- und Amtsgeldern. ${ }^{171}$ Nach Meinung des Bischofs sollten die Erhebungen

relegiunariu l'au creatu si multitut, ca ‘beseric'a g.or. - societatea adeca a acestei beserice, sê se foloséasca déa elu in causele lu cele vitale « [Der Religionsfonds der Bukowina war eine umfassende und ausreichend frühe Hilfe für das unglückliche Volk, dessen gute Eltern und Urgroßeltern so wie auch die heutige Generation diesen Fonds gegründet und vermehret haben, damit die gr.-orth. Kirche - also die Mitglieder (Gesellschaft) dieser Kirche ihn für ihre lebenswichtigen Notwendigkeiten nutzen sollen.]; Albina I/21, 27.V./8.VI.1866, Bucovina, if.

169 "In dram’a de dóedieci de ani a bisericei ortodocse din Bucovina, carea infatisiédia luptáa principiului de sinodalitate in contra absolutismului ierearchicu, totu o data si salvarea caracterului natiunale romanu alu diecesei bucovinene contra incercariloru slavisatórie, vediuramu desfasiurandu-se astadi in senatulu imperiale unu actu, care ne face a crede cà e dejá aprópe diu’a de mantuire a noului Israilu din Bucovina de suferintiele indelungate « [Mit dem zwanzigjährigen Drama der orthodoxen Kirche der Bukowina, das sich im Kampfe um das Prinzip der Synodalität gegen den hierarchischen Absolutismus geäußert hat, geht die Rettung des nationalen rumänischen Charakters der Diözese der Bukowina gegen die slawisierenden Versuche einher. Heute sehen wir im Reichsrat einen Akt, der uns glauben lässt, dass der Tag der Erlösung des neuen Israels der Bukowina von seinem langen Leiden schon nahe ist.]; Albina III/61, 9./21.VI.1868, Caus'a autonomiei biserici gr. or. din Bucovina'a in senatului imperiale, if.

170 "Ciocoii Bucovinei. Comedia in un actu"; Scena II, Secretarienbach: "si vladică m’a facutu o casa cu caramidile de la Residenz - Saperment! Da habe ich auch frumosa casa pe perde lui Religionsfond.« [Die Emporkömmlinge der Bukowina. Komödie in einem Akt. Szene II, Sekretarienbach: "Und der Herr hat mir ein Haus aus Ziegeln der Residenz gabaut (d.h., die von der Residenz stammen; Anm. K.S.) - Saperment! Da habe ich auch ein schönes Haus auf Kosten des Religionsfonds]; Gura Satului Nr. 17 v. 10./22.V.1868, 66; Abschrift zit. nach DACZ 320/3/2901, fol. 165-167.

171 Landespräsidium v. 30 .XII.1868, Z. 2292 ; zit. nach DACZ $320 / 3 / 2901$, fol. 198 ; eine detaillierte Darlegung aller Anschuldigungen (auf Basis des Berichtes der Disziplinarkommission?) findet sich 
durch einen Rat der Landesbehörde unter Hinzuziehung eines "geistlichen Mitkommissärs « durchgeführt werden. ${ }^{172}$ Die Idee der politischen Behörde, von Hackmann dazu lediglich eine Stellungnahme einzufordern ${ }^{173}$, empfand der Hierarch, der sich in dieser Angelegenheit sehr wohl als zuständig sah, aus kanonischer Perspektive als eine "Zumuthung«. Denn, so Hackmann weiter, »hier klagt nicht ein Kleriker seinen Bischof an, sondern es ist der Bischof, welcher gemäß den kirchlichen Satzungen gegen einen mehrerer Vergehen beschuldigten Kleriker das Disciplinarverfahren zu veranlassen verpflichtet ist «. ${ }^{174}$ Letztlich designierte der Bischof den Archimandriten Bendella als ,Mitkommissär`, der gemeinsam mit einem politischen Vertreter der Landesregierung die Kommission übernahm. ${ }^{175}$ Die Einwendungen von Morariu-Andriewicz, wonach das übergeordnete und aus seiner Sicht unparteiische Metropolitankonsistorium von Karlowitz ein Mitglied entsenden sollte, ließ das Ministerium nicht gelten. ${ }^{176}$ Die damit schließlich eingerichtete Disziplinarkommission sprach sich in ihrer Beschlussfassung für die Verlängerung der sowohl gegen Morariu-Andriewicz als auch Zurkanowicz bestehenden Suspendierungen $a b$ officio und $a$ sacris aus. ${ }^{177}$ Gegen Morariu-Andriewicz waren schon in den Jahren zuvor heftige Vorwürfe beim Ministerium laut geworden. Diese hatten ihn, ob nun der Wahrheit entsprechend oder nicht, für die Stelle eines Archimandriten vorerst desavouiert und wohl bewusst im Vorfeld den Boden für diese Entscheidung dahingehend aufbereitet. Hingegen wurde Czuperkowicz als geeigneter Bischofskandidat ins Spiel gebracht. ${ }^{178}$ Als Reaktion darauf nominierte das rumänische

unter Erkenntnis Landespräsident v. 7.VIII.1873 Z. 1151 Präs. (Abschrift); DACZ 320/3/2901, fol. 308-320.

172 "Bemerkungen des Bukowinaer Bischofs über die vom Consistorialrathe Samuil Andriewicz bei dem Hohen Cultus-Ministerium sub präs: $25 . I I .1869$ Nr. 101. Präs: überreichte Excipirung dieses Bischofes und des ganzen bischöflichen Consistoriums von der Einflussnahme auf die gegen den Excipienten angeordnete Disciplinaruntersuchung «, Czernowitz v. 14./26.X.1869; DACZ 320/3/2901, fol. 195-212.

173 Landespräsidium Bukowina an Konsistorium v. 3.III.1869; DACZ 320/3/2901, fol. 169.

174 DACZ $_{320 / 3 / 2901}$, fol. 195-212 (wie Anm. 24).

175 Hackmann v. 31.X.1869, ZZ 420 u. 190; DACZ $320 / 3 / 2901$, fol. 227.

176 Landespräsidium Bukowina an Hackmann, Czernowitz v. 7.VII.1870, Z 1032 Präs.; DACZ 320/3/2901, fol. 226; die Eingabe von Andriewicz war am 21.II.1869 an das Ministerium f. Cultus und Unterricht erfolgt.

177 Suspendierung vom Dienst im Konsistorium (Enthebung von der erzpriesterlichen Geschäftsführung am 19./31.II.1867) als auch eine Verbannung vom Altar als Pfarrer; Sitzung Disziplinarkommission v. 17./29.VIII.1871; DACZ 320/3/2901, fol. 255-257.

178 OSTA-AVA, Kultus NK akath. gr.-or. Karton 6, Ministerium des Cultus und Unterrichtes, 8341/144 v. 30.V.1856; Weltpriester Prokopowicz an Ministerium, Czernowitz v. 21.V.1856. 
nationale Wahlkomitee Morariu-Andriewicz neuerlich als Abgeordneten zum Landtag der Bukowina. ${ }^{179}$

Im Frühjahr 1872 hatte der von Morariu-Andriewicz wohl als zermürbend empfundene Prozess gegen ihn immer noch keine Ende gefunden, zudem kannte er offiziell die vorgebrachten Klagpunkte nach wie vor nicht. ${ }^{180}$ Erst im Jänner 1873 , kurz vor dem Ableben Hackmanns, richtete Morariu-Andriewicz (auch im Namen von Zurkanowicz) einen Brief an seinen Bischof, den mittlerweile designierten Metropoliten:

Es sind bereits fünf Jahre, seit dem Eure Excellenz befunden haben, uns die väterliche Gnade zu entziehen [und wir die] Zuchtruthe der Suspension durch 16 Monathe empfunden haben, daher »wagen wir [...] zum dritten Mahle an die Pforten des väterlichen Herzens Eurer Excellenz zu pochen und um wohlwollenden Einlaß in den Tempel der evangelischen Liebe zu bitten. ${ }^{181}$

Der Landespräsident - Hackmann war mittlerweile verstorben - bestätigte erst im August 1873 die meisten Vorwürfe gegenüber Morariu-Andriewicz. Den für das Konsistorium und für Hackmann wahrscheinlich zentralen Punkt, die »Herbeiführung von nationalen Parteiungen und [die] feindliche Spaltung der Diözese, Aufhetzung schuldbarer Priester gegen ihre kirchliche Autorität «, erachtete die Behörde hingegen als "nicht genügend erwiesen«. Die Suspendierung $a$ sacris und $a b$ officio wurde aufgehoben. Morariu-Andriewicz konnte den Titel eines Konsistorialrates behalten, vom Konsistorialdienste blieb er allerdings vorläufig noch enthoben. ${ }^{182}$ Das sollte sich erst mit seinem Übertritt in den Regularklerus im darauffolgenden Jahr ändern.

\section{Erzbischof \& Metropolit}

Zwei Jahre nach der Ernennung zum Archimandriten nahm Morariu-Andriewicz 1879 mit allerhöchster Resolution die Ehrendoktorwürde der theologischen Fakultät der

179 "Comitetul are deci onoarea a Vă propune după seriosă dejudecare a tuturor împrejurărilor, și a calităţilor D.Sale, pre Domnul Samuil Andrievicu Moraru de candidat de deputat pentru ţinutul.« [Das Komitee hat nach langen Untersuchungen aller Umstände sowie seiner Qualitäten die Ehre, Herrn Samuil Andrievicu Moraru als Kandidat für den Kreis vorzuschlagen]; Comitetul naţional de alegeri an Andriewicz, Cernăuți v. 5./12.XII.1871; DACZ 320/3/2901, fol. 264.

180 Andriewicz an Hackmann, Czernowitz v. 2./14.IV.1872; DACZ 320/3/2901, fol. 268-271.

181 Andriewicz/Zurkanowitz an Hackmann, Wien v. 16./28.I.1873; DACZ 320/3/2901, fol. 299 f.

182 Erkenntnis Landespräsident v. 7.VIII.1873 Z. 1151 Präs. (Abschrift); DACZ 320/3/2901, fol. 312; die Suspendierung gegen Zurkanowicz wurde mit gleichem Datum aufgehoben; Erkenntnis Landespräsident, Z. 1178 Präs. (Abschrift); DACZ 320/3/2901, fol. 316. 
Alma Mater Francisco-Josephina (der Universität von Czernowitz) entgegen. Damit dürfte der Geistliche endgültig rehabilitiert worden sein. Zudem hatte sich - spätestens mit dem Ableben von Theophil Bendella 1875 - sein allmählicher (Wieder-)Aufstieg innerhalb der gr.-orient. Kirche abzuzeichnen begonnen. Der Archimandrit - 1879 neuerlich als Landtagsabgeordneter tätig - behielt seinen Kurs und die Forderung nach einem Kirchenkongress bei. Gleichzeitig versuchte er jedoch die im Kultusministerium nach wie vor an seiner patriotischen Gesinnung gehegten Zweifel auszuräumen. Letztere hatten bislang offensichtlich seine anstehende Ernennung zum neuen Erzbischof - wenn schon nicht verhindert, so doch bis dato hinausgeschoben:

In Anerkennung der großen Wohlthat, die der Bukowina durch die Einverleibung mit den österreichischen Staaten zu Theil wurde, habe ich schon in meiner Jugend, als Studierender der Theologie, durch Abhaltung von [? unleserliche Textstelle] Reden bei der in der Seminaranstalt alljährlich stattgefundenen Feier am Vorabende des kaiserlichen Geburtstagsfestes zur Werdung und Pflege patriotischer Gefühle in den Herzen des jungen Clerus wirksam beigetragen. In der Prüfungszeit der Jahre 1848 und 1849 wurde ich ausersehen, bei den durch die Behörden einberufenen Versammlungen an das Volk Belehrungen und Ermahnungen zur Ruhe, Folgsamkeit « [zu sprechen].

Morariu-Andriewicz befürchtete - so seine Sicht der Dinge -, dass eine Fortführung dieses Schwebezustandes das »niedrige Werk der Verhetzung (bei den russophylen Geistlichen) « begünstigen würde und die »Machinationen gegen meine Person desto mehr ausarten werden, je länger ich als Administrator der Diözese die bequeme Zielscheibe « bilde. ${ }^{183}$ Seine wenige Monate später erfolgte Inthronisierung als Erzbischof und Metropolit am 9. Mai 1880 in Czernowitz verschob schließlich die Lagerungen dieses Diskurses auf Jahre hinaus ganz klar zugunsten rumänisch nationaler Interessen. In Anwesenheit des Landespräsidenten Alesani als kaiserlichem Kommissär erfolgte denn auch die feierliche Amtseinführung. Am Ende der Festlichkeiten dankte der Metropolit "vom Balcone des Residenz-Gebäudes für die Ovation in kräftigen deutschen Worten. Sodann bewegte sich der Fackelzug zum Palais des Landespräsidenten ${ }^{184}$

Gleichwohl gestaltete sich die allgemeine Stimmung in der Bukowina und ihrer gr.orient. Landeskirche in der Alltagsrealität insgesamt weit weniger harmonisch, als es die Schilderung der Feier vermuten ließe. Die zahlenmäßige Bevölkerungsentwicklung

$183 \mathrm{DACZ}_{320 / 3} / 8_{3}$, handschriftliches Konzept Archimandrit Morariu-Andriewicz an Ministerium f. Cultus und Unterricht, Czernowitz v. 4.X.1879[?], fol. 3-13.

184 Neue Freie Presse Nr. 5639 v. 10.V.1880, Czernowitz, 4. 
zugunsten der Ruthenen in der Bukowina nährte das ständige Misstrauen nationaler Kreise, die sich zusehends in die Defensive gedrängt fühlten. ${ }^{185}$ Die allmähliche Nationalisierung des Konfessionsbewusstseins einer vorwiegend bäuerlichen Bevölkerung trug darüber hinaus zur wachsenden Aufladung dieses Konflikts bei. ${ }^{186}$ Gerüchte um die Einrichtung eines röm.-kath. Bischofssitzes empfand man seitens der Orthodoxie wohl auch in Erinnerung an die polnisch-galizische Zeit - zudem als ernst zu nehmende Bedrohung, besonders im Hinblick auf die Volksschulen, ihre Verwaltung, Finanzierung und die Unterrichtssprache. ${ }^{187}$ Obwohl bereits 1844 eine allerhöchste Entschließung verordnet hatte, dass der gr.-orient. Religionsfonds "Zum Unterhalte griechisch-nicht unierter Volksschulen zu verwenden « sei und damit auch die Aufsicht dem gr-orient. Konsistorium oblag, behauptete noch 1860 die von Galizien aus gesteuerte katholische Kirche ihre vormalige Stellung als Schulbehörde. Ein Großteil der betroffenen Schulen blieb folglich noch unter der Kontrolle des r.k. Erzbischofs in Lemberg. Ungeachtet dessen musste die Finanzierung der Bukowiner Religionsfonds bestreiten. ${ }^{188}$

Derartige Versuche galten jedenfalls schnell als "polnische Propaganda«, wogegen sich vor allem rumänische akademische Studentenkreise äußerten ${ }^{189}$, zumal man im selben Jahr (1886) in der Bukowina der Errichtung der gr.-orient. Diözese vor 100 Jahren gedachte. ${ }^{190}$ Obwohl die überwiegende Mehrheit der Bevölkerung dem gr.-orient. Ritus angehörte und die katholische, aber auch die unierte Kirche im Kronland nur einen sehr kleinen Anteil der christlichen Konfession ausmachten, zeigte man sich von beiden Seiten dazu als überaus empfindlich. ${ }^{191}$ Einiges an der angesprochenen smisslichen Lage der Volksschulen in der Bukowina war indes zu einem Gutteil auf eigenes Verschulden und weniger allein auf den bremsenden Einfluss der katholischen Kirche zurückzuführen. So

185 Das absolute Verhältnis Rumänen und Ruthenen in der Bukowina lag 1869 noch bei $209.000 \mathrm{zu}$ 191.000 (Gesamteinwohnerzahl des Kronlandes 511.000); 1900 bei $229.000 \mathrm{zu} 297.000$ (730.000) und 1910 bei $273.000 \mathrm{zu} 305.000$ (795.000); STATISTISCHES LANDESAMT 1913, Ergebnisse; ANoNYMUS 1872, Ort-Repertorium; zur Dynamisierung der nationalen Frage im Zusammenhang mit den Volkszählungen in der Habsburgermonarchie vgl. GöperLe 2016, Zensus.

$186 \mathrm{Im}$ Überblick für die Jahrhundertwende vgl. SCHARR 2011, Religionsfonds.

187 GĂINA 1907, Arhiepiscopul, 20; "Consistoriul nostru a lucrat pentru școalele noastre poporale în decurs de 9 ani de trei ori mult decât Leșii Galiţieni în decurs de 64 de ani.« [Unser Konsistorium hat für unsere Volksschulen während der neun Jahre dreimal mehr gearbeitet als die galizischen Polen im Laufe von 64 Jahren]; MorariU 1893, Păți, 106.

188 Fremden-Blatt. Außerordentliche Beilage zu Nr. 267, Verhandlungen des verstärkten Reichsrathes, Sitzung v. 18.IX.1860, Volksschulwesen Bemerkungen Baron Petrinos, 17 f.; dazu im Detail UNGUREANU 2015, Sistemul, 67-73; ders. 2007, Invățământul, 36-39.

189 Neue Freie Presse Nr. 7791 v. 6.V.1886, 4.

190 AKademischer Senat (Hg.) 1900, Universität, LIX.

191 Anonymus 1891, Apologie; Neşciuc 1893, Istoricul, 28; Popovici 1891, Brief. 
verzögerte etwa der landesinterne Streit um die Verfügungsgewalt an den Fondsmitteln zwischen der gr.-orient. Kirche und der Regierung Investitionen größerer Beträge. ${ }^{192}$

In der verpflichtenden Verwendung des Rumänischen erhoffte sich die Kirchenführung den durch die Bevölkerungsentwicklung offensichtlich gewordenen Prozess vermeintlich wachsender ruthenischer Dominanz zu stoppen und dem als historisch verbrieft dargestellten Recht der Rumänen die ihnen angestammte Stellung im Land zurückzugeben. ${ }^{193}$ Unter dem neuen Erzbischof vollzog sich seit 1880 im Konsistorium ein Verdrängungsprozess gegen das Ruthenische als zweiter Amtssprache, der 1888 in einen veritablen Skandal münden sollte, als sechs Dörfer des Radautzer Bezirks aus Protest geschlossen zur gr.-kath. Kirche übertraten. ${ }^{194}$ Die Bukowinaer Rundschau brachte dazu in der Folge eine Artikelserie, in der die Tageszeitung die Politik der Kirchenführung - i.e., der "gegenwärtigen gr.-or. Zionswächter, vulgo Metropolit und Consistorium « - in polemischer Weise angriff und gar von "öffentlichen Sünden des Metropoliten « sprach. ${ }^{195}$ Das Kultusministerium, darauf einmal aufmerksam geworden, bat den Metropoliten zu diesen Vorwürfen um eine Stellungnahme. ${ }^{196}$ Morariu-Andriewicz antwortete mit einer gedruckten mehrseitigen Gegendarstellung unter Beilegung zahlreicher amtlicher Dokumente und Visitationsberichte. Gleich eingangs zu dieser Verteidigungsschrift charakterisiert er die Pressefreiheit generell als ein Gemeingut mit »unsaubere[n] Hände[n], an denen oft der Schmutz der Habsucht kleben und die Kainszeichen verbrecherischer Thaten kenntlich sind «. Im Weiteren wirft er der Bukowinaer Rundschau (aber nicht nur dieser) dezidierte Kirchenfeindlichkeit sowie dem Verfasser der konkreten Artikelserie persönlich motivierte Rachsucht vor. ${ }^{197}$ Letztlich wies der Metropolit diese Anschuldigungen weit von sich und unterstrich im Gegenteil die eigentlichen Einigungsbestrebungen der Kirche:

192 Freie Pädagogische Blätter Nr. 49, 3. Jg. V. 4.XII.1869, 9, Bukowina Mißliche Zustände.

193 Morariu [nicht der Erzbischof!] 1893, Părți; NeşciUC 1893, Istoricul.

194 Bukowinaer Rundschau VII. Jg. Nr. 505 v. 15.IV.1888, Kirchliches.

195 Bukowinaer Rundschau VII. Jg. Nr. 511 v. 29.IV.1888; Laienstimmen aus der Provinz; Nr. 516, 10.V.1888, Teil II; Nr. 521, 24.V., Teil III; Nr. 522, 27.V., Teil IV, 2-3; Nr. 525, 3.VI., Teil V. Die Zitate stammen aus der Ausgabe Nr. 511 und 521 . Alle Beiträge mit Ausnahme des vierten Teils sind titelseitig platziert; Nr. 530, 14.VI.1888, Katholische Stimme aus der Bukowina I; Nr. 531, 17.VI., 2, Teil II; Nr. 537, 1.VII., 2, Teil III; Nr. 539, 5.VII., 1f., Teil IV.; Nr. 540, 8.VII., 2, Nationaler Uebermuth. Die Nummern 527 und 535 beschlagnahmte die Staatsanwaltschaft auf Grund der Artikelserie >Laienstimmen`; Nr. 536, 28.VI. Die Autorenschaft der Artikelserie ,Laienstimmen` weist Morariu-Andriewicz dem ehemaligen Gymnasialprofessor Wilhelm Schmidt zu; MORARIU-ANDRIEWICZ 1890, Apologie, 7; auch bei GĂINA 1907, Arhiepiscopul, 21.

196 Minister f. Cultus und Unterricht v. 6.VIII.1888, Z. 1356, Landespräsidialschreiben v. 30.VIII.1888, Z. 1110; zit. nach MORARIU-ANDRIEWICZ 1890, Apologie.

197 MorariU-AndriewicZ 189o, Apologie, 2f. u. 8. 
Diese wiederholte Aufwärmung des sprachlichen Kohls, an dem jedoch in den gr.-or. Kirchengemeinden slavischer Zunge Niemand einen Geschmack findet, ist vom Standpunkte der ukrainophilen Theorie und der Unionsbestrebungen begreiflich, aber vom Standpunkte der wohlverstandenen Lebensinteressen der orthodoxen Kirche und des kirchlichen Friedens in der durch die Bande des Glaubens und des religiösen Cultus geeinigten gr.-or. Bevölkerung des Landes beider Zungen ist die beliebte Anregung und Verfechtung von Nationalitätsfragen überhaupt verderblich. ${ }^{198}$

Drei Jahre darauf, 1891, berief Morariu-Andriewicz einen Kirchenkongress nach Czernowitz ein, der nunmehr endlich die Frage nach einer längst fälligen Normierung der gr.-orient. Kirche behandeln sollte. Allerdings brachte diese Konferenz in ihrem Fortgang ein völlig anderes als das vom Erzbischof zuvor in der Apologie geschilderte Bild nämlich kirchlicher Einheit im Glauben abseits nationaler Konfessionalisierung - zu Tage. Schon die Eröffnung führte zu einem veritablen Skandal zwischen den Teilnehmern und dem amtierenden Landespräsidenten Anton Graf Pace als kaiserlichem Vertreter. Pace war Hieronymus Freiherrn von Alesani in diesem Amt nachgefolgt und vertrat im Gegensatz zu seinem Vorgänger, der die rumänische Adelspartei gestützt hatte, eine gänzlich andere Politik. ${ }^{199}$ Pace hatte in seiner Eröffnungsrede mit Nachdruck die "Aufrechterhaltung der Gleichberechtigung beider Nationalitäten der Ruthenen und Rumänen « innerhalb der gr.-orient. Kirche verlangt, nachdem die Kongressmitglieder ausschließlich Rumänisch als Diözesansprache (und folglich auch im Kongress) durchsetzen wollten. Letzteres widersprach der gültigen Konsistorialgeschäftsordnung von 1869. ${ }^{200}$ Die Bukowinaer Rundschau - und damit weite Teile der auf diesem Feld ohnehin sensibilisierten Öffentlichkeit des Kronlandes - vermerkte diesen Vorfall als neuerlichen Auftakt zu nationalen Querelen innerhalb der Kirche: »Was nun geschehen wird, wir wissen es nicht. Aber es fiel der erste Schuß und dies bedeutet immer Kriegsgefahr. ${ }^{201}$ Der Kongress verlief - zumindest in der Außenwahrnehmung - ohne größere Resultate. ${ }^{202}$ Die ruthenischen Angehörigen der Landeskirche bzw. ihre Eliten sahen sich indes im Recht, nunmehr auch ihre Forderungen vorzubringen. In einer Ar-

198 MorariU-ANDRIEWICZ 1890, Apologie, 32.

199 Corbea-Hoișie 2010, Czernowitz, 38; Anonymus 1891, Apologie, 20; Corbea-Hoișie 2005, Wende.

200 "Bezüglich der Sprache, in welcher die Verlautbarungen gedruckt werden sollen, hat der Grundsatz zu gelten, daß dabei der gleichen Berechtigung der beiden Diöcesansprachen, nämlich der romanischen und slavischen, volle Rechnung getragen werde«; Bukowina. Landes- und Amtszeitung VI. Jg. Nr. 148 v. 15 .XII.1867, 2.

201 Bukowinaer Rundschau X. Jg. Nr. 1041 v. 4.X.1891, 1f., Chauvinismus.

202 Bukowinaer Rundschau X. Jg. Nr. 1051 v. 27.X.1891, 2. 
tikelserie der Bukowinaer Rundschau mit dem Titel »Die Wünsche der Bukowinaer Ruthenen « konnte Silvester Daszkiewicz seine angekündigte und später auch erschienene Druckschrift ${ }^{203}$ zu einer breiteren Öffentlichkeit verhelfen. ${ }^{204}$ Das Schreiben richtete sich bewusst gegen eine zwei Jahre zuvor ebenfalls von Morariu-Andriewicz herausgegebene Apologie. ${ }^{205}$ Jetzt, vor dem Hintergrund des Kirchenkongresses und der dort aufgekochten nationalen Stimmung, erfuhr diese Schrift zusätzliche Aktualität. Die darin als legitim präsentierten Forderungen passten voll und ganz in die revolutionäre Stimmung der rumänischen Partei, wollte man doch eine Teilung der Diözese bewirken und die kirchlichen Institutionen national-paritätisch besetzen. Der Religionsfonds allerdings sollte ungeteilt belassen werden:

Wir fordern hier nichts, was die nationalen Rechte der gr--or. Romänen auch nur im geringsten beeinträchtigen würde, sondern nur das, was den Ruthenen nach göttlichem und menschlichem Recht zukommt und die Romänen längst besitzen, was den Ruthenen aber durch die Ungunst der Verhältnisse bisher versagt bliebt. ${ }^{206}$

Rumänische Pfarrer zeigten sich alarmiert und glaubten darin bereits »Hannibal ante portas « zu vernehmen bzw. eine srussische Diözese auf sich zukommen zu sehen. ${ }^{207} \mathrm{Die}$ Ruthenen hingegen sahen sich einer zunehmend als repressiv empfundenen Haltung des Metropoliten ausgesetzt und bekräftigten ihrerseits Forderungen nach nationalparitätischer Besetzung der Kirchenämter. ${ }^{208}$

203 DAsZKIEWICZ 1892, Lage; die Arbeit trägt den programmatischen Untertitel: »zugleich Antwort auf die >Apologien des Bukowinaer gr.-or. Metropoliten Silvester Morariu-Andriewicz im Auftrage der weltlichen gr.-or. Mitglieder der Czernowitzer ruthenischen Vereine verfasst«; ein Exemplar dieses Buches wurde 1891 vorab an Ministerpräsident Taaffe übermittelt; DACZ $320 / 3 / 67$, fol. $34 f$.

204 Bukowinaer Rundschau X. Jg. Nr. 1056 v. 8.XI.1891, 2; Nr. 1061 v. 19.XI., 2; Nr. 1064 v. 26.XI., Titelseite und Nr. 1065 v. 29.XI., 2 f.

205 Morariu-AndrieWiCZ 1885, Apologie.

206 Bukowinaer Rundschau X. Jg. Nr. 1064 v. 26.XI.1891, Titelseite u. Nr. 1065 v. 29.XI., 3.

207 \#Cotind prin gazete, că partidă rutenilor tinere lucră între acolo, că să se despărtescă arhidiecesa or.ort a Bucovinei între’o diecesă rusèscă.« [In den Zeitungen kann man nachlesen, dass die Partei der Jungruthenen auf eine Trennung der russischen Diözese von der gr.-ort. Diözese der Bukowina hinarbeitet]; DACZ $320 / 3 / 67$, fol. 37 f., Brief rumänischer Pfarrer an Erzbischof Morariu-Andriewicz undatiert (undatiert, um 1894), mit Bezug auf einen Zeitungsartikel des Deutschen Volksblattes Nr. 2086 v. 23.X.1894, 2. Der Artikel hatte zuvor über die Bereitstellung eines >Administrators zur Erleichterung der Amtsführung des Erzbischofs berichtet, was den Wirkungskreis des gr-orient. Kirchenoberhauptes der Bukowina in seiner Entscheidungsfreiheit eingeschränkt hätte.

208 »Im Gegentheil geht der Metropolit durch die Erfolglosigkeit der Bemühungen der Ruthenen ermuthigt, aggressiver und rücksichtsloser gegen alle culturellen Bestrebungen der Ruthenen [vor], 
Anton Graf Pace hatte erst wenige Monaten zuvor, am 1. August 1891, sein Amt als Landespräsident angetreten. Sein Versuch, die offensichtliche rumänische Dominanz in den diversen Institutionen des Kronlandes zurückzudrängen, brachte ihm zwar die Unterstützung der Ruthenen, aber auch die Feindschaft der mächtigen rumänischen Adelspartei ein. ${ }^{209}$ Der Eklat zur Eröffnung des Kirchenkongresses lieferte daher nur mehr den nötigen Auftakt für eine Reihe politischer Sticheleien und Unruhen in der Bukowina, die in der Neuwahl des Landtages gipfelten und schließlich im Mai 1892 in der Abberufung Paces mündeten. ${ }^{210}$ Außenpolitisch - und das darf in der Bukowina keinesfalls unterbewertet werden - mag hier auch der zwischen Österreich-Ungarn und dem Königreich Rumänien seit Jahren schwelende Handelskrieg mithin ein Faktor gewesen sein. ${ }^{211}$

Insgesamt hatte diese Situation - nicht unwesentlich mitverursacht durch den Erzbischof und seine Rolle in der >rumänischen Sache - die Innenpolitik des Kronlandes erheblich erschüttert. Die Bukowinaer Rundschau sah sich gar veranlasst, dem neuen Landespräsidenten Franz Freiherr von Krauß gleich einen guten Ratschlag mit auf den Weg zu geben: „Und mehr denn drei Monate kochte wirklich alles durcheinander [...]. Ja Frieden ist es, der uns noth thut. ${ }^{212}$

\section{Zusammenfassung}

Die allgemeine Entwicklung der Habsburgermonarchie nach dem Ausgleich mit Ungarn im Jahr 1867 hatte es aus Sicht der Bukowiner Eliten notwendig gemacht, gleichfalls einen nächsten Schritt zum Ausbau der Landesautonomie zu wagen. Die Forderung nach einem konstituierenden Kirchenkongresses verbunden mit einem modernisierten Statut für die gr.-orient. Kirche und den Religionsfonds zählte zu den zentralen Anliegen. Morariu-Andriewicz stand über Jahrzehnte hinweg im Zentrum dieser Bemühungen.

als je, er sät in einer beispiellosen Weise Hader und Zwietracht. « Zudem sollten Rumänisch und Ruthenisch als gleichberechtigte Amtssprachen in der Kirche und ihren Institutionen gelten und alle Priester müssten dazu verpflichtet werden, die "gründliche Kenntnis beider Landessprachen in Wort und Schrift nachzuweisen «; DACZ $320 / 3 / 67$, Pfarrer Demeter Dann u.a. an Minister f. Cultus und Unterricht (Abschrift), undatiert (1891 ?).

209 Bukowinaer Rundschau XI. Jg. Nr. 1104 v. 28.II.1892, 2; Pace wird am Czernowitzer Bahnhof nach seiner Rückkehr aus Wien von Ruthen und Liberalen freundlich empfangen.

210 Corbea-Hoișie 2010, Czernowitz; Neue Freie Presse Nr. 9954 v. 11.V.1892, 5, Abberufung Paces; über eine mögliche Ablösung des Landespräsidenten hatte man in der Czernowitzer Öffentlichkeit schon im Vorfeld spekuliert; Bukowinaer Rundschau XI. Jg. Nr. 1090 v. 26.I.1892, 2.

211 Harre 2009, Wege, 86.

212 Bukowinaer Rundschau XI. Jg. Nr. 1140 v. 24.V.1892, Titelseite; Zwei Worte an den neuen Landespräsidenten. 
Zum einen - und das musste ihm als Reichsratsabgeordneter durch die Debatten um den letztlich gescheiterten ersten böhmischen Ausgleichsversuch 1871 bewusst geworden sein - erstarkten dadurch von Neuem die national-polnischen Kräfte im benachbarten Galizien-Lodomerien als dringend benötigte Mehrheitsbeschaffer der Wiener Regierungen. Es stand aus seiner Position zu befürchten, dass damit der Einfluss Lembergs neuerlich auf die Bukowina übergreifen könnte, zum Nachteil der gr-orient. Kirche sowie des Religionsfonds. Administrativ hatte man sich ja erst vor wenigen Jahren begonnen, langsam voneinander zu entflechten. Die Direktiven des röm.-kath. Konsistoriums in Lemberg zu den Schulen der Bukowina besonders während des Neoabsolutismus hatte man noch in lebhafter Erinnerung, Morariu-Andriewicz, der u.a. dieser Schulpolitik seinen Doppelnamen verdankte, am allermeisten. ${ }^{213}$ Andererseits schien der Zeitpunkt für die Bukowina denkbar günstig, dem geschwächten Zentrum gegenüber $\mathrm{Zu}$ geständnisse mit Erfolg abringen zu können, die letztlich sowohl auf die Annahme des neuen Statuts für den Religionsfonds (1870) - gegen das sich Morariu-Andriewicz in dieser Form teilweise ausgesprochen hatte - als auch auf die Einrichtung einer eigenen Metropolie (1873) hinausliefen.

Morariu-Andriewicz erkannte in dieser Konstellation auch die realpolitische Chance, von ihm als legitim wahrgenommene Rechte der rumänischen Bevölkerung des Kronlandes einzufordern. Eine der Ursachen dafür lag sicherlich im wachsenden Bevölkerungsdruck seitens ruthenischer Einwanderer aus Galizien und in der unmissverständlichen politisch-konnotierten Wahrnehmung dieses Phänomens innerhalb der Bukowina bzw. ihrer rumänischen Eliten; selbstverständlich aber ebenso in den damit vorgebrachten ruthenischen Ansprüchen auf Mitbestimmung gegenüber einer rumänisch dominierten Kirchenhierarchie.

Die persönlich angespannte Situation zwischen Bischof Hackmann und Morariu-Andriewicz fügte diesem komplizierten Verhältnis eine weitere Facette hinzu. Hackmann als absolutistisch denkender Kirchenhierarch wollte und konnte die Eigeninitiativen seines Konsistorialrates nicht dulden bzw. konnte diese Subordination nur als mangelnde Loyalität und Disziplinlosigkeit interpretieren. Zudem musste Hackmann in der betont nationalen Haltung von Morariu-Andriewicz die aufdämmernde Gefahr der Nationalisierung seiner Diözese gespürt haben, die er ebenfalls keinesfalls bereit war zu tolerieren. Die auf Jahre hinaus verzögerte Inthronisierung sowie die geradezu intrigenhafte

$213 \mathrm{Ob}$ dabei die vermutete ruthenische Herkunft seiner Vorfahren, wie sie verschiedentlich in der Literatur angedeutet worden ist, auch eine Rolle gespielt hat, ist in dieser Form nicht zu beantworten, zumal Morariu-Andriewicz selbst bereits in einem rumänischen Umfeld aufgewachsen war und derartige nationale Zuweisungen in der Bukowina politisch gerne instrumentalisiert wurden; vAN DRUNEN 2015, Bunch, 170. 
Formen annehmenden Prozesse gegen seine Person mussten Morariu-Andriewicz wohl nicht nur persönlich verbittert, sondern ihn offensichtlich auch in seinen kirchenpolitischen Anliegen bestärkt haben. Obwohl es ihm letztlich nicht gelang, der gr--orient. Kirche die angestrebte volle Autonomie sowie die Verfügungsgewalt über die Mittel des Religionsfonds zu verschaffen, konnte er langfristig doch zahlreiche Bauprojekte von Kirchen, der Universität (der theologischen Fakultät), die bessere Ausstattung der Pfarreien, aber ebenso eine höhere Entlohnung der Pfarrer und anderes mehr aus diesen Mitteln zu Gunsten der Gesamtkirche umsetzen. Die fortschreitende Nationalisierung der Diözese hingegen erfuhr gerade durch sein Wirken bleibende Impulse. Die gr.orient. Kirche schlitterte damit in ein Fahrwasser, dessen Gerinne in der Folge für das Kronland bis zum Ausbruch des Ersten Weltkrieges die Tagespolitik bestimmen sollte.

\section{Ausgleichsversuche - Arkadius Czuperkowicz \& Wladimir v. Repta (1896-1924)}

Kurz nach dem Ableben von Silvester Morariu-Andriewicz ernannte der Kaiser am 16. Februar 1896 den 73-Jährigen bisherigen Diözesanadministrator und Generalvikar Arkadius Czuperkowicz (rum. Arcadii Ciupercovici) zum Erzbischof und zum Metropoliten von Bukowina-Dalmatien mit Sitz in Czernowitz. ${ }^{214}$ Der am 14. April 1823 in Kimpolung (rum. Câmpolung) in einer orthodoxen Pfarrersfamilie geborene Alexandru Czuperkowicz hatte bis zu diesem Zeitpunkt eine nahezu mustergültige Karriere in der gr.-orient. Kirche hinter sich: 1847 Priesterweihe, 1848 Pfarrer, 1865 - nach dem Tod seiner Frau (1861) - Übertritt in den Mönchsstand mit dem Namen Arkadius, 1866 Igumen in Putna, 1873 Archimandrit, 1878 Konsistorialrat, 1880 Generalvikar und seit 1895 Diözesanverwalter. ${ }^{215}$ Einen Tag vor seinem Geburtstag vereidigte Franz Joseph I. den designierten Erzbischof der Bukowina und Dalmatiens in Wien und am 19. April 1896 empfing er in der gr.-orient. Kirche der Reichshauptstadt seine Weihe. ${ }^{216}$ Genau einen Monat später, am 19. Mai, feierte man in Czernowitz die Installation des neuen Hierarchen. ${ }^{217}$ Auf die Stelle des Archimandriten im gr.-orient. erzbischöflichen Konsistorium rückte Universitätsprofessor Dr. Basil (Wladimir) v. Repta (rum. Vladimir de Repta) nach. ${ }^{218}$

214 Das Konkordat zwischen Wien und dem ökumenischem Patriarchen aus dem Jahre 1880 erlaubte es dem Kaiser, Metropoliten zu ernennen; PLÖCHL 1972, Kirche, $27 \mathrm{f}$.

215 Bukowinaer Post Nr. 609 v. 7.XI.1897, 1, 50 Jahre Priester.

216 Wiener Zeitung Nr. 85 v. 13.IV.1896, 2, Vereidigung durch den Kaiser; Nr. 91 v. 20.IV.1896, 5, Beilage der Wiener Abendpost.

217 Neue Freie Presse Nr. 11401 v. 20.V.1896, 2.

218 Wiener Zeitung Nr. 50 v. 29.II.1896, 1, amtlicher Theil. 


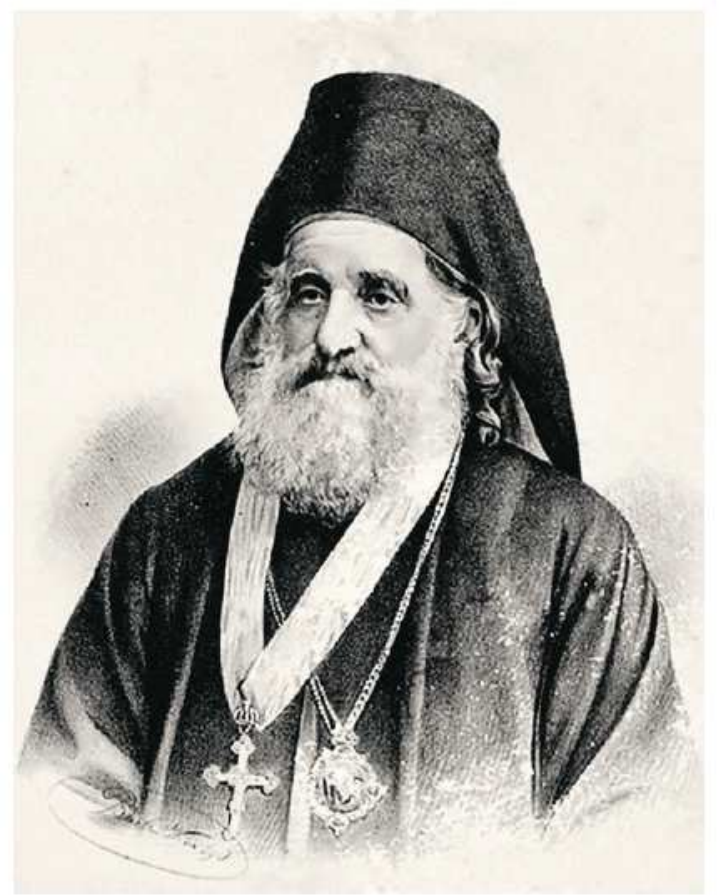

Abb. 21: Arkadius Czuperkowicz als Erzbischof und Metropolit der Bukowina und Dalmatiens. ${ }^{219}$

Diese Entscheidung der Wiener Behörden muss wohl eher pragmatisch denn strategisch interpretiert werden. Laut bislang gepflegtem Usus der gr.-orient. Kirche folgte stets der amtierende Generalvikar dem verstorbenen (Erz-)Bischof nach. In der kurzen - in Rumänisch wie Deutsch vorgetragenen - Ansprache nach dem Empfang seiner Weihe in Wien betonte der Erzbischof Czuperkowicz - ganz im Sinne der Reichsideologie und gewiss auch aus tiefer eigener Überzeugung -, »daß die patriotische und dynastische Gesinnung der gr.-orient. Kirche nicht nur gepflegt, sondern auch vermehrt werde, bis in alle Zukunft und Ewigkeit «. ${ }^{220}$ Diese mit der Idee des Habsburgerreiches unter Franz Joseph I. konforme, jedoch praktisch wenig konkrete Aussage lässt zwar die persönlich unzweifelhafte Einstellung des neuen Metropoliten erkennen, deutet jedoch im damaligen Kontext zugleich offen auf die in der Bukowina herrschenden politischen Probleme hin. So gelangte etwa sein Bukowiner Zeitgenosse, der rumänisch-nationale Historiker und Politiker Ioan Nistor (1876-1962) zu einem - wenngleich ex negativo formulierten - weit weniger charmanten Urteil dieser ausgleichenden Charaktereigenschaft, wenn er meint, dass Czuperkowicz den »wahrhaften Typ des alten Bukowiners verkörpert, als

219 [http://putna.ro/revista2011/lib/images/imagini-articole/articol_10_3.jpg] 220 Wiener Zeitung Nr. 91 v. 20.IV.1896, 5, Beilage der Wiener Abendpost. 
Rumäne geboren und als Deutscher erzogen «. ${ }^{221}$ Indes sollte die praktische Umsetzung der im kaiserlichen Wahlspruch Viribus Unitis symbolisch ausgedrückten Einigkeit den orthodoxen Erzbischof noch vor große Schwierigkeiten stellen. Er hatte eine Diözese übernommen, in der die nationalen Gegensätze zwischen den Ruthenen und Rumänen stetig anwuchsen. Die parteipolitische Instrumentalisierung der weitgehend bäuerlichen Bevölkerung des Kronlandes begann in zunehmendem Maße von verschiedenen Seiten her um sich zu greifen. Bald sollte das auch der Metropolit zu spüren bekommen.

Vorerst jedoch bedachte ihn die Bukowiner Öffentlichkeit anlässlich seines 1897 gefeierten 50-jährigen Priesterjubiläums noch mit Vorschusslorbeeren: „Das Jubelfest des ersten Priesters der Bukowina " - so die Bukowinaer Post in ihrem Leitartikel - sollte "in eminenter Weise ein Friedensfest des Landes werden « und dem Erzbischof "Zeit gönnen, das schöne, echt priesterliche Ziel in seiner Diöcese zu verwirklichen, daß in derselben nur gr.-or. Gläubige vorhanden sind, ohne Unterschied der Nation «. ${ }^{222}$ Die nachträglich verschiedentlich negative Einschätzung seiner vergleichsweise kurzen Amtszeit erscheint parteiisch und vor allem vom Ende her gedacht. So beschreibt ihn etwa Erich Prokopowitsch als einen »kränklichen und initiativlosen Greis « ${ }^{223}$, und Nicolae Iorga, der Doyen der rumänischen Historiographie, erachtete Czuperkowicz als Nachfolger von Morariu-Andriewicz auf dem Metropolitenstuhl geradezu als unwürdig. ${ }^{224}$ Die schwierige Ausgangssituation, mit der sich Czuperkowicz wie später auch Wladimir v. Repta in der Bukowina konfrontiert sahen, wird dabei keineswegs in ausreichendem Maße berücksichtigt.

Auf dem weiten Feld des nationalen Zwists innerhalb der Bukowiner gr-orient. Diözese nahm der Religionsfonds als wirtschaftlich potente Landesinstitution eine prominente Stellung ein. Obwohl im Zentrum des z. T. heftig geführten Diskurses zur "griechisch-orientalischen Kirchenfrage" (so eine regelmäßige in den Czernowitzer Tageszeitungen erscheinende Rubrikbezeichnung) die Frage um den Zugriff auf das Fondsvermögen stand, wurde in der breiteren Öffentlichkeit zumeist die jeweils von ruthenischer wir rumänischer Seite mit unterschiedlichen Begründungen eingeforderte

221 "Arcadie reprezintă tipul adevărat al vechiului bucovinean, născut român și crescut nemţește « ; NisTOR 2003, Istoria, 137.

222 Bukowinaer Post Nr. 609 v. 7.XI.1897, 1, 50 Jahre Priester.

223 Prokopowitsch 1965, Nationalbewegung, 81; IoRgA 1938, Românismul, 114.

224 "[...] succesorul lui fu, din pricina bătrânețelor și a nedestoiniciei lui absolute, Arcadie Ciupercovici, care n’a avut niciodată curagiul să vorbească despre partea, încă naţională, a eparhiei sale." [(...) Zum Nachfolger wurde aus Gründen der Seniorität und seiner absoluten Unfähigkeit Arcadie Ciupercovici, der niemals die Courage aufbrachte, über diese Sache noch das Nationale seiner Diözese zu sprechen]; Repta hingegen bezeichnete Iorga als einen der gebildetsten Rumänen; IoRGA 1938, Românismul, $114 \mathrm{f}$. 
nationale Selbstbestimmung nach vorne gekehrt. Hauptsächliches Ziel dieses Kapitels soll daher eine politische Gesamtbetrachtung der Bukowiner Kirchenfrage bis zum Ausbruch des Ersten Weltkrieges sein. Dabei gilt es, die allgemeine politische Situation des Kronlandes mit jener der Kirche sowie ihrer Institutionen, ausgehend von den beiden Erzbischöfen Czuperkowicz und Repta, miteinander zu verknüpfen. Abschließend dazu soll - über die Person Wladimir v. Repta - eine überleitende Betrachtung der Ende 1918 vor allem auch für die Kirche spürbaren politisch-nationalen Eingliederung der Bukowina in das rumänische Königreich und die damit verbundene Neustrukturierung ihrer Institutionen stehen.

\section{Kirchenfrage und Nationalisierung}

Der Universitätsprofessor Dr. Stephan Smal-Stockyj (1859-1939) ${ }^{225}$, seit 1893 Abgeordneter zum Bukowiner Landtag, führte die jungruthenische Bewegung des Kronlandes an. Der Ruthenist engagierte sich für die nationale Autonomie der Ruthenen in der Bukowina. Zudem hatte diese Gruppe seit 1898 mit Nikolai Ritter v. Wassilko (1868$1924)^{226}$ (rum. Nicolae de Vasilco; ruth. Mykola) einen politisch schwergewichtigen Vertreter im Landtag sitzen, der ab 1904 an der Spitze des `Freisinnigen Clubs`, ein übergreifendes Parteienbündnis, agierte. ${ }^{227}$ Den Jungruthenen gelang es allmählich, die ukrainisch-nationale Bewegung ${ }^{228}$ auf eine gesellschaftlich breitere Basis zu heben und ihr vermehrt Gehör in der Öffentlichkeit zu verschaffen. Mit ihrer politischen Agenda gerieten die Jungruthenen allerdings in Opposition zu rumänisch-nationalen Kreisen und ebenso zu weiten Teilen der gr.-orient. Kirchenhierarchie des Kronlandes ${ }^{229}$, betrachtete doch die orthodoxe Landeskirche der Bukowina besonders seit Morariu-Andriewicz die nationalen "Aspirationen der Ruthenen " gegenüber der »autochthonen « Bukowiner Bevölkerung mit Argusaugen. Die Angst vor den Ideen der "ruthenischen Wortführer", wonach die "confessionellen Marksteine ", eine Anspielung auf die demographischen Verhältnisse - die seit Jahren zugunsten der Ruthenen ausfielen - schon von selbst fal-

225 Angaben lt. Österr. Biograph. Lexikon 1815-1950, Bd. 12 (Lieferung. 58, 2005), 363 f.

226 Angaben lt. SATCO 2004, Enciclopedia, 557.

227 TURCZYNSKI 1993, Geschichte, $203 \mathrm{f}$.

228 In der Habsburgermonarchie hatte sich, beginnend vom 18. bis ins 20. Jahrhundert, offiziell die Bezeichnung > Ruthenen ` eingebürgert. Diese leitet sich ursprünglich von $>$ Rutheni`, einer latinisierten Form von Rus, Rusyn, etc. ab. Obwohl in der politischen Alltagssprache die Benennung ,Ukrainer für die Ruthenen der Doppelmonarchie schon um die Jahrhundertwende durchaus gebräuchlich war, setzte sich diese in der Amtssprache erst während des Ersten Weltkrieges allmählich durch.

229 Bihl 1980, Ruthenen, 583; CeAUșU 2000, Landtag, 2189f.; DoвRžANs'кY 2000, Czernowitz, 50 ; Hitchins 1980, Rumänen, 615-625. 
len würden, sobald die "genetische Scheidewand zwischen der Bukowina und Galizien « nur beseitigt wäre, bestärkte diese Haltung. ${ }^{230}$ Die Diözesanverwaltung gab sich folglich gegenüber derlei Strömungen besonders hellhörig und versuchte ihre Priesterschaft entsprechend anzuweisen. ${ }^{231}$ Innerhalb der ruthenischen Nationalbewegung der Bukowina zeichnete sich zu diesem Zeitpunkt bereits eine Spaltung der verschiedenen politischen Interessen ab. So intervenierten etwa die "konservativen Ruthenen gr.-or. Confession " (Altruthenen) beim Erzbischof gegen eine Berücksichtigung der Jungruthenen bei der Mandatsverteilung zum Landtag. ${ }^{232}$ Durch das geltende Kurienwahlrecht konnte der Religionsfond als Großgrundbesitzer über das gr--orient. Konsistorium Mandate vergeben.

Diese streckenweise aufgeladene und emotionale Stimmung griff die oftmals parteiisch agierende Presse der Landeshauptstadt bereitwillig auf. Durch ihren Zugang zur Öffentlichkeit schürte sie damit das Feuer der Zwistigkeiten zusätzlich. ${ }^{233}$ Dabei übernahm im Spiel der politischen Interessen und der Öffentlichkeit die von Moritz Stekel herausgegebene Bukowinaer Post eine nicht unwichtige Rolle. Diese Tageszeitung vollzog um die Wende zum 20. Jahrhundert einen deutlichen politischen Schwenk, von einem pro-rumänischen hin zu einem dezidiert pro-ruthenischen Kurs, was vor allem mit dem wachsenden Einfluss eines ihrer Eigentümer und hauptsächlichen Financiers, N. v. Wassilko, zu erklären ist. ${ }^{234}$ Letzterer hatte sich, ursprünglich aus dem rumänischen Lager kommend, zunächst den Alt- und schließlich den Jungruthenen der Bukowina zugewandt, zu deren politischem Führer er in der Folge aufsteigen sollte.

So löste denn auch die Ernennung gleich zweier Ruthenen - Eugen Kozak (18571933) und Dionys Jeremijczuk ${ }^{235}$ - zu ordentlichen Universitätsprofessoren an der theo-

230 Morariu-Andriewicz 1885, Apologie, 4.

$231 \mathrm{DACZ}_{320 / 3 / 67}$, Landesregierung an Consistorial-Archimandrit v. 8.V.1895, worin die Behörde vor dem »bekannten panslavischen Agitator Gregor Kupczanko« warnt, ihre »Pfarrlinge von jedem Verkehre mit demselben [i.e. Kupczanko; Anm. K.S.] durch entsprechende Belehrung abzuhalten«; DACZ $_{320 / 3 / 67}$ Präsidium gr.-orient. Consistorium v. 29.IV./11.V.1895, Rundschreiben an Pfarren.

232 DACZ $_{320 / 3 / 87}$, fol. 56 f. Centralwahlcomite der konserv. Ruth. gr.-orient. Confession an Erzbischof v. 4.II.1897.

233 "Weit reichte die Dreistigkeit der von Dr. Stocki und des von ihm verführten Pihuliak geleiteten jungruthenischen Clique, allein daß diese es wagen würde, jeden Seelsorger, der nicht in ihr Horn bläst, sofort zum Rumänisator zu stempeln«; Bukowinaer Post Nr. 705 v. 23.VI.1898, 1, Die Jungruthenen und die gr-orth. Kirche; vgl. dazu auch die Studie von Moroșan 2005, Lupta. Letzterer streicht - teilweise aus fehlender kritischer Distanz und nicht ganz frei von nationaler Perspektive besonders die, aus seiner Sicht, bewusste Bevorzugung des ruthenisch-deutschen Elementes durch die österreichischen Behörden und die Haltung der von ihm untersuchten Periodika heraus; ebd. 15.

234 Corbea-Hoișie et al. (Hg.) 2012, Prolegomene, 224-231.

235 Kozak war seit 1899 Professor für Kirchenslawische Sprache und Literatur in Czernowitz; zu Jeremijczuk lassen sich keine näheren biographischen Angaben finden. 
logischen Fakultät heftige Gegenwehr der rumänischen Seite aus, die mehr und mehr alle kirchlichen Angelegenheiten als ihr ureigenes, nationales Terrain betrachtete. 1896 hatte das Kultusministerium eine ordentliche Lehrkanzel für praktische Theologie mit ruthenischer Vortragssprache an der Alma Mater Franciso Josephina freigegeben bzw. systemisiert. ${ }^{236}$ Besetzt wurde die Professur im März 1899 mit dem bisherigen Gymnasialkatecheten Dionys Jeremijczuk. Die Bukowinaer Post vertrat in diesem Fall noch den grundsätzlichen Standpunkt, dass die gr.-orient. Kirche »nach ihrer Geschichte eine rumänische Kirche« sei. Sie bezeichnete den Erzbischof und den amtierenden Landespräsidenten Friedrich Bourguignon ${ }^{237}$ als dezidierte Ruthenenfreunde. ${ }^{238}$ Jeremijczuk sei mithin auf Betreiben Smal-Stockyjs »ohne wissenschaftliche Eignung [...] mit rasender Eile zum Universitätsprofessor für die gr.-or. Theologie befördert worden «. ${ }^{239}$

Noch ein Jahr zuvor, zu Pfingsten, schlug der Landtagsabgeordnete Hierotheus Pihuliak (1851-1924) ${ }^{240}$ anlässlich einer Volksversammlung, die beim ruthenischen Nationalhaus in Czernowitz ihren Ausgang genommen hatte und dann im Musikvereinssaal tagte, andere Töne an. Ein Leitartikel der ruthenischen Zeitung Буковина [Bukowina] druckte die Ansprachen der Hauptredner Pihuliak und Smal-Stockyj in voller Länge ab. ${ }^{241}$ Letzterer erhob insbesondere die Forderung einer Öffnung der Wahlkurien, sodass endlich auch die bäuerliche Bevölkerung eine angemessene Vertretung im Landtag wie im Wiener Reichsrat bekommen könne. Dabei zeigte sich deutlich die soziale (und nationale) Dimension dieses politischen Anliegens sowie die schon erwähnte Rolle des Religionsfonds, mithin der gr.-orient. Kirche, als größtem Grundbesitzer des Kronlandes. Zwischen den Zeilen der Kritik versteckte sich darüber hinaus ein gezielt angebrachter Unterton gegen die jüdische Bevölkerung der Bukowina, die gemeinhin in ihrer Form als Pächter (von Religionsfondsgütern) und damit als Ausbeuter der Bauern adressiert wurde. ${ }^{242}$ Ein entsprechendes Memorandum sollte dem Kaiser vorgelegt werden. Die eigenen Bauern hingegen forderte man auf, dem Verein Rus'ka Rada, der

236 Erlass Ministerium für Cultur und Unterricht v. 24.XI.1896, Zl. 28.772; nach AKADEMISCHER SENAT (Hg.) 1900, Universität, 52.

237 Bourguignon vertrat zwischen 1897 und 1903 als Landespräsident die Interessen des Kaisers bzw. der Wiener Regierung in der Bukowina.

238 Bukowinaer Post Nr. 834 v. 27.IV.1899, 5, Zum Falle Jeremijczuk.

239 Bukowinaer Post Nr. 857 v. 25.VI.1899, 2, Smal-Stockis jüngste That.

240 Rum. Ierotei Pihuleac, Mitglied der Nationaldemokratischen Partei, Abgeordneter zum Landtag der Bukowina (1890-1918) und zum Reichsrat (1898-1918); nach SATCO 2004, Enciclopedia, 213.

241 Буковина Nr. 62/63 v. 27.V./8.VI. und v. 29.V./10.VI.1898, Народне віче в Чернівцах [Die nationale Volksversammlung in Czernowitz], nach einer Abschrift im DACZ $320 / 3 / 4$, fol. 124-151.

242 Dieser antisemitische Unterton beschränkte sich freilich nicht ausschließlich auf die Vertreter der Jungruthen (etwa bei Pihuliak), sondern dieser Stimmung bediente sich in gleichem Maße auch die rumänische demokratische Bewegung unter Aurel Onciul; vgl. seinen Artikel in Die Wahrheit 
seit Beginn der $1890 e r$ Jahre in Czernowitz aktiv war, beizutreten, um ihm ein politisch gestärktes Mandat zu sichern. ${ }^{243}$

Wir haben einen Religionsfond, dem $1 / 4$ des Landes gehört. Er hat 21000 Faltschen ${ }^{244}$ Ackergrund und 20000 Faltschen Wiesen und Weiden. Der Religionsfonds verpachtet jetzt diese Felder und Wiesen fast ausschließlich an Nichtchristen und wir bearbeiten dieselben um einen Spottpreis für fremde Leute. Wenn der Religionsfonds diese Felder und Wiesen den Landleuten verpachten würde, dann hätten wir hier wovon zu leben und brauchen nicht unser Land zu verlassen [...] Dieser Fond hat den Gutsherren geholfen [...] möge er nun jetzt den orthodoxen Bauern helfen. ${ }^{245}$

Pihuliak brachte, mit Verweis auf die Ergebnisse der letzten Volkszählung 1890 und die wachsende Anzahl der Ruthenen im Kronland, in seiner Rede bei der erwähnten Versammlung im Musikverein die Sprache auf religiöse Bedürfnisse der ruthenischen Bauern in der Bukowina. Angesichts der relativen ruthenischen Mehrheit, so der Landtagsabgeordnete überspitzt, könnte man ebenso von einer »ruthenischen Kirche« sprechen. Zugleich kritisierte Pihuliak die sprachliche wie religiös-konfessionelle Indifferenz, die "falschen Angewöhnungen" seiner Landsleute, die sich selbst oftmals als Teil der »walachischen Confession « sehen würden, obwohl sie Ruthenen seien und eben damit dem fortdauernden »Verfolgungswerk [des Konsistoriums; Anm. K.S.] gegen die Ruthenen " selbst nichts entgegensetzen würden.

Diese unsere romanisatorische Geistlichkeit geht mit unserem ruthenischen Volke um, wie ein jüdischer Pächter mit fremdem gutem Felde und Wirtschaftsgebäuden. Er trachtet aus dem selben in möglichst kurzer Zeit den größten Nutzen zu ziehen, es fällt ihm gar nicht ein, dieses Feld in gutem Zustande zurückzulassen. Ja unsere romanisatorische Geistlichkeit geht mit unserem Volke noch schlechter als jener Pächter um [...] Ja, die Intoleranz gegen alles was ruthenisch ist, hat sich sogar noch mehr verschärft, denn der gegenwärtige Metropolit empfängt jetzt nicht einmal in Audienz die ruthenischen Priester, was selbst sein Vorgänger nicht wagte. Daher bleibt uns jetzt nichts andere übrig, als uns noch an den erhabensten Herrn zu wenden; wir müssen Abgeordnete zum durchlauchtigsten Kaiser schicken, welche Seiner Majestät diese

Nr. 61, v. 18.IX.1909, 1-11, Die Religionsfondsdomänen; ergänzend dazu CORBEA-HOIșIE 2012, Onciul.

243 Auch Russka Rada, ukr. Руська Рада; Kappeler 2003, Weg, besonders 70-87; BotuschansкIJ et al. (Hg.) 1998, Bukowina, $172 \mathrm{ff}$.

244 Flächenmaß, ca. 1,4 ha.

$245 \mathrm{Vgl}$. Anm. 28, fol. 13 of. 
Ungerechtigkeiten auf kirchlichem Gebiete vorbringen und bitten, daß Seine Majestät geruhen, die Bukowinaer orthodoxe Diöcese in zwei orthodoxe Diöcesen zu theilen: in eine ruthenische und eine walachische Diöcese, oder wenigstens eine Theilung des Consistoriums. ${ }^{246}$

Die Versammlung verabschiedete alle Anträge zugunsten der Rus'ka Rada einstimmig. Es war offensichtlich, dass Pihuliak, wie schon sein Vorredner Smal-Stockyj, damit die noch kaum nationalisierten Bauern politisch zu mobilisieren gedachte. Die politische Sprengkraft der fraglos in der Bukowina weit verbreiteten sozialen Missstände ließ sich dergestalt leicht auf vermeintlich gezielt nationale Benachteiligungen der Ruthenen übertragen. Aus Sicht der rumänisch dominierten Kirchenhierarchie und rumänisch politischer Kreise glaubte man wiederum, darin eine potentielle Gefahr für das ebenso vermeintlich eigene nationale Erbe, die Kirche (und den Religionsfonds), am Horizont aufsteigen zu sehen. Die rumänische Zeitung Patria [Vaterland] druckte in Auszügen die in den Ansprachen "gegen die rumänischen Priester abgeladenen Abscheulichkeiten « des "Ausländers « (rum. veneticul) Smal-Stockyj und des "Zigeuner Renegaten « (rum. ţiganul renegat) Pihuliak. ${ }^{247}$ Zwischenzeitlich hatte das erzbischöfliche Konsistorium auf diese "in unerhörte Leidenschaftlichkeit ausgearteten Verunglimpfungen gegen die gr.-or. Curatgeistlichkeit « entsprechend empfindlich reagiert und drohte mit einer gerichtlichen Klage. ${ }^{248}$ Die in der Folge vom Konsistorium angerufene Staatsanwaltschaft sah indes keinen ausreichenden Anlass zur strafrechtlichen Verfolgung des Abgeordneten Pihuliak. ${ }^{249}$ Schließlich schien das Landtagsmitglied selbst doch noch einzulenken - Pihuliak sah sich wohl mit der Ernennung von Jeremijczuk zum Universitätsprofessor ebenso bestätigt - und drückte in einem persönlichen Schreiben den Metropoliten seine Hoffnung aus, in ihm - dem adressierten Kirchenhierarchen - einen »Friedensstifter « zu finden..$^{250}$ Das (rumänisch dominierte) Konsistorium wollte allerdings von seiner Haltung vorerst noch nicht zurückstehen und empfahl dem Erzbischof, mit seiner >Vergebung ‘ abzuwarten, bis ein öffentlicher Widerruf von Pihuliak erfolgt sei. Erst dann wollte das Konsistorium seine Klage zurückziehen. ${ }^{251}$ Innerhalb der rumänischen Fraktion der gr.-orient. Kirche, wie etwa seitens des Kirchenrechtlers

\footnotetext{
246 Vgl. Anm. 28, fol. $136 f$.

247 Das rumänische Blatt Patria [Heimatland] brachte eine Úbersetzung des Beitrages aus der ruthenischen Буковина; Nr. 231 v. 23.I./5.II., 2 und Nr. 232 v. 27.I./8.II.1899, 2.

$248 \mathrm{DACZ}_{320 / 3 / 4}$, fol. 109-120, hier fol. 115 u. 119, Sitzungsbericht des Konsistoriums v. 11./23. VI.1898.

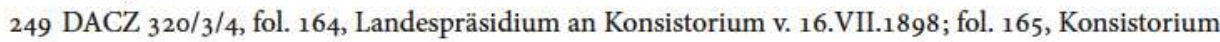
an Landespräsidium v. 7./19.VII.1898.

250 DACZ $_{320 / 3 / 67}$, fol. 57-59, Pihuliak an Erzbischof v. 25.II.1899.

$251 \mathrm{DACZ}_{320 / 3 / 67}$, fol. 63, Konsistorium an Erzbischof v. 19./31.III.1899.
} 
Eusebius Popowicz, gab es durchaus Stimmen, die im "Interesse des Friedens " ganz pragmatisch eine Teilung befürworteten, zugleich aber dabei stets den ausgesprochen rumänischen Charakter der Diözese betonten und »für alle Dienststellen der Zentralverwaltung « Rumänisch als erste Diözesansprache verlangten. ${ }^{252}$ Für die Jungruthenen galten diese Argumente wenig, stand doch Popowicz als Altruthene dem nationalrumänischen Lager nahe. ${ }^{253}$

In der Öffentlichkeit hingegen waren andererseits die von der Bukowinaer Post noch zum Priesterjubiläum des Metropoliten reichlich gestreuten Rosen eineinhalb Jahre später bereits merklich vergessen. In einem fordernden Tonfall verlangte dieselbe Zeitung jetzt ein entschiedeneres Auftreten gegen die politischen Bestrebungen der Ruthenen.

Herr Erzbischof Czuperkowicz, Anwalt Ihrer Kirche, wo sind Sie? Imponieren Sie uns, aber imponieren Sie auch jenen Aufdringlichen, die unberufen sich in Angelegenheiten der gr--or. Kirche mengen mit Sendschreiben, gleich dem Hakmann'schen! $!^{254}$

Die Abgeordneten Pihuliak und N. v. Wassilko setzten zeitgleich im Gegenzug alles daran, den Rückhalt für ihre Partei innerhalb der ruthenischen Bevölkerung der Bukowina weiter auszubauen bzw. sich selbst als ihre alleinigen Sprecher in der Öffentlichkeit zu stilisieren. Im Jänner 1899 überreichten beide dem Erzbischof ein auf Beschluss der 1898 erfolgten Versammlung verfasstes und gedrucktes dreiseitiges Memorandum, in dem sie neuerlich auf die "traurige Lage des orthodoxen ruthenischen Volkes [der] Bukowina auf kirchlichem Gebiete" aufmerksam machten. Nur in einer nationalen Teilung der gr.-orient. Diözese glaubten beide Politiker noch einen gangbaren Ausweg zu sehen. Da dieses Ziel unter den gegebenen Umständen wenig Aussicht auf Erfolg hatte, unterbreiteten Wassilko und Pihuliak dem Metropoliten vorerst einmal eine Reihe von Vorschlägen zur Entspannung der Situation. So sollten beispielsweise das Konsistorium in zwei nationale Sektionen geteilt und der Erzbischof sowie der Bischof von Radautz jeweils abwechselnd aus dem rumänischen bzw. ruthenischen Klerus heraus besetzt werden. ${ }^{255}$

252 ANB - Iancu Flondor 945, fol. 17-22; Eusebius Popowicz (rum. Eusebiu Popovici) war von 1875 bis 1908 ord. Universitätsprofessor für Kirchengeschichte an der theologischen Fakultät der Czernowitzer Universität; seit 1908 Ehrenmitglied der Rumänischen Akademie der Wissenschaften.

253 Р Rокорошітsсн 1965, Nationalbewegung, 82.

254 Bukowinaer Post Nr. 858 v. 27.VI.1899, 1, Smal-Stockis jüngste That.

255 Das Memorandum liegt in gedruckter Form sowohl in Deutsch als auch in Ruthenisch vor; DACZ 320/3/67, fol. 67 (ruthenisch); DACZ 320/3/4, fol. 186f., Heilige orthodox-katholische Metropolitansynode! (deutsch, mit Originalunterschriften von Wassilko und Pihuliak). 


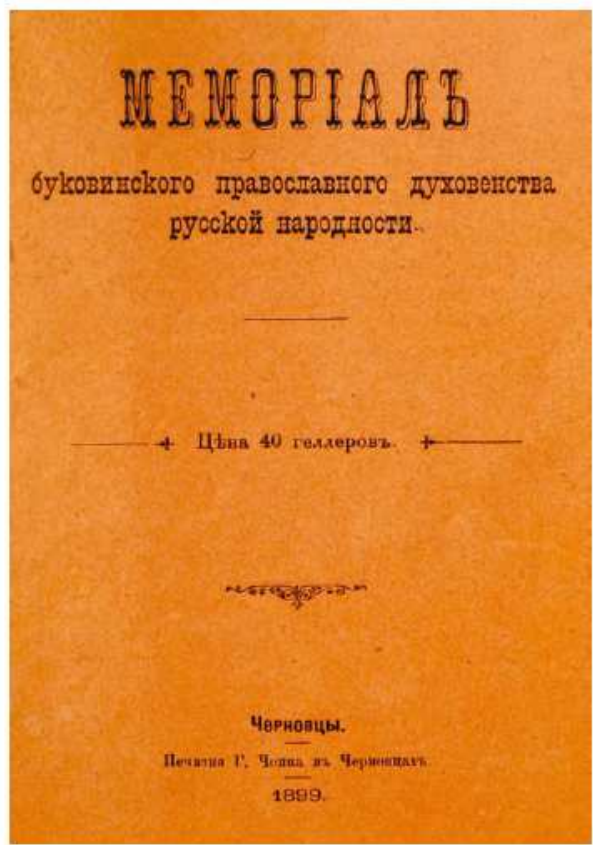

\section{М E М ОРІ А Л \\ бykoвzвсkого православного духовенства pycckoü народностz.}

Bи полопинђ января мњеяпа сето года внесли дша послы буконипекого Сойа, ироф. Героней Пи гу а кт и Николаі рыңарь В а ияько nо адрееу Cпnтhimero Синода Буковипь и Аамаціи меморіаль, вт. которомт. они, пре, ставивши печамное половевіе православного буковпгеко-русекого парода пт, перкошной облаети и поднесши кривды, икіи тернить тоть-яке ео стороны душшастиреĭ, неумфющихт по русски,

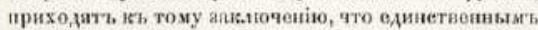
пеходом' изи того иеаลиидного полозкеня быль

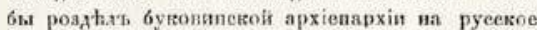
и румынекое епископетиа. Но такь якь переве,деніе той и, еи пока-что евявано еъ, большими трудноетями, потому навванвьи поелы ире,дожияи:

а) чтобь 6 уковиская архіепистопекая кон-

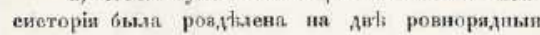
секціи, руескую и руанынекую, которыи совыща.иеь

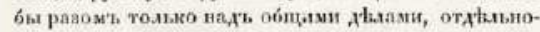
яе надь церкопными дылами обоихт автохтонных народовь ватего края :

6) ттобы на перемтну разъ архіепиекошь

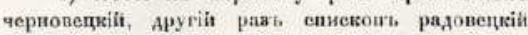

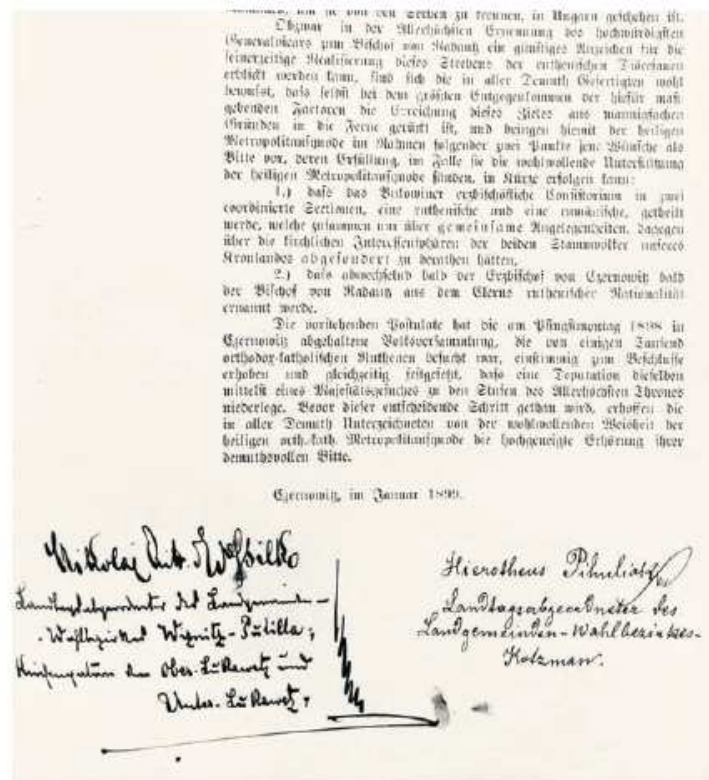

Abb. 22-24: Memorandum der Jungruthenen an den Erzbischof 1899 in ruthenischer Sprache. Titelblatt und erste Seite der ruthenischen (Abb. 22 u. 23), letzte Seite der deutschen Ausgabe (Abb. 24). Die letzte Seite der deutschen Version trägt die Unterschriften von Wassilko und Pihuliak ${ }^{256}$

$256 \mathrm{DACZ}_{320} / 3 / 67$ u. $320 / 3 / 4$. 
Kircheninnenpolitisch hatten beide Politiker offensichtlich bereits den Versuch gestartet, den gr.-orient. Bischof von Zadar, Dr. Nikodim Milaš $(1845-1915)^{257}$, für ihre Sache einzunehmen und ihm ebenfalls, anlässlich der Weihe von Repta zum Bischof von Radautz, ein Memorandum übermittelt. Die Bukowinaer Post - zu diesem Zeitpunkt in ihrer Blattlinie noch eine radikale Gegnerin der jungruthenischen Bewegung - beantwortete diesen Vorgang mit einem geharnischten Leitartikel unter dem Titel "Sursum Corda!« [Hoch die Herzen!]. Dabei scheute sie sich nicht, darin zeitgleich die (ohnedies zahlenmäßig wenigen) Unierten des Kronlandes anzugreifen. Diese vorwiegend aus dem benachbarten Kronland Galizien-Lodomerien in die Nordbukowina eingewanderten Ruthenen empfand die Orthodoxie - nicht zuletzt wegen einiger spektakulärer Kirchenübertritte während der Amtszeit von Morariu-Andriewicz - als regelrechte Gefahr für die Landeskirche. Rumänische Kreise befürchteten daher, die Bukowina würde seitens der Wiener Regierung als Kompensation für die Ruthenen und ihre unerfüllten Erwartungen im benachbarten Galizien herhalten müssen. ${ }^{258}$

Wir tangiren ungern Familienverhältnisse, aber wenn wir sehen, daß Männer, wie Pihuliak und Philippowicz ${ }^{259}$, beide gr.-orthodox, aus reinster Liebe und Anhänglichkeit zur Orthodoxie ihre Sprößlinge griechisch-katholisch oder katholisch taufen lassen, weiters wie Dr. Stocki und Landesgerichtsrath v. Jasieniecki, beide ausgesprochene Partisanen der unirten Confession, sicher hervordrängen, um die griechisch-orthodoxe Kirche vor ihrem Untergange zu wahren, wenn wir sie im dauernden Umgange mit Dr. Milas wissen, diesen sich von ihnen über die Verhältnisse der Kirche, der er angehört, der aber seine Bukowinaer Zuträger durch ihr Verhalten den Rücken kehren, informiren lassen, dann müssen wir uns fragen, ist denn Dr. Milas hierher gekommen, um über Metropolit und Consistorium zu Gericht zu sitzen und allen jenen, bis zum Ekel wiedergekäuten, unwahren Beschwerden, die in dem jüngsten ruthenischen Pamphlete, das sich 'Memorandum ‘ betitelt und die Unterschriften der beiden Ueberläufer Nikolaj v. Wassilko und Hierotheus Pihuliak trägt, bischöfliches Gehör zu schenken [...] Wir constatieren, daß in der gr.-or. Priesterschaft es zwischen Rumänen und Ruthenen, insofern die Interessen der Orthodoxie in Frage kommen, keine Differenzen bestehen und blicken frohen Muthes in die Zukunft, weil wir der Zuversicht leben, daß es gerade dem geeinten Priester-

257 Milas (auch Nikodim Milaš) war seit 1890 Bischof von Dalmatien mit Sitz in Zadar, das als Suffraganbistum zur Metropolie von Czuperkowicz gehörte. Er zählte seinerzeit zu den führenden Experten für ostkirchliches Recht.

258 Nistor 2003, Istoria, 149.

259 Direktor der Bukowiner Landeskrankenanstalten, kandidierte im August 1903 für die Jungruthenen. 
stande gelingen muß, die giftige und verderbensäende Schlange des Jungruthenismus mit Putz und Stengel auszurotten. ${ }^{260}$

In der Zwischenzeit eskalierte die Situation in der Czernowitzer Öffentlichkeit zusehends. War der Metropolit nach seiner Weihe in Wien bei der Ankunft am Bahnhof der Landeshauptstadt im Mai 1896 noch feierlich empfangen worden, so begann im April 1899 seine Reise zu einer kaiserlichen Audienz in die Reichshauptstadt mit einem handfesten Skandal, der in der ganzen Monarchie Aufsehen erregte. In der Öffentlichkeit schien der Vorfall das ohnehin schon geläufige Vorurteil von den sogenannten >Bukowiner Zuständen $\iota^{261}$ nur noch zu bestätigen. ${ }^{262}$ Die politisch aufgeheizte Stimmung des Kronlandes entlud sich während einer Demonstration von Studenten gegen den Metropoliten am Bahnhof von Czernowitz.

Der Metropolit, welcher als Gegner der rumänischen Chauvinisten gilt, wurde im Perron mit ohrenbetäubenden Pereat-Rufen ${ }^{263}$ empfangen und einer der Demonstranten, der Universitätshörer Dionys Sluzanski, Sohn eines griechisch-orientalischen Pfarrers, erhob zweimal drohend den Stock gegen den Metropoliten, dessen Tochter die Hiebe auffing und sich dadurch Verletzungen zuzog. ${ }^{264}$

Die Universitätsleitung unter ihrem Rektor Arthur Skedl reagierte daraufhin scharf und relegierte bzw. erteilte den darin verwickelten Studierenden einen strengen Verweis. ${ }^{265}$ Auch in strafrechtlicher Hinsicht zeitigte dieser Vorfall für die Beteiligten ernste persönliche Konsequenzen. ${ }^{266}$ Die rumänischen Studenten hatten ursprünglich offenbar auch die Absicht gehabt, den Erzbischof in Wien mit ähnlichen Protesten ebenso gehörig zu empfangen. Der Landespräsident wusste dies zu verhindern und informierte die Poli-

260 Bukowinaer Post Nr. 800 v. 5.II.1899, If., Sursum corda! Der Artikel liegt dem Konsistorialakt bei, DACZ $_{320 / 3 / 4}$, fol. 158 .

261 Corbea-HoIșie 2010, Czernowitz.

262 U.a. Neue Freie Presse Nr. 12448 v. 19.IV.1899 (Morgenblatt), 4; Vorarlberger Landes-Zeitung Nr. 91 v. 21.IV.1899, 2, Ein Attentat.

263 Lat. Studentenjargon $»$ Nieder $[\mathrm{mit}$ ihm] ! .

264 Neuigkeits-Welt-Blatt, 2. Bogen v. 21.IV.1899, Demonstrationen gegen einen Metropoliten.

265 »stud. jur. Sluşanschi« (auch Sluzanski) und »stud. jur. Eus. Antonovici« erhielten drei bzw. ein Semester Studiensperre; »stud. phil. Em. Antonovici« fasste eine Rüge des Senats aus und »abs. theol. Adrian P. Deseanu « verlor sein Recht auf weitere Rigorosen an der Universität Czernowitz; nach Bukowinaer Post Nr. 846 v. 30.V.1899, 2, Tagespost. Von der Universität.

266 Sluzanski bekam eine Strafe von $100 \mathrm{fl}$., die Brüder Antonovici sowie Deseanu jeweils 50 fl. Letzterer musste die Bukowina in Richtung Ungarn verlassen; er wurde mit einem Aufenthaltsverbot für das Kronland belegt; nach BĂLAN 2002, Arhiva, 143. 
zei der Reichshauptstadt. ${ }^{267}$ Während besonnenere Zeitungen noch von der "hitzigen und unüberlegten Jugend « berichteten ${ }^{268}$, stichelte die Bukowinaer Post weiter. Czuperkowicz kehrte in der Folge erst am 9. Juli 1899, nach dreimonatiger Abwesenheit und einer Kur, in aller Stille nach Czernowitz zurück, wo ihn - neben offiziellen Repräsentanten des Landes und der Stadt - lediglich ein »bedeutendes Polizeiaufgebot, sowie alle Detectivs « ${ }^{269}$ empfingen und das obwohl seine Ankunft am Tag zuvor öffentlich angekündigt worden war. ${ }^{270}$

Während der letzten Jahre war die Parteienlandschaft des Kronlandes durch die laufenden Wahlreformen und die sich wechselnden politischen Agenden sichtlich in Bewegung geraten. So etwa übernahm 1897 der mjunge und energische rumänische Nationalist« Iancu Ritter v. Flondor (1865-1924) die Führung der Partidul Naţional Român din Bucovina [Rumänische Nationalpartei der Bukowina]. ${ }^{271}$ Letztere büßte nicht zuletzt aufgrund des Wechsels von N. v. Wassilko (von den Altruthenen zu den Jungruthenen) ihre bisherige Regierungsmajorität im Bukowiner Landtag ein. Als unmittelbare Folge reagierte die Parteipolitik aus diesem Winkel noch empfindlicher auf Forderungen der Jungruthenen oder deren angebliche Sympathisanten, wie man sie unter anderem in der Person des Erzbischofs auszumachen glaubte. ${ }^{272}$ Die vom Metropoliten vertretene Idee des nationalen Dualismus innerhalb der Kirche schrieb man "Einflüsterern « und vor allem den »Unierten galizischer Herkunft« zu. Der »Renegat Koko Wassilko« hätte zu diesem Zweck in Wien eine wahre "Tartuferie « arrangiert. ${ }^{273}$ Allein die von Czuperkowicz eingeforderte Umkehr zur Vernunft seitens der Nationalpartei stellte sich indes nicht in der erwarteten Weise ein. Daran war freilich der amtierende Landespräsident Friedrich Bourguignon nicht ganz unbeteiligt. Den "hohen Grad nationaler Erregung" nahm der kaiserliche Vertreter in einer Rede zum Geburtstag des Kaisers zum Anlass, die vermeintliche Illoyalität jenes gr.-orient. Klerus anzukreiden, der die rumänische Trikolore am Revers zu tragen pflegte, also eigentlich für einen anderen Staat eintrete. Zugleich richtete der Landespräsident eine Spitze gegen eben jene beiden Konsistori-

267 BĂLAN 2002, Arhiva, 136.

268 Bukowinaer Rundschau Nr. 3003 v. 19.IV.1899, 1, Die Demonstration gegen den Erzbischof.

269 Bukowinaer Post Nr. 863 v. 9.VII.1899, 3, Tagespost.

270 Bukowinaer Rundschau Nr. 3066 v. 7.VII.1899, 3, Kleine Chronik.

271 Politiker und Großgrundbesitzer in der Bukowina; CeAușu 200o, Landtag, 2189; Hitchins 1980, Rumänen, 617.

272 "Mit der frischen Brise im rumänischen Parteilager hängt die Agitation gegen das kirchliche Oberhaupt der Nation, gegen den Erzbischof selbst auf das Engste zusammen «; Bukowinaer Rundschau Nr. 3068 v. 9.VII.1899, 1f., Einkehr oder Umkehr.

273 Morariu 1914, Bucovina, 76 u. 79. 
alräte, Dionys Ritter v. Bejan (1837-1923) $)^{274}$ und Myron Calinescu (1837-1912) 275 , die in scheinbar demonstrativer Absicht gar nicht erst zum Empfang des Metropoliten am Bahnhof erschienen waren. ${ }^{276}$ In seinem überparteilichen Streben als österreichischer Spitzenbeamter und Vertreter der Wiener Regierung hatte Bourguignon die nationalistischen Rumänen des Kronlandes gegen sich aufgebracht, die dahinter lediglich eine verdeckte Bevorzugung der Ruthenen vermuteten.

Schon zuvor hatten sich nationale Kreise Bourguignon gegenüber überaus reserviert gezeigt. So beschrieb die rumänische Zeitung Patria den Landespräsidenten bei seinem Amtsantritt als einen Beamten "în sens strict austriac « [im strengen österreichischen Sinne]. ${ }^{277}$ Als Ersatz für die vakanten Sitze im erzbischöflichen Konsistorium oblag es ihm, die Kandidaten bei der Neubestellung stellvertretend für die Interessen Wiens zu unterstützen. Die Entscheidung fiel auf die ruthenischen Priester Artemon Manastyrski $(1857-1923 \text { ? })^{278}$ und Gheorghe Hanicki. Hanicki (1843-1910) stand den Altruthenen nahe, trat politisch allerdings kaum in Erscheinung, die Einheit der Landeskirche vertrat er im Konsistorium jedoch mit Vehemenz. ${ }^{279}$ Bourguignon setzte sein politisches Gewicht für die Ernennung von Repta als Generalvikar - und damit in der Hierarchie als Nachfolger des amtierenden Metropoliten vorgesehen - ein, den er als ein dem Kaiserhause unzweifelhaft loyalen Kirchenmann schätzte. ${ }^{280}$

Noch einmal zurück zu den derart kritisierten Konsistorialräten. Der Archimandrit Calinescu übte ein Landtagsmandat aus und gehörte zusammen mit Alexandru v. Hormuzaki (1869-1946) ${ }^{281}$ sowie Flondor seit Anfang Juli 1899 der neu aufgestellten Ru-

274 Mitbegründer der Gazeta mazililor şi răzeşilor bucovineni (1910-1914) [Zeitung der Mazilen und Rezeschen der Bukowina; i.e. des Kleinadels/derFreibauern], Vizepräsident und später Präsident der Societăţii pentru Cultura şi Literatura Română în Bucovina (1900-1922) [Verein für rumänische Kultur und Literatur in der Bukowina], Ende Oktober 1918 fungierte Bejan als Vorsitzender des Nationalkongresses der Bukowina; nach SATCO 2004, Enciclopedia, $96 \mathrm{f}$.

275 Rum. Mihai Miron Călinescu.

276 Neue Freie Presse Nr. 12378 v. 29.VIII.1899, 4, Gegen den rumänischen Chauvinismus.

277 Patria Nr. 74 v. 21.XII.1897/2.I.1898; nach BĂLAN 2002, Arhiva, 121; Iorga beschreibt den Landespräsidenten wenig versöhnlich im Nachhinein als »duşman îndârjit al Românilor « [starrsinnigen Feind der Rumänen]; Iorga 1938 Românismul, 114; Bukowinaer Post Nr. 354 v. 8.III.1896, 1, Aus dem Jungruthenischen Lager II.

278 Ruthenischer Redakteur der Zeitschrift Candela [Kerze/Licht]; nach SATCO 2004, Enciclopedia, 8. 2791899 Konsistorialrat, seit 1901 Diözesaninspektor für die Erzpriesterschaftsbezirke Kotzmann, Putilla, Dniester und Czermosz (sic!), Mitglied im Bukowiner Landesschulrat, 1905 Übertritt in den Regularklerus (mit den Namen Genadie); nach Czernowitzer Allgemeine Zeitung Nr. 1823 v. 12.II.1910, 3, Konsistorialrat Hanicki; Nr. 1825, 15.II.1910, 4, Czernowitzer Angelegenheiten.

280 BALLAN 2002, Arhiva, 130.

281 Rum. Alexandru Hurmuzachi, Sohn von Nikolaus Hormuzaki. 
mänischen Nationalpartei an. ${ }^{282}$ Gerüchtehalber hatten Calinescu und Bejan gegen eine Kandidatur des Erzbischofs für den Reichsrat gestimmt. ${ }^{283}$ Über den Religionsfonds konnten als Vertreter des Großgrundbesitzes Mandate in der entsprechenden Kurie vergeben werden, der Metropolit gehörte ohnedies kraft seines Amtes automatisch dem Herrenhaus an. Schwerwiegender in der Sache schlug sich indes die von den beiden erwähnten Konsistorialräten an führender Stelle mitorganisierte rumänische Priesterversammlung in Czernowitz nieder - die von den Äußerungen Bourguignons aufgebracht ihren Unmut freien Lauf ließ. Die Initiative der Kirchenfunktionäre mündete in einem Disziplinarverfahren. ${ }^{284}$ Sowohl Calinescu als auch Bejan sollten mit Zustimmung des Erzbischofs im Anschluss an das Verfahren in den Ruhestand übertreten, ganz so wie es Bourguignon ursprünglich eingefordert hatte. ${ }^{285}$ Der Landtagsabgeordnete und Rektor der Universität Skedl legte darüber hinaus ein auf die »extrem radicalen Rumänen « abzielendes Memorandum vor, das entschieden zur »Verhetzung der Bevölkerung gegen den Erzbischof Czuperkowicz und den Landespräsidenten « Stellung bezog. Eine Deputation ruthenischer Priester dankte daraufhin sowohl Bourguignon als auch dem Metropoliten für ihre »Objectivität und Gerechtigkeit« in der Sache. ${ }^{286}$ Inwiefern allerdings diese - freilich ins Bild passende - Willenskundgebung der Gläubigen freiwillig oder gezielt inszeniert worden war, lässt sich aus heutiger Sicht kaum mehr einschätzen. Zur ursprünglich anvisierten Versetzung in den Ruhestand sollte es jedoch nicht kommen, im Gegenteil, M. Calinescu stieg später zum Generalvikar der Diözese auf.

Die diametrale Wende der Bukowinaer Post in ihrer Positionierung als Teil einer parteipolitisch agierenden Öffentlichkeit verbildlichte sich in der Person des Archimandriten ausgesprochen deutlich. In einem Rückblich von N. v. Wassilkos zum Ableben von Calinescu 1912 meinte dieser, dass Czuperkowicz letztlich "Zu schwach" gewesen sei und "seinem guten Willen weiters auch ein Konsistorium, erfüllt vom Geiste Morarius, in dem ein Calinescu und Bejan das große Wort führten, als unüberwindliches Hindernis« entgegen gestanden hätte. ${ }^{287}$ Obgleich aus einer subjektiven Position heraus argumentierend, lag N. v. Wassilko mit dieser Charakterisierung der Übergangsära von Morariu-Andriewicz auf Repta nicht gänzlich falsch. Der alternde Erzbischof Czuperkowicz verfügte von Beginn an kaum über eine reale Chance, aktiv in die zunehmend national

282 Neue Freie Presse Nr. 12522 v. 4.VII.1899 (Abendblatt), Telegramme.

283 Bukowinaer Post Nr. 891 v. 12.IX.1899, 1, Bejan-Calinescu!

284 Deutsches Volksblatt Nr. 3850 v. 20.IX.1899, 3, Czernowitz.

285 Deutsches Volksblatt Nr. 3906 v. 15.XI.1899, 2, Die Zustände in der Bukowina.

286 Neue Freie Presse Nr. 12610 v. 30.IX.1899 (Abendblatt), 3, Telegramme.

287 Bukowinaer Post Nr. 2828 v. 7.IV.1912, 1-3, Die Antwort der gr.-or. Ruthenen. 
aufgeladene Situation seiner Diözese eingreifen zu können, um das Heft des Handelns zu übernehmen. Eingeklemmt zwischen der schweren Erbschaft einerseits, die ihm sein Vorgänger überlassen hatte, und den wachsenden Forderungen einer nationalisierten ruthenischen Bevölkerung andererseits, flüchtete er sich - gesundheitlich ohnedies angeschlagen - in eine Situation, die ihm von außen unter den gegebenen Umständen wiederum als Unentschiedenheit oder gar Parteilichkeit ausgelegt wurde. Dieser Eindruck traf allerdings nur mit Einschränkung zu und gründete vielfach auf den Meinungen der parteipolitisch in der Öffentlichkeit agierenden nationalen Gruppen. So stellte sich etwa die Haltung des betroffenen ruthenischen Klerus im Kronland gegenüber der sie svertretenden jungruthenischen Partei von N. v. Wassilko keineswegs so homogen dar, wie das ihre Vertreter gerne gesehen hätten. Das 1899 an den Metropoliten Czuperkowicz überreichte, von N. v. Wassilko und Pihuliak unterzeichnete Memorandum provozierte im Gegenteil - unter einem erklecklichen Teil der ruthenischen Priester eine dezidierte Ablehnung.

Solche ungesunden Verhältnisse einerseits und die zielbewusste Agitation und systematische Propaganda andererseits, riefen diese so kritische Lage unserer bukowinaer orthodoxen Kirche hervor, sie verursachten auch die in letzterer Zeit sich so oft wiederholenden Apostasien von unserem orthodoxen Glauben. Als Symptom eben dieser ungesunden Verhältnisse ist unter vielen anderen Stimmen auch das eingangs erwähnte Memorandum der Abgeordneten $\mathrm{Pi}$ huliak und Wassilko zu betrachten. Belehrt durch die Geschichte unseres Volkes, in welcher das verhängnisvolle `divide et impera eine so abschreckende Rolle gespielt hat und Wünsche, dass unsere Kirche unabhängig bleibt von auswärtigen Einflüssen, stehen wir, die Bukowinaer orthodoxe Geistlichkeit ruthenischer Nationalität, und mit uns das gesammte ruthenische, orthodoxe Volk und werden stets verbleiben auf dem Standpuncte der Untheilbarkeit der Bukowinaer Erzdiöcese und ihres Consistoriums. Deshalb erklären wir unsere Nichtübereinstimmung mit dem Memorandum des Herrn Pihuliak und Wassilko und protestieren entschieden gegen die dort angeführten Agitationsreden des Abgeordneten Pihuliak, besonders aber gegen dessen Rede auf der vorjährigen Volksversammlung zu Czernowitz 6. Juni, die wesentlich gegen die gesammte orthodoxe Geistlichkeit Bukowinas gerichtet ist [...] In Anbetracht [...] d) des jahrhundertelangen Zusammenlebens und der öfteren Blutverwandtschaft der beiden Völker, endlich e) mit Rücksicht auf die ererbte Liebe zu unserer Mutter-Kirche - stehen wir treu und unerschütterlich bei der Untheilbarkeit unserer dem Schutze Gottes anempfohlenen Erzdiöcese. $^{288}$

288 DACZ $_{320 / 3 / 67}$ fol. 68f. u. 72; Memorandum ruthenischer Geistlicher an Erzbischof (zugleich an Landespräsidenten) Czernowitz v. 31.V./12.VI.1899; Unterschrift von 65 Geistlichen; in hektographierter Form auch unter DACZ $320 / 1 / 57$, fol. 3-11. 
Der Metropolit hatte die Situation sehr wohl korrekt eingeschätzt und wies das Landespräsidium darauf hin, dass viele Vorwürfe einer Benachteiligung der Ruthenen realiter ins Leere gingen, aber eben in der Öffentlichkeit so nicht wahrgenommen wurden oder werden wollten. Vor allem der Verwendung der ruthenischen Sprache sowohl in den betroffenen Pfarren als auch im innerkirchlichen Schriftverkehr stand zumindest de jure ohnedies nichts entgegen.

Trotz dem es sehr darauf gesehen wird, daß während des Gottesdienstes abwechselnd rumänisch und ruthenisch gelesen und gesungen werde, scheint es oft dem Ruthenen zuviel des Rumänischen und umgekehrt dem Rumänen zuviel des Ruthenischen gehört zu haben und so kommt es, daß bald die ruthenischen Zeitungen über zuviel des Rumänischen, bald die rumänischen über zuviel des Ruthenischen in der Kathedralkirche u. d. Pfarrkirchen klagen. ${ }^{289}$

Im Verordnungsblatt der Diözese gelangten alle Zirkulare zweisprachig, in Rumänisch und in Ruthenisch (zum Teil auch in Deutsch), zum Abdruck. ${ }^{290}$ Darüber hinaus galt seit 1873 das Ruthenische als gleichberechtigte Kirchensprache in der Bukowina. ${ }^{291}$ Das Bekenntnis des Erzbischofs zu einer supranationalen Haltung seiner Kirchenführung mag beim Landespräsidenten Gehör gefunden haben, konnte jedoch in der Öffentlichkeit, wo wesentlich schneller agierende politische Parteien und ihre spezifische Interesse die Richtung bestimmten, nur wenig ausrichten.

Ich muß vielmehr meinerseits nochmals wiederholen und für mein durch meine bisherige Wirksamkeit bethätigtes und unwandelbares Princip erklären, daß bei mir die Confessionalität allein maßgebend und es für mich ganz irrelevant ist, zu welcher Nationalität ein Priester sich bekennt. Ich verlange von ihm nicht Angehörigkeit zu derselben, sondern blos Kenntnis der Sprache und ziehe denjenigen vor, der beide Diöcesansprachen beherrscht. ${ }^{292}$

289 DACZ $_{320 / 3 / 67}$, fol. 93-104, hier fol. 95; Erzbischof an Landesregierung v. 8./21.II.1902.

290 Foaia ordinăciunilor Consistoriului archiepiscopesc în afacerile Archidiecesei ortodoxe-orientale a Bucovinei /Verordnungsblatt des erzbischöflichen Konsistoriums die Angelegenheiten der orthodox-orientalischen Erzdiözese der Bukowina betreffend.

291 Verordnung des Konsistoriums v. 4./16.X.1873 Nr. 4192; nach MorariU 1914, Bucovina, 73 ; zur Sprachenfrage im Kronland Bukowina vgl. ZUB 2015, Traducerile; die Autorin berührt darin allerdings lediglich die staatliche Seite auf Zentralstaats- sowie Landesebene; die kircheninternen Regelungen behandelt sie nur am Rande, ebd. 162-170.

$292 \mathrm{DACZ}_{320 / 3 / 67}$, fol. 93-104, hier fol. 105, Erzbischof an Landesregierung v. 8./21.II.1902. 


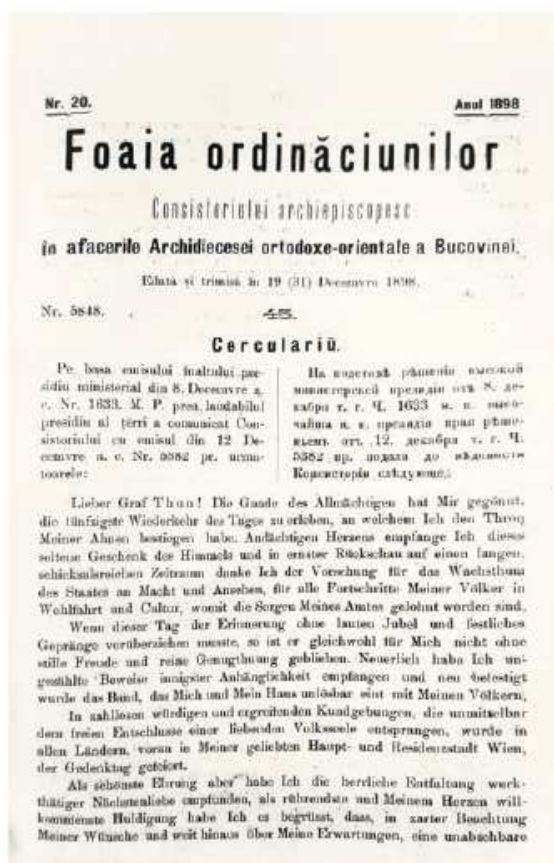

Abb. 25: Foaia ordinăciunilor - Dreisprachiges Verordnungsblatt der Bukowiner gr-orient. Erzdiözese. $^{293}$

\section{Foaia ordinăciunilor}

Consis̆teriutei arehiegniscupus:

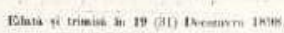

$\pm B$

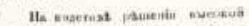

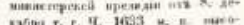
gahua is. vean. Boprocropin ataysue:

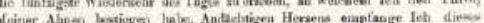

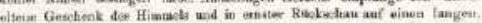

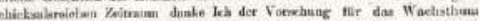
Wohlfalirt and Culturi, wamit die Borger Meinee Amter gelohint worden wiad. Wean dinser Tag der Dritanreng chise laules Jubel und Festliches

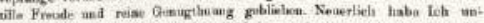

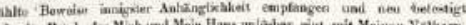

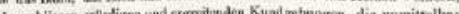

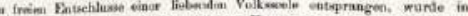

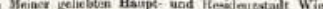

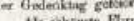

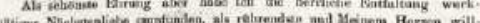

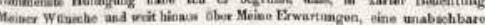

Auch die vom Landespräsidenten im Sinne der österreichischen Regierung durchgesetzten Entscheidungen in der Kirchenfrage zielten zwar im Grunde auf einen Ausgleich zwischen den rivalisierenden nationalen Gruppen ab, allein resultierten sie immer öfter in beidseitig wachsender Unzufriedenheit innerhalb der Diözese des Kronlandes. Insgesamt geriet der dominierende Elitenkonsens, der sich der deutschsprachigen österreichischen Kultur verpflichtet sah, nach der Jahrhundertwende in steigendem Maße unter den Druck der jeweils eigenen nationalen Kreise. Die schwelende Kirchenfrage der Bukowina blieb unter dem Nachfolger von Czuperkowicz bis Kriegsausbruch für die politische Diskussion um das weitere Schicksal der gr.-orient. Diözese und seiner wirtschaftlichen Machtbasis - dem Religionsfonds - entscheidend.

\section{Von der Kirchenfrage zum Kirchenstreit}

Der Landtagsabgeordnete Aurel v. Onciul versuchte im Vorfeld zu den Reichsratswahlen ausführlich ein Konzept darzulegen, das die nationalen Spannungen zwischen Ruthenen

293 DACZ $_{320 / 1 / 3342, \text { fol. } 18 .}$ 
und Rumänen der Erzdiözese strukturell lösen wollte. ${ }^{294}$ Onciul griff darin neuerlich den Ruf nach Gewährung eines Kirchenkongresses auf, also einer breiten Laienbeteiligung für die Regelung kirchlicher Angelegenheiten. Damit berührte er jedoch die ohnedies überaus sensible Frage vom Verhältnis orthodoxe Kirche - Staat bzw. der Autonomie der Kirche innerhalb des Staates. Der Rückgriff auf bereits früher geführte Diskussionen um das Statut der orthodoxen Kirche in Österreich im Allgemeinen erschwerte indes die Ansätze zur Entflechtung dieser komplexen Thematik in der Bukowina mehr als sie zu deren Lösung beitrug. Nicht nur bei den Personalentscheidungen sicherten sich die Behörden und in letzter Instanz der Kaiser das entscheidende Wort, sondern auch in der Verwaltung des Kirchenvermögens, das sich im gr--orient. Religionsfonds befand und über diesen verwaltet wurde. Die Kirchenfrage berührte also über kurz oder lang stets jene der Autonomie und der Verfügungsgewalt über die beträchtlichen Mittel dieses Fonds. Zugeständnisse Wiens gegenüber derlei Vorschlägen hätten einerseits das Risiko eines erheblichen politischen Kontrollverlustes seitens des Staates innerhalb des Kronlandes in sich getragen. Immerhin war das Investitionspotential des Fonds für die Landesentwicklung - wie sich schon in den Jahrzehnten zuvor etwa an den Beispielen der Manzschen Eisenwerke oder der Errichtung der Universität gezeigt hatte - von entscheidender Bedeutung in diesem ansonsten strukturschwachen Gebiet. Wien musste andererseits auf landespolitischer Ebene eine möglicherweise nicht mehr einhegbare Eskalation der nationalen Verhältnisse befürchten, sobald man den Entscheidungsprozess über kirchliche Angelegenheiten in diesem Ausmaß zu weit in die Bevölkerung hineintragen würde. Dazu kamen die politischen Parteien und ihr wachsendes Verlangen - wie das Erzbischof Czuperkowicz an der eigenen Person erleben musste -, diese Strukturen für ihre eigenen, oftmals kurzfristigen Zwecke zu instrumentalisieren (vgl. Abb. 26). Kurz nach der Jahrhundertwende formulierte die Partidul Poporal Naţional [Nationale Volkspartei] Kirchenautonomie und Verfügungsgewalt über das Religionsfondvermögen als eines ihrer zentralen politischen Ziele. ${ }^{295}$

Onciul jedoch blieb fest bei seiner Ansicht, dass die nationalen Spannungen in einem Kirchenkongress kanalisiert werden könnten und gerade damit gleichzeitig eine demokratisch verfasste Prüfstelle "gegenüber den Herren im Konsistorium " geschaffen wäre, die »sich frei von jeder Kontrolle wissen und ihrer Willkür die Zügel schießen lassen«. ${ }^{296}$

294 Bukowinaer Post Nr. 1714 v. 19.I.1905, 1, Zur gr.-or. Kirchenfrage. Von Dr. Aurel Onciul; Nr. 1719 v. 2.II.1905, 2, Die gr.-or. Kirchenfrage im Parlamente. Interpellation; Nr. 1728 v. 21.II.1905, 1f., Die Mißstände in der gr.-or. Diezöse (sic!). Interpellation; Nr. 1729 v. 23.II.1905, 2f., Die Mißstände in der gr.-or. Diezöse (Schluß).

295 Gafiţa 2004, Considerații, 226.

296 Bukowinaer Post Nr. 1714 v. 19.I.1905, 1. 
Zwei national beschickte Kurien (jeweils eine für die gr--orient. Rumänen und Ruthenen des Kronlandes) sollten die Parität sicherstellen. Die Wahlaufsicht wie deren Durchführung wäre laut Onciul von den politischen und nicht den geistlichen Behörden zu tragen gewesen. Zugleich hätte eine solche Regelung - ganz im Sinne der von Onciul geführten Partidul Ţărănesc Democrat [Rumänisch demokratische Bauernpartei] - eine nachhaltige Schwächung des Großgrundbesitzes eingeleitet. Wäre damit doch unter anderem die Aufhebung der zumeist von den Agrareliten der Bukowina ausgeübten Kirchenpatronate und ihrer Privilegien einhergegangen. Insgesamt verlangte Onciul im Vorschlag für einen künftigen Kirchenkongresses folgende Kompetenzen:

- Vorschlagsrecht für die Besetzung des erzbischöflichen Stuhls, der Weihbischöfe sowie der Mitglieder des Konsistoriums;

- Entscheidung über Beschwerden gegen die Amtsführung des Erzbischofs und sein Konsistorium;

- Mitsprache in der kirchlichen Gesetzgebung und

- Kontrolle sowie Verwaltung des gr--orient. Religionsfonds. ${ }^{297}$

Aus staatsrechtlicher Sicht bemühte sich das Kultusministerium mehrfach, vertreten durch seinen Sektionschef Johann v. Spaun (1840-1911) $)^{298}$, in einem ausführlichen Gutachten eine ganze Reihe der seitens Onciuls eingebrachten Vorschläge zu widerlegen, nicht allerdings ohne im Generellen darauf hinzuweisen, dass »manche die Kirche angehenden Normen den Stempel ihrer Entstehungszeit tragen und daher eine Revision beziehungsweise Verjüngung auf manchen Gebieten am Platze sein dürfte «. ${ }^{299}$ Dezidiert sprach sich der Ministerialbeamte im Gutachten jedoch gegen die Berücksichtigung nationaler Kriterien bei der Besetzung kirchlicher Ämter aus und wies den Vorwurf Onciuls zurück, dass der Staat die Entwicklung der Kirche hemmen würde. Im Gegenteil, so Spaun, die »k.k. Regierung wahrt notorisch mit peinlicher Gewissenhaftigkeit die Kompetenz der kirchlichen Autorität « ${ }^{300}$

Wie die Dinge liegen und wohl noch lange liegen werden, würde die Ernennung eines Vorgeschlagenen als Mißerfolg und Kränkung jener Nation aufgefaßt werden, deren Kurie ihn nicht

\footnotetext{
297 Bukowinaer Post Nr. 1717 v. 26.I.1905, if.

298 Spaun war Sektionschef im Kultusministerium sowie Mitglied des Reichsgerichtshofes.

299 SPAUN 1907, Kirchenfrage, 344; auch Osterreichische Zeitschrift für Verwaltung Nr. 6 v. 11.II.1909, 21-23, Zur griechisch-orientalischen Kirchenfrage in der Bukowina (Johann v. Spaun); Nr. 7 v. 18.II.1909, 25f.; Nr. 8 v. 25.II.1909, 29f.; Nr. 9 v. 4.III.1909, 33-35.

300 Osterreichische Zeitschrift für Verwaltung Nr. 9 v. 4.III.1909, 33.
} 
vorschlug. Schon den Vorschlägen würden erbitterte politische Kämpfe vorausgehen. Eine solche Prozedur wäre nicht geeignet, das Ansehen und die Würde der Krone zu fördern und die Wahl des Würdigsten sicherzustellen. Für die obersten Beamten der Hierarchie sollen der Regel nach nur Eigenschaften den Ausschlag geben, welche mit einer bestimmten Nationalität nicht zusammenhängen. Es wäre z. B. durchaus verfehlt, die Person des Erzbischofs abwechselnd der einen und der anderen Nation zu entnehmen, wenngleich es sehr naheliegend erscheint, aus politischen Gründen einen derlei Turnus einzuführen. Uberhaupt scheint das Hereinziehen der Nationalität in die Organisation und Verwaltung der Kirche als eine sehr bedenkliche Neuerung, weil eben die Gefahr besteht, daß nationale Rücksichten alle anderen sachlichen zurückdrängen werden. ${ }^{301}$

Im Vordergrund steht in unserem Falle die zweckmäßige Bewirtschaftung des großen Grundbesitzes, man denke sich nun, ein gewiß unter politischen Einflüssen zustande gekommener Kongreß soll über Einführung neuer Wirtschaftsmethoden, Grund-An- und -Verkäufe, Investitionen, Abschließung von langandauernden Abstockungsverträgen, Anstellungen u. direkt oder durch das Mittel der Budgetierung entscheiden. Andererseits soll der Kongreß über organisatorische Maßnahmen der eigentlichen Kultusverwaltung, über Gehalte und Aushilfen für Geistliche das entscheidende Wort sprechen. ${ }^{302}$

Allein der Versuch des Sektionschefs, der über eine langjährige persönliche Innensicht der Verhältnisse in der Bukowina verfügte ${ }^{303}$, hier objektiven Kriterien im Sinne der supranationalen österreichischen Ideologie das Wort zu reden, entsprach wenig den politischen Gegebenheiten des Kronlandes. Der Wiener Regierung und ihren Repräsentanten in Czernowitz bot sich in dieser Angelegenheit kaum mehr Spielraum. Lediglich eine auf Lavieren und Ausgleich bedachte Politik konnte aus ihrer Perspektive noch zur Deeskalation beitragen, mit dem Resultat, letztlich von beiden nationalen Seiten im Kirchenstreit aus ihrer jeweils spezifischen Unzufriedenheit heraus angefeindet zu werden.

Als am 5. März 1902 Czuperkowicz stirbt, übernimmt der bereits seit 1896 als Generalvikar amtierende Wladimir v. Repta die Leitung der Erzdiözese. Repta hatte schon 1898 mit der Ernennung zum Bischof von Radautz höhere Weihen empfangen. Der Czernowitzer Universitätsprofessor für Bibelstudium und Exegese, mit weltlichem Namen Basil/Vasile, kam am 25. Dezember 1841 in Russisch Banilla (rum. Bănila pe Ceremuş, auch Bănila rusească) in der Bukowina zur Welt. Seine Familie gehörte dem

301 SpaUn 1907, Kirchenfrage, 370.

302 Osterreichische Zeitschrift für Verwaltung Nr. 8 v. $25 . I I .1909,30$.

303 Spaun war über Jahre hinweg Mitglied im Verwaltungsrat der Bukowiner Lokalbahnen; Grazer Tagblatt Nr. 172 v. 23.VI.1911, 22. 


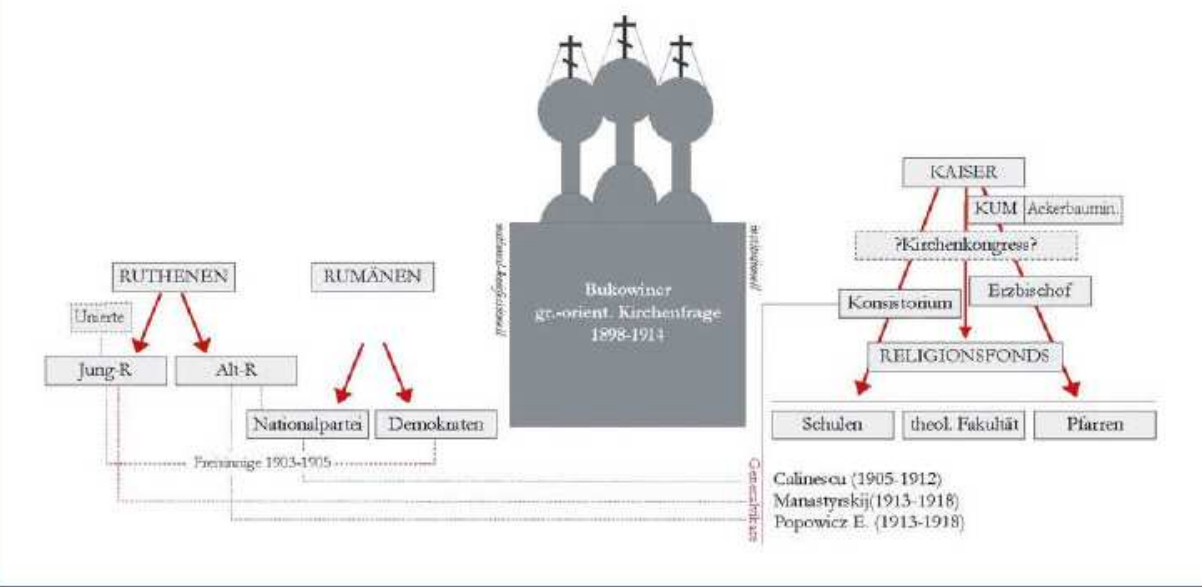

Abb. 26: Bukowiner gr-orient. Kirchenfrage, schematische Darstellung.

kleinen Landadel an. Nach Abschluss des Staatsgymnasiums in Czernowitz setzte er seine Studien zunächst am theologischen Institut der Landeshauptstadt fort. Danach trat der junge Theologe - ausgestattet mit einem Stipendium des gr-orient. Religionsfonds - ein Auslandsstudium (1870-72) in den Fächern Theologie und Psychologie an, das ihn an die Universitäten Wien, München, Bonn und Zürich führen sollte. 1873 - als Lehrender an das theologische Institut von Czernowitz zurückgekehrt - wirkte er ab 1875 aktiv am Aufbau der neuen Universität mit, wo er in der Folge bis 1896 als Lehrstuhlinhaber arbeitete. Im gleichen Jahr trat Repta in den Mönchsstand ein. Im Oktober 1902 rückte der Theologe als Archimandrit und Generalvikar im gr-orient. Konsistorium schließlich über kaiserliches Dekret auf den Stuhl des Metropoliten der Bukowina und Dalmatiens auf (vgl. Abb. 27). ${ }^{304}$

Das Festdiner fand im Anschluss an die Installation des neuen Erzbischofs, welche zuvor in der Kathedralkirche von Czernowitz erfolgt war, in der Residenz statt. Währenddessen wurden auf seine Person mehrfach dreisprachige »Stürmische Hoch! Să-trăiasca! Mnohaja lita-Rufe« ausgebracht. Sie sollten - unter der musikalischen Begleitung der Militärkapelle des 41. Infanterieregiments - geradezu den symbolischen Auftakt und zugleich programmatischen Rahmen zu seiner Amtszeit setzen. Die Wünsche des Reichsratsabgeordneten Georg Baron Wassilko-Serecki $(1864-1940)^{305}$, „daß der Erzbi-

304 Angaben nach CÂNDEA 1924, Mitropolitul; Candela XVIII/2 (1899), 137f.; am 10.XI.1902 legte der designierte Erzbischof beim Kaiser den Eid ab; Neues Wiener Tagblatt Nr. 309 v. 10.XI.1902, 5.

305 Rum. Gheorghe, seit 1918 Graf. 
Abb. 27: Mitropolitul Bucovinei şi Dalmației Dr. Vladimir de Repta. Postkarte undatiert, ungelaufen. Sammlung K.S.

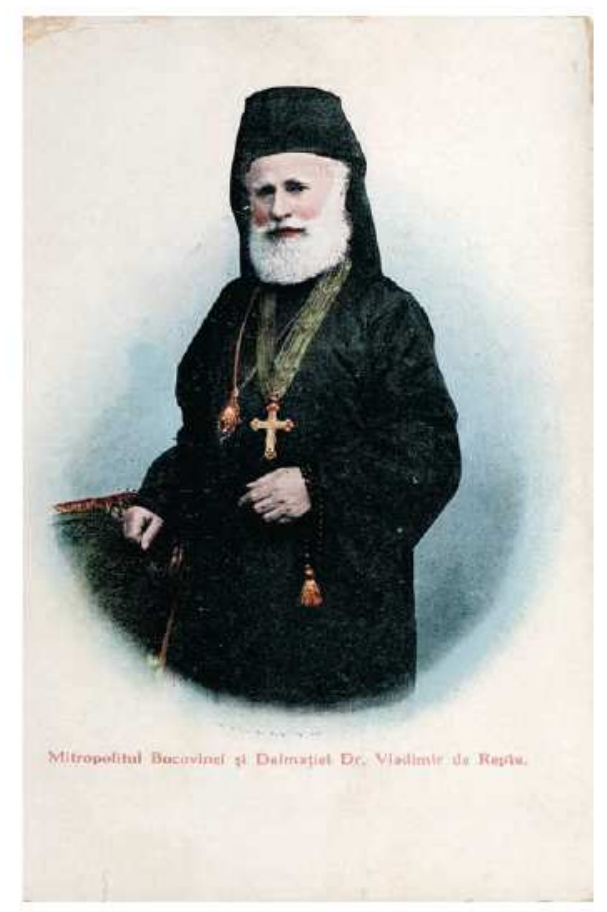

schof Dr. von Repta dazu beitragen werde, den Frieden, welcher im Lande herrscht, zu erhalten ${ }^{306}$, überdeckten indessen ein sich allmählich virulent äußerndes Problem der orthodoxen Erzdiözese. Als einer seiner ersten offiziellen Amtshandlungen nahm der Metropolit am 6. Dezember 1902 die Einweihung des Denkmals für das 41. Infanterieregiment, das Hausregiment der Landeshauptstadt, vor (vgl. Abb. 28). Auf dem Sockel umlaufend erinnert dieses Denkmal, dessen gespaltener Sockel 1991 symbolisch wieder eingeweiht worden war, dreisprachig an die Gefallenen dieser Armeeeinheit. In Czernowitz sollte der Erzbischof nicht nur dafür »den reichsten Dank für sein segensreiches Werk finden «, so ein zeitgenössischer Kommentar zu diesem Ereignis. ${ }^{307}$

Mit der Inthronisation von Repta fiel im Konsistorium neuerlich der Rang des Generalvikars bzw. Archimandriten - traditionell der Nachfolger des amtierenden Erzbischofs - vakant. Die Frage der Neubesetzung geriet wie schon die Jahre zuvor allerdings mit wachsender Emotionalität zum unbedingten nationalen Anliegen, sowohl der Ruthenen als auch der Rumänen des Erzbistums. In der Öffentlichkeit hatten sich zwischenzeitlich die Nuancen leicht verschoben. Ihre politische Aufmerksamkeit richtete

306 Bukowinaer Rundschau Nr. 4067 v. 26.XI.1902, 1f., Die Installation des Erzbischofs.

307 Sport৮Salon Nr. 49 v. 6.XII.1902, 6; Nr. 50 v. 13.XIII.1902, 11. 


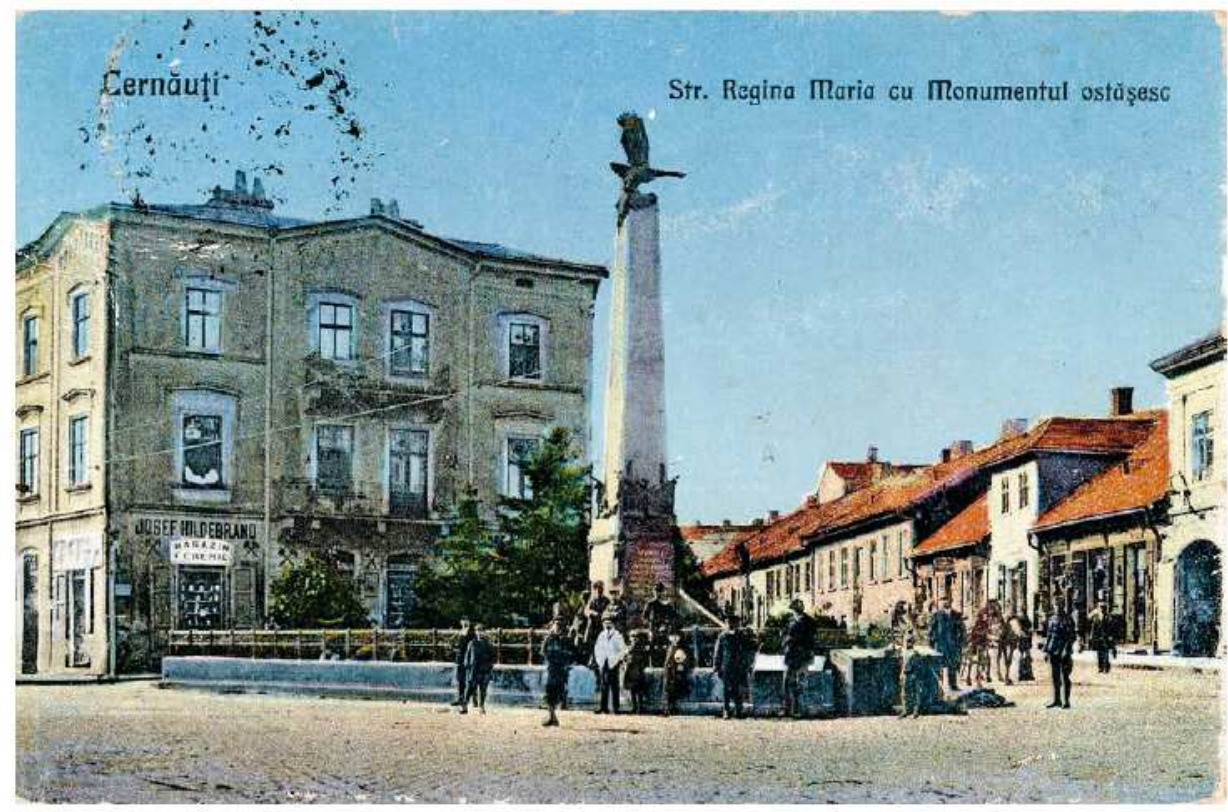

Abb. 28: Das 1902 eingeweihte Denkmal für das 41. Infanterieregiment, Czernowitz Siebenbürgerstraße (nach 1918 Str. Regina Maria), Rumänische Ansichtspostkarte, gelaufen nach 1918, Sammlung K.S.

sich 1903 auf die Flondor-Wassilko-Affäre, der ein antisemitischer Artikel im Bukowinaer Journal vorausgegangen war und die schließlich zum Austritt Georg v. Wassilkos aus dem Rumänenklub im Landtag führte. ${ }^{308}$ Kurzzeitig verlagerte sich damit der nationale Zwist zwischen Rumänen und Ruthenen auf die Juden des Kronlandes. ${ }^{309}$ Die darauf folgenden »stürmischen" Landtagssitzungen lenkten von der Besetzungsfrage des Konsistoriums vorerst noch ab. ${ }^{310}$ Politische Ruhe gönnte die Situation allerdings nur kurz. Im Juli 1903 versammelten sich in Czernowitz auf der Schützenhöhe unweit des Volksgartens mehrere tausend Ruthenen, sowie die Reichsratsabgeordneten Pihuliak, N. v. Wassilko, Benno Straucher sowie die Abgeordneten zum Landtag Onciul und SmalStockyj. Der Zug setzte sich alsbald in Richtung erzbischöflicher Residenz in Bewegung. Man verlangte vom Metropoliten unumwunden die Ernennung eines ruthenischen Generalvikars. Ebenso gab man sich über die letzte Wahlentsendung aus dem Konsistorium in die Kurie unzufrieden. Trotz seines Verständnisses für die Anliegen betonte

308 Corbea-Hoișie 2005, Politik; Anonymus 1903, Flondoraffaire; Anonymus 1903, Affaire. 309 Corbea-Hoişie 1994, Culture.

310 Illustriertes Wiener Extrablatt Nr. 346 v. 17. XII.1903, 4, Wenn es nur arbeiten würde. 
Repta nochmals im Gespräch mit den Abgeordneten, dass ihnen »kein Recht zu stehe, die Bevölkerung in kirchlichen Angelegenheiten zu vertreten «. ${ }^{311}$ Pihuliak und Wassilko hatten hingegen offenbar schon zu Beginn des Jahres als Reichsratsabgeordnete das Gespräch mit Ministerpräsident Ernest v. Körber gesucht, wohl um die Nominierung des Archimandriten in ihrem Sinne zu beschleunigen. ${ }^{312}$ Eingedenk der Zwistigkeiten blieb das Czernowitzer Tagblatt trotz allem in seiner Stimmung gegenüber dem neuen Erzbischof hoffnungsfroh,

daß die Rumänen darauf hinweisen können, daß der gr.-or. Religionsfonds, aus dessen reichen Mitteln die gr.-or. Kirche in der Bukowina dotiert wird, aus moldauischen Klöstern gebildet wurde, daß es also rumänisches Gut ist, das den materiellen Grundstock der gr-or. Kirche bildet und daß es eine allgemeine menschliche Schwäche ist, daß man von ererbtem Gut nicht gerne an Andere abgibt [...] Glücklicherweise steht jetzt an der Spitze der gr.-or. Kirche der Bukowina ein Mann, der dem rumänischen Stamme angehört, der aber so viel Adel des Geistes und des Herzens in sich vereint, daß es unter seinem Regime zu kleinlichen Streitigkeiten nicht kommen kann. Die überragende Persönlichkeit Repta’s ist die Bürgschaft für den Frieden im Schoße der gr.-or. Kirche. ${ }^{313}$

Indes währte auch diese Bürgschaft für den Frieden nur kurz und blieb einseitig. So griff denn während der Eröffnung des Bukowiner Landtages am 10. September $1903 \mathrm{~N}$. v. Wassilko den Erzbischof und die rumänischen Konsistorialräte heftig an. Die im Juli anlässlich der Versammlung artikulierten Wünsche nach einem ruthenischen Generalvikar waren bislang - aus seiner Sicht - unerfüllt geblieben. Wassilko unterstellte daher den betroffenen Konsistorialräten "die Unterstützung der ruthenenfeindlichen Bestrebungen seitens der rumänischen Priester «. ${ }^{314}$ Der schon Monate zuvor angebrachte Verweis des Kultusministeriums, dass die rumänischen Priester in den ruthenischen Gemeinden durchaus »der Sprache der Parochianen « mächtig sein müssten, um überhaupt dort eingesetzt zu werden, blieb ungehört. Auch die auf Drängen des Ministeriums erfolgte Einrichtung eines vom Religionsfond getragenen Stipendiums für ruthenische Gymnasialschüler änderte daran wenig. ${ }^{315}$ In einem Interview - just zum Geburtstag des Erzbischofs - versuchte Repta ausgleichend zu wirken und betonte die Offenheit der

\footnotetext{
311 Neues Wiener Tagblatt Nr. 185 v. 8.VII.1903, 11, Eine Ruthenendemonstration in Czernowitz. Szenen in der Residenz des Erzbischofs Repta.

312 Neues Wiener Tagblatt (Tagesausgabe) Nr. 25 v. 25.I.1903, 3.

313 Czernowitzer Tagblatt Nr. 30 v. 4.III.1903, 1, Ruthenen und Rumänen.

314 Neues Wiener Abendblatt Nr. 249 v. 11.IX.1903, 2, Die Landtage der Bukowina.

315 Czernowitzer Tagblatt Nr. 78 v. 1.V.1903, 1f., Die ruthenischen Beschwerden.
} 
mit Wassilko wie Onciul geführten Diskussion. Einem Kirchenkongress stand er dabei nicht völlig ablehnend gegenüber, allerdings fehlten aus seiner Sicht dafür die gesetzlichen Grundlagen. Was jedoch die Einheit der Diözese betraf, so blieb der Erzbischof unbewegt bei seinen Vorsätzen der Unteilbarkeit. ${ }^{316}$

Das neue Jahr brachte erst einmal eine politische Zusammenarbeit über nationale Grenzen hinaus, deren Stoßrichtung in mehrerer Hinsicht auf die gr.-orient. Kirche und ihre politische wie wirtschaftliche Machtposition abzielte. Sowohl die Jungruthenen als auch die rumänischen Demokraten näherten sich in ihren sozialen Forderungen insbesondere gegen die gr.-orient. Kirche als Großgrundbesitzerin im Lande an. Im Herbst 1904 hatte der Freisinnige Verband - ein politischer Zusammenschluss von Ruthenen, Rumänen und Juden des Kronlandes - die Wahlen zum Landtag für sich und "gegen die konservative Oligarchie der meist rumänischen Großgrundbesitzer « entscheiden können. ${ }^{317}$ Hinter der zurückhaltenden Aufteilung von Ackergrundstücken aus dem Besitz des gr.-orient. Religionsfonds auf Bauern in der nördlichen, also ruthenisch dominierten Bukowina, oder der so interpretierten, bevorzugten Subvention von rumänischen $\mathrm{Ge}$ nossenschaften durch ebendiese Institution verbargen sich etwa indes nicht nur soziale Forderungen, sondern auch ganz offen die Frage nach den Zugriffsrechten auf den Fond selbst. ${ }^{318}$ Wenige Monate später, Anfang Jänner 1905, löste ein gegen Onciul (Mitglied der Freisinnigen) seitens des Konsistoriums beim Kultusministerium eingebrachter Antrag um Einrichtung einer Disziplinarkommission ${ }^{319}$ in der Folge eine Interpellation der Abgeordneten Pihuliak und N. v. Wassilko im Reichsrat aus, die eine Stellungnahme des Erzbischofs verlangte. Die Aufstellung von Abgeordneten und Mitgliedern des Konsistoriums gestaltete sich aus dem Blickwinkel der Freisinnigen unverändert im Interesse des Großgrundbesitzes bzw. der Kirchenhierarchie:

316 Czernowitzer Allgemeine Zeitung Nr. 298 v. 25.XII.1904, 1f., Erzbischof Dr. von Repta über den Kirchenstreit (Ein Interview).

317 CORBEA-HoIșie 1996, Kohabitation, 81.

318 Czernowitzer Allgemeine Zeitung Nr. 1803 v. 19.I.1910, 1f., Bukowinaer Landtag. Die Aufteilung der Ackergrundstücke des Religionsfondes; Allgemeine österreichische Gerichtszeitung Nr. 49 v. 7.XII.1912, 534, Zusammenbrüche der Genossenschaften während der letzten Jahre; Bukowinaer Post Nr. 1739 v. 19.III.1905, 2, Der Geist des Konsistoriums in den ruthenischen Pfarren oder das fünfblättrige Unglück der Bukow. Ruthenen.

319 Der Auslöser dafür war ein Artikel Onciuls in der Voința Poporului [Volkswille], auf den hin die Mitglieder des erzbischöflichen Konsistoriums mit einer Erklärung reagierten; Czernowitzer Allgemeine Zeitung Nr. 324 v. 25.I.1905, 5, Erklärung. Zeitgleich hatte Onciul im Jänner 1905 die programmatische Artikelserie Zur gr.-or. Kirchenfrage in der Bukowinaer Post veröffentlicht, auf die sich Pihuliak und Wassilko in ihrer Interpellation ebenfalls, inhaltlich weitgehend damit übereinstimmend, beziehen; Anm. 107. 
Das Volksinteresse wahrnehmende Abgeordnete hatte das rumänische Volk der Bukowina nicht; der rumänische Bauer sowie die, wenn auch nicht allzu häufig, aber doch vorhandenen volksfreundlichen rumänischen Priester waren in allen Vertretungskörpern ohne Vertretung, denn die von den rumänischen Kirchenpatronen im Einvernehmen mit der Konsistorialklique vorgeschlagenen und von den jeweiligen Landeschefs im Wege der k.k. Bezirkshauptmannschaften der rumänischen Bevölkerung aufoktroyierten Abgeordneten, größtenteils Großgrundbesitzer oder der Klique des Konsistoriums angehörende wohlgenährte Priester waren selbstverständlich nur Vertreter ihrer Auftraggeber: des Adels, des Großgrundbesitzes und des Konsistoriums $!^{320}$

Constantin Popowicz (1846-1938), Professor für Kirchenrecht an der Czernowitzer Universität $^{321}$, übernahm es als Nachfolger von Repta im Reichsrat - der durch seine Ernennung zum Erzbischof in das Herrenhaus aufgerückt war - diesen Vorwürfen entgegenzutreten. Der Vertreter des Großgrundbesitzes konzentrierte sich darin allerdings auf die Versuche der jungruthenischen Partei, unter der Wählerschaft des Landes Terrain zu gewinnen und bezog im Sinne seines Erzbischofs zur Vertretungsfrage der Bukowiner Untertanen im Parlament nur indirekt über die Kirchenkongressfrage Stellung.

Während nämlich früher der einheitliche historische Charakter der Bukowinaer Erzdiözese von allen griechisch-orientalischen Glaubensgenossen ohne Unterschied der Nationalität anerkannt worden war, strebt nunmehr die von der jungruthenischen Partei vertretene ruthenische Bevölkerung die Spaltung der Diözese und die Einführung eines rumänisch-ruthenischen Dualismus dadurch an, daß dieses Postulat auf das Programm der jungruthenischen Partei geschrieben worden ist. In Ermangelung eines Kirchenkongresses, auf welchem die griechischorientalische Bevölkerung ihre Beschwerden und Wünsche auf kirchlichem Gebiete vorbringen könnte, machen sich die Bestrebungen aller mit den gegenwärtigen Verhältnissen in der Kirche unzufriedenen Elemente auf andere Weise Luft, sie betreten den Boden der Agitation [...] Bei diesen Besetzungen macht sich nämlich der Einfluß der politischen Repräsentanten

320 Interpellation der Abgeordneten Pihuliak, Wassilkó und Genossen an Seine Exzellenz den Herrn Minister für Kultus und Unterricht Dr. v. Hartel in Angelegenheit der vom orthodox-katholischen [sic!] erzbischöflichen Konsistorium in Czernowitz auf Grund des vom Landtagsabgeordneten Dr. Aurel Ritter v. Onciul in der $>$ Bukowinaer Post` v. 19., 22., 26. und 29. Jänner 1905 erschienenen Artikel ,Zur griechisch-orientalischen Kirchenfrage angeblich beim Kultusministerium angesuchten Disziplinaruntersuchung; StenoProt, XVII. Session, 299. Sitzung, 6.II.1905, 26790-26792, hier 26791; auch Bukowinaer Post Nr. 1719 v. 2.II.1905, 2, Die gr.-or. Kirchenfrage im Parlamente. Interpellation. Nr. 1728 v. $21 . I I .1905$, If., Die Mißstände in der gr.-or. Diezöse. Interpellation; Nr. 1729 v. 23.II.1905, 2f., Die Mißstände in der gr.-or. Diezöse (Schluß).

321 Rum. Constantin Popovici (als Mönch mit den Namen Clement). 
der griechisch-orientalischen Glaubensgenossen dadurch geltend, daß sie derartige Besetzungsfragen zu Parteifragen erheben. ${ }^{322}$

Mehrere Leitartikel der Czernowitzer Allgemeinen Zeitung unterstützen die Abgeordneten in diesem Anliegen und versuchten damit wohl auch die nationale Frage aus dem Blickwinkel der sozialen Problematik zu erklären. "Österreich und die österreichische Regierung können immer ruhig bleiben, wenn auf den Ruthenenbänken des Abgeordnetenhauses nationale Wutausbrüche erfolgen, denn - eine ruthenische Frage existiert vielleicht, aber sicherlich ist sie keine nationale, sondern eine soziale«, so die Meinung eines Leitartikels. ${ }^{323}$ Der Herausgeber dieser Tageszeitung lobte darin den "seltenen Freimut « und die der Diskussion in dieser Angelegenheit »wohltuende Objektivität « von Popowicz. $^{324}$

Die Einsetzung von Calinescu zum Generalvikar im März 1905 und die im Herbst bevorstehenden Wahlen zum Reichsrat trugen indes wenig zur Entspannung der Lage sowohl im Kronland selbst als auch innerhalb der gr--orient. Kirche bei. Die Czernowitzer Allgemeine Zeitung versuchte darüber trotzdem möglichst objektiv zu berichten. ${ }^{325}$ Sichtlich enttäuscht von der letztendlichen Ernennung Calinescus zum Generalvikar der gr.-orient. Landeskirche interpellierte der Reichsratsabgeordnete Pihuliak in dieser Angelegenheit im Wiener Parlament. Seiner Ansicht nach wolle der Erzbischof von einer "paritätischen Berücksichtigung würdiger ruthenischer Priester nichts wissen«.

So bestand denn auch Seine erzbischöfliche Gnaden darauf, daß zum Generalvikar der national gemischten Diözese nur der bei den Ruthenen berüchtigte und mit Recht gefürchtete Archimandrit Miron Calinescu befördert werde [...] Miron Calinescu hat sich auch in der Bedrückung, Verfolgung, Verkürzung, Kränkung und Schädigung der Ruthenen auf dem kirchlichen Gebiete jahrzehntelang bewährt und in dieser Richtung einen traurigen Ruf erworben. ${ }^{326}$

322 Interpellation des Abgeordneten Popoviči [gemeint ist hier C. Popowicz; Anm. K.S.] und Genossen, betreffend die Regelung der Rechtsverhältnisse der griechisch-orientalischen Kirche in der Bukowina und die Besetzung mehrerer höherer kirchlicher Stellen beim griechisch-orientalischen erzbischöflichen Konsistorium in Czernowitz, an Seine Exzellenz den Herrn Minister für Kultus und Unterricht; StenoProt, XVII. Session, 307. Sitzung, 17.II.1905, 27265-27267, hier 27266.

323 Czernowitzer Allgemeine Zeitung Nr. 1927 v. 19.VI.1910, 2, Falsches Pathos.

324 Czernowitzer Allgemeine Zeitung Nr. 348 v. 25.II.1905, 1, Die Rechtsverhältnisse der gr-orient. Kirche in der Bukowina; Nr. 448 v. 29.VI.1905, 1, Die gr.-or. Kirchenfrage im Abgeordnetenhause.

325 Czernowitzer Allgemeine Zeitung, Nr. 508 v. 10.IX.1905, 1, Jung- und Altruthenen; Nr. 516 v. 20.IX.1905, 1, Ueber die politische Situation in der Bukowina u. ihre weitere Entwicklung (Von Dr. v. Wolczynski); dazu die Ausgaben Nr. 537, 539, 541, 543.

326 Interpellation des Abgeordneten Pihuliak und Genossen an Seine Exzellenz den Herrn Leiter des $k . k$. Ministeriums für Kultus und Unterricht in Angelegenheit der jüngsten Ernennungen höherer kirchli- 
Abseits des Konsistoriums geriet mittlerweile nahezu jedwede von den Kirchenbehörden mitgesteuerte Besetzung zum ausgesprochenen Politikum und damit zu einer dem Ansehen der Kirche wie des Fonds an sich schädlichen Diskussion in der Öffentlichkeit. Ende Jänner 1906 nominierte der Erzbischof den Konsistorialrat Georg Hanicki, der dem altruthenischen Lager zugezählt wurde, zum Mitglied des Bukowiner Landesschulrates. ${ }^{327}$ Die jungruthenische Seite hatte im Sinne der von ihr so interpretierten Gleichberechtigung wohl ihren Vertreter Manastyrski erwartet und war ob dieser Entscheidung herb enttäuscht. ${ }^{328}$ Aus dieser politischen Ecke vermutete man einen Schachzug des Metropoliten, der darauf hinaus laufen sollte, den Jungruthenen im Landtag die Mehrheit zu entziehen. ${ }^{329}$ Hanicki verdächtigte man der Absicht, N. v. Wassilko aus seinem Wahlbezirke verdrängen zu wollen.

Also die Landtagsmajorität und der Kirchenfürst der Bukowina unterstützen sich gegenseitig zwecks Demoralisierung der ruthenischen Bevölkerung in der zielbewußten Absicht, für die kommenden Wahlen den bisherigen Abgeordneten der Ruthenen der Bukowina den Boden zu entziehen. ${ }^{330}$

Die Jungruthenen beschlossen daher, sich in ihrer kompromisslosen Forderung nach einem ruthenischen Konsistorium und einem ruthenischen Bischof mit einer weiteren Petition direkt an den Kaiser zu wenden. ${ }^{331}$ So legten sie denn auch die srasche` Bestellung von Calinescu einerseits und die zeitgleiche >Verzögerung der Ernennung ihres eigenen Kandidaten Metelius Halip für das Konsistorium andererseits als gezielte Zurücksetzung aus. ${ }^{332}$ Die Bukowinaer Post spielte mittlerweile perfekt ihre Rolle als jungruthenisches Sprachrohr in der Öffentlichkeit des Kronlandes. ${ }^{333}$ Zwischenzeitlich ließen die Abgeordneten Pihuliak und N. v. Wassilko mit Verweis auf die Schulpolitik der gr.-orient. Kirche

cher Funktionäre in der orthodox-katholischen [sic!] Diözese der Bukowina; StenoProt, XVII. Session, 369. Sitzung v. 18.XII.1905, 33445-33447, hier 33445, vgl. auch Bukowinaer Post Nr. 1874 v. 4.II.1906, 2, Ernennungen im gr.-or. Konsistorium.

327 Czernowitzer Allgemeine Zeitung Nr. 629 v. 11.II.1906, 2, Der gr.-or. Kirchenstreit in der Bukowina. 1910 sollte Manastyrski in Nachfolge Hanickis zum Diözesaninspektor für die erzpriesterschaftlichen Bezirke Kotzmann, Wiznitz, Putilla und Czermosz (sic!) aufsteigen; Czernowitzer Allgemeine Zeitung Nr. 1836 v. $27 . I I .1910,5$.

328 Bukowinaer Post Nr. 1865 v. 14.I.1906, 1f., Zum gr-or. Neujahrstage.

329 Bukowinaer Post Nr. 1875 v. 6.II.1906, 1, Eine Herausforderung.

330 Bukowinaer Post Nr. 1883 v. 25.II.1906, 1f., Zur Ernennung Hanickis.

331 Pihuliak \& Anonymus 1906, Beitrag.

332 Bukowinaer Post Nr. 1874 v. 4.II.1906, 2, Ernennungen im gr.-or. Konsistorium.

333 Bukowinaer Post Nr. 1913 v. 6.V.1906, 3, Zur kirchlichen Frage; Nr. 2048 v. 21.III.1907, 1, An das ruthenische Volk in der Bukowina. 
via Bukowinaer Post der Wiener Regierung ausrichten, eigentlich nur dem »romanisatorischen Treiben des Konsistoriums wohlgefällig « zuzuschauen, während sich der "granitfeste romanisatorische Metropolit Dr. Repta die Hände « reibe. ${ }^{334}$

Die Folgen einer derart dauerhaft in die Landbevölkerung hineingetragenen politischen Agitation ließen nicht lange auf sich warten und mündeten in einem kleinen Eklat. So verweigerte während der kanonischen Visitation einer Volksschule im Kotzmanner Bezirk in der Nordbukowina einer der anwesenden Lehrer ostentativ und aus Protest den vom Erzbischof angebotenen Handschlag. ${ }^{335}$ Die Jungruthenen blieben bei ihrer in erster Linie vorgebrachten Forderung nach einer paritätischen Besetzung des Konsistoriums; eine Forderung, die sie sowohl beim Erzbischof als auch beim Landespräsidium deponierten und das nicht ohne gleichzeitig bewusst drohend den sprichwörtlichen Teufel der Union mit Rom an die Wand zu malen.

Leider hat das Rechtsempfinden der eigenen, der anderen Nationalität angehörenden Cultusgenossen bisher nur zu wenig Objektivität aufgebracht, als dass die bedrängte Situation der gr. ort. Ruthenen dieses Landes auf dem Feld der Kirche auch nur einigermassen hätte verstanden werden wollen. Der nationale Antagonismus war stärker und mächtiger als der Sinn für die Erhaltung der auf sich allein angewiesenen orthodox-katholischen Kirche und ihrer Glaubenslehren. Chauvenistische (sic!) Führer haben es unumwunden offen erklärt, die orthodoxe Kirche dieses Landes lieber nach Rom auszuliefern, ehe sie eine faktische Gleichberechtigung der Ruthenen mit den Rumänen erleben würden. ${ }^{336}$

Aber auch die Altruthenen versuchten sich im Gegenzug neuerlich in Position zu bringen und politisches Terrain zu gewinnen. In Folge einer Volksversammlung formulierten sie ihrerseits Wünsche und überreichten diese während einer Audienz dem Erzbischof, nicht ohne sich damit zugleich von den Jungruthenen und der von ihnen angestrebten Teilung der Diözese deutlich zu distanzieren. ${ }^{337}$ Diese Differenzen hielten die Altruthenen indes keineswegs davon ab, ebenso wie ihre politischen Gegner, die Bewilligung eines Kirchenkongresses zu erbitten. ${ }^{338}$ Jene schon erwähnte, im Kontext mit der

334 Bukowinaer Post Nr. 1998 v. 22.XI.1906, 2, Ruthenischer Religionsunterricht.

335 Czernowitzer Allgemeine Zeitung Nr. 710 v. 19.V.1906, 1, Schrankenlose Agitation.

$336 \mathrm{DACZ}_{320 / 3 / 87}$ Verein Towarystwo Ruskych Prawoslawnych Swiaszczennykiw na Bukowyni [Verein der ruthenisch-orthodoxen Pfarrer in der Bukowina]an Erzbischof 15.II.1909, gez. Dionys Jeremijczuk (Obmann); sowie Landespräsidium an Erzbischof v. 27.VIII.1909 mit der Bitte um Äußerung zur Eingabe des Vereins.

337 Czernowitzer Allgemeine Zeitung Nr. 695 v. 1.V.1906, If., Zur gr.-or. Kirchenfrage. Ein Memorandum der Altruthenen.

338 Czernowitzer Allgemeine Zeitung Nr. 692 v. 27.IV.1906, 3, Der Kirchenstreit in der Bukowina. 
Interpellation von Onciul durch Sektionschef Spaun verfasste Stellungnahme konnte trotz ihrer besonnenen Argumentationsweise auf diesem Feld nur mehr wenig bestellen. Ganz im Gegenteil, die Bukowinaer Post legte noch drauf und verstieg sich dazu, den Erzbischof als »einen Förderer der national-russischen Propaganda « zu bezeichnen, der sich im Dienste des "galizischen Statthalters« befinden würde. ${ }^{339}$ Damit waren sowohl die Ångste gegen die in der Bukowina aus eigener Erfahrung bekannte polnische Verwaltung als auch gegen die panslawischen Aspirationen St. Petersburgs bedient. Darüber hinaus hatte sich mittlerweile die Zusammenarbeit der Freisinnigen als kurze Episode im politischen Leben der Bukowina erwiesen und 1905 wieder aufgelöst. Hiermit zerbrach eine Koalition, die über Partei- und Nationalitätengrenzen hinweg versucht hatte, zum Wohl des gesamten Kronlandes zu agieren. Die dergestalt nationalisierte Elite beschäftigte sich in der Folge verstärkt mit der nationalen Indifferenz der bäuerlichen Bevölkerung des Landes und versuchte dieses Wählerpotential in ihre jeweiligen Lager zu manövrieren. ${ }^{340}$ Die rumänischen Demokraten unter der Führung von Onciul stellten sich jetzt vor allem in Kirchenfragen teilweise in eine Fundamentalopposition zu den Jungruthenen. ${ }^{341}$

Um eine Basis für die Diskussion zu gewinnen, stelle ich eine Behauptung auf, von der ich sicher bin, daß sie allgemeine Zustimmung finden wird, u. zw.: 'Der Charakter der gr. or. Kirche in der Bukowina war und muß rumänisch bleiben«. Daraus folgt: Der Metropolit muß ein Rumäne sein, die Kirchensprache ist die rumänische, die Amtskorrespondenz muß in rumänischer Sprache geführt werden, der gr. or. Religionsfond hat für kulturelle Zwecke der Rumänen zu dienen etc. Oder: die gr. or. Ruthenen sind Mitglieder der rumänischen Kirche der Bukowina, da sie keine eigene ruthenische Kirche, keinen Bischof und keinen Metropoliten haben. Es ist als nur Privatsache der Ruthenen, wenn sie sich von der rumänischen Kirche separieren und ein Bistum oder Erzbistum errichten wollen. Daß sie dazu Geld und andere Dinge brauchen, geht die Rumänen nichts an, und kein Rumäne hat ein Recht, den Ruthenen zu diesem Zwecke aus dem gr. or. rumänischen Religionsfonde einen Kreuzer zu schenken. ${ }^{342}$

Onciul repräsentierte mit seiner Meinung allerdings keineswegs alle Rumänen der Diözese. Es kam neuerlich dem emeritierten Universitätsprofessor Eusebius Popowicz zu,

339 Bukowinaer Post Nr. 2197 v. 5.I.1908, 3, Erzbischof Dr. Repta im Dienste des galizischen Statthalters. 340 van Drunen 2015, Bunch, 132, 161 u. 164.

341 Czernowitzer Allgemeine Zeitung Nr. 2271, 13.VIII.1911, 1f., Die Kirchenfrage. Eine Unterredung mit einem ruthenischen Würdenträger der Landeskirche; sowie Nr. 2276, 20.VIII.1911, 1f., Die Kirchenfrage.

342 Die Wahrheit Nr. 124 v. 25.IX.1911, 6-15, hier 8, Zur gr.-or. Kirchenfrage. Zweiter Anhang zu den kritischen Fragmenten (Aurel Onciul). 
1911 ein Majestätsgesuch der gr.-orient. Rumänen in der Bukowina mit der Bitte »um Errichtung eines abgesonderten Bistums für die gr. or. Ruthenen « einzureichen. ${ }^{343} \mathrm{Da}$ mit wollte der Kirchenrechtler einerseits einen bewussten Schritt zum Frieden in der Erzdiözese setzen, zugleich aber andererseits der in Zukunft absehbaren Möglichkeit eines (jung)ruthenischen Erzbischofs vorbauen. Weniger besonnen argumentierende Kreise der orthodoxen Rumänen sprachen mittlerweile bereits von der »Unmöglichkeit eines weiteren aufrichtig friedlichen und brüderlichen Zusammenlebens mit den Ruthenen in einer und derselben Diöcese «. ${ }^{344}$ Das Kultusministerium jedoch hatte Czernowitz schon Jahre zuvor wissen lassen, dass eine Teilung der Diözese nicht in Frage komme. Es blieb bis zum Ausbruch des Weltkrieges bei der zugestandenen paritätischen Organisation, d.h. nationalen Aufteilung des Konsistoriums. ${ }^{345}$

Insgesamt engte sich damit der Handlungsspielraum des Metropoliten, aktiv in die Entwicklung einzugreifen, mit jedem Jahr mehr ein. So konnte selbst der beherzte Aufruf Reptas in einem auf Ruthenisch wie Rumänisch verfassten Hirtenbrief, den der Erzbischof mit dem Wahlspruch des Kaisers, Viribus Unitis, als Devise für alle Gläubigen seiner Kirche abschloss, nur mehr unmerklich zur Entspannung der Gesamtsituation beitragen. ${ }^{346}$

Zwei Jahre vor Kriegsausbruch begann sich mit dem Tod Calinescus 1912 das Besetzungskarusell im Konsistorium neuerlich zu drehen. Obwohl man in der Czernowitzer liberalen Öffentlichkeit die komplexe Situation einigermaßen objektiv und weitgehend richtig einschätzte, änderte das wenig an den daraufhin erneut einsetzenden wechselseitigen Vorwürfen und Ansprüchen der daran beteiligten Gruppierungen. ${ }^{347}$ Diesmal versammelten sich, einberufen vom Landeshauptmann Hormuzaki sowie Flondor und Theodor Stefanelli (1849-1920) ${ }^{348}$, die Rumänen auf dem Sokolplatz beim Czernowitzer Volksgarten. Unter Betonung ihrer dynastischen Gesinnung sollte eine Deputation mit

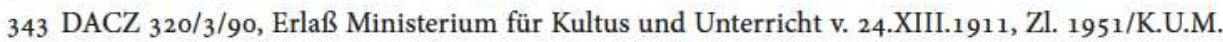
Landespräsidium Bukowina an Repta v. 22.X.1911, Ubermittlung des Majestätsgesuchs in Abschrift mit der Bitte um Gutachten; das Gesuch trägt laut der Zusammenfassung von E. Popowicz 2.700 Einzelunterschriften und 13.700 Unterschriften über entsprechende Vollmachten.

344 Czernowitzer Allgemeine Zeitung Nr. 2293 v. 10.IX.1911, 1, Die Kirchenfrage. Ein Bukowiner gr.-or. Priester rumänischer Nationalität.

345 Erlass Ministerium f. Kultus und Unterricht v. 20.VII.1908, Zl. 1970, sowie ksl. Entschließung v. 9.XI.1908; nach Bukowinaer Post Nr. 2828 v. 7.IV.1912, 1-3, Die Antwort der gr-or. Ruthenen.

346 Rum. "cu puteri unite«/ruth. »со единеными силами«; REPTA 1908, Лист/Epistola, Schlusswort.

347 Czernowitzer Allgemeine Zeitung Nr. 2454 v. 28.III.1912, 1, Die gr.-or. Kirchenfrage.

348 Rum. Teodor V. Ștefanelli (auch ruth. Theodor V. Stefaniuc), Schriftsteller und Rechtshistoriker, vormaliger k.k. Oberlandesgerichtsrat in Lemberg. 
entsprechenden Forderungen und dem klaren Bekenntnis zum rumänischen Charakter der Bukowiner Landeskirche nach Wien entsandt werden. ${ }^{349}$ Gedruckte Publikationen der politischen Akteure sowie Meinungsäußerungen zur Stellenvergabe bedienten dabei regelmäßig die Öffentlichkeit. Argumentationslinien und Beweisführung zum jeweils eigenen, historisch scheinbar gerechtfertigten Standpunkt der einzelnen politischen Gruppierungen änderten sich im Vergleich zu den vorangegangenen Diskussionen allerdings kaum. Diese reichten von der bekannten Forderung nach einer Teilung der Diözese ${ }^{350}$ über die These der allmählichen Ruthenisierung der gr.-orient. Landeskirche ${ }^{351}$ hin zur Verteidigung des Status quo. ${ }^{352}$ Eine Territorialaufteilung der Diözese in einem gemischt bevölkerten Gebiet wie der Bukowina hätte nur zu absehbaren Folgeproblemen geführt, wovor bereits die Zeitgenossen eindringlich warnten. Zudem hegten die Rumänen nach wie vor die Befürchtung, dass sie mit der zu erwartenden demographischen Verschiebung letztlich von einer ruthenischen gr.-orient. Landeskirche >beherrscht « werden könnten. ${ }^{353}$

Das Kultusministerium entschied sich diesmal jedoch für den Ruthenen Artemon Manastyrski als Generalvikar. Wien wollte dabei auch in Richtung der rumänischen Fraktion ein Zeichen setzen und ernannte Eusebius Popowicz zum Vikar ad personam. Beide Konsistorialarchimandriten waren als Stellvertreter des Erzbischofs gleichgestellt. Ebenso - und darauf legte Wien besonderen Wert - sollten diese Stellen auch in Zukunft im nationalen Proporz besetzt werden, »daß stets einer der Konsistorial-Archimandriten ein Bukowiner Rumäne, der andere ein Bukowiner Ruthene zu sein hat «. ${ }^{354}$ Das veranlasste die diesmal >leer` ausgegangene rumänische Seite zur lapidaren Feststellung "deci Ruteni cu putera, Românii cu cinstea « [also den Ruthenen die Macht, den Rumänen die Ehre]. ${ }^{355}$ Eine eilig in die erzbischöfliche Residenz nach Czernowitz einberufene Versammlung des rumänischen Klerus konnte sich mit dem Entschluss der Regie-

349 Czernowitzer Allgemeine Zeitung Nr. 2453 v. 27.III.1912, 1, Die Kirchenfrage. Das rumänische Meeting.

350 PIhUliaK 1913, Kirchenstreit; ders. 1914, Kirchenfrage. Eine Klarstellung durch Eusebius Popowicz in Bezug auf die Vorwürfe von Pihuliak in der Reichspost wollte dieselbe Zeitung nicht abdrucken. Daraufhin veröffentlichte die Czernowitzer Allgemeine Zeitung diese klärende Gegenmeinung; Czernowitzer Allgemeine Zeitung Nr. 3322 v. 30.XI.1913, 1, Zur gr.-or. Kirchenfrage.

351 Ștefanelli 1912, Chestiunea.

352 Popovici 1913, Kirchenfrage.

353 HormuZachi 1913, Chestia, 1 u. 5. Konstantin Hormuzachi hatte schon mehr als zehn Jahre zuvor vor einer schleichenden Slawisierung der Bukowina gewarnt; HoRMZUAKI 1900, Slawisierung.

354 DACZ 320/3/86 Landespräsidium an Erzbischof v. 3.VII.1914, allerhöchster Entschluss v. 11.IX.1913, hier fol. 37 .

355 CÂNDEA 1924, Mitropolitul, 13; Czernowitzer Allgemeine Zeitung Nr. 3225 v. 4.X.1913, 1, Zur gr-or. Kirchenfrage. Die Beschlüsse der gestrigen Priester-Versammlung. 


\begin{tabular}{|c|c|c|c|c|c|c|}
\hline Stand & $1880^{1}$ & $1899^{2}$ & $1902 / 03^{3}$ & $1905^{4}$ & $1906 / 08^{5}$ & $1913^{6}$ \\
\hline Erzbischof & $\begin{array}{l}\text { Andriewicz-Morariu } \\
\text { Silvester }\end{array}$ & Czuperkowicz Arkadi & unbesetrt & \multicolumn{3}{|c|}{ Repta } \\
\hline $\begin{array}{c}\text { Konsistorialrat } \\
\text { (Archimandrit/ } \\
\text { Generalvikar) }\end{array}$ & $\begin{array}{c}\text { Czuperkowicz } \\
\text { Arkadie }\end{array}$ & \multicolumn{2}{|c|}{ Repta Basil } & \multicolumn{2}{|c|}{ Calinescu } & unbesetot \\
\hline \multirow{4}{*}{ Konsistorial räte } & $\begin{array}{c}\text { Zurkanowicz } \\
\text { Johann }\end{array}$ & \multicolumn{2}{|c|}{ Calinescu Miron } & \multicolumn{3}{|c|}{ Bejan } \\
\hline & $\begin{array}{l}\text { Illasiewicz } \\
\text { Basil }\end{array}$ & \multicolumn{2}{|c|}{ Bejan Dionys } & \multicolumn{2}{|c|}{ Hanicki } & Manastyrski \\
\hline & $\begin{array}{c}\text { Komoroszan } \\
\text { Michael }\end{array}$ & \multirow{2}{*}{ unbesetzt } & $\begin{array}{l}\text { Hanicki } \\
\text { Georg }\end{array}$ & \multicolumn{2}{|c|}{ Manastyrski } & Halip \\
\hline & unbesetzt & & $\begin{array}{l}\text { Manastyrski } \\
\text { Alexander }\end{array}$ & unbesetzt & $\begin{array}{l}\text { Halip } \\
\text { Weletin }\end{array}$ & unbesetzt \\
\hline
\end{tabular}

\begin{tabular}{|c|c|c|c|}
\hline \multicolumn{5}{|c|}{ nationale,Gesinnung } \\
\hline & österreichisch & & jungnuthenisch \\
\hline & numänisch & & altruthenisch \\
\hline
\end{tabular}

1 ÖTA-AVA, Neuer Kultus akath. gt.-or. K23 (1880), Personal-Stands-Ausweis.

2 ÖTA-AVA, Neuer Kultus akath. gt.-or. K23 (1899), Voranschlag 1899, Personalstandstabelle.

3 ÖSTA-AVA, Neuer Kultus akath. gr.-or. K25 (1903), Voranschlag 1903, Personalstandstabelle.

${ }_{4}$ DACZ 320/1/3976, Bukowiner Landestegierung, Voranschlag 1905, Personalstandstabelle.

5 ÖSTA-AVA, Neuer Kultus akath. gr.-or. K26 (1906), Voranschlag 1906 u. 1908 , Personalstandstabelle.

${ }^{6}$ DACZ 320/1/4532. Bukowiner Landestegierung, Voranschlag 1913. Personalstandstabelle. 
rung, Manastyrski zum Generalvikar gegen den Willen des Erzbischofs zu ernennen, nicht einverstanden erklären, aber ebenso wenig etwas daran ändern. ${ }^{356}$ Die Bukarester Zeitungen reagierten völlig ungehalten darüber. Hatte es doch ihrer Ansicht nach »die österreichische Regierung verstanden, im Bukowinaer rumänischen Volke die letzten Lebenskräfte zu erschlagen «. Der »präsumptive Metropolit « wäre zudem ein »moralisch gefallener Süffling «, der die "Ruthenisierung des Landes " gewiss vorantreiben würde. ${ }^{357}$ Nicht anders zu erwarten, begrüßten die Anhänger der Jungruthenen diesen Schritt und dankten in einer Versammlung dafür; zugleich bekräftigten sie bei dieser Gelegenheit ihre Opposition zu den rumänischen Beschlüssen und die weiterhin vertretene Forderung nach einer Teilung der Diözese sowie einem eigenen Bischof. ${ }^{358}$

\section{Exil, Rückkehr, Wiederaufbau und Neubeginn}

Knapp drei Wochen nach Kriegsausbruch und zwei Tage vor dem Evakuierungsbefehl der Behörden vom 24. August 1914 meldete sich Repta mit einem Hirtenbrief zu Wort. Sein Aufruf erinnerte die Gläubigen an ihre Pflichten gegenüber dem Kaiser. Gemeinsam sollte man jetzt die Ernte einbringen, sich gegenseitig ohne Rücksicht auf den Stand helfen und, ganz so wie Joseph II., sich hinter den Pflug stellen. ${ }^{359}$ Allein, die Ereignisse begannen sich zu überschlagen.

Im Verlauf des Krieges gelang es russischen Truppen, Teile der Bukowina zweimal für eine jeweils längere Periode zu besetzen: vom 30. August 1914 bis zum 13. Juni 1915 und vom 10. Juni 1916 bis zum 7. März 1918. Czernowitz war dreimal davon betroffen, vom 2. September bis zum 2. Oktober, vom 28. November 1914 bis zum 16. Februar 1915 und vom 18. Juni 1916 bis 3. August 1917. Eine offizielle Beendigung des Kriegszustandes für die Bukowina wurde erst im Mai 1918 ausgesprochen. ${ }^{360}$ Der Erzbischof, Geistliche anderer Konfessionen, der Bürgermeister und weitere Repräsentanten der Stadt verblieben in Czernowitz, nicht zuletzt, um die Ordnung innerhalb der Bevölkerung trotz der Besatzung aufrechtzuerhalten. Der Metropolit versuchte sich beim russischen Gouverneur S. Efreinow für die Freilassung der Zivilgeiseln, unter denen sich auch der Czernowitzer Bürgermeister befand, einzusetzen. Trotz allem konnte Repta hier wenig bewegen. Allerdings gelang es ihm, die anfänglich hohe Kontributi-

356 Czernowitzer Allgemeine Zeitung Nr. 3220 v. 3.X.1913, 4, Zur gr.-or. Kirchenfrage.

357 Universul Z. 257 v. 18.IX.1913; nach Bukowinaer Post Nr. 3090 v. 6.I.1914, 2, Die Kirchenfrage in der Bukowina.

358 Bukowinaer Post Nr. 3060 v. 12.X.1913, 2f., Versammlung der gr.-or. Priesterschaft i.d. Bukowina.

359 Czernowitzer Allgemeine Zeitung Nr. 3532 v. 22.VIII.1914, 4, Ein Hirtenbrief des Metropoliten Dr. Wladimir v. Repta.

360 ZAPOLOVS'кIJ 2003, Буковина, 194. 
onssumme der russischen Besatzer, die der Stadt auferlegt worden war, herabzusetzen. Zudem war er bereit, die fehlende Summe aus eigenem Vermögen beizusteuern. ${ }^{361}$ Diesen persönlichen Einsatz des gr-orient. Erzbischofs erwähnte selbst Eduard Fischer. Letzterem oblag zu dieser Zeit das Kommando über die verbliebenen österreichischen Gendarmerietruppen, die sich in die südliche Bukowina zurückgezogen hatten. ${ }^{362} \mathrm{Fi}$ scher hatte wie andere Kommandeure der regulären Armee auch unter ruthenischen wie rumänischen Geistlichen einen regelrechten Spionagewahn gegen vermeintliche Russophile gefördert und damit - abseits des Krieges - nicht unwesentlich zum Stimmungsumschwung in der Bevölkerung beigetragen. ${ }^{363}$

Der russische Gouverneur verlangte von Repta ziemlich forsch die Abhaltung eines Dankgottesdienstes für den Zaren. ${ }^{364}$ Dem konnte sich der Metropolit kaum entziehen.

Im Einverständnis mit dem russischen Herrn Statthalter in Czernowitz habe ich, Metropolit der Bukowina und Dalmatiens, in meinem Konsistorium folgende Verordnung an meine Pfarrgeistlichen erlassen und trage Ihnen auf, sie genau durchzuführen:

Ich trage Ihnen auf, gelegentlich des Gottesdienstes Gebete zu veranstalten für das Wohl und Gedeihen des Allerfrömmsten und Allgewaltigen großen Herrschers, des Zaren aller Reußen, Nikolaj Alexandrowitsch, seiner Mutter, der Allerhöchsten Herrscherin Zarin Maria Theodorowna, seiner Gemahlin, der Herrscherin Zarin Alexandra Theodorowna, seines Thronfolgers, des glaubenstreuen Herrschers des Zesarewitsch und Großfürsten Alexej Nikolajewitsch, seiner dafür zu beten, daß dem allrussischen, rechtgläubigen und christliebenden Heere der Sieg zuteil werde. Ich trage Ihnen weiterhin auf, in Ihren Predigten die Bevölkerung aufzufordern, das russische Heer und die Russen als Brüder zu empfangen, die hierher gekommen sind, sie vom fremdgläubigen Joch und Druck zu befreien, auf das sie unter der herrschenden Gewalt des russischen Zaren mit dem großen Rußland zu einem Ganzen verwachse. ${ }^{365}$

361 ČuČKо 2014 (I), Церковь, $92 \mathrm{ff}$; zusammenfassend ČuČко 2015, Горнилі.

362 FISCHER 1935, Krieg, 95.

363 BĂLAN 1923, Suprimarea.

364 ČUС̌ко 2014 (I), Церковь, 93.

365 Verordnungsblatt des gr-orient. Konsistoriums, Zl. 7941 v. 2.X.1914, gez. Repta/Manastyrski, nach Czernowitzer Allgemeine Zeitung /Czernowitzer Tagblatt (gemeinsame Kriegsausgabe) Nr. 326 v. 31.VIII.1918, 2, Zum Wechsel in der Leitung der griechisch-orientalischen Bukowinaer Erzdiözese. In jener Version, die 1918 in Österreichs Illustrierte Zeitung (Nr. 51 v. 22.IX.1918, 818) veröffentlicht wurde, fehlt der erste Absatz. Repta selbst versuchte, diese Situation differenziert darzustellen. Er wies darauf hin, stets seinem Kaiser "Treue und Ergebenheit geschworen « zu haben, zudem hätten ihm untergebene Priester und nicht er den angekreideten Gottesdienst geleitet; Neues Wiener Tagblatt v. 17.XII.1914, Eine Audienz beim Erzbischof Dr. Wladimir v. Repta, nach OSTA-HHSTA, Zeitungsarchiv Karton 161 Ministerium d. Äußeren. 
Obwohl diese Weisung an die Pfarrer unmittelbar nach dem Abzug der russischen Truppen von Repta wieder rückgängig gemacht worden war, begegneten ihm die österreichischen (Militär-)Behörden in der durch den Krieg aufgeheizten Situation des allgemeinen Misstrauens fürderhin mit Misstrauen. ${ }^{366}$ Repta hatte sich auch deswegen auf Weisung noch vor der zweiten russischen Besatzung mit dem Konsistorium nach Dornawatra (rum. Vatra Dornei) zu begeben. ${ }^{367}$ Man misstraute ihm. ${ }^{368} \mathrm{Im}$ Dezember 1914 traf man indes Überlegungen, zivile Behörden wie das Konsistorium und damit auch den Erzbischof aus dem Kurort noch weiter ins Landesinnere der Monarchie zu verbringen. ${ }^{369}$ Zur Evakuierung schritt man de facto allerdings erst während der Brussilow-Offensive im Sommer 1916. Der Evakuierungszug, drei Waggons für 90 Personen stellte man dem Konsistorium sowie dem Erzbischof zur Verfügung, verließ den Kurort am 23. Juni 1916 in Richtung Klausenburg (heute Cluj-Napoca) und fuhr von dort über Wien nach Prag. Die kirchlichen Behörden als auch die Landesregierung der Bukowina führten ihre Geschäfte in Prag weiter. Das Konsistorium war im Hotel Blauer Stern (Prag II.) einquartiert. ${ }^{370}$ Den Beamten und Bediensteten des Konsistoriums, die Czernowitz verlassen mussten und dadurch materielle Einbußen zu tragen hatten, gestattete die Landesregierung nachträglich »einmalige Aushilfen im Ausmaße eines Monatsbezuges « aus Mitteln des Religionsfonds. Der Fonds hatte ebenso die Evakuierungskosten der kirchlichen Einrichtungen zu begleichen. ${ }^{371}$ Mit dem Zurückdrängen der russischen Armee während des Herbstes 1917 stellte Repta den Antrag auf Rückkehr nach Czernowitz, der jedoch von den Behörden abgelehnt

366 Рвокорошітsсн 1959, Ende, 14; mit seinem 1924 eingereichten endgültigen Rücktritt erinnerte und dankte hingegen v.a. die jüdische Bevölkerung dem Erzbischof Repta für seinen Einsatz auch während der russischen Besatzung; Czernowitzer Morgenblatt Nr. 1661 v. 27.I.1924, 2, Metropolit Repta.

${ }_{367}$ Von rumänischer Seite wurde damit argumentiert, dass die unfreiwillige Ubersiedlung des Erzbischofs nach Dornawatra v.a. deswegen erfolgt sei, damit die österreichischen Behörden weiterhin Zugriff auf das Religionsfondsvermögen bei den Wiener Banken hätten, d.h. nicht zuletzt, um daraus Kriegsanleihen zeichnen zu können (dazu Kapitel 9); Adevărul anul XXVIII, Nr. 10.090 v. 17.IV.1915, Martiriul românilor bucovineni (Ion Grămadă), ıf., nach: PAPUC 2010, An, 180-189, hier 183. Der Historiker und Publizist I. Grămadă (1889-1917) hatte 1915 die Bukowina verlassen und war 1916 in die rumänische Armee eingetreten.

368 Ganz im Gegensatz dazu scheint aus der Erinnerung heraus die Haltung der Bevölkerung gegenüber dem Erzbischof eine durchaus positive gewesen zu sein; vgl. dazu die Gedanken des ukrainischen Bahnwärters Peter in WIT TLINS Roman Das Salz der Erde (16of.)

${ }_{369}$ DACZ $_{320} / 1 / 17$, fol. 4f., Landespräsident an Konsistorium, Dorna Watra v. 2.XII.1914, sowie Konsistorium an Landesregierung, Dorna Watra v. 4.XII.1914, fol. 7.

370 DACZ $_{320 / 1 / 17}$, fol. 13-19, Landespräsident an Konsistorium, Dorna Watra v. 21.VI.1916.

$371 \mathrm{DACZ}_{320 / 1 / 17}$, fol. 9, Landesregierung an Konsistorium, Dorna Watra v. 24.IV.1915; fol. 19, Landesregierung ans Konsistorium, Prag v. 30.V.1917. 
wurde. Lediglich die Landesregierung durfte ihren vorläufigen Sitz von Prag ins galizische Stanislau verlegen. ${ }^{372}$ Dem Konsistorium hatte man das gleichfalls angeboten, offensichtlich entschied sich Repta jedoch, die Kirchenbehörden vorerst nach Wien zu übersiedeln, wo man im Hotel Kaiserin Elisabeth Quartier gefunden hatte. ${ }^{373}$

In Czernowitz kursierten in den ersten Augusttagen 1918 bereits Gerüchte über einen Rücktritt des Erzbischofs, und politische Akteure wie der Reichsratsabgeordnete Onciul lancierten über die Medien ihre Vorlieben für eine Neubesetzung. ${ }^{374}$ Ende des Monats enthob der Kaiser schließlich den Erzbischof, der mittlerweile wieder in Czernowitz residierte, seines Amtes unter Beibehaltung seines Titels und der Bezüge. ${ }^{375}$ Einen Rücktritt hatte Repta aus kanonischen Gründen entschieden abgelehnt. ${ }^{376}$ Ebenso akzeptierte der Kaiser die Gesuche der Konsistorialräte Manastyrski und E. Popowicz um Übernahme in den Ruhestand und auf Auszahlung eines Ruhegenusses aus Mitteln des Religionsfonds. ${ }^{377}$ Wien ernannte in der Folge den Klostervorsteher von Mitoka-Dragomirna, Ipolit Vorobchievici $\left(1849\right.$ ?-1939) ${ }^{378}$ zum Administrator und rumänischen Archimandriten der Erzdiözese sowie den Erzpriester Titus Tyminski (1858-1927) ${ }^{379}$ zum ruthenischen Archimandriten. Eine nationale Teilung der Diözese auf zwei Bischöfe schien immer wahrscheinlicher. ${ }^{380}$ Die ruthenischen Abgeordneten legten zeitgleich einen Plan für den weitergehenden Umbau des Konsistoriums vor. Die St. NikolausKirche in Czernowitz sollte dabei zwischenzeitlich zu ihrem Hauptsitz bestimmt werden. Zuversichtlich dachte man bereits jetzt an einen monumentalen Neubau, der - die Lage völlig verkennend - in der Einschätzung der ruthenischen Politiker wohl spätes-

372 DACZ $_{320 / 1 / 17}$ fol. 24-28, Antrag Erzbischof auf Rückkehr des Konsistoriums nach Czernowitz, 28.VIII./10.IX.1917; Sitzungsprotokoll Konsistorium v. 28.X./10.XI.1917; Landesregierung an Konsistorium v. 29.IX.1917.

373 DACZ $_{320 / 1 / 17}$ fol. 34, Erzbischof Repta an Konsistorialarchimandrit Manastyrski in Prag, Wien v. 27.IV./10.V.1918.

374 Czernowitzer Allgemeine Zeitung /Czernowitzer Tagblatt (gemeinsame Kriegsausgabe) Nr. $312 \mathrm{v}$. 14.VIII.1918, 1f., Vom gr.-or. Konsistorium; Nr. 327 v. 1.IX.1918, 3, Ist Repta noch Herrenhausmitglied?

375 Pвокорошітsch 1959, Ende, 14 f.

376 Prager Abendblatt Nr. 194 v. 28.VIII.1918, 5, Vermischte Nachrichten; auch ČUČко 2014 (II), Церковь, 20.

377 Manastyrski erhielt 12.500 und Popowicz 15.000 Kronen jährlich zugesprochen; Czernowitzer Morgenblatt Nr. 104 v. 1.IX.1918, 3, Zur Kirchenfrage.

378 Vorobchievici stammte aus Gura Humora, seit 1905 Igumen des Klosters Mitoka-Dragomirna, leitete während der kurzen Übergangsphase 1918 das Erzbistum und wurde am 1./14.IX.1919 zum Bischof von Radautz ernannt.

379 Taufname Taras, stammte aus dem Kotzmanner Bezirk in der Nordbukowina.

380 Osterreichs Illustrierte Zeitung Heft 51 v. 22.IX.1918, 818; Neue Freie Presse Nr. 19382 v. 11.VIII.1918, 7f., Inland. 
tens in zehn Jahren stehen würde. ${ }^{381}$ Noch im Oktober 1918 stellten sich die orthodoxen Militärgeistlichen Victor Baron Wassilko, Demeter Ritter von Bejan sowie Simeon Reli für die zu besetzenden Stellen in der Erzdiözese und im Konsistorium zur Verfügung. ${ }^{382}$ Der ukrainische Reichsratsabgeordnete Nikolaus von Wassilko forderte zwar eine Volksabstimmung, ging aber zur selben Zeit noch überzeugt davon aus, dass sich die Bukowina einhellig als Teil der Monarchie erklären werde. ${ }^{383}$ Die wenig später erfolgte Übernahme der Verwaltung der Stadt Czernowitz und der ukrainischen Gebiete der Bukowina durch den ukrainischen Nationalrat am 6. November 1918 blieben nur eine Episode. ${ }^{384}$ Während der Herbstwochen überstürzten sich indes die politischen Ereignisse in der österreichisch-ungarischen Monarchie, sodass keines der Vorhaben in der ursprünglich vorgesehenen Form umgesetzt werden konnte. Der Rumänische Nationalrat, der sich in der Zwischenzeit in der erzbischöflichen Residenz im Synodalsaal konstituiert hatte, riss mithilfe des rumänischen Militärs, das am 11. November 1918 einmarschiert war, die Macht in der Bukowina an sich. Der Anschluss an das Königreich Rumänien stand unmittelbar bevor. Repta setzte man wieder in alle seine Ämter ein.

Die Regierung hat sich auch zur Aufgabe gemacht, Sr. Exzellenz den Erzbischof Dr. von Repta zu rehabilitieren und dem greisen Kirchenfürsten für die erlittene Unbill (Rufe: Fischer) volle Genugtuung zu verschaffen. (Lebhafter Beifall.) ${ }^{385}$

\section{Zusammenfassung}

Die nationale Frage in der Bukowina, vor allem im Hinblick auf die Situation und das Verhältnis zwischen Ruthenen und Rumänen des Kronlandes, spitzte sich von Jahr zu Jahr zu. Die Kirchenfrage bildete innerhalb dieses Komplexes eine zentrale Achse des Diskurses. Mit jeder Vakanz bzw. anstehenden Neubesetzung einer Stelle in entschei-

381 Czernowitzer Allgemeine Zeitung /Czernowitzer Tagblatt (gemeinsame Kriegsausgabe) Nr. $326 \mathrm{v}$. 31.VIII.1918, 2, Zum Wechsel in der Leitung der griechisch-orientalischen Bukowinaer Erzdiözese sowie Die Neuordnung im gr.-or. Konsistorium.

382 ÖSTA-AVA Kultus NK akat. gr.-or. Karton 6; Im Namen der bukoviner gr-or. Militärgeistlichen rom. Nationalität an Kriegsministerium; »Mit Rücksicht auf die geänderten Verhältnisse ad acta «, Wien v. 20.XII.1918.

383 Czernowitzer Morgenblatt Nr. 143 v. 19.X.1918, Titelseite, Die Abtretung der Bukowina eine Fabel.

384 Czernowitzer Morgenblatt Nr. 159 v. 7.XI.1918, Titelseite, Bukowina (1775 - 6. November 1918). Ein historischer Tag.

385 Czernowitzer Allgemeine Zeitung /Czernowitzer Tagblatt (gemeinsame Kriegsausgabe) Nr. 391 v. 15.XI.1918, 2, Das Programm der neuen Regierung. Große Debatte im rumänischen Nationalrat; HAUSLEITNER 2001, Rumänisierung, 108-111. 
dender Position wie etwa im erzbischöflichen Konsistorium erhielt der politische, zudem in wachsendem Ausmaße emotional geführte Diskurs neuerlich Nahrung. Darüber hinaus erweiterte sich durch die Wahlrechtsreform, d.h. durch die Einführung des allgemeinen, gleichen und geheimen Männerwahlrechtes von 1907 und die Abschaffung der Kurien, das Wählerspektrum in Cisleithanien erheblich. ${ }^{386}$ Die Beteiligung einer breiten Bevölkerungsbasis an politischen Entscheidungsprozessen geriet indes - wie das schon die Kirchenkongressfrage gezeigt hatte - nicht unbedingt zum alleinigen Vorteil dieses Demokratisierungsprozesses insgesamt. Noch mehr als zuvor waren die sich im Kronland allmählich formierenden politischen Parteien jetzt darum bemüht, ihre jeweilige Legitimation durch den Ausbau des Stimmenanteils zu stärken. Die Politisierung - und in diesem Fall auch Emotionalisierung - von Themen kirchlicher Autonomie bis hin zur Vermögensverwaltung des Religionsfonds amalgamierte soziale Forderungen mit Fragen nach nationaler Selbstbestimmung und projizierte in letztere die unbedingte Hoffnung auf eine Verbesserung der Lage. Aus dem benachbarten rumänischen Königreich erfuhren die damit ohnedies fragilen innenpolitischen Verhältnisse des Kronlandes zusätzlich radikalisierende Impulse, wie etwa durch die politische Tätigkeit von Iorga ${ }^{387}$ und regelmäßige Kommentare Bukarester Zeitungen. Allein all das war in Summe kaum dazu geeignet, eine sachliche Diskussion um die Zugriffs- oder zumindest Kontrollrechte auf bzw. über den gr.-orient. Religionsfonds zu führen, sodass der Ausbruch des Ersten Weltkrieges lediglich die Fronten in der Bukowina noch unüberwindlicher machte und letztlich mit Ende des Jahres 1918 zugunsten der Rumänen Tatsachen geschaffen wurden, die ohnedies keiner demokratischen Diskussion unter allen Betroffenen mehr bedurften. Trotz dessen werden in der historiographischen Einschätzung von rumänischer (wie auch ruthenischer) Seite die Jahrzehnte vor 1914 gerne als Periode des Kampfes bezeichnet. Dem ist nicht in allem zuzustimmen. ${ }^{388}$ Das Bemühen der staatlichen Behörden - obwohl es oftmals einem unentschlossenen Lavieren gleichen mag - um einen Ausgleich vermochte die Situation dennoch immer wieder vorübergehend zu kalmieren. ${ }^{389}$ Landespräsidenten wie Oktavian Regner v. Bleyleben hatten dabei wiederholt den Versuch unternommen, die Bedeutung des gr--orient. Religionsfonds für die Landesentwicklung und dessen durchaus positive Leistungen für das Allgemeinwohl

386 COHEN 1998, Absolutism.

387 CoRbeA-HoIșIE 1996, Kohabitation.

388 CÂNDEA 1924, Mitropolitul, 6.

389 Vgl. dazu die Sammlung diverser Beschwerden gegen Pfarrer u.a. in DACZ $320 / 1 / 18$ fol. 34-174 für die Jahre 1912-1925. Die Landesregierung leitete diese in der Regel mit der Bitte um Klärung des Sachverhaltes an das Konsistorium weiter. Sie war allerdings zumeist darauf bedacht, den religiösen Bedürfnissen sowohl der rumänischen als auch der ruthenischen orthodoxen Bevölkerung des Landes gleichermaßen Rechnung zu tragen. 
herauszustreichen. So äußert sich etwa Bleyleben in einer Erwiderung auf Onciul im Bukowiner Landtag:

Ich verwalte den Religionsfond bereits sechs Jahre und ich habe gesehen, daß alles Gute und Schöne, welches für das Land geschaffen wurde, zum größten Teile vom Religionsfond herstammt. ${ }^{390}$

Auch der Kirchenführung unter Repta darf dieses auf Ausgleich gerichtete Anliegen grundsätzlich nicht völlig abgesprochen werden, obgleich die Reserviertheit in der Frage nach demokratischer innerkirchlicher Mitbestimmung, wie sie im Kirchenkongress immer wieder über diese Jahre zur Sprache gekommen war, vielfach der traditionell hierarchischen Grundhaltung der Amtskirche, die hier zugleich als Großgrundbesitzerin auftrat, geschuldet war. Darin blieben sich Repta und seine Amtsvorgänger seit Hackmann - ungeachtet ihrer nationalen Präferenzen - stets einig.

Sie sehen, in welchem prachtvollen Palais ich wohne. Das sieht doch nicht nach Unterdrückung aus [...]. Der Religionsfonds, den Kaiser Franz Josef durch seine Beamten verwaltet, sorgt dafür, daß wir eine ganz vorzügliche Bildung erhalten. Unsere Pfarrer sind sehr gut gestellt. $^{391}$

Dabei darf insgesamt nicht übersehen werden, dass Wien zwar einerseits eine Politik des Ausgleichs zwischen den rivalisierenden Nationalitäten und politischen Parteien anstrebte, andererseits aber wenig Interesse aufbrachte, seinen Einfluss auf die Kirche des Landes und ihr Vermögen in irgendeiner Weise einschränken zu lassen. Diese Haltung hatte sich schon Jahre zuvor in der Diskussion um eine einheitliche wie zeitgemäße Verfassung für die orthodoxe Kirche des österreichischen Reichsteils abgezeichnet. Dabei war selbst die Frage der Benennung, ob nur `orientalisch « oder `orthodox «, nicht einfach zu klären, hätte das doch letztlich ein Zugeständnis des Staates in Richtung mehr Autonomie bedeutet, also einen Schritt, den Wien nicht wirklich bereit war zu setzen. So ergab sich in den Verhandlungen um die Normierung der gr.-orient. Kirche seitens der Synode eben die Frage nach der korrekten Bezeichnung. Die Synode verwies auf die "Naturwidrigkeit der heutigen officiellen Benennung unserer Kirche [als] 'griechischorientalisch«. Repta hatte im Einvernehmen mit der Synode von Karlowitz 1903 ei-

390 Czernowitzer Allgemeine Zeitung Nr. 1803 v. 19.I.1910, 1f., Bukowiner Landtag. Die Aufteilung der Ackergrundstücke des Religionsfondes.

391 Czernowitzer Allgemeine Zeitung Nr. 2931 (Mittagsausgabe) v. 9.IV.1913, 1, Erzbischof Dr. von Repta über die Beschuldigungen der Panslavisten gegen Osterreich-Ungarn. 
nen neuerlichen Anlauf gestartet, diesen Missstand zu beheben. ${ }^{392}$ Der gültige Name beruhte auf einer allerhöchsten Beschlussfassung aus dem Jahre 1864, die allerdings im inneren Verkehr die Verwendung des Begriffes >orthodox serlaubte. ${ }^{393} 1906$ lag der Antrag immer noch in Wien. Diesmal schlug der Bischof von Hermannstadt dem Metropoliten Repta vor, mit der Umbenennung aufgrund der schwierigen Zeiten vorerst noch abzuwarten. Damit spielte der Kirchenhierarch wohl auf die nationalen Zwistigkeiten rund um die Wahlrechtsdiskussion an. Eine spätere Amtserinnerung, die das Wiener Ministerium auf den Beschluss der Hl. Synode neuerlich hinwies, blieb gleichfalls bis Kriegsausbruch unerledigt. ${ }^{394}$

Die langersehnten Erwartungen rumänisch-nationaler Kreise auf eine Autonomie der Bukowiner Landeskirche schienen im Spätherbst 1918 mit dem Anschluss an das Königreich Rumänien endlich greifbar nahe. Indes sollte der Traum nach einer rumänischorthodoxen Kirche der Bukowina und einem selbstverwalteten Religionsfonds als Teil eines rumänischen Nationalstaates ebenso auf Schwierigkeiten stoßen wie die von einigen Czernowitzer Kreisen angedachte Fortsetzung des bisherigen politischen Lebens als vergleichsweise vom Zentrum sautonomes` österreichisches Kronland. Die Umbrüche des ausgehenden letzten Kriegsjahres und ihre Folgen gaben den Weg für eine am Ende bedingungslose Ausrichtung aller Sphären nach der neuen Hauptstadt Bukarest und ihrer strikt zentralisierenden Politik frei.

$392 \mathrm{DACZ}_{320 / 3 / 83}$, fol. 77 , Verhandlungsgegenstand der Hl. Synode v. 5./18.VII.1903, Amtserinnerung betreffend die Änderung der gegenwärtigen officiellen Benennung unserer Kirche.

393 Reichsgesetzblatt Nr. 91 v. 29.XI.1864, 307, Verordnung des Staatsministeriums, des Kriegsministeriums, der königlich-ungarischen, siebenbürgischen und kroatisch-slawonisch-dalmatinischen Hofkanzlei.

394 DACZ $_{320 / 3} / 83$, fol. 85, Bischof von Hermannstadt an Repta v. 22.III.1906; 29.XI./12.XII.1908, Amtserinnerung, Beschluss der hl. Synode v. 15./28.XI.1908. 


\section{Die wirtschaftliche Situation des Religionsfonds bis 1914}

Mit der Einrichtung einer zentralen Güterdirektion für den Bukowiner gr.-orient. Religionsfonds im Jahr 1870 erfolgte in administrativer Hinsicht zeitgleich der Übergang in der Zuständigkeit der Wiener Oberbehörden vom Finanz- auf das Kultusministerium. Im Sommer 1872 trat eine weitere Kompetenzverschiebung in Kraft. Die Agenden für den gr.-orient. Religionsfonds und seine Güter fielen per 1. Juli hauptsächlich dem Ackerbauministerium zu. ${ }^{1}$ In Kultusangelegenheiten behielt sich allerdings das dafür zuständige Ministerium seinen behördlichen Einfluss auf den Fonds vor. ${ }^{2}$ Lediglich die unmittelbare Leitung der ebenfalls zum Eigentum des Religionsfonds gehörenden Montanwerke in der südlichen Bukowina war einer eigenen k.k. Bergverwaltung in Jakobeny, die ihren Sitz vor Ort hatte, übertragen worden. Mit Ausnahme des Werkbetriebes blieb letztlich auch hier die Güterverwaltung in Czernowitz zuständig. ${ }^{3}$ Diese gliederte sich seit der Reform von 1887 (mit nachträglichen Anpassungen) den Arbeitsbereichen entsprechend in fünf Abteilungen: das juridisch-administrative Departement; das Forst-, Domänen- sowie das Bau- und Rechnungsdepartement. ${ }^{4}$ Die Trennung von Forst- und Domänenangelegenheiten innerhalb der Güterdirektion erwiesen sich unter den geänderten Umständen der Zeit als hinderlich, sie wurde 1912 wieder abgeschafft. ${ }^{5}$ Allerdings verlagerte Wien 1909 die Regierungszuständigkeit der Bukowiner Montanwerke vom Ackerbauministerium ins Ministerium für öffentliche Arbeiten. ${ }^{6}$

Allein bei der Güterdirektion in Czernowitz arbeiteten im Jahr 191342 Beamte, im für die Forste verantwortlichen Departement gab es weitere 14 pragmatisierte Dienststellen. Insgesamt hatte die Güterdirektion eine Fläche von fast 74.000 Hektar zu betreuen. ${ }^{7}$ Damit stand dem Religionsfonds eine bis 1918 weitgehend unverändert bleibende Grundstruktur zur Verfügung, innerhalb derer sich eine - sowohl für den spezifischen Wirtschaftsraum des Kronlandes als auch im Vergleich zu Cisleithanien - durchaus bemerkenswerte ökonomische Entwicklung vollziehen konnte. ${ }^{8}$

1 SChindler 1889, Forste, 58; GUZMAnN 1901, Forstwirtschaft, 113.

2 Kapitel 6 (Hackmann).

3 Kapitel 10 (Jakobeny); ANoNy mUS 1909, Dienstinstruktion, $\ 5$ u. 7; die ältere Instruktion und der Wirkungskreis für die k.k. Direktion der Güter des Bukowinaer gr.-orient. Religionsfonds v. 21.IV.1888 (Z. 539/A.M.) wurde damit außer Kraft gesetzt.

4 ANONYMUS 1909, Dienstinstruktion, 16.

5 Czernowitzer Allgemeine Zeitung Nr. 2842 v. 12.V.1912, 1, Güterdirektor Hofrat Ritter von Ullmann.

6 (Neuigkeits)Welt Blatt Nr. 221 v. 28.IX.1909, 13, Industrie-Unternehmungen.

7 TitTeL 1913, Schematismus, 1283.

8 "Mit den Achtziger-Jahren vollzog sich dann vorzüglich infolge der von der Verwaltung der Religionsfondsforste eingeleiteten Maßnahmen jener gewaltige Umschwung im Fortwirtschaftsbetriebe 


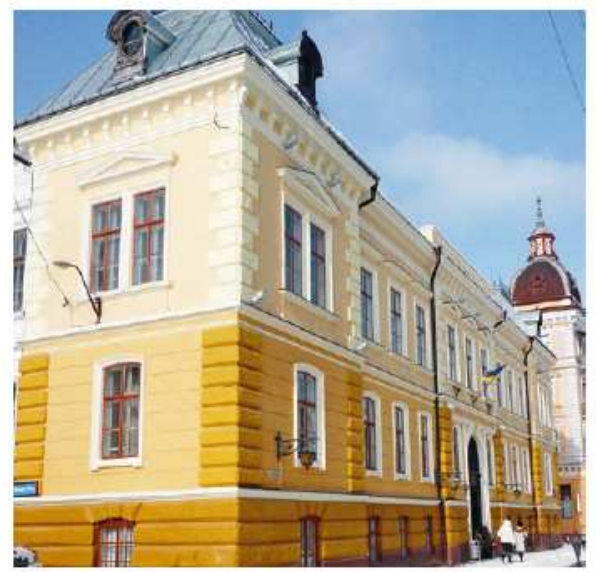

Abb. 29 und 30: Amtslokalitāt der Güterverwaltung des Bukowinaer gr-orient. Religionsfonds in Czernowitz. Das repräsentative Gebäude wurde 1875 (mit Erweiterungen 1897 und 1905) in unmittelbarer Nähe der Kathedrale in der Herrengasse errichtet, umfasste in seiner ursprünglichen Ausführung 47 Zimmer auf $1172 \mathrm{~m}^{2}$ und bot für den Güterdirektor eine eigene Dienstwohnung. Seit 1956 ist hier das landeskundliche Museum der Oblast' Černivci - wie auf dem ukrainischen Briefcouvert zu dessen 150-Jahr-Jubiläum dargestellt - untergebracht. Zuvor hatten der sowjetische Inlandsgeheimdienst (1940/41) und ab 1945 die Gebietsparteileitung ihren Sitz in diesem Haus. ${ }^{9}$ Aufnahme 2009/Sammlung K. Scharr.
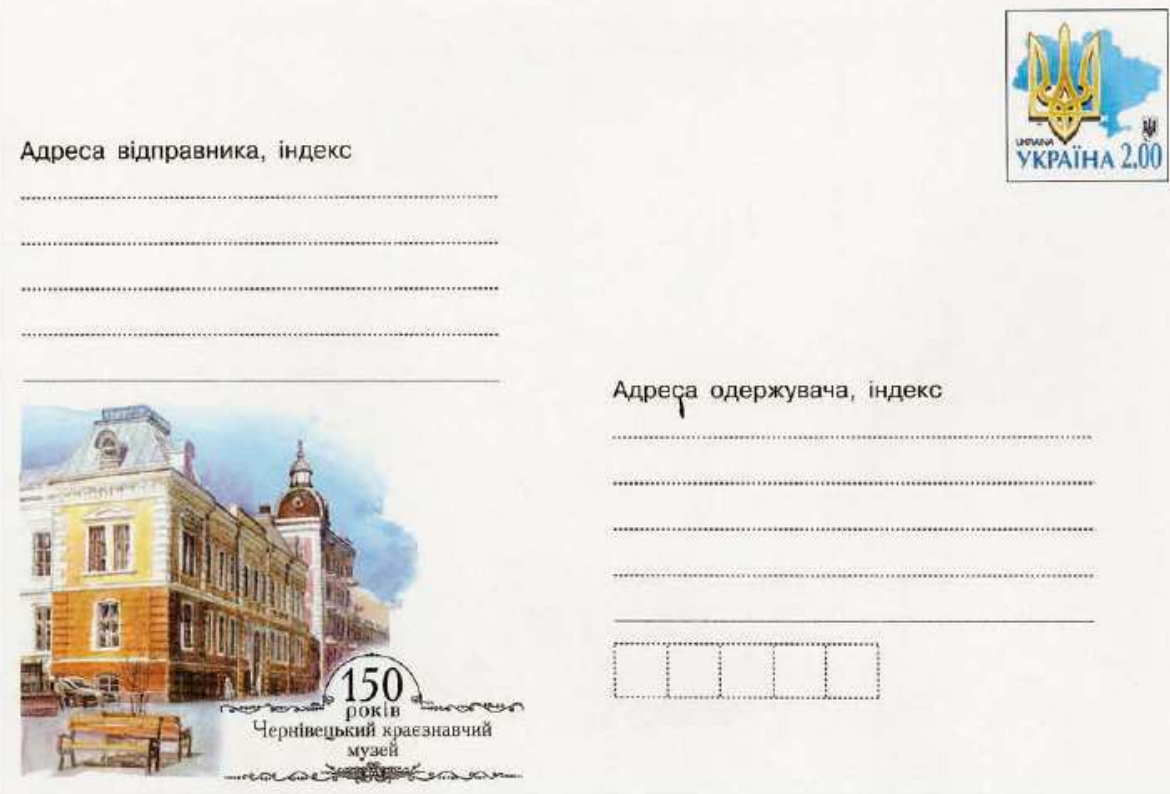

Адреса одержувача, індекс

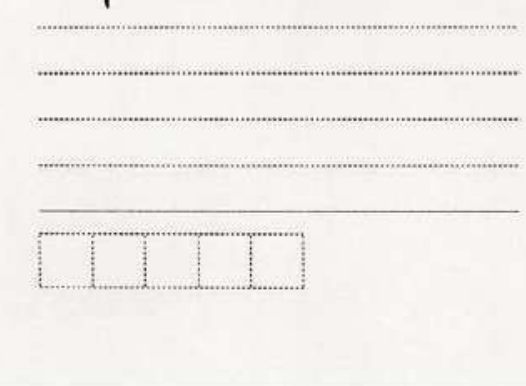

der Bukowina, welcher insbesondere die mächtigen Gebiete der eigentlichen Gebirgsforste in stetig wachsendem Masse zum hauptsächlichen Träger der forstlichen Produktion machte «; GuZMANN 1901, Forstwirtschaft, 141f.

9 MeL'NiK et al. 2015, Czernowitz, $126 \mathrm{ff}$. 
In Fortsetzung des Querschnittskapitels zur Wirtschaftssituation des Religionsfonds um die Mitte des 19. Jahrhunderts und die rechtlich-politischen Veränderungen, wie sie im Abschnitt zur Ära von (Erz-)Bischof Hackmann zur Diskussion standen, soll hier nunmehr der Schwerpunkt auf einem Überblick zur ökonomischen Gesamtsituation der Fondsgüter bis Kriegsausbruch gelegt werden. Einen zentralen Baustein besetzen darin die Forste als hauptsächliche Einnahmequelle. Der exemplarische Blick auf einzelne ausgewählte größere Investitionsvorhaben und Bauten, die eine oftmals enorm symbolische Bedeutung für das Kronland an sich besaßen, sowie auf die gemeinnützige Fördertätigkeit des Fonds bis Kriegsende rundet dieses Kapitel ab. Eine kurze Darstellung der Rückführung von Fondskapitalien aus der Republik Österreich in den `neuen ‘ Staat Rumänien nach 1918, als Teil einer generellen strukturellen Umorientierung, sowohl des vormaligen Kronlandes in eine Provinz des Königreiches als auch der Institution Religionsfonds, leitet schließlich zum letzten größeren Abschnitt, der Zwischenkriegszeit, über.

Von einer rein quantitativen wirtschaftshistorischen Analyse wird hier abgesehen. Einerseits gestattet die Quellenlage dafür kaum eine einigermaßen homogene Betrachtung über diesen vergleichsweise langen Zeitraum. Zudem birgt die Archiv- und Datensituation des rumänischen Staates in ihren mehrfachen Brüchen nach 1918 insgesamt eine Reihe von nur schwer zu bewältigenden methodischen Hürden. Andererseits bleibt die für die vorliegende Monographie gewählte übergeordnete Fragestellung, wie schon in den vorangegangenen Abschnitten, auch hier zentraler Ansatzpunkt: die Fokussierung einer Epochen übergreifenden institutionellen Rolle des Religionsfonds für die Bukowina.

\section{Die Institution in Bilanzdaten: die Jahre 1864 bis 1913}

Wirft man einen Blick auf die Budgets des gr--orient. Bukowiner Religionsfonds der Jahre 1864 bis 1913, so gründete in absoluten Zahlen der überwiegende Teil aller Ausgaben auf den Bedürfnissen des `Kultus`. Dazu gehörten Auslagen für (Erz-)Bistum und Konsistorium, die bestehenden aktiven Klöster (Putna, Suczawitza, Dragomirna) sowie die von der Kirche betriebenen geistlichen Bildungsanstalten in Czernowitz. Darunter das gr--orient. Seminar, die gr--orient. Gesangsschule sowie das angeschlossene Internat und ab 1875 die gr--orient. theologische Fakultät der Franz-Josephs-Universität. Einen erheblichen Betrag bezifferten in diesem Posten die aufzubringenden Gelder für den repräsentativen Neubau der Metropolitanresidenz des Erzbischofs und deren laufenden Betrieb. Allein für die Errichtung waren von 1864 bis 1882 über 700.000 Gulden, gänzlich aus Religionsfondsmitteln, veranschlagt worden. ${ }^{10}$ Zudem hatte bereits 1843

10 Anonymus 1864, Voranschlag. 
die Hofkanzlei in Wien die Bewilligung für den Bau einer neuen Kathedrale - selbstredend auf Kosten des Religionsfonds - erteilt. Bis zur Fertigstellung der Bischofskirche in Czernowitz, die 1864 eingeweiht wurde, flossen dafür 200.000 Gulden aus dem Fonds in das markante Bauwerk zwischen oberer Herrengasse und späterem Austriaplatz. ${ }^{11}$ Für den österreichischen Staat ergab das eine bequeme Situation, mussten doch kaum nennenswerte Mittel für Kultuszwecke oder den Erhalt kirchlicher Bauten in der Bukowina aus dem Zentralbudget eingesetzt werden. ${ }^{12}$ In ähnlicher Weise verhielt sich die Wiener Regierung bei der Übertragung der Kirchenpatronatsrechte der eingemeindeten Vororte von Czernowitz, als sie diese (und die damit verbundenen finanziellen Verpflichtungen) 1847 dem Fonds abgetreten hatte. ${ }^{13} \mathrm{Im}$ Fall des Gebäudes der Bukowiner Landesverwaltung streckte der Religionsfonds - auf Weisung des Kultusministeriums und mit allerhöchster Sanktion - immerhin nur ein auf 35 Jahre zurückzahlbares Darlehen von 175.000 Gulden zum Ankauf der Gründe und zum Bau selbst vor. ${ }^{14}$

Den zweiten in seiner Höhe entschieden geringer ausfallenden Posten bestimmten die unter >Unterricht`summierten Aufwendungen. So finanzierte der Fonds in der Landeshauptstadt zur Gänze die gr.-orient. Oberrealschule (seit 1853), die höhere Töchterschule $^{15}$ (seit 1864) sowie eine Volksschule. Dazu kam noch das gr.-orient. Oberrealgymnasium $^{16}$ in Suczawa (seit 1860) und die jährlichen Zuschüsse in den allgemeinen Landesschulfonds der Bukowina.

In der Betrachtung beeindrucken insbesondere die enormen Steigerungsraten seit 1864 , sowohl ausgaben- als auch einnahmenseitig, sieht man einmal von den allein durch die

11 Gubernialverordnung an Bukowiner Kreisamt v. 15.VII.1843, Zl. 43309; nach ONCIUL 1891, Fondul, $195 \mathrm{ff}$. Pahomi gibt $1.830 .000 \mathrm{fl}$. als Baukosten für Kathedrale und Residenz an, die vom Religionsfonds zu bestreiten waren. Die Zahl lässt sich in den Quellen nicht verifizieren; vgl. РАномI 1998, Biserici, 138.

12 Bukowinaer Post Nr. 2194 v. 27.II.1908, 2, Die Bukowina und das Reich (VIII).

13 DACZ $320 / 2 / 35$ Landesgubernium Lemberg an Konsistorium Czernowitz v. 13.XII.1847, Gubernialverordnung v. 8.III.1844, Zl. 10500 , Entschluss Sr. Majestät v. 27.I.1844; damit übertrug das Gubernium die Patronate der gr.-orient. Pfarreien in den Städten Suczawa, Czernowitz und Sereth sowie (Zl. 55385) jene der nunmehrigen Czernowitzer Vorstädte (Rosch, Klokuczka, Kaliczanka und Horecze) dem Religionsfonds.

14 OSTA-AVA Ministerium des Inneren A45 (1848-1899) 1614/1870 3/Buk, Ministerium für Cultus und Unterricht an Ministerium des Inneren v. 8.IV.1870 (sowie nachfolgende Zahlen 3039/1869; 2200/1869); Der Staatsschatz sollte »nicht ohne zwingende Nothwendigkeit in Anspruch genommen werden«; Zahl 2017/1869 allerhöchster Vortrag 4.V.1869 Wien, kaiserliche Ermächtigung v. 8.V.1869 Gödöllö.

151902 hatte der Religionsfonds für den Neubau 360.000 K bereitgestellt; Neues Wiener Tagblatt Nr. 211 v. 2.VIII.1902, 6, Grundsteinlegung gr.-or. höhere Tochterschule.

$16 \mathrm{Zu}$ den höheren Schulen vgl. FoDOR 2014, Învățământul, 103-123; 205-219; 252-256. 
ökonomischen Rahmenbedingungen bedingten Zuwächsen bzw. Teuerungen und dergleichen ab. Absolut gesehen verzeichneten, den Statuten folgend, die Kosten unter der Rubrizierung 'Kultus` den größten Zuwachs (1864: 431.00o Gulden; 1913: 1.369.0oo gerundet), gefolgt vom ,Unterricht` (1864: 65.000 Gulden, 1913: 501.000 gerundet). Relativ gesehen kletterten jedoch die Steigerungsraten für diese Posten bis 1913 wesentlich stärker auf über $700 \%$, wogegen jene des Kultus nur knapp mehr als das Dreifache von 1864 erreichten. Diese ansehnliche Differenz unterstreicht mithin mehr als deutlich die zunehmende Verantwortung und die enge Verflechtung des Religionsfonds in/mit der sich sukzessive verdichtenden Bildungslandschaft des Kronlandes, die zudem 1875 durch die Gründung einer eigenen Universität alle (akademischen) Ausbildungsstufen, ausgehend von der Volksschule, anbot. Andererseits hatten sich zur Mitte des 19. Jahrhunderts die meisten Kirchen des Landes in einem beklagenswerten baulichen Zustand befunden. Selbst von den 85 über das Patronatsrecht dem Religionsfonds als Grundherren unterstellten Pfarren verfügten lediglich 25 über »aus hartem Materiale gemauerte Kirchengebäude«. Noch viel schlechter stand es mit den Pfarreien privaten Patronats bzw. von Gemeinden. Das Konsistorium, das diese Mängel minutiös in einem Bericht auflistete, schlug vor, dass der Religionsfonds die notwendigen Gelder für die Herstellung der Kirchen und deren weiteren Bedürfnisse (Ausstattung, Kirchenbücher etc.) bereitstellen solle. ${ }^{17}$ Das dürfte mithin auch die erheblichen Steigerungsraten in dieser Kategorie bis 1913 erklären.

Die Deckung für diese stetig steigenden Summen floss hauptsächlich aus den Erträgen der Domänen und Forste, deren Zuwächse mit über 1000\% (Basis 1864) selbst jene des Unterrichts noch weit übertrafen. ${ }^{18}$ Auf die Forstwirtschaft und ihre mit Abstand zentrale Rolle für die Finanzgebarung des Religionsfonds soll daher weiter unten noch näher eingegangen werden. Außerdem hatte der Fond nach der Jahrhundertwende begonnen, z.T. mehrheitliche Beteiligungen an den Bukowiner Lokalbahnen ${ }^{19}$ und an der aufstrebenden Zuckerindustrie zu erwerben, die einiges an Profit einspielten und damit ebenfalls zum Ausgleich des Budgets eine erkleckliche Summe beisteuerten. ${ }^{20}$ Bei Kriegsausbruch beliefen sich die Werteffekten des Religionsfonds auf mehrere Millionen Kronen. ${ }^{21}$

17 OSTA-AVA, Neuer Kultus NK akath. gr.-or. K 22, Entwurf ex 1859.

18 AnONymus 1864, Voranschlag; ANonymus 1864-1881, Voranschlag (1875); ANoNymus (18821910), Voranschlag (1885, 1895, 1905 u. 1910); Voranschlag 1913; letzterer handschriftlich im DACZ $_{320} / 1 / 4532$; alle anderen liegen gedruckt mit Erscheinungsort Czernowitz vor.

19 Bukowinaer Post Nr. 3141 v. 10.V.1914, 6, Bukowinaer Lokalbahnen.

20 Bukowinaer Rundschau Nr. 3398 v. 19.VIII.1900, 1, Przeworsk-Chropin; der Religionsfonds hatte sich in die Zuckerfabriks-Actiengesellschaft mit $350.000 \mathrm{~K}$, das Kronland selbst mit $100.000 \mathrm{~K}$ eingekauft.

21 Allein die Beteiligungen beim galizischen Bankkreditverein, den Bukowiner Lokalbahnen, der galizisch-bukowiner Zuckerindustrie, der Portland und Roman Zement, der Landesbank der 
Tab. 10: Domänen und Güter des Bukowinaer gr--orient. Religionsfonds am Vorabend des Krieges. Nach Tittel (1913), Schematismus, 1283-1290 u. 1327-1328.

\begin{tabular}{|c|c|c|c|c|c|c|}
\hline \multirow{2}{*}{\multicolumn{2}{|c|}{ Herrschaft }} & $\begin{array}{l}\text { Höhen- } \\
\text { erstre- } \\
\text { ckung } \\
\end{array}$ & $\begin{array}{l}\text { Katast- } \\
\text { ralreiner- } \\
\text { trag }\end{array}$ & $\begin{array}{l}\text { Grund- } \\
\text { steuer }\end{array}$ & \multirow{3}{*}{$\begin{array}{l}\begin{array}{l}\text { Bediens- } \\
\text { tete }\end{array} \\
13\end{array}$} & \multirow{3}{*}{\begin{tabular}{|l} 
Industrien/ \\
Meierhöfe
\end{tabular}} \\
\hline & & $\begin{array}{l}\text { in } \mathrm{m} \\
\text { Meeres- } \\
\text { höhe }\end{array}$ & \multicolumn{2}{|c|}{ in Kronen gerundet } & & \\
\hline 1 & Brodina mit Paltin, Sadeu & $\begin{array}{l}600- \\
1382\end{array}$ & 56.500 & 12.800 & & \\
\hline 2 & Frassin mit Falkeu & $\begin{array}{c}264- \\
860 \\
\end{array}$ & 57.600 & 13.000 & 3 & $\begin{array}{l}1 \text { Meierhof, } \\
2 \text { Brettsägen }\end{array}$ \\
\hline \multirow[t]{2}{*}{3} & Hardeggthal inkl. & \multirow[t]{2}{*}{410} & \multirow[t]{2}{*}{128.000} & \multirow[t]{2}{*}{9.700} & \multirow[t]{2}{*}{8} & \multirow[t]{2}{*}{1 Meierhof } \\
\hline & $\begin{array}{l}\text { Ober- / Unter-Horodnik, } \\
\text { Wolowetz, Satulmare }\end{array}$ & & & & & \\
\hline \multirow[t]{2}{*}{4} & Kotzmann inkl. & \multirow[t]{2}{*}{241} & \multirow[t]{2}{*}{20.500} & \multirow[t]{2}{*}{4.700} & \multirow[t]{2}{*}{20} & \multirow{2}{*}{$\begin{array}{l}2 \text { Meierhöfe, } \\
3 \text { Mahlmūhlen }\end{array}$} \\
\hline & $\begin{array}{l}\text { Laszkowka, Suchowerchow, } \\
\text { Kliwodyn, Dawidestie }\end{array}$ & & & & & \\
\hline 5 & $\begin{array}{l}\text { Mardzina mit Suczawitza / } \\
\text { Fürstenthal }\end{array}$ & $\begin{array}{l}709- \\
1172\end{array}$ & 52.500 & 11.900 & 1 & $\begin{array}{l}1 \text { Meierhof, } \\
1 \text { Dampfsäge }\end{array}$ \\
\hline 6 & Neufratautz & 420 & 62.300 & 7.900 & 11 & - \\
\hline 7 & Ober-Wików / Unter-Wików & 462 & 11.900 & 2.700 & 12 & - \\
\hline 8 & $\begin{array}{l}\text { Putna mit Karlsberg und } \\
\text { Bordeleu }\end{array}$ & $\begin{array}{l}473- \\
580\end{array}$ & 62.900 & 14.300 & 14 & - \\
\hline 9 & $\begin{array}{l}\text { Seletin mit Ploska, Ruska, } \\
\text { Schypot }\end{array}$ & 1567 & 30.700 & 7.000 & 7 & 3 Dampfsägen \\
\hline \multirow[t]{2}{*}{10} & \multirow[t]{2}{*}{ Radautz (K.K. Staatsgestüt) } & \multirow[t]{2}{*}{$\begin{array}{l}370- \\
1590\end{array}$} & \multirow[t]{2}{*}{-} & \multirow[t]{2}{*}{400} & \multirow[t]{2}{*}{20} & $\begin{array}{l}5 \text { Meierhöfe, } \\
11 \text { Filialhöfe }\end{array}$ \\
\hline & & & & & & $\begin{array}{l}1 \text { Brettsäge, } \\
1 \text { Ziegelei }\end{array}$ \\
\hline & Summe & & 482.900 & 84.400 & 109 & \\
\hline
\end{tabular}

Bukowina sowie die Darlehen an das Kronland waren mit mehr als 16,6 Millionen zu beziffern; DACZ $_{319 / 2 / 117}$, fol. 59, Ministerium für Kultus und Unterricht an Landespräsidium Bukowina v. 6.V.1915. 


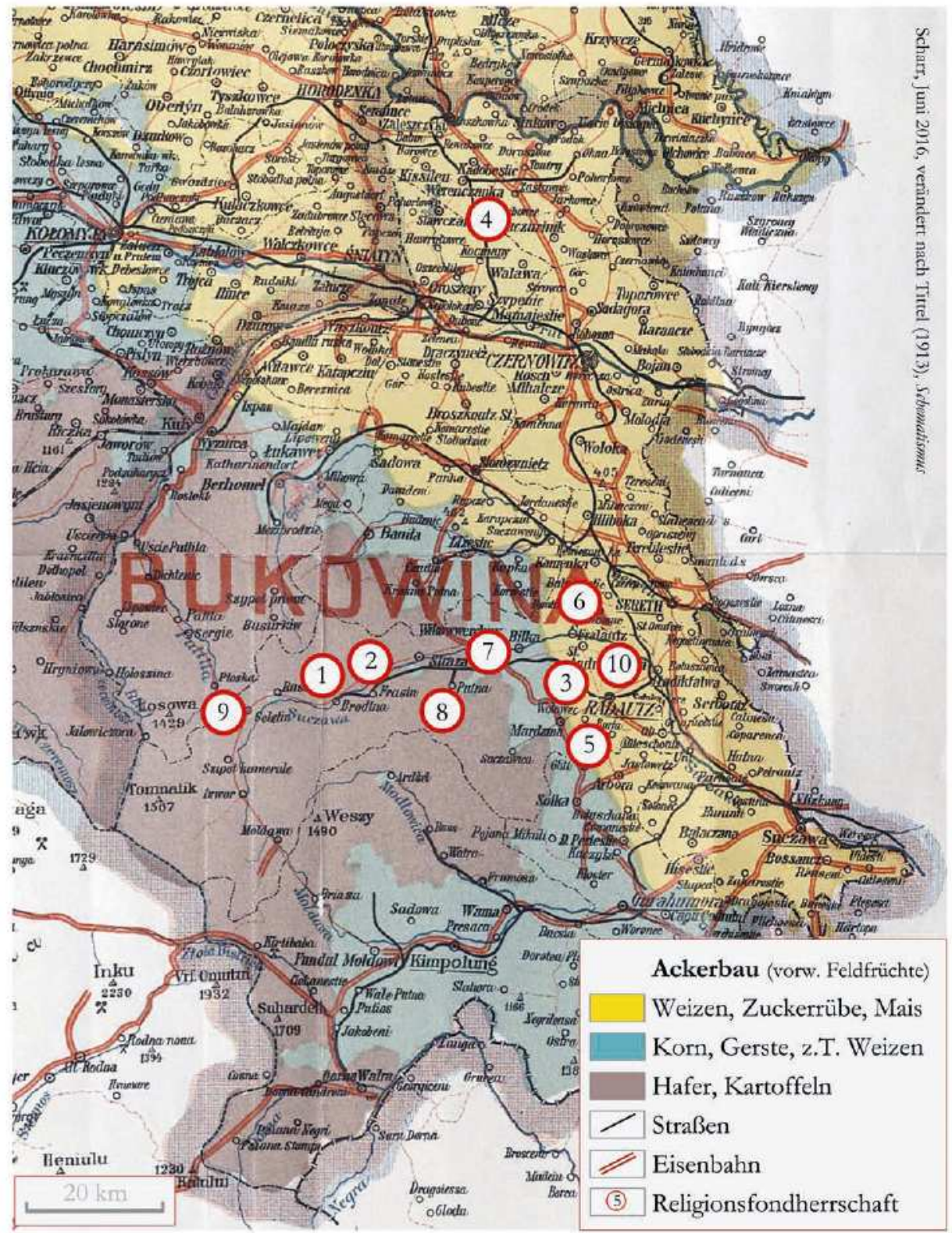

Abb. 31: Agrar- und forstwirtschaftliche Zonen der Bukowina, mit Berücksichtigung der Religionsfondsherrschaften 1913. (vgl. Tab. 10). 
... als Quelle von Förderungen

Die bisherige Darstellung konnte aufzeigen, welche physische Präsenz der gr--orient. Religionsfonds in der Bukowina besaß. Aus dieser Situation heraus erklärt es sich fast schon von selbst, dass der Fonds für unterschiedlichste kulturelle Projekte des Kronlandes über die Jahrzehnte hin auch immer wieder kleinere Summen bereitstellte. Vielen dieser vom Konsistorium oder dem Erzbischof mitgetragenen Initiativen kam ein hoher Symbolgehalt zu, wenngleich sie buchhalterisch kaum nennenswerte Größen erreichten. So half der Fonds beispielsweise beim Bau eines jüdischen (sic!) Bethauses im Ort Straza, Bezirk Radautz mit einer Bauholzspende im Wert von 300 Kronen aus. An der Eröffnung dieser Einrichtung nahm denn auch - mit Selbstverständlichkeit - Erzbischof Repta persönlich teil. ${ }^{22}$ Wiederholt mit kleineren Summen subventionierte der Religionsfonds bis 1914 unter ausdrücklicher Zustimmung des Kultusministeriums die Übersetzung von Lehr- und Schulbüchern ins Rumänische. ${ }^{23}$ So erschien - wohl als Ausdruck dynastischer Loyalität - 1908 zum Thronbesteigungsjubiläum im Verlag des Fonds eine kleine Festschrift als Lesebuch für Bukowiner Volksschulen, mit der notierten Kaiserhymne in rumänischer Sprache im Anhang. ${ }^{24}$ Darüber hinaus hatte sich der Fonds immer wieder an der Finanzierung von Denkmälern beteiligt. Selbst während des Krieges er steuerte für die Errichtung eines solchen auf dem Soldatenfriedhof von Czernowitz 10.000 Kronen bei. ${ }^{25}$

Überdies vergab der Fonds auf Antrag oder zu besonderen Anlässen regelmäßig Stipendien zum Besuch von Schulen und Universitäten. ${ }^{26}$ Im Vergleich zu den Gesamt-

22 Bukowinaer Rundschau Nr. 5181 v. 12.IX.1906, Zur kanonischen Visitation des Erzbischofs Dr. von Repta.

$23 \mathrm{DACZ}_{320 / 2 / 2244}$, fol. 8, Landesregierung v. 21.XII.1898, Nr. 22257 : Manual de istorie universală I, Istoria vechie (Isopescul Samuil), Istoria Bisericeasca (Calistrat Coca); fol. 22 Landesregierung an Konsistorium v. 9.III.1908, Zl. 8859, Carte de citire germana pentru clasa II gimnasiala (Gerasim Bulega); fol. 34, Abschrift Zl. 21593 v. 1.VI.1909 an Steueramt: Zweitauflage einer rumänischen Grammatik für Mittelschulen (erscheint hier ohne Titel) (Eusebius Popowicz). Ähnlich gelagerte Zuweisungen für ukrainische Lehrmittel konnten hingegen nicht belegt werden.

24 DAN 1908, Împăratul.

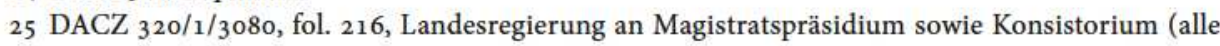
Prag) v. 14.IX.1916, Erlass des Ministeriums für Kultus und Unterricht v. 30.VIII.1917, Zl. 25643.

26 Bukowinaer Post Nr. 2313 v. 1.XII.1908, 2, Wohlfahrtsstiftungen anlässlich des Regierungsjubiläums; der Religionsfonds stiftete mehre Stipendien zu $120 \mathrm{~K}$ »für arme, doppelt verwaiste Mädchen gr-or. Konfession«. Im Studienjahr 1917/18 standen »für Söhne gr.-or. Priester aus der Bukowina, welche sich dem forstwirtschaftlichen Studium an der kk Hochschule für Bodenkultur widmen « >mehrere Stipendien des gr.-orient Religionsfonds à 800 bzw. 1.ooo K pro Jahr zur Verfügung; Programm Hochschule für Bodenkultur Wien, Studienjahr 1917/18, Wien 1917, 13ff. 
ausgaben besaßen diese Beiträge ökonomisch freilich kaum größere Relevanz, nicht so allerdings aus politischer Perspektive. Dass der Fonds - trotz gelegentlich von ukrainisch-nationaler Seite geäußerter Vorwürfe, mit derlei Zuweisungen in der Hauptsache die Rumänen des Kronlandes zu bevorzugen - dennoch nicht immer aus freien Stücken zahlte, zeigt der Fall eines wohltätigen rumänischen Damenkomitees in Czernowitz, der sich über mehrere Jahre hinzog. Im Jahr 1893 reichte das Comitetul societaţii doamnelor române din Bucovina erstmals ein Ansuchen beim gr.-orient. Konsistorium mit der Bitte um Finanzierung eines Sprachkurses in der Höhe von 1.200 Gulden ein. Das zuständige Kultusministerium befürwortete »unter Hervorhebung des religiös-sittlichen und confessionellen Moments, die diesem Sprachkurse abgeht, jedoch mit Rücksicht auf das culturelle Streben des genannten Vereins « die Förderung auf drei Jahre. In der Folge erhöhten sich die von Wien bewilligten Summen von 1.500 (1900), 2.500 (1901) auf 3.500 Gulden (1906) ${ }^{27}$ jährlich. Als 1909 neuerlich um eine Subvention von nunmehr allerdings 5.000 Gulden (10.000 Kronen) angefragt wurde, setzte sich das Konsistorium, das damit schon zuvor nicht ganz einverstanden gewesen war, vor dem Hintergrund der eigentlichen Zweckwidmung des Fonds und entsprechend dringender Kultusbedürfnisse zur Wehr. Der Religionsfonds, so ein Vertreter des Konsistoriums, sei von derartigen Ausgaben zu entlasten und Wien sollte »das Konsistorium bei der Abwehr solcher Ansprüche an den Buk. gr. or. Religionsfonds geneigtest unterstützen«. Dennoch entschied die österreichische Regierung auch diesmal wieder zugunsten der gemeinnützigen rumänischen Institution, sagte allerdings kompromissbereit lediglich 2.500 Gulden zu. Bis Sommer 1914 sollte sich dieses Karussell von Antrag und Bewilligung - stets im Sinne des Antragstellers - noch mehrmals drehen. ${ }^{28}$ Mit Kriegsende nahm der Damenverein seine Aktivitäten in Czernowitz von neuem auf. Er erhielt, soweit nachweisbar, zumindest bis 1922 weiterhin Mittel des Religionsfonds zugesprochen. Die Weisung dafür hatte jetzt allerdings die Bukarest unterstellte Kultusdirektion der Landeshauptstadt erlassen, eine Diskussion über die Zweckentfremdung blieb diesmal aus. ${ }^{29}$

27 Kronenäquivalent umgerechnet auf Gulden: $3.000 \mathrm{~K}$.

28 DACZ $_{320 / 1} / 6880$, fol. 1, Konsistorium an Landesregierung v. 28.I/9.II.1893; fol. 8f. Konsistorium Prot.-Nr. 2345 v. 6./18.V.1898; fol. 10, Landesregierung v. 10.VII.1900; fol. 11, Erlass Landesregierung v. 14.II.1901, Zl. 3557; fol. 14f., Landesregierung an Konsistorium v. 31.III.1904; fol. 15f., Konsistorium v. 20.VI./3.VII.1906, fol. 2of., Konsistorium v. 30.VII.1909; fol. 23, Abschrift Czernowitz 15.VI.1910, Zl. 27288, Schuljahr 1909/10, Erlass Ministerium für Kultus und Unterricht Nr. 17050 v. 4.VI.1907; fol 24f., Landesregierung an Konsistorium v. 30.V.1912; zuletzt Landesregierung v. 28.VIII.1912, Zl. 42739, Erlass Ministerium für Kultus und Unterricht v. 20.VIII.1912, Zl. 37520.

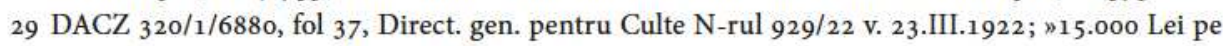
seama fondului rel. ortod. buc. Tit. III Art. II ,Contribuiri«". 
Weitaus größere ausgabenseitig wirksame Fixposten im Budget des Religionsfonds bis 1914 belegten indes Bukowiner Landesschulfonds und Universität. Innerhalb der Rubrik `Unterricht` ist hier an erster Stelle der seit 1872 jährlich mit 50.000 Gulden bemessene Beitrag in den Landesschulfonds zu nennen. Der Landtag hatte 1893 in einer Petition die Erhöhung der Mittel auf 150.000 Gulden "Zur weiteren Hebung des Volksschulwesens [...; eingefordert], weil die Schulgemeinden [...] überlastet, ja leistungsunfähig " wären und zudem der Religionsfonds "seiner Natur [nach] auch für die Bedürfnisse des Volksschulwesens bestimmt « sei. Aus eigener Kraft konnte das Kronland für den Schulfonds nur 126.00o Gulden von insgesamt 240.000 stemmen. In seiner Stellungnahme verlangte das Konsistorium vom Kultusministerium einen ablehnenden Bescheid und drängte darin auf die Einhaltung der wwidmungsmässigen Zwecke« des Religionsfonds. ${ }^{30}$ Das Ministerium entschied sich letztlich wieder für einen Kompromiss und bewilligte die Anhebung auf 80.000 Gulden jährlich. ${ }^{31}$ Diese Summe blieb bis 1913 unverändert. ${ }^{32}$

Auch beim Aufbau der Universität als höchster Bildungseinrichtung des Landes übernahmen Religionsfonds bzw. Konsistorium von Beginn an eine tragende Rolle sowohl inhaltlicher (theologische Fakultät) wie pekuniärer Natur (Finanzierung). Die Versuche des Konsistoriums unter Hackmann und Bendella, die Universitätsgründung - von der theologischen Fakultät abgesehen - nur einmalig zu unterstützen und sich damit »von jeder weiteren Beitragsleistung zu Universitätszwecken für alle Zukunft freizuhalten«, blieben von Beginn an absehbar eine Wunschvorstellung. ${ }^{33}$ Nach der Jahrhundertwende machte sich alsbald ein eklatanter Platzmangel für die wachsende Bildungseinrichtung bemerkbar, sodass die Landesregierung beim Konsistorium neuerlich mit dem Ansinnen "auf einen angemessenen Beitrag des griechisch-orientalischen Religionsfondes, der auch seinerzeit zur Herstellung des Gebäudes für die Lehrkanzeln der Physik, Chemie und Mineralogie einen Beitrag geleistet hatte, und der an dem Bestande der Universität

30 $\mathrm{DACZ}_{320 / 3 / 3431}$ Landesregierung an Konsistorium mit der Bitte um Stellungnahme v. 12.IX.1893, fol. $97-121$, hier 98 u. $119 \mathrm{ff}$.

$31 \mathrm{DACZ}_{320 / 3 / 3431}$ allerhöchster Entschluss v. Jänner 1895, Ministerium für Kultus und Unterricht v. 22.I.1895, Zl. 1541, Landesregierung v. 1.II.1895.

32 S. Anm. 10, Voranschlag.

33 DACZ $_{320 / 2 / 50}$ Vortrag Konsistorium, Plenarsitzung v. 13./26.I.1905, fol. 4. Die Sitzung nahm darin auf die Umwidmung eines gerade neu errichteten Priesterhauses zum Universitätsgebäude unter Bischof Hackmann v. 2./14.I.1873 Bezug. Nachdem man jedoch zwei Jahre später das Gebäude für die Zwecke der Universität als wenig geeignet erkannt hatte, wurde es mit Zustimmung des amtierenden Erzbischofes Bendella (v. 29.III./10.IV.1875) mit 60.00o fl. aus Religionsfondsmitteln zurückgekauft. 


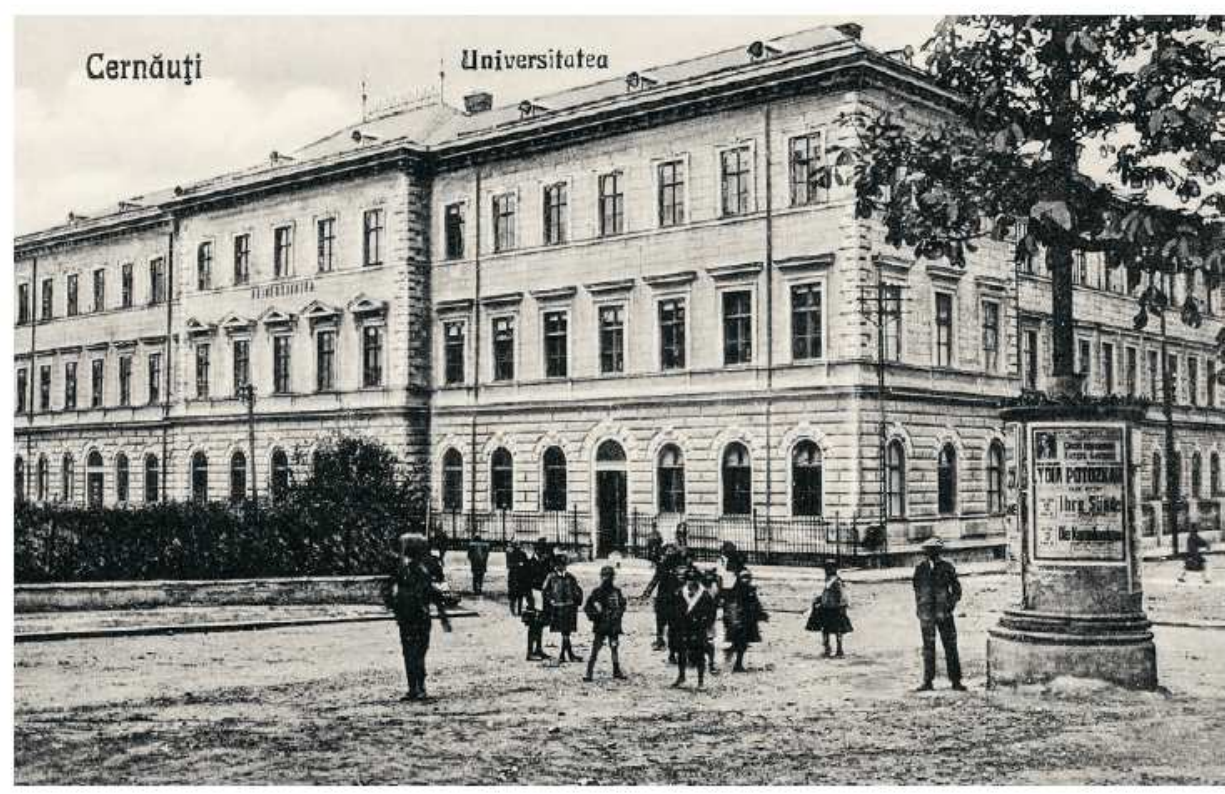

Abb. 32: Cernăuți Universitatea. Ansichtspostkarte der Zwischenkriegszeit. Hauptgebäude der damaligen König-Ferdinand-Universität. Der Religionsfonds investierte nicht nur bei der Gründung 1875, sondern auch in den Betrieb und Ausbau der Hochschule beträchtliche Summen. Sammlung K. Scharr.

als Erhalter der gr. or. Fakultät interessiert ist«, auftrat. ${ }^{34}$ Zudem habe der Fonds - so die Regierung weiter - seinerzeit bereits 120.000 Kronen »mit Rücksicht auf die erhabene Stellung der Universität als der höchsten Kulturstätte des Landes" geleistet. Letztlich erklärte sich das Konsistorium nolens volens bereit, zum Erweiterungsbau des Universitätshauptgebäudes zusätzlich 100.000 Kronen in zehn gleichen Jahresraten zu stiften. ${ }^{35}$ 250.000 Kronen steuerte das Land bei. ${ }^{36}$ Die Regierung hatte jedoch offensichtlich kein Interesse daran, die Gelder auf Jahre hin kleinteilig zugewiesen zu bekommen, sondern wollte dies sofort beglichen wissen, wogegen das Konsistorium - obgleich nur mit bekannt mäßigem Erfolg - opponierte. Nach jahrelanger Kontroverse einigten sich beide Parteien schließlich, beginnend mit 1911, auf zwei gleiche Raten. Zwischenzeitlich meldete die Landesregierung erneut Begehrlichkeiten an. Diesmal dachte man an die Überlassung von frei gewordenen Baugründen in Czernowitz, die im Eigentum des Fonds standen und derer ebenfalls die Universität dringendst für ihre Erweiterungspläne be-

$34 \mathrm{DACZ}_{320 / 2} / 50$, fol. If., Landesregierung an Konsistorium v. 31.XII.1904.

35 DACZ $_{320 / 2 / 50}$, fol. 3, Konsistorium an Landesregierung v. 12./26.I.1905.

36 Bukowinaer Post Nr. 2660 v. 7.III.1911, Die Bukowina im Reichsbudget 1911 (VII). 


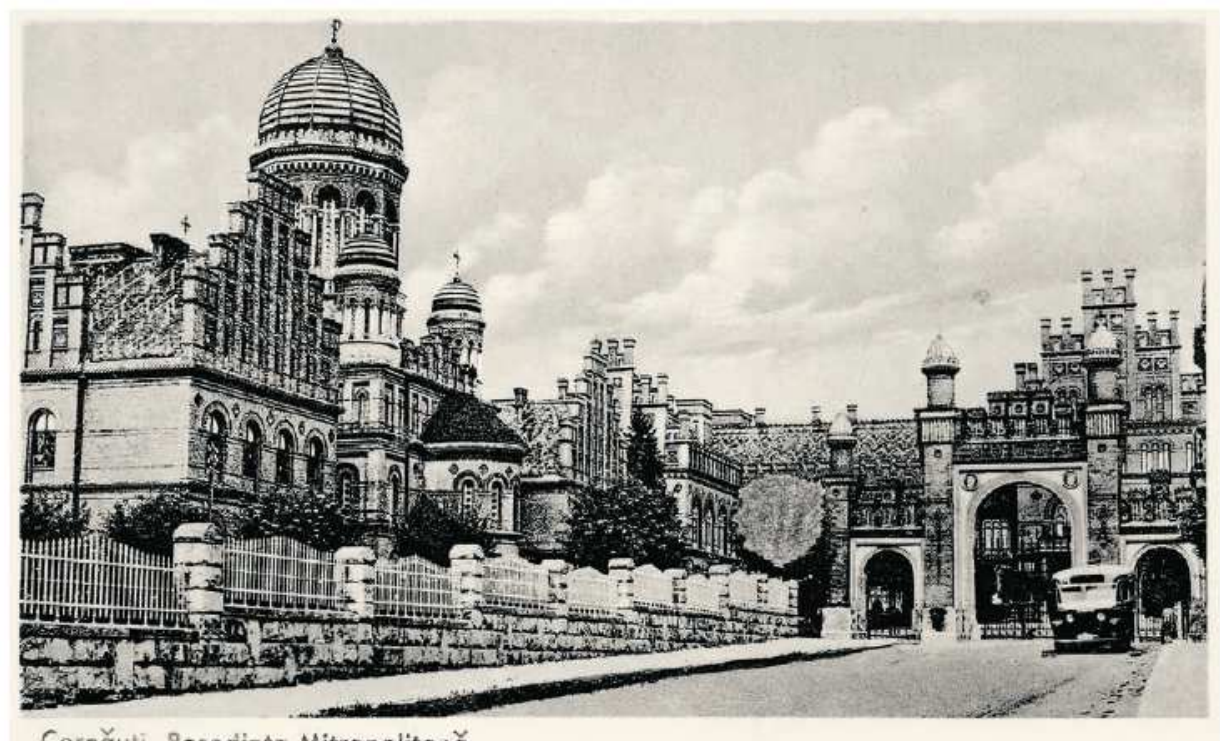

Cernăuți. Reşedinț Mitropolitonă

Abb. 33: Cernăuți. Reşedința Mitropolitană. Die Ansichtspostkarte der Zwischenkriegszeit zeigt die in den Jahren 1864-1882 aus Religionsfondsmitteln erbaute Residenz der Erzbischöfe und Metropoliten der Bukowina und Dalmatiens in Czernowitz. Sammlung K. Scharr.

durfte. Im konkreten Fall blieb das Konsistorium ausnahmsweise erfolgreich, d.h. es konnte die Gründe an den Ärar verkaufen. ${ }^{37}$

Ungeachtet der - rückblickend betrachtet - ebenso massiven wie breit angelegten Investitionstätigkeit des Religionsfonds, und obgleich diese meist nicht auf eigene Initiative, sondern vielfach auf Wunsch der Wiener Regierung betrieben wurde, blieb die Unzufriedenheit einzelner national argumentierender Teile der Bukowiner Öffentlichkeit bis zum Schluss ungebrochen. Diese Gruppen interpretierten die Fondsmittel als Landesvermögen, über das man nur allzu gerne selber verfügen wollte, ohne Kontrolle oder Mitsprache von außen. ${ }^{38}$

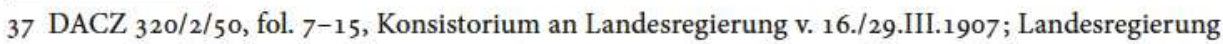
an Konsistorium v. 30.X.1909 und v. 3.V.1910; Konsistorium an Landesregierung v. 24.IV./7.V.1910 und v. 25.X./7.XI.1910; Gründe der Pfarrkirche St. Paraskiewa $\left(5.375 \mathrm{~m}^{2}\right)$ gingen für $81.000 \mathrm{~K}$ an den Staat. Die Gründe hinter dem bestehenden Universitätsbau wurden durch die Auflassung bzw. Verlegung des gr.-orient. Friedhofs frei. Sie waren u.a. für das juridische Gebäude und die Universitätsbibliothek vorgesehen; dazu Czernowitzer Allgemeine Zeitung Nr. 1860 v. $27 . I I I .1909,9$, Der Universitätsneubau.

38 Bukowinaer Post Nr. 2125 v. 19.IX.1907, 1, Noch eine Finanzquelle; Nr. 3118 v. 15.III.1914, 3f., Der 


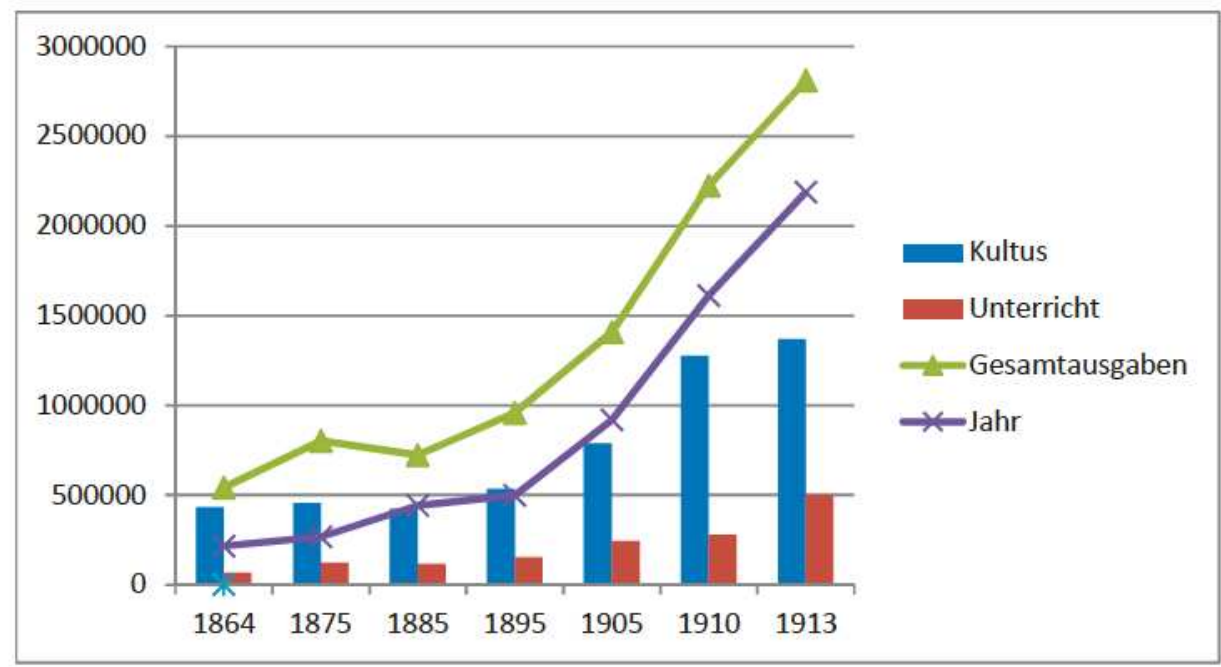

Abb. 34: Budgetvoranschläge der Güter des grr-orient. Religionsfonds für die Jahre 1864-1913, dargestellt nach den hauptsächlichen Ausgaben und Einnahmen. Quelle vgl. Anmerkung 18, Voranschlag.

Das Land aber, diese arme, der Förderung so sehr bedürftige Bukowina, ging beim Aufschwunge des Religionsfonds leer aus [...] Im Lande ist der reiche Religionsfond stark seßhaft; aus dem Lande zieht er Schätze und Reichthümer; aber für das Land in jenem höheren Sinne [...] war der Fond nicht, weder ein Kultur- noch ein Wirtschaftsfaktor. ${ }^{39}$

\section{... als Unternehmer: die Forstwirtschaft}

Im österreichischen Reichsteil der Habsburgermonarchie konzentrierte sich die Masse der sogenannten Fondsforste, deren Einrichtung nach der Aufhebung der Klöster unter Kaiser Joseph II. stattgefunden hatte, in der Bukowina. Von in Summe 330.808 Hektar entfielen allein auf dieses Kronland 255.149 Hektar, $68 \%$ aller Fondsforste. ${ }^{40}$ Die zahlenmäßig weit geringer zu beziffernden Staatsforste der Bukowina - nach dem Verkauf von Kimpolung und Zuczka an den Religionsfonds - beschränkten sich mit knapp 1.500 Hektar auf Franzthal ${ }^{41}$, südöstlich von Czernowitz. Mit einer Bewaldung von annähernd

Religionsfond und der Notstand; Nr. 3142 v. 12.IV.1914, 2, Das forstliche Bringungswesen und die zufolge Modernisierung desselben erhöhten Forsterträgnisse.

39 Bukowinaer Post Nr. 2842 v. 12.V.1912, 1, Güterdirektor Hofrat Ritter von Ullmann.

40 ENDRES 1905/1922, Handbuch, 650.

41 Rum. Codrul Cosminului, heute ukr. Валя Кузьмина /Valja Kuz’mina. 


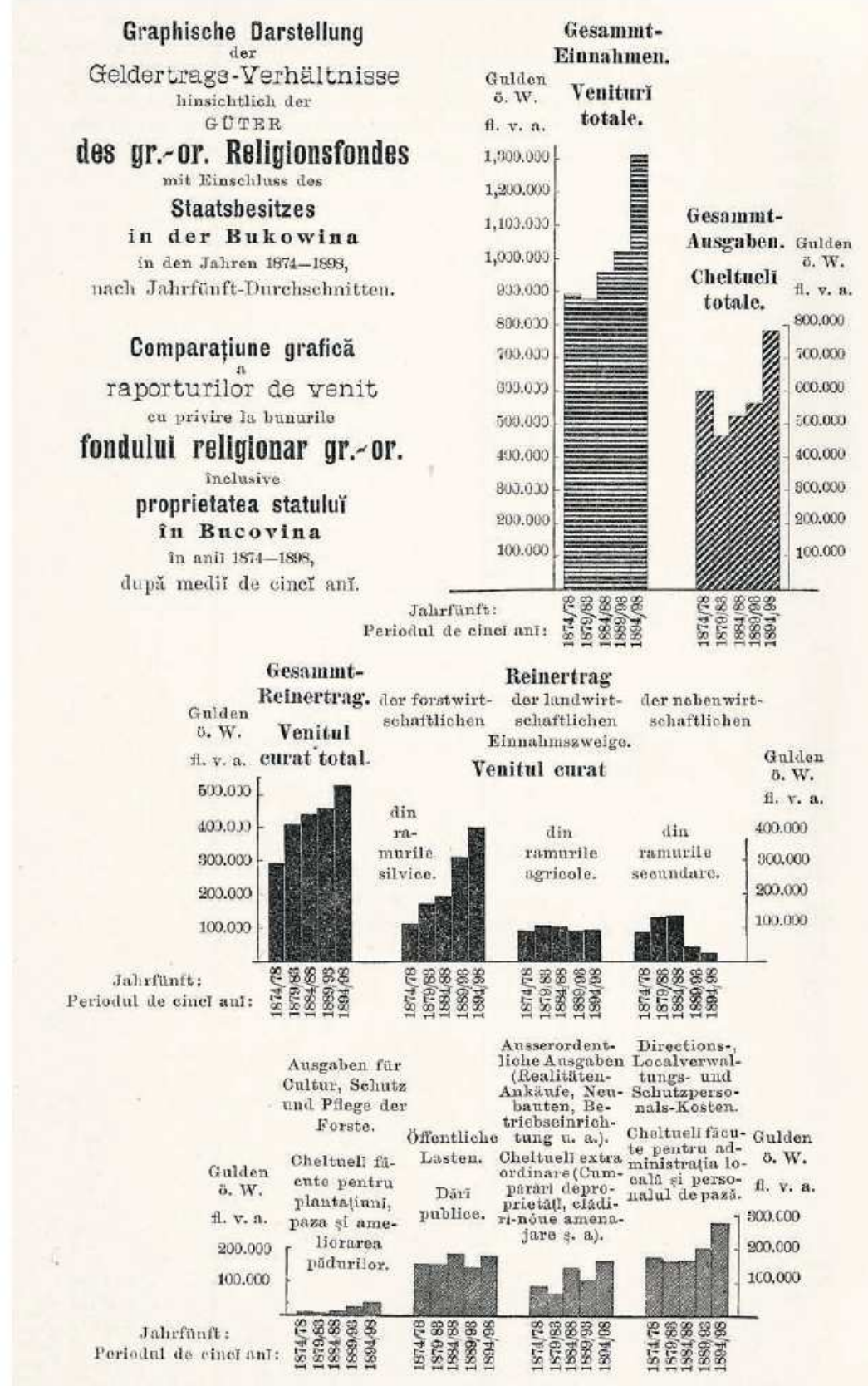

Abb. 35: Geldertrags-Verhältnisse hinsichtlich der Güter des gr-orient. Religionsfonds 1874-1898. Nach Guzmann (1901), Forstwirtschaft, 224. 
43\% der Gesamtfläche des Kronlandes, bei einem absoluten Waldanteil im Jahr 1895 von 447.868 Hektar, lag die Bukowina in Österreich nach der Steiermark (48\%), der Krain sowie Kärnten (jeweils 44\%) auf dem vierten Platz. Die räumliche Verteilung dieser Forste ( $80 \%$ Bergland und $20 \%$ Ebenen sowie Hügelland) ${ }^{42}$ lässt allerdings ein Strukturproblem der Bukowina erahnen: die schwierige und kapitalintensive Erschließung bzw. die vergleichsweise zu westlichen Kronländern erst um die Wende zum 20. Jahrhundert allmählich spürbare Kapitalisierung der großen Waldflächen. Der Ausbau des regionalen Eisenbahnnetzes in der Bukowina (1907: ca. $530 \mathrm{~km}$ ) sowie der Anschluss an das europäische Bahnnetz (1867), die steigenden Holzpreise und laufende Investitionen in die technische Forsterschließung zählten für die Inwertsetzung der Wälder, die zum größten Teil zuvor kaum kostendeckend genutzt werden konnten, als entscheidende Faktoren. ${ }^{43}$ So wies etwa die Grundsteuerregulierungskommission im Rahmen der Katastralaufnahme um 1830 noch 224.00o Hektar des Landes, darunter vor allem die Wälder, als weitestgehend unproduktive, daher nicht besteuerbare Fläche aus. ${ }^{44}$ Ein halbes Jahrhundert später zeigt sich die sichtbar höhere Produktivität und die Effizienz in der wirtschaftlichen Nutzung dieser Güter der Bukowina augenscheinlich im Abgleich mit der benachbarten galizischen Fondsdirektion. Bei 294.000 (Direktion Lemberg) zu 228.00o Hektar Waldfläche (Direktion Czernowitz) erwirtschaftete letztere im Jahresdurchschnitt aus ihren Forsten zwischen 1889 und 1893 annähernd 459.00o Gulden Überschuss nach Abzug der Ausgaben, während die größeren galizischen Fondsforste lediglich 390.000 Gulden verbuchen konnten. ${ }^{45}$ Schon aus diesem Vergleich erahnt man die zentrale Bedeutung dieses Wirtschaftszweiges nicht nur für den gr-orient. Religionsfonds selbst, sondern für die Bukowina als Ganzes. Dementsprechend spiegeln die aus den Fondsgütern erwirtschafteten Überschüsse im hier fokussierten Zeitraum beachtenswerte Steigerungsraten wider. Lagen letztere von 1874 bis 1878 bei ungefähr 288.00o Gulden, so erzielte die Güterverwaltung für das Jahr 1895 allein einen Überschuss von gerundet 538.000 Gulden, der sich im Wesentlichen wiederum aus den Erträgen der Forstwirtschaft speiste. Nicht ohne Stolz strich das Ackerbauministerium in

42 Guzmann 1901, Forstwirtschaft, 102f; Ackerbauministerium (Hg.) (1907), Holzproduktion, $4 \mathrm{f}$.

43 Auf die zentrale Bedeutung des Eisenbahnanschlusses für den Holzabsatz verweist ein zeitgenössisches Gutachten des Landespräsidiums; DACZ $3 / 1 / 3213$ Landespräsidium an Kultusministerium v. 29.IX.1869, fol. 56.

44 Ackerbauministerium (Hg.) 1907, Jahrbuch, 154ff.; ders. (Hg.) 1897, Verwaltung, 73 f.; zu den technischen Investitionen in unterschiedliche Bringungseinrichtungen (Bahnen, Straßen, Flöße, Sägen etc.) vgl. Josef Opletal, Forstliche Bauinvestitionen im Bereiche der k.k. Direktion der Güter des Bukowinaer griechisch-orientalischen Religionsfonds in Czernowitz; in: ACKERBAUMINISTERIUM (Hg.) 1907, Jahrbuch, 153-230.

45 Ackerbauministerium (Hg.) 1897, Verwaltung, 75. 
seiner Zusammenstellung des Jahres 1907 daher heraus, dass der erwirtschaftete Gewinn aus den Forsten des Bukowiner gr.-orient. Religionsfonds im Vergleich zu 1874 einem Zuwachs von $600 \%$ entsprach.

Die rechtlichen Rahmenbedingungen hatten dafür ebenso einen entscheidenden Beitrag geleistet. Erst das Forstgesetz von 1852, seine Novellierungen von 1873 und 1883 sowie das Landesgesetz von $1897^{46}$ schufen die zeitgemäße Basis, auf dem sich eine, nunmehr einheitlich für den Gesamtraum gültige, moderne Forstwirtschaft entwickeln konnte. Dieser gesetzliche Rahmen löste in der Bukowina endgültig ältere Waldnutzungsbestimmungen der josephinischen Epoche aus den Jahren 1782 und $1785 \mathrm{ab}^{47}$

Landtags- wie Reichsratsabgeordnete des Kronlandes artikulierten vor diesem Hintergrund immer wieder Begehrlichkeiten, die einen `stärkeren ‘ Landeszugriff auf die Mittel des Religionsfonds anpeilten. Als treibende Kraft dahinter stand das Streben des Landtages nach größerer finanzieller Autonomie sowie einem daraus abzuleitenden politischen Machtgewinn. In dieser Hinsicht vertrat ebenso die gr.-orient. Kirchenhierarchie wie schon zuvor dargestellt - das Ziel, ihre äußerst beschränkte Verfügungsgewalt über die Institution des Fonds auszudehnen bzw. - aus ihrer Perspektive - >zurückzuholen`. Die Wiener Regierung, die Religionsfondsmittel weitestgehend zum Wohl des Landes und zur Schonung des Staatshaushaltes einsetzte (wie es etwa am Beispiel der Montanwerke offenbar wurde), zeigte indes wenig Willen, hier wirklich das Heft des Handels aus der Hand zu geben. Die Ministerien erteilten derlei Ansinnen regelmäßig Abfuhren. Dass die Bukowina damit in Cisleithanien kein Einzelfall war, belegen vergleichbare Eingaben von Landtagsabgeordneten anderer Kronländer. ${ }^{48}$ Allerorten zeigten sich entsprechende Bemühungen regionaler Eliten, dem Staat eine höhere finanzielle Dotierung für die Länder abzuringen, um damit zugleich einen Autonomiezuwachs zu ergattern. Vor allem bei dringend nötigen Investitionen in die Infrastruktur bekamen sie dies re-

46 RGBl. Nr. 250, Kaiserliches Patent v. 3.XII.1852, wirksam für die Kronländer [...] und die Bukowina, wodurch für diese Kronländer ein neues Forstgesetz erlassen, und vom 1. Jänner 1853 angefangen, in Wirksamkeit gesetzt wird; Gesetz- und Verordnungsblatt f. d. Herzogthum Bukowina Nr. 34, Verordnung des Ackerbauministeriums betreffend die genauere Handhabung des Forstgesetzes [...], sowie Landesgesetzblatt Nr. 15 v. 2.VII.1897.

47 Anonymus (Hg.) 2000/01, cod silvic; Kirileanu (Hg.) 2001, Orinduala; Guzmann urteilt über die ältere Waldordnung folgendermaßen: „Sie war in ihrer Art und für ihre Zeit ein Meisterstück landesväterlicher Fürsorge und Weisheit, hatte aber wohl einzig und allein bei der Bewirtschaftung der Staats- und Religionsfondsforste Beachtung gefunden"; GUZMANN 1901, Forstwirtschaft, 109.

48 Beispielhaft dazu Salzburger Chronik Nr. 48 v. 27.II.1896, 1, Rede des Abgeordneten Dr. Viktor von Fuchs. 
gelmäßig schmerzlich zu spüren, litten doch die Kronländer seit der Grundentlastung vermehrt an chronischem Kapitalmangel. ${ }^{49}$

Trotzdem signalisierte Wien einzelnen Interessensgruppen gerade dort, wo an sich kaum Verluste zu befürchten und zudem der geringste Widerstand zu erwarten waren, auch ein Entgegenkommen. So verhalf etwa die mit dem Jahr 1909 in Kraft getretene Gemeindeordnung den Gemeinden und ihren nunmehr gewählten Vertretungsorganen zu einer größeren Autonomie, indem sie unter anderem deren rechtlichen Zuständigkeitsbereich erweiterte. Dadurch erhielt die seit 1859 als kleinste Verwaltungseinheit des Staates bestehende Institution der politischen Gemeinde ${ }^{50}$ die vormals politischadministrativ als eigenständig behandelten Gutsgebiete zugesprochen. ${ }^{51}$ Für den wirtschaftlichen wie sozialen Gegensatz zwischen Gutsgebieten und Gemeinden konnte jedoch kurzfristig kein Ausgleich erreicht werden; außerdem befürchtete man seitens der Gutsherrschaft ein "Hineinverwalten « der als Gemeindeorgane gewählten Bauern. Hätten diese doch "bei Ausübung ihrer amtlichen Funktionen die Verwaltung und Bewirtschaftung ehemaliger Gutsgebiete beeinträchtigen und auf diese Weise die soziale Machtstellung der Gutsbesitzer ungerechtfertigterweise schmälern " können. ${ }^{52}$ Obwohl gerade der Religionsfonds als einer der größten Gutsbesitzer der Bukowina davon erheblich betroffen war $^{53}$, gestattete ihm als juristische Person die Gesetzeslage - ganz im Gegensatz zu den privaten Gutsherren - keine Übergangsregelung in Form zeitweiliger von der Gemeinde separierter eigener Geschäftsführungen. ${ }^{54}$ Damit hatte sich die Zentralregierung in Wien geschickt nötigen Freiraum geschaffen und soziale Spannungen in den Gemeinden des Kronlandes abdämpfen können. Zugleich gelang es dadurch, den wenigen jedoch politisch bedeutenden Gutsbesitzern, die schon ein halbes Jahrhundert zuvor über die Grundentlastung Einbußen in ihrer Machtstellung erfahren hatten, einigen Wind aus den Segeln zu nehmen.

Allerdings darf in diesen politisch motivierten Forderungen nicht unbeachtet bleiben, dass der Großgrundbesitz - solange er mit Hilfe des geltenden Kurienwahlrechts Landesparlament und Reichsrat dominierte - neben den vorgebrachten legitimen Landesinteressen nicht selten zunächst seine eigenen Ziele verfolgte. In einer ausführlichen Rede

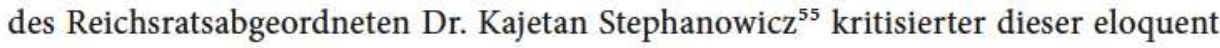

49 Bukowinaer Rundschau Nr. 2219 v. 26.VIII.1895, 1f., Die todte Hand.

50 Kaiserliches Patent v. 24.IV.1859; RGBl. Nr. 58 v. $27 . I V .1859$.

51 Gemeindeordnung v. 29.III.1909; Landesgesetzblatt der Bukowina Nr. 42 v. 28.VIII.1908.

52 DUTCZAK 1912, Geschäftsführungsanspruch, 6; ders. 1909, Gestaltung.

53 Vgl. Tab. 6.

54 DutCZAK 1912, Geschäftsführungsanspruch, 5.

55 Dr. Kajetan Stephanowicz (auch Stefanowicz) gehörte der Kurie der Großgrundbesitzer an, war Landesausschussbeisitzer und Präsident des Landeskulturrates des Herzogtums, dessen Leitung er seit 
eine seiner Ansicht nach nachlässige, geradezu schädliche Verwaltungspraxis des Bukowiner Religionsfonds. ${ }^{56}$ Obwohl von der gegnerischen rumänischen Partei, stimmte dem auch der Abgeordnete und Großgrundbesitzer Baron Georg v. Wassilko-Serecki zu. Stephanowicz sprach für den armeno-polnischen Club im Landtag. ${ }^{57}$ Beide Abgeordnete galten im Kronland gemeinhin als »Waldriesen «, die Fondsforste folglich als ihre Konkurrenz. ${ }^{58}$ Vielfach blieben die Anschuldigungen von Stephanowicz tatsächlich unbegründet, wenig konkret oder entsprachen - wie im Falle der angeblich durch den Fonds »ruinierten « Bergwerke - schlichtweg nicht der Realität. ${ }^{59}$ Das kommentierten die politischen Gegner des Abgeordneten in der Czernowitzer Öffentlichkeit nicht ohne einen süffisanten Unterton. ${ }^{60}$ Der in dieser Angelegenheit damit konfrontierte Ackerbauminister bot daraufhin dem Abgeordneten an, gemeinsam mit ihm, in einer Bereisung der Bukowina, den aufgeworfenen vermeintlichen Missständen nachgehen zu wollen. ${ }^{61}$ In seiner an die Reise anschließenden ausführlichen Berichterstattung entkräftete

1912 innehatte; wurde zuletzt noch 1918 für die Funktionsperiode bis 1923 gewählt; Wiener Landwirtschaftliche Zeitung Nr. 14 v. 16.II.1918, 95.

56 Bukowinaer Rundschau Nr. 2311 v. 16.XII., 1f.; Nr. 2312 v. 17.XII., 1f.; Nr. 2313 v. 18.XII., if. und Nr. 2314 v. 19.XII.1896, If., Die Bukowina im Reichsrat. Rede des Abgeordneten Stefanowicz.

57 Bukowinaer Post Nr. 483 v. 10.I.1897, 2, Gehässigkeit oder Perfidie.

58 Bukowinaer Post Nr. 515 v. 25.III.1897, 1, Woran es fehlt; allein Wassilko-Serecki besaß bei seinem Gut in Berhometh eine Waldfläche von 22.522 ha (1905); Aскеrbauministerium (Hg.) 1907, Holzproduktion, LVIII. 1913 werden für den Baron 28.506 ha ausgewiesen; dazu SANDGRUBER 1978, Agrarstatistik, 239, Tab. 183. Für Stephanowicz konnten hingegen mit Ausnahme der Bukowiner Zeitungen in den Quellen keine Latifundien dieses Umfangs belegt werden. Zwei landtäfliche Güter befanden sich im Besitz der Familie Stephanowicz (Terescheni und Rarancze); Tit TEL 1913, Schematismus, $1328 \mathrm{f}$.

59 "Auch da ist der Religionsfond von Schuld nicht freizusprechen. Er hat eine von der Familie Manz gegründete, an den heimischen Bergbau angelehnte, glänzende Industrie mit eiserner Faust zerschlagen und zerstört"; Bukowinaer Rundschau Nr. 2670 v. 5.III.1898, If., Bukowiner Landtag 8. Sitzung v. 23.II.1898, Landeskulturangelegenheiten, Rede Dr. Stefanowicz.

60 "Herr Dr. Stefanowicz begann seine Rede sehr vorsichtig mit der Versicherung, daß er snicht um eine wohldurchdachte, akademische Rede zu halten sich zum Worte gemeldet hat. Wir wollen ihm dies gerne glauben. Denn weder seine Vergangenheit, noch seine gegenwärtige politische Haltung haben ein wohl Durchdenken bewiesen und - akademisch zu sein, ist ihm immer ferne gelegen. Seine uns vorliegende Rede rechtfertigt seine Vorausschickung und unsere Behauptung. Sie ist nichts anderes als ein Sammelsurium von Gemeinplätzen - es ist dies die Specialität dieses Abgeordneten «; Bukowinaer Post Nr. 72 v. 6.V.1894, If., Landesklänge im Reichsrathe; ähnlich Bukowinaer Post Nr. 339 v. 2.II.1896, 1, Noch einmal: ein mißglückter Coup.

61 Vorarlberger Landeszeitung Nr. 63 v. 16.III.1896, 2, Abgeordnetenhaus; eine detaillierte Beschreibung der Bereisung durch den Minister findet sich in der Osterreichischen Forst- und Jagdzeitung Nr. 42 v. 16.X.1896, 329-332, Die Forstwirtschaft des Bukowinaer griechisch-orientalischen Religionsfonds. Zur Reise des Ackerbauministers in die Bukowina. 
der Minister die Vorwürfe weitgehend sachlich. Die Kritik war seinerseits insofern zu relativieren, als sich die Forstverwaltung der Bukowina zu diesem Zeitpunkt mitten in einem Umstrukturierungsprozess befand und noch vielorts improvisiert werden musste. So fehlten etwa aufgrund der eingeschränkten Zugänglichkeit der meisten Wälder im Gebirge nach wie vor befriedigende Kartenunterlagen. Die Forstbehörden mussten folglich vorerst mit den im Waldbereich zu ungenauen Katasteraufnahmen vorliebnehmen oder bei ihrer Arbeit auf die maßstäblich ungenügende Spezialaufnahme der Österreichisch-Ungarischen Monarchie (M 1:75.000) zurückgreifen.

Im Zeitraum zwischen 1840 bis 1898 hatte sich zudem das Netz der Forstwirtschaftsbezirke sowie des Personals erheblich verdichtet. ${ }^{62}$ Der Minister unterstrich in seiner Antwort den unmittelbaren finanziellen Beitrag des Fonds, etwa im Ankauf der verschuldeten Montanwerke oder in Form der Geldzuweisungen bzw. Darlehen aus diesem Topf an Private wie Gemeinden der Bukowina. Letztere beliefen sich in seinem Überschlag für die Jahre von 1859 bis 1895 immerhin auf mehr als acht Millionen Gulden. ${ }^{63}$ Unerwähnt ließ der Minister indes, dass sich der Staat als Verwalter des Fonds, wie im Falle der schon mehrfach angesprochenen Montanwerke - obwohl meist zu Gunsten des Landes -, ‘bediente`, um gleichzeitig den Einsatz von Budgetmitteln der Wiener Regierung möglichst gering zu halten. Abschließend konnte sich der Ackerbauminister einer Spitze in Richtung des Abgeordneten nicht ganz versagen. Zur 100-Jahr-Jubiläumsfeier der Vereinigung der Bukowina mit dem Habsburgerreich war eine gedruckte Schautafel mit den Errungenschaften dieser Periode erschienen ${ }^{64}$, auf die ging der Minister am Ende seiner Darstellung näher ein:

Es ist selbstverständlich, daß im Laufe von hundert Jahren ein cultureller Fortschritt stattfinden muß; daran wird niemand gezweifelt haben. Nichtsdestoweniger möchte ich den Herrn Abgeordneten Stefanowicz bitten, sich dieses interessante Tableau unter Glas und Rahmen in seinem Zimmer anzubringen; es wird ihn erinnern, daß unter dem österreichischen Szepter doch manches geschehen ist. ${ }^{65}$

62 Guzmann 1901, Forstwirtschaft, Tabelle B, 121.

63 Bukowinaer Rundschau Nr. 2336 v. 19.I.1897, 1ff., Rede des Ackerbauministers Grafen Lebedur als Antwort auf die Rede des Abgeordneten Dr. Stefanowicz gehalten am 14.I.1897; Nr. 2337 v. 20.I.1897 (Fortsetzung), If.; auf die Angelegenheit Stephanowicz wird in Acкеrвauministerium (Hg.) 1897 , Verwaltung verwiesen, darin findet sich eine umfangreiche Darstellung von Verwaltung und Wirtschaft des Fonds.

64 Mikulicz 1875, Kulturzustände.

65 Bukowinaer Rundschau Nr. 2338 v. 21.I.1897, 2 (Schluss). 
Nicht zu überlesen ist im konkreten Fall die zeitweise Affinität der Bukowinaer Post für die Jungruthenen gegen den (polnischen) Großgrundbesitz sowie den (rumänischen) Religionsfonds. Beide betrachtete die Redaktion aus diesem Blickwinkel gleichsam als "Ausbeuter des ruthenischen Volkes «. ${ }^{66}$ Die Bukowinaer Rundschau äußerte sich dazu mit klar abweichenden Ansichten. ${ }^{67}$ Aus dem Gesamtkontext ist unschwer zu ersehen, dass die Haltung der Rundschau in Bezug auf den Religionsfonds parteiisch gesteuert oder zumindest politisch eingefärbt war. Deren Auslöser ist wohl im Leerausgehen einflussreicher Großgrundbesitzer der Bukowina (u.a. von Stephanowicz) bei den kurz davor neu abgeschlossenen Holzabstockungsverträgen des Fonds zu suchen. ${ }^{68}$ Ein Jahr später sollte sich ein ähnlich gelagerter Vertragsabschluss mit dem Fonds zu einem handfesten Czernowitzer Skandal ausweiten. ${ }^{69}$ Außenstehende unbeteiligte Beobachter kamen indessen zum Schluss, dass die Forstverwaltungen des Fonds insgesamt die Ortsinteressen durchaus zu fördern verstanden: "Es geht doch vorwärts, wenn auch langsam. ${ }^{70}$ Der im Raum schwebende Vorwurf an das Ackerbauministerium, sich nicht um dringend nötige Änderungen in der Verwaltung des Religionsfonds zu kümmern, muss hier relativiert werden. Im Gegenteil, gerade das Ministerium hatte schon früh beim Konsistorium den unbefriedigenden Zustand der Forste moniert, bzw. eine rasche Besserung angemahnt. Es gab also hinreichend Anlass für eine grundlegende Änderung in der Verwaltung und in der Art der Bewirtschaftung, wobei Wien außerordentlichen Wert auf eine künftighin größere Selbständigkeit in der Entscheidungsbefugnis der Forstbeamten innerhalb der Güterdirektion legte. Nicht zuletzt deswegen hatte man zunächst auf die bereits erwähnte, 1912 wieder aufgehobene Trennung von Forst- und Domänenverwaltung der Direktion gedrängt. ${ }^{71}$

66 Bukowinaer Post Nr. 745 v. 27.IX.1898, 1, 16 u. 36.

67 Entsprechend anders fällt die Charakterisierung von Stephanowicz aus: „Herr Dr. Stefanowicz wägt sorgsam seine Worte, und seine Argumente sind stets aus Tatsachen gezogen «; Bukowinaer Rundschau Nr. 2316 v. 22.XII.1896, Es dämmert. In späteren Artikeln polemisiert die Rundschau weiter gegen den Religionsfond; vgl. Nr. 3319 v. 13.V.1900, 1f., Die Culturmission der »todten Hand «. Darin meint die Rundschau über den Fonds, dass die Bevölkerung "gleichsam erdrückt [wird] von der schweren Masse dieses trägen Kadavers, von den breiten Fettablagerungen dieses gefräßigen Ungethüms, welches von Jahr zu Jahr an Ausdehnung zunimmt und das Land durch seine eigenartigen Lebensfunctionen mit einem Schleier überzieht, welcher der Bevölkerung schier das Athmen benimmt«; auch Nr. 3272 v. 18.III.1900, 1, Der arme Bauer.

68 Bukowinaer Rundschau Nr. 2694 v. 3.IV.1898, if., Deutsch gesprochen.

69 Bukowinaer Rundschau Nr. 3164 v. 5.XI.1899, 1f., Das neueste Pasquil.

70 Вӧнм 1897, Bukowina, 25.

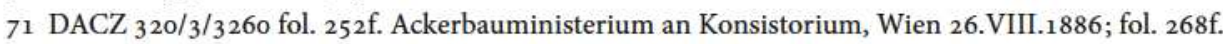
Direktion der Güter an Konsistorium Nr. 9029 Note v. 1.IX.1887, allerhöchste Entschließung v. 6.VIII.1887, Ackerbauministerium v. 14.VIII.1887, Zl. 1030. 
Obwohl die in der Bukowinaer Rundschau darüber hinaus aufgeworfene Beschuldigung in Richtung Religionsfonds, unter den Bauern neue Leibeigene schaffen zu wollen ${ }^{72}$, allein aus der spürbaren Parteilichkeit des Mediums heraus an Glaubwürdigkeit verliert, so lässt sich doch die grundsätzliche Eigenschaft der Güterverwaltung als Repräsentanten des Großgrundbesitzes nicht völlig in Abrede stellen. Einzelne Gemeindevertretungen beschwerten sich etwa ganz offen, dass es gerade der Religionsfonds sei, der "das Leben über alle Maßen erbittert $«{ }^{73}$ Zudem galt der Grundbesitz in der Bukowina insgesamt als sehr zersplittert; ein Umstand, der allen anderen voran die Bauern und Kleinpächter besonders hart traf. ${ }^{74}$ Auch das waren Themen, welche die Presse und der Bukowiner Landtag regelmäßig, unter Verweis auf den Fond, bereitwillig aufgriffen. ${ }^{75}$ Hinter den Vorwürfen an Ungleichbehandlung lauerte jedoch stets die Gefahr nationaler Aufladung, waren doch bei der Verpachtung bzw. Zuteilung von Ackergründen des Religionsfonds im nördlichen Landesteil hauptsächlich Ruthenen betroffen. Bei den dahingehenden Beschwerden der Czernowitzer Zeitungen übersahen die Redakteure allerdings geflissentlich die eigenen Meldungen im Inneren ihrer Blätter über zahlreiche Investitionstätigkeiten des Fonds in den Landesausbau. ${ }^{76}$ Dennoch, durch die in wachsendem Aus-

72 Bukowinaer Rundschau Nr. 2665 v. 27.II.1898, 1, Das Gespenst des Elends.

73 Die Gemeindevertretung von Suczawitza hatte direkt die Landesregierung adressiert und hoffte damit auf Vermittlung ihrer Anliegen gegenüber der Güterverwaltung des Fonds. Steigende Kosten für Weidebenutzung und Holzbezug warfen für die Dörfer schwerwiegende Probleme auf. Nicht selten entschieden sich daher die Bewohner zur Auswanderung: "Wie es Einem hohen k.k. Landespräsidium bereits bekannt sein dürfte, sind am 20. Mai l.J. über 40 Seelen aus unserer allseits verdrängten Gemeinde nach Canada ausgewandert und es fehlt nicht viel bis sämmtliche Insassen dieser Gemeinde ihr theuerstes Nest, ihr kostbarstes Österreich zu verlassen bemüssigt sein werden, um ein Ort zu suchen, in welchem das Erwerben einiger Imbisse Brotes leichter wäre «; DACZ 3/1/8211 Gemeindevertretung Suczawitza an Landespräsidium Bukowina v. 24.V.19o1.

74 Die Gesamtwirtschaftsfläche des Kronlandes von 1.044.141 ha verteilte sich bei 230.229 Grundsteuerträgern auf 1.147.647 Parzellen, davon gehörten wiederum 45\% in den Kleinbesitz. Die über 400.000 ha des Großgrundbesitzes teilten sich hauptsächlich der Religionsfonds ( $26 \%$ ) und Private (19\%). Czernowitzer Tagblatt Nr. 1913 v. 4.VII.1909, 1-3, Budgetrede des Abg. Dr. Straucher; dazu SANDGRUBER 1978, Agrarstatistik, 146, Tab. 79.

75 Bukowinaer Rundschau Nr. 3279 v. 27.III.1900, 1f., Auswanderung aus der Bukowina; Antrag des Abgeordneten Pihuliak und Genossen wegen pachtweiser Ueberlassung der verfügbaren Ackergründe der Religionsfondsgüter an die Bukowinaer Bauernschaft; in: StenoProt der X. Sitzung des Bukowinaer Landtages am 2.V.1893 (1. Session), 294-301; sowie XVI. (Schluß-)Sitzung am 20.V.1893 (1. Session), 553-560.

76 Bukowinaer Post Nr. 4286 v. 13.I.1910, 2, Bukowinaer Landtag; der Fonds beteiligte sich an der Regulierung des Moldawaflusses mit $130.000 \mathrm{~K}$ (der Landesausschuss brachte dafür 1,8 Millionen K ein); Bukowinaer Post Nr. 2779 v. 10.XII.1911, 4, Pellagrabekämpfung; hier steuerte der Fonds 10.000 $\mathrm{K}$ bei (Regierung $60.000 \mathrm{~K}$, Land $30.000 \mathrm{~K}$ ). 
maße technisierte wie kapitalisierte Forstwirtschaft des Religionsfonds drang selbst in die entlegenen Urwälder der Bukowina unaufhaltsam die Moderne mit all ihren Facetten ein. Die sozialkritische zeitgenössische Prosa einer Olga Kobyljanska (1863-1942) verleiht, wohl geprägt aus persönlicher Beobachtung, diesen oftmals überaus greifbaren Missständen eine eigene Sprache. Die Schriftstellerin zeichnet in einer ihrer Erzählungen, getragen von Sozialromantik, das Bild einer untergehenden Welt. In einer ungleichen Schlacht, in der die Eisenbahn im Verbund mit gedungenen, willenlosen Söldnern gegen die Natur antritt, sind die betroffenen Arbeiter der Abhängigkeit von in »Wohlstand schwelgenden Kirchenratten « ausgeliefert. Die Problematik der verschachtelten Verpachtungspraxis in der Bukowina, die den am Ende der Kette eigentlich Grund und Boden bearbeitenden Bauern kaum genug zum Leben bot, wird bei Kobyljanska ebenso angesprochen wie der auch von politischer Seite immer wieder eingebrachte Vorwurf des Ausverkaufs vermeintlich Gott gegebener heimischer Reichtümer des Landes.

An einem nebelgrauen Morgen begann die Schlacht.

Auf dem durch den engen Thalraum gebauten Bahnwege, dessen Schienen sich wie Silberschlangen in koketten Krümmungen um den dicht neben ihnen laufenden Bach wanden kam die Rollbahn gefahren.

Ein feindseliges Gezisch, ein gellendes, durchdringendes Pfeifen kündigte ihre Ankunft an. Nicht weit vom Ende dieses Weges hielt sich unter Schnauben an, zornige, schwarze Dampfringe pfeilschnell in die Höhe stoßend...

Sie hatte den Feind gebracht.

Er stieg aus. [...]

"Ja, ja, « hörten sie einen Arbeiter erzählen, den man den 'Närrischen nannte, "so verheeren ausländische Antichristen die schönen Waldungen, die Gotte unserem Lande zur Freude wachsen ließ!... Weiß Gott... die Kutten behüteten ihn schlecht und werden dereinst schwer zu verantworten haben. Und nun soll all dies wunderschöne $\mathrm{Holz}$ fort, vielleicht übers Meer? Und was unser Land davon hat? Frage man nur die Kirchenratten, die das große Wort bei der Verwaltung reden, die im Wohlstand schwelgen und fasten, dass ihre sündigen Leiber aus den Fugen gehen. Fraget sie, was unser Land davon hat! - Und nach einer Weile, während welcher er die Sägespäne aus den Augen gewischt hatte, rief er weiter: "Man baut schon nach der anderen Seite hin den Bahnweg. Es heißt wieder : 'Auf neue zehn Jahre gepachtet! ‘ Ja, nur noch zehn Jahre und dann noch einmal zehn Jahre, und aus wird es sein mit dem Reichtum unseres Landes. Verfluchte Gerechtigkeit! - dass ich doch nicht lieber deinen Leib zersägen kann, anstatt dieses Stammes da, und alle die Höllenöfen da unten nicht lieber mit jenen Teufelsbr... "eine schallende Ohrfeige des Sägemeisters machte dieser Rede ein Ende. ${ }^{77}$

77 KoByLANSKa 2013 , Valse, 46 u. 62. 
Trotz allem wollte die Kritik am Fonds und seiner über Wien gesteuerten Wirtschaftspolitik nicht enden. In den auf die Interpellation von Stephanowicz folgenden Jahren unterstrichen politische Vertreter der Bukowina in Wien die enorme Bedeutung der Holzindustrie als "nahezu dem einzigen Industriezweig des Landes«. Man mahnte eine stärkere Rücksichtnahme auf die bäuerliche Bevölkerung ein und damit wohl auch eine bessere Einbindung des landeseigenen Großgrundbesitzes, auf dass die »bodenständige Bukowinaer Holzindustrie gegenüber nichtbukowinaer Firmen nicht zurückgesetzt werde ${ }^{78}{ }^{7}$ In der an Wald traditionell armen, agrarisch geprägten nordöstlichen Bukowina, zwischen den Flüssen Pruth und Dnister, stellte sich hingegen ein ganz anderes Problem, für dessen Lösung man ebenso den Fonds in der Pflicht sah. Das Brennholz und dessen stete Teuerung - kurz als >Holznot bezeichnet - belastete viele ärmere Bewohner dieser Bezirke schwer. Obwohl die Abgeordneten wiederkehrend die Einrichtung von Holzdepots und den Verkauf in kleinen Mengen zu leistbaren Preisen durch den Religionsfonds einforderten, blieb dieser Missstand bis Kriegsbeginn ungelöst. ${ }^{79}$

Ungeachtet dessen ist alles in allem gerade die Entwicklung der Forste, als dem Standbein des Bukowiner gr.-orient. Religionsfonds, als ökonomische Erfolgsgeschichte zu verbuchen. Wenngleich die mannigfachen Probleme des Kronlandes nur langsam und in Ansätzen auf eine Lösung zusteuerten, so ist der Charakterisierung des Fonds in dieser letzten Periode - vor dem Ausbruch des Weltkrieges - durch das Ackerbauministerium weitgehend zuzustimmen, auch wenn diese nicht ganz frei von Eigenlob scheint:

In den meisten bis vor wenigen Jahren kaum zugänglich gewesenen großen Gebirgstälern erscholl der Pfiff der Waldbahnlokomotiven, die abgelegeneren Seitentäler wurden durch StraBen- und Wegbauten belegt, die unwegsamen Gebirgsreviere durch die Anlage eines Steignetzes dem täglichen Dienste erschlossen, und nun stellte sich mit einem Male eine Detailarbeit und Regsamkeit ein, die den toten Koloß, als welcher früher die unwegsamen Gebirgsforste galten, in allen seinen Gliedern zum Leben erweckten. ${ }^{\mathbf{8 0}}$

78 Neues Wiener Tagblatt Nr. 175 v. 28.VI.1907, Die Holzwirtschaft in der Bukowina. Zum Vergleich: von den im Jahr 1909 gezählten 128.000 Betrieben des Kronlandes mit 296.00o Beschäftigten waren allein 109.000 land- und forstwirtschaftlicher Natur. Die 19.000 Gewerbebetriebe boten Arbeitsplätze für 43.00o Personen; Czernowitzer Tagblatt Nr. 2058 v. 25.XII.1909, 1, Das Industrieland Bukowina. Die Bukowina wies 1910 immer noch fast $72 \%$ landwirtschaftliche Bevölkerung aus, nur Galizien und Dalmatien hatten mit knapp $74 \%$ sowie $83 \%$ noch höhere Werte; SAND GRUBER 1978, Agrarstatistik, 222, Tab. 165.

79 Bukowinaer Post Nr. 2154 v. 26.XI.1907, 2, Gegen die Holzteuerung; Nr. 2442 v. 3.X.1909, 1, Holznot; Nr. 2478 v. $25 . X I I .1909,5$, Winter; Nr. 2894 v. 12.IX.1912, 4, Landespolitik; Czernowitzer Allgemeine Zeitung Nr. 2794 v. 16.I.1913, 4, Die Brennholzmisere.

8o ACKerbauministerium (Hg.) 1907, Jahrbuch, $228 \mathrm{f}$. 
Als Ausdruck dieses Selbstbewusstseins ist schließlich auch die maßgebliche Beteiligung des Fonds - in organisatorischer wie finanzieller Hinsicht - an mehreren Großausstellungen vor 1914 zu verstehen. War etwa im Jahr 1870, während der ersten derartigen Landesschau in Czernowitz, der Religionsfonds nur unscheinbar am Rande vertreten gewesen $^{81}$, so präsentierte sich die Güterdirektion bei der zweiten land- und forstwirtschaftlichen Ausstellung in der Landeshauptstadt 1886 bereits mit einem eigenen Pavillon. Die Vizepräsidentschaft im Organisationskomitee der Leistungsschau hatte der amtierende Direktor der Fondsverwaltung übernommen. Besonderes Lob von auswärtigen Besuchern ernteten die gezeigten kartographischen Darstellungen der Forstdirektion. ${ }^{82}$ Auch auf den entsprechenden Ausstellungen in der Reichs- und Residenzhauptstadt Wien während der Jahre 1890, 1898 und 1908 setzte sich der Bukowiner gr--orient. Religionsfonds gekonnt in Szene. Der dezidierte Auftrag, hierfür Mittel einzusetzen und daran teilzunehmen, kam jeweils aus dem Ackerbauministerium. ${ }^{83}$ Bei der Kaiser Jubiläumsausstellung 1898 präsentierten sich die Bukowina und der Fonds großzügig in einem geräumigen Holzpavillon - dem einzigen eines Kronlandes - zur allgemeinen Begeisterung des Publikums. Die Forstzeitung kürte das Ensemble gar »Zu den bestgelungenen und bestarrangierten Expositionen der Jubiläumsausstellung " und würdigte das Ereignis mit einem Sonderbericht sowie drei Photographien. ${ }^{84}$ Nicht weniger von $\mathrm{Be}-$ deutung, vor allem politisch aufgeladen war die internationale Jubiläumsausstellung des Jahres 1906 in Bukarest anlässlich der 40-jährigen Thronbesteigung Carols I. Innerhalb des österreichischen Pavillons belegte die Güterdirektion des gr-orient. Religionsfonds eine eigene Abteilung, wo sie ihre Forste, die Meierhöfe, Kuranlagen und Montanwerke ins beste Licht rücken konnte. Das Ackerbauministerium >bewilligte für die Ausstellung eine Kostenbeteiligung von $20.000 \mathrm{~K}$ aus Fondsmitteln (bei insgesamt $80.000 \mathrm{~K}$ ). ${ }^{85} \mathrm{An}$ der Spitze des zuständigen Komitees stand der amtierende Güterdirektor. ${ }^{86}$

\footnotetext{
81 Anonymus 1870 , Katalog.

82 Anonymus 1886, Ausstellung, 58 u. $66 \mathrm{f}$.

83 Czernowitzer Allgemeine Zeitung Nr. 934 v. 21.II.1907, 4, Das Jubiläumsjahr 1908.

84 Osterreichische Forst-Zeitung Nr. 33 v. 19.VIII.1898, 3, Forstwirtschaft und Jagd der Bukowina in der Land- $u$. forstwirthschaftlichen Jubiläumsausstellung Wien 1898; ähnlich äußerte sich bereits im Vorhinein die Badener Zeitung Nr. 83 v. 16.X.1897, 5, Vermischtes. Land- und forstwirtschaftliche Jubiläumsausstellung 1898 .

85 Czernowitzer Allgemeine Zeitung Nr. 1184 v. 21.XII.1907, 3, Bukowinaer Landeskomitee für die Bukarester Jubiläumsausstellung.

86 Czernowitzer Allgemeine Zeitung Nr. 728 v. 12.VI.1906, If., Bukarester Jubiläums-Ausstellung. Kollektiv-Ausstellung des Herzogtums Bukowina (I); Nr. 729 v. 13.VI.1906, 3 (II); Nr. 730 v. 14.VI.1906, 2 f. (ohne Nummer); Nr. 731 v. 16.VI.1906 (III).
} 


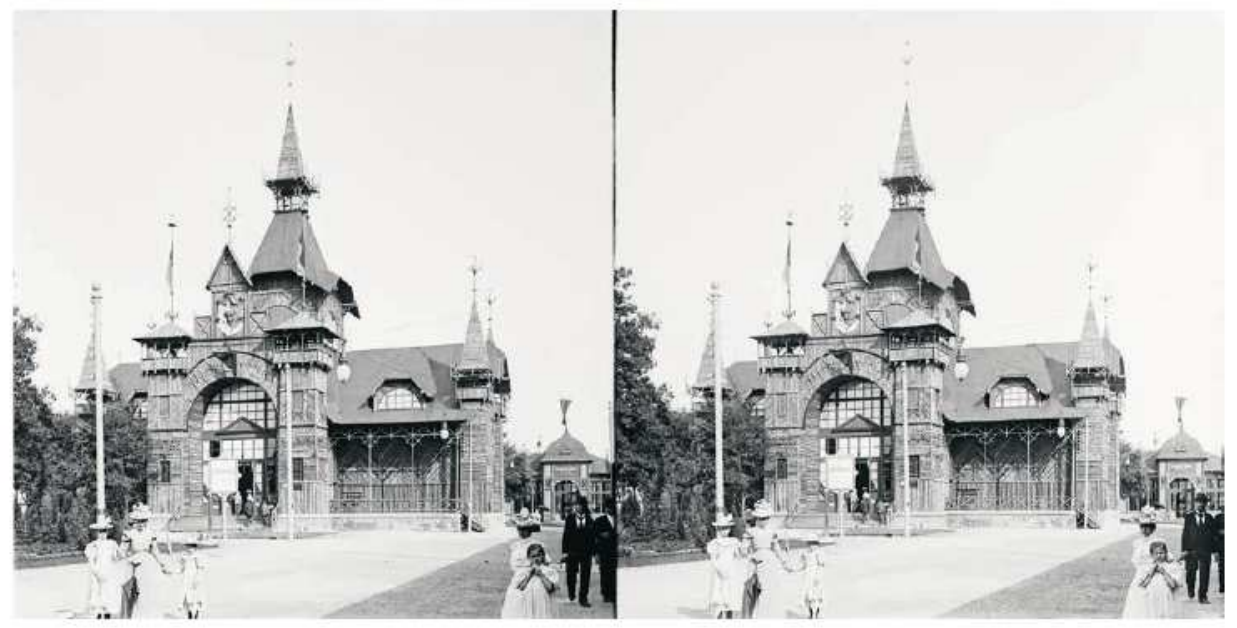

Abb. 36: Kaiser Jubilāumsausstellung Wien 1898 , Pavillon der Bukowina. Die Architektur zitiert bewusst den Stil einer gr-orient. Kirche. ${ }^{87}$ @ ÖNB-Wien http-//data.onb.ac.at/rec/baa13752293

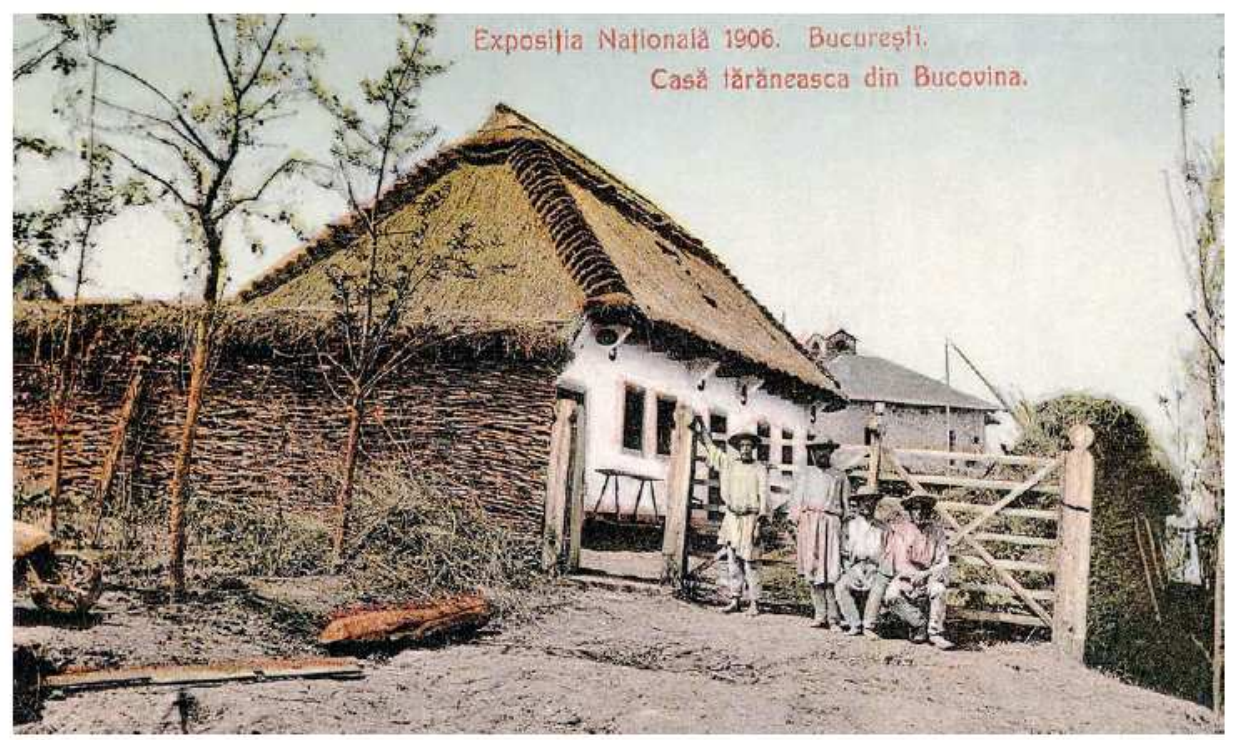

Abb. 37: Exposiția Națională 1906. Bucureşti. Casă tărăneasca din Bucovina. Ansichtspostkarte der Ausstellung in Bukarest 1906 mit einem Bauemhaus aus der Bukowina. Das Kronland war mit einem eigenen ethnographischen Objekt, gleich dem hier abgebildeten Hof, vertreten. Sammlung K. Scharr.

87 Bukowinaer Post Nr. 693 v. 24.V.1898, If., Die Bukowina in der Jubiläumsausstellung (I); Nr. 695 v. 19.V.1898, 3f. (II); Bukowinaer Rundschau Nr. 2769 v. 6.VIII.1898, 1, Der Bukowiner JubiläumsAusstellungs-Pavillon. Von Alexander Bossowicz. 
... als Kriegsverlierer nach 1918?

Schon wenige Tage nach Ausbruch des Krieges evakuierte man die Güterverwaltung des Religionsfonds nach Dornawatra, der Erzbischof verblieb während der ersten russischen Besatzung in der Landeshauptstadt. ${ }^{88}$ Wirtschaftsgebäude und Güter des Fonds wie die Waldkulturen hatten schon während der ersten Wochen empfindliche Zerstörungen zu verzeichnen. ${ }^{89}$ Der russische Militärgouverneur, der seinen Sitz im Gebäude der Güterverwaltung in der Herrengasse bezogen hatte, erklärte den Fonds kurzerhand zum Eigentum des russischen Staates und unterstellte die Kontrolle darüber den Militärbehörden. ${ }^{90}$ Bargeld sowie Werteffekten konnten noch kurz zuvor in versiegelten Kisten nach Wien gebracht werden, wo sie bei der Staatszentralkasse bzw. dem Postsparkassenamt hinterlegt wurden. Die Finanzkasse der Landesverwaltung, wo ebenso Effekten des Fonds deponiert waren, befand sich während dieser Jahre in Salzburg. ${ }^{91}$ Czernowitzer Zeitungen berichteten von fünf Kisten, unter anderem mit den Kriegsanleihen des Fonds, die in Depots in Salzburg gelagert gewesen wären. ${ }^{92}$ Eine genaue Bezifferung der beträchtlichen Summe an Wertpapieren lässt sich allerdings auf Grund der schütteren Quellenlage nicht aufstellen. Insgesamt dürfte der Wert der in Wien und Salzburg deponierten Effekten mehr als 25 Millionen Kronen betragen haben. ${ }^{93}$ Nach Kriegsende hatte eine eigene Liquidierungskommission der rumänischen Regierung in Wien den Auftrag, den Verbleib dieser Wertpapiere und Barschaften in Österreich festzustellen und diese ins Königreich zurückzuführen. Eugen Guzmann, den noch amtierenden Direktor der Güterverwaltung in Czernowitz, hatte Bukarest beauftragt, nach Wien zu reisen um die Angelegenheit zu klären. Die vollständige Freigabe der Mittel zog sich jedoch über das Jahr 1923 hinaus, da die österreichischen Behörden darauf bestan-

88 Kapitel 6 (Repta).

89 Vorarlberger Volks-Blatt Nr. 291 v. 20.XII.1914, 2, In der Bukowina. Neben den Forsten wurden auch einzelne Landgüter des Fonds bereits während der ersten russischen Besatzung völlig zerstört. Laut Presseberichten gehörten dazu »Tepereutz, Michalcze, Jablonitza, Kuczurmare, Dubowa, Czahor, Kotulostritza, Rehezna, Mamajestie«; Zeit v. 16.XII.1914, Die Russen gegen die Bukowinaer Orthodo$x e n$; nach OSTA-HHSTA, Zeitungsarchiv Karton 161, k.k. Ministerium des Äußeren.

90 Pilsner Tagblatt Nr. 340 v. 18.XII.1914, 2, Vom russischen Kriegsschauplatze. Die Kämpfe in der Bukowina; DACZ 320/1/90, Приказ (Verordnung) Nr. 2 v. 18.XI.1916, erlassen auf Basis einer Verordnung des Stabschefs des Oberkommandos der russischen Armee v. 14.X.1916, Nr. 1418 (Kopie).

91 DACZ $_{319 / 2 / 117}$, fol. 44, Comisiunea Română pentru Lichidare Viena an Delegatul Ministerului Cultelor pentru fondul religionar v. 13.III.1920; OSTA-AVA, Neuer Kultus akath. gr-or. K22, Finanzdirektion Salzburg an Unterstaatssekretariat für Unterricht v. 4.IX.1919.

92 Czernowitzer Morgenblatt Nr. 2106 v. 29.VII.1925, Titelseite, Die Salzburger Depots in Czernowitz.

93 OSTA-AVA, Neuer Kultus akath. gr.-or. K22, Kultus 1919 Nr. 18061L v. 15.VIII.1919, Weisung des Bukowiner Landespräsidenten v. 2.VIII.1914, Zl. 3004 prs. 
den hatten, dass vor einer Restitution zunächst die noch offenen Schulden des Fonds in Österreich zu begleichen waren. ${ }^{94}$ Die vom Religionsfonds im Zuge der allgemeinen patriotischen Begeisterung gezeichneten Kriegsanleihen mussten hingegen mehr oder weniger vollständig abgeschrieben werden. Der Fonds hatte - mit Weisung bzw. Bewilligung des Kultusministeriums - schon bei der ersten Kriegsanleihe im November 1914 einen Betrag von 972.000 Kronen investiert ${ }^{95}$, das wohl auch in der Hoffnung auf eine baldige Entsetzung der Bukowina. Die Option sich andererseits dem öffentlichen 'Zwang zu entziehen, war offensichtlich keine, und Fondsmittel wurden - nicht zum ersten Mal - außerhalb ihres eigentlichen Widmung eingesetzt. ${ }^{96}$ Bis 1918 sollten noch weitere Zeichnungen in Millionenhöhe folgen. ${ }^{97}$ Die Güterdirektion rechnete daher für das Jahr 1919 mit einem schmerzlichen Defizit im Fondsbudget. ${ }^{98}$

Geradezu abenteuerlich schilderte der mit der Rückführung der Fondskassa beauftragte Güterdirektor in seinem Abschlussbericht die Rückreise von Wien nach Czernowitz. Da die Bahnverwaltungen der Nachfolgestaaten Gepäckwaggons aus Österreich zurückbehielten, sah sich die rumänische Kommission gezwungen, gleich einen ganzen Schlafwaggon zu mieten, zumal pro Person nur 30 Kilogramm an Gepäck erlaubt waren

$94 \mathrm{DACZ}_{319 / 2 / 117}$, fol. 4-110, Aktenkonvolut zur Restitutionsfrage der in Österreich während des Krieges deponierten Finanzwerte des gr--orient Religionsfonds der Bukowina. Die Mittelfreigabe erfolgte über eine Entscheidung der Reparationskommission v. 22.VIII.1922, Zl. 2116; dazu Bundesgesetzblatt für die Republik Österreich v. 6.X.1921, 209. Stück, Verordnung des Bundesministeriums für Finanzen Nr. 536 v. 4.X.1921.

95 DACZ $_{319 / 2 / 117}$, fol. 53, Ministerium für Kultus und Unterricht an Landespräsidium Bukowina v. 6.V.1915.

96 Das Bukarester Blatt Universul schrieb 1914, das in Wien befindliche Vermögen des Religionsfonds sei auf Weisung der Behörden für den Kauf von Kriegsanleihen verwendet worden. Die in Wien erscheinende Zeit v. 16.XII.1914 wies das zurück und antwortete: "Das ist ganz freiwillig in Ausübung der patriotischen Gesinnung der Orthodoxie in der Bukowina geschehen «; nach OSTA-HHSTA, Zeitungsarchiv Karton 161, k.k. Ministerium des Äußeren. 1919 berichtete das Czernowitzer Morgenblatt, dass "während des Krieges die österreichische Regierung willkürlich jede Prärogative des Konsistoriums ausgeschaltet" hätte, "um den Religionsfond zu einer Kriegsanleihezeichnung in der Höhe von 130 Millionen heranzuziehen «; Nr. 244 v. 20.II.1919, Titelseite, Der Bukowiner griechischorientalische Religionsfond. Von Professor Dr. Kotlarczuk.

97 Nachweisbar sind zumindest Ankäufe der IV., V. und VI. Kriegsanleihe mit jeweils 15, 9 und 11,7 Millionen Kronen sowie der VII. und VIII. (ohne Beträge) durch den Religionsfond; OSTA-AVA, Neuer Kultus akath. gr.-or. K 22, österreichisches Staatsamt für Inneres und Unterricht (Kultusamt) Zl. 443, 1920, Osterreichisch-Ungarische Bank, fällige Kriegsanleihe per 25.V.1919; Kultusamt Nr. 19540 v. 12.IX.1919, Österreichische Länderbank an Kultusamt, Kriegsanleihen des gr-orient Religionsfonds. Prager Tagblatt Nr. 349 v. 17.XII.1916, 7, Die Millionen-Zeichner.

98 DACZ 6/1/242, Direcția Generală a bunurilor fondului religionar ort.-or. din Bucovina an Ministrul delegat (I. Nistor) v. 18.XI.1919. 
(und bis heute sind). Mit fast 500 Kilogramm an Wertpapieren, verteilt auf acht Koffer, traf die Kommission schließlich nach zwei Tagen und zwei Nächten Fahrt auf dem Hauptbahnhof in Czernowitz ein. ${ }^{99}$ Insgesamt zog sich dieser finanzielle Entflechtungsprozess allerdings bis Mitte der 1920er Jahre. So leitete Ion Nistor etwa noch 1924 eine entsprechende diplomatische Mission in der Republik Österreich, unter anderem mit der Aufgabe, Religionsfondsmittel zurückzuholen. ${ }^{100}$

\section{Zusammenfassung}

Insgesamt lassen sich rückblickend drei Phasen in der Entwicklung des Religionsfonds bis 1918 konturieren. ${ }^{101}$ Die erste Phase, die etwa bis 1867 andauert, ist vorwiegend durch eine extensive Nutzung der Ressourcen des Fonds gekennzeichnet. Es fehlten noch die nötigen wirtschaftlichen Rahmenbedingungen, die erst während der zweiten Phase (bis etwa 1898) geschaffen wurden und dann allmählich zum Tragen kamen. Vor allem der Anschluss an das Eisenbahnnetz förderte auf nachhaltige Weise >Industrialisierung ‘ wie Kapitalisierung der Fondsressource Wald. Für die dritte Phase sind wirtschaftliche Verdichtung, der weitere Ausbau von Infrastruktur und eine zunehmende Professionalisierung wie Modernisierung in der Organisation charakteristisch. Resümierend lassen sich daher am Ende der österreichischen Herrschaft in der Bukowina für dieses Kapitel zumindest zwei zentrale Aspekte herausheben. Einerseits kann, beginnend mit der Neustrukturierung am Ende des 19. Jahrhunderts, eine sichtlich erfolgreiche wirtschaftliche Konsolidierung des gr.-orient. Religionsfonds konstatiert werden. Diese äußerte sich nicht nur in einer zunehmend effizienteren Verwaltung und modernen Bewirtschaftung seiner Güter, sondern bildete sich auch in steigenden Einnahmen ab, welche ihrerseits wieder investiert wurden. Den Wiener Zentralstellen war freilich viel an dieser Entwicklung gelegen, konnten sie sich doch regelmäßig der gut gefüllten Taschen des Religionsfonds bedienen, um das Staats- wie Landesbudget bei notwendigen Investitionen im Kronland zu entlasten. Die Gelder flossen in ihrer überwiegenden Mehrheit stets in die Region, von den Kriegsanleihen einmal abgesehen. Die Entscheidungsstrukturen blieben allerdings klar nach Wien ausgerichtet. Das Konsistorium konnte de facto bis 1918 ohne Zustimmung der staatlichen Behörden nichts beschließen, was die Fondsgebarung betraf. Trotz dessen achtete der Staat weitgehend auf die Zweckbindung der Mittel,

\footnotetext{
99 DACZ $_{319 / 2 / 117}$, fol. 110, Schlussbericht Oberregierungs-Rat Enis und Güterdirektor Guzman, Czernowitz v. 16.VIII.1921.

100 Alexa 1996, Nistor, 284f.; Glasul Bucovinei Nr. 1606 v. 1.VIII.1924, Titelseite, Interview cu d-l ministru I. Nistor.

101 GÂRBU 1931, Originea, 7 f.
} 
wenn der Interpretationsspielraum auch manchmal etwas weiter ausgelegt wurde. Wien lavierte in seiner Politik dem Fonds gegenüber geschickt zwischen Forderungen wie sie etwa im Landtag der Bukowina aber auch in der Öffentlichkeit in regelmäßigen Abständen artikuliert wurden und der eher reservierten, auf den sursprünglichen Zwecken` des Fonds beharrenden und manchmal geradezu bremsenden Haltung des erzbischöflichen Konsistoriums. Diese Gratwanderung war jedoch, ohne dabei die Möglichkeiten des Fonds zu überdehnen, nicht nur in finanzieller Hinsicht zu meistern; auch aus politischer Perspektive galt es, den aus den Höhen nationaler Bewegungen zunehmend lauter werdenden Zurufen mit überzeugter Haltung entgegenzutreten und ungeachtet dessen dabei dennoch ausgleichend, aber keinesfalls polarisierend zu handeln.

Andererseits brachte die Analyse in einem nicht weniger entscheidenden Punkt der historischen Bewertung dieser Institution schärfere Konturen zum Vorschein: in seiner für das Kronland ökonomisch wie gesellschaftlich integrierend wirkenden Funktion. Freilich agierte der Fonds in erster Linie als Großgrundbesitzer und verfolgte seine eigenen Interessen. Die initiative Steuerung oblag vielfach zunächst der Wiener Regierung und wurde oftmals erst im zweiten Schritt vom gr.-orient. Konsistorium sowie seinem Erzbischof mitgetragen bzw. in dieselbe Richtung gelenkt.

Die damit angesprochene Dominanz bzw. Verflechtung des Bukowiner gr.-orient. Religionsfonds mit der Gesellschaft des Kronlandes lässt sich an einem - wenngleich wirtschaftlich unbedeutenden - Beispiel anschaulich illustrieren. Zur Jahrhundertwende hatte der Tourismus als eigener Wirtschaftszweig vor allem in den Alpen der Habsburgermonarchie (speziell in Tirol) bereits eine ökonomisch tragende Bedeutung erlangt. Im östlichsten Kronland war davon wenig zu spüren. Trotzdem beging die Sektion `Bukowina des österreichischen Touristenklubs unter ihrem Obmann, dem Forstmeister Franz Bittner, 1913 mit einem Fest ihr 25-jähriges Bestandsjubiläum. ${ }^{102}$ Anlässlich der anstehenden Feierlichkeiten hatte der Religionsfonds schon ein Jahr zuvor, unweit des Rărău (1.650 m), einem der markantesten Erhebungen in den Waldkarpaten, "zur Hebung des Fremdenverkehrs« dafür in seinen Forsten eine elf Kilometer lange 'Gebirgskunststraße anlegen lassen. Damit war das 1906 eröffnete und ganzjährig bewirtschaftete Schutzhaus mit seinen im Endausbau 100 Plätzen leicht erreichbar geworden und - aus militärischer Sicht - wohl auch die nahegelegene rumänische Grenze. Die Erbauung der Hütte hatte ebenfalls im Wesentlichen der Religionsfonds gefördert. ${ }^{103}$ Besucher schwärmten vom Komfort des »einladenden Berggasthauses« und bemerk-

102 Czernowitzer Allgemeine Zeitung Nr. 3154 v. 22.VIII.1913, 3, Das 25jährige Bestandsjubiläum der Sektion »Bukowina" des österr. Touristenklubs (Dr. Max Rosenberg).

103 Czernowitzer Allgemeine Zeitung Nr. 738 v. 24.VI.1906, 4, Eröffnung des Erzbischof Repta-Schutzhauses auf dem Rareu. 


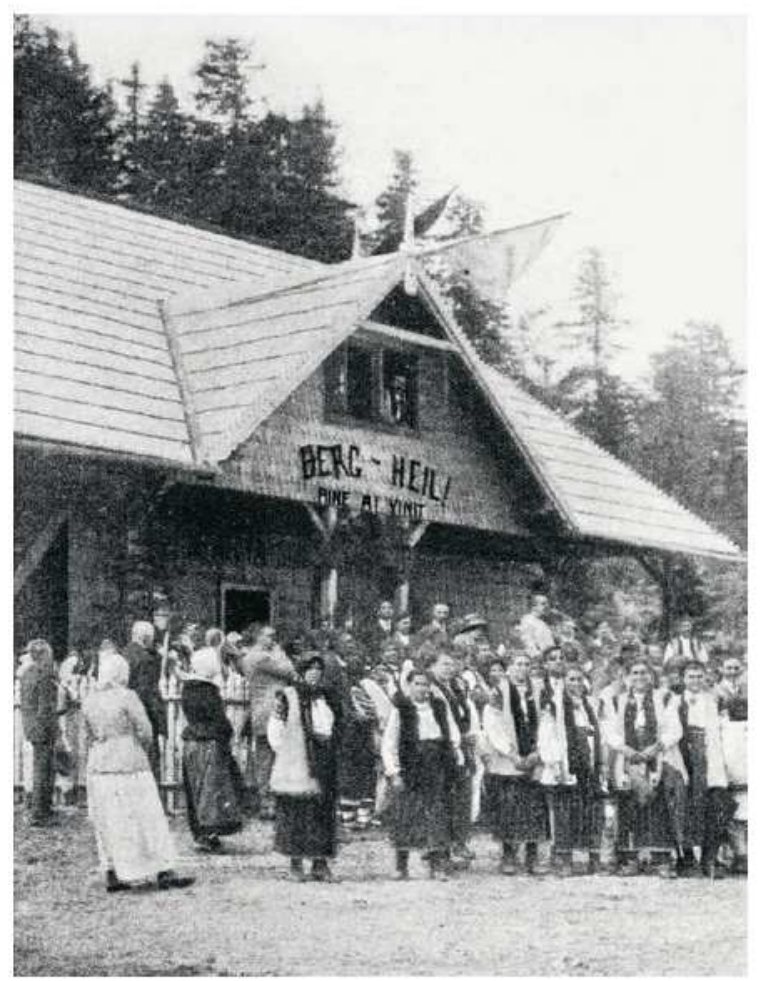

Abb. 38: Jubiläumsfeier der

Sektion "Bukowina" des Oest. Touristenklubs: Das neugeweihte Erzbischof Repta-Schutzhaus, nach erfolgtem Umbau und Erweiterung. Über dem Eingang ist der deutschrumänische Schriftzug Berg-Heil! Bine aț[i] vinit zu erkennen. Wiener Bilder 14.IX.1913.

Abb. 39: Rarău cu casa de adăpost "Mitropolitul Visarion*. Rumänische Ansichtspostkarte. In den 1930er Jahren trug das Schutzhaus zwischenzeitlich den Namen des späteren Metropoliten der Bukowina Vissarion. Heute steht an diesem Platz die Cabana Rărău. Sammlung K. Scharr.

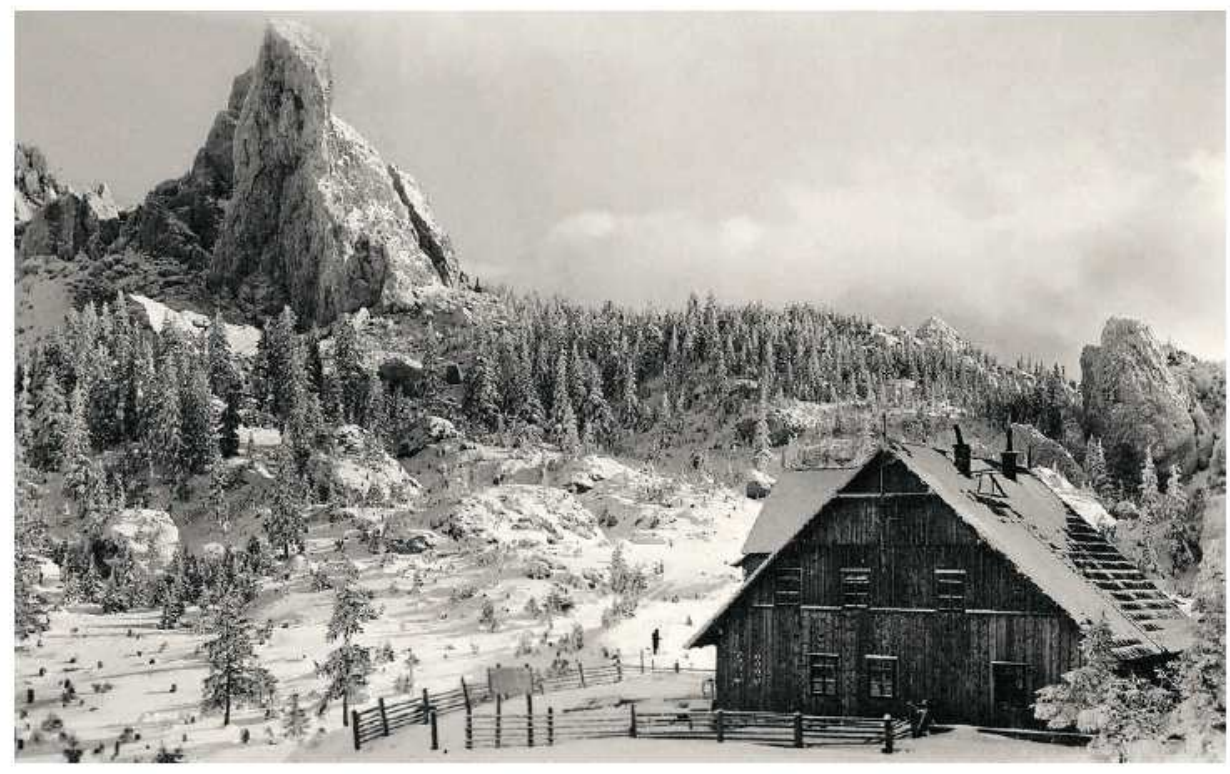


ten, nicht ohne damit zugleich einen gewissen Lokalstolz zu demonstrieren, dass dieses Haus als »eines der wenigen in ganz Österreich « selbst im Winter bewirtschaftet wird. ${ }^{104}$ $\mathrm{Zu}$ Kriegsbeginn quartierten sich an der strategisch wichtigen Stelle zunächst österreichische Patrouillen ein, die Mitte Jänner 1915 den Ort für einige Wochen russischen Truppen überlassen mussten, bevor sie im Februar zurückkehren konnten. ${ }^{105}$ Der bei der Einweihungsfeier gewählte Name - „Erzbischof-Repta-Schutzhaus « - hatte symbolischen Charakter für die umfassende Stellung der hinter der Erbauung dieser alpinen Unterkunft stehenden Institution im Land. ${ }^{106}$ Beide, Schutzhaus wie Namenspate, begleiteten den Religionsfonds für die Jahre des Übergangs in die rumänische Zeit. Mehr als ein Jahrzehnt später sollte das Haus auf den Namen eines Nachfolgers von Repta auf dem Metropolitenstuhl, Vissarion Puiu, umbenannt werden.

104 Czernowitzer Allgemeine Zeitung Nr. 2595 v. 15.IX.1912, 3, Vom Rareu.

105 Grazer Tagblatt Nr. 49 v. 18.II.1915, 11, Der Kampf um das Schutzhaus am Rareu.

106 Wiener Bilder Nr. 37 v. 14.IX.1913, 11, Jubiläumsfeier der Sektion »Bukowina" des österr. Touristenklubs. 


\section{Fondul Bisericesc Ortodox Român 1918-1948}

"Se va întroduce timpul de București înaintându-se orarul cu un ceas. “ ${ }^{1}$ Dieser einfache Satz, mit seinem aus der zeitlichen Distanz unscheinbar anmutenden Charakter einer gewöhnlichen Verordnung, drückt für die Epochengrenze der Bukowina, wie Mariana Hausleitner die Herbstwochen des Jahres 1918 benennt $^{2}$, mehr als bloße Symbolhaftigkeit einer neu angebrochenen Zeit für die Provinz aus. Mit Umstellung der Uhren in der Bukowina, wo bis zum 25. November 1918 Wiener Zeit gegolten hatte (also eine Stunde früher als Bukarest), fand nicht nur eine rein praktischen Gesichtspunkten folgende Homogenisierung statt. Im Fahrwasser der Einführung der osteuropäischen Zeit und der damit einhergehenden definitiven Ausrichtung auf die Hauptstadt des rumänischen Königreiches zeichneten sich markante inhaltliche Brüche ab. Das betraf in gravierender Weise die Idee von Region, des von ihr ausgehenden Identitätsangebotes und -verständnisses sowie eben auch die in Cisleithanien bis dahin zumindest ansatzweise vorherrschende föderalistische Auffassung des Staatsaufbaues. Damit hob ein sich letztlich über die gesamte Zwischenkriegszeit hinziehender komplizierter Entflechtungs- wie genereller Umorientierungsprozess an, der bis zur ersten Teilung der Bukowina durch die sowjetische Invasion im Jahr 1940 wohl administrativ abgeschlossen gewesen sein mag, gesellschaftlich jedoch noch weitgehend im Laufen war. Erst durch den Zweiten Weltkrieg, die Pariser Friedenskonferenz von 1946 und ihre Folgen fand auch diese Ebene eines 1918 eingesetzten Integrationprozesses ihr jähes Ende. Dabei hatte sich allerdings nicht sbloß \& die hinzugekommene Region neu auszurichten und anzupassen, auch der gerade erst im Entstehen begriffene rumänische Zentralstaat musste sich von Grund auf neu konstituieren, um die Folgen von 1918 überhaupt bewältigen zu können. ${ }^{3}$

Die synthetische Formel des gemeinsamen rumänischen Raums als politischer Losung - die 1918 in Erfüllung gegangen zu sein schien, Rumänien vom Dnister bis zur Theiss (România de la Nistru pân' la Tisa) - verdeckte im allgemeinen Jubel weitgehend die enorme gesellschaftliche Heterogenität des sich mit Kriegsende neu definierenden Staats. Letztere war ein unmittelbares Resultat der beträchtlichen Gebiets- wie Bevölkerungsgewinne. Die Idee des 1916 noch lediglich imaginierten größeren zentralisierten Nationalstaates fußte auf einer Gesellschaft, in der rund $80 \%$ der bäuerlichen Bevölkerung angehörten, von denen (im Altreich) wiederum 60\% weder in der Lage waren zu schreiben

1 [Es wird die Bukarester Zeit eingeführt und die Uhr um eine Stunde vorgestellt.] Monitorul Bucovi$n e i$, 1918, Decretul-lege, Fascicula 3, ordonanța Nr. 6, Introducere timpului de București în Bucovina 17. XII.1918.

2 Hausleitner 2000, Epochengrenze, 119.

3 Murgescu 2010, România. 


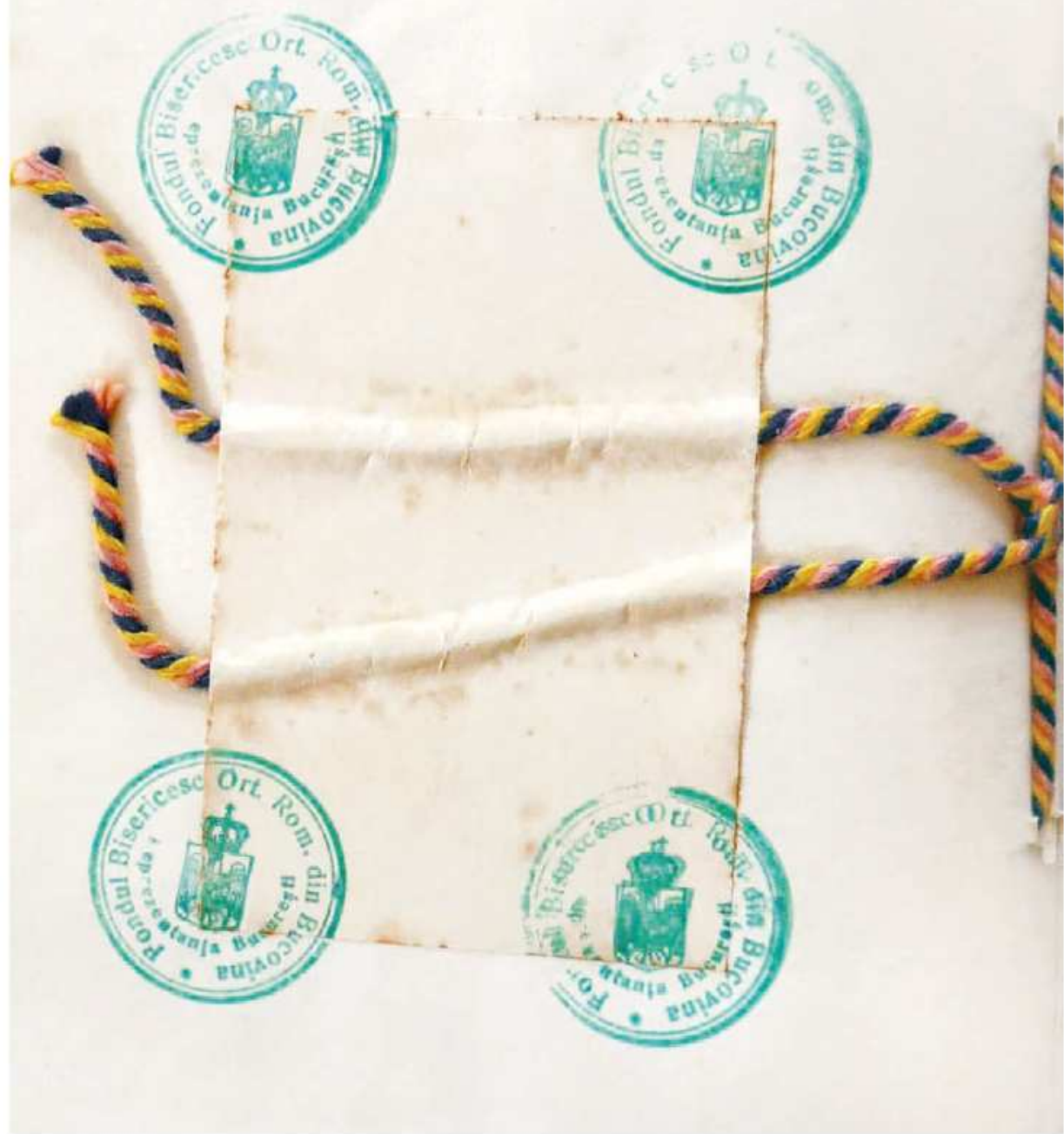

Abb. 40: Rumänien vom Dnister bis zur Theiss als Formel und politische Losung wird bildlich auch in der alltäglichen Verwaltung des Religionsfonds greifbar und nicht nur in der Ausrichtung der Uhrzeit; hier die letzte Seite eines offiziellen Fondsdokumentes, gesiegelt mit dem neuen rumänischen Namen, dem Staatswappen und dem amtlichen Bindfaden in den drei Farben des Königreiches: blau-gelb-rot. (c) DACZ 321/5/3 Raport Trimestrial 1940. 
noch zu lesen. Diese Schichten konnten im Alltag nur wenig mit der nationalen Idee oder der Vorstellung von übergeordneter Staatlichkeit anfangen, ganz im Gegenteil. Der Preis, zu den Siegern des Weltkrieges zu gehören und Siebenbürgen und die Bukowina, neben Bessarabien hinzugewonnen zu haben, schien für die maßgeblichen Eliten des Staates und die Mehrheit seiner Bürger vorerst überzeugend genug, um die augenscheinlichen Differenzen zu den anderen srumänischen< Ländern zu vergessen. ${ }^{4}$ Der Befreiungsmythos, das Erreichen ersehnter nationaler Einheit, deren vermeintliche Ursprünge dabei tief in die Vergangenheit zurückprojiziert wurden, geriet zur staatstragenden Ideologie der Gegenwart. Ihre Kohäsionskraft sollte die Teile zu einem Ganzen verbinden. ${ }^{5}$

Innerhalb des 1914 noch bestehenden österreichischen Kronlandes hatten sich hingegen die nationalen Streitparteien im Landtag, der zu Beginn dieses Jahres ausgesetzt worden war, auf einen Burgfrieden zwischen Rumänen und Ruthenen einigen können. Das politisch-gesellschaftliche Zusammenleben funktionierte zwar einigermaßen, aber war keinesfalls spannungsfrei gewesen. Die russische Besatzung während des Krieges einerseits und der Kampf der österreichischen Zivilbehörden, der Armee und der Fischerschen Polizeitruppen andererseits hatten in der Bukowina mithin einen radikalen Stimmungsumschwung begünstigt. ${ }^{6}$ Auch wenn die bäuerliche Bevölkerung nach wie vor Habsburg loyal war, so hatten doch national-radikale Stimmen der dominierenden politischen Lager beträchtlich an Oberwasser gewonnen. ${ }^{7}$ Die Ansicht Oszkár Jászis in seiner frühen Darstellung des Zerfalls der Habsburgermonarchie von der ungleich größeren Bedeutung wie Rolle der irredentistischen Bewegung in Siebenbürgen sollte daher differenziert bewertet werden. ${ }^{8}$ Vor 1916 trifft das sicherlich im Vergleich zum transleithanischen Siebenbürgen zu. Spätestens mit Herbst 1918 schärfte sich aber auch in der Bukowina die angesprochene Epochengrenze. Andererseits hatte jedoch nicht nur in Siebenbürgen auf vergleichsweise breiter Basis der "Geist des Okzidents« tief in großen Teilen der Bevölkerung Wurzeln geschlagen, wohingegen im rumänischen Altreich dieser lediglich die Eliten erreicht hatte. ${ }^{9}$ Auch für die Bukowina ist von einer derartigen

4 BoIA 2014, Război, 69.

5 Vgl. die Rede von Nistor beim rumänischen Generalkongress v. 28.XI.1918 in Czernowitz; NisToR 1940, Vereinigung, 38-42.

6 MAIOR 2016, Ani, 220 u. 226.

7 Am 3.X.1918 fand anlässlich der wenige Wochen zuvor erfolgten Rückführung der Gebeine des Heiligen Johannes Novus von Wien nach Suczawa eine Bauernwallfahrt statt, verbunden mit einer patriotischen Kundgebung gegenüber dem Kaiserhaus; PRокороwiтsch 1959, Ende, 21 ff.; (Neuigkeits)Welt Blatt Nr. 170 v. 28.VII.1918, 4, Die Heimreise der Gebeine des griechischen Landespatron der Bukowina aus Wien.

8 JÁszI 1929, Dissolution, 398.

9 BoIA 2014, Război, 80. 
organischen Verbindung mit dem `Westen « auszugehen. Die zentralen Regierungsstellen der Habsburgermonarchie und - was die Bukowina betrifft - der österreichischen Reichshälfte im Besonderen - hatten indes spätestens im Jahr 1918 ein "unfassbar « realitätsfernes Bild von der Wirklichkeit oder - positiver formuliert - »ihre Erörterungen hinkten den Ereignissen immer um mindestens ein halbes Jahr hinterher «. ${ }^{10}$

Mit dem Kriegseintritt des Königreiches Rumänien 1916 auf Seite der Entente verschob sich auch in der Bukowina allmählich die nationale und kirchenpolitische Situation. Die irredentistischen Zentrifugalkräfte, die bei Jászi im Gegensatz zu Siebenbürgen vor dem Sommer 1914 noch durch den Zwist mit den Ruthenen gebunden waren, hatten sich auf breiterer Basis radikalisiert und eine Richtung eingeschlagen, die immer mehr auf eine Vereinigung mit Rumänien hinauslief. Die ideologisch-politische Führung der Rumänen übernahmen Intellektuelle wie Nistor und Flondor. In einem ersten Schritt ist es daher Aufgabe dieses Kapitels, die sich im Spätherbst 1918 abzeichnenden Grundtendenzen der Politik Bukarests in der Bukowina vorwiegend auf Basis der Literatur und ergänzend der Quellen zu skizzieren. Dafür bietet sich beispielhaft der Machtkampf zwischen den erwähnten beiden Proponenten der rumänischen Nationalidee in der Bukowina an. Daran anschließend gilt es, die schrittweise Eingliederung der bisherigen Landeskirche in das Königreich und das Verhältnis der Bukowiner zur Bukarester Metropolie bzw. dem späteren Patriarchat so weit als nötig auszuleuchten. Zentral zu analysieren bleibt insgesamt die Frage nach Kirchenautonomie, Kirchenkongress, Religionsfonds und seiner Struktur bzw. Neuaufstellung im geänderten politischen Kontext. In der Analyse der Neuverhandlung des Verhältnisses von Kirchen und Staat darf allerdings ein dritter Faktor in diesem Beziehungsgeflecht nicht übersehen werden: die Politik. Die Politik als Massenphänomen hatte schon nach der Jahrhundertwende in der österreichischen Bukowina begonnen, Landeskirche und Religionsfonds eigennützig zu instrumentalisieren. Jetzt, vor dem Hintergrund eines vergleichsweise schwachen Staates, gewann die politische Sphäre sichtlich an Oberwasser, das ihre Proponenten zu nutzen wussten.

\section{Zwischen Autonomie und Zentralregierung}

Die mit 1918 einsetzende Problematik der notwendigen Umstellung auf den neuen Staat lässt sich mithin an den gehegten Erwartungen wie realen Schwierigkeiten der Bukowiner Institutionen und ihrer Vertreter messen, sich gegen die von Bukarest schrittweise ausgreifende neue Zentralmacht zu behaupten. Dieses Konfliktpotential

10 SUndhaussen 2000, Multiethnizität, 89; RAUChensteiner 2013, Weltkrieg, 999-1002; Rumpler 1966, Völkermanifest. 
betraf vor allem die Ebene von Autonomiefragen der Regionen sowie des neuen Zentrums und befeuerte zugleich die Diskussionen der Eliten mit ihren sehr unterschiedlichen Erfahrungen wie Vorstellungen von Staatlichkeit. ${ }^{11}$ Das betraf selbstverständlich auch den Nerv der orthodoxen Landeskirche, den Erzbischof, das Konsistorium und den Religionsfonds. Innerhalb der Bukowina zeichneten sich zu diesem Zeitpunkt erste Linien ab, welche die Epochengrenze deutlich umrissen und für die Jahre bis 1940 bestimmend bleiben sollten: eine ungeteilte Bukowina unter rumänischer Herrschaft, eine Agrarreform - die den Landhunger der mehrheitlich bäuerlichen Bevölkerung stillen und in der Luft hängende soziale Unruhen von vornherein entschärfen sollte -, sowie die Autonomiefrage.

Flondor hatte zunächst den nicht rumänischen Gruppen in der Bukowina eine Beibehaltung ihrer Autonomie in kulturellen Fragen versprochen, was allerdings schon bald von den königlichen Militärbehörden in der Realität weitgehend ignoriert wurde. ${ }^{12}$ Dieser Aspekt rückte politisch ohnedies rasch in den Hintergrund, wenngleich er weiterhin ausreichend gesellschaftlichen Konfliktstoff barg, der das Leben in der Bukowina während der beiden Jahrzehnte nach 1918 dominierte. ${ }^{13}$ Innerhalb der rumänischen Fraktion im Lande kristallisierten sich zwei Richtungen heraus, jeweils getragen von ihren politischen Vertretern: dem Großgrundbesitzer Flondor und dem Universitätsprofessor für Südosteuropäische Geschichte an der Universität Czernowitz Nistor. Flondor war politisch im Kronland um die Jahrhundertwende mit der Gründung der Rumänischen Nationalpartei (Partidul Naţional Român din Bucovina) in Erscheinung getreten. Er versuchte mit seiner Bewegung - in offenem Gegensatz zu Nistor - die sozialen Nöte der rumänischen Bauern und Landpriesterschaft politisch zu kanalisieren. Bei Nistor stand hingegen die nationale Idee als richtungsweisende politische Losung im absoluten Vordergrund, weniger das Ziel einer Lösung der sozialen Frage. Das hatten seine bisherigen Arbeiten als Historiker schon erkennen lassen. ${ }^{14}$ Flondors Forderungen nach einem Kirchenkongress und nach Reformen im Agrarbereich waren stets sowohl an die österreichische Verwaltung als auch an die gr-orient. Kirchenhierarchie, als Vertreter des Großgrundbesitzes im Lande, adressiert. ${ }^{15}$ Während des Krieges verblieb der Großgrundbesitzer aus Storożynetz in der Bukowina. Seine Verhandlungen mit der russischen Besatzungsmacht - zugunsten der Bevölkerung - brachten ihm jedoch in der

\footnotetext{
11 Dazu im Wesentlichen für Siebenbürgen: MÜLLER 2015, Geschichtsregionen.

12 HaUsleitner 2000, Epochengrenze, 113.

13 HAUSleitner 2001, Rumänisierung; ders. 2002, Zwangsrumänisierung.

14 Valenciuc 2011, Preotimea, 8; Hausleiter 2014, Historiker, 74.

$15 \mathrm{Zu}$ Person und politischer Tätigkeit von Flondor vgl. GafiŢA 2004, Considerații; ders. 2008, Débuts; PURICI 2004, Flondor.
} 
Folge, ähnlich wie dem Metropoliten Repta, Schwierigkeiten ein. Die österreichischen Behörden interpretierten beider Handeln als offene Kollaboration mit dem Feind. ${ }^{16}$

Im Gegensatz zu Flondor flüchtete Nistor bereits mit Kriegsausbruch aus der Bukowina ins damals noch neutrale Königreich Rumänien. Schon drei Jahre zuvor hatte ihn die Rumänische Akademie der Wissenschaften in Bukarest, auf Fürsprache Nicolae Iorgas, als korrespondierendes Mitglied in ihre Reihen aufgenommen. Nistor verfügte über hervorragende gesellschaftliche Anbindungen im Altreich. In seinem, in politischer Hinsicht programmatischen Buch "Zur Geschichte der Kirche in der Bukowina", das er 1916 in Bukarest veröffentlichte, legte Nistor seine Haltung zu einer zukünftig rumänischen Kirche und eines entsprechend rumänischen Religionsfonds offen. Damit artikulierte Nistor zugleich die Ziele radikaler irredentistischer Kräfte des Kronlandes. Der darin beschriebene vermeintliche Kampf der Rumänen, den diese in seiner Rückdeutung (und der seines Mentors Iorga) schon seit Jahrhunderten um ihre Unabhängigkeit geführt hätten, nahm mit dem Krieg an Dynamik auf. Dadurch lag gleichzeitig das ersehnte Wunschziel der tonangebenden rumänischen Intellektuellen nach (ethnisch) nationaler Einheit in einem Staat in greifbarer Nähe. Die gr.-orient. Kirche und ihre Institutionen gerieten zum Angelpunkt dieses Konzeptes:

Biserica din Bucovina a fost și trebuie să rămână românească, acesta este imperativul categoric al datorinţii noastre naţionale. Lupta noastră pentru biserică este totodată o luptă pentru conservare a neamului românesc în Bucovina. Ea nu este o ceartă dogmatică, ci să este o luptă de apărare împotriva neîntemeiatelor aspiraţii ale coreligionarilor noștri ruteni, care sub masca confesionalismului au reușit să usurpe drepturi și să cucerească o poziție după alta în biserica noastră strămoșeasă. Ca Români buni și ca fii credincioși ai credinţei ortodoxe datori suntem să apărăm cu toate mijloacele și cu orice jertfă caracterul istoric al bisericii noastre din Bucovina, întemeiată de Alexandru cel Bun, adăugată de Ștefan el Mare și înzestrată cu bogate moșii de voevozii și boierii moldoveni. Așa să ne ajute Dumnezeu! $!^{17}$

16 PURICI 2004, Flondor, 267.

17 [Die Kirche der Bukowina war und muss rumänisch bleiben, das ist der kategorische Imperativ unserer nationalen Verpflichtungen. Unser Kampf für die Kirche ist immer ein Kampf für die Erhaltung des rumänischen Volkes in der Bukowina. Das ist kein dogmatischer Zwist, sondern das ist ein Verteidigungskampf gegen die unbegründeten Ziele unserer co-religiösen Ruthenen, denen es unter der Maske des Konfessionalismus gelang, Rechte zu usurpieren und in unserer altväterlichen Kirche eine Position nach der anderen zu erobern. Als gute Rumänen und als gläubige Söhne des orthodoxen Glaubens haben wir mit allen Mitteln und mit allen Opfern den historischen Charakter unserer Kirche in der Bukowina zu verteidigen, gestiftet von Alexander dem Guten, vermehrt von Stefan dem Großen und ausgestattet mit reichen Besitzungen der moldauischen Wojewoden und Bojaren. So uns Gott helfe!] NISTOR 2003/1916, Istoria, 165. 
Damit hatte Nistor die Gedanken seines Mentors Iorga aufgegriffen und in Politik umzusetzen begonnen. ${ }^{18}$ Zehn Jahre nach Kriegsende konstatierte Nistor für die Bukowiner Kirche im Rückblick auf die mit dem Gesetz von 1925 endgültig geschaffenen Fakten und der definitiven Umbenennung von Kirche wie Fonds: „Fondul religionar grecooriental din Bucovina este și rămâne o fundaţiune specială de sine stătătoare, care va purta de acum înainte numirea de >Fondul bisericesc ortodox român al Bucovinei « ${ }^{19}$

Mitte Dezember 1918 hatte die Bukarester Regierung für die Verwaltung der Bukowina zwei Staatssekretariate ohne Portefeuille (Ministrul-delegat al guvernului român) eingerichtet. Sie hatten den Auftrag, die Umsetzung der administrativ-politischen Vereinigung des vormaligen österreichischen Kronlandes mit dem Königreich in die Wege zu leiten.$^{20}$ Flondor übernahm das Amt des Staatsekretärs mit Sitz in Czernowitz und Nistor jenes mit Sitz in Bukarest. Dem Ministrul-delegat in Czernowitz arbeitete zudem ein ihm direkt unterstelltes Generalsekretariat, das sich in neun Abteilungen mit jeweils fachspezifischen Aufgaben untergliederte, $\mathrm{zu}^{21}$ Nistor gelang es mithilfe seines Bukarester Netzwerkes jedoch recht bald, die politische Macht in der Bukowina in seinen Händen zu kumulieren. ${ }^{22}$ Flondor hingegen kritisierte die wachsende wie zunehmend absolute Dominanz Bukarests in regionalen Angelegenheiten und die spiegelbildlich dazu seit 1918 steigende als Belastung empfundene, Anzahl der Beamtenschaft vor Ort. ${ }^{23}$

18 \#Ce e Biserica, ortodoxă saû naţională ? [ [Was ist die Kirche, eine orthodoxe oder nationale?], hatte sich Iorga in seiner Reisebeschreibung der Bukowina 1905 gefragt und die Antwort gleich mitgeliefert: „Naţională, spun Romîniĭ cu iubire de neam, cari naûu uitat trecutul și nu încep a număra de la anul 1775, sfirşit al barbareĭ moldovenești și început al civilisaţiei; ortodoxă, spun consilieriĭ rutenĭ, agitaroriĭ rutenĭ, cari caută să întemeieze bine Biserica unită la hotarul de spre Rusia, iar în lăuntru socot că poate sluji maĭ mult pravoslavia « [National, sagen die Rumänen mit Liebe zum Volk, die ihre Vergangenheit nicht vergessen haben und die nicht mit dem Jahr 1775 zu zählen beginnen, dem Ende der moldauischen Barbarei und dem Beginn der Zivilisation; orthodox, sagen die ruthenischen Beamten, die ruthenischen Agitatoren, die einen guten Grund für eine vereinigte Kirche über die Grenze hinweg zu Russland suchen, die abermals im Inneren erwägen, wie sie noch mehr der Orthodoxie dienen können.]; IoRG A 1905, Neamul, 208.

19 [Der gr-orient. Religionsfonds der Bukowina ist und bleibt eine besondere dauerhafte Stiftung, die fortan den Namen Rumänisch-Orthodoxer Religionsfonds der Bukowina tragen wird.] NiSTOR 1928, Zece, 125 ; Monitorul Oficial Nr. 97 v. 6.V.1925, Nr. 261 v. 26.XI.1925, Artikel 39-43; Foaia ordonantelor şi comunicărilor Consistoriului arhiepiscopesc în afacerile Arhidiecezei ortodoxe a Bucovinei Nr. 8 o v. 10. XII.1925, Art. 1.

20 Monitorul Oficial v. 1.I.1919, Dekret Nr. 3715, Art. II-IV u. Dekret Nr. 3746 v. 18.XII.1918; nach Nistor 1928/2010, Unirea, Anhang, $247 \mathrm{ff}$. u. 25 of.

21 Kgl. Dekret Nr. 2212 v. 18.XII.1918, Nr. 3715 v. 18.XII.1918, Gesetz Nr. 1476 v. 3.IV.1920; nach DACZ 6/opis'1, Vorwort.

22 HaUsleitner 2001, Rumänisierung, 142-147.

23 AleXa 1996, Nistor, 278. 
Abb. 41: Demission I. Flondors. Titelblatt Glasul Bucovinei Nr. 121 v. 15.IV.1919.

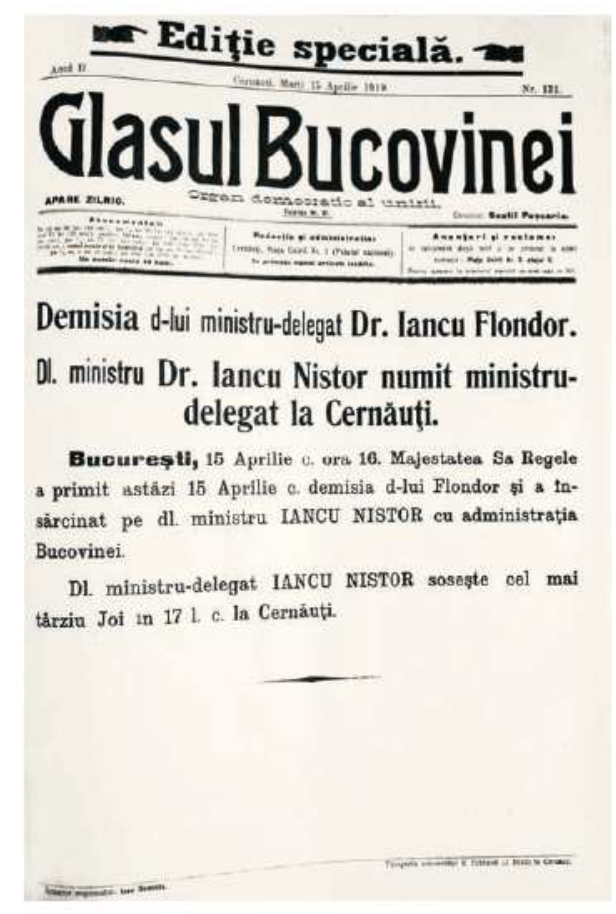

Als Antwort darauf warf Nistor seinem politischen Gegner vor, einerseits gezielt die "Spaltung im Rumänenlager " zu betreiben und andererseits bei der Gestaltung der Geschicke des Religionsfonds den legalen Weg verlassen zu haben. ${ }^{24}$ Mehr noch, die Schuld für die Diskrepanz zwischen dem Reichtum des Religionsfonds und der angeblichen Misere der Pfarrer in der Bukowina sei, so Nistor weiter, in der "Inkompetenz « des delegierten Ministers zu suchen. ${ }^{25}$ Darüber hinaus erteilte Nistor über die parteinahe Zeitung Glasul Bucovinei (Stimme der Bukowina) dem Konzept des 'Homo Bucovinensis`als ein desavouiertes »Element des österreichischen Geistes «, wie es Flondor und Teile der alten Provinzeliten vertraten, zugunsten neuer Staatlichkeit eine definitive Absage. ${ }^{26}$

Specia aceasta de bipezi s’a desvoltat în pepiniera politică a fostului regim austriac. E tipul renegatului lipsit de convingere naţionale [... În urma actului de unire, 15/28 Noemvrie Buco-

24 Czernowitzer Morgenblatt Nr. 459 v. 14.XI.1919, Titelseite, Nistor-Flondor; Glasul Bucovinei Nr. 575 v. 28.XI.1920, Titelseite, Fondul religionar.

25 ANR-B Fond 2719 pach. 108-1921, fol. 14, Senator Nistor an Domnule Președinte [i.e. Wladimir Repta erster Senatspräsident des vereinigten Rumäniens nach 1918], o.D.

26 Glasul Bucovinei Nr. 567 v. 19.XI.1920, Titelseite, Bucovina şi remanierea ministerială. 
vina s’a realipit la România, în hotarile cărora nu este loc pentru homo bucovinensis ce numai pentru civis Romaniae. ${ }^{27}$

Im April 1919 gelang es Nistor schließlich den Konflikt für sich zu entscheiden und den »Bojaren aus Storożynetz« aus seinen politischen Ämtern zu verdrängen. Flondors Autonomisten hielt das allerdings keineswegs davon ab, in Bukarest weiterhin die Beibehaltung regionaler Rechte einzufordern. ${ }^{28}$ Entzündet hatte sich der zwischen den beiden Persönlichkeiten schon seit längerem schwelende Konflikt um die politische Deutungshoheit in der Provinz an der angestrebten Verlagerung der Eisenbahndirektion von Czernowitz nach Jassy (rum. Iași). Flondor sah darin nicht ganz zu Unrecht die Gefahr eines schleichenden Autonomieverlustes aufziehen und wandte sich mit der Bitte um Unterstützung direkt an König Ferdinand. Eine Antwort blieb ihm Letzterer allerdings schuldig, folgedessen reichte Flondor als Regionsminister seine Demission ein. ${ }^{29}$ Das Amt des delegierten Ministers in Czernowitz wurde aufgelöst und durch das eines Präsidenten für die Vereinigung (Preşedinte al comisiunei regionale de unificare) ersetzt. ${ }^{30}$ Diese Funktion bekleidete Nistor. Die autonomistischen Bestrebungen der Region vermochten sich letztendlich gegen den Willen der Zentralregierung nicht durchzusetzen. Wenige Monate später ließ Bukarest auch die bis dahin in der Bukowina noch existierende Landesregierung auflösen. ${ }^{31}$ Die Partidul Democrat al Unirii din Bucovina und ihr Parteichef Nistor erwiesen sich in der Folge als ideale Partner des amtierenden Ministerpräsidenten Ion I. C. Brătianu, mit dessen Nationalliberalen man 1923 fusionierte. Nistor hatte im Vereinigungsprozess ein scharf umrissenes Ziel vor Augen: die »idei de stat român naţional și unitar «. ${ }^{32}$ Eine spätere historiographische Einschätzung seiner Person meint, "Ion Nistor had been the point man for the government on Bucovinean issues throughout this period «. Das darf vor dem Hintergrund dieser Ereignisse wohl

27 [Diese zweibeinige Spezies hat sich im politischen Kindergarten des früheren österreichischen Regimes entwickelt. Diesem Typen eines Renegaten fehlt nationale Überzeugungskraft. (...) Durch das Vereinigungsgesetz vom 15./28. November ist die Bukowina wieder zu Rumänien zurückgekehrt, in dieser Bestimmung ist kein Platz für einen Homo Bucovinensis sondern nur mehr für den civis Romaniae.] Glasul Bucovinei Nr. 23 v. 11.XII.1918, Titelseite, Homo bucovinensis. In Hakmann sah Nistor einen der zentralen Betreiber und Begründer des Bukowinismus; v. DrunEN 2015, Bunch, 72.

28 Rum. »boierul din Storijineţ«; GAFIŢA 2003, Aspecte, 70; ders. 2005, Considerații, 62; PURICI 2004, Flondor, 267.

29 Gafiţa 2005, Considerații, 69; ECONOMU 2011, Unirea, 66-72.

30 Nistor 1928, Ani, 13; Hausleitner 2001, Rumänisierung, 144.

31 Czernowitzer Morgenblatt Nr. 570 v. 6.IV.1920, Titelseite, Ein schwerer Schlag für die Bukowina. Auflösung der Landesregierung.

32 [Idee eines rumänischen Staates, national und einheitlich.]; ALEXA 1996, Nistor, 277; zuletzt HAUSLEITNER 2014, Historiker, $65 \mathrm{ff}$. 


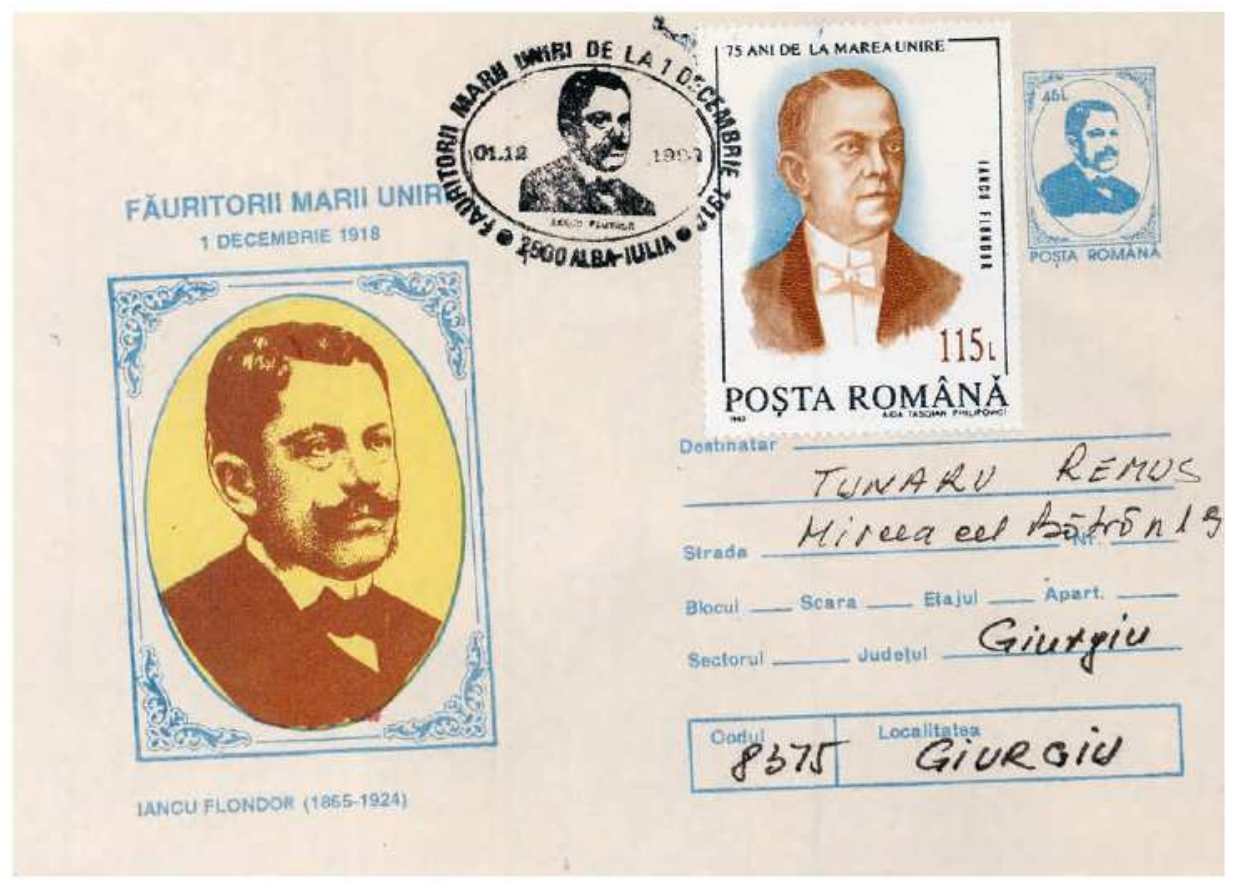

Abb. 42: Briefcouvert, Sonderstempel und -briefmarke zur 75-Jahr-Feier 1993. lancu Flondor gilt bis in die Gegenwart des heutigen Rumāniens als einer der "Schmiede" der großen Einheit (Făuritorii Marii Unirii). Sammlung K. Scharr

als weitgehend zutreffend gesehen werden. ${ }^{33}$ Die neue Verfassung des Königreiches vom 20. MärZ 1923 markierte schließlich die offizielle Beendigung des administrativ-politischen Vereinigungsprozesses und setzte nunmehr auch die bis dahin in der Bukowina angewandten österreichischen Gesetze endgültig außer Kraft. ${ }^{34}$ Der Kommissionspräsident beendete seine Tätigkeit kurz zuvor. ${ }^{35}$ Nistor hingegen nahm weiterhin aktiv seine

33 Michelson 2011, Nistor, 131; v. Drunen meint über Nistor ähnlich: Nistor war, »like Iorga and others, much more a political activist than an unbiased historian «; v. DRUNEN 2015, Bunch, 71; dazu Chioveanu 2010, Istoricii.

34 Das trotzdessen weiterhin vorhandene sandere Denken in weiten Teilen der Bukowiner Gesellschaft bestimmte auch ihr Verhältnis zur Zentralregierung in Bukarest. Das zeigten beispielhaft die Parlamentswahlen von 1926 und ihre Erinnerung daran: »Aber nirgends in Rumänien waren die Wahlen so frei wie in Czernowitz. Keine Regierung wagte es, die üblichen Wahltricks - Wahlschwindel anzuwenden. Es war eine zur Freiheit erzogene Bevölkerung «; REIFER 1947, Mayer, 121ff. (hier 123).

35 Nistor 1928, Ani, 13 
gestaltende Rolle als Politiker wahr und übte auch in den folgenden Jahren beträchtlichen Einfluss auf die Entwicklung der Bukowina aus.

\section{Rumänische Kirche - Rumänischer Fonds?}

Der generelle territoriale wie gesellschaftliche Vereinigungsprozess, in den Rumänien mit Ausgang des Ersten Weltkrieges eingetreten war, stellte die orthodoxe Kirche vor eine Reihe von Schwierigkeiten. Dabei galt es unter anderem, vier Traditionslinien kirchlicher Verwaltung und kirchlichen Selbstverständnisses vor dem Hintergrund ebenso vieler heterogener staatlich-regionaler Kontexte (Siebenbürgen, Bukowina, Bessarabien und Regat) zusammenzuführen. ${ }^{36}$ Der Zielpunkt einer einheitlichen autokephalen rumänisch orthodoxen Landeskirche mit einem zu schaffenden Patriarchat ${ }^{37}$ ließ sich aus der Perspektive des Jahres 1918 indes nur unscharf bestimmen. Zudem berührte gerade dieses Hinarbeiten auf eine Neukonstituierung der Kirche grundlegende Fragen bisher in den angesprochenen historischen Räumen zum Teil völlig unterschiedlich erfahrener Autonomie. Die Kirchenhierarchie der Bukowina hatte sich - mit Ausnahme von Metropolit Morariu-Andrievici - immer wieder gegen eine breit verstandene Laienbeteiligung in Form eines Kirchenkongresses ausgesprochen, jedoch zugleich eine größere Autonomie, vor allem eine weitgehende Verfügungsgewalt über die Religionsfondsmittel vom Staat eingefordert.

Aus der spezifischen Czernowitzer Perspektive lagen für das Vereinigungsprojekt konkrete Vorschläge vor, die im Wesentlichen von einer dezentralen Kirchenorganisation Rumäniens in Form von gleichberechtigten Metropolien ausgingen. Darin hatten die beteiligten Czernowitzer Theologieprofessoren auch einen Eparchialkongress, lediglich mit einem konsultativen Charakter ausgestattet, vorgesehen. ${ }^{38}$ Derlei Vorschläge der Regionen fanden jedoch nur begrenzt Eingang in Realität wie Umsetzung der Bukarester Kirchenpolitik. Schon die 1923 eingeführte Staatsverfassung ließ eine sich immer mehr abzeichnende Zentralisierung innerhalb der orthodoxen Kirche in Rumänien deutlich erkennen.

\footnotetext{
36 BRUSANOWSKI 2011, Kirchenordnungen.

371919 hatte man den Bischof von Caransebeş, Miron Cristea, zum Metropoliten von Bukarest gewählt und ihn damit gleichzeitig zum Metropolitprimas der rumänisch orthodoxen Kirche erhoben; MANER 2007, Multikonfessionalität, 177.

38 ȘESAN 1920, Proiect; BRUSANOWSKI 2007, Autonomia, bes. 145-158.
} 
Biserica ortodoxa română fiind religia marei majorităti a Românilor este biserica dominantă a Statului român [...] In tot Regatul României biserica creștină ortodoxă va avea o organizare unitară cu participarea tuturor elementelor ei constitutive, clerici și mireni. ${ }^{39}$

Obwohl die Orthodoxie im Königreich mit der Verfassung von 1923 offiziell nicht den Status eine Staatskirche, sondern die Stellung einer >dominanten Kircher besetzte ${ }^{40}$, gestalteten sich die Verflechtungen zwischen beiden Institutionen auf politischer wie gesellschaftlicher Ebene in der Verfassungsrealität in gegensätzliche Richtungen. ${ }^{41}$ Wenngleich sich die offizielle Kirche während der beiden Jahrzehnte aus verschiedenen Gründen weitgehend vor direkter Teilnahme am politischen Geschehen distanzierte, so waren doch nicht wenige ihrer amtstragenden Mitglieder auf jeweils individuelle Weise in der Politik aktiv. ${ }^{42}$ Zudem ist im Rahmen der Identitätsdiskussion des Staates nach 1918 der Beitrag der rumänischen Orthodoxie zur Sakralisierung des nationalen Selbstbildnisses von nicht geringer gesellschaftlicher Bedeutung. ${ }^{43}$ Die Autonomie der Kirche und ihr Verhältnis zum Staat bedurften steter Neuverhandlungen und unterlagen letztlich politischen Weisungen bzw. Einflussnahmen seitens der Parteien, welche ihre Anliegen je nach aktueller Machtkonstellation mehr oder weniger durchzusetzen vermochten. ${ }^{44}$

Die zunächst aus historischen Gründen noch angestrebte (Wieder-)Vereinigung der Bukowiner Erzdiözese mit der Kirchenprovinz von Jassy traf in Czernowitz auf heftigen Widerstand seitens der Kirchenführung. Bukarest musste das Projekt schließlich fallen lassen. Die Metropolie (in ihrer neuen Bezeichnung: Mitropolia Bucovinei și Hotinului) blieb in veränderter rechtlicher Form und innerhalb neuer Territorialgrenzen bestehen. Sie setzte sich aus zwei Eparchien zusammen, dem Erzbistum von Czernowitz und dem durch Gebietserweiterung hinzugekommenen Suffraganbistum Hotin (heute ukr. Хотин), das vor 1918 zu Bessarabien (Russländisches Kaiserreich) gehört hatte. ${ }^{45}$

39 Monitorul Oficial Nr. 282 v. 29.III.1923, Constituţia României; Art. 22 [http://www.cdep.ro/pls/legis/ legis_pck.htp_act_text?idt=1517].

40 STAA B 2011, Kultur, 119; im Regat hatte die Orthodoxie den Status einer Staatskirche; Maner 2007, Multikonfessionalität, 59.

41 Symbolisch für diese während der Zwischenkriegszeit verschwimmenden Grenzen zwischen Orthodoxer Kirche und Staat in Rumänien, aber auch die versuchte Distanz zwischen Kirche und Parteipolitik führt Minai die `Roten Handschuhe` des Patriarchen an, die dieser als Mitglied des Senats bei der Eröffnung der Parlamentssession im Herbst 1929 trug; MIHAI ${ }^{2}$ 2014, Biserica, 77 f.

42 BĂNIC̊̃ 2007, Biserica, 248.

43 StАав 2011, Kultur, $26 \mathrm{f}$.

44 MAner 2007, Multikonfessionalität, $64 \mathrm{f}$.

45 Foaia ordonanțelor și comunicărilor Consistoriului arhiepiscopesc în afacerile Arhidiecezei ortodoxe a Bucovinei Nr. 7 v. 28.V.1925, Lege pentru organizarea Bisericii ortodoxe Române, Art. 2. 1937 wurde auf Initiative von Metropolit Visarion hin die orthodoxe (nicht unierte) Diözese der Marmarosch 

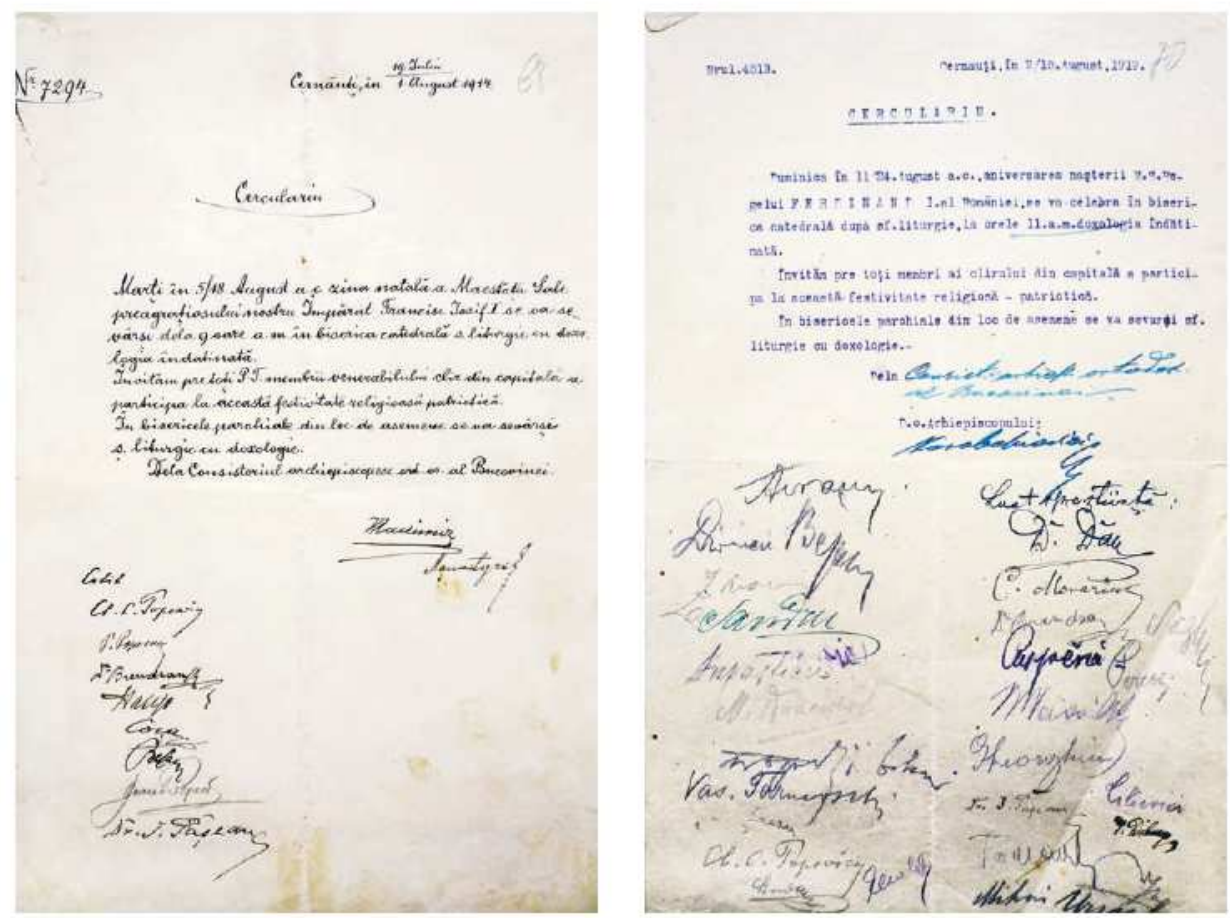

Abb. 43 und 44: Kontinuitäten einer Epochengrenze. Zwei Zirkulare des Metropoliten Repta, jeweils unterzeichnet von führenden Klerikern und Mitgliedern des Konsistoriums. Bereitete man sich für den 18. August 1914 mit einer Feiertagsliturgie (festivitate religioasă patriotică) noch auf den Geburtstag Kaiser Franz Josephs vor, so lädt der idente Text für den 24. August 1919 (allerdings schon ohne die ruthenischen Konsistorialräte) zu einer ebenso religiös patriotischen Feier anlässlich des Geburtstages von König Ferdinand ein. ${ }^{46}$

Die Autonomiefrage berührte die Landeskirche der Provinz auch in anderer Hinsicht, zumal sich die Kirchenhierarchie mit Kriegsende zunehmend politisch aktiv gezeigt hatte und jetzt ziemlich konkrete Erwartungen mit der Wiedervereinigung verband. Während der letzten Wochen des Jahres 1918, in einer von sich überschlagenden Ereignissen bewegten Öffentlichkeit, spielten hochrangige Vertreter der orthodoxen Kirche der Bukowina eine zentrale Rolle. So versammelte sich am 27. Oktober die Constituanta im rumänischen Nationalhaus der Landeshauptstadt. Deren Eröffnung leitete Konsistorialrat Be-

(mit Sitz in Sighet) neu gegründet und in der Folge (bis zur kirchlichen Neustrukturierung 1950) zu einem weiteren Suffraganbistum der Bukowiner Metropolie; LISNIC 2013 Puiu, sowie VAlenciuC 2001, Ierarhi.

46 DACZ $_{320 / 2 / 2783}$, fol. 68 u. 70 . 
jan, der in einem ersten Schritt Flondor, mit breiter Zustimmung der Anwesenden, zum Präsidenten dieser Versammlung vorschlug. Nach einer - in der Diktion Nistors - emotionsgetragenen Sitzung kam es schließlich zum feierlichen Absingen der rumänischen Nationalhymne. Danach trat der damals bereits über achtzigjährige Konsistorialrat Bejan auf den Balkon des Hauses, der auf den Ringplatz vor dem Rathaus hinausführt, und paraphrasierte, auf die Situation hin zugeschnitten, vor der versammelten Menge eine Bibelstelle: "Nun befreie, o Herr deinen Diener, denn meine Augen haben die Erlösung meines Volkes gesehen. ${ }^{47}$ Die Kirchenleitung der Bukowina sah mit dem eingeleiteten Prozess der Wiedervereinigung nicht nur ihre in entscheidenden Teilen seit langem gehegten nationalen Anliegen erfüllt, sondern erwartete von der Bukarester Regierung zusätzlich eine weiter als bisher gefasste Autonomie. Dementsprechend erklärte Minister Flondor als eine seiner ersten Amtshandlungen im Februar 1919 de jure (de facto war es ohnedies nicht mehr zu einer Teilung gekommen) die noch im vorangegangenen August vom österreichischen Landespräsidenten verordnete Teilung der gr.-orient. Diözese in zwei nationale Sektionen umgehend als nichtig. Das Statut von 1869 wurde damit vorläufig wieder eingesetzt, die eben erst geschaffene Stelle eines zweiten (ruthenischen) Konsistorialarchimandriten und der Posten eines Erzpriesters der gr-orient. Kirche zu St. Nikolaus in Czernowitz aufgehoben. ${ }^{48}$ Kurz darauf dekretierte Flondor auf Basis von Beschlüssen einer Versammlung des rumänischen Klerus vom 26. Dezember 1918 die Rückstellung des gesamten Kirchenvermögens in die unmittelbare Verwaltung der orthodoxen Erzdiözese. Erzbischof Repta interpretierte diesen Schritt zugunsten seines Amtes wie folgt:

Als oberster Chef der Verwaltung des Bukowiner Religionsfondes behalte ich [Wladimir v. Repta, Anm. K.S.] mir jene Kompetenzen vor, welche gemäß den in Kraft stehenden Instruktionen der österreichischen Ministerien für Ackerbau, für Kultus und Unterricht und für öffentliche Arbeiten vorbehalten waren. ${ }^{49}$

47 "Acum slobozește Doamne pe robul tău, căci îmi văzură occhii mântuirea neamului«; NisToR 2010 (1928), Unirea, $57 \mathrm{ff}$ (15ff.); zuletzt Economu 2011, Unirea, 16f.; Lukas, 2. Kapitel 30-32: "Denn meine Augen haben das Heil gesehen, / 31 das du vor allen Völkern bereitet hast, 32 ein Licht, das die Heiden erleuchtet, /und Herrlichkeit für dein Volk Israel «; freundliche Auskunft Assoz.-Prof. Priv.-Doz. Dr. Bruno Niederbacher SJ, Institut für christliche Philosophie der Leopold-FranzensUniversität Innsbruck v. 7.VII.2016.

48 Monitorul Bucovinei v. 19.II.1919, Fasc. 13 Lege și ordonanțe Nr. 16, Ordonanța Ministrului delegat al Guvernului Român din 18 Faur 1919 relativă la organizarea consistoriului archiepiscopesc ort. al Bucovinei; DACZ 320/3/86, fol. 47, Administraţia Bucovinei Ministrul delegat al Guvernului Român an Repta v. 18.II.1919; Czernowitzer Morgenblatt Nr. 246 v. 22.II.1919, 2, Die Organisation des Konsistoriums.

49 Flondor an Repta v. 2.IV.1919, sowie (Zitat) Repta an Generaldirektion der Güter; nach Czernowitzer Morgenblatt Nr. 294 v. 23.IV.1919, 2, Uebergang des Bukowiner gr.-or. Religionsfondes in die 
Tab. 11: Kirchenhierarchie der gr-orient. Erzdiözese Bukowina per 20. Mai $1919^{50}$

\begin{tabular}{|l|l|l|}
\hline \multicolumn{1}{|c|}{ Stand } & \multicolumn{2}{|c|}{} \\
\hline Arhiepiscop şi Mitropolit & & Vladimir Repta \\
\hline \multirow{2}{*}{ Arhimandritul de scaun } & $\begin{array}{l}\text { Episcop de Rădăuți } \\
\text { per 3. Juli 1919 }\end{array}$ & Ipolit Vorobchievici \\
\hline Protopopul catedralei & & Dr. Ipolit Tarnavschi \\
\hline \multirow{3}{*}{ Consilieri consistoriali } & & Zaharie Voronca \\
\cline { 2 - 3 } & & Constantin Morariu \\
\cline { 2 - 3 } & & Dimitrie Dan \\
\cline { 2 - 3 } & & George Şandru \\
\hline \multirow{2}{*}{ Consilieri onorari } & Profesor de Teologie & $\begin{array}{l}\text { Archimandrit Clementie C. } \\
\text { Popovici }\end{array}$ \\
\cline { 2 - 3 } & Profesor de Teologie & Dr. Ştefan Saghin \\
\hline
\end{tabular}

Die damit ausgedrückte Zuweisung der Verfügungsgewalt über das Fondsvermögen auf den amtsführenden Metropoliten widersprach dem unter österreichischer Herrschaft bislang gültigen Usus einer geteilt wahrgenommenen Kontrolle. Diese Entscheidung bekommt vor dem Hintergrund der kirchlichen Situation Altrumäniens, wo 1864 das Kirchenvermögen gänzlich säkularisiert worden war, eine nicht unwesentliche Facette realökonomischer innerkirchlicher Machtverhältnisse. Allerdings blieb diese Situation nur von kurzer Dauer. Mit dem Rücktritt Flondors annullierte Nistor diesen Akt des entmachteten politischen Gegners. Damit griff er de facto auf das erste Statut von 1786 zurück und übertrug das Patronatsrecht über den Religionsfonds an den rumänischen König. Die Verwaltung der Religionsfondsforste und der Domänen unterstellte Nistor dem Ackerbauministerium, die Bergwerke des Fonds administrierte vorläufig das Ministerium für öffentliche Arbeiten. ${ }^{51}$ Argumentativ ging man dabei von zweierlei Positionen aus: Einerseits handle es sich bei den Werten des Religionsfonds um das Eigentum einer rgottgefällig-kulturellen Stiftung (fundaţione pios-cultural). Andererseits sei die kanonische Begründung der kirchlichen Verwaltung von Kirchengut mittlerweile veraltet und die Interessen der Kirche wären nunmehr mit jenen des rumänischen Staates konform. Zudem hätte der damalige

Verwaltung der ort.-or.[sic!] Kirche; Monitorul Bucovinei Fasc. Nr. 10 v. 24.I.1919, Ordonanţa Nr. 109 v. 23.I.1919; nach ClipA 2006, Fondul, 62. Ein Teil der Dokumente ist bei SÂRBU 1931, Reflexiuni im Anhang abgedruckt.

50 ŞESAN 1928, Ani, 95 .

51 Nistor an Repta v. 26.IV.1919; abgedruckt in SÂRBU 1931, Reflexiuni, Anexa 4. 
Bischof von Radautz seine Rechte an den Gütern ohnedies gegen ein jährliches Salär abgetreten und darüber hinaus habe bereits davor, unter dem Fürsten Cuza Vodă, eine Säkularisierung der Klostergüter stattgefunden, woraus im Hinblick auf die Wiederherstellung des ursprünglichen Rechtes wiederum ein nachvollziehbarer Anspruch des Staates darauf abzuleiten sei. Insgesamt legte die Gruppe um Nistor jedoch zumindest in der Öffentlichkeit Wert darauf, den »desaströsen Einfluss der Politik « auf die Kirche zurückdrängen zu wollen. ${ }^{52}$ Trotz eines unmittelbaren Protestes des Erzbischofs war diese Entscheidung nicht mehr rückgängig zu machen. ${ }^{53}$ Die bis zum Zusammenbruch des Habsburgerreiches übliche Konsenspraxis einer weitgehenden Übereinstimmung bzw. eines Akkordierens von Beschlüssen zwischen den Staatsbehörden und den kirchlichen Organen wurde damit von Nistor gezielt geschwächt und später gänzlich aufgehoben. ${ }^{54} \mathrm{Im}$ Februar 1922 dekredierte der König, bei gleichzeitiger Bestätigung der grundsätzlich kirchlichen Eigentumsrechte, die Übertragung der Religionsfondsagenden an das Landwirtschaftsministerium. ${ }^{55} \mathrm{Als}$ direkte Folge politischer Instabilität der Bukarester Regierungen verschoben sich bis zur Schaffung einer einheitlich organisierten orthodoxen Kirche des Königreiches 1925 die ministeriellen Verantwortlichkeiten nochmals. ${ }^{56}$ So setzte die Regierung Octavian Goga - die Liberalen unter Bratiănu fanden sich auf der Oppositionsbank wieder - kurzzeitig Repta als alleinig bevollmächtigten Leiter des Religionsfonds ein. ${ }^{57}$ Das Vermögen der Kirche verwaltete der Kirchenkongress, in den sowohl Vertreter des Erzbischofs als auch des Konsistoriums mit Sitz und Stimme entsandt wurden. Erstmals war diese neu geschaffene Institution 1921 zusammengetreten. Sie bestand aus 60 Mitgliedern, davon zwei Drittel Laien. Staatssekretär Dr. Dori Popovici, zugleich Präsident der Vereinigungskommission, nahm die Bukarester Interessen als Regierungsvertreter im Kongress wahr. ${ }^{58}$ Außerdem behielt sich der König vor, die zwei weltlichen und zwei kirchlichen Beisitzer - auf Vorschlag des Erzbischofs - per Dekret zu ernennen. Dem Kongress wiederum oblagen zwar alle un-

52 Glasul Bucovinei Nr. 128 v. $25 . I V .1919$, Titelseite, Trecerea fondului religionar in administraţia mitropolitului [Dr. Vasile Bodnărescu]; Nr. 473 v. 21.VII.1920, Titelseite, Discuțiuni asupra administrării averiolor fondului [Dr. Aurel Morariu]; Bodnărescu ebenso wie Aurel Morariu gehörten als Gefolgsleute zum engeren Kreis um Nistor; HAUSLEITNER 2001, Rumänisierung, 142.

53 Repta an Nistor v. 14./27.IV.1919; SÂRBU 1931, Reflexiuni, Anexa 5.

54 Valenciuc 2010, Fondul, 58.

55 Decret Regal Nr. 838 v. 14.II.1922; Dimitrovici 1922, Istoricul.

56 Entsprechend wurde die endgültige Regelung der Religionsfondfrage bis zur gesetzlichen Klärung der Kircheneinheit aufgeschoben; Adresa Ministerului Cultelor și Artelor v. 12.IV.1921 Nr. 20375 sowie deciziunea Consiliului de Miniștri v. 31.III.1921 Nr. 606; ANB 2719 108/1921, fol. 68, Extras din Protocolul ședinței solenare Consistoriului arhiepiscopesc ortodox al Bucovinei v. 20.IV./3.V.1921.

57 Goga an Repta Nr. 20375 1/24 1921; nach SÂrBU 1931, Reflexiuni, Anexa 9.

58 Telegraful Român Nr. 39 v. 14./27.V.1921, 3 ; Nr. 48 v. 18.VI./1.VII.1921, 1; nach BrUSANOWSKI 2007, Autonomia, $157 \mathrm{f}$. 
mittelbaren administrativen Fondsangelegenheiten, es bedurfte jedoch für die Umsetzung einmal gefasster Beschlüsse stets der Zustimmung des ministeriellen Delegierten. ${ }^{59}$ Bukarest sicherte sich darüber hinaus Einfluss in Diözesanfragen, indem die Konsistorialräte und - in der Form neue installierte - Diözesaninspektoren ebenfalls auf Vorschlag des Kultusministeriums bestellt werden mussten. ${ }^{60}$

Ende des Jahres 1925, bereits auf Basis des nationalen Kirchenorganisationsgesetzes, erhielt der Religionsfonds (nunmehr mit seiner neuen Bezeichnung Fondul bisericesc ortodox român al Bucovinei) eine gesetzliche Regelung, die sich in ihrer Grundstruktur (theoretisch) nur wenig von der bisherigen Handhabung seit 1919 abhob (vgl. Abb. 45). Ausgehend vom neuen Organisationsgesetz erlangte die Landeskirche bedeutend größere Befugnisse als dies während der österreichischen Herrschaft der Fall gewesen war. Dem 18-köpfigen Eparchialrat (Consiliul Eparhial) als Exekutivorgan der Eparchialversammlung (Adunarea Eparhială, Kirchenkongress) unterstand unmittelbar die Fondsdirektion (Administrația generală a Fondului bisericesc ortodox român al Bucovinei). Den Vorsitz übernahm der Bukowiner Metropolit. Innerhalb des Rates verteilte sich die Zuständigkeit - nach den verschiedenen Fragen der Religionsfondsverwaltung - auf drei getrennte Sektionen (administrativ-kirchlich, kulturell, ökonomisch). Die Ministerien für Landwirtschaft und Domänen sowie für Kultus übten - wie schon während der Übergangsjahre - eine Kontrollfunktion aus. ${ }^{61}$ Versammlung und Rat kontrollierten damit faktisch den Fonds. Tatsächlich neu war hingegen die strukturell darin verankerte Verbindung der Institution des Bukowiner Religionsfonds zum allgemeinen orthodoxen Religionsfonds Rumäniens. Artikel 8 des Regulaments sah vor, dass nach Abdeckung aller im Regelwerk definierten Ausgaben die verbleibenden Überschüsse in diesen Zentralfonds zu überweisen waren. ${ }^{62}$ Damit hatte sich das Bukarester Patriarchat indirekt Zugang zur Bu-

59 ANR-B Fonds 2719 pach. 100-1921, fol. 1, Ferdinand I. v. 26.XII.1921, București, Statul organic pentru Congresul Bisericesc al Arhidiecezei ortodox române din Bucovina, Art. 5, 21 u. 24; ANR-B Fonds 2719 pach. 108-1921, fol. 28, Ferdinand I. v. 15.IV.1921, Art. 1.

60 ANR-B Fonds 2719 pach. 106-1921, fol. 1 u. 6ff., Direcţiuneă generală pentru Culte an Minister Nistor, Cernăuţi v. 9.VII.1921. In seiner Begründung gegenüber Repta schreibt Nistor von der Bukowina als "orthodoxer Oase«, als etwas im Verband der Habsburgermonarchie nach Volk und Konfession Fremdem, umgeben von einer "konfessionell wie national feindlichen Konzeption «.

61 ANR-S inv. 35-I pach. 4-1925, Foaia ordonanțelor şi comunicărilor Consistoriului arhiepiscopesc în afacerile Arhidiecezei ortodoxe a Bucovinei, Decret Nr. 82 v. 28.XI.1925, Regulament pentru organizarea şi funcţionarea Consiliului eparhial al Arhiepiscopiei ortod. rom. în Cernăuţi. Das Kultusministerium - eine wichtige Schaltstelle zwischen Kirche(n) und Staat, die seit 1921 bestand - wurde in dieser Form 1930 aufgelöst und 1934 neu eingerichtet.

62 ANR-S inv. 35-I pach. 4-1925, Foaia ordonanțelor și comunicărilor Consistoriului arhiepiscopesc în afacerile Arhidiecezei ortodoxe a Bucovinei Circular Nr. 80 v. 26.XI.1925, Regulament, Art. 3, 4, 7 und 8; DACZ 320/2/57 Regulament 1925. 


\section{Verwaltung des Religionsfonds 1925}

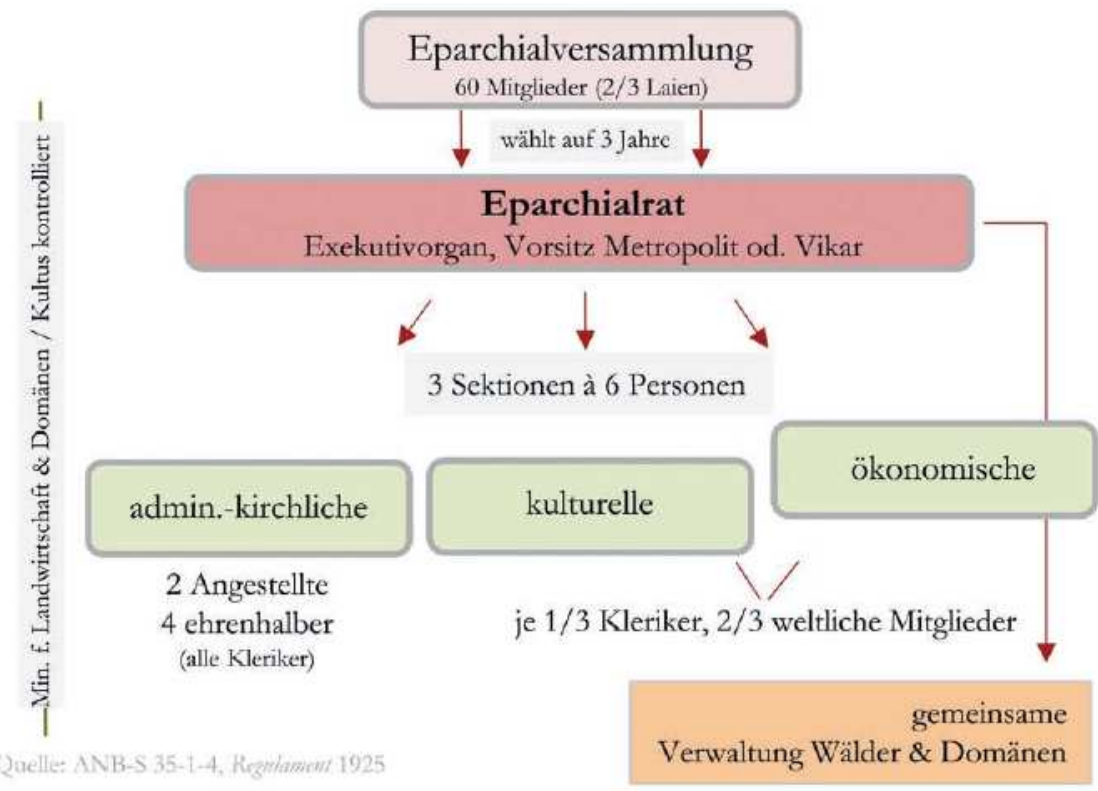

Abb. 45: Schematische Darstellung. Organisation des Bukowiner Religionsfonds 1925.

kowiner Institution und ihrem wirtschaftlichen Potential gesichert. Umgekehrt blieben die realen Einflussmöglichkeiten der Czernowitzer Erzdiözese auf die Gesamtkirche des Königreiches vergleichsweise bescheiden. So sah das orthodoxe Kirchenorganisationsgesetz von 1925 zwar einen nationalen Kirchenkongress vor, in den allerdings jede Eparchie zwei Kleriker und vier weltliche Vertreter entsenden konnte. ${ }^{63}$ Die Parteigänger um Nistor hefteten sich diese Entwicklung selbstgefällig auf ihre Fahnen, kritisierten jedoch Iorga. Die Partidul Național hatte sich ursprünglich gegen die Artikel 39, 40 und 41 ausgesprochen und wollte die Fondsmittel für die gesamte historische Moldau zugänglich machen ${ }^{64}$ Die Glasul Bucovinei glaubte indes im neuen Kirchenorganisationsgesetz eine große Hilfe für die Bauern der Bukowina auszumachen, die nunmehr vom Reichtum des Fonds profitieren würden. Es sei schließlich dem Einsatz von Minister Nistor zu verdan-

63 Foaia ordonanțelor și comunicărilor Consistoriului arhiepiscopesc în afacerile Arhidiecezei ortodoxe a Bucovinei Nr. 7 v. 28.V.1925, Lege pentru organizarea Bisericii ortodoxe Române, Art. 6.

64 Glasul Bucovinei Nr. 1799 v. 5.IV.1925, Titelseite u. 2, Fondul Bisericesc; Partidul național împotriva fondului bisericesc al Bucovina. 
ken, dass der Fonds weiterhin ausschließlich der Bukowina zugutekomme, daher auch der entscheidende Annex bei dessen Umbenennung: ein rumänisch-orthodoxer Kirchenfonds (Fondul bisericesc ortodox român) jedoch al Bucovinei. ${ }^{65}$

Für diese Konstruktion praktisch entscheidend jedoch war die damit möglich gewordene Entsendung einflussreicher und für konkrete Beschlussfassungen letztlich ausschlaggebender Persönlichkeiten (vor allem von Laien) durch Bukarest und die regierenden Parteien sowie ihr erst dadurch gesicherter, dauerhaft politischer Einfluss auf die Kirchengremien.

Insgesamt erlangte die rumänisch orthodoxe Kirche während der Zwischenkriegszeit formal zwar ein Mehr an Autonomie, diese wurde allerdings durch führende Politiker und ihre Parteien über Interventionen von vornherein entschieden ausgehöhlt. ${ }^{66}$ Die mehrfachen Querverbindungen zwischen Nistor als zuständigem und mit weitgehenden Rechten ausgestatteten Regionsminister wie auch als Politiker (mit eigener Partei und Zeitungen) zu Bukarester Regierungskreisen einerseits, sowie die Absicht eines gezielt vorbereiteten Kontrollzugriffes auf die Mittel des Bukowiner Religionsfonds andererseits, lassen sich in der personellen Besetzungen der Kirchengremien mitunter deutlich erkennen. So leitete Vasile Marcu etwa am Beginn der 1920er Jahre die Filiale der rumänischen Nationalbank in Czernowitz und fungierte zeitgleich als Regierungsemissär im Religionsfonds. ${ }^{67}$ Die Familie Brătianu wiederum stellte nicht nur während dieser Periode mehrfach den Ministerpräsidenten des Königreiches, sondern war darüber hinaus an der Nationalbank mit erheblichen Kapitaleinlagen beteiligt. Überdies traten, verursacht durch die häufigen Wechsel in Regierung und Parlament, zahlreiche Gesetze per Verordnung in Kraft, ohne irgendeine parlamentarische Kontrolle durchlaufen zu haben.

Der greise und mit der Gesamtsituation des Wandels sichtlich überforderte Metropolit Repta konnte dieser Entwicklung nichts entgegensetzen. Zudem hatte der Erzbischof zu offensichtlich für Flondor Partei ergriffen und sich damit wohl den Missmut Nistors zugezogen. ${ }^{68}$ Das Fondsvermögen geriet in Folge zum Spielball der Politik, repräsentiert vor allem in der Person Nistors. Anfang des Jahres 1924 zog sich Wladimir von Repta von den Amtsgeschäften der Metropolie zurück. ${ }^{69}$ Zwischenzeitlich führte

65 Glasul Bucovinei Nr. 1804 v. 11.IV.1925, Titelseite, Noua lege a fondului bisericesc; Nr. 1839 v. 30.V.1925, Titelseite, Fondul bisericesc [Vasile Grecu].

66 MIHAI $^{2} 2014$, Biserica, 61 u. 70; MANER 2001, Voraussetzungen, 448.

67 Hausleitner 2001, Rumänisierung, 144.

68 VALENCIUC 2010, Fondul, 61f.; Valenciuc bezieht sich auf ein Zirkular Reptas, das im Foaia Oficială (Nr. 9 v. 24.XII.1918/6.I.1919, 42) veröffentlicht worden war und den auf die Metropolie beschränkten Verwendungszweck des Religionsfondsvermögens besonders hervorhob.

69 Trotz der gesundheitlichen Angeschlagenheit von Repta äußerte sich im >langen` Rücktritt des Erzbischofs offenbar eine schwelende Rivalität zu Minister Nistor. Einige Kreise protestierten gegen 


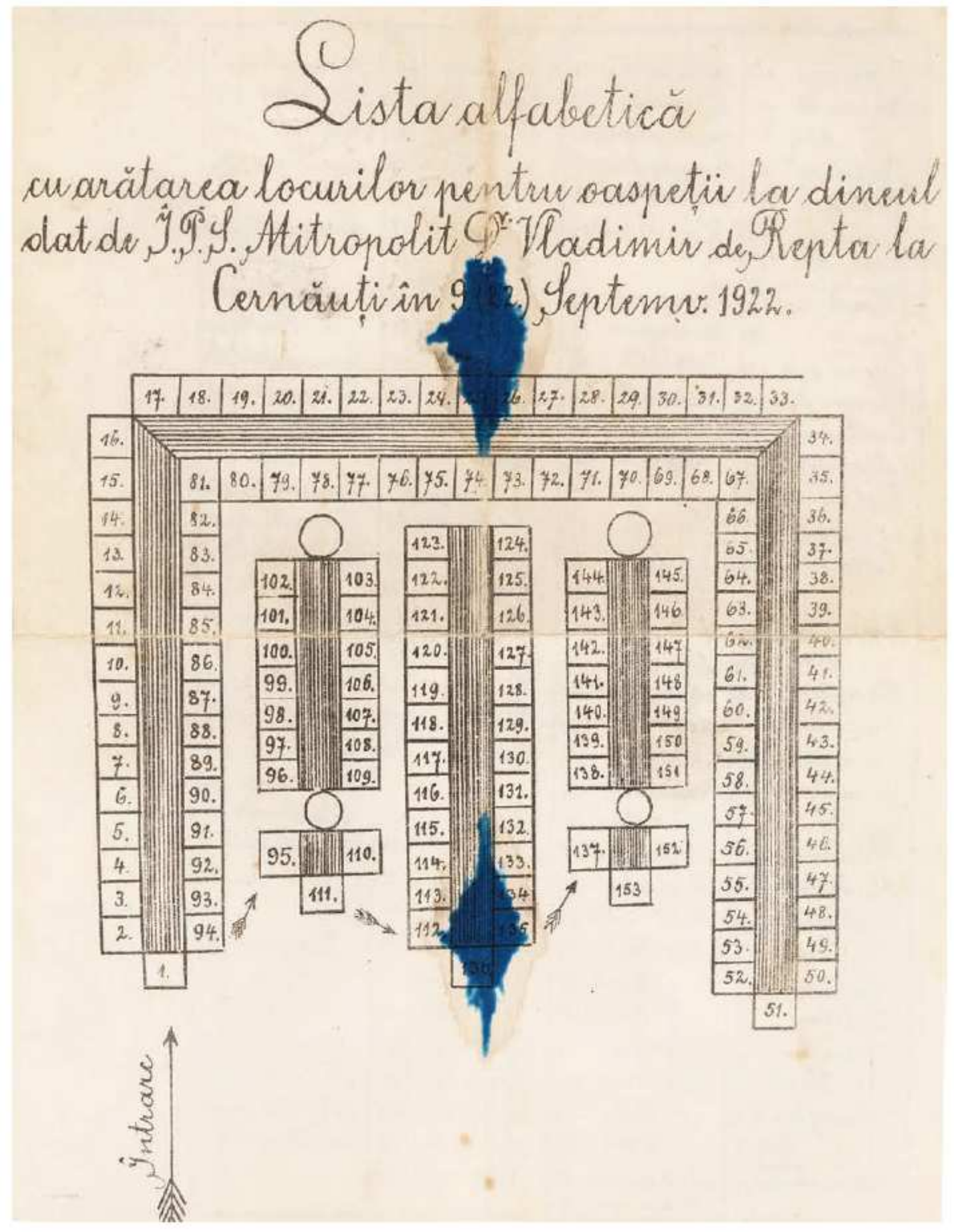

Abb. 46 und 47: Tafelplan und Gästeliste. Metropolit Repta lädt am 9./22. Sep. 1922 zu einer offiziellen Feierlichkeit in die Residenz. Gleich neben dem Erzbischof (25) die Plätze für Minister Nistor (26) sowie seine Gattin (23). Flondor (73) sitzt Nistor gegenüber, flankiert vom Archimandriten Vorobchievici (72), dem Theologen Şesan (78) und Puiu (76). Letzterer war seit 1921 Bischof von Argeş und wird 1935 Nachfolger von Cotlarciuc. Der unmittelbare Nachfolger Reptas, Cotlarciuc (41), sitzt noch am Tafelrand. Sammlung K. Scharr. 


\begin{tabular}{|c|c|c|c|}
\hline 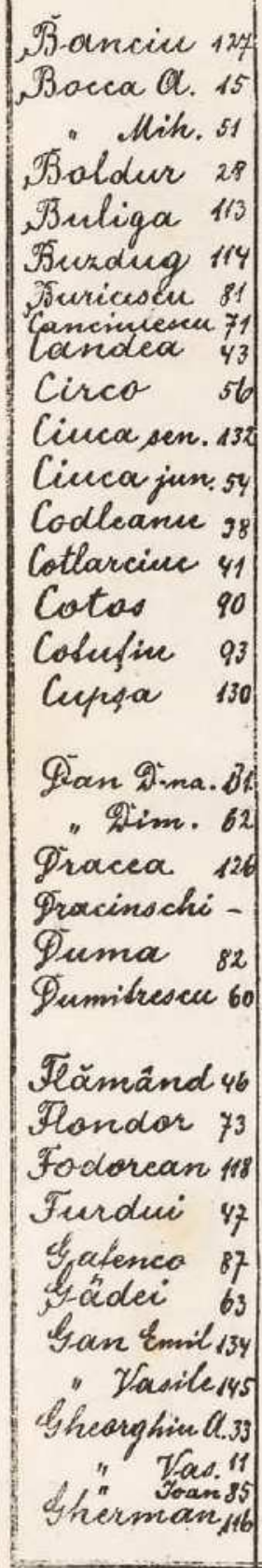 & 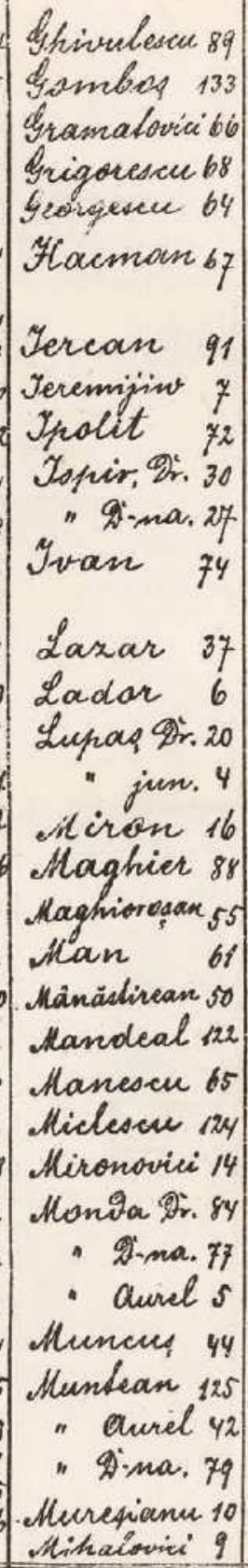 & 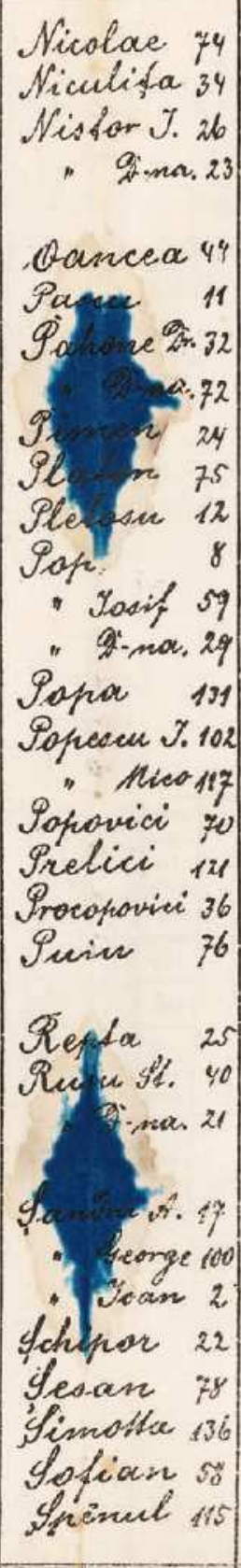 & 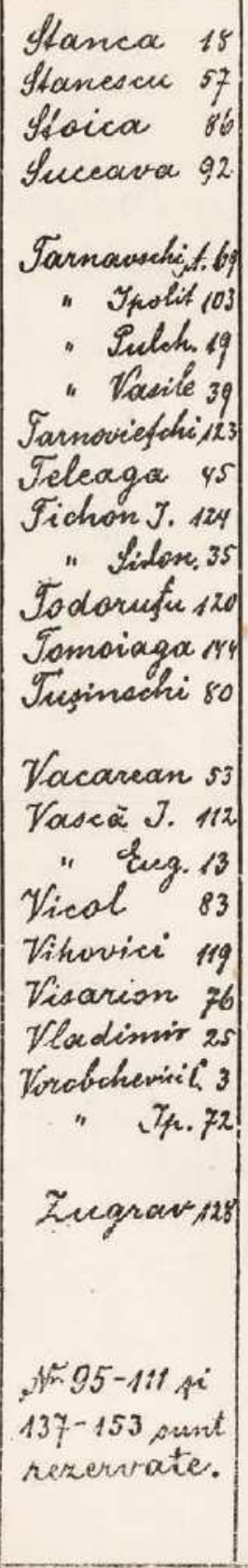 \\
\hline
\end{tabular}


diese stellvertretend der Bischof von Radautz, Archimandrit Ipolit Vorobchievici (18751937). ${ }^{70}$ Noch im selben Jahr wurde, abweichend von der bislang gängigen Nachfolgepraxis, der Theologe Nectarie Cotlarciuc als Erzbischof von Czernowitz und Metropolit der Bukowina (Arhiepiscop al Cernăuților și Mitropolit al Bucovinei, 1924-1936) inthronisiert. $^{71}$

\section{În biserică nu e politică: Konsolidierungsversuche versus Dauerkrise}

Vom neuen Erzbischof Cotlarciuc war für die Zentralisten um Nistor nur geringer Widerstand zu erwarten gewesen, zumal er zu diesen schon zuvor ein gewisses Naheverhältnis unterhalten hatte. ${ }^{72}$ In einer gedruckten umfangreichen Verteidigungsschrift deckte der ehemalige Leiter der Güterdirektion Georgi Sârbu unter Beibringung einer Reihe von Dokumenten die überaus enge personelle Verflechtung der Religionsfondsverwaltung und der Liberalen Partei sowie die angeblich regelmäßige Begünstigung ihrer Mitglieder bei Verpachtungen, der Vergabe von Verträgen u. ä. auf. ${ }^{73}$ Die Liberalen

diesen Akt, indem sie darin "keinen Ausdruck des freien Willens eines alten Hierarchen, sondern ein direktes Produkt gezielten Einflusses « zu erkennen glaubten; ANR-B Fonds 2719 pach. 11-1924, fol. 12, Președintele Organizatiei Part. Poporului din Bucovina, Cernăuţi v. 6.XI.1924.

70 Czernowitzer Morgenblatt Nr. 1656 v. 22.I.1924, 2, Wechsel in der Leitung der Czernowitzer Metropolie; Vorobchievici hatte schon 1918 - unter österreichischer Herrschaft - interimistisch die Diözese geleitet. Das offizielle Rücktrittsschreiben selbst ist mit 14.X.1924 datiert. Repta belegte bis zu seinem Tod am 24.IV.1926 weiterhin einige Zimmer der Residenz und bezog ein Holzdeputat von $216 \mathrm{~m}^{3}$ aus dem Religionsfonds. Beides hatte ihm das Kultusministerium unter Zustimmung Nistors auf Ansuchen hin bewilligt; ANR-B Fonds 2719 pach. 11-1924, fol. 45ff.; DACZ 988/1/229 Repta an Minister Nistor v. 14.X.1924.

71 Geb. als Nicolae Cotlarciuc in Stulpikani (rum. Stulpicani) in der Bukowina, Studium der Theologie und Philosophie in Wien, Bonn und Würzburg, seit 1901 Gymnasialprofessor in Czernowitz, 1901 bis 1915 Direktor der Universitätsbibliothek Czernowitz, nach dem Tod seiner Frau (1918) als Nectarie Übertritt in den Mönchsstand, 1915-1923 Professor für praktische Theologie an der Universität Czernowitz, 1923 zum Bischof von Cetatea Albă /Ismail geweiht; nach SATCO 2004, Enciclopedia, $277 ; 1907$ hatte Cotlarciuc u.a. eine Studie über Stifterrecht und Kirchenpatronat in der Bukowina veröffentlicht; CoTLARCIUC 1907, Stifterrecht.

72 In einer Stellungnahme gegenüber der Glasul Bucovinei betonte Cotlarciuc, dass die Priesterschaft der Bukowina grundsätzlich nichts dagegen hätte, wenn die Fondsadministration durch den rumänischen Staat ausgeübt werden würde, wenn dabei gleichzeitig einem Kirchenkongress die übergeordnete Kontrollfunktion zukäme. Eine völlige Säkularisierung des Fonds lehnte Cotlarciuc hingegen ab; Glasul Bucovinei Nr. 77 v. 8./21.II.1919, 2, Fondul religionar al biserici din Bucovina. Convorbire cu d. Profesor N. Cotlarciuc; Nr. 85 v. 17.II./2.III.1919, 2, Fondul religionar [Dr. N. Cotlarciuc].

73 SÂRBU 1931, Reflexiuni, XVIIff.; Sârbu hatte 1919 kurzzeitig als Güterdirektor den Fonds geleitet und dann in der Folge 1926-1930 als technischer Konsulent des Religionsfonds den Eparchialrat beraten; ders. 1931, Reflexiuni, XXV. 
versuchten diese Vorwürfe als "famoses Pamphlet " herunterzuspielen, ${ }^{74}$ hatte man sich doch schon die Jahre zuvor wiederkehrend von derartigen Anschuldigungen distanziert, und sie betonten im Gegenzug die sautonome Fondsverwaltung ‘ durch den Eparchialrat. ${ }^{75}$ Tatsächlich hatten sich mit der administrativen Umgestaltung in Folge der neuen Kirchenverfassung auch die Aufgaben der ehemaligen Güterdirektion verändert, die nunmehr in ihrer Leitung unmittelbar diesem Rat Rechenschaft schuldig war. Wiederum war es Nistor, der dem Bukowiner Eparchialrat als führendes Mitglied ebenso angehörte wie dem Nationalen Kirchenkongress. ${ }^{76}$ Trotz dieser für die Liberalen günstigen Ausgangsposition schien es ihrem Zeitungsorgan wichtig, darauf hinzuweisen, dass der Religionsfonds keineswegs ausschließliches Eigentum der Eparchie sei. ${ }^{77}$ Völlig ungeachtet der sich bereits anbahnenden Schwierigkeiten, die sich im Verlauf des Jahres durch die auch auf die Bukowina durchschlagende Weltwirtschaftskrise verstärkten, bot der Bericht des Erzbischofs anlässlich der Eparchialversammlung noch im Frühjahr 1929 zumeist nur Positives, vor allem im Hinblick auf die Leistungen des Religionsfonds. Nistor betonte darüber hinaus in einer Grundsatzrede, dass die Kirche unpolitisch sei (În biserică nu e politică). ${ }^{78}$ Eine gewisse Entfremdung zwischen der Landbevölkerung der Bukowina und dem Religionsfond mussten jedoch selbst die Liberalen eingestehen. Verantwortlich dafür machte man allerdings den Umstand, dass der neue Geist der rumänischen Gesetze nach 1918 noch nicht überall durchgedrungen sei. In bewährter Weise suchte man die Schuld bei "fremden Elementen«, vor allem "jüdischen «, die dem nach wie vor gezielt entgegenarbeiten würden. ${ }^{79}$

74 Voloșciuc 1932, Darea, 7; Glasul Bucovinei Nr. 3675 v. 16.XII.1931, Titelseite, Salvatori Fondului bisericesc; Nr. 3676 v. 17.XII.1931, Titelseite u. 2, Din isprăvile unui consulent tehnic al Fondului bisericesc; Nr. 3680 v. 25.XII.1931, 6, Salvatorii fondului bisericesc. Isprăvile d-lor Homiuca şi Holca; darin kritisieren die ,Nistoristen « massiv die Idee der Reorganisation des Religionsfonds, wie sie von den ehemaligen Mitarbeitern Cornel Homiuca, Georgi Sârbu und Leon Holca aufgebracht worden war.

75 Glasul Bucovinei Nr. 2861 v. 22.I.1929, 2, Din activitatea Consiliului Eparhial; Nr. 2870 v. 5.III.1929, Titelseite, Campania contra fondului bisericesc.

76 Aurel Morariu, Problema fondului bisericesc ort.-rom. al Bucovinei. In: Nistor 1928, Zeci, 127; Deschiderea Adunării Eparhiale Cuvântarea I.P.S.S. Mitropolitului Nectarie. In: Glasul Bucovinei Nr. 2398 v. 2.VI.1927, Titelseite; Adunărea Eparhială [Grigore Ciobanu]. In: Glasul Bucovinei Nr. 2399 v. 4.VI.1927, Titelseite.

77 Glasul Bucovinei Nr. 2666 v. 15.V.1928, o.S., Ître autonomie şi birocratism.

78 Glasul Bucovinei Nr. 2936 v. $30 . I V .1929$, Titelseite, Cuvântarea I.P.S.S. Mitropolitului Nectarie ținută la deschiderea Adunarii Eparhiale in ziua de 28 Aprilie a.c.; Nr. 2938 v. 3.V.1929, 2, Ședința de inchidere. Cuvântarea d-lui Ion I. Nistor.

79 Tома 1927, Fundul, 2 u. 17; Iorgu Toma wurde von Zeitgenossen etwas süffisant als »sehr wertvolles und der Liberalen Partei treu ergebenes« Mitglied der Liberalen Partei beschrieben; TIMU 1933, Dezastrul, 13 . 


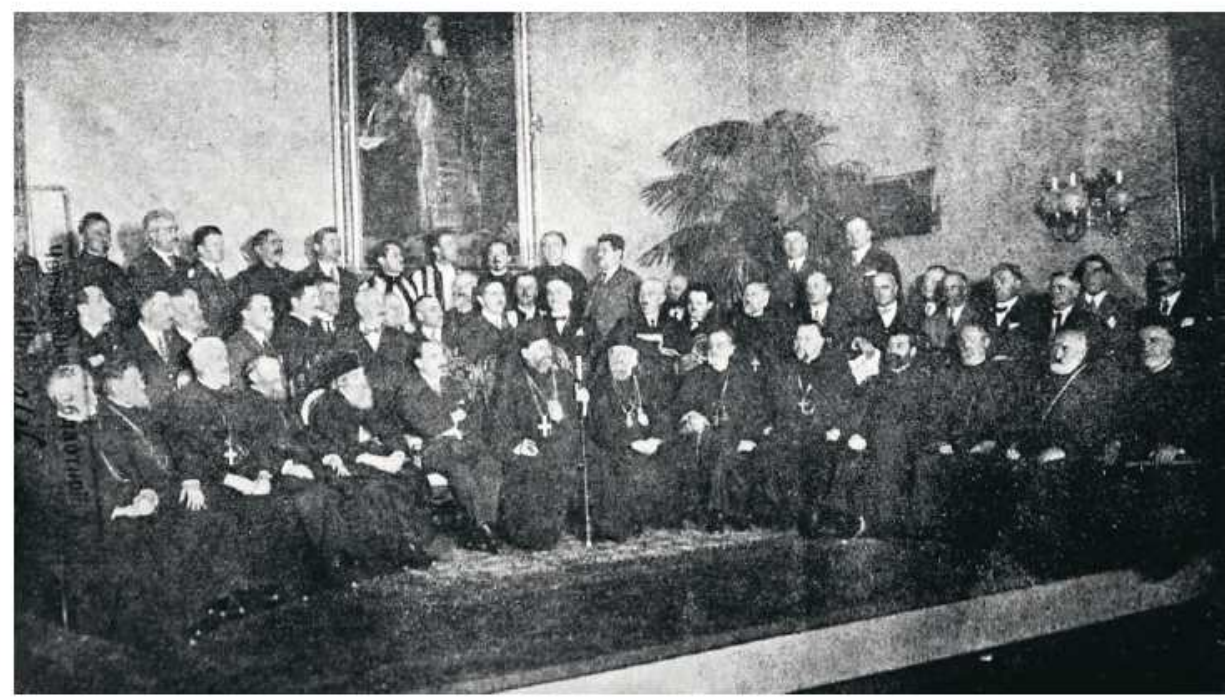

Abb. 48: Eparchialversammlung der Bukowina, Dezember 1931. Nistor sitzt in der ersten Reihe, rechts neben dem Metropoliten Cotlarciuc. ${ }^{80}$

Nistor hatte in diesem Fall allen Grund, das Unpolitische der Kirche herauszustreichen und zugleich auf den Regionalismul bucovinean gegenüber der Bukarester Regierung zu bestehen. Obwohl er dieses Konzept als Zentralist bei Flondor noch entschieden zurückgewiesen hatte, schien es ihm jetzt, da die gegnerische Nationale Bauernpartei (Partidul NaționalȚărănesc) ${ }^{81}$ die Regierung stellte (1928-1931), umso mehr von Bedeutung, den »Import « von Beamten aus Siebenbürgen, die über keinerlei Lokalkenntnisse in der Bukowina verfügen würden, zu hinterfragen. ${ }^{82}$ Zudem bezichtigte man seinerseits die Ţărănisten, die Verstaatlichung des Religionsfonds betreiben und damit bewusst die vom Staat garantierte Autonomie der Kirche untergraben zu wollen. ${ }^{83}$ Ungeachtet der von den Nistoristen selbstverständlich strikt zurückgewiesenen Anschuldigungen einer eigennützigen Politisierung des Religionsfonds sowie den vorerst noch in Abrede gestellten, dringend nötigen strukturellen Reformen, musste man trotzdem auch von dieser Seite ökonomische Schwierigkeiten, etwa durch den Preisverfall bei Holz sowie fehlende Investitionsmittel, eingestehen. ${ }^{84}$

8o Nistor 1932, Ani, 17.

81 Zur Geschichte der Nationalen Bauernpartei vgl. MülLeR 2001, Agrarpopulismus.

82 Glasul Bucovinei Nr. 3635 v. 28.X.1931, Titelseite, Regionalismul bucovinean [Ion Nistor].

83 Glasul Bucovinei Nr. 3114 v. 13.XII.1929, Titelseite, Autonomia bisericii în primejdie. Inconsiştența național-țărănistă pregătește etatizarea fondului bisericesc.

84 Glasul Bucovinei Nr. 3595 v. 6.IX.1931, Titelseite, Greutăţile dela Fondul bisericesc. 
Die Reform von 1925 hatte alle den Fonds betreffenden Kompetenzen und die gesamte Verantwortung seiner Verwaltung dem Eparchialrat übertragen (vgl. Abb. 45). In der Kritik der Zeitgenossen führte der damit begründete strukturelle Mangel an einer einheitlich wie fachlich versierten Leitung des Religionsfonds zu einer schleichenden Politisierung der Institution. ${ }^{85}$ Reformvorhaben und von der Eparchialversammlung eingesetzte Kommissionen zu seiner Reorganisation zeitigten real nur wenig Wirkung. Dabei rekurrierte man regelmäßig auf die mittlerweile nahezu inhaltsleere Aussage von der Autonomie der Kirche »im Dienst der Idee nationalen orthodoxen Glaubens«. Deutlich war hingegen der Einfluss der Parteien wie ihrer Vertreter spürbar. So forderte etwa die Eparchialversammlung, Fondsgelder künftighin nicht mehr bei ausländischen sondern ausschließlich bei jenen Banken zu deponieren, die "rumänische Interessen « vertraten, womit freilich wiederum auch die Brătianu-Familie davon profitiert hätte. ${ }^{86}$ Mit dem Machtwechsel in Bukarest erhielten die Vorwürfe gegen die bisher dominierende Politik der Liberalen allerdings erstmals breiteren Raum im öffentlichen Diskurs. Nistor wies man seitens der Bauernpartei nicht nur die Schuld für die Situation in der Bukowina zu. Er hätte vielmehr systematisch die Politisierung der gesamten Öffentlichkeit der Region betrieben (a introdus politicanismul în toate domeniile publice din Bucovina). Den Liberalen wäre es nach 1918 gelungen - so die Ţărănisten weiter - die ehemalige Bukowiner Landesbank, welche unter anderem die Einlagen aus dem Religionsfonds zu verwalten und daraus land- wie forstwirtschaftliche Kredite zu vergeben hatte, nunmehr völlig unter ihren Einfluss zu bringen. Eine effektive wie unabhängige Kontrolle der Forste, des Fonds und seiner übergeordneten Verwaltung, den Eparchialrat, der mit Liberalen durchsetzt war, fehlte aus Sicht der Bauernpartei gänzlich. ${ }^{87}$ Schon zwei Jahre zuvor unterstrich man in diesem Lager, wohl als Spitze gegenüber Nistor gedacht, absichtlich die Leistungen von Flondor als Regionsminister für den Religionsfonds während der unmittelbaren Nachkriegszeit. ${ }^{88}$ Die Reaktion darauf ließ nicht lange auf sich warten. Die Glasul Bucovinei protestierte lauthals gegen den »Terror" der Bukarester Maniu-Regierung sowie - in retardierender Argumentation - ihre vermeintlichen Angriffe auf die Autonomie der Bukowiner Eparchie. ${ }^{89}$ Die Ţărănisten wollten mit einer staatlichen Direktverwaltung des Fonds - so die Nistoristen - dem sich immer

85 PAșcovicı 1936, Contribuțiuni, 27.

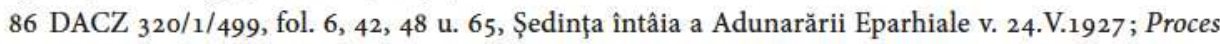
verbal, şedința din sesiunea ordinară a Adunării Eparhiale v. 26.V.1927, sowie v. 13.XI.1927; DACZ 320/1/7414, Senatsrede Metropolit 1927.

87 Alvirescu 1929, Probleme, 10 u. $25 \mathrm{ff}$.

88 Cuvântul Țărănimii Nr. 3 v. 16.I.1927, Titelseite, Contractele fondului bisericesc.

89 Glasul Bucovinei Nr. 3124 v. 29.XII.1929, Titelseite, Terorarea guvernului față de Eparhia Bucovinei; Uneltirele uniţilor contra bisericii ortodoxe. 
mehr abzeichnenden Desaster offensichtlich entgegensteuern. Dagegen formierte sich der unerwartet heftige Protest von Gläubigen der Diözese. ${ }^{90}$ Man adressierte in dieser Angelegenheit selbst ein Telegramm an den König und bat ihn, das Erbe des Religionsfonds für die Eparchie zu beschützen. ${ }^{91}$ Es bleibt jedoch zu vermuten, dass die Liberalen um Nistor auch diesen Protest gezielt initiiert hatten, um die Bukarester Regierung in der Öffentlichkeit zu desavouieren. Selbst wenn diese Anschuldigungen letztlich von politischen Gegnern mit ihren jeweils eigenen Interessen formuliert wurden, so waren sie dennoch nicht völlig aus der Luft gegriffen. Das mehr und mehr in politischen Sackgassen festgefahrene System der Religionsfondsverwaltung wäre zu diesem Zeitpunkt bereits gründlich zu reformieren gewesen. Die Ende 1929 ausgebrochene Wirtschaftskrise legte seit der Gründung des Fonds in dieser Form noch nie dagewesene strukturelle Mängel offen. So geriet der Fonds 1932 beispielsweise selbst bei der Anweisung von Gehältern an Geistliche der Bukowina regelmäßig in monatelangen Zahlungsverzug. ${ }^{92}$ Gerade diese Mängel aber stellte Nistor stets wortreich in Abrede. Für ihn arbeitete die Fondsverwaltung in keinster Weise schlechter als während der österreichischen Periode und die Kritik der Regierung, so Nistor, würde nur bekannt stereotype Phrasen hervorbringen..$^{93}$

Als am 4. Juli 1935 der amtierende Metropolit Cotlarciuc verstarb, wurde der Weg für die Neuwahl eines Nachfolgers frei. Am 17. Oktober desselben Jahres entschied sich die Synodalversammlung, Visarion Puiu ${ }^{94}$ - der seit 1923 als Bischof von Hotin in Bălți residierte - zum neuen Metropoliten der Bukowina zu bestellen. Die feierliche Inthronisierung fand am 10. November 1935 in der Kathedrale von Czernowitz statt. Damit war erstmals ein Geistlicher zum Metropoliten der Bukowina geweiht worden, der selbst

9o DACZ 988/1/71, Aufruf der Gläubigen an den Eparchialrat, mit seinen Abgeordneten gegen die Reformvorlage der Bukarester Regierung einzutreten v. 25.III.1933.

91 ANR-B Fonds 2720 pach. 71-1933, fol. 24, Telegramm orthodoxer Gläubiger der Bukowiner Eparchie an König Carol II. v. 25.III.1933; die Gläubigen hatten sich dazu zuvor im Synodalsaal der Residenz in Czernowitz versammelt.

92 Timu 1936, Dezastrul, 5.

93 Nistor 1932, Ani, 5 u. 25.

94 Am 27.II.1879 in Pașcani, einem Ort in der nordwestlichen Moldau, als Sohn eines Zugsführers geboren, studierte Theologie in Roman, Iași, Bukarest und an der geistlichen Mohila-Akademie in Kiew. Er erhielt seine ersten Weihen 1905, stieg 1908 zum Archimandriten auf; 1909 zum Vikar der Eparchie Untere Donau ernannt, leitete von 1909-1918 das theologische Seminar zum Hl. Andreas in Galaţi. 1921 ging er zunächst als Bischof nach Argeș (Muntenien) und 1923 in die neu gegründete Diözese von Hotin, einem Suffraganbistum von Czernowitz; biographische Angaben nach VALENCIUC 2004, Puiu, 41f., ANR-B Fonds 823 Visarion Puiu, Prefaţă (1995); PUIU 2014, Însemnări, Addenda. 
nicht aus dieser Region stammte. Für Puiu brachte der Wechsel vom bessarabischen Hotin (und zuvor von Argeș, das sich in der Ärmlichkeit der Diözese nur wenig von Hotin unterschied) nach Czernowitz eine Reihe von persönlich tiefgreifenden Veränderungen.

După examenu dat într-o eparhie totalemente săracă, voia lui Dumnezeu a fost să trec în alta bogată, cea mai bogată din Ortodoxie, și din episcopiile fără locuinţă să ajung să am cea mai frumoasă reșidinţă, cum este palatul mitropolitan din Cernăuţi, în cara am locuit patru an și jumătate. $^{95}$

Obwohl Außenstehender, hatte Puiu nach kurzem die Situation in der Bukowina gründlich erfasst und in Nistor die Graue Eminenz der Politik ausgemacht. Schon wenige Tage nach der feierlichen Inthronisation wurde ihm die angespannte Situation in der Diözese vollauf bewusst. Misstrauisch beäugte man Puiu in Czernowitz als "Regățean", als jemandem aus dem Altreich. ${ }^{96}$ Der Czernowitzer Historiker Teodor Bălan zerstreute in einem persönlichen Brief an Puiu noch vor der eigentlichen Wahl offensichtliche Bedenken, das Amt des Metropoliten anzunehmen und versuchte den "Regionalismus der Bukowiner Priesterschaft « zu relativieren. Puiu - so Bălan weiter - werde durch seine »Energie und Intelligenz« überzeugen können. Allem voran, gleich einer Mahnung, unterstrich Bălan einleitend zu seinem Schreiben die außerordentliche Bedeutung des Religionsfonds, der »das ganze ökonomische Leben in der Bukowina beherrscht «. ${ }^{97}$

Für den neuen Metropoliten stellten sich in Czernowitz folglich, anders als bisher gewohnt, zweierlei zentrale Aufgaben: die spirituelle Führung der Diözese als auch die Leitung und Verwaltung ihres beträchtlichen Vermögens. Nach ersten Treffen und Besprechungen mit Funktionären der Kirchen- wie Fondsverwaltung musste er jedoch enttäuscht ein »Umfeld, das am Vergangenen gefesselt, erstarrt und decouragiert « war, feststellen. Zudem scheuten die meisten Funktionäre aus Angst vor Drohungen der Politiker, Reformen anzupacken. ${ }^{98}$ Gerade letzteres wollte Puiu hingegen energisch angehen. ${ }^{99}$ Noch vor der Wahl des Metropoliten hatten die Liberalen um Nistor sich selbstsicher die Reformagenden des Fonds ans Revers geheftet und losungshaft eine

95 [Nach den Weihen in eine völlig arme Gemeinde eingetreten, war es der Wille Gottes, in eine andere reiche, die reichste der Orthodoxie zu wechseln, und von einer Diözese ohne Obdach in einer so wundervollen Residenz anzukommen, wie es der Metropolitanpalast von Czernowitz ist, in welchem ich viereinhalb Jahre wohnte]; PUIU 2014, Însemnări, 92.

96 VALenCIUC 2004, Puiu, 43.

97 ANR-B Fonds 823 pach. 44-1935, Bălan an Puiu, Czernowitz v. 11.X.1935.

98 PUIU 2014, Însemnări, 94-100.

99 Glasul Bucovinei Nr. 4705 v. 8.XII.1935, Titelseite, Cuvântul Mitropolitului. 
Steigerung der Produktivität eingefordert. Nistor feierte man dabei gar als wiederholt erfolgreichen Retter des Fonds. ${ }^{100}$ Die strengeren Kontrollen, die sowohl der Landwirtschaftsminister als auch der Patriarch gelegentlich einer 1932 abgehaltenen Parlamentsdebatte angekündigt bzw. verlangt hatten ${ }^{101}$, bewirkten indes bislang wenig, sodass eine grundsätzliche Reform kaum mehr zu umgehen war.

Mit der Reform von 1935 verschaffte sich Metropolit Visarion ein unmittelbares Kontroll- und Entscheidungsrecht über den Fonds (vgl. Abb. 49). Damit verfügte er als Erzbischof über eine entscheidend aktivere Rolle als zuvor und konnte direkt in die Geschickte des Fonds eingreifen. Das Statut von 1925 hatte dem Eparchialrat als Exekutivorgan noch die direkte Verfügungs-, Kontrollgewalt sowie die Budgethoheit über den Fonds zugespielt. Der Eparchialversammlung (i.e. dem Kirchenkongress) war man regelmäßige Rechenschaft schuldig gewesen. Ihr hatte auch die endgültige Beschlussfassung über Hypotheken, den Verkauf von Produkten etc. zugestanden. ${ }^{102}$ Mit dem neuen Regulament besaß der Eparchialrat zwar weiterhin ein Entschlussfassungsrecht, das auf einer einfachen Mehrheit beruhte. Beschlüsse mussten jetzt jedoch durch den Metropoliten approbiert werden. Ausdrücklich verwies der Artikel 12 darauf, dass keine Entscheidung des Rates umgesetzt werden darf, bevor nicht der Metropolit seine dezidierte Zustimmung erteilt habe. Artikel 13 legte fest, dass der Kirchenkongress über das jährliche Budget zu befinden und nach Prüfung den Rat zu entlasten hatte. Ein weiterer wichtiger Punkt, der die Stellung Puius als Erzbischof im Vergleich zur vorangegangenen Regelung erheblich stärkte, lag in der völlig umgekrempelten Verwaltungsorganisation des Religionsfonds selbst. Diese wurde jetzt wieder von einem eigenen Güterdirektor, der unter Aufsicht des Metropoliten stand und auch von diesem bestellt wurde, geführt. Der Eparchialrat konnte hier nur administrativ unterstützend wirken. Sechs Organe dirigierten und kontrollierten ab sofort den Religionsfonds: Metropolit, Direktionskomitee, Güterdirektor, Kommission für Vorschläge und Nominierungen, Disziplinarkommission, Inspektoren mit Kontrollfunktionen sowie eine Pensionskasse. Die auf drei Jahre bestellte Vorschlagskommission formierte sich wiederum aus Güterdirektor, Mitarbeitern der Fondsverwaltung, einem Referenten des Eparchialrates und einem direkt durch den Metropoliten delegierten Anwalt. Der Metropolit musste zudem die Kommission in ihrer Zusammensetzung bestätigen. Die Bestimmungen von 1925 hatten ursprünglich den Einfluss des

100 Glasul Bucovinei Nr. 4482 v. 22.I.1935, o.S., Intensificarea productiei Fondului; Nr. 4545 v. 21.IV.1935, Titelseite, $A$ două salvare a Fondului Bisericesc.

101 Timu 1933, Dezastrul, 23 f.

102 ANR-S inv. 35-I, pach. 4-1925, Foaia ordonanţelor și comunicărilor Consistoriului arhiepiscopesc în afacerile Arhidiecezei ortodoxe a Bucovinei Nr. 80 v. 10.XII.1925, Art. 7, 8 u. 10; Monitorul Oficial Nr. 261 v. 26.XI.1925, unterzeichnet vom Kultusminister und vom Metropoliten Puiu; MitropoLiA Bucovinei 1936, Regulament, 8, Art. 12 u. 13. 
Metropoliten noch auf ein einfaches Vorschlagsrecht für das Administrationspersonal reduziert. ${ }^{103}$ Der vormals mächtige Eparchialrat und die Eparchialversammlung verloren, ausgehend von ihrem bisherigen Einfluss, auf allen Ebenen beträchtlich an Macht, die nun dem Metropoliten zufiel. Damit war eine, der kurzen Periode unter Repta nach 1918 ansatzweise vergleichbare Situation eingetreten, die Puiu theoretisch mit weitgehenden Kompetenzen ausstattete. Praktisch verfügte diese doch tiefgreifende Strukturreform nicht über die nötige Zeit, sich in der Realität voll entfalten zu können. Zugleich verordnete die Religionsfondsverwaltung - wohl auch vor dem Hintergrund der allgemeinen Radikalisierungstendenzen im Königreich - für alle ihre Funktionäre ein strenges Politikverbot, das jedwede Mitgliedschaft in einer Partei oder Bewegung untersagte. ${ }^{104}$

Diese Situation war jedoch keineswegs im Sinne von Nistor. Als Reaktion warf man dem Metropoliten seitens der Nistoristen vor, mit seinem Reformvorhaben das konstitutionelle Prinzip der Kirche zu zerstören. Die neue Fondsverwaltung kenne zudem nur mehr ein Prinzip: »Totul trebue schimbat, reorganizat, răsturnat!! « ${ }^{105}$ Plötzlich stand für die Liberalen wieder das Wohlergehen der Landbevölkerung hoch im Kurs, deren Vernachlässigung man der gegenwärtigen Bukowiner Kirchenhierarchie und ihrer Fondsverwaltung ankreidete. Das neue Organisationsgesetz trat mit Ende November 1937 in Kraft. ${ }^{106}$ Daran konnten selbst die heftigen parlamentarischen Interventionen und persönlichen Vorwürfe der Liberalen nichts mehr ändern. Einen Monat später legte Nistor sein Kontrollmandat über den Religionsfonds mit der Begründung der Machtausweitung des Staates gegenüber dem Fonds sowie der Belastung seiner anderwärtigen Verpflichtungen nieder. ${ }^{107}$

In politischer Hinsicht vertrat Metropolit Visarion durchaus großrumänische Ideen. Die Bilder des österreichischen Kaisers, die er allenthalben in der Bukowina bei Geistlichen und manchen Funktionären seiner Kirche antraf, erschienen ihm geradezu symbolisch für das "morbide Phänomen « des Gestrigen. In gleicher Weise empfand er im Religionsfonds allerorts den ungesunden Einfluss »kapitalistischer Juden «. ${ }^{108}$ Während

103 Mitropolia Bucovinei 1936, Regulament, 10, Art. 14 u. 19; ANR-S inv. 35-I pach. 4-1925, Foaia ordonanțelor şi comunicărilor Consistoriului arhiepiscopesc în afacerile Arhidiecezei ortodoxe a Bucovinei Nr. 81 (Regulament interior) v. 28.XI.1925, Art. 3, Absatz 6.

104 DACZ $_{302 / 2 / 3511}$ AFBis an Consiliul Eparhial v. 5.III.1938. Funktionäre aller Religionsfondseinrichtungen mussten das entsprechende Gesetz (Decretul-lege Nr. 87o, Monitorul Oficial Nr. 39 v. 17.II.1938) persönlich zur Kenntnis nehmen. Es basierte auf einer allgemeinen Aufforderung des 1937 in Kraft getretenen Strafgesetzbuches, dass Geistliche sich vom politischen Leben der Parteien fernzuhalten hatten; MANER 2001, Voraussetzungen, 456.

105 [Alles muss ausgewechselt, reorganisiert, umgeworfen werden!]; MORARIU 1937, Apărarea, 31, 45 u. 68. 106 Monitorul Oficial Nr. 269 v. $20 . X I .1937$

107 Glasul Bucovinei Nr. 523 o v. 1.I.1938, 3, D-l profesor Ion I. Nistor a despus mandatul de control la Fondul bisericesc.

108 PUIU 2014, Însemnări, 94, 97, 99 u. 104. 


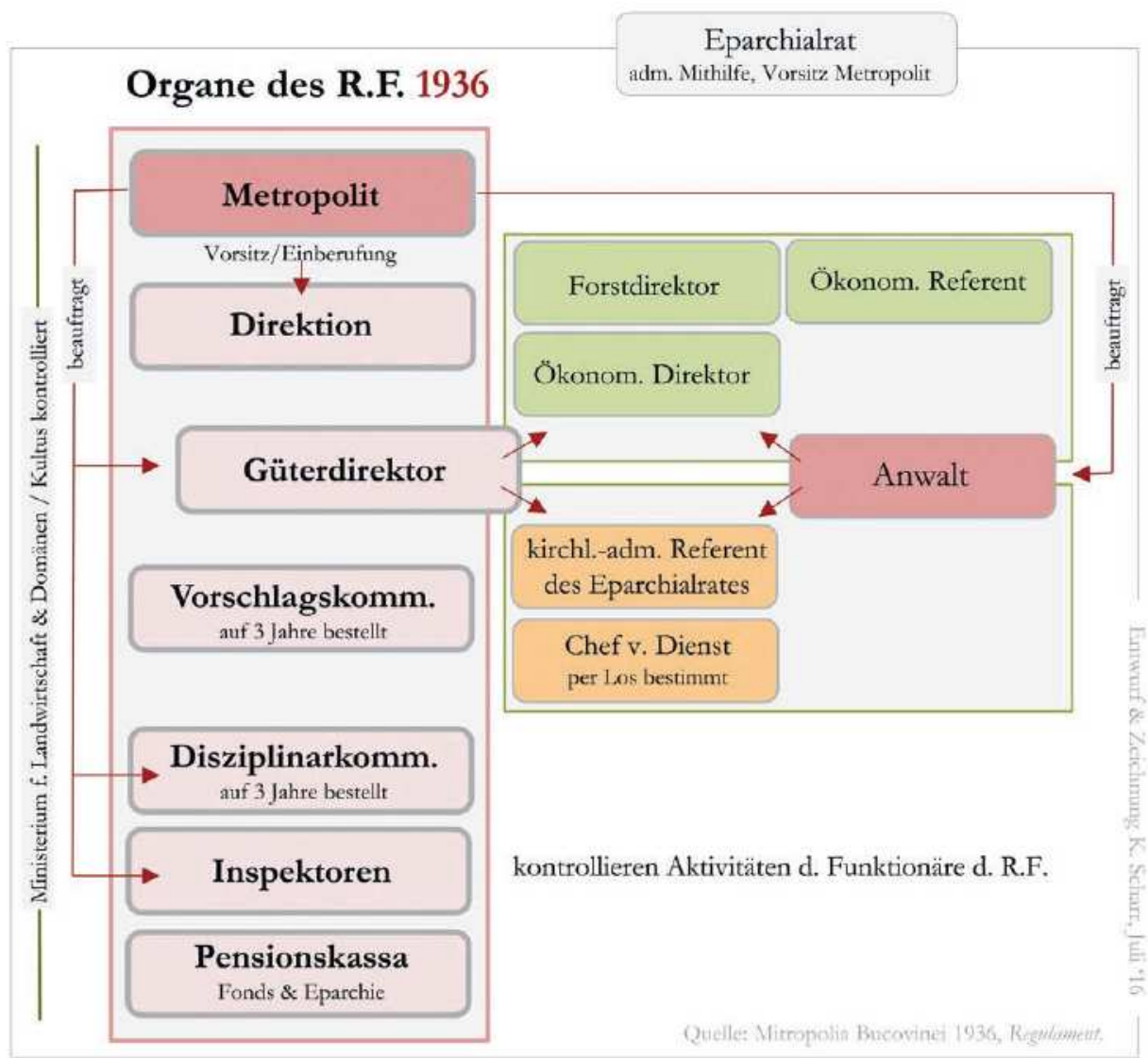

Abb. 49: Schematische Darstellung. Organisation des Bukowiner Religionsfonds 1936.

seiner Amtszeit als Metropolit der Bukowina wurden Anordnungen getroffen, die - in Übereinstimmung mit den staatlichen Vorschriften - eine Rumänisierung der Familiennamen des Kirchenpersonals widerspruchslos empfahlen. ${ }^{109}$ In gleicher Weise stand man seitens der Erzdiözese allen Bitten um Zulassung der ukrainischen Sprache in den Dörfern für den Gottesdienst sowie im Religionsunterricht ablehnend gegenüber und erachtete diese als schiere Provokation gegenüber dem rumänischen Staat. ${ }^{110}$

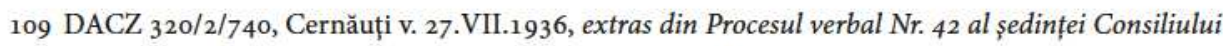
eparhial ortodox al Bucovinei, Secția Ia v. 21.VII.1936, ad Nr. 43; HAUSLeIt NER 2001, Rumänisierung, 224-233.

110 Mehrere ukrainische Dörfer im Norden der Bukowina hatten diesbezüglich eine Bitte an den Erz- 


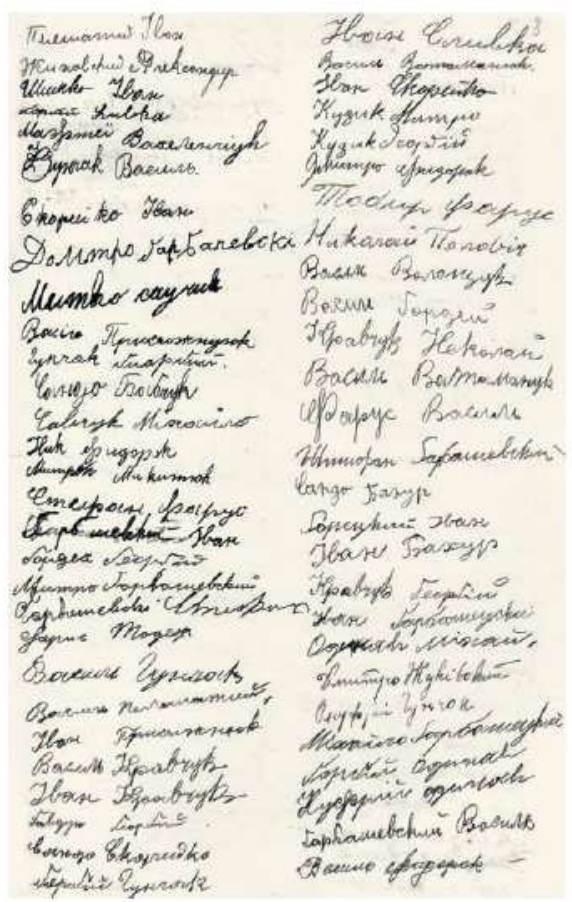

Abb. 50: Unterschriften von Gläubigen aus der Gemeinde Borăuți in Kyrillisch. In der in Rumānisch verfassten Bittschrift an den Metropoliten baten die Bewohner darum, für den Gottesdienst und religiöse Unterweisungen doch die ukrainische Sprache verwenden zu dürfen. Die wenigsten von innen beherrschten die neue Staatssprache ausreichend. ${ }^{111}$

Das Interesse am Religionsfonds gab Nistor allerdings nicht auf. Im Hintergrund agitierte er weiterhin gegen die Amtsführung von Puiu und arbeitete gezielt auf dessen Entlassung hin. ${ }^{112}$ Metropolit Puiu ersuchte im Sommer 1939 das Kultusministerium, eine Kommission mit jeweils einem Delegierten des Kultus-, des Landwirtschafts- und des Finanzministeriums einzurichten, um die seitens anonymer Kritiker gegen die Religionsfondsverwaltung öffentlich vorgebrachten Anschuldigungen $\mathrm{zu}$ untersuchen bzw. zu entkräften. ${ }^{113}$ Als im Dezember 1938 die Liberalen in Bukarest kurzzeitig an die Macht gelangt waren, kehrte Nistor als Arbeitsminister neuerlich an die politische Spitze

bischof gerichtet, da ihr Dorfklerus die Staatssprache zu wenig beherrschte; DACZ 320/1/129, Vizitația arhierească în 14 enorii din Protoieria Nistrului v. 20.VIII.1936.

111 Österr. Boroutz; ukr. Борівці; DACZ 320/1/129, fol. 3 .

112 Ein undatiertes und anonymes Schreiben an den Metropoliten berichtet von einer Sitzung der $>$ Nistoristen`, die scheinbar an einem Kompromat am königlichen Hof zur Demission des Metropoliten arbeiteten. "Vedeţi, ce mare ciudă au Nistoreștii împotriva Voastră « [Sehen Sie, welch großen Groll die Nistoristen gegen Sie haben]; ANR-B Fonds 823 pach. 10/1936-40, fol. 81, Anonymus an Puiu v. 21.X.1939.

113 Academia Română, Arhivea Marea A 2703a, Mitropolia Bucovinei an Kultusministerium v. 24.VII.1939. 
des Staates zurück. ${ }^{114}$ Sofort bemängelte er als bevollmächtigter Vertreter der staatlichen Aufsichtsorgane die unzureichende Versorgung der Bukowiner Bauern mit Brenn- und Bauholz durch den Religionsfonds. ${ }^{115}$ Damit deutete Nistor unverhohlen auf die seit der Reform, seinem Dafürhalten nach, eingetretene Misswirtschaft. Ende des Jahres 1938 erreichten die kirchlichen Zustände tatsächlich ein beklagenswertes Ausmaß. Deren Ursache war allerdings in den seit Jahren anhaltenden wie wiederholten politischen Interventionen zu suchen. Das Ausmaß der Hoffnungslosigkeit gab schlussendlich ausreichend Grund für den amtierenden Metropoliten, beim König um Entlassung aus seiner Position - jedoch ohne Erfolg - anzusuchen.

Clerul înalt e complectamente dezagregat [...] Monastirile, complect dezorganizate, somnolente, cu o conducere divizată pe eparhii [...] Iar clerul de mir [...] având pregătirea unor instituţii slab organizate și fiind încă sub o mai slabă conducere eparhială, vegetează în neacţiune, mişcându-se nu-mai din imboldul preocupărilor existenţei sale zilnice... ${ }^{116}$

Mit der Auflösung des Ministerrates im darauffolgenden Jänner 1939 stellten sich vorerst jedoch keine Konsequenzen für den amtierenden Metropoliten der Bukowina ein. Ab November 1939 stand Nistor (bis Mai 1940) allerdings dem Kultusministerium vor und dirigierte jetzt noch stärker die ganze Macht des Regierungsapparates gegen Puiu. Nach einer Reihe von Vorwürfen, die auf angeblichen Unregelmäßigkeiten in der Fondsgebarung aufbauten und den amtierenden Güterdirektor, Gheorghe Constantinescu, ins Visier nahmen, versuchte sich Puiu direkt mit einem klärend ausführlichen Brief an den König zu wenden. Constantinescu hatte sich davor mit seiner kritischen, von der Metropolie herausgegebenen Publikation über den Besitz des Religionsfonds der Bukowina politisch besonders bei den Nistoristen unbeliebt gemacht. Im Vorwort zu dieser Arbeit unterstrichen die Herausgeber klar, dass ihnen mit der Reform seit 1936 eine deutliche Verbesserung der Situation des Fonds gelungen war und die »Jahre des

114 Die national-liberale Übergangsregierung (eigentlich ein Rumänien regierender Ministerrat) unter Gheorghe Tătărescu demissionierte bereits am 28.XII.1938.

115 Ministerul Agriculturi și domeniilor, adresa nr. 290499 v. 15.XII.1937, Entscheidung des Ministerrates Nr. 3847 v. 15.XII.1937, Delegierter des Ministerrates Arbeitsminister Nistor; nach ANR-B 823-10/1936-40, fol. 36f., Mitropolia Bucovinei Nr. 33142/37 v. 22.XII.1937, Referat $c u$ răspunsurile Administrației Fondului.

116 [Der höhere Klerus zerfällt völlig (...) die Klöster sind gänzlich desorganisiert, schlaftrunken, mit einer geteilten Führung in der Diözese (...) Und der weltliche Klerus (...), basierend auf schwach organisierten Institutionen und zudem unter einer noch schwächeren eparchialen Führung, vegetiert in Passivität, die vorwiegend mit ihrer Alltagsexistenz hadert (...)]; Puiu an Carol II. v. 1.IX.1938; nach einer Abschrift in ANR-B Fonds 823 pach. 10/1936-40, fol. $179 f f$. 


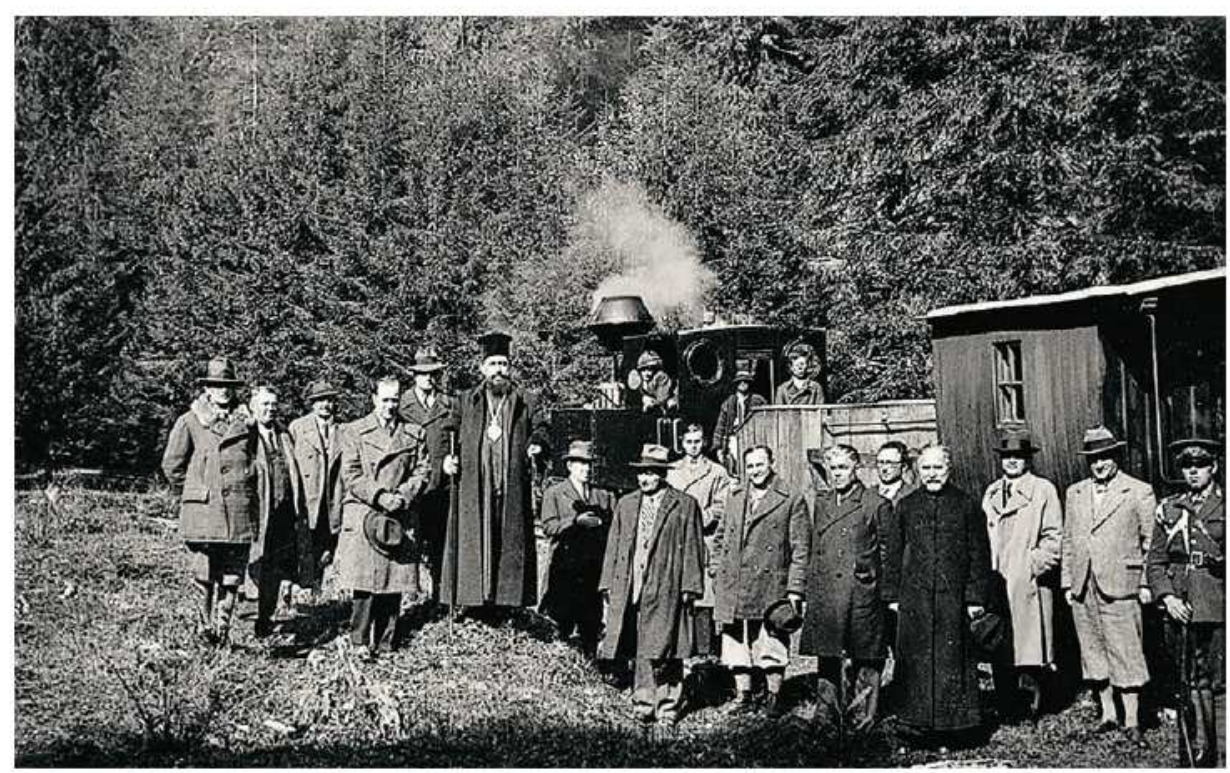

Abb. 51: Der Metropolit als ,oberster Herr; im Kreise von Forstingenieuren der Fondsverwaltung. 1939. Quelle: http://fototecaortodoxiei.ziarullumina.ro Nr. 849

Politicanismul« damit ein Ende gefunden hätten. ${ }^{117}$ Der Metropolit ließ dem König eigens zwei Exemplare übermitteln. Er versuchte gegenüber dem Monarchen die aus seiner Sicht ungerechtfertigten Vorwürfe zu entkräften, blieb damit indes erfolglos. ${ }^{118}$

Mit dem Einmarsch sowjetischer Truppen in der nördlichen Bukowina und deren kompromisslose Abtretung an die Sowjetunion als Folge des Ribbentrop-Molotow-Paktes im Juni 1940 stellte sich für die Eparchie und den Fonds eine überraschende Realität des Faktischen ein. In hastig getroffenen Gesetzesänderungen, die eng aufeinanderfolgten, erhielt zunächst der König das Patronat (Augustul Patron) über den Fonds bestätigt. Der Eparchialrat delegierte seine Verwaltung an eine aus vier (später nur mehr aus drei) Personen bestehende neu eingerichtete Ephorie (kirchliches Aufsichtsamt). ${ }^{119}$ Es bleibt anzunehmen, dass die erste Modifikation noch von Nistor als Kultusminister auf den

117 Constantinescu 1939, Averile, $6 \mathrm{f}$.

118 Mitropolia Bucovinei an Ministru al Palatului Regal Nr. 12588 v. 28.XII.1939; Puiu an Carol II. v. 26.XII.1939; nach einer Abschrift in ANR-B Fonds 823-10/1936-40, fol. 85 u. 18of.; abgedruckt in CliPA 2006, Fondul, $71 \mathrm{ff}$.

119 Monitorul Oficial Nr. 12136 v. 29.VI.1940 (Decretul-lege Nr. 148); Nr. 240 v. 14.X.1940 (Decretullege Nr. 3434); Gesetz Nr. 134 v. 21.II.1942; nach CLIPA 2006, Fondul, 71. 
Weg gebracht worden war, begünstigte sie doch seinen persönlichen Einfluss auf den Fonds. Das Kultusministerium entsandte ebenfalls einen Stellvertreter in die Ephorie des Fonds. ${ }^{120}$ Es ist daher wenig verwunderlich, dass gerade diese Verordnung aus Sicht der Kirche insgesamt in krassem Widerspruch zu den bisherigen Prinzipien der orthodoxen Kirchenverwaltung stand.

Die zweite Modifikation vom Oktober 1940 schwächte dies zwar zum Teil wieder ab und erhob den Metropoliten zum Vorsitzenden der Ephorie, blieb jedoch gleichermaßen ohne Übereinstimmung mit den erwähnten Prinzipien. Die Änderung von 1940 erweiterte zusätzlich die Befugnisse des Königs. Er nominierte fortan die Mitglieder der Ephorie, den Güterverwalter sowie seinen Stellvertreter und approbierte zugleich das Budget. Die Ausführung war dem Landwirtschafts- und Domänenministerium überlassen. Dezidiert unterstrich das geänderte Organisationsstatut den nach wie vor erhobenen Anspruch von Fonds und rumänisch orthodoxer Kirche auf die (besetzte) Nordbukowina. ${ }^{121}$ In ihrem ersten Bericht an den König gestand die Ephorie in einem resümierenden Rückblick überraschend ein, dass »keine der rumänischen Reorganisationen $(1925,1938,1940)$ bessere Resultate geliefert « hätte als sie während der österreichischen Periode (sic!) und der kurzen Zeit bis 1925 zustande gebracht wurden. Eine Aussage von General Ion Antonescu ${ }^{122}$ zitierend, lieferte die Ephorie, in geradezu anbiedernder Weise zur neuen politischen Situation des Staates, gleich eine passende Begründung dafür mit, wonach im Leben des Staates nicht so sehr die Gesetze zu den Hauptaufgaben gehören würden, sondern viel mehr das Gewissen seiner Führer und Funktionäre. ${ }^{123}$

Die von Nistor massiv befeuerten Intrigen gegen Puiu hatten am 11. Mai 1940, auf Basis eines - wie Puiu selbst schreibt - »illegalen königlichen Dekrets ${ }^{124}$ und einer zeitgleichen Pressekampagne ${ }^{125}$ de facto zu dessen Demission »aus Krankheitsgründen " geführt. Der Minister bezog sich dabei auf frühere Rücktrittsgesuche Puius. ${ }^{126}$ Das wollte und

120 ANR-S inv. 35/1 pach. 3-1940, fol. 19, Metropolie an Eforia FBis v. 16.X.1940, worin Prof. Constantin Zappa auf fünf Jahre zum Repräsentanten des Ministerul Educaţiei Naţionale, Cultilor şi Artelor in der Ephorie ernannt wird.

121 Monitorul Oficial Nr. 12136 v. 29.VI.1940 (Decretul-lege Nr. 148), Capitolul I, Dispoziţiuni generale; nach DACZ $321 / 5 / 162$, fol. 44 ; ANR-S inv. $35 / 1$ pach. 3-1940, fol. 2-3, Monitorul Oficial Nr. 148 v. 29.VI.1940.

122 Antonescu oblag mit dem Staatsumbau de facto auch die Einsetzung der Ephorie-Mitglieder des Religionsfonds; ANR-S inv. 35/1, pach. 3-1940, fol. 2, Ministerul Justiţiei, București v. 18.X.1940.

123 DACZ $_{321 / 5 / 3}$, fol. 7, Eforia FBis, Raport Trimestrial 1.X.1940-31.XII.1940, Vatra Dornei v. 14.II.1941.

124 Puiu an Antonescu v. 16.IX.1940; ANR-B Fonds 823 10-1936-40, fol. 178-182, hier 178.

125 Dazu ausführlich die Anmerkungen bei CLIPA 2006, Fondul, 68.

126 Decret Carol II., Februar 1940 sowie Schreiben Nistors an Carol II. o.D.; nach ŞTEFANOviCI 1996, Documente, 445 ff.; Monitorul Oficial Nr. 108 v. 11.V.1940; nach VALENCIUC 2004, Puiu, 78. Puiu datiert 
konnte der Metropolit wohl auch nicht anerkennen. Ganz im Gegenteil, der Kirchenhierarch beschuldigte jetzt, nach dem neuerlichen erfolgten Machtwechsel in Bukarest, offen den vormaligen Kultusminister und seine »Bande« als Widersacher. Zeitgleich eröffnete er General Antonescu, dass er nunmehr das Amt endgültig zurücklegen möchte:

Cu venirea în guvern a D-lui Ion Nistor, însă, d-sa, împreună cu o bandă de doritori de a pune mâna pe conducerea administraţiei averilor bisericești ale Fondului din Bucovina, între care și câtiva palatişti, se începe o campanie cumplită, atât împotriva conducătorului fondului, Inginerul Gh. Constantinescu, cu învinuiri pe care Justiţia le-a găsit neîntemeiate, cât și împotriva mea, am cerut de repetate ori Regelui Carol II audiențe lămuritoare, dar mi s’a răspuns mereu că acestea sunt suspendate pentru toată lumea. ${ }^{127}$

Puiu zog sich für fast zwei Jahre nach Neamţ zurück, bevor er im Sommer 1942 nach Transnistrien ging, um auf Wunsch von Marschall Antonescu die dortige orthodoxe Kirche zu reorganisieren. ${ }^{128}$ Nach Kriegsende floh der Geistliche aus Rumänien, ein Volkstribunal verurteilte ihn in Abwesenheit zum Tode. ${ }^{129}$ Eine Rückkehr war ihm bis ans Lebensende unmöglich.

das Dekret fälschlicherweise in seinen Erinnerungen auf den 15. Mai; PUIU 2014, Însemnări, 108. Inwiefern hier ein mehrseitiger Brief, den Puiu im Herbst 1939 direkt an Stalin geschrieben hatte, eine Rolle spielte, muss an dieser Stelle ungeklärt bleiben, ebenso die eigentlichen Beweggründe dieses Schrittes. Puiu, der in Kiew studiert hatte, beherrschte offensichtlich auch Russisch. Im erwähnten Schreiben bezog er, zwei Wochen nach Kriegsbeginn, für die orthodoxe Kirche in der Sowjetunion Stellung. Puiu argumentierte mit den Prinzipien der Freiheit, die während der Revolution in Russland deklariert worden waren. Zudem könnte das Regime, so Puiu weiter, bei einer geänderten Haltung gegenüber der Orthodoxie auch international Sympathien erwerben; Academia Română, Arhivea Marea A 3339 Puiu an Stalin (in rumänischer Ubersetzung des Kultusministeriums), Cernăuţi v. 14.IX.1939.

127 [Mit Aufnahme von Herrn Ion Nistor in die Regierung aber, gemeinsam mit einer Bande von Gierigen, legte er die Hand auf die Führung der Fondsgüterverwaltung der Bukowina, unter ihnen auch einige Höflinge - setzte eine schlimme Kampagne gegen den Fondsdirektor, Ingenieur Gh. Constantinescu ein, mit seitens der Justiz unbegründeten Schuldzuweisungen, ebenso gegen mich; mehrfach habe ich um eine aufklärende Audienz bei König Carol II. angesucht, aber immer nur zur Antwort erhalten, dass diese für alle ausgesetzt wären]; Puiu an Antonescu v. 16.IX.1940; ANR-B Fonds 823 pach. 10/1936-40, fol. $178-182$, hier 180 .

128 PUIU 2014, Insemnarile, 109.

129 Ein von Puiu an das rumänische Außenministerium gestelltes Ansuchen um Rekurs des Urteils lehnte Petru Groza de facto ab: »Redeschiderea procesului cred că s'ar putea face numai la cererea personală a condamnatului în absenţă - urmând ca acesta să se prezinte în instanţa « [Ich denke, dass eine Wiederaufnahme des Prozesses nur durch ein persönliches Gesuch des in Absenz Verurteilten gemacht werden kann, folgend, dass dieser sich selbst (sic!) den Instanzen präsentiert]; ANR-B Fonds 3039 10-1947 Consiliul de Miniștri. 
Abb. 52: Metropolit Visarion. Ansichtspostkarte mit Unterschrift des Metropoliten, Czernowitz 1940. http://www.ortodoxia.de/ $\mathrm{html} /$ mitropolitul_roman_visarion_puiu.html

Abb. 53: Metropolit Visarion beim Verlassen der Kathedrale in Czernowitz, 10. März 1938, begleitet vom Präfekten Oberst Gheorghe Teodorescu, General Florea Tenescu und dem Kultusminister Alexandru Lapedatu. (C) Fototeca Ortodoxiei Romanesti ${ }^{130}$

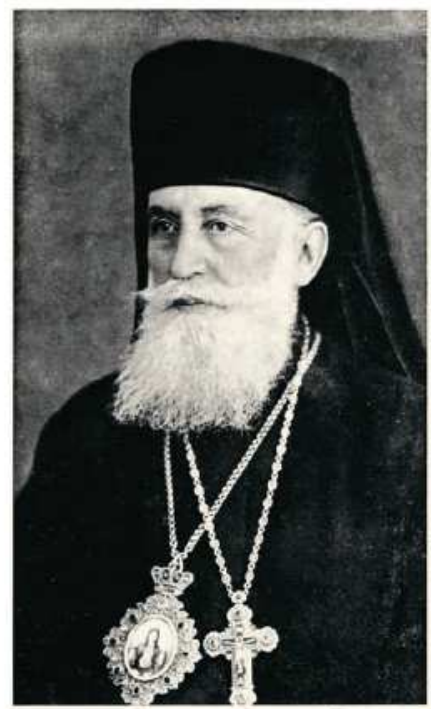

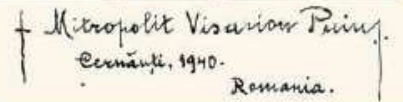

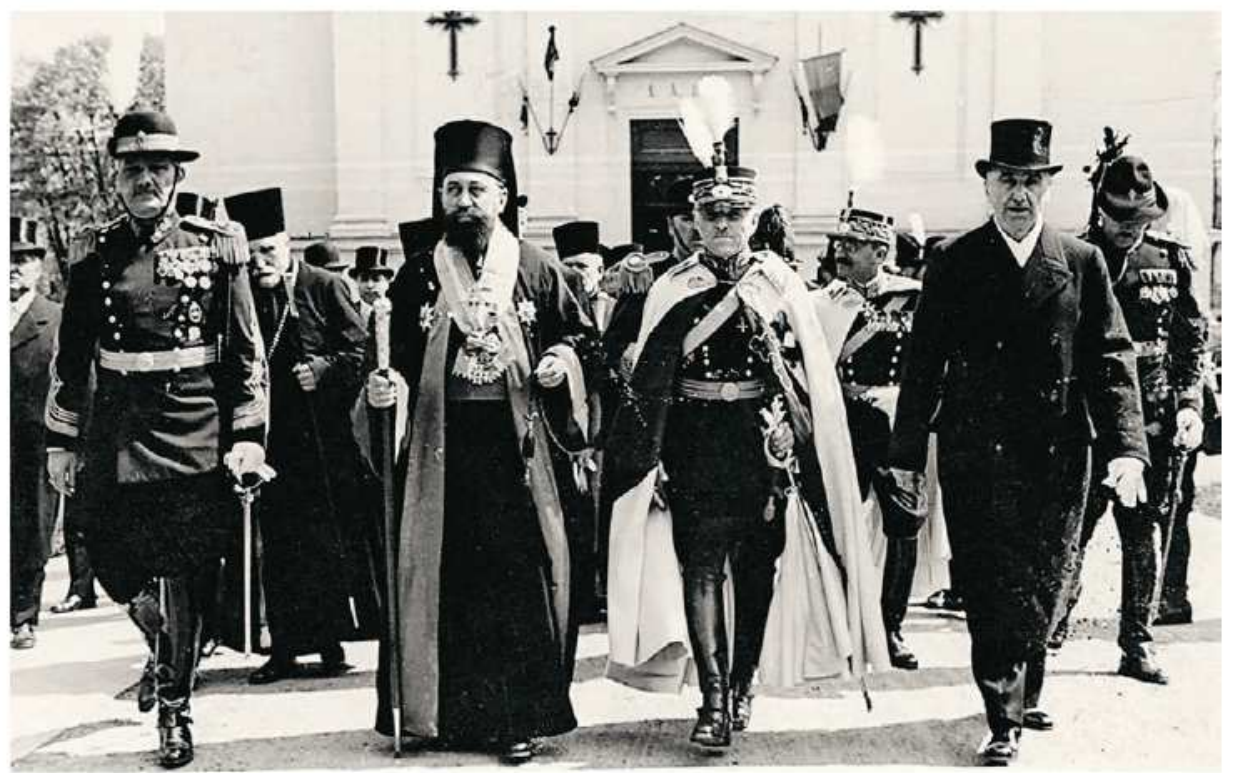

130 Die Abbildung ist der Online-Sammlung des rumänischen Patriarchats entnommen; Fototeca Ortodoxiei Romanești [http://fototecaortodoxiei.ro/visarion-puiu]. 


\section{În caz de evacuare . Der Krieg und seine Folgen}

Der Nachfolger von Puiu, Tit Simedrea, wurde als letzter Metropolit der Bukowina zwar noch am 13. Juni 1940 gewählt, konnte allerdings vor dem Hintergrund des Nachfolgestreites und der außenpolitischen Situation des Königreiches erst am 25. März 1941 inthronisiert werden. ${ }^{131}$ Simedrea war mit einem auf Grund der vorangegangenen innenpolitischen Ereignisse rund um die Reformen und die Absetzung von Puiu zutiefst gespaltenen wie misstrauischen Klerus konfrontiert. Ein interner Bericht des Religionsfonds vom Jänner 1941 sparte etwa nicht mit heftigen Vorwürfen gegenüber der »jahrelangen Patronage diverser politischer Parteien «, welche den Fonds in große Schwierigkeiten manövriert hatte. Gleichzeitig setzte man große Hoffnungen auf die neue Ordnung im Land. ${ }^{132}$ Zudem hatte der Religionsfonds durch die fast einjährige Besatzung sowjetischer Truppen von 1940 bis 1941 massive finanzielle Einbußen und materielle Verluste hinnehmen müssen. ${ }^{133}$ Der Krieg und sein zunehmend für Rumänien erfolgloser Verlauf erschwerten außerdem in erheblichem Maße die nötige Restrukturierung von Religionsfonds und Eparchie, sodass bis Kriegsende die Institution ebenso wie ihre Verwaltung vor allem mit dem ohnedies schon schwierigen Erhalt des Status quo beschäftigt waren.

In der Metropolitanverwaltung hatte man schon bei Ausbruch des Krieges, im September 1939, Überlegungen zur Evakuierung getroffen. Wiederum stand Vatra Dornei zur Debatte. Aber auch das Kloster Vovidenia bei Neamţ, wo Puiu ein eigenes Haus besaß, wurde für die Unterbringung von Wertgegenstände und Akten in Betracht gezogen. Hier spielten offensichtlich die schmerzlichen Erfahrungen des Ersten Weltkrieges herein. ${ }^{134}$ Letztlich zogen sich sowohl Fondsverwaltung als auch Metropolitanbehörden

131 Geb. 1886 in Naipu (Muntenien), gest. 1971, studierte in Jassy, von 1916-1920 Militärgeistlicher, danach Pfarrer in Bukarest, Studium der Theologie in Montpellier und Paris, 1923-1925 Direktor der Synodalkanzlei und Pfarrer der Metropolitankirche in Bukarest, seit 1935 Bischof von Hotin, nach 1945 zog sich Simedrea ins Kloster Cernica zurück, wo er auch verstarb; nach SATCO 2004, Enciclopedia, $388 \mathrm{f}$.; bis 1948 war noch ein Vertreter des Metropolitansitzes der geteilten Bukowina tätig; allerdings wurde die Metropolie bereits im Mai 1947 zum Erzbistum (Arhiepiscopia Sucevei şi Rădăuţilor) herabgestuft und danach in die Metropolie von Jassy überführt; kurzzeitig (1948-1950) existierte eine Arhiepiscopia Sucevei şi Maramureşului; seit 1991 heißt das Erzbistum (der Südbukowina) wieder offiziell Arhiepiscopia Sucevei şi Rădăuţilor; VALENCIUC 2001, Ierarhi.

132 ANR-S inv. 35/1 2-1940, fol. 1-21, hier fol. 1 und 21, FBis, Raport de activitate v. 15.I.1941.

133 Die Sowjetunion nutzte die staatlich eingezogenen Güter des Religionsfonds in der Nordbukowina als willkommene Möglichkeit, Land an Bauern und das ländliche Proletariat zu verteilen; HAUsLEITNER 2009, Pakt, 212.

134 ANR-B Fonds 823 pach. 10/1936-40, fol. 71f. (bezieht sich auch auf das Zitat in der Abschnitts- 
im Sommer 1940 nach Vatra Dornei zurück, wo die Ephorie Mitte August 1940 bereits ihre Arbeit wieder aufnehmen konnte. ${ }^{135}$ Als eine Folge der katastrophalen Situation, in der sich das Königreich - nach der sowjetischen Okkupation großer Landesteile und dem ein Jahr darauf erfolgten Kriegseintritt an Seite des Deutschen Reiches - befand, beorderte Bukarest im Zuge der Neuorganisation des Religionsfonds im Herbst 1941 zusätzlich zur Ephorie einen Regierungskommissar in dessen Verwaltung. Seine Ernennung erfolgte auf Vorschlag des Ministeriums für Landwirtschaft und Domänen. Dieser Kommissar erhielt die Befugnis, Beschlüsse der Ephorie auszusetzen, sollten sie den »übergeordneten Interessen des Staates « widersprechen. ${ }^{136}$ Der bewusst unklar gefasste Handlungsrahmen setzte de facto die Bukarester Regierung in eine nahezu vollständige Verfügungsgewalt über den Religionsfonds. Zudem prüfte ab 1942 eine interministerielle Kommission - soweit das während des Krieges überhaupt möglich schien - die Zustände innerhalb des Fonds eingehend. Dabei lag der Fokus vor allem auf den Budgets. ${ }^{137}$ So ließen etwa wachsende Unstimmigkeiten innerhalb der Fondsadministration als auch von dort an die Mitarbeiter gerichtete Appelle an Disziplin und Solidaritätsgeist die allgemeine Krisensituation sowie eine um sich greifende Verunsicherung des Personals zunehmend offen zu Tage treten. ${ }^{138}$ Von einer »energischen « Demonstration eigener Leistungsfähigkeit - wie man sie im Juli 1942 anlässlich der Teilnahme des Fonds an der Provinzausstellung, vor dem Hintergrund einer gänzlich anderen außenpolitischen Lage, noch nach außen getragen hatte - war man mittlerweile denkbar weit entfernt. ${ }^{139}$

überschrift); Mitropolia Bucovinei (Puiu) an Preşidintele sf. Sinod (Nicodem), Cernăuţi v. 19.IX.1939; dafür nicht unwesentlich dürften ebenso die Berichte geflohener hoher polnischer Offiziere gewesen sein, die der Metropolit für einige Zeit in seiner Residenz in Czernowitz beherbergt hatte; diese hatten ihm ihr Fluchtauto, einen Cadillac, als Geschenk überlassen; es spricht für die Korrektheit Puius, dass er das Fahrzeug sogleich dem Ministerrat zur Verfügung stellte; detto, fol. 178f., Puiu an Antonescu, București v. 12.IX.1940.

135 Am 20.VI.1940 trat die Ephorie in Czernowitz das letzte Mal zusammen; ANR-S inv. 35/1, pach. 1-1940. Bis zur Rückverlegung der Religionsfonds- und Metropolitanämter nach Czernowitz fanden zumindest nachweislich drei Sitzungen der Ephorie statt: 9.VI., 5. und 6.VII.1941; pach. 4-1940, Eforia FBis, Vatra Dornei v. 16.VIII.1940. Die erste Sitzung im wiedereingerichteten Hauptsitz tagte bereits am 7.VIII.1941, pach. 1-1941.

136 Monitorul Oficial Nr. 221 v. 18.IX.1941, 5595-5599; Decretul-lege pentru organizarea FBis, modificat conform decret-lege de reorganizare Nr. 409 v. din 21 Februarie 1941 v. 18.IX.1941.

137 Legea Nr. 134 v. 21.II.1941 u. Legea Nr. 969 sowie Verordnung v. 16.II.1942; Decizia ministerială Nr. 10953 v. 19.I.1943; Nr. 21279 v. 2.II.1943 u. Nr. 216961 v. 12.X.1943; nach ClipA 2006, Fondul, 71f., ebenso DACZ 321/5/162; sowie 321/5/601, fol. 32, Copia Referatul D-lui Inspector General la Minister sub Nr. $191.818 / 944$.

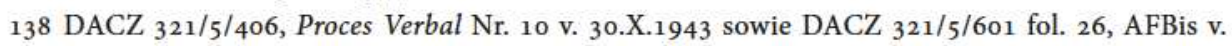
7.IV.1944.

139 DACZ $_{321 / 5 / 1}$ fol. 84 u. 86, Zirkulare AFBis v. 3. u. 9.VII.1942. 
Ab Ende Mai 1944 verlegte die zentrale Religionsfondsverwaltung ihren Sitz von Sânnicolau-Mare (Groß Sankt Nikolaus im äußersten Westen des Banats) - wo man seit April aufgrund der vorrückenden sowjetischen Front bzw. nach der erfolgten Evakuierung von Czernowitz untergebracht worden war ${ }^{140}$ - wieder in Etappen in den nicht besetzten Teil der Bukowina, nach Vatra Dornei. ${ }^{141}$ Wenige Monate später, im August, verließ das Königreich das Bündnis mit dem Deutschen Reich und wurde von der Roten Armee besetzt. Die Südbukowina geriet kurzfristig zum Kriegsschauplatz. Die zentrale Religionsfondsverwaltung hatte sich im Spätsommer 1944 in die ehemalige Vertretung des Fonds nach Bukarest zurückgezogen, die Administration vor Ort in der Südbukowina hingegen verblieb in Suceava. Um jedoch den Betrieb der Fondseinrichtungen aufrechtzuerhalten, trachtete man nach dem Waffenstillstand danach, sowohl Personal als auch Verwaltung so schnell wie möglich wieder in die Südbukowina zurückzuverlegen. ${ }^{142}$

Ein knappes Jahr nach Einsetzung der Regierung Petru Groza, im März 1945, begann der Staat bereits nach dem Religionsfonds zu greifen. Als Vorsitzender des Ministerrates richtete Groza eine ausführliche Begründung für die Abänderung des geltenden Organisationsstatutes an König Mihai I. Dem Fonds - so Groza darin - fehle es an einer demokratischen Organisation. Obwohl das Volk der Bukowina seit der Revolution von 1848 nach einem Kirchenkongress verlangte, hätten die Reformen von 1918 und 1925 dies nur zum Teil erfüllt und wären zudem später wieder rückgängig gemacht worden. ${ }^{143}$

140 ANB-S inv. 35, pach. 6-1944, fol. 28f., AFBis Serviciul Administrativ, Plan de Evacuare; fol. 43 f., Referat 11.I.1944; fol. 42-44, Referat 21.I.1944; trotz der panikartigen Situation in der Stadt hatte man seitens der Religionsfondsverwaltung minutiös eine Liste von ca. 140 Funktionären des Fonds mit der Anzahl der zu evakuierenden Familienangehörigen und dem zu erwartenden Gepäck angefertigt; fol. 127-129, AFBis Serviciul Administrativ, Tablou; die Transporte setzten in größerem Umfang im März 1944 ein; zu den Evakuierungen einzelner Verwaltungseinheiten des Religionsfonds im Detail vgl. ANB-S inv. 35, pach. 8-1944.

141 DACZ $_{321 / 5 / 601}$ fol. 132 v. 6.VI.1944, MAD v. 27.V.1944; eine Auflistung der Verwaltungseinheiten mit den zuständigen Leitern findet sich unter ANB-S inv. 35, pach. 5-1944, fol. 8-10, AFBis Serviciul Administrativ Suceava v. 18.X.1944; dazu die Transportlisten für die aus Sânnicolau-Mare zurückkehrenden 95 Funktionäre des Fonds und die damit nötige Umorganisation der Verwaltung; ANB-S inv. 35, pach. 10-1944, fol. 24f., FBis v. 27.IX.1944, Tabel; sowie fol. 34-41, FBis Serviciul Administrativ București v. 8.XII.1944, Organisarea Ad-f̧iei Fondului Bisericesc și fixarea cadrelor functionalilor.

142 Bd. Dacia Nr. 7; ANR-S inv. 35, pach. 49-1944, fol. $36 f$., FBis an AFBis 3.XI.1944; fol. 64f., FBis an Președinte al comisiunei pentru aplicarea armistitului București, o.D; eine Liste (Name, Stellung, Funktion) mit dem gesamten (?) Fondspersonal von 614 Personen findet sich unter fol. 69-8o, datiert nach März 1945; einige darunter waren gefallen, als ıabgängig` gemeldet oder mit dem Verweis »concentrat" in Lager bzw. Gefängnisse eingewiesen worden.

143 Monitorul Oficial Nr. 92 v. 17.IV.1946, 3922-391, hier 393 of.; ANB-S, inv. 35, pach. 3-1946, fol. 
Abb. 54: Dienstabzeichen (Nr. 4891) eines Jägers der Domeniile Bucovina; mit dem Bukowiner Aur im Zentrum umgeben von einem stilisierten Zahnrad; zu datieren nach 1945(?). Sammlung K. Scharr.

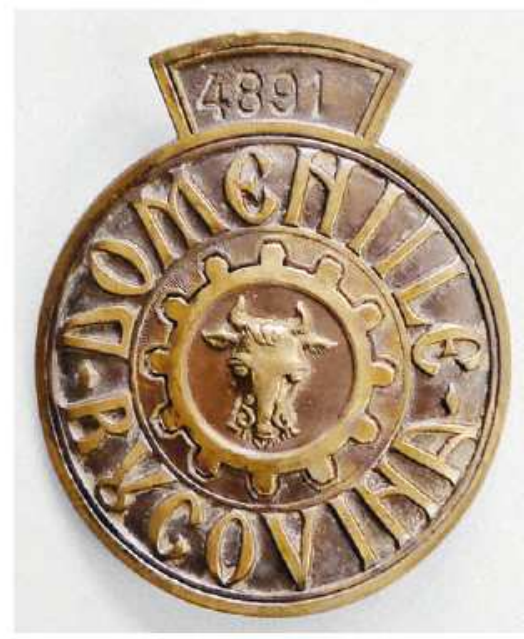

Die Regierung schlug zunächst die Einrichtung eines Verwaltungsrates vor, bestehend aus sieben Personen unter dem Vorsitz des statthaltenden Bischofs der Metropolie ${ }^{144}$ sowie eines Regierungskommissars. Zu diesem Rat gehörten der Protopope Dumitru Matei, Forstingenieur Victor Turcan, Universitätsassistent Ilie Grămădă, der Landarbeiter Dumitru Juravlea sowie die Forstarbeiter Irimia Pardău und Ipolit Buzilă. Dabei handelte es sich jedoch tatsächlich mehr um eine Scheinkonstruktion. Artikel III des neuen Gesetzes sah nämlich bis zu Konstituierung bzw. Wahl der Fondsorgane durch eine erst einzuberufende Eparchialversammlung vor, dass der Vorsitzende des Ministerrates, Groza, den Eparchialrat bis dahin vertritt. ${ }^{145}$ Die regionalen Kräfte waren damit de facto zugunsten der von den Sowjets gestützten Bukarester Regierung entmachtet worden. Zwischenzeitlich hatte man die Wirtschaftsstruktur des Fonds mit der Eisenbahn-

1-54, Regulament pentru desvoltarea statutului pentru organizarea şi funcţionarea Fondului bisericesc orthodox român din Bucovina; Decret-lege pentru repunerea în vigoare şi modificarea art. 39, $40,41,42$ și 43 din legea pentru organizarea Bisericii Ortodoxe Române, publicată în Monitorul Oficial Nr. 97 v. 6.V.1925.

144 Seit 1945 fungierte Bischof Emilian Antal Târgovișteanul als Statthalter des Erzbischofs und Metropoliten in der Südbukowina.

145 Monitorul Oficial Nr. 92 v. 17.IV.1946, Legea Nr. 295 prin decretul 2136; Monitorul Oficial (Partea I B) Nr. 99 v. 28.IV.1946, 427 of., Deciziuni președinția consiliului de miniștri; ANR-S inv. 35 pach. 4-1946, fol. 25, Extras din Monitorul Oficial (Partea I B) Nr. 99 v. 28.IV.1946; Groza und sein Kabinett hatten ein neues Organisationsgesetz für die orthodoxe Kirche in Aussicht gestellt; zur Situation der orthodoxen Kirche in Rumänien während der ersten Jahre kommunistischer Herrschaft vgl. VASILE 2005, Biserica, hier 82; ebenso LeUSTEAN 2009, Orthodoxy, bes. 81-88. 
verwaltung zu einer gemischten Gesellschaft mit beschränkter Haftung verschmolzen (Societatea Anonimă Domeniile Bucovina) ${ }^{146}$ Letztere wurde schließlich mit dem Gesetz Nr. 119 vom 11. Juni 1948 nationalisiert, d.h. zum Eigentum der neu proklamierten Volksrepublik Rumänien erklärt und nach einer kurzen Periode der physischen Liquidation 1949 endgültig aufgelöst. ${ }^{147}$

\section{Zusammenfassung}

Die Umbrüche des Jahres 1918 brachten in allen gesellschaftlichen Bereichen und historischen Räumen Rumäniens erhebliche Veränderungen mit sich. Die orthodoxe(n) Kirche(n) waren davon in besonderer Weise betroffen, galt es hier doch, mit Verweis auf das neue Königreich, eine ebensolche strukturelle wie inhaltliche Einheit zu finden. Innerhalb dieses komplexen Vereinigungsprozesses kam der Bukowina sicherlich eine besondere Stellung zu. Die orthodoxe Landeskirche hatte zuvor als Teil des Habsburgerreiches in der Region eine privilegierte Position inne und dabei zahlreiche Freiheiten genossen, wenngleich sie dennoch stets gewissen Vorgaben Wiens untergeordnet blieb. Zudem verfügte sie - als einzige der orthodoxen Kirchen Rumäniens - über ein beträchtliches Vermögen und ein dementsprechendes Selbstwertgefühl, das zu einem nicht geringen Teil eben aus diesem >Reichtum ‘ erwachsen war. Das imposante Residenzgebäude des Metropoliten und die Universität in Czernowitz mit ihrer theologischen Fakultät standen geradezu als Symbol für diese Haltung.

Die Epochengrenze zeigte sich für die Bukowina und die Öffentlichkeit ihrer Gesellschaft auch in anderer Hinsicht. In den deutschsprachigen Zeitungen von Czernowitz und das steht in einem auffallenden Gegensatz zur Periode vor 1918 - verschwand die Thematik `Religionsfonds` oder >orthodoxe Kirche` allmählich. Das nunmehr als Teil einer nationalen Minderheit eingestufte deutschsprechende Bürgertum hatte mit dem Verlust seiner politischen Macht als ehemaliger Staatsnation schrittweise auch die kulturelle Deutungshoheit über den öffentlichen Raum abgeben müssen. Beide Themenbereiche waren aus diesem Blickwinkel offensichtlich >rumänisch`geworden und nicht

146 Monitorul Oficial Nr. 82 v. 5.IV.1947, Decretul-lege Nr. 267 v. 16.XI.1946; nach CiobanU 1993, Fondul, 9; auch CLIPA 2006, Fondul, 77. Monitorul Oficial Nr. 8 v. 8.IV.1947, Legea Nr. 911/1946 prin decretul-lege Nr. 3255/1946.

147 Die Liquidierungskommission (sie arbeitete von 19.VIII.1949 bis 31.III.1950) basierte auf dem Decretul Prezidial Nr. 273/1949 u. Deciziunii Ministerului Finanțelor Nr. 68.081 v. 19.VIII.1949; ANRS inv. 35 pach. 2-1950, fol. 2, Comisia de Lichidare Fondului Bisericesc Ort. Rom. din București Nr. 374/949; ANR-S inv. 35, Prefaţă dazu im Überblick Deletant 2004, România sowie TismaneANU 2003, Stalinism. 
mehr - sowie die Jahrzehnte zuvor - integrativer Teil einer von ebendieser Gruppe mithin imaginierten Landesidentität.

Mit der Wiedervereinigung glaubte man die vielfach seit langem ersehnte nationale Einheit endlich erreicht zu haben. Zugleich nährte sie die Erwartung der Kirche, über ihr Eigentum - den Religionsfonds - nunmehr auch selbst und ohne die bisherigen Einschränkungen verfügen zu können. In dieser komplexen Situation arbeiteten jedoch zwei wesentliche Faktoren gegen diese Hoffnungen. Zum einen erreichte das Königreich während der gesamten Zwischenkriegszeit als Staat keine ausreichende Stabilität, die eine derartige Entwicklung hätte fördern können. Im Gegenteil, der Staat und seine Institutionen funktionierten nur leidlich, gerieten in einseitige Abhängigkeiten von Parteien wie persönlichen Interessen und verloren nicht zuletzt deswegen zusehends an Vertrauen in der Bevölkerung. Zum anderen konnte die Kirchenführung der Bukowina die kurze Zeit der vergleichsweise freien Gestaltungsmöglichkeiten bis zur Herstellung der kirchlichen Einheit in Rumänien und der Annahme der neuen Verfassung nicht genügend für sich nutzen. Metropolit Wladimir von Repta, wie auch seine Konsistorialräte, waren zu alt und der Situation nicht mehr gewachsen. In dieses Machtvakuum konnten die politischen Parteien und ihre Akteure ohne viel Aufwand vordringen. Führungspersönlichkeiten wie Nistor wussten das geschickt für sich zu nutzen. Auf Basis regionaler Machtfülle und durch seine exzellenten Beziehungen nach Bukarest gelang es Nistor, seinen realen Einfluss in der Bukowina und innerhalb ihrer Institutionen nahezu unbegrenzt auszuüben. Staatliche Kontrollinstanzen konnten dem indes kaum etwas entgegensetzen. Lediglich politische Machtwechsel an der Spitze des Königreiches gefährdeten die Konstellation für die jeweils oppositionelle Partei kurzfristig, änderten jedoch nichts an dem zunehmend korrupten System politischer Einflussnahme (Politicanismul), die das Land mehr und mehr lähmte. Der Religionsfonds als eine in gesellschaftlicher wie ökonomischer Hinsicht zentrale Institution der Bukowina geriet dabei immer mehr in Bedrängnis. Einerseits verlor er durch Misswirtschaft, politische Interventionen und äußere Faktoren wie der Weltwirtschaftskrise erheblich an ökonomischer Vitalität. Andererseits wuchs innerhalb seiner eigenen Strukturen durch die gängige Personalbesetzungspolitik, Intrigen und in aller Öffentlichkeit ausgetragene Machtspiele das gegenseitige Misstrauen. Darunter litt wiederum das Ansehen von Institution wie Kirchenführung. Beides führte zu einem spürbaren Verlust an Gestaltungsmöglichkeiten für die Region durch und mit dem Religionsfonds.

Die zwischen 1918 und 1942 betriebenen Reformversuche lassen sich in ihrer Bewegungsrichtung sind einem Pendel vergleichbar. So wechselte - zumindest theoretisch durch die mehrfachen Statutenänderungen die Macht im Religionsfonds mehrfach in unterschiedlicher Ausprägung zwischen der Kirche, dem Metropoliten, zu den Parteien und ihren Vertretern. Der Staat nahm dabei zumeist nur eine mehr oder weniger nütz- 
liche Statistenrolle wahr. Die Totalisierung Rumäniens durch die Königsdiktatur und später durch das autoritäre Führerregime von General Antonescu schuf erstmals die Möglichkeit einer direkt durch den Staat ausgeübten Kontrolle über den Bukowiner Religionsfonds. Die innenpolitischen Zustände und der Krieg verhinderten allerdings ein nachhaltiges Aufbrechen des in der Zwischenkriegszeit gewachsenen Systems. Letztlich setzte sich mit der kommunistischen Machtübernahme der Staat kompromisslos durch. Der Bukowiner Religionsfonds und die kirchliche Autonomie der Region hatten damit aber aufgehört zu existieren. 


\section{Die wirtschaftliche Situation um 1938}

Die Jahrzehnte nach 1918 brachten für den Religionsfonds gravierende Veränderungen. Dominierten während der Zwischenkriegszeit mit der Eingliederung in einen neuen Staat, das Königreich Rumänien, die Triebkräfte des strukturellen Wandels bzw. der allmählichen Umgestaltung oder die wachsende politische Einflussnahme, wie das bereits dargestellt wurde, so beherrschten während des Krieges freilich existentiellere Fragen den Fonds. Die letzten vier Jahre von 1944 bis zur Auflösung des Religionsfonds im Verlauf des Jahres 1948 waren geprägt von neuerlichen Anpassungsversuchen in einem sich verändernden politischen System, die allerdings in der Realität der Institution nur mehr geringe Auswirkungen zeigten. Im Hinblick auf die wirtschaftliche Situation ist daher hier für den Fonds - großzügig um das Jahr 1938 herum ausgreifend - der Fokus vertiefend zum vorausgegangenen Kapitel auf die Agrarreform, den Bau des Czernowitzer Kulturpalastes und die Kriegsjahre selbst zu richten.

\section{Agrarreform und Religionsfonds}

$\mathrm{Zu}$ den zentralen Reformen des rumänischen Staates der ersten Jahre nach 1918, die sich allerdings bis Kriegsbeginn hinzogen und die den Fonds unmittelbar in wirtschaftlicher Hinsicht betrafen, gehörte die angestrebte großflächige Umverteilung des Agrareigentums. Die sozial, politisch wie wirtschaftlich angespannte Situation Großrumäniens, insbesondere wegen seiner nach der beträchtlichen Gebietserweiterung mit dem Ende des Ersten Weltkrieges strukturell so heterogenen Teilräume, drängte nach umfassenden Veränderungen in der bisherigen Agrarpolitik des Altreiches. Aus der Sicht Bukarests bot der ländliche Raum bzw. die Landwirtschaft die größtmögliche Reichweite für derlei Maßnahmen. Mit einer breit angelegten Agrarreform - nicht der erste Versuch im Regat - sollten vorrangig die Ansprüche der Bauern befriedigt und damit zumindest der von ihnen ausgehende massive politische Druck, der spätestens seit dem Aufstand von 1907 auf den jeweiligen Regierungen lastete, wegfallen. Bukarest trachtete wohl ernsthaft danach, mit der Lösung der Bauernfrage den Kern der sozialen Probleme anzupacken. Dem Agrarfeudalismus, wie er vor allem im rumänischen Altreich dominiert hatte, sollte dadurch unwiederbringlich ein Ende bereitet werden. Ein erster Anlauf dazu im Jahr 1864 war noch am massiven Widerstand der Großgrundbesitzer gescheitert. Das Landreformgesetz von 1921 stellte nunmehr dafür eine neue Grundlage bereit. Allerdings gestaltete sich die konkrete Umsetzung von Provinz zu Provinz sehr verschieden und war weit entfernt von Einheitlichkeit. ${ }^{1}$ Im Gegenteil, die

1 Hitchins 2004, Desăvârșirea, 359f.; im Überblick MüLler 2006, Zwischenkriegszeit; die von ŞANDRU vorgelegte Arbeit zur rumänischen Agrarreform (1975, Reforma) gilt nach wie vor als 
Enteignungsquote in den neu hinzugekommenen Provinzen lag bezeichnenderweise deutlich höher als im Regat selbst. ${ }^{2}$ In der Bukowina war die Agrarfrage allerdings schon vor dem Ersten Weltkrieg ein Politikum gewesen, das auch in der Öffentlichkeit kontrovers diskutiert wurde. ${ }^{3}$ Das österreichische Kronland wies neben dem Religionsfonds eine Reihe von Großgrundbesitzern aus, die insgesamt fast $64 \%$ des kultivierbaren Bodens zu eigen hatten, sodass der Rest bei einer entsprechenden Bevölkerungsdichte von teilweise 80 Personen auf einen Quadratkilometer nur auf vergleichsweise kleine Wirtschaftseinheiten von oftmals weniger als einem Hektar zurückgreifen konnte. ${ }^{4}$ Im Hinblick auf die davon betroffene Fläche von etwa sechs Millionen Hektar ist die Agrarreform des Königreiches jedoch durchaus als bedeutend einzuschätzen. Sie transformierte ein Land der Großgrundbesitzer in ein Land der Kleinbauern. ${ }^{5}$ Eine überbordende Bürokratie ${ }^{6}$, fehlender politischer Wille, die Ansätze auch konsequent umzusetzen, sowie die technisch und personell vielfach ungenügenden Rahmenbedingungen führten indes die Reform trotz der realisierten Landumverteilungen in eine Sackgasse. Der angestrebte großflächige Abbau sozialer Polarisation konnte auf weiten Strecken in keinster Weise auch nur annähernd erreicht werden. ${ }^{7}$

In der Bukowina erfuhr die praktische Umsetzung durch die schon genannten Gründe ebenso erhebliche Verzögerungen. Die Realisierung der Reformbemühungen schleppte sich oftmals bis zum Ausbruch des Zweiten Weltkrieges. Dadurch gelangten Vorhaben vielfach gar nicht mehr zu einer definitiven Regelung. Es sollte den rigiden sozialistischen Kollektivierungsmaßnahmen der Zeit nach 1948 überlassen werden, hier diesmal unumkehrbar - völlig neue Strukturen zu schaffen.

So konnten in den fünf betroffenen Județe (Kreis) des ehemaligen österreichischen Kronlandes (Cernăuţi, Rădăuţi, Suceava, Storojineț und Câmpolung) im Zeitraum von

Standardwerk und liefert einen detaillierten Uberblick zu den gesetzlichen Grundlagen der Reform, ihrer Anwendung sowie ihren Folgen; allerdings lässt die Darstellung bei ŞA NDRU nur schwer einen Vergleich zwischen den so heterogenen Regionen des Königreiches zu; in der Beziehung erscheint die Analyse bei Bulgaru (2003/1968, Reforma) zielführender, besonders die Zusammenfassung im Vorwort von Păun Ion OTIMAN (V-XXIV).

2 HUber 1973, Grundzüge, 119.

3 Rumpler \& Scharr (Hg.) 2015, Kataster.

4 ŞANDRU 1975, Reforma, 25.

5 MÜLleR 2001, Agrarpopulismus, $77 \mathrm{f}$.

6 Für die Bukowina existierte - wie für alle anderen Provinzen auch - ein eigenes Agrarreformgesetz, online-Version [http://www.monitoruljuridic.ro/], Legea nr. 3608/1921 pentru reforma ăgrară din Bucovina v. 30.VII.1921 sowie Decret Nr. 4.823 v. 22.XI.1921 privind aprobarea Regulamentului pentru punerea in aplicare a legii agrare din Bucovina, Monitorul Oficial nr. 192 v. 26.XI.1921; ebenso hatte Bukarest für die Bukowina besondere Durchführungsbestimmungen erlassen, ANR-B FMAD, inv. 1486, pach. 138, Regulamentul Special pentru Aplicarea pe teren a lucrărilor de expropr. în Bucovina, fol. 33-38.

7 Murgescu 2015, Agriculture, 57. 
1919 bis 1928 zwar mehr als 195.000 Hektar neu eingemessen werden, davon wurden allerdings nur 90.000 Hektar auch endgültig parzelliert bzw. unter neuen Besitzern aufgeteilt. ${ }^{8}$ Mitverantwortlich an dieser Situation waren unter anderem die durch den Krieg teilweise fehlenden oder auf unterschiedliche Orte verstreuten Verwaltungsakten aus der österreichischen Zeit. Das betraf konkret Grundbücher und Kataster, die zunächst erst mühsam wieder zusammengesellt werden mussten. ${ }^{9}$ Obwohl die Bukowina nach Kriegsende als einziges Gebiet des rumänischen Königreiches eine laufende Evidenzhaltung der Kataster sowohl im städtischen wie im ländlichen Raum (verteilt auf 24 Katastralevidenzhaltungsbüros) vorweisen konnte, verzögerten sich die Arbeiten an der Agrarreform selbst hier bis ins Jahr 1938. Die dafür in Czernowitz zuständige Verwaltung gestand das auch offen ein, verwies jedoch auf hinderliche Umstände wie fehlendes Personal und mangelhafte technische Ausstattung. So mussten die Beamten für die Vermessungsarbeiten vor Ort beispielsweise auf öffentliche Verkehrsmittel zurückgreifen, da sie über keine eigenen Fahrzeuge verfügten. Zusätzlich hatte die Bukowina mit der administrativen Neuaufstellung zu einem Tinut (’Kreis`) Gebiete des Altreiches und des ehemaligen zaristischen Bessarabiens (Dorohoi und Hotin) übertragen bekommen, wo - wie generell im Regat - vergleichbare Einrichtungen wie Grundbuch und Kataster weitestgehend fehlten. ${ }^{10}$ Hauptverantwortlich für diese Entwicklung war insgesamt die prinzipiell reservierte Haltung der Bukarester Regierung gegenüber den vormals habsburgischen Gebieten. Ihr lag offensichtlich wenig daran, vakante Stellen in den Vermessungsämtern mit qualifiziertem Personal auszustatten bzw. diese überhaupt neu zu besetzen. ${ }^{11}$

In der Bukowina standen in Summe etwas mehr als 74.000 Hektar für die Enteignung bzw. Umverteilung zur Verfügung. Von den betroffenen mehr als 800 Liegenschaften ent-

8 ANR-B, FMAD, inv. 1486, Direcția Cadastrului (1864-1948), pach. 9o, Situaţia lucrărilor de măsurătoare și parcelare pe județe, în perioda 1919-1928, fol. 1; eine Aufstellung der in der Bukowina durchgeführten Maßnahmen zur Agrarreform in den Jahren 1922-1937 (z.T. gegliedert nach Katastralämtern für 1932-1938) findet sich unter pach. 138, Situație Generală, Reforma Agrară, fol. 131 u. 135.

9 ANR-B, FMAD, inv. 1486, Direcția Cadastrului (1864-1948), pach. 91, Referat v. 24.VII.1924, fol. 5-8.

10 ANR-B, FMAD, inv. 1486, pach. 177, Inspectoratul Cadastral Cernăuţi v. 1.IX.1938, Lucrările Reformă Agrară în Bucovina, fol. 126-129; dabei war der Vorgang der Zuteilung im Vergleich zur Größe der Einheiten vergleichsweise aufwendig: die neu eingemessenen Parzellen wurden je Gemeinde Einzelpersonen zugewiesen; die Verrechnung erfolgte über Hypothekarkredite der Bauern; für die Vermessungsarbeiten wurden zusätzlich Spesen angesetzt, so fielen 1926 beispielsweise für die Gemeinde Voroneț (Gura Humorului) aus Religionsfondsgründen knapp unter dreieinhalb Hektar an, die auf 24 ,Locuitori (Einwohner) zu verteilen waren; die Belastung belief sich auf gerundet 5.200 Lei; zudem kosteten die Vermessungen selbst 2.600 Lei; ANR-B, FMAD, inv. 469, Direcţia Funciară, pach 20-5, fol. 2-5 v. 1.I.1926.

11 MÜLLER 2015, Geschichtsregionen, $69 \mathrm{f}$. 
fielen allein 113 (mit 27.500 Hektar) auf Eigentum des Religionsfonds. Berechnet man allerdings die darüber hinaus betroffenen Pfarren (mit weiteren 252 Liegenschaften verteilt auf knapp 3.300 Hektar), die unabhängig vom Fonds erfasst wurden, mit ein, so ist der kirchliche Beitrag zur Agrarreform in der Bukowina vergleichsweise groß. ${ }^{12}$ Diese Situation erklärt sich mithin in der nach 1918 geschwächten Stellung der Metropolie gegenüber dem rumänischen Staat. Das bedingte, jedoch weitgehend konsensorientierte Mitentscheidungsrecht der Landeskirche am Umgang mit dem Vermögen des Religionsfonds, wie es vor dem Weltkrieg existiert hatte, war - wie schon dargestellt - durch die Zentralregierungen in Bukarest erheblich eingeschränkt worden. Zudem verbuchten die in der Provinz politisch entscheidenden nationalen Kreise um Ion Nistor nur allzu gerne die Agrarreform in der Öffentlichkeit als eigenen Erfolg für die rumänische Sache, hatte sie doch - aus dieser Perspektive - Eigentum, das sich bislang in vermeintlich 'fremden « Händen befand, der Nation zurückgegeben. ${ }^{13}$ Das beließ für die Kirche wenig Handlungsspielraum, dem offen zu widersprechen. Kritische - wohl auch persönlich enttäuschte - Stimmen wie jene des früheren Direktors der Bukowiner Religionsfondsverwaltung Georgi Sârbu warfen Bukarest unverhohlen vor, das betroffene Fondseigentum im Mantel der Agrarreform bewusst weit unter Wert zu »Bagatellpreisen « angesetzt zu haben. ${ }^{14}$ Selbst die Ablösungszahlungen des Staates an den Fond für die enteigneten Grundstücke ließen mitunter Jahre auf sich warten. ${ }^{15}$ Teilweise dürften bei der Vergabe der Fondsgründe zu derart günstigen Preisen auch handfeste politische Interessen von Einzelpersonen eine entscheidende Rolle gespielt haben. So sollte etwa der unmittelbar hinter Vatra Dornei gelegene `Parcul Runcului<, der zum Fondseigentum gehörte, ebenfalls enteignet und dann in der Folge mit einem vergleichsweise wertlosen Grundstück im umliegenden Gebirge kompensiert werden. Dagegen opponierten allerdings nicht nur Fondsverwaltung, Kurstadt und ihre Einwohner, sondern ebenso die Medien. ${ }^{16}$ Auf die

12 Dово\$̧ 1928, ani, 159.

13 Dовоş 1928, ani, 156.

14 SÂrBU 1931, Reflexiuni, XI; eine Bestätigung dieser Aussage muss hier ausbleiben, allerdings lässt sich zumindest der im Jahr 1928 angesetzte Hektarpreis für Religionsfondsgüter im südlichen Landesteil (mit lokalen Unterschieden) zwischen 735 und 773 Lei beziffern; ANR-B, FMAD, inv. 469, pach. 39, fol. 1, Consilieratul Agricol Câmpolung an Casa centrală a improprietarii direcţiunea funciară București v. 4.X.1928; pach. 46, fol. 1 v. 26.VI.1928; dazu ŞANDRU 1975, Reforma, 218-222.

15 ANR-S inv. 35/I, pach. 29-1938, fol. 1-4; MAD, Lichidarea definitivă v. 20.VI.1929 sowie FBis an MAD v. 25.IX.1937; betreffend knapp 72 ha an Fondsgründen bei Cotul Ostriţa zum Preis von 81.700 Lei, deren ausständige Bezahlung der Fonds noch im 1937 beim Ministerium urgierte.

16 Ziarul Țara Nr. 34 v. 21.III.1930, 3, Ancheta noastră în Bucovina. Pentru d. ministru al Domeniilor. La ce se pretează administrația Fondului bisericesc. Un schimb oneros de terenuri la Vatra Dornei care trebue zădărnicit; ANR-B, FMAD-CA (județe din Basarabia și Bucovina), inv. 48o, pach. 7-1924, fol. 4, Comisia Balneară Vatra Dornei an MAD București v. 3.VIII.1930, worin sich die Kurkommission 
vergleichsweise zum Altreich vorherrschende Radikalität der Reform in der Bukowina und ihre vermeintlichen Betreiber, die Liberalen unter Nistor, hatte bereits Flondor 1919 hingewiesen: "Nu înţeleg ca din grădina Bucovinei să facem o băltoacă «. ${ }^{17}$

Auch in anderen Fällen formierte sich in der Fondsverwaltung teilweise erfolgreicher Widerstand gegen konkrete, obgleich in der Masse wenig bedeutende, Enteignungsvorhaben. Dabei argumentierte man vor allem mit dem Hinweis, dass der Religionsfonds im Grunde eine nationale Stiftung sei, mit dem dezidierten Auftrag zur Erhaltung von Schulen sowie Kirchen. ${ }^{18}$ Nach Vorschlägen der für das Gebiet eingesetzten Agrarreformkommission 1923 waren mehrere Gebäude sowie Gründe des Bergbaugebietes Iacobeni zu enteignen. Daraufhin intervenierte Metropolit Nectarie persönlich beim Minister in Bukarest und verlangte im Hinblick auf die Bedeutung der Werke eine Rücknahme dieser Verordnungen. ${ }^{19}$ Das verantwortliche Agrarkomitee hingegen notierte, dass die Enteignung keine Einschränkungen in der wirtschaftlichen Aktivitäten nach sich ziehen würde. ${ }^{20}$ Die in diesem Falle beharrlich gebliebene Verwaltung des Religionsfonds hatte letztlich vor dem Ministerium Erfolg, und die avisierten knapp 18 Hektar in Iacobeni verblieben im Fondseigentum. ${ }^{21}$ In anderen Gemeinden der Bukowina gelang es offenbar wiederum durchaus betroffenen Bauern, sich Fondsgründe anzueignen.

Aus dem vorliegenden Bild erhärtet sich insgesamt die Annahme, dass die Regierung den Fonds absichtlich dafür nutzte, die Reform in der Bukowina gerade hier, wo nur geringer Widerstand zu erwarten war, durchzudrücken. ${ }^{22}$ Auch wenn sich der Staat zur Umsetzung der Agrarreform des Religionsfonds vergleichsweise zu anderen Großgrundbesitzern einfacher bedienen konnte, so darf das insgesamt nicht darüber hinwegtäuschen, dass gerade in der Bukowina das angestrebte Ziel einer weitreichenden

gegen die Enteignung von 1922 aussprach, da der Park seit mehr als fünf Jahrzehnten der Erholung diente; fol. 42, Bürger von Vatra Dornei an MAD București v. 2.VIII.1929.

17 [Ich verstehe nicht, wie man aus dem Garten Bukowina einen Sumpf machen kann], Chemarea (Iași) Nr. 14, 4./17.IV.1919, Interview Flondor; nach ЕсомомU 2011, Unirea, 68.

18 ANR-B, FMAD-CA (județe din Basarabia și Bucovina), inv. 480, pach. 2-1923, fol. 9, Expropriera moșiei Iacobeni, Direcția Generală a FBis an FMAD-CA București v. 22.I.1924.

19 Wie Anm. 18, fol. 24-26, Metropolit Nectarie an Minister v. 1.XII.1924.

20 Wie Anm. 18, fol. 34, CA Sitzung v. 22.XII.1927, Hotararea $n$ r. 54.

21 Wie Anm. 18, fol. 40-42, Administraţia Generală a FBis an CA București v. 17.XI.1928.

22 Neuere Untersuchungen zu Wirkungen wie politischen Hintergründen der Agrarreform von 1921 im Vergleich der einzelnen Regionen Großrumäniens fehlen bislang; eine umfassende Regionalanalyse (etwa zum Verhältnis der Großgrundbesitzer, den politischen Entscheidungsträgern, den lokalen Auswirkungen etc.) ebenso, sodass das hier gezeichnete Bild vorerst unvollständig bleiben muss; in Auswahl ŞANDRU 1975, Reforma; BULGARU 2003, Reforma; vergleichend bei vanMeURs 1999, Land Reform; Florin 2009, Colectivizarea. 
Landumverteilung letztlich nicht erreicht werden konnte. ${ }^{23}$ Mit Blick auf die anderen Regionen Rumäniens (Vechiul Regat, Basarabia, Transilvania) blieb der durchschnittliche Anteil landwirtschaftlich genutzter Fläche pro Bauer unter einem Hektar. In Siebenbürgen lag dieser Wert immerhin bei mehr als vier Hektar. ${ }^{24}$

\section{Kulturpalast Czernowitz}

Die Errichtung des nationalen (rumänischen) Kulturpalastes in Czernowitz Ende der 1930er Jahre gehörte sowohl für die Stadt wie für den Religionsfonds, als dessen hauptsächlichem Financier, zu den größten weltlichen Bauvorhaben der Zwischenkriegszeit in der Bukowina (vgl. Tab. 12). Sein prominenter Standort unweit des Theaters, die massive Kubatur und die Fassadengestaltung mit den Städtewappen der Bukowina - inklusive der nach 1918 hinzugekommenen Kreise (Suceava, Rădăuţi, Cernăuţi, Câmpolung, Hotin, Storojineţ, Dorohoi) - waren gleichsam ein im urbanen Raum greifbar gewordenes politisches Programm der >Wiedervereinigung (vgl. Abb. 55). In einer etwas weniger auffälligen Weise spiegelt sich dieser nicht unproblematische Prozess auch in der Baugeschichte selbst deutlich wider.

Tab. 12 - Ausgaben (vorwiegend Investitionen) des Religionsfonds 1930-1940, in Lei gerundet. ${ }^{25}$

\begin{tabular}{|l|r|}
\hline Bau und Erhaltung von Kirchen & 42.800 .000 \\
\hline Restaurierung von historischen Denkmālern & 3.500 .000 \\
\hline Bau und Erhaltung von Pfarrgebäuden & 8.700 .000 \\
\hline Gebäude von kulturellem, nationalen, sozialen Interesse ${ }^{1}$ & 110.200 .000 \\
\hline Stipendien, Veröffentlichungen, Kultur- u. Kirchenpropaganda & 9.600 .000 \\
\hline Unterstützung der Orthodoxie (Kirchen außerhalb der Eparchie etc.) & 6.500 .000 \\
\hline Wohlfahrt & 5.000 .000 \\
\hline Holzzuschüsse f. bedürftige Institutionen / Bevölkerung (letzte 3 Jahre) & 26.000 .000 \\
\hline Theologische Fakultät, Internat, Kantorschule etc.) & 50.000 .000 \\
\hline Ausgaben in Summe & 262.300 .000 \\
\hline
\end{tabular}

1 davon u.a. 92 für den Kulturpalast in Czernowitz, 7 für ein Wohnhausund 3 Millionen für die Universitätsbibliothek.

\footnotetext{
23 SANDRU 1975, Reforma, 62.

24 Bulgaru 2003, Reforma, XIX (Vorwort P. I. ОтомAN).

25 DACZ $_{320 / 1 / 2765}$, fol. 7-9, hier: fol. 9, Mitropolia Bucovinei, Mitropolit an Ministru al Cultelor și Artelor, Tablou rezumativ, Cernăuţi v. 26.IV.1940.
} 
Der Linguist und rumänische Kulturschaffende Grigore Nandriş (1895-1968) hatte 1929 die Stelle eines außerordentlichen Professors am Lehrstuhl für slawische Philologie an der nunmehr rumänischen Universität von Czernowitz angetreten. Zeitgleich avancierte er zum Präsidenten der `Gesellschaft für rumänische Kultur und Literatur der Bukowina، (Societatea pentru Cultura și Literatura Română din Bucovina). Bereits 1919 hatte der Bukowiner Politiker und Großgrundbesitzer Flondor der 1862 gegründeten Societatea im Zentrum der Landeshauptstadt - auf der seit Kriegsende rumänisch benannten Piaţa Vasile Alecsandri (heute ukr. Tеатральна площа /Tetral'na Ploschtscha) einen Baugrund überlassen. Allerdings führten die komplizierten juristischen Ablösungsverhandlungen mit den dort ansässigen Geschäften und die politischen Interventionen Bukarests zu einer Verzögerung von mehr als eineinhalb Jahrzehnten. Außerdem blieb die eigentliche Frage nach der Finanzierung des vierstöckigen Gebäudes lange Zeit unbeantwortet. Ein Treffen zwischen Nandriș und Nistor am 4. April 1937 legte schließlich diesen Rechtsstreit bei. ${ }^{26}$ Den Baugrund steuerte die Societatea bei, die Kosten von etwa 100 Millionen Lei übernahm der Religionsfonds ${ }^{27}$, wobei dem Fonds als Gegenleistung zumindest die Hälfte des Gebäudes zur Nutzung zur Verfügung gestellt werden sollte. Ein 1937 verabschiedetes Gesetz der Bukarester Regierung brachte das Vorhaben, dessen Fertigstellung man in etwas mehr als einem Jahr anstrebte, auf die Zielgerade, vorläufig zumindest. ${ }^{28}$ Sowohl Fonds als auch Societatea fungierten dabei zu gleichen Teilen als Bauherren, allerdings blieb in Konsequenz unbeantwortet, wer nun der eigentliche Eigentümer des Kulturhauses war. ${ }^{29}$ Die überraschende sowjetische Besatzung des nördlichen Landesteils verhinderte indes eine Fertigstellung des Baus, die erst in der zweiten Hälfte des Jahres 1941 vorgenommen werden konnte. Ein nach der Befreiung verfasstes Schreiben der Ephorie stilisierte folglich den Bau in patriotischer Form zum »Leuchtturm, von dem das rumänische Licht auch außerhalb der Nordbukowina erstrahlen « sollte (vgl. Abb. 55$).^{30}$

26 Maria ToACĂ : Cum s-a construit palatul cultural al românilor din Cernăuţi cu leul săracului, in: Zorile Bucovinei - Ziarul românilor din ucraina ziarul românilor din ucraina v. 23.IV.2015 [http://www. zorilebucovinei.com/news/show/1088/]; ders.: Cum s-a construit Palatul Cultural al Românilor din Cernăuţi, in: Crai Nou v. 12.V.2015 [http://www.crainou.ro/2015/05/12/cum-s-a-construit-palatulcultural-al-romanilor-din-cernauti/].

$27 \mathrm{DACZ}_{321 / 5 / 51}$, fol. 138f., Referat nr. 7608/40, Vatra Dornei v. 4.XI.1940.

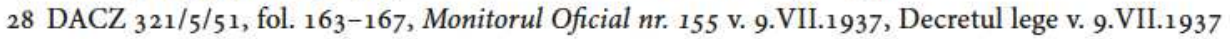
und Conventiune.

29 "[...] Că nu știe precis cine e proprietarul lui« [(..) Man weiß nicht genau, wer der Eigentümer davon ist], DACZ $321 / 5 / 161$, fol. 2-36, hier fol. 5, Comisiunea de control financiar a FBis v. 20.XI.1942.

$30 \mathrm{DACZ}_{321 / 5 / 51}$, fol. 140-142, FBis Eforia an Ministru al Finanțelor București, Memoriu, Vatra Dornei v. $12 . X I .1940$; fol. $163-167$. 


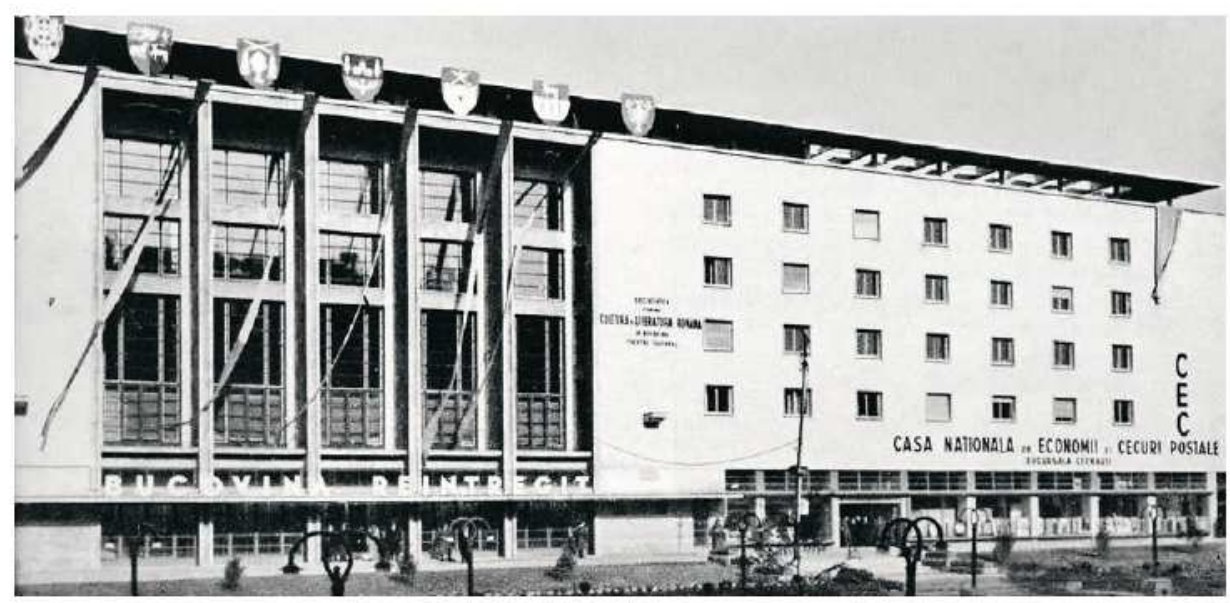

Abb. 55: Palatul cultural conceput că o operă arhitectonică românească monumentală ('Der Kulturpalast ist als monumentales Werk rumänischer Architektur konzipiert‘). Photographie des Kulturpalastes v. 1.XI.1942, nach Wiedereingliederung der Bukowina, worauf die Inschrift über dem Eingangsprotal (Bucovina Reintregit) deutlich verweist. ${ }^{31}$

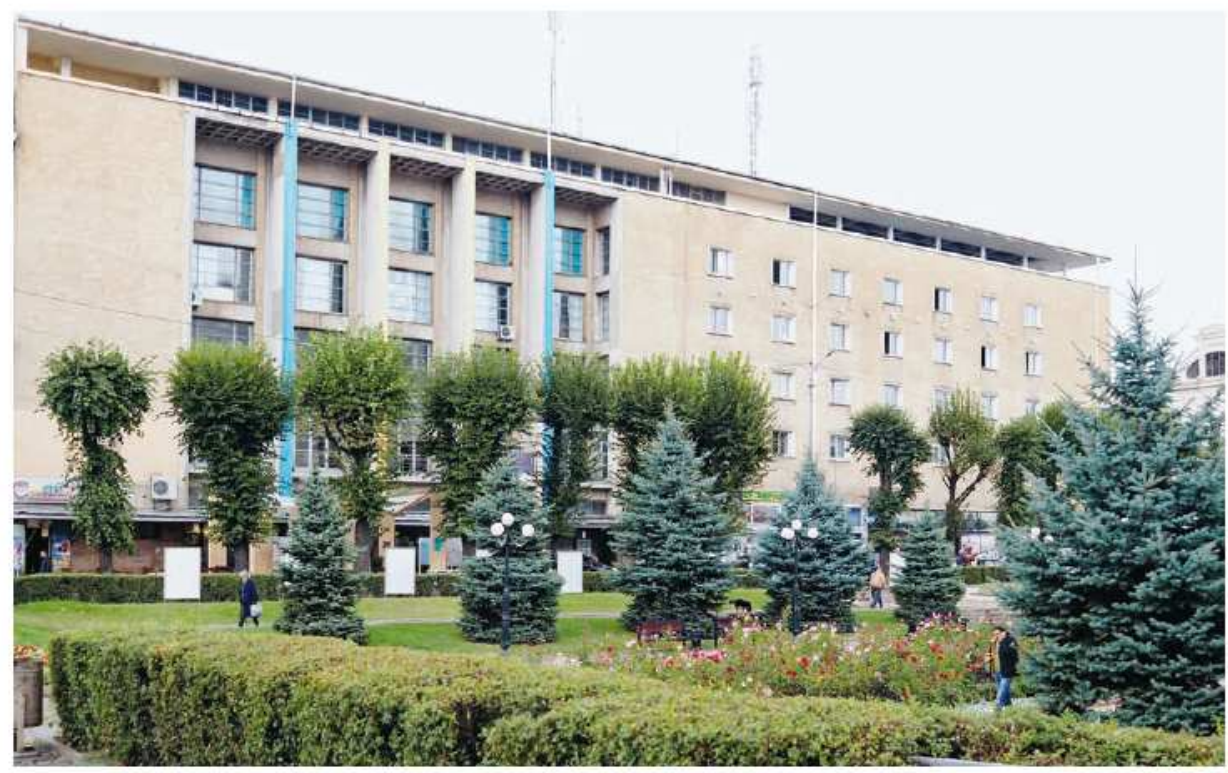

Abb. 56: Das Gebäude des vormaligen rumänischen Kulturpalastes von Cernăuți heute. @Aufnahme K. Pierer Sep. 2016.

31 DACZ $_{321 / 5 / 51}$, fol. 165, Monitorul Oficial Nr. 155 v. 9.VII.1937, Decretul lege pentru aprobarea Convenţiei relative la Palatul Cultural din Cernăuți v. 9.VII.1937; dazu die Online-Dokumentation 


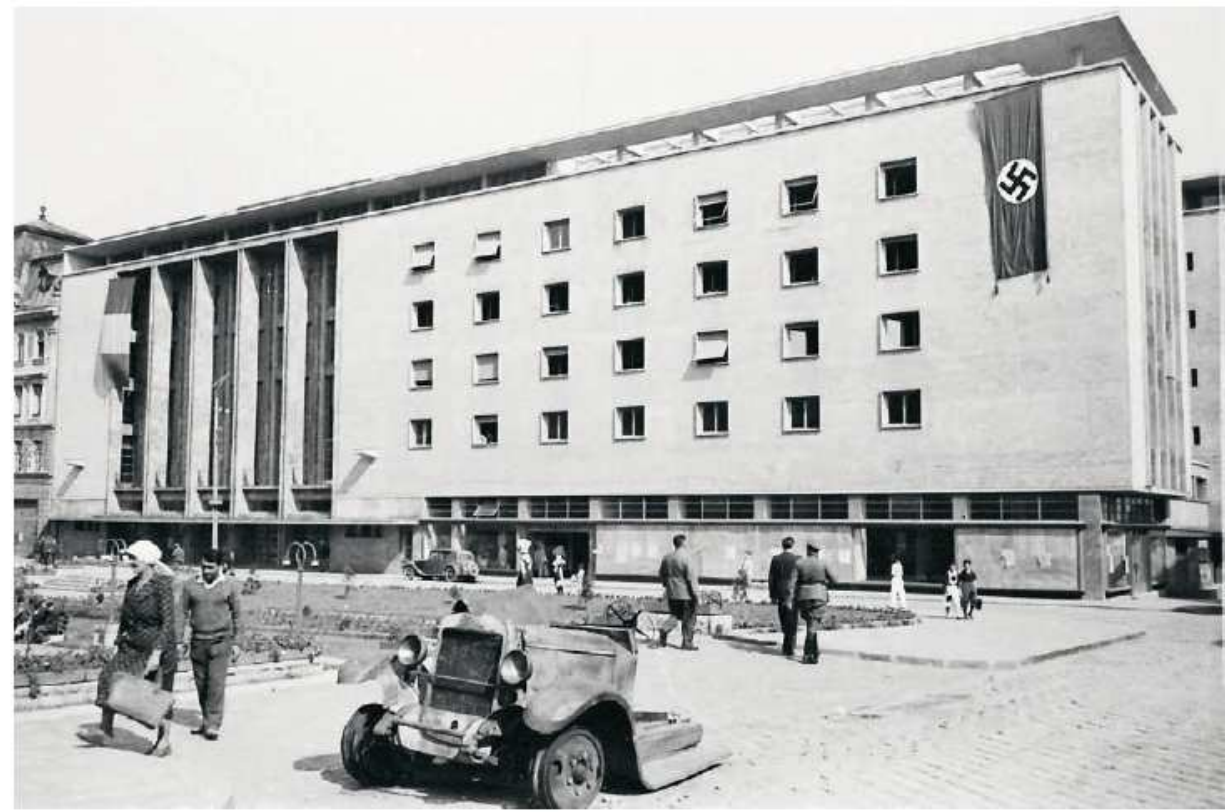

Abb. 57: Der noch nicht gãnzlich fertiggestellte Kulturpalast kurz nach der Wiedereroberung der Nordbukowina durch rumänisch-deutsche Truppenverbände, mit der rumänischen Trikolore links und der Hakenkreuzfahne rechts. (C) Aufnahme Willy Pragher v. 24.VII.1941.32

\section{Kriegswirtschaft und Religionsfonds}

Die Ereignisse vom Juni 1940 hatten die Institution des Religionsfonds gleich in mehrerer Hinsicht schwer getroffen. ${ }^{33}$ Nicht nur, dass die Landeshauptstadt von sowjetischen Truppen besetzt war, auch wichtige Wirtschaftsflächen gingen dem unmittelbaren $\mathrm{Zu}$ griff des Fonds verloren. Obwohl der meiste Fondsbesitz und damit die zentralen wirtschaftlichen Einrichtungen (etwa die Bergwerke von Iacobeni) in den südlichen Landesteilen lagen, hatte der Fonds neben dem allgemeinen Chaos zusätzlich die Probleme der neu zu organisierenden Verwaltung und der merkbar fehlenden Arbeitskräfte zu stemmen. Sowohl die Güterverwaltung des Religionsfonds als auch die Metropolitanad-

,Stilurile Art Deco și Modernist‘ [http://artdeco-modernist.blogspot.com/2011/o6/palatul-culturalnational-al-romanilor.html].

32 Mit freundlicher Genehmigung des Landesarchivs Baden-Württemberg v. 17.01.2017; Staatsarchiv Freiburg, Photograph Willy Pragher; Rumänienbilder, 1941-1944 (Ordner 290) W134 Nr. 031838b; die Originalbeschriftung "Postgebäude» nimmt keinen Bezug auf das Kulturhaus; eine ähnliche Aufnahme aus anderer Perspektive (=Nr. 031838a) findet sich bei PRAGHER 2007, Brechungen, 254. 33 CÁruntu 2004, Bucovina, 176-195. 
ministration hatten Czernowitz überstürzt verlassen müssen und ihren Sitz nach Vatra Dornei verlegt. Offenbar war in den Evakuierungsplänen von 1940 vorgesehen gewesen, das gesamte Fondsarchiv mit einem Eisenbahnwaggon über die Demarkationslinie in Sicherheit zu bringen. Doch selbst ein Jahr später, im Juni 1941, fehlte den Fondsbehörden über den Verbleib von großen Teilen der für die Verwaltung unabdingbaren Akten nach wie vor jedweder Hinweis. ${ }^{34}$ Außerdem wurden Kirche und Fonds seitens Bukarest im Sommer 1940 mit einer neuen Verwaltungsstruktur, die der Regierung noch mehr Einfluss als bisher einräumen sollte, konfrontiert. ${ }^{35}$

Von den unmittelbar beim Fonds in den nördlichen Landesteilen beschäftigten Funktionären flüchteten 44 Personen mit der Verwaltung nach Vatra Dornei, 22 in andere Teile des Königreiches und weitere 64 verblieben vor Ort im sowjetischen Besatzungsgebiet. ${ }^{36}$ Die im Herbst 1940 durchgeführte Umsiedlung deutscher Bewohner der gesamten Bukowina ins Reich verstärkte den ohnedies schon seit den $1930 e r$ Jahren, unter anderem auf Grund der rigiden Sprachgesetze, merkbaren Facharbeiterschwund. ${ }^{37}$ Über 52.000 Personen verließen die Südbukowina, die Volkszählung von 1941 erfasste in diesem Raum nur mehr ca. 3.700 Deutsche. ${ }^{38}$ Die Folgen dieser Politik zeigten sich besonders in den Forstbezirken des Fonds ${ }^{39}$, aber freilich auch im Bergbau, wo die Mangangewinnung in katastrophaler Weise einbrach. ${ }^{40}$ Zusätzlich zur deutschen Auswanderung verschärften laufende Einberufungen zum rumänischen Heer diesen strukturellen Mangel. ${ }^{41}$ Der Fonds forderte daher bei der Regierung unter anderem die Zuweisung von Juden zum Arbeitseinsatz

34 ANR-S inv. 35/I, pach. 6-1940, Memoriul cu privire la evacuarea Fondului bisericesc din Cernăuţi, Ioan Bilețchi, Director la Fondul bisericesc v. 13.XI.1942.

35 Kapitel 8, Fondul Bisericesc Ortodox Român; ANR-S inv. 35/I, pach. 11-1940, fol. 217, Șeful serviciului administrativ, Referat, Vatra Dornei v. 6.IX.1940.

36 ANR-S inv. 35/I, pach. 11-1940, fol. 198-203, Nr. 498/40 Referat asupra situaţiunii funcţionarilor bugetari din administrația FBis.

37 Die Umsiedlung aus der sowjetischen Nordbukowina dauerte von 9.IX. bis 17.XI.1940 und umfasste rund 44.00o Personen, jene aus der Südbukowina wurde im Dezember 1940 abgeschlossen; zur Umsiedlung Hausleitner 2001, Rumänisierung, 366-374; OsatschuK 2004, Pereselennja,

38 CÁRUNT 2004, Bucovina, 183.

39 Mit Ende 1940 werden beispielsweise, verteilt auf 16 Forstbezirke allein in der Südbukowina 60 Personen angegeben, die sich für die Auswanderung entschieden haben; ANR-S inv. 35/I, pach. 142-1941, fol. 49, Gura Humorului v. 18.I.1941; ANR-S inv. 35/I, pach. 11-1940, fol. 493, Mişcarea Legionară Regiunea VIII-A, Serviciul Economic an Deutsches Umsiedlungskommando, Hauptstab Gura Humora, Suceava v. 27.XI.1940.

40 CĂ RUNTU 2004, Bucovina, 184.

41 Auch abseits der deutschen Auswanderung verstärkten die laufenden Einziehungen ins rumänische Heer diesen Mangel; so setzte sich etwa die Minenverwaltung von Jakobeny vehement dafür ein, zumindest das für den Betrieb unabdingbare Fachpersonal vom Militärdienst freizustellen; ANR-S inv. 35, pach. 2-1946, fol. 11, Administraţia Minelor Iacobeni an AFBis, Cernăuţi v. 11.X.1941. 
an. ${ }^{42}$ Indes belastete über den ganzen Krieg hinweg nicht nur das Fehlen an Arbeitskräften die Fondswirtschaft. Jetzt begannen sich neben den üblichen >Differenzen` mit der Staatsverwaltung in Bukarest auch die ungenügenden Zuteilungen an Transportmaterial seitens der rumänischen Eisenbahn negativ auszuwirken. Vielfach konnten deswegen Lieferungen nicht zeitgerecht erfolgen. ${ }^{43}$ Selbst die an sich dringend nötige Wiedereingliederung des verbliebenen und zum Teil aus der Nordbukowina geflohenen Personals in den Arbeitsprozess bereitete ungeahnte Schwierigkeiten, da - so der Vorwurf der Fondsverwaltung - eine "effektive Hilfe seitens des Staates « weitgehend ausgeblieben war. ${ }^{44}$

Das Vermögen der nördlichen Gemeindegebiete (ohne Czernowitz) in der sowjetisch besetzten Bukowina (Ciudei, Codrul Cosmin, Cuciurul Mare, Frătăuţi Noi, Jucica, Revna, Vicovul de sus, Pescaria Cosmeni) ging dem Zugriff des Fonds gänzlich verloren. Die südlichen Landesteile hatten fallweise größere (Moldovița, Ostra, Pojorâta, Solca, Stulpicani, Vama, Vatra Dornei) oder geringere (Argel, Cârlibaba, Dorna Candrenilor, Frasin, Gura Humorului, Iacobeni, Ilișești) Gebietsverluste, abhängig von der Grenzziehung, zu beklagen (vgl. Tab. 13). In Summe musste die Fondsverwaltung während der ersten sowjetischen Periode beträchtliche Verluste verbuchen. ${ }^{45}$ Wohl gerade deswegen organisierte Bukarest zur Wiedereingliederung der nördlichen Bukowina ein Jahr später eigens eine

42 DACZ $_{321 / 5 / 168}$, Instruktion 1941/43; 321/5/598, fol. 8-9, FBis an Guvernământul Bucovinei, comisiunea pentru verificarea evreilor, Cernăuți v. 5.VIII.1943; dem Schreiben liegt eine Liste mit Personenamen, ihrem Einsatzort sowie ihrer Funktion bei; der tatsächliche Umfang sowie Verlauf des Arbeitseinsatzes von Juden in der Bukowina für den Religionsfonds kann hier nicht zufriedenstellend dokumentiert werden, da die Akten dafür in den Fondsbeständen weitgehend fehlen.

43 ANR-S inv. 35/I, pach. 33-1942, fol. 3-40, FBis Eforia v. 9.VIII.1943, Raport de activitate.

$44 \mathrm{DACZ}_{321 / 5 / 10}$, fol. 1-12, FBis, Raport de activitate pe trimestrul 1/I-31/III 1941, Vatra Dornei v. 21.VI.1941.

45 An direkten Verlusten werden in Summe 198 und als indirekte 27 Millionen Lei genannt; ANR-S FBis inv. 35, pach. 23-1941, Repartizarea Pagubelor rezultate in urma invaziei inamice resp. evenenimentelor de războiu, Cernăuți v. 25.XII.1941; an anderer Stelle wird der Verlust für den Religionsfonds in der Nordbukowina mit einer Höhe von 480 Millionen Lei berechnet, davon entfallen über 360 Millionen auf Forste, Gebäude, Fischzuchten und andere bauliche Einrichtungen; bei einem Gesamtvermögen (ohne Finanzmittel; Stand v. 31.III.1939) von knapp 1,94 Milliarden Lei wäre das immerhin ein Viertel, DACZ 321/5/161, fol. 2-36, hier fol. 4 u. 12, Comisunea de control financiara FBis, Proces verbal nr. 2 v. 20.XI.1942; in der Nachtragsbilanz auf Vergleichsbasis zum Jahr 1939 belaufen sich die Gesamtverluste für den Religionsfonds für die Zeit der sowjetischen Besatzung auf über zwei Milliarden Lei, ANR-S inv. 35, pach. 135-1941, fol. 6-8; allein die persönlichen deklarierten Verluste der betroffenen Funktionäre des Fonds erreichten 25 Millionen Lei, ANR-S inv. 35/I, pach. 111-1942, fol. 36, Borderou de pagubele declarate de funcționarii FBis, Cernăuți v. 21.XII.1942; allerdings lassen sich die Berechnungen aufgrund ihrer jeweils unterschiedlichen Zusammenstellung heute nur mehr schwer in absoluten Zahlen quantifizieren, zudem schwanken die Angaben wie gezeigt - zum Teil beträchtlich. 
Ausstellung in Czernowitz, an der sich der Religionsfonds an prominenter Stelle beteiligte, allerdings nicht ohne diese auch mit einer Summe von 800.000 Lei finanziell zu stützen. ${ }^{46}$

Tab. 13: Forstwirtschaftsbezirke des Religionsfonds 1938/1940 47

\begin{tabular}{|c|c|c|}
\hline \multirow{2}{*}{1938} & \multicolumn{2}{|c|}{ Verluste Juni 1940} \\
\hline & gänzlich & teilweise \\
\hline Argel & & $x$ \\
\hline \multicolumn{3}{|l|}{ Breaza } \\
\hline Brodina & & $x$ \\
\hline Cârlibaba & & $x$ \\
\hline Ciudeiu & $x$ & \\
\hline Codrul Cozminului & $x$ & \\
\hline \multicolumn{3}{|l|}{ Codrul Voevodesei } \\
\hline Cuciurul Mare & $x$ & \\
\hline \multicolumn{3}{|l|}{ Falcău } \\
\hline Gurahumorului & & $x$ \\
\hline lacobeni & & $x$ \\
\hline Ilişeşti & & $\mathrm{x}$ \\
\hline Jucica & $x$ & \\
\hline \multicolumn{3}{|l|}{ Marginea } \\
\hline Moldovița & & $x$ \\
\hline \multicolumn{3}{|l|}{ Pătrăuți } \\
\hline Pojorâta & & $x$ \\
\hline \multicolumn{3}{|l|}{ Putna } \\
\hline Revna pe Prut & $x$ & \\
\hline Seletin & & $x$ \\
\hline Solca & & $x$ \\
\hline \multicolumn{3}{|l|}{ Straja } \\
\hline Vama & & $x$ \\
\hline Vatra Dornei & & $x$ \\
\hline Vicovul de jos & V. de sus & \\
\hline
\end{tabular}

46 Die Eröffnung der Ausstellung fand am 1.XI.1942 in Czernowitz statt; ANR-S inv. 35/I, pach. 331942, fol. 19-20, FBis Eforia v. 9.VIII.1943, Raport de activitate.

47 ANR-S inv. 35, pach. 135-1941, fol. 6-8, Referat Patrimoniul fondului bisericesc, Serviciul financiar, Cernăuţi v. 12.IX.1941; DACZ 320/2/3511, fol. 13, Tabloul unităţilor administrative (Monitorul Oficial nr. 17/II. 1938, decret lege Nr. 870). 


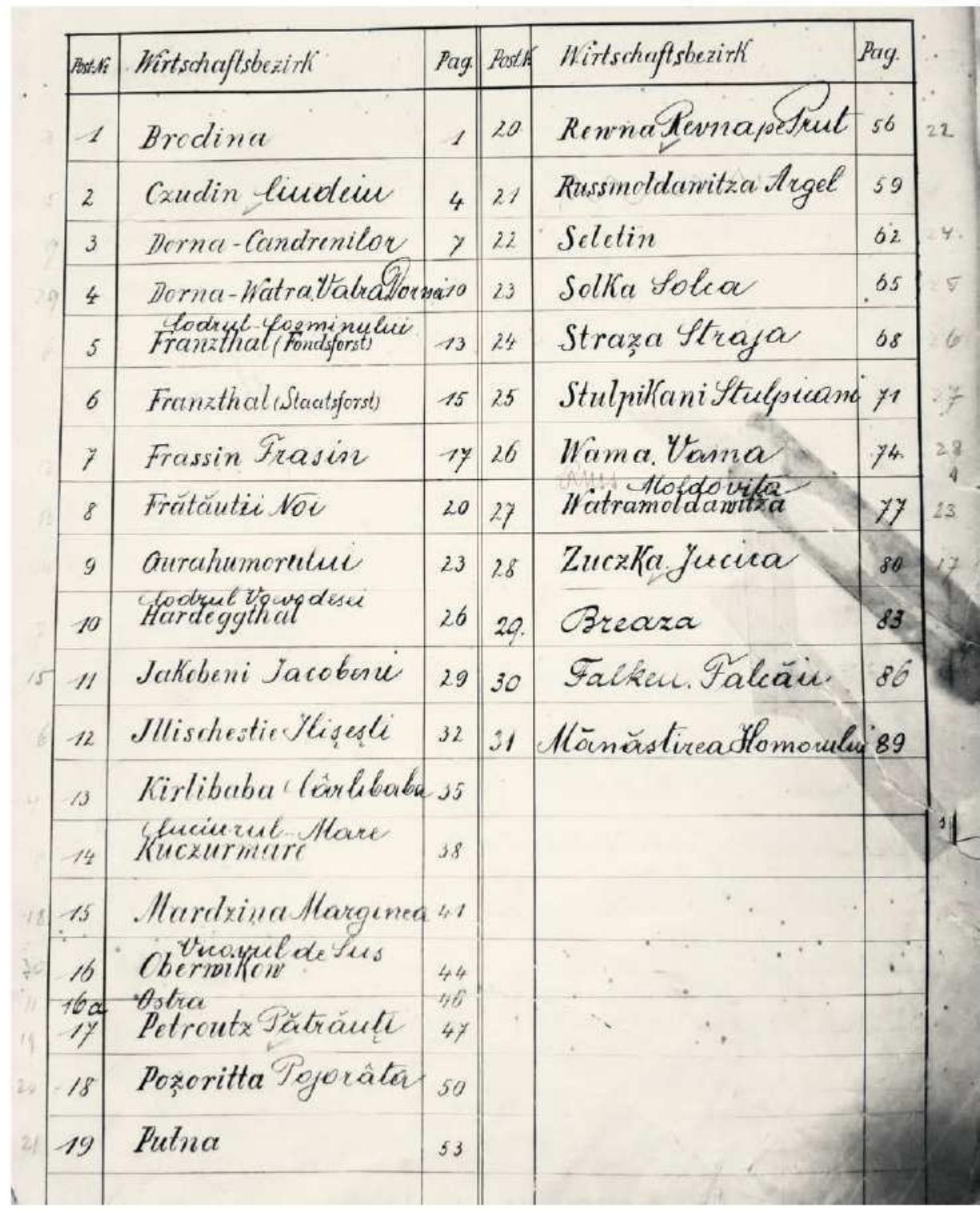

Abb. 58: Forstwirtschaftsbezirke des Religionsfonds. Die noch vor 1918 angefertigte Aufstellung wurde nach 1918 mit den rumänischen Ortsnamen ergänzt und weitergeführt. Von den hier aufgezählten 31 Bezirken existierten 1938 durch administrative Veränderungen noch 24.48

48 ANR-S inv. 35/1, pach. 1-1871, Betriebseinrichtungs-Cataster. 


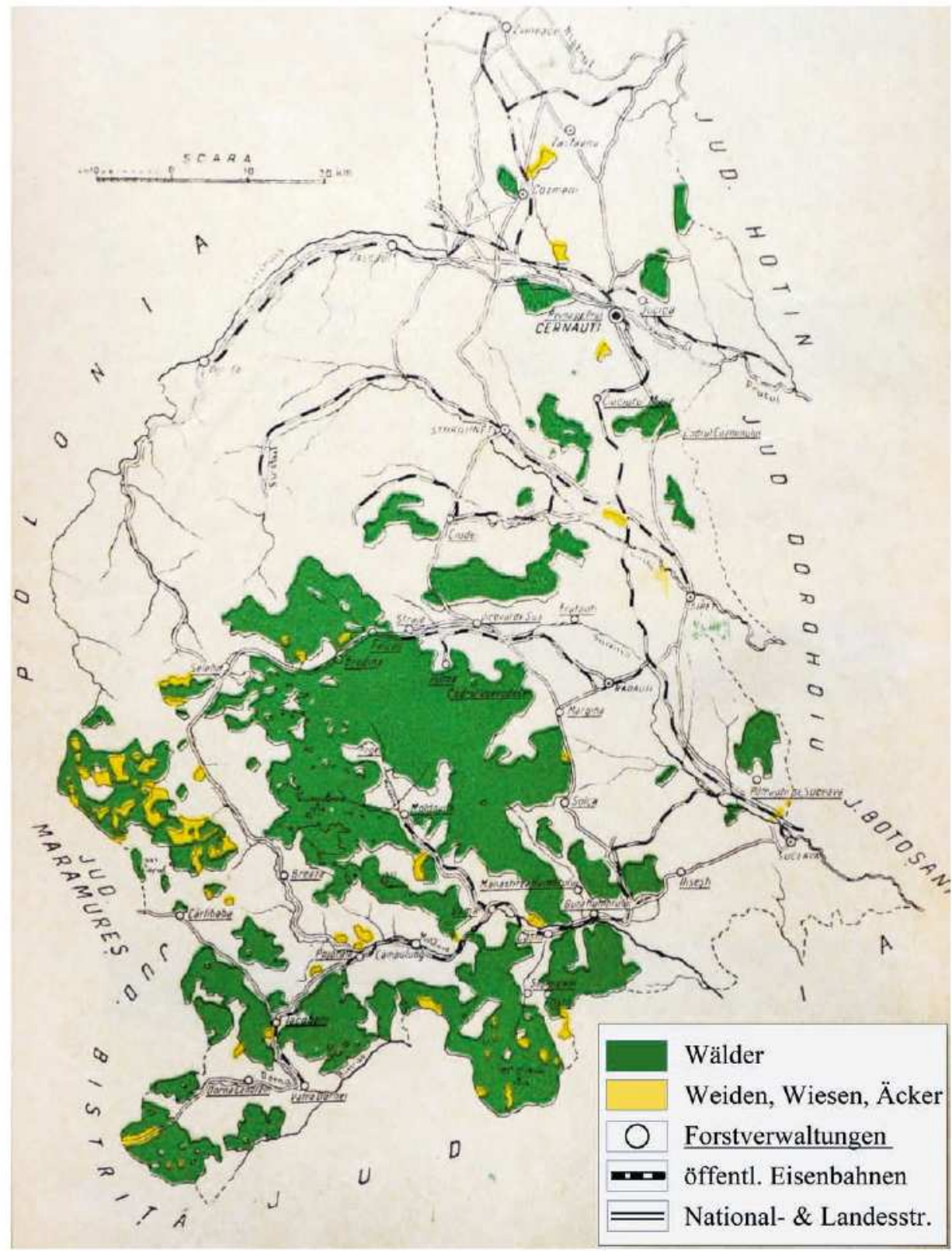

Abb. 59: Religionsfondsbesitz in der Bukowina 1939. Mitropolia (Hg.), 1939, Administrația. 
Ungeachtet der sowjetischen Aggression, die das Königreich an den Rand des Kollapses gebracht hatte, blieben die Geschäftsbeziehungen zum Nachbarn aufrecht. Die noch funktionsfähigen Holzfabriken des Religionsfonds in Putna, Falcău und Moldoviţa lieferten ihre Produkte sowohl in die UdSSR als auch in das Deutsche Reich. Die Ausfuhr wurde weitgehend über den Hafen Constanţa und den Eisenbahngrenzübergang bei Ungheni, einer Kleinstadt östlich von Iași am Pruth gelegen, abgewickelt. ${ }^{49}$ Bis Mitte März 1941 überstellte der Religionsfonds allein über Ungheni 175 Waggons mit einem Wert von über 11,8 Millionen Lei an die Sowjetunion. ${ }^{50}$ Zwischen März und April desselben Jahres gingen weitere 431 Waggons mit fast elf Millionen Kubikmeter Material aus den Fabriken und Forsten des Fonds sowie einem Geldwert von etwa 30 Millionen Lei an die UdSSR. Die Produkte umfassten unter anderem hochwertige Furniere für den Flugzeugbau. ${ }^{51}$ Ähnlich große Mengen verkaufte man während dieser vergleichsweise kurzen Periode an Abnehmer im Deutschen Reich. ${ }^{52}$

Nach dem Waffenstillstandsabkommen des Königreiches mit der Sowjetunion im August 1944 wurden vergleichsweise rasch die regulären Lieferungen von Holzprodukten wieder aufgenommen. ${ }^{53}$ So orderte beispielsweise die neu eingerichtete interstaatliche sowjetisch-rumänische Holzgesellschaft (Sovromlemn) zwischen 1946 und 1948 mehr als 173.000 Kubikmeter Holz aus den auf die südlichen Landesteile der Bukowina reduzierten Fondsforsten der Județe Falcău, Brodina, Straja. ${ }^{54}$ Der Norden war neuerlich nicht nur von der Roten Armee besetzt, sondern auch dem Territorium der UdSSR wieder einverleibt worden. Allein 1949 lieferte der schon in Auflösung begriffene Religi-

49 ANR-S inv. 35, pach. 73-1940, fol. 9-20, Tabel de marfa angajată U.R.S.S., Proces verbal v. 13.I.1941 sowie pach. 74-1940, fol. 2, FBis v. 11.XII.1940, Referat asupra vânzării materialului de cherestea câtre Sindicatul Sovietic, Exportlessı din Moscova U.R.S.S.

50 ANR-S inv. 35 , pach. 74-1940, fol. 226, AFBis, Serviciul comercial, Raport, Vatra Dornei v. 26.III.1941.

51 Wie Anm. 50, fol. 240, AFBis, Serviciul III Fabrici, Referat, Vatra Dornei v. 27.V.1941; fol. 308311, Raport de cheltuilele avute in vederea livrărei contractului de cherestea către firma, Exportlessi v. 5.V.1941.

52 ANR-S inv. 35, pach. 561-1941, fol. 1-34, Recapitulaţie asupra materialului de cherestea eşit din depozitul fabricei Falcău dela 1 Aprilie 1941 la 31 Martie 1942; auch pach. 75-1942, fol. 1, Situaţia comenziler pentru export in Germania, Cernăuți v. 25.I.1942; zudem schien der Fonds (zumindest zwischen 1941 und 1942) in Berlin einen eigenen Holzmakler zu beschäftigen, um den deutschen Markt vor Ort zu betreuen, pach. 75-1942, fol. 62, AFBis, Serviciul comercial, Referat, Cernăuţi v. 25.VI.1942.

53 ANR-S inv. 35, pach. 52-1944, fol. 97f., Proces verbal v. 31.XII.1944; pach. 53-1944, fol. 15f., FBis an Eforia, București v. 22.XI.1944.

54 ANR-S inv. 35, pach. 6-1948, Delegatul direcţiei generale Sovromlemn București, Proces verbal v. 9.V.1948. 
onsfonds Holz in verschiedenen Qualitäten zu einem Wert von 25 Millionen Lei an die Sovromlemn. ${ }^{55}$ Letztlich hatte die für die Auflösung des Fonds zuständige Kommission in den Județe Câmpolung, Rădăuţi und Suceava immerhin noch über 192.000 Hektar, aufgeteilt auf 27 Forstbezirke, zu verwalten. ${ }^{56}$ Die mit Juni 1948 eingeleitete Nationalisierung des Kircheneigentums in der bei Rumänien verbliebenen südlichen Bukowina (zuletzt unter der Bezeichnung S.A. Domeniile Bucovina) ${ }^{57}$ bewirkte, dass die im letzten Fondsbudget ausgewiesenen Überschüsse sowie die Rückflüsse aus den getätigten Holzverkäufen (für 1949 immerhin knapp 16 Millionen Lei) bereits direkt in die Staatsbank der nunmehrigen Volksrepublik Rumänien flossen. ${ }^{58}$

\section{Zusammenfassung}

Die unterschiedlichen Vorhaben des Bukowiner Religionsfonds sowie die einschneidenden politischen Ereignisse in Rumänien um das Jahr 1938 offenbarten in aller Deutlichkeit die teilweise erheblichen Schwachstellen in Verwaltung und Wirtschaft dieser Institution. Obwohl es dem Metropoliten Visarion noch einigermaßen gelungen war, die Autonomie der Landeskirche als auch des Fonds zurückzugewinnen und damit das Heft des Handelns wiederzuerlangen, rächten sich jetzt jene über die Jahrzehnte seit 1918 angehäuften strukturellen Mängel und der Filz politischer Interventionen. Schon die Maßnahmen der Agrarreform in der Bukowina zeigten, dass sich auch der neue rumänische Staat durchaus darauf verstand, den Fonds für die eigenen Zwecke einzuspannen. Selbst das Prestigebauvorhaben eines millionenschweren rumänischen Kulturpalastes in Czernowitz als Symbol einer erfolgreichen Vereinigung der Bukowina mit dem Königreich hatte darunter sichtbar zu leiden, sodass sich dessen Verwirklichung um Jahrzehnte verzögerte.

55 ANR-S inv. 35, pach. 1-1949, fol. 20-27, Raport de expertiza contabila v. 28.XI.1949. Absolute Zahlenangaben lassen sich aus der Quellenlage nur mit Einschränkung rekonstruieren. Huţu errechnet etwa auf dieser Basis allein für den Zeitraum Juni bis November 1944 einen durch die Rote Armee verursachten Verlust für den Religionsfonds von ca. 14 Millionen US-Dollar (umgerechnet zum Wert von 1938; bzw. 81.00o US-Dollar zum freien Wechselkurs vom November 1944). Das wären Huţu zufolge (zum Basiswert 1938) annähernd fünf Prozent der von Rumänien seitens der Sowjetunion eingeforderten Reparationszahlungen; HUȚU 2010, Bucovina, 79-84.

56 ANR-S inv. 35, pach. 1-1950, fol. 1f., Comisa de lichidare an FBis, Tablou al suprafatelor de proprietăți ale fostului Fond Bisericesc Ortodox Român.

57 ANR-S inv. 35, pach. 159-1948, fol. 1of., Direcţia Financiară Nr. 16.072/1948, Circulară, Câmpolung v. 17. V.1948.

58 ANR-S inv. 35, pach. 2-1950, fol. 1, Ministerul Finanţelor, Direcţiunea Bugetului an Comisia de lichidare a FBis v. 10.I.1950; pach. 2-1950, Comisia de lichidare, Nota v. 16.XII.1949. 
Die sowjetische Besatzung der Nordbukowina, das daraufhin einsetzende Chaos in einem merklich geschwächten Staat und der Kriegsausbruch im Juni 1941 schufen schließlich eine Situation, in der die Gesamtsituation des Religionsfonds der nötigen Ruhe zur inneren Konsolidierung gänzlich entbehren sollte. Unter der Belastung einer aufgezwungenen Kriegswirtschaft und einem weitgehend autoritär agierenden Staat konnten sich Religionsfondsverwaltung als auch Bukowiner Kirche eigentlich nur mehr um Schadensbegrenzung bemühen. Der staatliche Dirigismus griff darüber hinaus immer mehr in die Verwaltung dieser Institution ein. Der dafür geradezu beispielhafte Export von Hölzern an die Sowjetunion noch vor dem 22. Juni $1941 \mathrm{nahm}$ dabei lediglich eine Situation zunehmender Fremdbestimmung vorweg, die sich nach 1944 und besonders ab 1948 - freilich unter jeweils anderen politischen Vorzeichen - fortsetzen sollte.

Hatten sich Kirche und Religionsfonds der Bukowina, obgleich mit nicht wenigen Schwierigkeiten in ihrer 'Eigenständigkeit' gegenüber Politik und Staat, während der Zwischenkriegszeit noch einigermaßen behaupten können, so setzte spätestens mit der Abtrennung der Nordbukowina an die UdSSR deren kontinuierlicher Machtverlust als Institutionen ein, auf wirtschaftlichem wie politischem Feld gleichermaßen. Die Gestaltungsfähigkeit des Fonds für die Region unterlag fortan weitgehend äußeren, von ihm und seinen Repräsentanten kaum mehr wesentlich lenkbaren Einflüssen. Am Ende dieser freilich nicht linear verlaufenden Entwicklung standen die vollständige Sequestrierung des Fonds zu Gunsten der Volksrepublik Rumänien und zugleich das Ende der Bukowiner Metropolie. 
In der auf weiten Strecken fast ausschließlich agrarisch - an der Wende zum 20. Jahrhundert mit einem wachsenden Anteil auch forstwirtschaftlich - dominierten Bukowina besetzte der industrielle Sektor und der ihm vorgeschaltete Bergbau ausgesprochene Randpositionen. Es verwundert daher kaum, wenn die Czernowitzer Allgemeine Zeitung 1906 in einem ihrer Leitartikel feststellt: »Nur langsam und unter Ueberwindung mannigfacher Schwierigkeiten geht die Industrialisierung der Bukowina voran. $\aleph^{1}$ Trotzdem kam zunächst gerade dem vergleichsweise bescheidenen Bergbau eine zentrale Bedeutung in den Industrialisierungsbestrebungen des Kronlandes zu. Jakobeny (dt. auch Jakobeni, rum. Iacobeni) - an der Grenze zu Siebenbürgen - gehörte in dieser Hinsicht gemeinsam mit dem späteren Kurort Dornawatra (dt. auch Dorna Watra, rum. Vatra Dornei) zu jenen Siedlungen, die vor 1914 als Modernisierungsinseln überregionale Ausstrahlung für die Provinz erlangten. Obgleich Abbau und Weiterverarbeitung der Bodenschätze bzw. die Nutzung der Forste und der Mineralquellen lange Zeit in ihrer Wirkung kaum über das Kronland selbst hinausreichten, entstanden im gebirgigen Südwesten des Landes erst dadurch dauerhaft größere Siedlungsstrukturen. Mit den Werken von Jakobeny verfügte die Bukowina über einen vergleichsweise zu anderen Provinzen des Habsburgerreiches nur bescheidenen Erzbergbau, der allerdings regional bemerkenswert war. Die zur Mitte des 19. Jahrhunderts im primären Wirtschaftssektor eintretende Krise drohte die Gesamtstruktur dieses Gebirgsrayons zu gefährden. Mit der Übernahme des Bergwerks durch den Religionsfonds gelang es indes, den drohenden Abschwung zu stoppen und eine für die Region erfolgreiche Umstrukturierung einzuleiten. Der Ausbau der nahegelegenen Heilquellen und Bäder bei Dornawatra zu einem mondänen und in der Monarchie weitbekannten Kurort begünstigte zudem dieses Modernisierungsvorhaben.

Im Weiteren solle es daher darum gehen, die verschiedenen Phasen des angesprochenen Strukturwandels in der Bukowina mit ihren weitreichenden Folgen punktuell nachzuzeichnen. Am Beispiel zweier für die Provinz bedeutender Siedlungen (Jakobeny, Dornawatra) und zeitlich ausgehend vom letzten Drittel des 18 . bis ins beginnende 20. Jahrhundert wird die Analyse in Form eines Längsschnittes vorgenommen. Ebenso sollen dabei wichtige ökonomische Facetten der rumänischen Zwischenkriegszeit, die den Religionsfonds als Institution betrafen - wiederum mit lokalem Fokus auf die ausgewählten Orte -, beispielhaft Eingang finden. Aus dieser Perspektive ist nicht nur die Rolle des gr--orient. Religionsfonds als quasi staatlichem jedoch regional verankertem Modernisierungsmotor auszuleuchten, sondern zugleich eine inhaltliche Brücke über einen längeren Zeitraum zu den als Querschnitten angelegten Kapiteln über die jeweilige Wirtschaftssituation des Fonds zu schlagen.

1 Czernowitzer Allgemeine Zeitung Nr. 605 v. 11.I.1906, Industriefragen, Titelseite. 


\section{Jakobeny und seine Bodenschätze}

Als die Bukowina Teil des Habsburgerreiches wurde, erschien das Land aus Wiener Perspektive gänzlich unerschlossen: "Man muß Galizien und die Buccowina in Naturhistorischer Hinsicht als eine terra incognita betrachten [...] dessen mineralische Schätze wir vielleicht kaum zur Hälfte kennen. ${ }^{2}$ So vermutete denn auch die Zentralverwaltung Rohstoffe "in den Eingeweiden der Bukowiner Kameralischen und Religions Fonds Gebürge «. ${ }^{3}$ Die zunächst noch militärische (durch den Hofkriegsrat in Wien) und später als Teil des Königreiches Galizien-Lodomerien zivile Zentralverwaltung (von Wien via Lemberg) konzentrierte folglich ihr oberstes Ansinnen in einer sukzessiven politischen als auch ökonomischen Einrichtung der Provinz. ${ }^{4}$ Um diesen Teil der ehedem Oberen Moldau schrittweise an den Stand der anderen Länder des Reiches heranzuführen, war nicht nur eine >Peuplierung « und eine von Grund auf neu aufgeführte administrative Ordnung nötig, sondern ebenso eine Steigerung der landwirtschaftlichen Erträgnisse sowie eine systematische Nutzung bzw. Erschließung der vermuteten Rohstoffvorkommen unerlässlich. Letztere sollten zunächst den Eigenbedarf der Provinz an Eisen bzw. Werkzeugen sowie anderen Materialien etwa für den Bau von Häusern und die Bestellung der Felder sichern. Bislang musste Eisen aus dem Osmanischen Reich, Russland oder Ungarn (Siebenbürgen) kostspielig angeschafft werden. ${ }^{5}$ Der erste Provinzverwalter General v. Splény und verschiedene andere Autoren früher Beschreibungen hatten zurecht vermutet, dass »das hohe Gebürg alle Hoffnung « ${ }^{6}$ zur Gewinnung verschiedenster Bodenschätze gäbe, ${ }^{7}$ was sich alsbald bestätigen sollte (vgl. Abb. 6o). ${ }^{8}$

2 OSTA-HHSTA, Faßbender Akten 5 XI/3-XII, fol. 51, Gehorsamster Bericht des k.k. Peczenyszyner Kameralverwalters Dans v. 28.III.1804 an Hofkriegsratspräsidenten.

3 OSTA-HHSTA, Faßbender Akten 5 XI/3-XII, fol. 138, Instruktion für die gelehrte Reisegesellschaft in Galizien und Bukowina v. 29.VI.1804.

4 SCHARR 2010, Landschaft.

5 "Eisen wird aus der Türkey, Moscau und Hungarn gebracht [...] Sensen [...] alle aus der Steyermark [...] allerley kleines Eisenwerk [...] aus Frankfurt [...] Waffen meistentheils aus der Türkey«; Grigorovici (Hg.) 1998, Bucovina, 68, Absatz 115; auch in Polek (Hg.) 1893, General; ähnlich in ANR-B CAR, Bericht Mappierungsdirektor Budinsky, Czernowitz v. 1.X.1782; "Ganz ordinäre einfache Schlösser « mussten in Bistritz/Siebenbürgen bestellt werden, ANR-B CAR X/23, Enzenberg an Hofkriegsrat v. 3.X.1783.

6 Polek (Hg.) 1897, Beschreibung, 14-17.

7 Grigorovici (Hg.) 1998, Bucovina, 49, Absatz 48.

8 "Une autre ressource du Pays, que la Natur semble également reserver pour des mains plus industrieuses, ce sont le mineraux de toutes especes, que tout concourt à faire supposer abondamment repandus dans les monts"; Grigorovici (Hg.) 1998, Bucovina, 282-323, hier 296, Absatz 46 [Description de la Bukovina. Extrait de louvrage de M. le Général Baron de Splény et d’un rapport de M. de 
Die Schuld an der bislang ausgebliebenen Ausbeutung dieser Bodenschätze schob man indes im Hinblick auf die vorhergegangenen Landesherren wahlweise dem »türkischen Geiz« oder den "polnischen Intrigen « zu. ${ }^{9}$ Tatsächlich trugen wohl die ausgesprochene Randlage des Gebietes, seine dünne Besiedlung und der geringe infrastrukturelle Erschließungsgrad der Gebirgsgegenden dafür die hauptsächliche Schuld.

In dem einmal ins Auge gefassten kommerziell betriebenen Abbau dieser Rohstoffe verfolgte die Staatsverwaltung nicht nur die Absicht der Versorgung der Provinz mit Industrieprodukten, sondern setzte darin auch die Hoffnung auf eine erfolgreiche Kolonisierung der ansonsten bevölkerungsarmen und wenig attraktiven Berggebiete um Jakobeny ${ }^{10}$, zumal hier die strategisch wichtige Verbindungsstraße über den Borgo-Pass (rum. Tihuţa) nach Siebenbürgen durchführte. ${ }^{11}$ Im Nachhinein kritisierte man diese frühen, staatlich initiierten Versuche. Diese kleinen "Schürfunternehmungen [seien] sämmtlich ohne die erforderliche Fachkenntnis, als reines Lottospiel betrieben « worden und daher nicht mehr als "planlose Maulwurfsminen " gewesen. ${ }^{12}$ Selbst ein amtlicher Bericht musste eingestehen, dass »verschiedene Schürfe in verschiedenen Gegenden mit namhaften Unkosten vergebens angelegt wurden «. ${ }^{13}$ Zeitgenossen wie der Lemberger Professor für Naturwissenschaften Balthasar Hacquet, der diesen Raum aus mehreren intensiven Bereisungen während des letzten Dezenniums des 18. Jahrhunderts genau kennengelernt hatte, erkannten den drohenden Teufelskreis, in den dieses Bergbaugebiet zu geraten drohte; nämlich, dass die ergiebigen Lagerstätten durch mangelhafte lokale Aufbereitungstechnik und fehlende Facharbeiter letztlich zu einer schlechten Qualität führen mussten, die sich dann wiederum selbst in der Region nur beschränkt und mäßig ertragreich absetzen ließe. ${ }^{14}$

Jenisch (Canzlers Magazin I, 289-307, Leipzig 1790)]; "An Mineralien ist die Bukowina eben nicht arm [...] bei Jacobeny sind ergiebige Eisen- und bei Kirlibaba, am Berge Dadul [?] Bleibergwerke"; Grigorovici (Hg.) 1998, Bucovina, 373-433, hier 378, Absatz 5 [Ioan Budai-Deleanu, Kurzgefasste Bemerkungen über die Bukowina 1813].

9 Grigorovici (Hg.) 1998, Bucovina, 298, Absatz 47; PoleK (Hg.) 1897, Beschreibung, 14.

10 nDie Eisengruben allein bey Jakobeni, die schon die nöthigen Werkstätte[n] haben, geben Versicherungen nach die Hofnung zu einer für die Gewerkschaften vortheilhaften Ausbeute, und für das Land zu einer guten Nahrungsquelle, wenn dazu die nöthige Unterstützung gegeben wird «; ANR-B CAR XXI/30, Rationarium-Provinciae 1786, fol. 25.

11 OSTA-HHSTA, Hofkanzlei Karton 234, Kolowrath an Kaiser v. 29.I.1787.

12 Czernowitzer Zeitung Nr. 23 v. 14.II.1868, Die Eisen-Industrie und die Montan-Werke der Bukowina (ANONYMUS).

13 ANR-B CAR XXI/30, Rationarium Provinciae 1786, fol. 24.

14 SCHARR (Hg.) 2004, Karpaten, 82-86; Original unter [http://www.literature.at/default.alo] abrufbar; in einem Bericht des Ministerialrates v. Beust an den Ackerbauminister werden eine Reihe solcher Mängel aufgelistet: „Anstatt von den vorhandenen schönen Wasserkräften für die Anlage von Walzwerken Gebrauch zu machen, hat man sich lediglich auf die Erzeugung von ordinärem Stabei- 


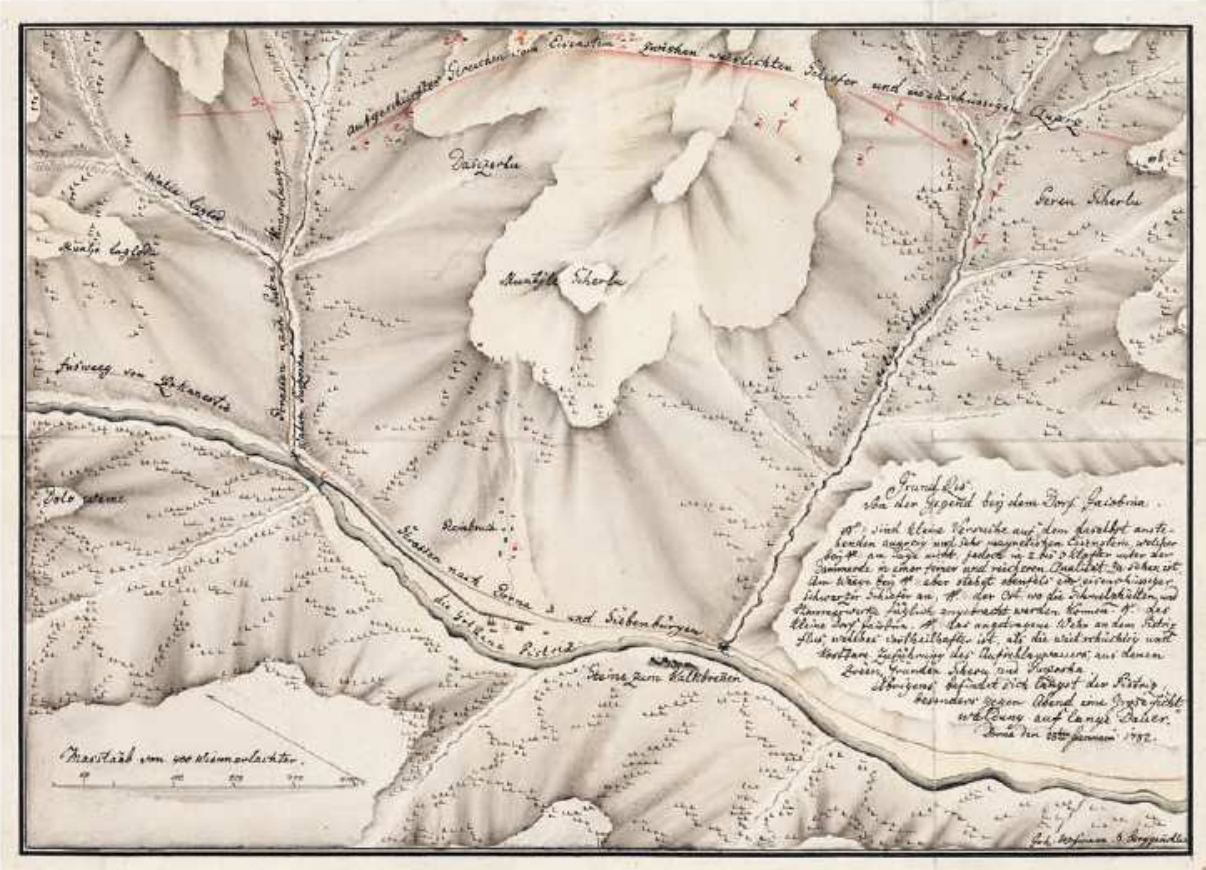

Abb. 60: Grund Ris Von der Gegend bey dem Dorf Jacobina, entstanden 1782 als Folge einer ersten staatlichen Prospektion des Gebietes. Die Skizze verzeichnet nicht nur mögliche Standorte für Schmelzhütten, Hammerwerke und ähnliches, sondern verweist auch auf bedeutende Waldungen (Übrigens befindet sich längst der Pistriz besonders gegen Abend eine Große Fichtwaldung auf lange Dauer). Nutzte man Letztere anfangs vorwiegend zur Verhüttung, so mutierte spātestens mit dem Eisenbahnanschluss der Bukowina die Forst- und Holzwirtschaft zur Grundlage der Prosperität des Religionsfonds. (c) ÖSTA-Finanzhofkammer SUS KS Pd153, 28.I.1782.

Die notwendige industrielle Erschließung der Bukowina blieb angesichts der schwerwiegenden Probleme des Landesaufbaus - etwa der zu Beginn der habsburgischen Herrschaft noch weitgehend fehlenden Verkehrsinfrastruktur - insgesamt erheblich hinter den anfänglich weit gesteckten Erwartungen zurück. Selbst Mitte des 19. Jahrhunderts war die Industrieproduktion der Bukowina streckenweise noch so gering, dass sie selbst den bescheidenen Landesbedarf kaum zu decken vermochte. ${ }^{15}$ Andererseits hatte der

sen beschränkt und sich dadurch selbst den Markt verdorben, ohne doch eine entsprechend große Menge von Eisen absetzen zu können «; BEUST 1873, Montanwerke, 17.

15 So vermerkte etwa die Handels- und Gewerbekammer, dass »die Glasindustrie hier noch nicht zu jener Vollkommenheit und Ausdehnung gelangt ist, der sie unter den günstig vorhandenen Bedin- 
Binnenmarkt aus sich heraus lange Zeit nicht genügend Kapital, um die teuren und z.T. in ihrem Wert letztlich minderen Produkte aus landeseigener Eisenerzeugung abzunehmen. Gusseisen, Nägel und Werkzeuge mussten daher vielfach aus den entfernt gelegenen galizischen oder steiermärkischen Bergwerken und ihren Verarbeitungsbetrieben bezogen werden. ${ }^{16}$ Die Handels- und Gewerbekammer der Bukowina sah sich noch 1852 zur Klage gegenüber den Wiener Ministerien veranlasst und vermerkte nachdrücklich die - geradezu symptomatisch für das Land - immer noch zu geringe Verbreitung von Eisenschaufeln und -pflügen. Allenfalls würden die Bauern »schwerfällige« Holzschaufeln und Pflüge verwenden, die nur am Rande mit Eisen verstärkt waren. ${ }^{17}$

Am Ende des 19. Jahrhunderts lag der prozentuelle Anteil des Bergbaus in der Bukowina im Vergleich zum restlichen Cisleithanien weit unter einem Prozent. Die Montanindustrie des Kronlandes "war von keinem Belang «. ${ }^{18}$ Während das Bergwesen trotz unbestreitbarer Verbesserungen vor dem Ausbruch des Ersten Weltkrieges noch »in den Kinderschuhen steckte", hatte die "großangelegte Verwertung des Holzes" nahezu industrielle Ausmaße angenommen. ${ }^{19}$ Aus regionaler Sicht bewirkte die Montanindustrie jedoch gerade für die Berggebiete der südlichen Bukowina erhebliche Veränderungen und begründete - wie noch zu zeigen sein wird - Strukturen für die später dort so erfolgreich tätige Holzindustrie des Religionsfonds.

\section{Die Manzschen Werke}

Auf der Suche nach einer günstigen Trasse für die anzulegende Reichsstraße vom siebenbürgischen Bistritz (rum. Bistriţa) kommend über den Borgo- und Mestecănesti-Pass nach Kimpolung (rum. Câmpolung) in die Bukowina hatten Generalstabsoffiziere um 1780 bei Jakobeny Manganerzvorkommen entdeckt. ${ }^{20}$ Wenig später ließ eine aus privaten

gungen fähig ist«, Wochenschrift der Bukowiner Handels- \& Gewerbekammer (Czernowitz) Nr. 44 v. 5.XI.1852, 351 .

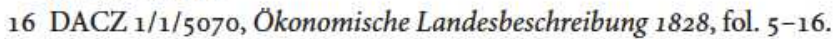

17 Wochenschrift der Bukowiner Handels- \& Gewerbekammer (Czernowitz) Nr. 44 v. 5.XI.1852, 360.

18 Romstorfer \& Wiglitzky (Hg.) 1886, Statistik, 27 Tabelle IX, Bergbau und Hüttenbetrieb; mit einem Gesamtwert aller Hüttenprodukte der Bukowina von knapp $190.000 \mathrm{fl}$. lag das Kronland 1872 in Cisleithanien (in Summe 36,9 Millionen fl.) mit Abstand an letzter Stelle, Mittheilungen des k.k. Ackerbau-Ministeriums 10/1873, Bergwesen, 11.

19 Czernowitzer Allgemeine Zeitung Nr. 1011 v. 28.V.1907, 5, Das Berg- und Hüttenwesen der Bukowina von seinen Anfängen an (Faustin v. KRASUSKI).

20 PRELICZ 1904, Geschichte, 84; mehrere Skizzen zu den 1788 bestehenden Anlagen in Jakobeny befinden sich im Osterreichischen Staatsarchiv, OSTA-FHKA SUS N-204/1-5, 1788; eine kolorierte "Ansicht der Eisenberg- und Hüttenwerke zu Jakobeny in der Bukkowina" (datiert nach 1810) liegt im Bildarchiv der OeNB [http://data.onb.ac.at/rec/baa13787265]. 
Investoren, zumeist Bojaren der Bukowina, bestehende Gewerkschaft das erste Eisenwerk der Bukowina mit Hochofen, dazugehörigen Hammerwerken und Arbeiterwohnungen erbauen und 1784 in Betrieb gehen. ${ }^{21}$ Obwohl ersten optimistischen Einschätzungen zufolge - so ein Bericht des Wiener Hofkriegsrates - sich »die Erzeugung des Eisen-Steins zimlich gut anlasset $\star^{22}$, so stellte sich dennoch kein dauerhafter Erfolg für den Betrieb ein. Ungeachtet staatlicher Förderung ${ }^{23}$, der Beiziehung von Handwerkern aus den siebenbürgischen Grenzregimentern und der kostspieligen Anwerbung von Bergleuten aus der Zips ${ }^{24}$, gelang es den Gewerken nicht, die wachsenden Kosten zu decken. Anlagen und Schürfrechte mussten schließlich 1796 an den aus der Steiermark stammenden Unternehmer Anton Manz v. Mariensee verkauft werden. ${ }^{25}$ Erzreichtum, Investitionen, technische Neuerungen und die Anwerbung erfahrener Bergarbeiter aus Leutschau (slowak. Levoča), Käsmark (slowak. Kežmarok) und anderen Zipser Orten bescherten dem Bergbau über die nächsten beiden Jahrzehnte einen gewissen Aufschwung. ${ }^{26}$

Aber selbst hier musste der Ärar durch Steuernachlässe, kostenfrei überlassenen Baugrund für Siedlungen und vergünstigten Holzbezug - zur Herstellung der für die Hochöfen und Schmieden benötigten Holzkohle - erhebliche Subventionen beisteuern. ${ }^{27}$ So erkannte man in Wien den Wert der Domäne Kimpolung mit ihren Wäldern zum ungarischen Grenzgebiet hin schon früh und hatte dabei stets davon abgeraten, diese zu verkaufen, gal-

21 Czernowitzer Allgemeine Zeitung Nr. 1011 v. 28.V.1907, 5, Das Berg-und Hüttenwesen der Bukowina von seinen Anfängen an (Faustin v. KRASUSKI).

22 ANR-B CAR XII 2/2a 1783, Hofkriegsrat an Galizisches Generalkommando, Wien v. 26.III.1783.

23 ANR-B CAR XIII 391783 , Kollowrath an Hofkriegsrat, Wien v. 16.VIII.1783, worin eine Unterstützung der Werke »in ihrem Anfang « durch den Hofkriegsrat erbeten wird.

$24 \mathrm{Zu}$ den Zipsersiedlungen der Bukowina liegt eine Monographie vor, die neben einem historischen Überblick v.a. eine Schwerpunktdarstellung der Zwischenkriegszeit und der Auswanderung ins Deutsche Reich 1940 liefert, HADBAwNIK et al. 1986, Zipser; zu den deutsch-böhmischen Siedlungen der Bukowina (ohne Jakobeny, v.a. über die Glashütte bei Karlsberg etc.) vgl. KLAUBE 1984, Siedlungen, 657-676.

25 Prelicz 1904, Geschichte, 84.

26 Eine zeitgenössische Kurzdarstellung des Werks von Jakobeny ging davon aus, dass aufgrund des Erzreichtums wvielleicht ganz Galizien mit diesem wichtigen Produkte hinreichend versehen werden könnte «, Vaterländische Blätter für den österreichischen Kaiserstaat Nr. 41 v. 20.V.1812, 245-246, Die Berg- und Hüttenwerke zu Jakobeny und Mariensee am Silberberge in Kirlibaba in der Bukowina (Anonymus); Kaiser Franz I. vermerkt in seinem Tagebuch der Bereisung der Bukowina - neben einer eingehenden Beschreibung der Hüttenwerke - den »von Man neu angelegten Ort aus lauter Zipsern, regulär gebaut, von hübschen hölzernen Häusern«; WAGNER (Hg.) 1979, Reisetagebücher, 59; zur deutschen Siedlung in der Bukowina vgl. zusammenfassend WELSCH 1986, Bukovina.

27 OSTA-FHKA Domänenakten 075 Fasz. 10 103/298 an Galizisches Gubernium v. 29.I.1801, Unterstützung des Eisenwerkbetriebes des Manz v. Mariensee durch die Herrschaft Kimpolung. 
ten sie doch ihrerseits wiederum als wichtige Energiespeicher der örtlichen Montanwerke. ${ }^{28}$ Erst durch diese Stützungen war Manz in der Lage, die hohen Lebenserhaltungskosten vor Ort und die schlechten Verkehrsanbindungen auszugleichen. Zusätzlich überließ ihm der Staat 1812 gegen einen niedrigen Pachtzins die Urbarialrechte (v.a. den Holzbezug) von fünf Dörfern der Kameralherrschaft Kimpolung und von neun Dörfern der Religionsfondsherrschaft Gura-Humora (rum. Gura Humorului). ${ }^{29}$ Die 1820 im Silber- und Bleiwerk von Kirlibaba (rum. Cârlibaba) durch die schwindende Erzergiebigkeit wachsenden Verluste konnte Manz vorerst noch durch den Ankauf des staatlichen Kupferbergwerkes bei Pozoritta (rum. Pojorâta) auffangen. Schon 1805 hatte hier der Ärar in Eigenregie bei Fundul Moldowi (rum. Fundu Moldovei) einen Schurfstollen angeschlagen (vgl. Abb. 61/62). ${ }^{30}$

Eine Reihe von Fehlinvestitionen, «altmodische Hüttenanlagen [...] vereint mit der bekannten minderen Qualität der bukowinaer Eisenerze [sowie] unverhältnismäßig hohe Gestehungskosten « führten nach dem Tod des Unternehmers 1832 unter seinen Erben zu einer schleichenden Verschuldung der Manzschen Betriebe. ${ }^{31}$ Allein schon die weitläufigen Schürfstellen im Gebirge zwischen den Flussläufen der Goldenen Bistritz (rum. Bistriţa) und der Moldowa (rum. Moldova) erschwerten bzw. verteuerten den Hüttenbetrieb in den Hauptorten Kirlibaba, Jakobeny und Pozoritta ungemein. 1827 liefen außerdem die vorteilhaften Pachtverträge für den Holzbezug und mit 1838 auch die bisherigen staatlichen Begünstigungen beim Holzpreis aus. ${ }^{32}$ Darüber hinaus galt für das ärarische Eisen eine Befreiung von Zwischenzöllen, sodass die oberungarischen Bergwerke ihre Produkte ohne Aufschlag auch nach Galizien und in die Bukowina exportieren konnten; ein Umstand, der zwar schon seit dem Erwerb Galiziens durch das Habsburgerreich rechtlich Geltung hatte, allerdings erst mit dem Ausbau der Straßenverbindungen zum Tragen kam und dadurch mit der Zeit den wirtschaftlichen Druck auf Jakobeny steigerte. ${ }^{33}$

28 OSTA-FHKA Präs. FM Beilage ad Zl. 19483, Protokoll, Kimpolung v. 25.X.1856, fol. 2.

29 PreliCZ 1904, Geschichte, 85; Kameralherrschaft Kimpolung: Jakobeny, Czokanestie (Ciocanești), Dorna-Watra (Vatra Dornei), Dorna Kandreni (Dorna Candrenilor), Pojana Stampi (Poiana Stampei); Fondsherrschaft Gura Humora: Woronetz (Voroneț), Bukschoja (Bucșoaia), Frassin (Frasin), Stulpikani (Stulpicani), Wama (Vama), Frumosa (Frumosu), Rus pe Boul und beide Moldawitza (Moldoviţa).

30 Zusammengefasst bei CEREDAREC 1983, Exploatarea; Franz I. bemerkt die gute Qualität und Ergiebigkeit der kaiserlichen Gruben, WAGNER (Hg.) 1979, Reisetagebücher, 62; ein Überblick zu den Gruben, Erträgen, der Bevölkerung etc. von Jakobeny, zusammengestellt von Manz v. Mariensee findet sich in einer für die zweite Bereisung Kaiser Franz I. angefertigten Vorlage; OSTA-HHSTA, Hofreisen Karton 501823 , Berg- und Hüttenwesen.

31 Czernowitzer Allgemeine Zeitung Nr. 1011 v. 28.V.1907, 4, Das Berg- und Hüttenwesen der Bukowina von seinen Anfängen an (Faustin v. KRASUSKI).

32 Prelicz 1904, Geschichte, 86 u. 89.

33 Sieghart 1915, Zolltrennung, 79. 
Abb. 61: Ansicht Der Eisenberg und Hüttenwerke zu Jakobeny in der Bukkowina nach 1810, gewidmet Kaiser Franz I. Der Ausschnitt zeigt einen Teil der Manzschen Anlagen (Öfen, Schmieden, Pochwerke) zur Erzverarbeitung. (๑) ŌNB PK 3.003 Blatt $641^{34}$

Abb. 62: Der Ausschnitt aus dem Franziszeischen Kataster (1856) zeigt Sensenschmiede und Hammer (vgl. Abb. 61) mit den Wasseranlagen zur Energiegewinnung; Katastralgemeinde Nr. 104 Jakobeny, Blatt 20 , nicht maßstabsgetreu! @ Oficiul de Cadastru şi Publicitate Imobiliară Suceava.
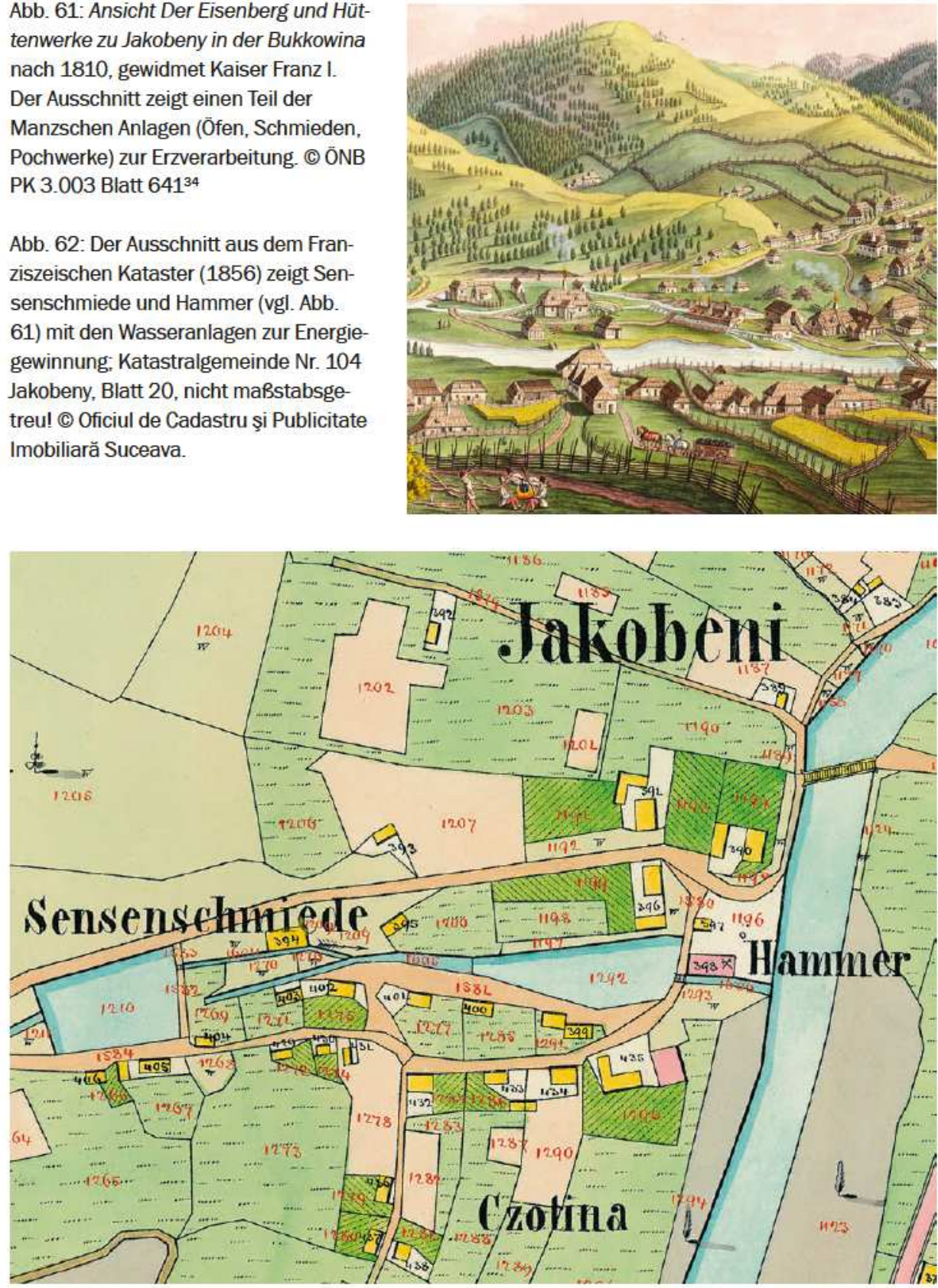

34 Gesamtansicht unter [http://data.onb.ac.at/rec/baa13787265]. 
Der Fortbestand des kaum kostendeckend laufenden Betriebes konnte nur mehr durch die Aufnahme von Krediten gewährleistet werden, darüber hinaus waren mit dem Verarmen der Kupferadern in Pozoritta auch die mittlerweile beträchtlichen Verluste des Blei- und Silberbergwerks Kirlibaba untragbar geworden. ${ }^{35}$ Die Werke in Jakobeny stellten ihren Betrieb 1849 ein. Kirlibaba musste letztlich 1859 geschlossen werden. ${ }^{36}$ Selbst die Roheisengewinnung verlor mit der Eröffnung der Bahnstrecke von Lemberg nach Czernowitz 1866 (1869 Czernowitz-Suczawa) gegenüber den Werken in Witkowitz (tschech. Vitkovice/Ostrava) und Teschen (heute poln. Cieszyn) ihre Konkurrenzfähigkeit und sollte alsbald auslaufen. ${ }^{37} \mathrm{Zu}$ Beginn des Jahres 1862 hatten die Manzschen Gewerke allein beim Religionsfonds, der im Auftrage des Staates als Hauptdarlehensgeber fungierte, eine Schuld von über 500.000 Gulden angehäuft, die schließlich zur Einleitung von langwierigen Vergleichsverhandlungen führte. ${ }^{38}$

\section{Übernahme durch den Religionsfonds}

Die in der Bukowina betriebene Erzverarbeitung umfasste - wie zu diesem Zeitpunkt auch in anderen Teilen der Monarchie - in der Regel den gesamten Produktionsgang vom Abbau über die Erzeugung und den Vertrieb der fertigen Waren. Vom seit der Mitte des 19. Jahrhunderts verstärkt einsetzenden Bahnbau profitierte die österreichische Eisenindustrie insgesamt, hingegen erfolgte die Anpassung an moderne Produktionsbedingungen vor allem in den entlegeneren Gebieten nur schleppend. ${ }^{39}$ Die schlechte Anbindung der Bukowina an die Zentralräume der Monarchie trug daher zusätzlich zur ungünstigen strukturellen Ausgangssituation der regionalen Montanindustrie bei. Zudem konnten die Hochöfen statt mit hochwertiger Steinkohle nur mit der qualitativ schlechteren Holzkohle befeuert werden, die für sich jedoch zusätzlich einen kostspieligen Herstellungs- bzw. Bringungsprozess erforderte. Letztlich mangelte es auch aus diesen Gründen an ausreichenden Investitionsmitteln zur Umsetzung dringend nötiger technischer Innovationen. Der in der Eisenindustrie Innerösterreichs schon zu Beginn des 19. Jahrhunderts merkbare Konzentrationsprozess auf einzelne Standorte und wenige tonangebende Unternehmen hatte spätestens zur Jahrhundert-

35 KleinWä́chter 1899, Bergbau, 508.

36 Catargi (Hg.) 1899, Bukowina, $468 \mathrm{f}$.

37 KLEINWÄCHTER 1899, Bergbau, 509.

38 Die Finanzprokuratur wies per 1862 eine Gesamtschuldenlast von 1,4 Millionen Gulden aus; DACZ 3/1/2125, fol. 18, Finanzprokuraturabteilung an Landespräsidium v. 20.III.1862; die Hypothekarforderungen des Religionsfonds gegenüber Vinzenz Manz v. Mariensee betrugen 525.0oo fl.; DACZ 3/1/2592, Landesgericht Czernowitz an Landespräsidium v. 9.V.1864.

39 Im Überblick Matis \& BACHINGER (Hg.) 1973, Entwicklung. 
mitte auch die peripheren Gebiete des Habsburgerreiches eingeholt ${ }^{40}$, was die allgemeine Situation für die Industrie der Bukowina zusätzlich erschwerte.

Die Siedlungen und Bewohner des Bergwerkskomplexes um Jakobeny waren in ihrer Existenz - abgesehen von der betriebenen Subsistenzlandwirtschaft - weitgehend von der Montanindustrie abhängig. Das "patriarchalische Verhältnis« der Gewerke zu den Bewohnern dieser Dörfer - wie ein zeitgenössischer amtlicher Bericht kritisch anmerkte $^{41}$ - betraf nicht nur das Einkommen der Familien, sondern vielfach ebenso die Versorgung mit Lebensmitteln, die gesamte soziale und medizinische Absicherung der Werksarbeiter und ihrer Familien sowie die schulische Ausbildung der Kinder. Aus den daraus entstandenen komplexen Abhängigkeiten großer Bereiche der Südbukowina erwuchs für die Provinz mit der Krise der Montanindustrie ein gravierendes strukturelles Problem, das dringend einer Lösung bedurfte. Die Handels- und Gewerbekammer der Bukowina verwies schon aus diesem Grund mehrmals auf die "fast gänzlich ins Stocken geratene " Montanindustrie des Landes sowie ihre soziale Bedeutung für die Berggebiete der südlichen Bukowina, ${ }^{42}$ kam doch etwa der Provinz die Anschaffung von qualitativ brauchbaren Eisenwaren aus entfernten Gebieten im Vergleich zum üblichen Marktwert des Materials um mehr als ein Drittel teurer. Daher forderte die Kammer eine Wiederinbetriebnahme des Werkes und Investitionen durch den Religionsfonds. ${ }^{43}$ In den Siedlungen Jakobeny, Kirlibaba, Eisenau (rum. Prisaca), Pozoritta, Freudenthal und Russ pe Boul (rum. Valea Boului, heute Teil von rum. Vatra Moldovița) waren immerhin mehr als 7.200 Einwohner davon betroffen ${ }^{44}$, was etwa einem Drittel der im Gerichtsbezirk Kimpolung ansässigen Bevölkerung entsprach (vgl. Abb. 63). ${ }^{45}$ Wohl nicht ganz zufällig richtete sich zeitgleich der Betreiber der Gewerke Joseph Manz v. Mariensee mit der Bitte um Unterstützung an die Landesregierung. Manz strich darin den wempfindlichen Mangel an Betriebskapital, welcher tag-täglich die Schwierigkeiten und Verlegenheiten vergrößert, und den Ruin der Bergwerke herbeiführt« heraus. Der das Schreiben einlei-

40 Im Überblick Jetschgo et al. (Hg.) 2004, Industriegeschichte, v.a. Einleitung u. 198.

$41 \mathrm{DACZ}_{3} / 1 / 2125$, fol. 8, Finanzprokuraturabteilung an Landespräsidium v. 20.III.1862; Kaiser Franz I. stellt bei seiner ersten Bereisung der Bukowina 1817 fest: "Die Gegend ist so kalt, daß nichts als Erdäpfel wächst, zuweilen Gerste reift. Die Menschen betrachten alle den Manz als ihren Vater. Er erhöhte bis jetzt ihnen die Löhnungen nicht, gab ihnen aber die Früchte im gleichen Preise, wie vorhin und nicht mehr, als so vieles sie mit ihrem Verdienste decken können«; WAGNER (Hg.) 1979, Reisetagebücher, 68.

42 Anonymus 1862, Hauptbericht, 14; AnONymUS 1872, Hauptbericht, 21 f.

43 Wiener Zeitung Nr. 242 v. 20.X.1862 (Abendblatt), 966f., Verhandlungen der Handels- und Gewerbekammer.

44 ANONYMUS 1862, Hauptbericht, 203.

45 Volkszählungsdaten 1869; SCHARR 2010, Landschaft, Anhang V. 
tende Hinweis auf die Rolle des Werkes für die "Gebirgsbewohner « als »einzige Quelle ihres Erwerbes und Existenz « durfte dabei wohl als dramatisierendes Argument nicht unerwähnt bleiben. ${ }^{46}$

Die Bukowiner Öffentlichkeit reagierte ungehalten auf die schleppenden Verhandlungen zwischen den Eigentümern der Manzschen Werke und dem Religionsfonds als größtem Gläubiger. In einer Artikelserie der Czernowitzer Zeitung kritisierte ein anonymer Autor offen Regierungskreise in ihrem »vagen Verständnis für die Tragweite [...] von Montanunternehmungen«, denen »rundweg alle Lebens- und Existenzfähigkeit abgesprochen « und »nicht einmal die Parität mit einem Bier- oder Brandwein-Erzeugungs-Etablissement " gewährt wird. ${ }^{47}$ In ähnlicher Weise rügte die Handels- und Gewerbekammer die "stiefmütterliche Behandlung [...] durch überspannte Holzpreise " seitens des Staates. ${ }^{48}$ Auch der Historiker Raimund F. Kaindl beklagte in seinen Studien Armut und Hoffnungslosigkeit unter den früheren Minenarbeitern. Er forderte in gleicher Weise vom Staat eine Wiedereröffnung der Werke (vgl. Abb. 64/65). ${ }^{49}$ Unter dieser Situation hatte letztlich ebenso die bislang von den Gewerken mitgetragene Verkehrsinfrastruktur rund um Jakobeny (vor allem die Straßenverbindungen ins Siebenbürgische) zu leiden. ${ }^{50}$ Selbst der zuständige Lemberger Berghauptmann Johann Juraski unterstrich bei aller Kritik zu deren momentaner Lage die »Wichtigkeit dieser [...] Montanwerke [als] der Mittelpunkt eines industriellen Culturlebens, dessen Verschwinden ein socialer Rückschritt für den Wohlstand der ganzen Provinz wäre [...] ein Stück Culturgeschichte des karpathischen Ostens ${ }^{51}{ }^{51}$

$46 \mathrm{DACZ}_{3 / 1 / 2125}$, Joseph Manz v. Mariensee an Landesregierung v. 25.II.1862, fol. 1.

47 Czernowitzer Zeitung 1868 Nr. 23 (14.II.), 24 (16.II.), 27 (21.II.), 30 (26.II.), 32 (1.III.), 40 (15.III.) und 101 (7.VII.); hier Nr. 30 (26.II.), Die Eisen-Industrie und die Montan-Werke der Bukowina (Anonymus).

48 Wochenschrift der Bukowiner Handels- und Gewerbekammer Nr. 44, Czernowitz v. 5.XI.1852, 363.

49 KAINDL 1902, Ansiedlungswesen, 343.

50 Czernowitzer Zeitung 1868 Nr. 40 (15.III.), Die Eisen-Industrie und die Montan-Werke der Bukowina (Anonymus); ANONYMUS 1862, Hauptbericht, 38; die Straße "von Jakobeni im Thale der goldenen Bistritz aufwärts über Kirlibaba in die Marmaros war vor Zeiten, wo sich die Montanindustrie in diesen Gegenden eines besonderen Aufschwunges erfreute, selbst von schwersten Wagen benützt und gut erhalten. Jetzt ist der Verkehr nur mehr mit Gefahr und bloß für schmale Erzkarren möglich «; DACZ 3/1/3556, Ministerium d. Inneren an Landespräsidium, Bericht ca. 1870.

51 JURASKI 1867, Berg- und Hüttenwerke, 146 und 156-160; das Zitat stammt aus der einleitenden Fußnote des Beitrages, die von der Redaktion der Zeitschrift hinzugefügt wurde, der verantwortliche Redakteur, Dr. Otto Freiherr v. Hingenau, war zu diesem Zeitpunkt Ministerialrat im Finanzministerium. 


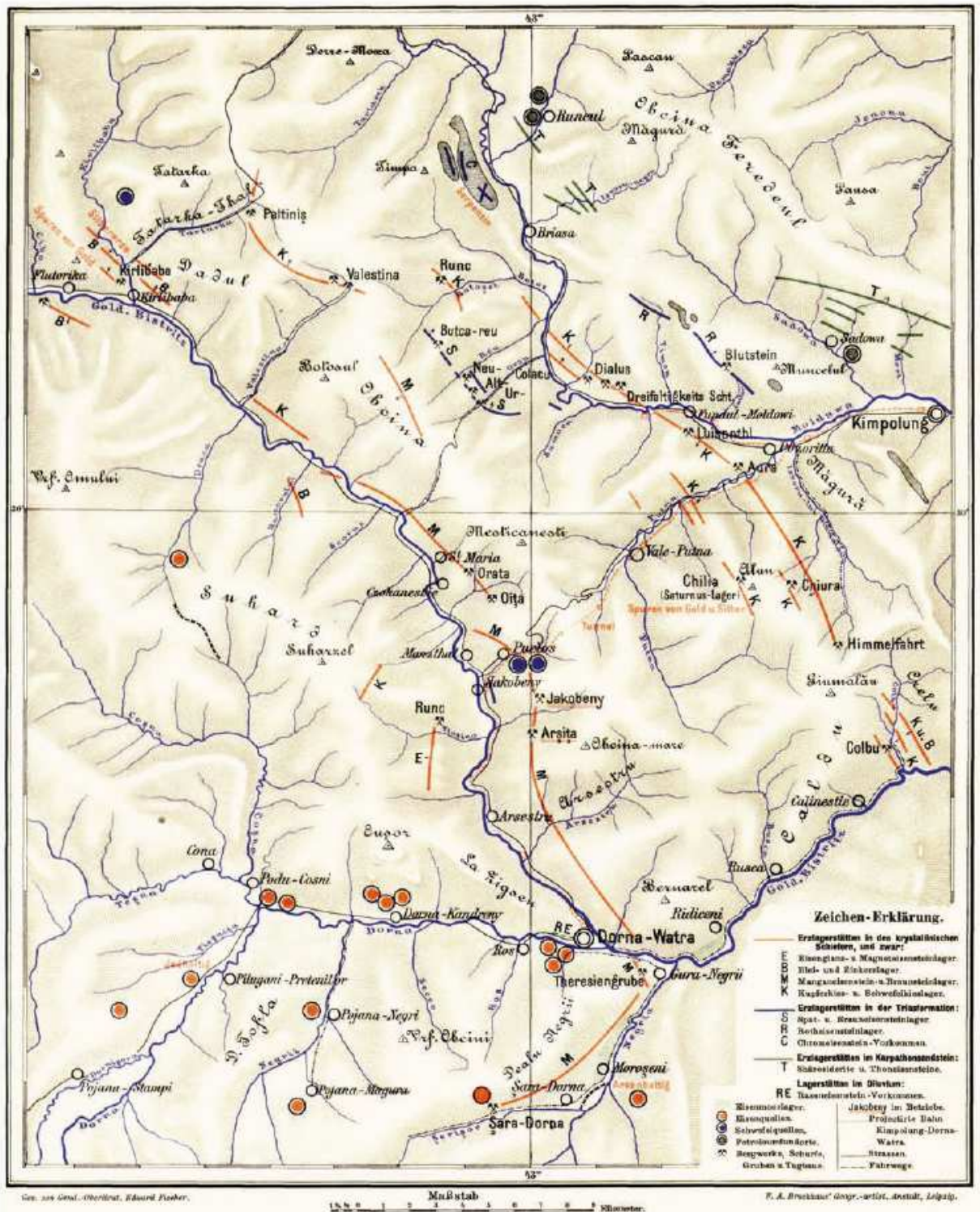

Abb. 63: Die Erzlagerstätten der südlichen Bukowina, Karte um 1899.52

52 Catargi (Hg.) 1899, Bukowina, 40. 


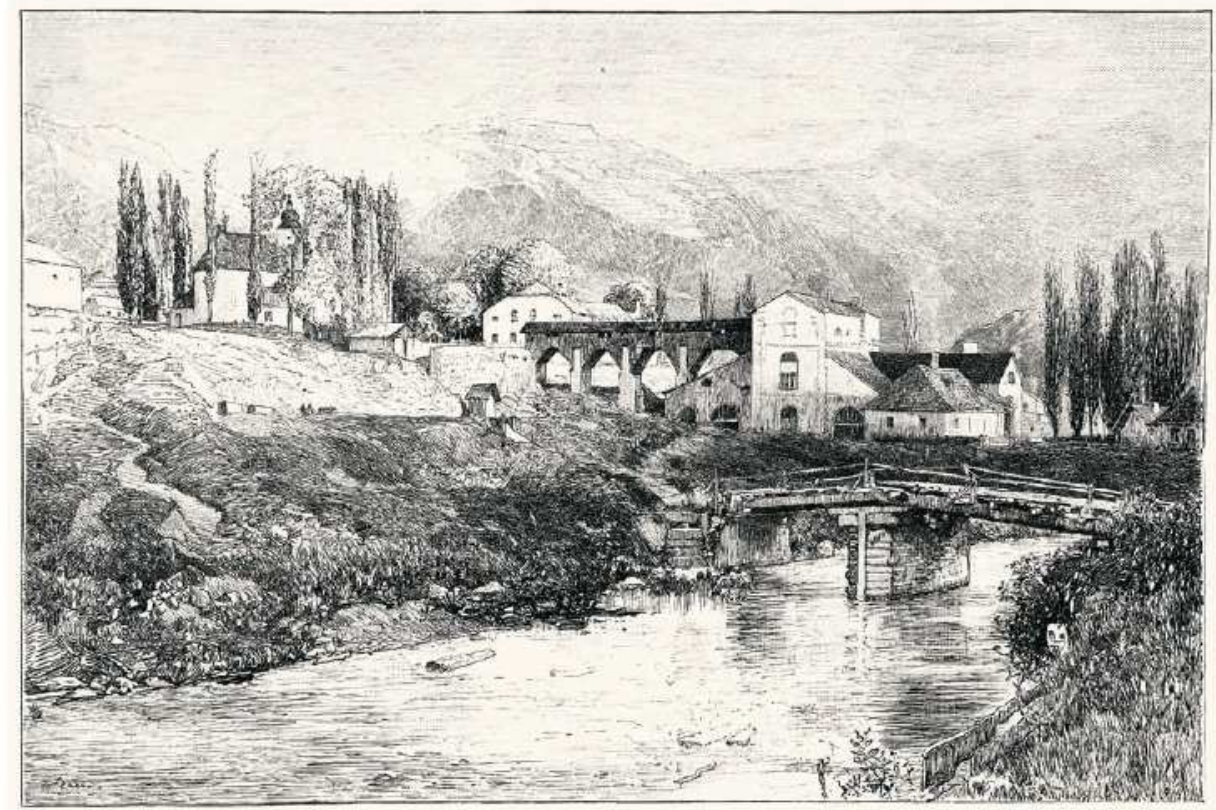

Abb. 64: Jakobeny an der Goldenen Bistritza. Illustration aus dem Kronprinzenwerk mit Teilen des Hüttenwerkes und der katholischen Kirche am linken Flussufer unweit der Straße. ${ }^{53}$

Angebrachte Kritik und öffentliche Aufregung sind indes vor dem Hintergrund gleich mehrerer Krisenjahre in der Bukowina zu sehen. Zu den Missernten der Jahre 1864 und 1865 gesellten sich 1866 verheerende Typhus- und Choleraepidemien, dass selbst der Religionsfonds gezwungen war, bei der Landesregierung um Kredite anzusuchen. Eine schrittweise Erholung trat erst in den darauffolgenden Jahren ein. ${ }^{54}$

Abgesehen vom komplizierten politischen Loslösungsprozess der Bukowina von Galizien-Lodomerien - die Bukowina war zwar seit 1849 ein eigenständiges Kronland im Status eines Herzogtums, wurde allerdings 1860/61 neuerlich der Lemberger Verwaltung unterstellt - befand sich der Religionsfonds zu diesem Zeitpunkt selbst in einer entscheidenden Phase des Wandels. Das trug freilich mithin zur Verzögerung der Abwicklung der Manzschen Gewerke entscheidend bei. Wohl aber hatte die Czernowitzer Finanzdirektion schon 1862 dem Präsidium der Landesregierung ein Gutachten zur "politischen Sequestration der Manzschen mit Steuern Rückständen belasteten Werke«

53 Die Vorzeichnung dazu von Robert Ruß liegt im Bildarchiv der Österreichischen Nationalbibliothek

[http://data.onb.ac.at/rec/baa12964391]; KLEINWÄCHTER 1899, Bergbau, 503.

54 ZACHAR et al., Entwicklung, 57. 


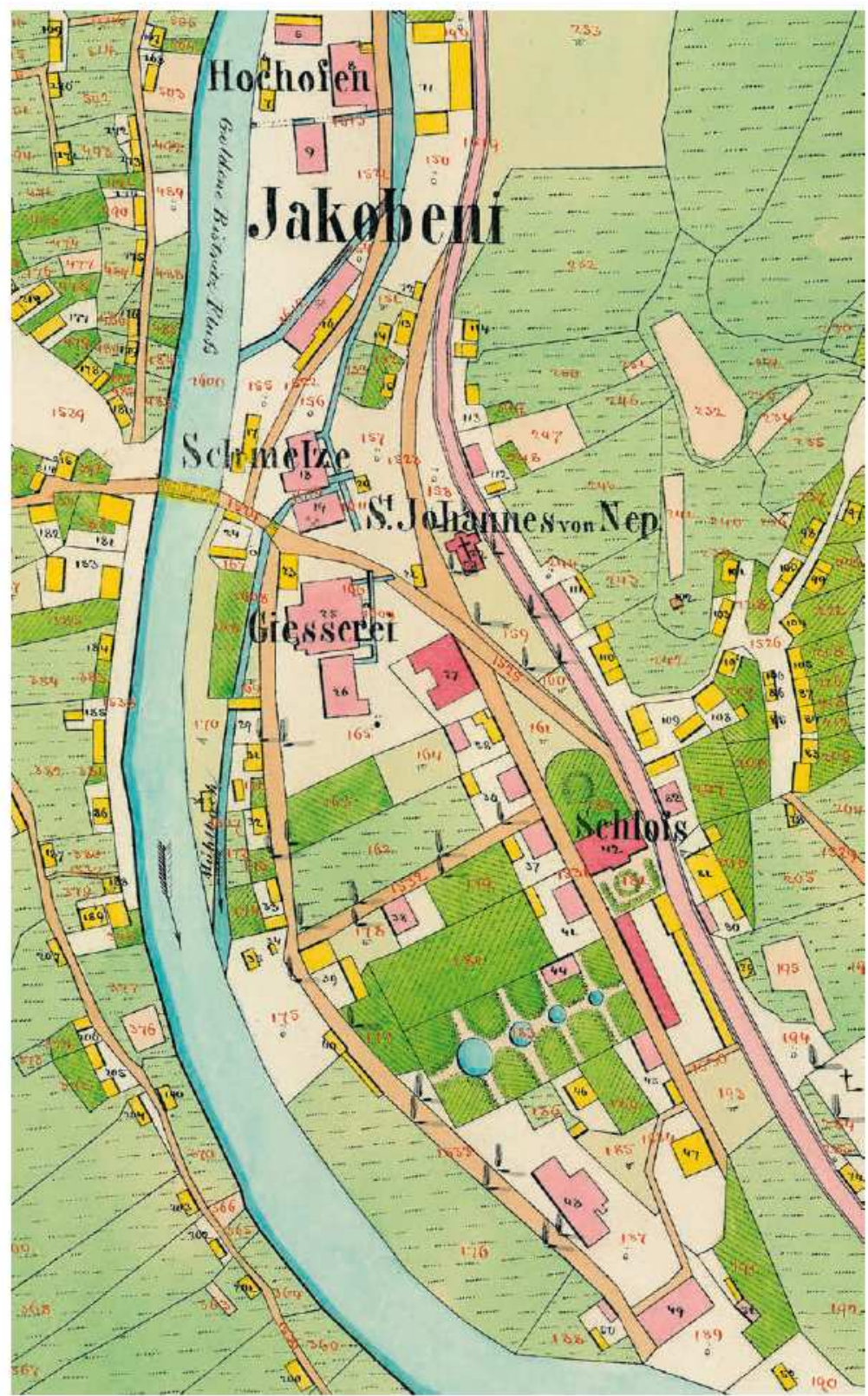

Abb. 65: Jakobeny um 1856. Die Katasteraufnahme zeigt die zentralen Werksanlagen der Siedlung (in Rot dargestellt sind gemauert aufgeführte Gebäude) sowie das iSchloss، der Gewerken von Manz und der es umgebenden kleinen Parkanlage. Katastralgemeinde Nr. 104 Jakobeny, Blatt 13, nicht maßstabsgetreu! (c) Oficiul de Cadastru şi Publicitate Imobiliară Suceava. 
vorgelegt. Die Finanzdirektion merkte darin zwar wiederholt die bedeutende Aufbauleistung der Werke für den vormals nur dünn besiedelten Gebirgsraum - der ehedem »einer Wüstenei ähnlich war" - ausdrücklich an, legte allerdings ebenso die strukturellen Mängel des Werkskomplexes offen und erarbeitete umfangreiche Vorschläge zu dessen Restrukturierung. ${ }^{55}$ Wie sich noch zeigen sollte, war die vollständige Umsetzung dieser rein ökonomischen Maßnahmen durch den neuen Eigentümer allein schon aus sozialer Rücksichtnahme nicht immer möglich. ${ }^{56}$

Im Herbst 1869 hatte das Landespräsidium bzw. Wien im Zuge der Beratungen über Reformen in der Güterverwaltung dem Bischof eine Beteiligung des Religionsfonds an der »Executivlizitation der Manz'schen Werke« vorgeschlagen. Im sich abzeichnenden Betrieb der Werke durch den Religionsfonds befürchtete Bischof Hackmann ein »Hazardspiel«. Selbst auf die Gefahr hin, den möglichen Anteil an einer Konkursmasse einzubüßen, lehnte er vorerst in seiner Stellungnahme dazu dem Ministerium gegenüber das Vorhaben entschieden ab. Vielmehr sollten die Werke »je eher je lieber « an Private veräußert werden. ${ }^{57}$ Noch im Frühjahr 1872 hatte sich eine Gruppe von vorwiegend Czernowitzer Honoratioren, unter ihnen der amtierende Landespräsident Felix Pino v. Friedenthal, Bürgermeister Anton Kochanowsky, Konsistorialsekretär Anton Schönbach, Archimandrit Theophil Bendella und der Bukowiner Reichsratsabgeordnete Theodor Endletsberger sowie der Ministerialsekretär F. Burian unter »strengstem Stillschweigen « zusammengefunden, um die Gründung einer Industriebank zu betreiben. Deren hauptsächliches Ziel sollte in der Hebung von "Land- und Forstwirtschafth, Bergbau, Handel und Industrie in der Bucowina « bestehen. Im Speziellen aber trug man sich mit der konkreten Absicht, die Manzschen Werke anzukaufen und sämtliche (sic!) Güter des Religionsfonds auf Jahrzehnte hinaus in Generalpacht zu betreiben. ${ }^{58}$ Diesen Vorschlägen schloss sich das Konsistorium als Ganzes freilich nicht unisono an. ${ }^{59}$

55 DACZ $_{3 / 1 / 2125}$, fol. 6-31; hier fol. 6, Finanzbezirksdirektion Czernowitz an Landespräsidium v. 8.III.1862.

56 Der Religionsfonds hatte nach Übernahme der Bergwerke von den dort wohnenden Familien Pacht für die von ihnen zuvor über Jahre hin kostenlos von den Gewerken zugeteilten und genutzten Gründe gefordert, ebenso für die Holzentnahme und die Bestoßung der Weidgründe. Nachdem sich eine Deputation der Bewohner an das Ministerium in Wien gewandt hatte, schlug der Fonds einen versöhnlicheren Kurs ein; DACZ $3 / 1 / 3356$, fol. $3-18$, Deputation in Vertretung von 800 Arbeiterfamilien der Bukowiner Montanwerke an Ministerium d. Innern v. 21.X.1870; sowie Abschrift Note Ministerium d. Innern an Ministerium f. Kultus \& Unterricht v. 7.XI.1870, Zl. 15792, fol. 2 of.

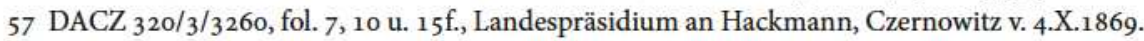

58 DACZ $_{320} / 3 / 3260$, fol. 22f., Protokoll v. 26.III.1872; fol. 51, Abschrift Nr. 57 Pino v. Freudenthal an Hackmann, Wien v. 20.III./1.IV.1872.

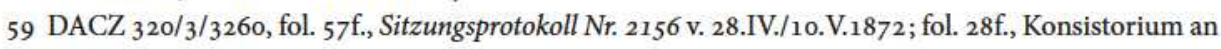
Hackmann v. 26.V./7.VI.1872. 
Die in der Sache insgesamt ablehnende Haltung des Kirchengremiums zeigte zugleich auch seine innere Gespaltenheit, war doch der amtierende Archimandrit ebenso in der Gruppe zur Gründung der Bukowiner Industriebank vertreten, wie er dem Konsistorium als Rat angehörte. Für Bendella musste wohl die Aussicht, die Bürde der im Raum stehenden Übernahme durch den Religionsfonds doch noch abwenden zu können, ausschlaggebend dafür gewesen sein. Aber selbst den anderen Teilnehmern kann man kaum eigennütziges Handeln vorwerfen. Sie hatten ihrerseits klar die veritable und unvermeidliche Strukturkrise in der Bergwerksregion wie in der allgemein schwachen Industrie des Kronlandes heraufziehen sehen, hätte man tatsächlich einen Konkurs der Werke in Kauf genommen. Andererseits musste der politischen Landeselite jedoch ebenso völlig klar gewesen sein, dass eine derartige Bank dieses strukturelle Defizit auf Dauer nicht aufzufangen im Stande gewesen wäre. Dafür sollten folglich die Mittel des potenten Religionsfonds, die sich aus seinen Gütern erwirtschaften ließen, herhalten. Das wiederum konnte die Kirche kaum gutheißen, musste sie doch ihrerseits befürchten, damit einer endgültigen Entfremdung ihres Eigentums selbst den Weg zu ebnen. Vor diesem Hintergrund stellte sich die Übernahme der Manzschen Werke durch den gr--orient. Religionsfonds und dessen organisatorische Neuaufstellung unter Wiener Dirigat als eine für alle Interessensgruppen durchaus konsensfähige wie pragmatische Lösung dar. Zudem gelangten im Frühsommer 1873 offensichtlich Informationen über eine Verpachtung der Güter vorzeitig an die Öffentlichkeit, sodass man kirchlicherseits aus dieser Richtung im Falle einer Zustimmung heftige Kritik befürchten musste. ${ }^{60} \mathrm{Al}$ lerdings war die offizielle Überschreibung der Werke in das Eigentum des Religionsfonds nach langwierigen Verhandlungen - ungeachtet des bischöflichen Protestes schon am 10. Jänner 1870 in Kimpolung erfolgt. ${ }^{61}$ De facto hatte man in der Bukowina wohl schon zuvor angenommen, dieser Entwicklung mit der Gründung der angestrebten Bank eine andere Richtung geben zu können.

Die mit der rechtlichen Übernahme eingerichtete Direktverwaltung oblag vorerst noch dem Landespräsidium der Bukowina als Vertretung der Wiener Zentralstellen. ${ }^{62}$ Zum neuen Berg- und Hüttenwerkverwalter bestellte der Landespräsident den aus Hannover stammenden Oberbergrat Bruno Walter. ${ }^{63}$ Mit der abgeschlossenen Restrukturierung des Fonds übernahm die neu eingerichtete »k.k. Direction der Güter des Bukowiner grie-

6o DACZ $320 / 3 / 3260$, fol. 32, Konsistorium an bischöfliches Ordinariat v. 21.VI./3.VII.1873; fol. 58 f., Konsistorium an Ministerium f. Kultus \& Unterricht v. 22.V./3.VI.1872; offensichtlich hatte die Zeitung Der Patriot. Wochenschrift für Politik und Volkswirtschaft (Nr. 9/1872) darüber berichtet und damit in der Bevölkerung für einigen Unmut gesorgt.

$61 \mathrm{DACZ}_{3} / 1 / 3412$, fol. 1, Bericht Oberfinanzrat Dr. Hammer an Landespräsidium v. 4.I.1870.

$62 \mathrm{DACZ}_{3 / 1 / 3413}$, fol. 2, Bergwerksverwaltung Jakobeny an Landespräsidium v. 4.IV.1870.

$63 \mathrm{DACZ}_{3} / 1 / 3412$, fol. 33, Bruno Walter an Landespräsidium, 22.III.1870. 
chisch-orientalischen Religionsfondes « in Czernowitz ${ }^{64}$ statutengemäß die Aufsicht über die nunmehr nach Pozoritta verlegte provisorische Montanverwaltung der vormaligen Manzschen Gewerke. ${ }^{65}$ Die Werksleitung besorgte seit 1890 Faustin v. Krasuski. Die Montanverwaltung selbst blieb zwar über die Güterdirektion Eigentumsbestandteil des Religionsfonds, wurde jedoch noch 1874 dem Ackerbauministerium, als der dem Fonds übergeordneten Behörde, direkt unterstellt. ${ }^{66}$ Die dadurch bedingte Fixierung der Bergwerkshauptverwaltung in Pozoritta mag politisch durchaus beabsichtigt gewesen sein, um die verfahrenen Strukturen in Jakobeny aufzubrechen. Das Provisorium lief dementsprechend erst 1894 aus und die Bergwerksverwaltung kehrte wohl auch aufgrund des erreichten Bedeutungszuwachses des Ortes wiederum nach Jakobeny zurück (vgl. Abb. 66). ${ }^{67}$

In wirtschaftlicher Hinsicht bedingte 1873 die Einrichtung eines Walzwerkes in Jakobeny durch den neuen Betreiber nur ein bescheidenes Aufflackern der Eisenindustrie. Der Schmelzofen und das Walzwerk verarbeiteten für den regionalen Bedarf vorwiegend Schmiedeeisen aus ausgemusterten Bahnschienen. Von größerer Bedeutung war hingegen der unter Walter in Angriff genommene Aufschluss reichhaltiger Manganerzvorkommen bei Jakobeny, wo um die Jahrhundertwende zwischen 59 und 124 Arbeiter ständig Beschäftigung fanden. ${ }^{68}$ Bis 1908 konnte deren Anzahl auf durchschnittlich 200 gesteigert werden. ${ }^{69}$ Das Braunsteingeschäft zählte zu den ergiebigsten Zweigen der Bergbauindustrie des Kronlandes. ${ }^{70}$ Nicht zuletzt die 1888 eröffnete Lokalbahnlinie Hatna-Kimpolung, vor allem jedoch der 1902 fertiggestellte Schienenstrang Kimpolung-Dornawatra und der in den darauffolgenden Jahren weitere Ausbau hin zum ungarischen Eisenbahnnetz sowie regelmäßige Investitionen trieben die wirtschaftliche Entwicklung der Region maßgeblich an. ${ }^{71}$ Die ehemalige Kupfergrube in Pozoritta bzw. die probeweise in Louisenthal (rum. Fundu Moldovei) angefahrenen Kupfer- und Schwefelkiesstollen zählten zu den Hoffnungsbauen. Bereits

64 Der Landespräsident vertrat als Vorstand der Direktion statutengemäß die Wiener Zentralstellen.

65 Die korrekte Bezeichnung dafür lautete K.k. Ober-Berg- und Hüttenverwaltung für die Montanwerke des Bukowinaer gr.-or. Religionsfondes; ONCIUL 1891, Fondul, $248 \mathrm{f}$.

66 GVBl. XXI. Stück v. 29.VIII.1874, 22. Gesetz, 61-64, Verordnung des Ackerbauministers v. 29.VII.1874.

67 GVBl. III. Stück v. 28.II.1894, 3. Gesetz, 7-9, Verordnung Ackerbauministerium v. 23.II.1894, allerhöchste Entschließung v. 5.I.1894; sowie CATARGI (Hg.) 1899, Bukowina, 217.

68 Catargi (Hg.) 1899, Bukowina, 339; KleinWÄCht ER 1899, Bergbau, $510 f f$.

69 NASKE 1908, Manganerzbau, 545; Irimescu gibt für den gesamten Bezirk Kimpolung zum 31.XII.1900 232 (in Abbau und Metallurgie) und 217 Personen (in der Metallverarbeitung) an; IRIMESCU 1981/82, istoria, 275 .

$70 \mathrm{DACZ}_{320 / 2 / 409}$, fol. 13, Konsistorialprotokoll Nr. 5126 v. 23 X./4.XI.1899, Voranschlag Jakobeny 1900.

71 Dazu die Darstellung der Investitionen und Werkserneuerungen bei KRASUSKI 1907, Bergwesen v. 2.VI. (4f.), 4.VI. (4), 5.VI. (3f.), 6.VI. (3), 7.VI. (3) und 9.VI. (4). 


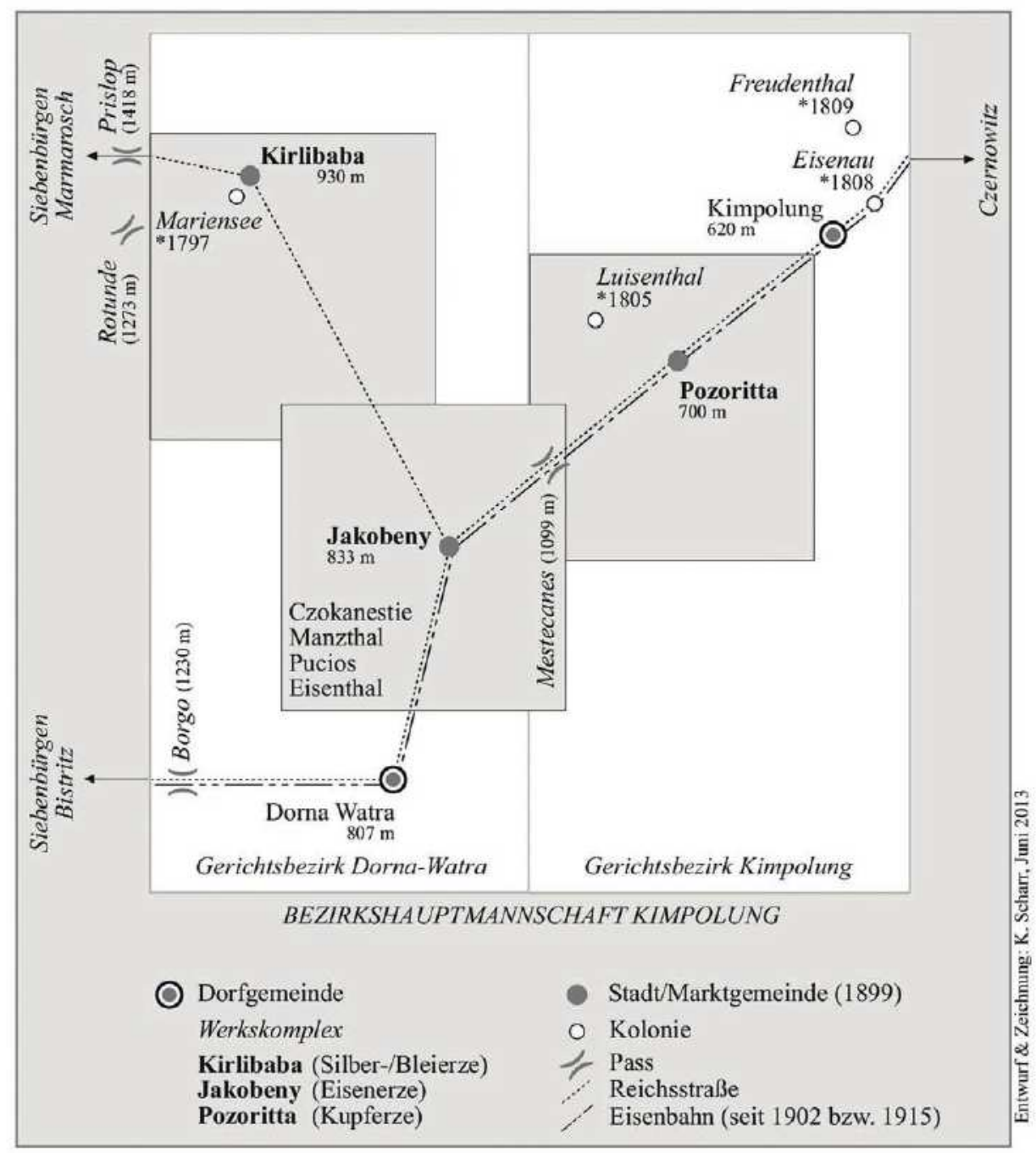

Abb. 66: Struktur und Lage des Bergbaugebietes Jakobeny vor dem Ersten Weltkrieg. Hōhenangaben nach Spezialkarte der Österreichisch-Ungarischen Monarchie (Normalnull Triest).

1805 hatte hier - wie schon erwähnt - der Ärar einen Schurfstollen angefahren. Für die Förderung und Aufbereitung der Louisenthaler Schwefelkieslager standen allerdings vorerst noch keine ausreichenden Investitionsmittel zur Verfügung. ${ }^{72}$ Durch die Ei-

72 KLEINWÄCHTER 1899, Bergbau, 511; vgl. auch DACZ 320/2/409, fol. 13, Konsistorialprotokoll Nr. 5126 v. 23.X./4.XI.1899, Voranschlag Jakobeny 1900. 
senbahn und erste Gewinne in Jakobeny war es der Güterverwaltung des Fonds allerdings bereits einige Jahre später unter der technischen Leitung von Krasuski möglich geworden, die nötigen strukturellen Vorleistungen zu finanzieren, sodass Louisenthal (das über einen eigenen sieben Kilometer langen Flügel an die Haupteisenbahnstrecke angebunden war) 1907 bereits 2000 Waggons Schwefelkies an die Werke in Teschen zur Weiterverarbeitung liefern konnte. ${ }^{73}$ Am Bau der erwähnten Bahnverbindung als auch der angeschlossenen Zweigstrecke Pozoritta-Louisenthal hatte sich der Religionsfonds mit über 750.000 Gulden beteiligt. ${ }^{74}$ Noch bis 1887 mussten die Erze teuer mit Fuhrwerken nach Suczawa gebracht werden. Ungeachtet dessen war es dennoch notwendig geworden, 1882 eine Reihe von veralteten und im Betrieb unwirtschaftlichen Werkseinrichtungen (die Hochöfen in Jakobeny und Pozoritta sowie die Eisenhämmer in Boul, Freudenthal und im zu Jakobeny gehörenden Ciotina) endgültig zu schließen bzw. abzutragen. ${ }^{75}$ Trotz der Eisenbahn blieb die Entfernung für die Frachtkosten allemal ausschlaggebend, zumal die Konkurrenz auf dem Braunsteinmarkt den Verkaufspreis drückte. ${ }^{76}$ Dieser Umstand stellte daher immer noch eine gewisse Belastung für einen rentablen Absatz bzw. Betrieb der Werke dar. ${ }^{77}$

Am Beispiel des zunehmend unrentablen Walzwerkes wie des Zeughammers in Eisenau kristallisierte indes auch eine Konfliktlinie entlang unterschiedlicher Interessen der Wiener Ministerien, als für den Religionsfonds entscheidenden Stellen, sowie des Czernowitzer erzbischöflichen Konsistoriums. Letzteres drängte schon seit längerem auf die endgültige Schließung der unrentablen und aus ihrer Sicht finanziell nur belastenden Eisenauer Montanwerke. Das Konsistorium forderte eine Übertragung der dadurch frei werdenden Gründe in den Forstwirtschaftsbezirk Wama (rum. Vama) ein. ${ }^{78}$ Zumindest bewilligte das Ackerbauministerium in Eisenau und Freudenthal einen vergleichsweise bescheidenen Verkauf von Grundstücken an Kolonisten. Die davon betroffenen etwa 50 Hektar, verteilt auf 177 Personen, lassen allerdings vermuten, dass es sich dabei lediglich um Zuerwerbsflächen handeln konnte. Die Kolonisten mussten folglich ihr Haupteinkommen aus anderen Bereichen bestreiten, etwa der aufstrebenden Forstwirtschaft. ${ }^{79}$

73 KRASUSKI 1907, Bergwesen, Nr. 1021 v. 9.VI.1907, 4; dazu detailliert NASKE 1908, Manganerzbau.

$74 \mathrm{DACZ}_{320 / 2 / 409}$, fol. 89, Konsistorialprotokoll Nr. 5082 v. 12./25.IX.1902.

75 Krasuski 1907, Bergwesen Nr. 1015 v. 2.VI.1907, 4 f.

76 Wie Anm. 74, fol. 63 .

77 NASKE 1908, Manganerzbau, 546; für 1853 werden 52 Fuhrleute mit 166 Pferden und 44 Ochsen angegeben, die für die Erzbringung der Werke nötig waren; ANONYMUS 1936, Manz.

78 DACZ $_{320 / 2 / 409}$, fol. 13 f., Konsistorialprotokoll Nr. 5126 v. 23.X./4.XI. 1899; fol. 65 ff., Konsistorialprotokoll Nr. 5082 v. 12./25.IX.1902.

79 DACZ $_{320 / 2 / 409}$, fol. 41-48, Konsistorialprotokoll Nr. 5126 v. 2VII.1897, Nachweisung; 35 Personen erhielten in Freudenthal 18 ha 71 a und $29 \mathrm{~m}^{2}$ im Wert von $4.427 \mathrm{fl}$. 89 x. sowie 142 Personen (141 


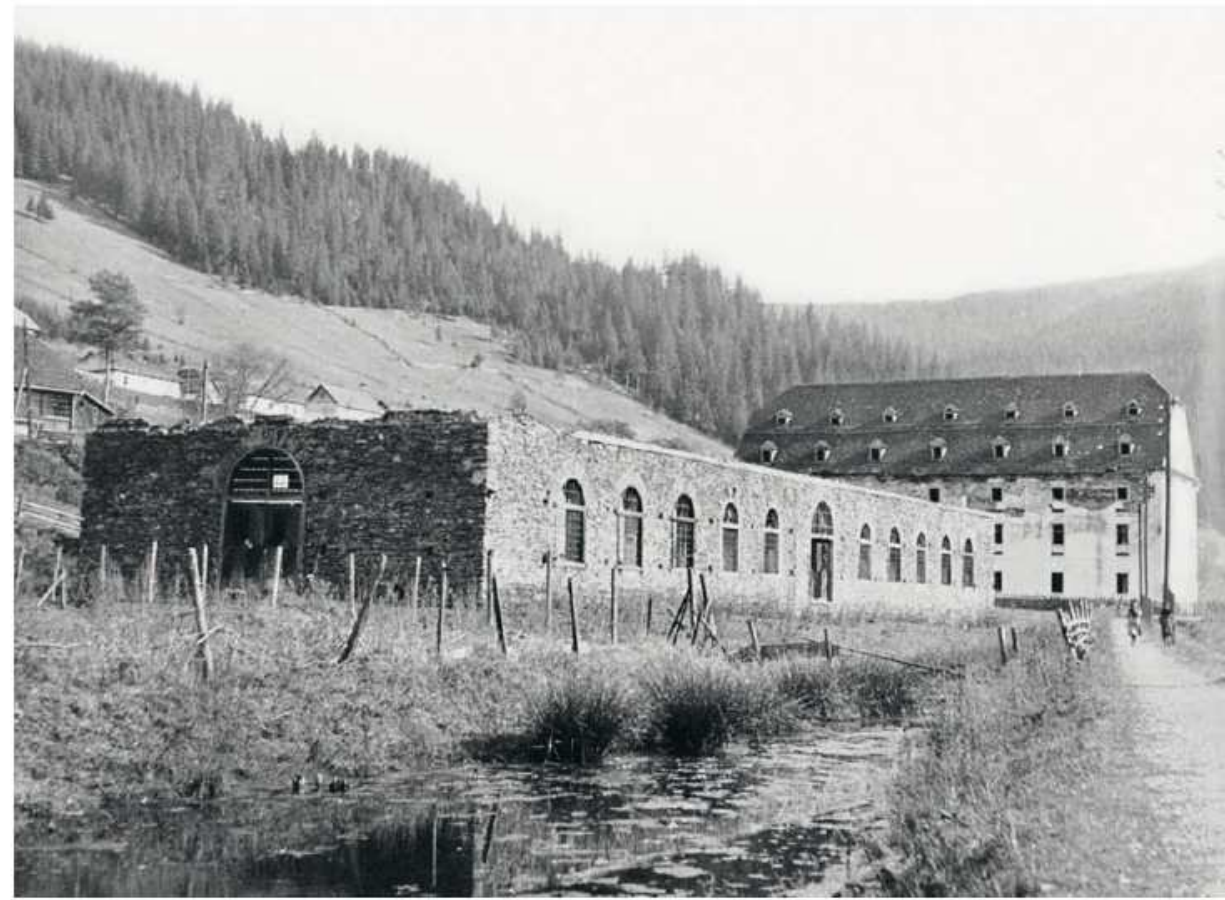

Abb. 67: Die Ruine der ehemaligen Manzschen Gießereihalle in Jakobeny, wie sie in der Zwischenkriegszeit noch Bestand hatte, wurde mit dem staatlichen Industrialisierungsprogramm des sozialistischen Rumäniens wahrscheinlich während der 1960 er Jahre endgültig abgetragen. ${ }^{80}$

Schon ein Vierteljahrhundert zuvor hatte Bejan - damals Pfarrer von Dornawatra, jetzt Konsistorialrat - die durch die Übernahme der Manzschen Werke gewachsene »Mißwirtschaft " und "Kopflosigkeit« der Religionsfondsverwaltung, in der er eine "große Gefahr « für die Interessen der Kirche selbst ortete, in einem Memorandum kritisiert. ${ }^{81}$ Dahinter verbarg sich wohl eine gewisse Unzufriedenheit, da mit der Schaffung der Religionsfondsverwaltung der unmittelbare kirchliche Einfluss in die Geschäftsführung und Gebarung der Güter erheblich schwieriger geworden war.

plus Gemeinde) in Eisenau 30 ha 28 a $63 \mathrm{~m}^{2}$ im Wert von $4.956 \mathrm{fl}$. 6 x; die Käufer werden im Dokument namentlich genannt.

80 BECK 1963, Bukowina, 180.

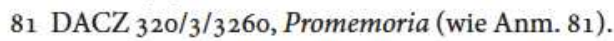


Tab. 14: Betriebsstätten der Bergwerke Jakobeny $1865 / 1880^{82}$

\begin{tabular}{|c|c|c|c|c|}
\hline Betriebsort & & bis 1865 & & 1880 \\
\hline \multirow{7}{*}{ Jakobeny } & 3 & Zeughämmer & 2 & Zeughämmer \\
\hline & 4 & Frischhämmer ${ }^{83}$ & & \\
\hline & 1 & Gussofen & & \\
\hline & 1 & Kuppelofen & 1 & Kuppelofen \\
\hline & 1 & Hochofen & & \\
\hline & 1 & Maschinenwerkstätte & 1 & Maschinenwerkstātte \\
\hline & & & 1 & Manganaufbereitung \\
\hline Manzthal & 6 & Frischhämmer & & \\
\hline \multirow{4}{*}{ Pozoritta } & 3 & Kupferöfen & & \\
\hline & 1 & Spleißofen ${ }^{84}$ & & \\
\hline & 2 & Kupferhāmmer & & \\
\hline & & & 1 & Zeughammer \\
\hline \multirow{2}{*}{ Fundul Moldovi } & 1 & Pochwerk mit & & \\
\hline & 3 & Stollen auf Kupfererze & & \\
\hline \multirow{2}{*}{ Eisenau } & 10 & Frischhämmer & & \\
\hline & & & 1 & Walzwerk \\
\hline Freudenthal & 6 & Frischhämmer & & \\
\hline Beamte/Diener & & 19 & & k.A. \\
\hline
\end{tabular}

Die Montanwerke gerieten in der Zwischenzeit zunehmend in die Mühlen der politischen Diskussion des Kronlandes. Trotz beträchtlicher anfänglicher Erfolge in der Erzgewinnung erfüllte der kurz nach der Jahrhundertwende durch den Religionsfonds wieder aufgenommene Bergbetrieb (vorwiegend Schwefel- und Montanerze) in Jakobeny, Louisenthal und Kirlibaba nicht die Erwartungen, sodass sich in Wien bald die unangenehme Frage nach neuerlichen Investitionen aufdrängte. Die Bukowiner Presse kolportierte zudem Gerüchte um eine bevorstehende Privatisierung oder Verpachtung der Werke. ${ }^{85}$ Schließlich verlor

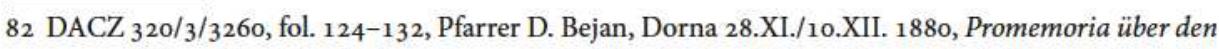
gegenwärtigen Stand der hiesigen dem gr. or. Religionsfonde gehörigen Bergwerke in Jacobeni, Pozoritta, Kirlibaba, Eisenau und Freudenthal etc.

83 Das im Hochofen gewonnene Eisen wurde neuerlich in einem sog. Frischfeuer aufgeheizt und mit einem Hammer bearbeitet, um das Material zu entkohlen.

84 Ofenform zur Kupferaufbereitung.

85 Für die Bukowina (österreichweit) werden im Jahr 1905 [1906] 8.291 [38.619] (84.073) Mtz. an Schwefelerzen im Wert von $11.607 \mathrm{~K}$ und 112.420 [103.942] (220.461) Mtz. an Manganerzen im Wert von 198.908 K ausgewiesen; Bukowinaer Post Nr. 2355 v. 9.III.1909, Titelseite, Unser Montan- 
sich in Louisenthal die anfängliche ergiebige Erzader und der Betrieb sollte 1911 gänzlich eingestellt werden ${ }^{86}$ Die Werksleitung fiel deswegen erheblich hinter ihren eingegangenen Lieferverpflichtungen gegenüber den österreichischen Berg- und Hüttenwerken zurück, woraufhin der Religionsfonds Entschädigungszahlungen zu befürchten hatte. Krasuski war es zuvor nicht gelungen, die Bedenken der Regierung auszuräumen und zusätzliche Mittel für eine weitere Erschließung des defizitären Abbaus in Louisenthal freizuspielen, obwohl das Manganwerk in Jakobeny überaus positiv bilanzierte ${ }^{87}$ Letztlich entschied sich das Ministerium zu Beginn des Jahres 1912 für eine Verpachtung des Schwefelkiesbergbaues an die Oberungarische Berg- und Hüttenwerks-Aktiengesellschaft in Budapest. Der Einstieg für die neuen Betreiber lohnte sich indes durchaus und der in Angriff genommene Schachtvortrieb konnte die versiegt geglaubte Erzader wieder aufdecken. ${ }^{88}$

Wenngleich die Bergwerke des Kimpolunger Bezirks durch ihre Neuaufstellung mit dem Religionsfonds als finanzstarkem Eigentümer bis 1914 einen gewissen Aufschwung zu verzeichnen hatten, so reichte die Montanindustrie in ihrer Bedeutung doch keineswegs an die mittlerweile florierende und für die Region bestimmende Forstwirtschaft des Fonds heran. Die mit 1870 aufgenommene innere Umstrukturierung des Religionsfonds und der Bau der Eisenbahn (sowie der Errichtung kleinerer Waldbahnen zur Holzbringung) begünstigten schlagartig die internationale Kapitalisierung des Holzbestandes dieses gebirgigen Teils der südlichen Bukowina, der zuvor größtenteils nur für die lokale Montanindustrie zur Holzkohlegewinnung Bedeutung hatte. ${ }^{89}$ Der Forstbezirk Kimpolung allein verwaltete 1901 insgesamt 286.000 Hektar an Waldflächen. ${ }^{90}$ Schon in den $1830 e r$ Jahren hatten private Unternehmer vorerst unter mäßigem Erfolg mit der Flößung von Bauholz aus der Bukowina über die Bistritz (rum. Bistriţa) in die rumänische Moldau und ins Osmanische

wesen. (Neuigkeits) Welt Blatt Nr. 64 v. 5.III.1909, 18 u. Nr. 63 v. 4.III.1909, 16, Die Verpachtung der Montanwerke des Bukowinaer Religionsfonds. Die dem Bukowiner Politiker Aurel Onciul nahestehende Zeitung Die Wahrheit polemisierte gegen die Güterverwaltung (v.a. gegen deren Leitung unter Krasuski) und verbreitete Gerüchte um eine schon abgesprochene Verpachtung Louisenthals an die Teschener Werke von Erzherzog Friedrich; Die Wahrheit Nr. 48/49 v. 14.V.1909, 25-27.

86 Czernowitzer Allgemeine Zeitung Nr. 1860 v. 27.III.1910, 11, Vom Bergbau in der Bukowina.

87 Oberbergrat Krasuski hatte in seinem Bericht ausdrücklich auf die für einen weiterhin erfolgreichen Abbau fehlenden Arbeitskräfte und Geräte hingewiesen; DACZ $320 / 2 / 409$, fol. 159 f. und 182, Motivenbericht zum Voranschlage der Berg- und Hüttenwerke des Bukowiner gr. or. Religionsfondes für das Jahr 1909 und 1911; sowie fol. 183ff., Protokoll aufgenommen in Louisenthal am 29.X.1910.

88 Czernowitzer Allgemeine Zeitung Nr. 2964 v. 29.IV.1913, 4, Die Verhältnisse im Bukowiner Bergbau.

89 GUZMAN 1901, Forstwirtschaft, 117 und 179.

90 Wie Anm. 89, 111; auf den politischen Bezirk Kimpolung entfielen davon rund 150.000 ha, insgesamt verfügte der Religionsfonds in der Bukowina über 228.915 ha Wald, das entsprach mehr als $85 \%$ der Gesamtwaldfläche des Kronlandes; CATARGi (Hg.) 1899, Bukowina, 342 u. 344. 
Reich begonnen. ${ }^{91}$ Allerdings brachte erst das letzte Drittel des 19. Jahrhunderts diesem Wirtschaftszweig in Jakobeny eine neue, für den Fonds bedeutende Erwerbsquelle, wenngleich auch dieser Sektor durchaus krisenanfällig blieb. ${ }^{92}$ So präsentierte der Religionsfonds beispielsweise anlässlich der land- und forstwirtschaftlichen Ausstellung in Wien gerade die Betriebsleistungen des Forstwirtschaftsbezirks Illischestie und Dornawatra. ${ }^{93}$

\section{Von Heilquellen zum Kurort: Dornawatra}

Dieser Badeort in einer Höhe von 860 Meter über dem Meeresspiegel gelegen, erfreut sich einer reizenden, mit Nadelhölzern bewaldeten Umgegend, und einer reinen, gesunden, ozonreichen Luft, welche die Oxydation des Blutes fördert, und die Respiration der Lunge erleichtert. ${ }^{94}$

So reizend, wie der Journalist der Bukowinaer Rundschau den Kurort zum ausgehenden 19. Jahrhundert schilderte, so schwierig gestaltete sich über Jahrzehnte hin dessen Aufstieg und das, obwohl schon Balthasar Hacquet in seinen Karpatenbeschreibungen auf die hervorragende Qualität des "Eisenwassers « von Dornawatra hingewiesen hatte. ${ }^{95}$ Nahezu fünf Jahrzehnte später kam Theophil Bendella zu keiner wesentlich anderen Einschätzung der Sauerquellen und ihrer nach wie vor nur bescheidenen Nutzung.

Dieses Mineralwasser ist stärkend, wird zum Trinken und Baden gebraucht und hat seine Heilkraft an vielen durch Krankheit geschwächten Personen vortheilhaft bewährt. Dieser Badeort wird jedoch, da für die Bequemlichkeit der Gäste gar nicht gesorgt ist, wenig besucht und nur in manchen Jahren sieht man Fremde aus der Moldau an dieser Quelle ihr Heil versuchen. ${ }^{96}$

Erste "auf das Minimale beschränkte« Bäder standen ab 1804 vorwiegend den Einheimischen zur Verfügung. ${ }^{97} \mathrm{Im}$ Jahr 1807 errichtete man ein festes Badhaus und ein Jahr später wurden die Quellen fachmännisch ausgezimmert. Kurzfristig (1834-1840) hatte

\footnotetext{
91 Der Export zwischen 1834 und 1837 wurde im Wesentlichen von privaten Unternehmern (Mahomet Jasiczy und Jenaki Lakerdopolo) organisiert und richtete sich auf den Markt des Osmanischen Reiches aus; LoEBEL 1895, Entwicklung, Nr. 7 (9.VI.1895), 2 ff. u. Nr. 9 (23.VI.), $2 \mathrm{ff}$.

92 Czernowitzer Allgemeine Zeitung Nr. 380 v. 5.IV.1905, if., Der Bukowiner Holzexport; Czernowitzer Tagblatt Nr. 1858 v. 25.IV.1909, Titelseite, Industrialisierung.

93 Czernowitzer Zeitung Nr. 97 v. 27.IV.189o, 3 f., Die Bukowina auf der allgemeinen land- und forstwirtschaftlichen Ausstellung in Wien.

94 MartynowiCZ 1885, Fragmente, Nr. 127.

95 HACQUET 1791, Reisen, 213-223, hier 223.

96 Bendella 1845, Bukowina, 25.

97 MartynowicZ 1885, Fragmente, Nr. 127.
} 
sogar der Bergbauunternehmer Manz v. Mariensee die unweit von Jakobeny gelegenen Quellen in Pacht genommen. ${ }^{98}$ Politische Unruhen zur Mitte des 19. Jahrhunderts und eine insgesamt wirtschaftlich wenig ersprießliche Lage der Bukowina hemmten jedoch die nötige Konsolidierung des Ortes, sodass - obwohl Dornawatra 1857 zum Markt erhoben worden war - im selben Jahr lediglich 83 Personen auf der Fremdenliste verzeichnet waren. In den $1860 e r$ Jahren überschritt die Zahl der Kurgäste allerdings bereits die Tausendermarke. ${ }^{99}$ Eine 1868 in Wien an prominenter Stelle erschienene Broschüre über die Mineralquellen dürfte hierfür mithin einen entscheidenden Popularisierungsschub des angehenden Kurortes bewirkt haben. ${ }^{100}$ Vielfach entsprachen jedoch die Anlagen in keiner Weise den steigenden Anforderungen der mittlerweile zumeist städtischen Besucher. So hatte etwa der Eisenbahnanschluss von Czernowitz in die Moldau (nach Roman und Jassy) zwischen 1867 und 1870 zwar zu einer Steigerung der Besucherzahlen geführt, ein entsprechend nötiger Telegraphenanschluss des Kurortes erfolgte allerdings erst $\mathbf{1 8 6 9}$, obwohl Suczawa bereits seit zehn Jahren über einen solchen verfügt hatte. ${ }^{101}$

Worin lag der Grund für diese zurückhaltende Investitionspolitik? Eine mögliche Antwort darauf mag in den gleichzeitig geführten Verhandlungen um die Übernahme der unweit von Dornawatra gelegenen Manzschen Werke durch den Religionsfonds liegen. Obwohl 1869 die Heilquellen zur Gänze an den Fonds - dem schon in Jakobeny staatlicherseits eingeübten Prinzip folgend - >verkauft` und 1872 der dortigen Wirtschaftsverwaltung eingegliedert worden waren, sperrten sich Teile des Konsistoriums, aber auch der Güterdirektion gegen die ihrer Meinung nach damit unvermeidlich einhergehenden Belastungen. Schließlich bremsten sie weitere Schritte auf Jahre hinaus erfolgreich aus. Zugleich argumentierten andere - wie Theophil Bendella - für einen dringenden Ausbau der Infrastruktur. ${ }^{102}$ Carl Denarowski hatte als Regierungsrat ein entsprechendes Memorandum vorgelegt, in dem er die wichtigsten Maßnahmen zur Verbesserung der Situation auflistete. Das unterstützten nicht nur Bergrat Walter in Jakobeny, sondern ebenso der Landespräsident sowie das Ackerbauministerium. ${ }^{103}$ Die Folgen dieser insgesamt unklaren Position höchster Verwaltungsstellen, lokaler Ak-

\footnotetext{
98 Loebel 1895, Entwicklung, Nr. 3 v. 12.V.1895, 1ff. u. Nr. 6 v. 2.VI.1895, 2 f.

99 Wie Anm. 98, Nr. 10 v. 10VI.1895, 2ff.; Nr. 12 v. 14.VII.1895, 2 f.

100 Denarows KI 1868, Mineralquellen; MartynowiCZ 1885, Badeort, Nr. 128.

101 Wie Anm. 98, Nr. 15 v. 4.VIII.1895, 3 f.

102 Konsistorialbericht v. 25.X./6.XII. 1869 Zl. 5040 u. Zuschrift Konsistorium v. 8./20.VI.1871 Z. 2521; wie Anm. 98, Nr. 14 v. 28.VIII.1895, 3; Bericht Güterdirektion v. 4.IV.1878 Z. 10252; wie Anm. 98, Nr. 19 v. 1 .XI.1895, 3 f.

103 Memorandum Regierungsrat Dr. Denarowski praes. 17.IX.1874 Z. 5682/1; wie Anm. 98, Nr. 17 v. 18.VIII.1895, $2 \mathrm{ff}$.
} 
teure und Beamter resultierten indes bald in dramatisch sinkenden Gästezahlen. Von 1878 auf 1882 fiel die Frequenz von 387 Besuchern im Jahr auf magere 193 ab. Die durch den Religionsfonds mittlerweile finanzierte Aufstellung von Straßenlaternen und die Eröffnung einer Apotheke vermochten daran zunächst nur wenig zu ändern. ${ }^{104} \mathrm{Mit}$ der schrittweisen Konsolidierung der Finanzen des Religionsfonds, die seit der Übernahme der Bergwerke erheblichen Belastungen ausgesetzt gewesen waren, konnte nunmehr auch in Dornawatra systematisch investiert werden. Die Gegenstimmen innerhalb des Konsistoriums wie der Güterverwaltung verschwanden allmählich. ${ }^{105}$ Zudem sah jetzt selbst das in der Sache kritische Konsistorium ein, dass man Einbußen an Gästezahlen an die im benachbarten moldauischen Piatra ebenfalls eröffnete Kuranstalt hinnehmen würde müssen, sollte man in Dornawatra nicht schnellstmöglich einen sichtbaren Akzent des Fortschrittes setzen. Das Ackerbauministerium hatte vor dem schon mehrfach Gutachten für Umbauten und Erweiterungen in Auftrag gegeben, dessen Annahme seitens der Fondsadministration jedoch zeitweise wenn nicht verschleppt, so doch hintangestellt wurde. ${ }^{106}$ Letztlich bewilligte der Kaiser als Schirmherr 1883 eine beträchtliche Summe aus Fondsmitteln zur Erbauung einer neuen Badeanstalt. Zeitgenossen wie der in Dornawatra viele Jahre tätige Kurarzt Dr. Arthur Loebel $^{107}$ betrachteten dies als »monumenthale That«, als Wendepunkt für den aufstrebenden Kurort. ${ }^{108}$ Wenig später, im Jahr 1884, erreichten Dornawatra die Eisenbahnschienen. Jetzt war eine vergleichsweise bequeme und schnelle Anreise von Czernowitz über Suczawa möglich geworden. ${ }^{109}$ Im Jahr 1906 weihte man mit >Dornawatra-Bad den zweiten Bahnhof ein. Letzterer fungierte bis zum Anschluss an das ungarische Netz 1915 als Endstation der Linie. Er ist bis heute in Betrieb und liegt direkt gegenüber den Kuranlagen (vgl. Abb. 68).

Selbst der »verwöhnte Westeuropäer « musste in dieser Hinsicht von den Anlagen des Ortes einigermaßen beeindruckt gewesen sein, schenkt man den lokalen Medien

\footnotetext{
104 Wie Anm. 98, Nr. 20 v. 8.IX.1895, 2f.

105 Metropolitankonsistorium Note v. 18.II./2.III.1882, Z. 2388, wie Anm. 98, Nr. 21 v. 15.IX.1895, 2 f. 106 Der Bautechniker v. 27.XI.1896, 1of.; so erfolgte 1883 der Auftrag des Ministeriums zu einem Gutachten über die Reorganisation der Kuranlagen, die Kosten dafür hatte der Fonds zu tragen; selbst mehrere Ackerbauminister hatten dem Ort (1871 u. 1896) einen Besuch abgestattet; wie Anm. 98, Nr. 15; Bukowinaer Rundschau Nr. 2228 v. 5.IX.1896, 2.

107 Dazu seine Schriften, die z.T. in Vorabdrucken in Czernowitzer Zeitungen erschienen; LoEBeL 1909, Dokumente; ders. 1899, Reconstructionsepoche; ders. 1896, Entwicklung.

108 Metropolitankonsistorium Zuschrift v. 27.V./8.VI.1882, Z. 2383; wie Anm. 98, Nr. 22 v. $22 . I X .1895$, 2f.; die Bewilligung ist mit 18.VIII.1883 - dem Geburtstag des Kaisers - datiert.

109 LoebeL 1899, Reconstructionsperiode, 1 ; auch Neuigkeits Welt-Blatt Nr. 169 v. 24.VII.1888, 5; Bukowinaer Rundschau Nr. 34 v. 26.VI.1884, 4.
} 


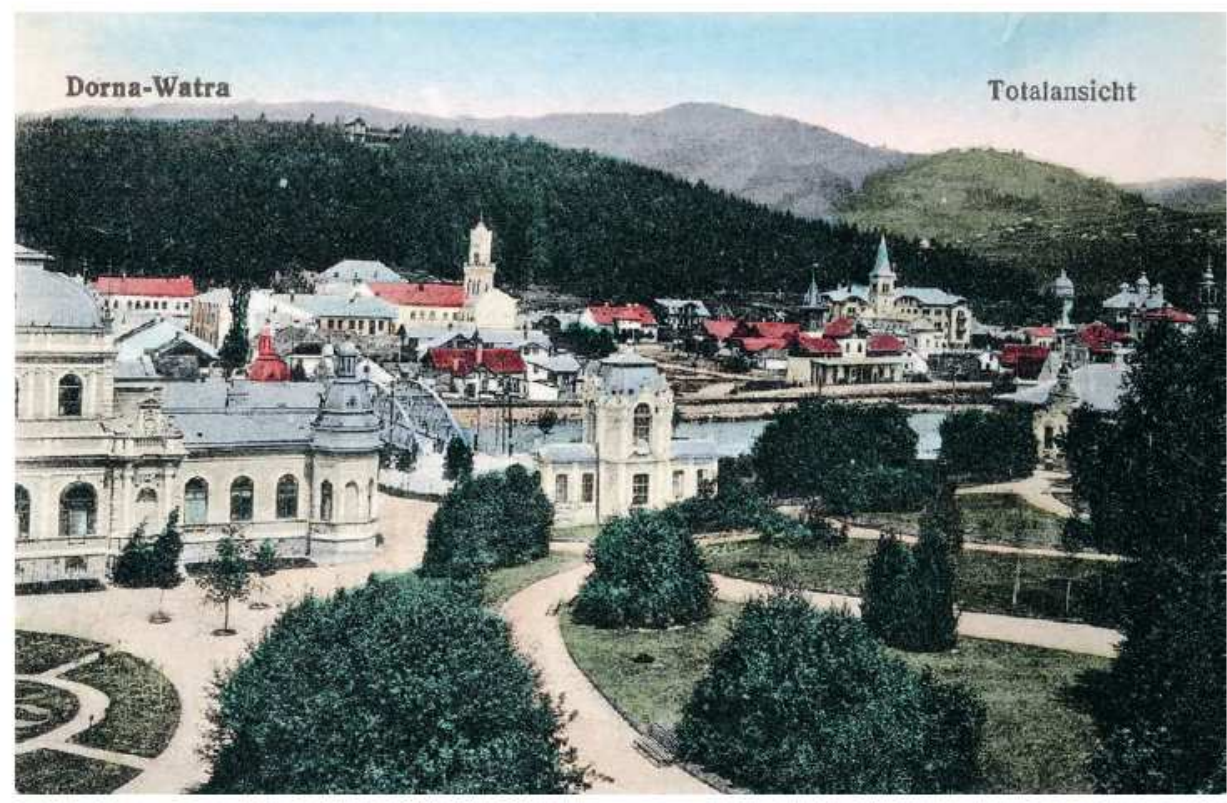

Abb. 68: Dorna-Watra Totalansicht. Ansichtspostkarte vor 1914 mit großem Kurhaus, der Johannesquelle - am linken Ufer der Dorna -, der Bahnhofstation Dorna-Bad und im Hintergrund der Fondswaldung, Parcul Runculuic. (C) Verlag Eisig Schäfer Dorna-Watra, Sammlung K.S.

Glauben. ${ }^{110}$ Als am 17. Dezember 1907 Dornawatra zur Stadt erhoben wurde ${ }^{111}$, hatte der Ort bereits einen Ruf erlangt, der weit über die Region hinaus reichte und den man gerne auch seitens des Religionsfonds als Aushängeschild vor sich hertrug. ${ }^{112}$

Kurz, das Gepräge, dann das Innere sowie Aeußere Dornas ist ein derartiges, daß es in jeder Provinz des Westens unseres Reiches stehen könnte [...] Die unzweifelhaft größte Bedeutung für den Ort sind die Anlagen des bukowiner gr.-or. Religionsfondes, die Dornawatra zu einem weit über die Marken unseres Kronlandes bekannten Kurorte gemacht haben. ${ }^{113}$

110 Bukowinaer Rundschau Nr. 2788 v. 28.VII.1898, Correspondenz; der Journalist bezog sich dabei auf die Eindrücke des Landespräsidenten Bourguignon, der in seiner Eigenschaft als Präsident der Güterdirektion des Religionsfonds den Kurort besucht hatte.

111 Loebel 1909, Dokumente, 9.

112 Die Kuranstalt des Bukowinaer gr.-or. Religionsfonds erhielt anlässlich der Wirtschaftsausstellung in Bukarest ein Ehrendiplom für die Darstellung ihrer Leistungen zuerkannt; Bukowinaer Rundschau Nr. 5281 v. 15. .I.1907, 2.

113 Czernowitzer Allgemeine Zeitung Nr. 1295 v. 5.I.1908, 5, Aus der Chronik von Dornawatra (Anläßlich der Erhebung zur Stadt) (J. BRAN). 


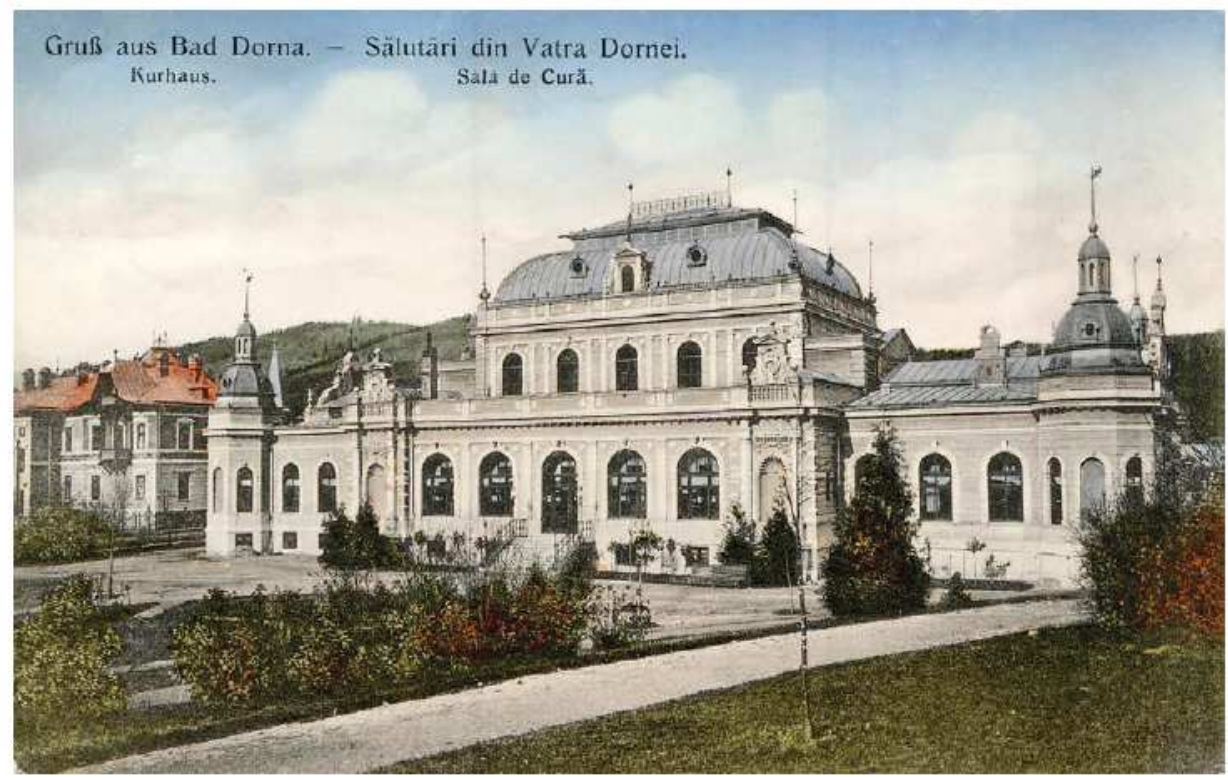

Abb. 69 - Gruß aus Bad Dorna. Sălutări din Vatra Dornei. Ansichtspostkarte des großen Kurhauses vor 1914. Aus zeitgenōssisch lokaler Sicht griff man gerne und selbstbewusst diesen Ort als herzeigbares Beispiel österreichischer Kulturleistungen auf: Dornas Geschichte erweist sich als ein farbenreicher Beitrag zum Culturgange des österreichischen Beamtenthums in der Bukowina und ist darum mehr als die reclamesūchtige Historie eines Provinzbades. ${ }^{114}$ @ Verlag der Papierhandlung Hammer, Bad Dorna, Sammlung K.S.

Nach jahrzehntelangem Zögern, geprägt von anhaltenden Unsicherheiten, setzte sich - wie schon in Jakobeny - der Zentralstaat gegenüber den vielfachen Bedenken des Religionsfonds bzw. des gr--orient. Konsistoriums durch. Der Fonds hatte schließlich alle Anlagen des bestehenden kleinen Bades in Dornawatra zu übernehmen und zeichnete in der Folge für ihr Gedeihen verantwortlich. Letztlich ging die Rechnung für beide Seiten dennoch auf und das »Franzensbad des Ostens ${ }^{115}$ entwickelte sich zu einer wichtigen wirtschaftlichen Stütze nicht nur der strukturschwachen Gebirgsregion, sondern auch des gr--orient. Religionsfonds selbst. Allerdings blieben die prinzipiellen Vorbehalte, die der Fonds regelmäßig gegen solche Investitionsbegehren des Staates und der Öffentlichkeit des Kronlandes auch weiterhin einbrachte, bestehen. So sollte es beispielsweise nicht lange dauern, bis man vom Fonds verlangte, im nahen Jakobeny zumindest eine kleinere Badeanstalt für die dortigen Bedürfnisse einzurichten. Dieser Prozess und damit dessen wirtschaftliche Fragwürdigkeit,

114 Osterreichisch-Ungarische Badezeitung Nr. 22 v. 22.IX.1895, (Schluß) 171.

115 Mittelmann 1907, Führer, 104. 
vor allem im Hinblick auf die Nähe zum mittlerweile potenten Kurort Dornawatra, zogen sich indes ungelöst bis Kriegsbeginn 1914 hin (vgl. Abb. 69). ${ }^{116}$

Die Besetzung der Bukowina durch russische Truppen sowie der nahe Frontverlauf zeitigten auch hier ihre weitreichenden Folgen. Einerseits beendete der Kriegsausbruch jedweden regulären Kurbetrieb. Dornawatra fungierte andererseits als Etappe für österreichische Truppen und Teile der Verwaltung. Zudem dienten die Einrichtungen im Verlauf der Kriegsjahre vorwiegend zur Unterbringung von Verwundeten. Zu alledem verzeichnete die Stadt mehrere Artillerietreffer, die unter anderem das Rathaus und Villen schwer beschädigten. ${ }^{117}$ Erst im Frühjahr 1918 sollte sich allmählich wieder ein einigermaßen normales Leben einstellen. Zunächst galt es die unmittelbaren Kriegsschäden zu beseitigen, sodass die Güterdirektion zumindest einen eingeschränkten Kurbetrieb im Juli aufnehmen und auch für das "Zivilpublikum « freigeben konnte. ${ }^{118}$ Allerdings wurden in der Öffentlichkeit auch kritische Stimmen dazu geäußert.

Dank der Fürsorge unseres hochlöblichen Ernährungsdienstes und Dank dem schleichhändlerischen Grenzverkehre bewegen sich die wohlgenährten Ortsinsassen und auch manche gutgelaunte Kriegsgewinner in den duftenden Kuranlagen, an den von der Kriegsfurie verschont gebliebenen Quellenpavillons vorüber. ${ }^{119}$

\section{Umbruchszeiten: 1918 bis 1948}

Sowohl Iacobeni als auch Vatra Dornei waren mit Ende des Ersten Weltkrieges gleichermaßen von den grundlegenden strukturellen Veränderungen im Königreich Rumänien, die den Religionsfonds im Besonderen betrafen, konfrontiert. Vor allem die Bergwerke bildeten mittlerweile ein finanziell gewichtiges Rückgrat des Fonds. Trotzdem mussten nach 1918 groß angedachte Ausbauvorhaben für die Gewinnung von Manganerz und dessen weitere Verarbeitung vorläufig aufgrund der Weltwirtschaftskrise zurückgestellt werden. Nur teilweise sollte sich das Werk davon in den 1930er Jahren wieder erholen können. ${ }^{120}$ Von 1910 bis Kriegsende hatten die Gruben zunächst

116 Bukowinaer Rundschau Nr. 3288 v. 6.IV.19oo, 2; Czernowitzer Allgemeine Zeitung Nr. 3115 v. 29.VII.1913 (Mittagsausgabe), 11.

117 Czernowitzer Allgemeine Zeitung / Tagblatt (Gemeinsame Kriegs-Ausgabe) Nr. 303 v. 3.VIII.1918, 2, Vom Kurort Dornawatra; dazu entsprechende Photographien des Kriegspressequartiers im Bestand der ÖNB über die Folgen des Weltkrieges; z.B. Brennendes Rathaus in Dorna Watra [http://data. onb.ac.at/rec/baa15734459].

118 Wie Anm. 117, Nr. 210 v. 24.IV.1918, 3 ; Nr. 284 v. 14.VII.1918, 4 ; Nr. 296 v. 26.VII.1918, 2.

119 Wie Anm. 117, Nr. 291, 21.VIII.1918, 4.

120 Dazu (mit einer detaillierten Aufstellung der zwischen 1936 und 1944 durchgeführten Arbeiten, 
jährliche Zuwächse in der Erzgewinnung verzeichnet und 1918 mit 46.000 Tonnen ihren absoluten Höchststand erreicht. Die darauffolgenden Jahre prägte indes ein lange andauernder wie massiver Einbruch. Erst im Jahr 1930 fuhr man wieder ein Produktionsergebnis von einigermaßen ansehnlichen 27.00o Tonnen ein. Mit der snationalen Katastrophe` von 1940 erlahmte die Erzgewinnung zeitweilig gänzlich. Danach spielte das Kriegsjahr 1943 mit 28.00o Tonnen nochmals eine beträchtliche Ausbeute ein. Insgesamt wuchs mit dem Ausbruch des Zweiten Weltkrieges die Bedeutung von Iacobeni als wichtigem nationalen wie internationalen Rohstofflieferanten erheblich an. Die Exportländer verlagerten sich dementsprechend deutlich auf die Verbündeten. Während bis 1939 Polen zu den größten Abnehmern von Manganerz zählte, so dominierten nach 1941 vorwiegend Unternehmen aus dem Deutschen Reich und Italien. ${ }^{121}$ Die Gruben in Iacobeni und Fundul Moldovi exportierten dabei neben Manganerz vorwiegend Schwefelkies (Pyrit). ${ }^{122}$ National gesehen hatten die Banater Werke in Reșiţa (dt. Reschitza) während der Kriegsjahre den meisten Bedarf an Erzen aus Iacobeni. ${ }^{123}$ Die Bukarester Regierung nutzte in dieser Situation ihre Position gegenüber dem Religionsfonds und drückte beim Verkauf an rumänische Firmen oder die Armee den Preis erheblich. Die Fondsverwaltung konnte lediglich dagegen protestieren und war mehr oder weniger gezwungen, zum Teil weit unter den eigenen Gestehungskosten zu liefern. ${ }^{124}$ Nachdem im Herbst 1944 das Gebiet durch sowjetische Truppen besetzt worden war, ging die Erzgewinnung neuerlich signifikant zurück. Zu alledem hatten die

Fördermengen, Absatzgebiete etc.) IRIMESCU 1982, istoria.

121 ANR-S inv. 35/II, pach. 72-1947, fol. 125-129, Camera Romano-Polona de industrie și comerţ din București, Contribuţiuni asupra problemei manganului, București v. 5.VIII.1945; die Produktion für 1948, aufgelistet nach den einzelnen Minen des Gebietes, fol. 255-256, Șeful serviciului exploatare miniere an Direcţia generala a controlului economic București, Vatra Dornei v. 12.IV.1948, Situaţia exploatărilor de minereu de mangan din sudul Bucovinei; ebenso die teilweise davon abweichenden Produktionsangaben bei w.v. pach. 210-1943, fol. 1-4, AFBis, Administraţia minelor Tacobeni, Darea de Seama, Iacobeni v. 29.II.1943.

122 Die Aktenlage zu diesen Wirtschaftsbetrieben erlaubt es auf Basis der vorliegenden Analyse nicht, eine detaillierte statistische-ökonomische Darstellung zu geben, sie lässt allerdings zu, einzelne Beispiele, stellvertretend für die Gesamtsituation, zu nennen; ANR-S inv. 35, pach. 171-1940, fol. 26-30, Caiet de Sarcini, licitația pentru pirită, Vatra Dornei v. XI.1940; fol. 43-47 und 55-58, Contractul ,Azienda Minerali Metallici Italiana Roma Italia v. 1.XII.1940; detto pach. 172-1940, fol. 95, Mitropolia Bucovinei Administraţia minelor Iacobeni v. 20.VIII.1940.

123 ANR-S inv. 35/II, pach. 126-1944, fol. 7, Tabloul sumelor incasat asupra livrărilor de mangan per 1942/43 și 1944 .

124 ANR-S inv. 35/II, pach. 210-1943, fol. 61-69, Referatul AFBis în chestiunea livrărilor de minereu de mangan către societatea ,Reşiţa ‘şi ,Nitrogen < impuse de ministerul economiei naționale şi inzestrarii armatei, Cernăuți v. 1.IV.1943. 
abziehenden deutschen Armeeverbände zuvor Teile der Werkseinrichtungen zerstört, die jetzt wieder instand gesetzt werden mussten. ${ }^{125}$

In der Folge von 1948 und besonders während der intensiven Industrialisierungsperiode der 'geschlossenen Mangelwirtschaft des sozialistischen Rumäniens behielten Manganerzgewinnung, aber auch Forstwirtschaft in Iacobeni ihre nationale Bedeutung weitgehend bei. ${ }^{126}$ Die politisch-gesellschaftliche Umgestaltung Rumäniens nach 1945 führte hingegen allmählich zum schleichenden Bedeutungsverlust dieses Industriezweiges für die Region. ${ }^{127}$ Mit der Wende 1989 kam der Bergbau in diesem Raum endgültig zum Erliegen, während die staatliche und mittlerweile auch wieder in kleineren Teilen private Forstwirtschaft - allerdings mit einem nicht mit der Situation vor 1948 vergleichbaren volkswirtschaftlichen Stellenwert - bis heute weiter besteht (vgl. Abb. 70/71).

In den Jahren nach 1918 erfuhr auch das Kurbad Vatra Dornei und das nahegelegene Iacobeni zahlreiche Erweiterungen und Umbauten. So ließ der Fonds etwa 1926 bei Pucios unweit des Bergwerksortes auf dem Weg zum Mestecănesti-Pass die schon bestehende Schwefelwasserquelle zu einer kleinen Badeanstalt ausbauen. ${ }^{128}$ Zusätzlich mussten die beträchtlichen Kriegsschäden beseitigt und notwendige Adaptierungen durchgeführt werden, ein in Betracht der Gesamtlage des Landes insgesamt schwieriger Prozess, der sich über ein Jahrzehnt hinzog. Trotzdem erlangte das Kurbad dafür anlässlich einer Ausstellung in Bukarest 1928 sogar drei Goldmedaillen (vgl. Abb. 72). Kritiker warfen jedoch dem zuständigen Eparchialrat und der Religionsfondsverwaltung vor, hinsichtlich der Neugestaltung des Bades baulich wie inhaltlich wenig aktiv zu sein. ${ }^{129}$ In den Kriegsjahren richteten sich in Vatra Dornei zudem mehrmals die Verwaltungssitze der Metropolie und des Religionsfonds ein. Die Kureinrichtungen dienten neuerlich der Unterbringung von Soldaten und Verwundeten. $\mathrm{Zu}$ alledem hinterließen deutsche Truppen, die 1941 vorübergehend in der Kurstadt Quartier bezogen hatten,

125 ANR-S inv. 35/II, pach. 126-1944, fol. 1, AFBis an Ministerul economiei naţionale, direcţiunea general a minelor București, București v. 2.XII.1944; eine Auflistung der Schäden findet sich unter w.v., pach. 237-1945, fol. 4, AFBis, Administraţia minelor Iacobeni, Recapitulaţia pagubelor provocate de către trupele germane v. 10.VIII.1945.

126 BodnARIUC et al. 1980, Suceava, 81; den durch die Manganerzgewinnung empfundenen wurbanen Aspekt« von Iacobeni, den ein älterer rumänischer Reiseführer hervorhebt, hat der Ort (1979: 5.00o Einwohner) mittlerweile weitgehend eingebüßt; Bojol et al. 1979, Suceava, 153; die Volkszählung von 2011 weist nur mehr 1.807 Einwohner (im Vergleich zu 3.399, Volkszählung 1956) aus, darunter sind wahrscheinlich auch eine Reihe von Personen, die gegenwärtig im EU-Ausland leben [http://www.recensamantromania.ro/wp-content/uploads/2012/o8/TS8.pdf].

127 BECK 1963, Bukowina, 162-185.

128 SÂRBU 1931, Reflexiuni, LXIIIf.

129 Wie Anm. 128, XXXIX-XLIV, hier XLI. 


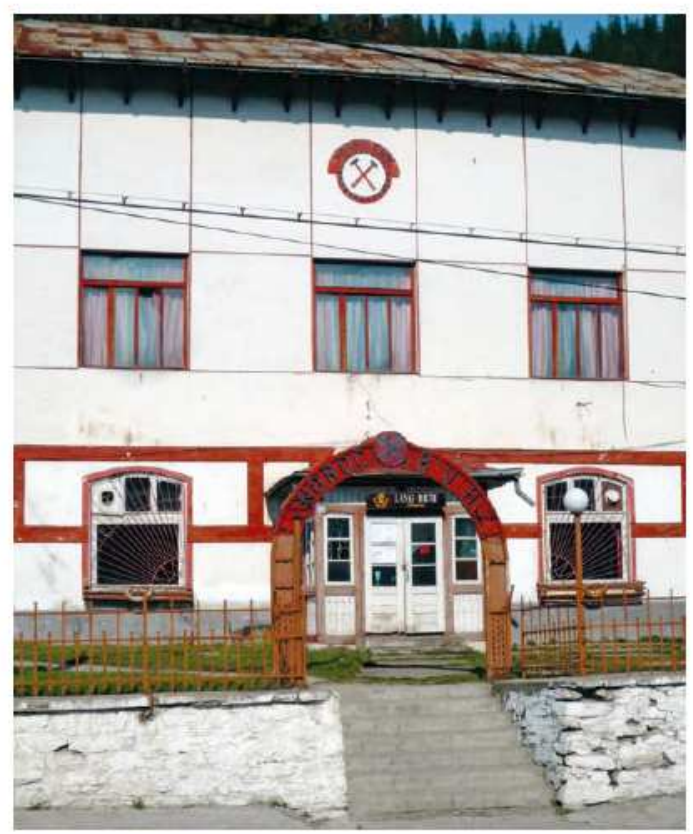

Abb. 70: Noroc Bun! (Glück Auf!), so der Bergarbeiterspruch über dem Hauseingang. Das ehemalige Deutsche Haus - unmittelbar an der Hauptstraße gelegen - diente bis zur Umsiedlung ins Deutsche Reich 1940 der bevölkerungsstärksten Gruppe des Ortes als Kultur- und Vereinszentrum, danach war es bis 1991 Treffpunkt der Bergarbeiter. (C) K. Scharr, April 2013.

Abb. 71: Verfallene Aufbereitungsanlagen und Abraumhalden des nach 1991 geschlossenen Manganwerkes bei Ciocaneşti. (c) K. Scharr, April 2013.

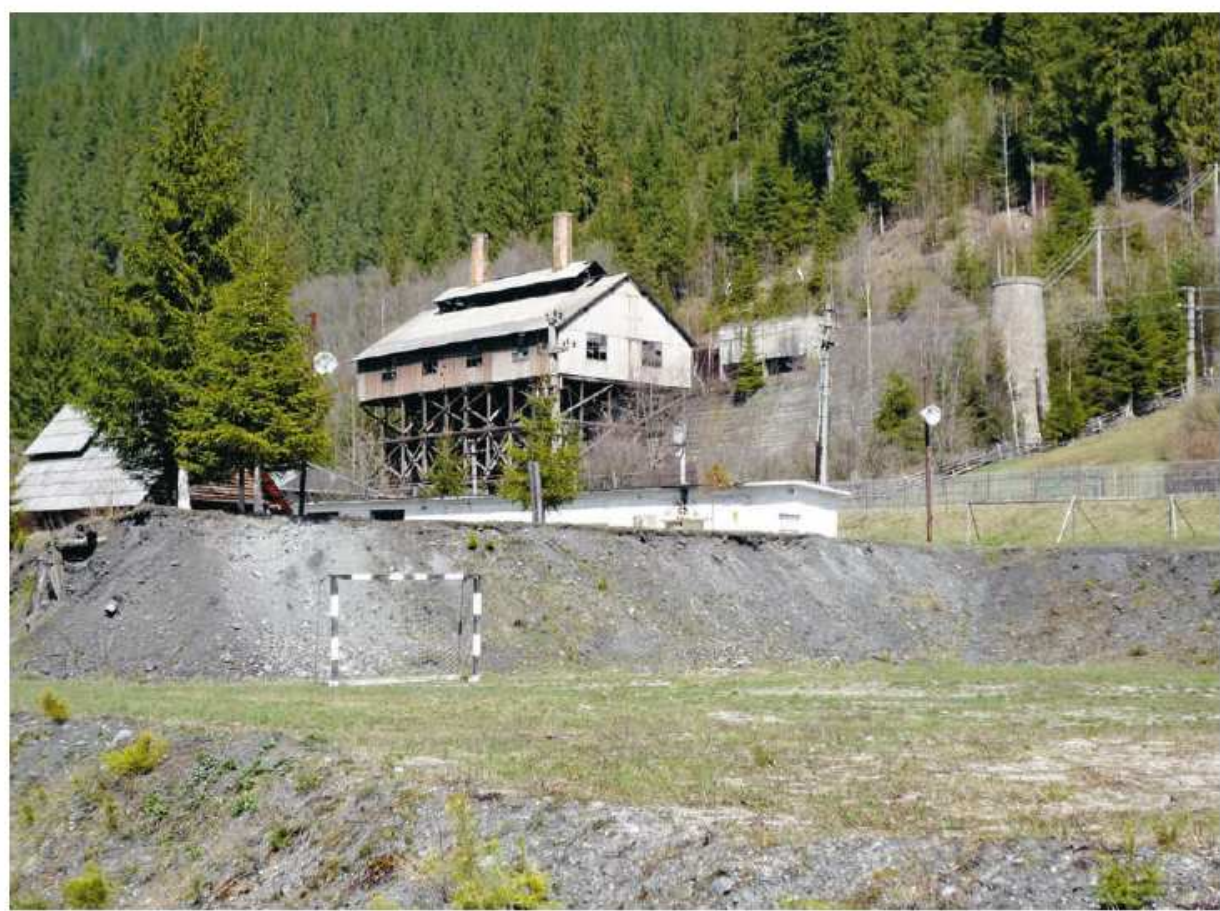




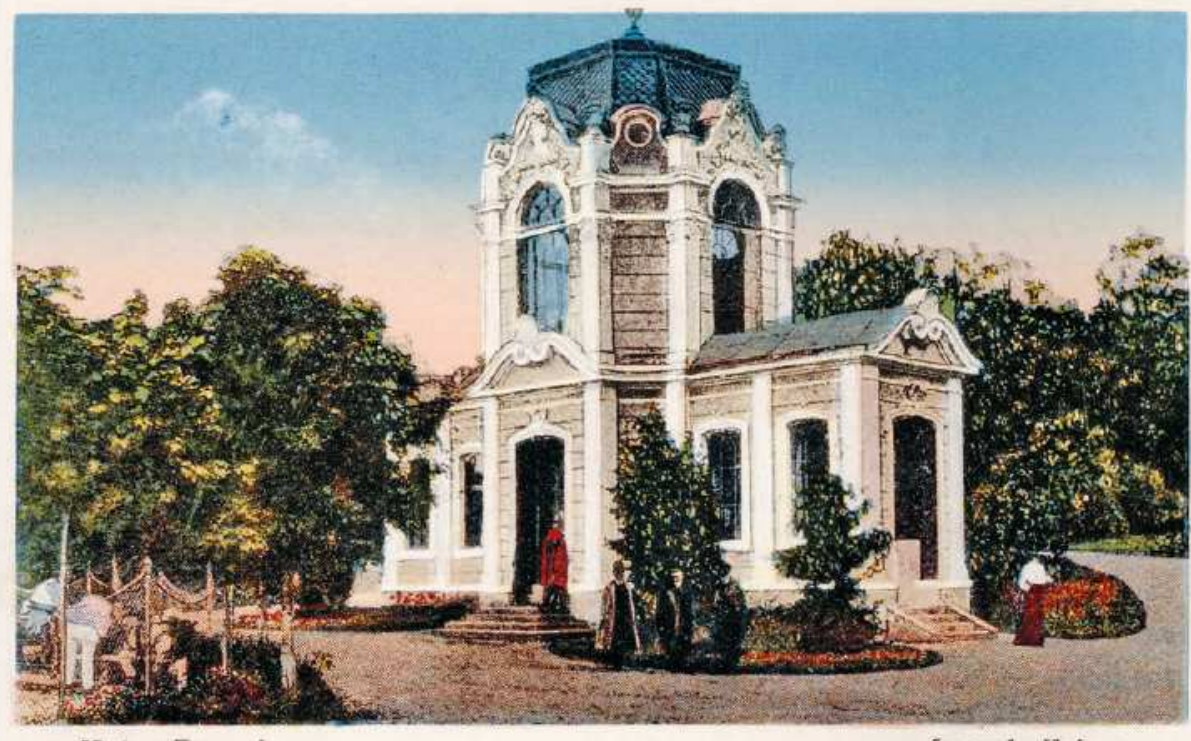

Vatra-Dornel

Izvorul sUnire

Abb. 72: Vatra Dornei. Izvorul ,Unirer. Ansichtspostkarte der Zwischenkriegszeit. Bis 1918 trug das Gebäude nicht den Namen ,Vereinigungs-r, sondern sohannesquelle، (C) Verlag Schaffer \& Fii, Sammlung K.S.

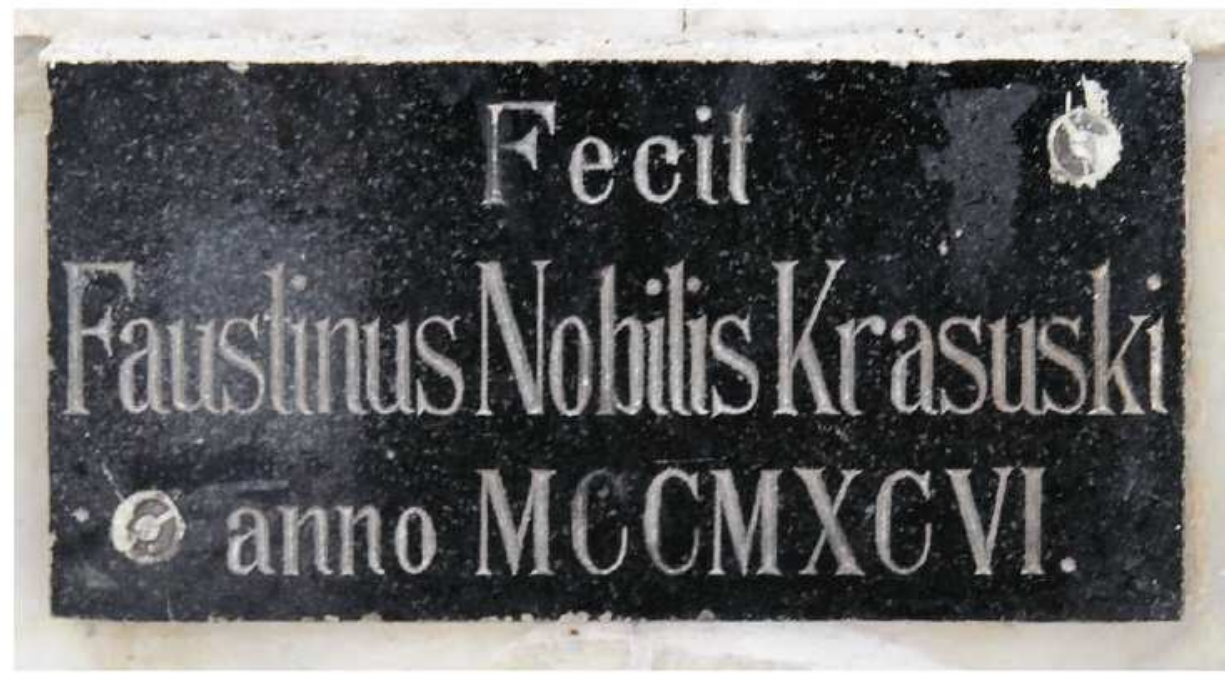

Abb. 73: Stiftungstafel über der Quelle der heutigen Izvorul Sentinela im Kurpark von Vatra Dornei. Faustin v. Krasuski leitete seit den 1890er Jahren die Manzschen Werke. @) Aufnahme K. Pierer, Sep. 2016. 
einigen Schaden. ${ }^{130}$ Mit der Ende der 1940er Jahre durchgeführten Sequestrierung gingen schließlich alle Fondseinrichtungen des Bades in das Eigentum des sozialistischen Staates über.

\section{Zusammenfassung}

Im Unterschied zum benachbarten siebenbürgischen Raum und den westlichen Gebieten der Habsburgermonarchie setzte der Bergbau in der Bukowina erst relativ spät und zögerlich ein. Von Beginn an bestand dessen Aufgabe nicht nur in der Bereitstellung von Rohstoffen und Produkten für den Bedarf der Provinz, sondern er sollte dezidiert auch einen Beitrag zur dauerhaften strukturellen Erschließung dieses Raumes und vor allem seiner entlegenen Berggebiete leisten. Obwohl die ärarischen Versuche, Gruben anzuschlagen bzw. in größerem Maßstab eigene Werke zu betreiben, relativ bald aufgegeben werden mussten, war der Staat nach wie vor allein schon aus Eigeninteresse darum bemüht, vorteilhafte Konditionen für einen auf privater Basis organisierten Abbau zu schaffen.

Wenngleich über den persönlichen Hintergrund des Gewerken Anton Manz v. Mariensee wenig bekannt ist, darf vermutet werden, dass sich dieser aus der Steiermark stammende Unternehmer bewusst der dort herrschenden Konkurrenz in der Eisenindustrie entzog, als er sich für den Ankauf der Werke im entlegenen Jakobeny entschied. Abseits der im Inneren Österreichs bereits unter Druck geratenen Bergbauindustrie konnte Manz - solange es Erzvorkommen und staatliche Unterstützung ermöglichten durchaus gewinnbringend arbeiten.

Im weit ins 19. Jahrhundert hinein nur schwach ausgeprägten Binnenmarkt der Bukowina und seiner östlichen Nachbarn keimte von Anfang an ein struktureller Mangel, der sich mit dem Rückgang staatlicher Förderungen und dem Nachlassen der Erzadern schmerzlich bemerkbar machte. Letztlich war eine ausgebaute Bergbauindustrie in ihrer ganzen Bandbreite in der Bukowina in größerem Umfange auch nach der Übernahme der Montanwerke durch den Religionsfonds nicht konkurrenzfähig, sodass eine Konzentration auf die reine Erzförderung - wie sie sich nach 1900 in Jakobeny durchgesetzt hatte - als konsequenter Prozess erscheint.

Die früh durch den Bergbau ausgelöste Notwendigkeit einer systematischen Waldwirtschaft kam letztlich nicht so sehr der Montanindustrie der Provinz zugute, deren Stellenwert vergleichsweise marginal blieb, sondern der durch den Eisenbahnanschluss

130 ANR-S inv. 35, pach. 111-1942, fol. 43f., Administraţia Băilor Vatra Dornei, Tablou asupra obiectelor de inventar pierdute cu ocazia ocupării imobilelor de către spitalele germane, Vatra Dornei v. 23.I.1942 und Socoteală, Vatra Dornei v. 28.X.1941. 
der Bukowina an Bedeutung gewinnenden Forstwirtschaft. Anders gesehen hatte die private Montanindustrie im Südwesten des späteren Kronlandes in den wenigen Jahrzehnten ihrer gewinnträchtigen Existenz das ursprünglich vom Staat intendierte Ziel der Erschließung dieses Raumes vollauf erreicht. Während der Insolvenz des Manzschen Unternehmens trat wiederum der Staat in Gestalt des Religionsfonds stärker in Erscheinung und federte den im Niedergang begriffene Bergbau ab bzw. stellte Mittel zu dessen Restrukturierung bereit. Die solide ökonomische Basis, die sich zu diesem Zeitpunkt der gr.-orient. Religionsfonds in den fast 70 Jahren seit seiner Gründung zu schaffen vermochte, ermöglichte jetzt sein gestalterisches Eingreifen für die ganze Provinz. Im Bergbau der Bukowina lässt sich folglich über den Verlauf des 19. Jahrhunderts nicht nur die Schwankungsbreite des staatlichen Interventionismus bei der Entwicklung einer Region nachverfolgen. Die Badeanlagen des Religionsfonds entwickelten sowohl in Dornawatra als auch in Jakobeny sich in der Nachbarschaft der Werke. Auch hier hatte der Einstieg des Fonds einen bemerkenswerten Impuls zum wirtschaftlichen Aufstieg gegeben.

Am Beispiel von Jakobeny und Dornawatra zeigt sich auch, dass der Staat - wenngleich in indirekter Weise über den Religionsfonds - einigermaßen erfolgreich in der Bukowina sintervenieren und konkrete Modernisierungsimpulse setzen konnte. Das Zusammenspiel nationaler wie internationaler ökonomischer Verhältnisse und die wachsend selbstbewusste Stellung des Fonds als Eckstein für die Entwicklung des Kronlandes darf dabei nicht außer Acht gelassen werden. Die nach 1918 daran anschließende neue Situation stellte beide Orte allerdings insofern vor große Probleme, als die relative Autonomie des Religionsfonds bzw. der Metropolie als Eigentümer im Königreich zunehmend schwand. Wie schon während der österreichischen Zeit bediente sich der Staat des Religionsfonds zur Durchsetzung eigener Interessen, ohne dass der Fonds jetzt über ebenso entsprechend wirksame Einspruchsmöglichkeiten verfügt hätte. Einerseits galt es, die zum Teil erheblichen Kriegsschäden zu beheben und die allgemeinen wirtschaftlichen Krisen dieser Jahre zu überstehen. Andererseits förderte die eingetretene staatliche Neuorientierung auch hier einen wachsenden politischen Einfluss in die Entscheidungsstrukturen beider Einrichtungen. Dazu gesellte sich eine dauerhafte Unsicherheit, die tief in den vielen laufenden Umstrukturierungsmaßnahmen und Skandalen dieser Jahre wurzelte. Die gesetzten Maßnahmen konnten in der gegebenen Zeit ihrerseits in den Betrieben des Fonds nicht wirksam werden. ${ }^{131}$ Ungeachtet dessen verblieben beide Orte die gesamte Zwischenkriegszeit über bis 1948 zentrale Pfeiler für die Wirtschaft und den regionalen Einfluss des Religionsfonds in der Bukowina.

$131 \mathrm{Vgl}$. Kap. 8 sowie 9. 


\section{Zusammenfassungen}

Der Bukowiner Religionsfonds: Kontinuität einer Institution?

Die Studie des Bukowiner gr.-orient. Religionsfonds hat in der Analyse (ausgehend von den hier als grundlegend erachteten Überlegungen bei Blänkner und Rehberg zur Institutionenforschung) versucht, methodisch den Fokus auf drei Betrachtungsebenen zu richten: Institutionalisierung, Institution und Akteure sowie institutionelle Mechanismen. Mit einzurechnen war der Faktor Zeit, abgebildet in Form des institutionellen Wandels, der sich für den Religionsfonds spätestens seit der Mitte des 19. Jahrhunderts in einem Spannungsbogen politischer Leitideen zwischen supranational-gesamtstaatlich und national-irredentistisch bewegte. Daraus wurden vier inhaltlich ineinander greifende Thesen formuliert: von der Gründung des Religionsfonds und seiner Aufgabe, vom institutionellen Wandel und der nationalen Frage, vom institutionellen Wandel und regionaler Modernisierung sowie von der Persistenz institutioneller Strukturen und ihrer langen Dauer. Im Hinblick auf die konkrete Institution, den hier im Mittelpunkt stehenden gr.-orient. Religionsfonds, ist festzuhalten, dass sich eine trennscharfe Unterscheidung zur gr--orient. Kirche der Bukowina nicht in allen Bereichen als möglich oder sinnvoll herausstellte. Das begründet sich allein schon in der institutionell-personellen Verflechtung von Bischof, den einzelnen Mitgliedern des Konsistoriums sowie den eigentlichen Agenden des Fonds bzw. wechselseitig der ihn kontrollierenden wie beeinflussenden kirchlichen Organe. Die Grenzen zwischen beiden Institutionen sind daher an und ab undeutlich und nicht immer in allen Fällen exakt zu ziehen gewesen.

Die abschließende Diskussion soll die nunmehr gewonnenen Erkenntnisse im gerafften Überblick einander gegenüberstellen. Sie will die Zusammenfassungen der einzelnen Abschnitte daher nicht doppeln und Details wiederholen, sondern auf die wesentlichen Punkte der eingangs gestellten Thesen eingehen.

Der Prozess der Institutionalisierung des Bukowiner Religionsfonds, also des allmählichen Übergangs von einer zunächst hauptsächlich normierenden Organisation hin zu einer aktiv Raum wie Gesellschaft gestaltenden Institution, ist für die Geschichtswissenschaften über den Faktor Zeit eng mit der Frage nach dem messbaren Erfolg aufklärerischer Reformmaßnahmen, wie sie Joseph II. gesetzt hat, verknüpft. ${ }^{1}$ Aus Sicht der soziologischen Forschung wiederum bezieht eine einmal bestehende Institution ihre Legitimität hauptsächlich aus ihrer eigenen zeitlichen Stabilität und mitunter ebenso aus ihrer Verbindung mit dem Ort (`sense of place`). ${ }^{2}$ Letzteres wäre im konkreten Fall wohl

1 Merker 1989, Aufklärung, 13; zuletzt Bendel \& SpANnenberger 2015, Aufklärung.

2 Lowndes 1996, Varieties, 182. 
auf `Raum` (`space`) zu erweitern. Was lässt sich nun aus diesen beiden Erkenntnissen für den Religionsfonds der Bukowina in einer Zusammenschau ableiten?

Die von den Ideen der Aufklärung getragenen Reformansätze des Kaisers zeigten sich in der peripher zum Zentrum Wien gelegenen Bukowina überaus nachhaltig, wie das schon an anderer Stelle in Bezug auf den allgemeinen Landesausbau des späteren österreichischen Kronlandes nachgewiesen werden konnte. ${ }^{3} \mathrm{Im}$ Speziellen lässt sich das unmittelbare Wirken der Organisation des gr.-orient. Religionsfonds bis ins 19. Jahrhundert und daran anschließend das der Institution bis zu seiner endgültigen Auflösung 1948 vor allem in der Region selbst aufspüren. Langfristig betrachtet gehört daher der Religionsfonds der Bukowina wohl zu den 'geglückten` Reformen des Josephinismus. Im geistlichen Regulierungsplan, der Einrichtung eines Konsistoriums für die gr.-orient. Kirche der Provinz sowie der Gründung des orthodoxen Religionsfonds treffen gleich zwei zentrale Reformbestrebungen des ausgehenden 18. Jahrhunderts aufeinander: der Versuch territorialer Arrondierung des Staates nach außen und die Neuorganisation der orthodoxen (Landes-)Kirche - gleichsam als Teil staatlicher Verwaltungsstrukturierung - nach innen. Beide Schritte bereiteten auf entscheidende Weise die Basis für das Entstehen eines Landesbewusstseins, einer regionalen Identität der Bukowina bzw. ihrer Bewohner (mit starkem Bezug zur österreichischen Gesamtstaatsidee). Damit gestaltete der Religionsfonds sowohl einen zentralen Teil der normativen, organisatorischen >Einrichtung der Provinz. Später begünstigte und förderte er das Entstehen von regionaler Identität eines bis dahin historisch so nicht existierenden Raumes der >Bukowina (i.e. die ehemalige Obere Moldau). Am Beispiel des Religionsfonds lässt sich daher offen die auf weiten Strecken herrschende Deckungsgleichheit eigener, d.h. jener des Fonds als Institution, wie staatlich vorgegebener Orientierungsmuster erkennen.

Die Beziehung und gegenseitige Beeinflussung von institutionellem Wandel wie nationaler Frage erscheint im Hinblick auf den gr.-orient. Religionsfonds der Bukowina indes äußerst komplex und nimmt in der Darstellung einen zentralen Platz ein. Kennzeichnend dafür waren die steten, jedenfalls aber mit jeder Bischofsbesetzung von neuem zu definierenden innerkirchlichen Standpunkte der Hierarchie. Das Verhältnis zum Staat folgte indes ohne größere Abweichungen einer weitestgehend loyalen Linie, die allerdings mit Ende des Ersten Weltkrieges einen markanten Schwenk erfuhr. Davon ausgehend kann der Religionsfonds der Bukowina zutreffend als imperiale Institution bezeichnet werden. So streicht etwa die jüngere Institutionenforschung - bezogen auf Ostmitteleuropa - für die Phase bis zum Ersten Weltkrieg den immanenten Zusammenhang institutioneller sowie rechtlicher Modernisierung besonders heraus. Allerdings sei dabei die Prägung dieses Konnexes weitgehend von den »Bedürfnissen des Imperial-

3 SCHARR 2010, Landschaft. 
staats « und weniger von jenen des Nationalstaats erfolgt. Begründet wird das mit einem im Vergleich zum westlichen Europa später greifenden Wechsel »vom imperialen zum nationalen System «. ${ }^{4}$ Dieser Aussage ist für den cisleithanischen Teil der Habsburgermonarchie grundsätzlich zuzustimmen, jedoch - und das belegen die Ergebnisse der Studie deutlich - darf dabei die Vorlaufzeit nationaler Entwicklung selbst in einem bis 1914/18 unbestritten gültigen wie wirksamen imperialen Rahmen nicht unterbewertet werden. So versteckt sich denn auch kein bemerkenswerter Widerspruch in der Institution des hier gegenständlichen Religionsfonds. Dieser vertrat bis zum Zerfall der Habsburgermonarchie einerseits die Interessen des Reiches, d.h. er arbeitete den (geforderten) Bedürfnissen des Staates durchaus zu. Er vertrat diese Bedürfnisse und Interessen selbst, durchlebte aber andererseits gleichzeitig innerhalb seiner eigenen Struktur z.T. heftige Diskussionen und Nationalisierungsschübe. Radikal nationalen Positionen gelang es erst außerhalb des imperialen Kontextes, im rumänischen Staat der Jahre nach 1918, den Ton innerhalb der Institution vorzugeben. Jetzt allerdings brachte der nunmehr massiv von Bukarest forcierte Nationalisierungsprozess einen allmählichen Verlust fondsinterner Steuerungsmöglichkeiten ins Rollen. Der Religionsfonds der Bukowina geriet mithin durch die schleichende Entmachtung seiner Akteure und Instanzen zunehmend zum politischen Spielball - weit mehr als dies vor dem Weltkrieg denkbar gewesen wäre.

$\mathrm{Zu}$ Beginn dieser Entwicklungen, in der Ära von Bischof Eugen Hackmann, wies dessen Episkopat gleich zwei zentrale und in ihrer Ausprägung durchaus ambivalente Facetten auf. Da war einerseits der Prozess allmählicher Institutionalisierung zu beobachten. Der Fonds bewegte sich peu à peu von seiner bislang ausschließlichen Verwaltungsaufgabe kirchlicher Güter weg und begann darüber hinaus selbst als Akteur auf dem politisch-gesellschaftlichen Feld des Kronlandes in Erscheinung zu treten. Zugleich - als zweite Facette - waren einsetzende nationale Forderungen, auch wenn diese in der Bukowina vorerst noch kaum Breitenwirkung in einer vorwiegend agrarisch dominierten Bevölkerung besaßen, seit 1848 nicht mehr zu überhören. Wertkonservative, durchaus staats- bzw. dynastieloyale Kirchenhierarchen wie Hackmann bezogen hierzu eine äußerst distanzierte Position. Gerade in der Diskussion um die Schaffung einer gemeinsamen gr.-orient. Diözese aller Rumänen innerhalb der Habsburgermonarchie (noch vor dem Ausgleich von 1867) zeigte sich diese offen in den inhaltlich konträren Haltungen von Andrei Schaguna und Hackmann. Dabei war die Frage eines Kirchenkongresses, wie ihn Schaguna forderte, indes keinesfalls einer grundsätzlich nationalisierenden Intention geschuldet, sondern stand sichtlich im Kontext der vielfach benachteiligten rumänischen Bevölkerung und ihres Alltags im strikt ungarisch dominierten

4 Siegrist \& Troebst 2012, Einführung, 322. 
Siebenbürgen. Aus Sicht Hackmanns hingegen hätte eine derartig verbreiterte Basis für die innerkirchliche Mitbestimmung eine unzulässige Einschränkung der hergebrachten, legitimen Hierarchie seiner Kirche zur Folge gehabt. Dass - wie Hackmann meinte - damit die Schafe den Hirten führen würden, war zwar überspitzt formuliert, traf jedoch unbeabsichtigt den Kern des merkbar voranschreitenden institutionellen Wandels.

Zusätzlich begann - dynamisiert durch die allgemeine politische Entwicklung der Habsburgermonarchie - immer stärker eine nationale Komponente diesen Wandel des Religionsfonds zu dominieren. Diese erweist sich allerdings bei genauerer Betrachtung als ein überaus heterogenes Gebilde. So verfolgte etwa die für den politischen Diskurs in der Bukowina bis zur großen Wahlrechtsreform von 1907 maßgebliche Gruppe der Großgrundbesitzer mit dem Laienbeteiligungsprozess in der orthodoxen Kirche des Landes vielfach in erster Linie ihre eigenen Interessen und nicht unbedingt jene der jeweils vorgeblich vertretenen nationalen Bevölkerungsgruppe.

Das nicht unmittelbar auf Hackmann folgende, aber in jeder Hinsicht für die gr.orient. Kirche und ihren Religionsfonds prägende Episkopat von Silvester MorariuAndriewicz lässt sich durch zwei potentiell gegeneinander arbeitende Grundtendenzen charakterisieren. Während Hackmann aus seinem Amtsverständnis heraus unbedingte wie absolute Loyalität der Priesterschaft gegenüber dem Bischof einforderte und mit einer - wie auch immer formulierten - erweiterten Mitbestimmung der Gläubigenbasis nur wenig anfangen konnte, bespielte Silvester Morariu-Andriewicz gerade über diese Basis bewusst das seiner Ansicht nach national rumänische Grundelement der orthodoxen Landeskirche und ihres Fonds. Als Priester durchbrach Morariu-Andriewicz die eingeforderte Loyalität seines Bischofs mehrfach. Somit öffnete sich einerseits nach seiner Amtsübernahme der zunächst innerkirchliche Diskurs um die eigene Ordnung und die Frage nach der Verfügungsgewalt über den Religionsfonds zunehmend dem Feld politischer Öffentlichkeit. Die dadurch beförderte Nationalisierung in der Kirchendebatte hatte jedoch andererseits auch zur Folge, dass Akteure wie der Bischof den Diskurs um die nationale Ausrichtung von Diözese und Fonds zwar befeuern, aber nur mehr begrenzt zu steuern vermochten. Kirche und Fonds hatten sich damit auf das politische Feld begeben, sie bildeten mithin einen der zentralen Schauplätze im vielfältigen Diskursgeflecht nationaler Interessen zwischen Rumänen und Ruthenen des Kronlandes. Reichs- wie Landespolitik besetzten bedeutend mehr als zuvor entscheidende Rollen in der Aufstellung dieser beiden Institutionen als auch ihrer Tätigkeit. Über die einzelnen Akteure waren dabei der Landtag und die Universität, vor allem in Form der gr--orient. theologischen Fakultät eingebunden, ähnliches galt gleichermaßen für die philologischen und historischen Lehrstühle. Außerhalb von Kirche und Religionsfonds schien schon aus zeitgenössischer Perspektive eine trennscharfe Unterscheidung der an diesem Diskursfeld des Kronlandes beteiligten Institutionen kaum mehr möglich. 
In der dadurch seitens einiger politischer Strömungen des Kronlandes gezielt geförderten Vermischung von sozialen mit nationalen Belangen gelang - wie auch in anderen Teilen der Monarchie - eine allmähliche Mobilisierung der bäuerlichen Bevölkerungsschichten zugunsten moderner Massenparteien. Der Religionsfonds musste hier geradezu in einer Zwitterstellung bestehen: zum einen als Grundherr und Großgrundbesitzer und zum anderen als Verwalter eines vermeintlich historisch legitimierten national-rumänischen kulturellen Erbes mit enormer wirtschaftlicher Potenz und dementsprechend, freilich nur für die eigene Nationalität, einzusetzendem politischen Kapital. Die Akteure innerhalb wie außerhalb des Fonds konnten kaum einer konsistenten Argumentationslinie folgen, sondern waren mehr oder weniger gezwungen, ihre Positionen situationsbezogen anzupassen; ein Umstand, der auf Dauer wiederum in der politisch ohnedies bereits sensibilisierten Öffentlichkeit weder ihrer persönlichen noch der institutionellen Glaubwürdigkeit gut tat. Insofern geben - aus einer resümierenden Betrachtung heraus - die Prozesse des institutionellen Wandels und der nationalen Frage innerhalb des Religionsfonds nicht nur einen Gutteil der das Kronland weithin vor 1914 bestimmenden politischen Diskurse wider, sondern sie selbst gehörten aktiv, mit unterschiedlicher Intensität, zu ihren jeweils treibenden Kräften.

Die Prozesse des institutionellen Wandels des gr.-orient. Religionsfonds sind jedoch nicht allein mit der eben angesprochenen nationalen Frage des Kronlandes und ihrer Entwicklung abzudecken. Regionale (wirtschaftliche) Modernisierung der Bukowina und der Fonds standen in einem ebenso engen Wirkungszusammenhang. Insgesamt lässt sich festhalten, dass der Religionsfonds bzw. seine mit der Zeit wachsenden Mittel und Möglichkeiten auf unterschiedlichste Weise wesentlich zur Verbesserung der ökonomischen Struktur des Kronlandes beigetragen haben. Das Spektrum reichte dabei von der nicht ganz freiwilligen Übernahme der maroden Bergwerke in Jakobeny bis hin zur vereinzelten (und aus der historischen Betrachtung zunächst unerwarteten) Unterstützung jüdischer Gemeinden u. ä. Die verständliche anfängliche Skepsis von Hackmann in Sache der Bergwerke und die selbstverständliche Zusage kostenloser Materialbereitstellung für eine kleine Dorfsynagoge durch Bischof Repta skizzieren indes eine weitere, über das rein Wirtschaftliche hinausgehende Facette dieses Wandels, die dem noch anzusprechenden Aspekt des Landesbewusstseins näher steht.

Der erwähnte Wirkungszusammenhang sollte sich in der Frage der Grundentlastungspolitik als Konsequenz des Jahres 1848 deutlich herausstellen. Strukturell gesehen begünstigte die alleinige wirtschaftliche Dominanz des Fonds durch seinen enormen Grundbesitz (und der damit verbundenen Möglichkeit eines unmittelbaren staatlichen Durchgriffes bis auf die lokale Ebene) eine derartige Reform. Das belegt ein Blick auf das benachbarte Kronland Galizien-Lodomerien, wo sich die Umsetzung der Grundentlastung durch zersplitterte Besitz- und Eigentumsrechte auf Jahrzehnte hinaus verzögerte. 
Der Fonds als bedeutendster Grundbesitzer der Bukowina bot für den Staat ebenso in sozialer Hinsicht Möglichkeiten, gegenüber privaten Gutsbesitzern ansonsten nur gegen großen Widerstand durchzudrückende Reformen umzusetzen oder über den Fonds zumindest hinreichend Druck für Veränderungen aufzubauen. Im konkreten Fall begünstigte diese Politik Wiens mittels Hebelwirkung des Fonds die Stärkung der seit 1849 in Österreich bestehenden politischen Gemeinden gegenüber den herrschaftlichen Gutsgebieten. Zudem hatte der Religionsfonds der Bukowina 1875 für die Verbesserung der inneren Organisationsstruktur eine eigene Güterdirektion erhalten, die mithin - neben staatlichen Stellen, Bischof und Konsistorium - ein weiteres Entscheidungsgremium stellte. Mit den nachfolgenden sukzessiven Anpassungen entstand daraus eine stabile und vergleichsweise effiziente Verwaltungsstruktur, welche die bis 1914 beachtliche ökonomische Entwicklung von Fonds und Kronland maßgeblich beförderte.

Die von der Institution Religionsfonds erwirtschafteten Ressourcen wusste der Staat geschickt in Bauprojekte zu investieren. Sie kamen sowohl der gr.-orient. Kirche zugute, entlasteten aber ebenso Landes- wie Zentralbudget, letztere zum Teil erheblich. Der Bau der Kathedrale, der Metropolitanresidenz, der Güterverwaltung und die Einrichtung der Franz-Josephs-Universität in Czernowitz etwa sind nur einige besonders repräsentative Beispiele für diese Wirtschafts- und Strukturpolitik über und mit dem Fonds. Gerade auf dem wirtschaftlichen Feld, mehr noch als auf dem politischen, zeigte sich dabei die enge Verflechtung von Religionsfonds und Bildungslandschaft des Kronlandes. Diese reichte von den Volksschulen bis hin zur Universität.

Nach 1918 war im Allgemeinen die Wirtschaftssituation des rumänischen Königreiches zunächst durchaus von Reformwillen gekennzeichnet, allerdings konnten viele der Vorhaben nicht auch nur in annähernd geplanter Weise verwirklicht werden. So zog sich etwa der komplizierte Prozess der Agrarreform bis in den Zweiten Weltkrieg. Die Bukowina war - sowie generell die Neoacquisita des Königreiches - von diesen Maßnahmen verhältnismäßig stärker als das Altreich betroffen. Das lässt sich nicht zuletzt durch die strukturell günstigere Disposition der Bukowina - etwa dem Vorhandensein von Katastern und Grundbüchern, aber eben auch dem Religionsfonds - erklären. Gerade dieser Befund traf in besonderem Maße auf die Fondsgüter zu und vergleichsweise weniger auf jene Güter anderer Großgrundbesitzer der Bukowina. Dennoch, selbst hier sollten die vom Staat gesetzten Ziele der Landumverteilung am Ende nicht erreicht werden.

Ähnlich wie vor 1918 bediente sich der Staat, nunmehr in Gestalt der Bukarester Regierung, der wirtschaftlichen Steuerungsmöglichkeiten des Fonds für die Region und - das war neu - auch darüber hinaus. Dieses Bild lässt sich an anderer Stelle, beispielsweise am Bau des neuen rumänischen Kulturpalastes in Czernowitz, bestätigen. In anderer Hinsicht zeigt sich ebenso ein Kontinuitätsstrang. Staatliche Ansätze zur Agrarreform, ob nun vor dem Wendejahr 1918 oder danach, mussten stets mit einer Reaktion 
seitens der Grundherrschaften ('manorial reaction`) rechnen, die dem Reformansinnen zumeist entgegenlief oder es zumindest abzuschwächen bzw. zu bremsen suchte. ${ }^{5}$ Mit der Institution Religionsfonds, die zwar gleichermaßen als Grundherrin auftrat, jedoch zudem über ihre Struktur einen starken Bezug zu Wien (bzw. Bukarest) hatte, war zugunsten des Staates (wie der Region) ein partielles Ausbrechen aus diesem hemmenden Interessenskonflikt möglich geworden. Aus methodischer Perspektive lassen sich außerdem gerade über diese Institution jene Scherkräfte greifbar machen, die aus dem Aufeinandertreffen unterschiedlicher gesellschaftlicher Konzepte in der Bukowina erwachsen waren.

Die mit Kriegsbeginn 1939/40 einsetzende staatlicherseits überaus stark regulierte Wirtschaft verschlechterte die ökonomisch ohnedies angeschlagene Situation des Religionsfonds neuerlich. Dabei traf diese existentielle Krise auf einen bereits seit über einem Jahrzehnt wirtschaftlich labilen Fonds. Die verschleppten strukturellen Mängel und die stete politische Einmischung in die inneren Angelegenheiten der Institution zeitigten jetzt ihre Wirkung. Zusätzlich bewirkten die unmissverständlichen staatlichen Interventionen bei Lieferanforderungen wie Preisgestaltung von Produkten und Leistungen des Religionsfonds das ihrige und beschleunigten dessen fortschreitende ökonomische Schwächung.

Im Rahmen der nationalen Frage hatte sich der Bezugspunkt von Werten mit 1918 von Wien nach Bukarest verschoben. Diese Situation pauste sich mit Verzögerungen auf das ökonomische Feld durch. Das Phänomen der Phantomgrenzen ${ }^{6}$ lässt sich in diesem Aspekt in der Bukowina nach 1918 deutlich ablesen. Im persönlichen Konflikt zwischen Iancu Flondor und Ion Nistor - bzw. auf kirchlicher Ebene das Ringen des Metropoliten um Kirchenautonomie gegenüber Bukarest - liefen diese auseinanderklaffenden Erwartungshaltungen schließlich auf eine Schwächung von Fonds und Landeskirche hinaus. Beide Institutionen wurden durch einen an Rigidität gewinnenden und an demokratischer Grundhaltung verlierenden zentralistischen Nationalstaat in ihren Bestreben enttäuscht. Kirche wie Fonds konnten sich während der Zwischenkriegszeit einer schleichenden Politisierung mit allen wirtschaftlichen wie gesellschaftlichen Konsequenzen nicht entziehen. Die institutionelle Glaubwürdigkeit als einem für Fonds wie Kirche grundlegen statischen Faktor hatte darunter dauerhaft zu leiden. Durch den politischen Kampf angeschlagen, büßte der Fonds als Institution zudem auch seine Flexibilität und Kooperationsfähigkeit (dynamischer Faktor) ein. Er verlor dadurch zunehmend seine seit der Gründung charakteristische Rolle als Mediator sozio-politischer Kollek-

5 Dazu Giordano 2003, Vielfalt, 126.

6 Dazu MÜLleR 2015, Geschichtsregionen; hier am Beispiel Siebenbürgens. 
tivinteressen in der Bukowina. ${ }^{7}$ Während der Königsdiktatur und der Kriegsjahre, unterbrochen von einer kurzen Periode letztlich erfolglosen Bemühens des Metropoliten Visarion, gewann der Prozess politischer und wirtschaftlicher Entmündigung des Fonds wieder erheblich an Fahrt. Diese Entwicklung sollte mit dem Ausscheiden Rumäniens aus dem Krieg bzw. der Besetzung durch die Rote Armee einen letzten Höhepunkt erreichen. Die Einrichtung der sowjetisch-rumänischen Holzgesellschaft `Sovromlemn « und die damit einhergehenden Zwangsaufträge markierten nunmehr den Punkt faktischer Enteignung des Religionsfonds sowie der Kirche und die endgültige Entrechtung ihrer Selbstverwaltungsgremien. Die 1949 erfolgte Auflösung des rumänisch-orthodoxen Religionsfonds der Bukowina durch die Volksrepublik Rumänen besaß nur mehr einen weitgehend formalen Charakter.

Über mehr als 150 Jahre hatte der Religionsfonds sowohl die wirtschaftliche als auch die gesellschaftliche Entwicklung der Bukowina - in besonderem Maße seit der Mitte des 19. Jahrhunderts - an zentraler Stelle mitgestaltet. Dabei zeigten Teile und Eigenschaften dieser Institution über die Zeit hinweg - ungeachtet der auftretenden Widrigkeiten eine erstaunliche Persistenz. Die Orientierungsleistung des Fonds `überholte` in ihrer Bedeutung die zunächst vom Staat bei seiner Gründung zugedachte reine Ordnungsaufgabe. In dem Maße, wie der Religionsfonds Werte des Staates zu übernehmen begann bzw. diese mit den eigenen Vorstellungen in Deckungsgleichheit zu bringen versuchte und sich zudem in nationalen Fragen dem allgemeinen politischen Diskurs öffnete, war die institutionelle Glaubwürdigkeit einem Prozess permanenter Rechtfertigung unterworfen, sei es gegenüber der Kirche als Ganzem, ihren Vertretern, den Gläubigen, den Co-Nationalen oder dem Staat. Der Religionsfonds schlitterte mit seiner Verfasstheit und den dadurch transportierten Werten jedoch erst in eine nachhaltige Krise, als die Parameter des staatlichen Kontextes sich nach 1918 erheblich zu ändern begonnen hatten. Die vermeintliche mit dem Ausgang des Weltkrieges erlangte Deckungsgleichheit nationaler Werte zum neuen, größeren rumänischen Staat, die bislang nur von einem Teil der Akteure innerhalb von Kirche und Fonds gefordert worden war, der sich allerdings seit der Jahrhundertwende in wachsendem Maße dem öffentlichen Diskurs darüber unterworfen hatte, geriet nunmehr unerwartet zum Menetekel der eigenen Existenz. Autonomie und Handlungsspielräume der Institution verengten sich im gänzlich anders aufgebauten politischen System des Königreichs zusehends. Ein wesentlicher Teil der Orientierungsleistung des Fonds hing jedoch mit Entstehen und Alltag eines regionalen

7 Diese beiden freundlichen Hinweise verdanke ich den Herrn Ao. Univ.-Prof. Dr. Harald Heppner und Priv.-Doz. Dr. Norbert Spannenberger, anlässlich des Innsbrucker Workshops v. 27./28. November 2014. 
Bewusstseins sowie der Vorstellung von einer gewissen Entscheidungs- und Handlungsfreiheit zusammen. Im Hinblick auf Ordnung und Orientierung waren daher sowohl die Existenz der Institution Religionsfonds als auch ihre Kontinuität auf das Engste über ein funktionierendes Zusammenspiel auf annähernd gleicher Höhe mit der Entwicklung des Staates verknüpft.

\section{The Bukovina Religious Fund: continuity of an institution?}

The study of the Bukovina Greek-Oriental Religious Fund put the methodological focus of its analysis (starting from the fundamental ideas of Blänkner and Rehberg on the study of institutions) on three levels of observation: institutionalisation, institution and actors, as well as institutional mechanisms. Time had to be factored in and was mapped in the form of the institutional change, which for the Religions Fund, certainly from the mid- $19^{\text {th }}$ century, occurred against the tensions between dominant political ideas of the supranational/whole-empire and the national/irredentist side. Four substantively linked theses developed from this situation: about the formation of the Religious Fund and its task, about the institutional change and the national issues, about institutional change and regional modernisation, and about the persistence of institutional structures and their longue durée. It should be noted that it has not always been possible or helpful to attempt a strict separation between the Religious Fund as a concrete institution and the Greek-Oriental Church of the Bukovina. There was, for instance, an institutional and personal overlap in the bishop, individual members of the consistory and in the real agenda of the Fund as well as in the Church bodies who controlled and influenced it. In some cases the boundaries between the two institutions are thus blurred and could not always be drawn precisely.

The final discussion aims to juxtapose the insights won in the form of a summarising overview. This is not to repeat summaries and details of the individual sections, but rather to respond to the main points of the theses listed at the beginning.

For historical studies, the institutionalisation process of the Bukovina Religious Fund, i.e. the gradual transition from an initially mainly standardising organisation into an institution that formed the space and the society of the area, is closely linked, in temporal terms, with the measurable success of enlightened reform measures introduced by Joseph II. ${ }^{8}$ Sociological research, in contrast, attributes legitimacy to an existing institution mainly on the basis of its temporal stability and sometimes also on its sense of

8 Merker 1989, Aufklärung, 13; recently Bendel \& SPANnenberger 2015, Aufklärung. 
place. ${ }^{9}$ In our case this should probably be expanded to space an overview, from these two insights for the Bukovina Religious Fund?

The emperor's reformist approaches, based as they were on the enlightenment, manifested themselves in a sustained way in the Bukovina, which was in a peripheral position to the centre of the empire, Vienna. I have already been able to show this elsewhere in terms of the general development of the later Austrian crown land. ${ }^{10}$ More precisely, the immediate effect of the work of the Greek-Oriental Religious Fund as an organisation can be traced mainly in the region itself into the $19^{\text {th }}$ century, and thereafter, as an institution, until its dissolution in 1948. Viewed over the longer term, the Bukovina Religious Fund should thus count as one of the ssuccessfuk Josephinian reforms. In the spiritual regulation plan, in the establishment of a consistory for the Greek-Oriental Church in the province, and the foundation of the Orthodox Religious Fund, two central reformist endeavours of the late $18^{\text {th }}$ century meet: the attempt at territorial consolidation of the state, externally, and the reorganisation of the Orthodox (regional) Church - as part of a (re) structuring of the state administration - internally. Both measures are essential stepping stones towards creating an awareness of the country, a regional identity of the Bukovina and its inhabitants (in close relation to the Austrian idea of the whole state). In this way the Religious Fund shaped a central aspect of the normative, organisational spreparation of the province and later furthered the emergence of a regional identity for the Bukovina (i.e. the former upper Moldova), a territory that did not previously exist in this form. The Religious Fund is a good example for the wide overlap of intrinsic orientation patterns of the Fund as an institution, and those set by the state.

The relation and mutual impact of institutional change and national question seems highly complex with regard to the Bukovina Greek-Oriental Religious Fund and takes a central place in the analysis. It was characterised by the internal positions on hierarchy, which had to be redefined with every new bishop. The relation to the state, however, remained loyal for the most part, without any major deviations, until the end of World War I, when it shifted markedly. We can thus call the Bukovina Religious Fund an imperial institution. Recent research on institutions in eastern Central Europe underlines the inherent connection of institutional and legal modernisation until World War I. It points out, however, that this connection was largely shaped by the "needs of the imperial state" rather than by those of the nation state. The reason given is a later shift "from an imperial to a national system"11 compared to Western Europe. I would agree with this

\footnotetext{
9 LOWNDES 1996, Varieties, 182.

10 SCHARR 2010, Landschaft.

11 Siegrist \& Troebst 2012, Einführung, 322.
} 
statement for the Cisleithanian part of the Habsburg monarchy, but, as the results of this study make clear, the lead time for developing a nation should not be underestimated, even within the, until 1914/18, uncontested and effective imperial framework. So there is no real contradiction in the Religious Fund, who furthered the interests of the empire until the dissolution of the Habsburg monarchy, on the one hand, i.e. assisted the needs (demands) of the state and represented them, and at the same time experienced fierce debates and pushes for nationalisation within its own ranks, on the other. It was only outside the imperial context, in the Romanian state of the post-war years, that radical national positions began to dominate within the institution. From that time on, however, the nationalisation process, massively forced by Bucharest, started a gradual loss of mitigating options within the Fund. The creeping deprivation of power of the Bukovina Religious Fund's actors and bodies put the Fund increasingly at the mercy of politics, much more than would have been thinkable before the World War.

Let us return to the start of these developments, the era of bishop Eugen Hackmann. His time in office presents two central and, in their manifestation, quite ambivalent aspects. There was the process of gradual institutionalisation. The Fund moved incrementally from its previous exclusive function of managing church property and became an actor in the political and social arena of the crown land. At the same time, early national demands became more noticeable from 1848 onwards, even if they did not yet reach many people in the Bukovina with its predominantly agrarian population. Church dignitaries of traditional values like Hackmann, loyal to state and dynasty, took up a position of great distance to such demands. Especially in the debate about creating a joint Greek-Oriental diocese of all Romanians within the Habsburg monarchy (even before the 1867 Austro-Hungarian Compromise) this became clear in the contrasting positions of A. Schaguna and E. Hackmann. Schaguna's demand for a Church congress did not, however, stem from a basically nationalising intention, but from the many obvious disadvantages of the Romanian population and its everyday life in Transylvania under strictly Hungarian domination. For Hackmann such a broadening of the basis would have led to an inadmissible restriction of the traditional, legitimate hierarchy of his Church on internal decision-making. Hackmann may have exaggerated when he said that the sheep would lead the shepherd, but he nailed the essence of the noticeable progress of institutional change.

In addition - boosted by general political developments within the Habsburg monarchy - a national component began to dominate this change in the Religious Fund. Under closer inspection this component reveals itself as rather heterogeneous. For instance, the group of the large land owners, who had an essential role in the political discourse in the Bukovina up to the big electoral reform of 1907 , pursued mainly their own interests in 
the process of lay people participation in the Orthodox Church of the country and not necessarily those of the national population they were supposed to represent.

The bishopric of S. Morariu-Andriewicz, which did not immediately follow Hackmann, but shaped the Greek-Oriental Church and its Religious Fund in most aspects, was characterised by two potentially opposed basic trends. While E. Hackmann, on the basis of his understanding of his role, demanded absolute and unconditional loyalty of the priests to the bishop and had little time for any participation of the humble congregation - no matter how it was conceived -, Morariu-Andriewicz used it deliberately to underline the national Romanian basis, as he saw it, of the Orthodox Church of the country and its fund. As a priest, Morariu-Andriewicz repeatedly withheld the loyalty demanded by his bishop. Once he became bishop, the internal discourse around internal hierarchy and control of the Religious Fund opened out onto the political public. While this furthered the debate about the nationalisation of the Church, it also meant that actors like the bishop were able to fuel the discourse on the national orientation of dioceses and Fund, but were limited in their power to control it. Church and Fund had entered the political arena, they became a central theatre within the complex discursive weave of national interests between Romanians and Ruthenians in the crown land. Politics, at imperial as well as crown land level, came to take on a much more decisive role in the positioning of these two institutions as well as in their activities. Individual actors provided a link to the regional parliament and the university, especially the Greek-Oriental theological faculty, but also the philology and history chairs. Even contemporaries outside Church and Religious Fund found it practically impossible to distinguish clearly between the institutions involved in this discourse in the crown land.

The conflation of social and national concerns, deliberately furthered by some political trends in the crown land, brought about the gradual mobilisation of the peasants in favour of modern mass parties, something that also happened in other parts of the monarchy. The Religious Fund had to maintain a dual position here: as large land owner, on the one hand, and, with supposedly historic legitimisation, as administrator of a national Romanian cultural heritage of enormous economic power. As such, it had political capital, ring-fenced for use in favour of a Romanian nation. Actors within and outside the Fund were unable to pursue a consistent line of argument, instead they were more or less forced to adapt their position to each situation, which, in the long run, damaged their personal and institutional credibility with a public already politically sensitised. Therefore, in sum, the processes inside the Religious Fund of institutional change and the national question not only reflect much of the political discourses dominating the crown land before 1914, they were also, in varying intensity, themselves drivers of these discourses. 
However, the processes of institutional change in the Greek-Oriental Religious Fund go beyond the national question of the crown land sketched above and its development. There was also strong interdependence between regional (economic) modernisation in the Bukovina and the Fund. Overall we can say that the Religious Fund contributed decisively to an improvement of the economic structure of the crown land by using its growing means and opportunities in a variety of ways. These ranged from the not entirely voluntary takeover of the dilapidated mines in Jakobeny to occasional targeted support of Jewish communities, which comes as a surprise from a historical viewpoint. Hackmann's understandable initial doubts about the mines and bishop Repta's automatic promise of free material for a small village synagogue stand for another facet of this change, which goes beyond pure economy and is closer to an awareness of the country as discussed below.

This interdependence became clear in the context of the agrarian reform policy (Grundentlastung) in the wake of 1848. In structural terms, the economic dominance of the Fund as a very large land owner (which meant that the state policies could affect all levels down to the local one) furthered this reform. All you need is a look at the neighbouring crown land of Galicia and Lodomeria, where the implementation of the agrarian reform was held up for decades by split-up property rights and land titles. In social terms, the Fund as major land owner in the Bukovina also gave the state an opportunity to implement reforms which would have met with great resistance from private land owners or, at least, to exert sufficient pressure for change via the Fund. Here the policies issued from Vienna, aided by the clout of the Fund, strengthened the position of municipalities (established in Austria from 1849) vis-à-vis the manorial areas. Moreover, in 1875, the Bukovina Religious Fund, in an effort to improve the internal organisational structure, had created an estate administration, which provided an additional decision-making forum alongside state bodies, bishop and consistory. With some gradual adaptations this developed into a stable and comparatively efficient administrative structure, which greatly furthered the considerable economic development of Fund and crown land until 1914.

The state cleverly invested the resources produced by the Religious Fund in construction projects. These benefitted the Greek-Oriental Church and at the same time reduced costs for the crown land and the national budget, considerably in the latter case. The most striking examples of this economic and structural policy involving the Fund include the construction of the cathedral, the metropolitan residence, the estate administration and the creation of the Francis-Joseph University in Chernivtsi. In economic more than in political terms, there is a close involvement of the Religious Fund in the education system of the crown land, from primary schools to university.

After 1918 there was indeed a general will to reform the economy of the Romanian Kingdom, but many of the measures could not be implemented in anything like the en- 
visaged form. The complicated process of agrarian reform lasted into the Second World War. The Bukovina, and the newly acquired areas of the kingdom, were more strongly affected by these measures than old Romania. One explanation for this is the structurally more favourable situation in the Bukovina, where cadastres and land registers existed, as well as the Religious Fund. This is especially true of the Fund estates, less so for the lands of other large land owners in the Bukovina. Even so, the state did not in the end achieve its aim of redistributing the land even on Fund estates.

Similarly to before 1918 , the state, now as the Bucharest government, used the economic controlling powers of the Fund for the region and now also beyond. Evidence for this is, for instance, the construction of the new Romanian cultural palace in Chernivtsi. Other continuities exist. State attempts at agrarian reform, whether pre-1918 or later, always had to face manorial reaction, usually opposed to the reform plans or at least aimed at weakening or slowing down any measures. ${ }^{12}$ The Religious Fund, as an institution that acted as land owner, but with strong ties to Vienna (and Bucharest) through its internal structure, offered a partial break from this obstructive conflict of interests. In methodological terms we can study this institution to identify the shearing forces emerging from the clash of different social concepts in the Bukovina.

With the start of the war in 1939/40, state regulation of the economy intensified and damaged the already weakened economic position of the Religious Fund further. This existential crisis hit the Fund after a decade of precarious economic circumstances. Now the delayed reform of the structural deficits and the constant political intervention in the inner matters of the institution began to show. In addition, the clear state intervention in the prices of products and services supplied by the Religious Fund weakened its economic base further.

As far as the nation is concerned, after 1918 the point of reference moved from Vienna to Bucharest. This situation eventually also affected the economy. In the Bukovina we can clearly observe the phenomenon of phantom borders ${ }^{13}$ after 1918 . The personal conflict between I. Flondor and I. Nistor - or, at Church level, the fight of the metropolitan for Church autonomy vis-à-vis Bucharest - and their divergent expectations weakened the Fund and the national Church in the long run. Both institutions were let down in their efforts by a centralist national state of increasing rigidity and declining democratic stance. During the inter-war period neither Church nor Fund were able to avoid the gradual political influence and its economic and social consequences. This permanently damaged the institutional credibility of Church and Fund, which had been a fundamental permanent factor for both. Weakened by the political struggle, the Fund as an

12 GIORDANO 2003, Vielfalt, 126.

13 MÜLLER 2015, Geschichtsregionen; here on the example of Transylvania. 
institution lost its flexibility and cooperative agency (dynamic factor). This also meant the deepening loss of its characteristic role as mediator of socio-political collective interests in the Bukovina, a role it had played from its foundation. ${ }^{14}$ During the dictatorship of the monarch and the war, with just a short break of ultimately unsuccessful efforts by metropolitan V. Puiu, the process of political and economic disenfranchisement of the Fund resumed and intensified. This development culminated, when Romania left the war, in the occupation by the Red Army. A Soviet-Romanian timber company, Sovromlemn, was established and issued coercive orders which amounted to the de facto expropriation of the Religious Fund and the Church and the definitive deprivation of the rights of their self-administration bodies. The dissolution in 1948 of the Bukovina Romanian-Orthodox Religious Fund by the People's Republic of Romania was largely a formal last step.

For more than 150 years the Religious Fund had shaped the economic and social development of the Bukovina - especially from the mid- $19^{\text {th }}$ century onwards - as a central player. Regardless of any obstacles they encountered, parts of the institution proved to be remarkably persistent. The orientation efforts of the Fund became more significant than the purely regulative tasks the state envisaged when the Fund was established. To the extent that the Religious Fund took on state values or brought them in line with its own vision and opened itself to the general political discourse on issues of the nation, its institutional credibility was subject to a process of permanent legitimation: vis-à-vis the Church as a whole, its representatives, against the Co-Nationals and the state. When the parameters of the state context changed markedly post-1918, the Religious Fund fell into a sustained crisis because of its characteristics and the values transported through them. The new, now bigger, Romanian state had been called for only by some of the actors within Church and Fund, but both had opened themselves increasingly to the public debate about it since the turn of the century. The supposed congruence of national values with this state now unexpectedly turned into the death sentence of the institution. Its autonomy and room for manoeuvre soon shrank in the completely different structure of the political system of the monarchy. An essential part of the orientation provided by the Fund was linked to the emergence and day-to-day life of a regional awareness and the idea of a degree of decision-making power and agency. In terms of regulation and orientation, the existence and continuity of the Religious Fund as an institution depended on the functioning interaction, at roughly eye level, with the development of the state.

14 I owe these two references to Ao. Univ.-Prof. Dr. Harald Heppner and Priv.-Doz. Dr. Norbert Spannenberger, given at the Innsbruck Workshops of 27/28 November 2014. 
Fondul religionar bucovinean: continuitatea unei instituții?

Studierea istoriei Fondului religionar greco-oriental (ortodox) a încercat în această analiză (pornind de la raționamentele lui Blänkner și Rehberg, considerate aici ca fiind fundamentale) să se focalizeze metodic asupra a trei niveluri de observație: instituționalizarea, instituția și actorii ei precum și mecanismele instituționale. Era de luat în calcul și factorul timp, reprezentat în forma transformării instituționale, care, în cazul Fondului religionar, a oscilat de la mijlocul secolului al XIX-lea pe o plajă a ideilor politice călăuzitoare între cea supranațional-suprastatală și național-iredentistă. Pornind de la acestea, au fost formulate patru teze care interferează între ele prin conținutul lor: cea privitoare la punerea bazelor Fondului religionar și misiunea acestuia, la transformarea instituțională și chestiunea națională, la transformarea instituțională și modernizarea regională precum și la persistența structurilor instituționale și durata lungă a acestora. Privitor la instituția concretă - Fondul religionar greco-oriental care se află aici în centrul atenției trebuie consemnat faptul că o diferențiere precisă faţă de Biserica ortodoxă din Bucovina s-a dovedit a nu fi posibilă sau adecvată în toate domeniile. Aceasta are la bază deja împletirea instituțional-personală între episcop, membrii luați individual ai consistoriului și agendele reale ale Fondului respectiv și a organelor ecleziastice care l-au controlat dar și influențat în mod alternativ pe acesta. De aceea, granițele dintre cele două instituții sunt din când în când neclare și nu puteau fi trasate în mod exact în toate cazurile.

Discuția din încheiere are menirea de a confrunta elementele obținute până acum într-o privire de ansamblu rapidă. Aceasta nu are menirea de a dubla rezumatele secțiunilor individuale sau de a repeta detalii, ci de a aborda punctele esențiale ale tezelor formulate la început.

Procesul instituționalizării Fondului religionar bucovinean, adică a trecerii graduale de la o organizație având la început o funcție cu precădere normativă la o instituție care forma în mod activ spațiul și societatea, este legată pentru perspectiva științei istorice, prin factorul timp, în mod strâns de chestiunea succesului măsurabil al inițiativelor reformiste iluministe, așa cum au fost acestea implementate de către Iosif al II-lea. ${ }^{15}$ Din perspectiva cercetării sociologice, o instituție deja existentă își datorează legitimitatea în mod principal stabilității sale în timp și de asemenea legăturii sale față de un anume loc (ssense of place ‘). ${ }^{16}$ Cea din urmă s-ar putea extinde, în acest caz concret, la noțiunea de 'spațiu` (ıspace`). Ce se poate deduce din aceste două elemente conclusive pentru Fondul religionar din Bucovina?

15 Merker 1989, Aufklärung, 13; în cele din urmă Bendel \& SPANNEnBERger 2015, Aufklärung. 16 LOWNDES 1996, Varieties, 182. 
Inițiativele reformiste ale împăratului, care aveau ca purtătoare ideile iluminismului, s-au dovedit a fi deosebit de durabile în Bucovina, un spațiu aflat într-o poziție periferică față de centrul reprezentat de Viena, așa cum s-a putut dovedi într-un alt loc, cu referire la consolidarea generală a viitoarei țări a Coroanei austriece. ${ }^{17}$ În mod special, acțiunea imediată a organizației Fondului religionar ortodox până în secolul al XIX-lea și apoi a aceleiași instituții până la dizolvarea ei definitivă în anul 1948 se poate identifica mai ales în această regiune. Privit în durata lungă, Fondul religionar al Bucovinei este, se pare, una dintre reformele >reușite` ale iosefinismului. În planul ecleziastic de reglementare a înființării unui consistoriu pentru Biserica ortodoxă a provinciei, precum și al punerii bazelor Fondului religionar ortodox se întâlnesc chiar două strădanii reformiste ale secolului al XVIII-lea care tocmai se încheia: încercarea arondării teritoriale a statului către exterior și noua organizare a Bisericii ortodoxe (a Bucovinei) - privită concomitent ca parte a structurii administrației statului către interior. Ambii pași au pregătit, într-un mod decisiv, bazele pentru geneza unei conștiințe a țării, a unei identități regionale a Bucovinei respectiv a locuitorilor acesteia (având o puternică relaţionare cu ideea statului-cadru austriac). Prin aceasta, Fondul religionar se pare că a modelat o componentă centrală a sconstituirii « normative, organizatorice a provinciei. Mai târziu, aceasta a înlesnit și susținut geneza identității regionale a unui spațiu al >Bucovinei` (adică al fostei Moldove superioare), care nu a existat până atunci din punct de vedere istoric. Exemplul Fondului religionar lasă să se întrevadă acțiunea identică, pe întinderi mari, a unei instituții proprii, aici a Fondului, ca reper de orientare stabilit de către stat.

Relația și influențarea reciprocă dintre transformarea instituțională și chestiunea națională apar, din perspectiva Fondului religionar ortodox al Bucovinei, ca fiind deosebit de complexe și ocupă în această descriere un loc central. Pentru aceasta erau caracteristice punctele de vedere constante ale ierarhiei, interne Bisericii, care însă erau definite din nou la fiecare nouă ocupare a scaunului episcopal. Relația cu statul a decurs în tot acest timp, fără mari devieri, pe o linie întrutotul loială, care însă a cunoscut o cotitură marcantă odată cu sfârșitul Primului Război Mondial. Pornind de la acestea, Fondul religionar al Bucovinei poate fi considerat în mod acurat ca fiind o instituție imperială. Astfel, cercetările instituționale mai recente, referitoare la Europa Centrală și de Est, evidențiază în mod deosebit pentru faza de până la Primul Război Mondial legătura imanentă dintre modernizarea instituțională și cea juridică. În mod cert, această caracteristică a legăturii amintite a fost conferită în cea mai mare măsură de »necesitățile statului imperial « și mai puțin de cele ale statului național. Acest fapt este motivat printr-o comparație cu trecerea, survenită mai târziu decât în Europa vestică »de la sistemul impe-

17 SCHARR 2010, Landschaft. 
rial la cel național «. ${ }^{18}$ Această afirmație poate fi confirmată în mod fundamental pentru partea cisleithană a Monarhiei Habsburgice, însă - așa cum dovedesc rezultatele acestei cercetări - nu trebuie subestimată perioada premergătoare dezvoltării naționale chiar și într-un spațiu imperial indisputabil valabil și activ până în anii 1914/1918. Astfel, nici în instituția analizată aici a Fondului religionar nu se ascunde vreo contradicție demnă de a fi remarcată. Acesta a reprezentat, până la destrămarea Monarhiei Habsburgice, pe de o parte interesele Imperiului, aceasta însemnând că asista întrutotul la îndeplinirea nevoilor (cerute) ale statului. Fondul reprezenta însuși aceste nevoi și interese, trebuia însă, pe de altă parte, să treacă, în interiorul propriei structuri, prin unele discuții și accese de impunere a ideii naționale care uneori deveneau puternice. Reprezentanții pozițiilor radical naționale au izbutit doar în afara contextului imperial, în statul român de după anul 1918, să dea tonul în interiorul instituției. Acum, în orice caz, procesul de impunere a unei linii naționale, forțat masiv din partea Bucureștiului, a dus la o pierdere graduală a posibilităților de ghidare din interiorul Fondului. Fondul religionar al Bucovinei a devenit astfel, prin deposedarea insidioasă de putere a actorilor săi și a instanțelor sale interne, în mod gradual o minge de joc a politicii - într-o măsură mult mai mare decât ar fi fost imaginabil înainte de Războiul mondial.

La începutul acestor evoluții, în epoca episcopului Eugen Hackmann, episcopatul acestuia prezenta concomitent două fațete centrale și întrutotul ambivalente în expresia lor. Pe de o parte era observabil procesul unei graduale instituționalizări. Puțin câte puțin, Fondul se depărta dinspre misiunea sa, care cuprindea până atunci pe un plan exclusiv administrativ îngrijirea bunurilor bisericești, dincolo de aceasta Fondul apărând ca actor în chestiunile politice și sociale ale provinciei. În mod concomitent - ca a doua fațetă - se aflau revendicările de tip național care apăreau, chiar dacă acestea abia dacă dispuneau la acel moment de o anvergură în Bucovina, țară cu o populație preponderent agricolă, chiar dacă nu se mai puteau trece cu vederea după anul 1848. Ierarhii bisericești, reprezentând valori conservatoare, întrutotul loiali statului și dinastiei, precum Hackmann, luau față de aceasta o poziție distantă. Tocmai în discuția privind crearea unei dieceze ortodoxe comune pentru toți românii din Monarhia Habsburgică (încă înainte de compromisul din 1867), această distanțare s-a evidențiat în pozițiile contrare ca și conținut ale lui Andrei Șaguna și Hackmann. Între acestea, chestiunea unui congres bisericesc, așa cum a fost cerut de către Șaguna, nu s-a datorat în niciun caz unei intenții care în mod fundamental vroia să-i confere un caracter național, ci era plasat în mod vizibil în contextul populației românești și al vieții cotidiene a acesteia, care era multiplu dezavantajată într-o Transilvanie aflată sub o dominație maghiară strictă. După părerea lui Hackmann însă, o asemenea bază largă a luării deciziilor în interiorul Bisericii ar fi

18 Siegrist \& Troebst 2012, Einführung, 322. 
determinat o nepermisă îngrădire a ierarhiei tradiționale și legitime a Bisericii sale. Faptul că - așa cum formula Hackmann - prin aceasta oile ar ajunge să-i conducă pe păstori, chiar dacă era o exprimare exagerată, nimerea tocmai miezul transformării instituționale care înregistra un progres vizibil.

La acestea s-a adăugat - într-un mod dinamizat prin evoluția politică generală a Monarhiei Habsburgice - o dominanță tot mai puternică a componentei naționale în această transformare a Fondului religionar. Aceasta se dovedește însă, la o observare mai atentă, ca având o structură întrutotul eterogenă. Astfel, grupul marilor proprietari agrari, foarte influent în discursul politic din Bucovina până la marea reformă a dreptului electoral din anul 1907, urmărea prin procesul implicării laicatului în Biserica ortodoxă a țării în primul rând interesele proprii și nu neapărat pe cele ale grupării naționale reprezentate în mod preponderent în cadrul acesteia.

Episcopatul lui Silvester Morariu-Andriewicz, care nu a urmat imediat celui a lui Hackmann dar a influențat puternic și din toate punctele de vedere Biserica ortodoxă și Fondul ei religionar poate fi caracterizat prin două tendințe fundamentale care în mod potențial acționau una împotriva celeilalte. În timp ce Hackmann solicita, bazat pe modul cum înțelegea el însuși oficiul său, o loialitate absolută a preoțimii față de episcop și nu putea să înceapă mare lucru cu ideea participării extinse a credincioșilor la luarea deciziilor, indiferent cum ar fi fost aceasta formulată, Silvester Morariu-Andriewicz s-a adresat tocmai acestei baze în mod conștient, luând în considerare elementul național al bazei românești a Bisericii ortodoxe a țării și Fondului acesteia. În calitate de preot, Morariu-Andriewicz a încălcat în repetate rânduri loialitatea solicitată de către episcopul său. Prin aceasta, prin preluarea de către acesta a scaunului episcopal, a debutat în interiorul Bisericii întâi discursul privind ordinea interioară și disputa asupra chestiunii dreptului de dispoziție asupra Fondului religionar, acestea deschizându-se tot mai mult în fața domeniului disputelor politice publice. Intensificarea caracterului național al dezbaterilor bisericești, susținută de această deschidere a avut, pe de altă parte, ca și urmare faptul că actorii precum episcopul puteau să anime discursul privind caracterul național al diecezei și al Fondului, însă doreau să controleze aceasta doar într-un mod limitat. Prin aceasta, Biserica și Fondul au pășit pe arena politicii, și reprezentau acum unul dintre locurile centrale în mănunchiul de discursuri privind interesele naționale între românii și rutenii provinciei. Politica Imperiului și a provinciei jucau acum, într-un mod mult mai semnificativ, rolurile decisive în poziționarea acestor două instituții, dar și în activitatea acestora. Prin actorii individuali, Dieta și Universitatea erau de asemenea implicate, cea din urmă mai ales prin intermediul facultății de teologie ortodoxă; la fel era și în cazul catedrelor de filologie și istorie. În afara Bisericii și a Fondului religionar era imposibil de diferențiat în mod precis, din perspectiva contemporanilor, între instituțiile implicate în planul acestui discurs la nivelul provinciei. 
În amestecarea chestiunilor sociale cu cele naţionale, promovată de către unele din curentele politice ale țării Coroanei în mod deliberat, s-a izbutit - ca și în alte părți ale Monarhiei - o mobilizare graduală a straturilor rurale ale populației în favoarea partidelor moderne de masă. Fondul religionar a trebuit să mențină în aceasta o poziție duală: pe de o parte, în calitate de stăpân și mare proprietar funciar și pe de alta ca administrator al unei moșteniri culturale presupus legitimate istoric ca fiind național-românească, având o putere economică enormă și, corespunzând acesteia, un capital politic de investit doar în favoarea propriei naționalități. Actorii, atât din interiorul cât și din exteriorul Fondului abia dacă puteau urmări o linie consistentă de argumentare, fiind mai mult sau mai puțin constrânși să-și adapteze atitudinile în funcție de situație; aceasta era o circumstanță, care mai ales în rândurile publicului oricum sensibilizat politic nu a adus în timp niciun serviciu credibilității personale, nici celei instituționale. În această privință, pe baza unei observații rezumative, procesele transformării instituționale și a chestiunii naționale din cadrul Fondului religionar redau nu numai o bună parte a discursurilor politice care au dominat provincia puternic înainte de 1914, ci acestea aparțineau în mod activ și cu intensități diferite, forțelor proprii care le puneau în mișcare.

Procesele transformării instituționale din cadrul Fondului religionar ortodox nu se pot acoperi doar cu amintita chestiune națională a provinciei și dezvoltarea acesteia. Modernizarea regională (economică) a Bucovinei și a Fondului s-au aflat într-o legătură la fel de strânsă. În mod sumativ se poate observa că Fondul religionar respectiv mijloacele și posibilitățile acestuia, care au crescut în timp, au contribuit în mod esențial și pe căi diferite la îmbunătățirea structurii economice a provinciei. Spectrul acestei contribuții pornește de la preluarea nu tocmai voluntară a minelor din Iacobeni, aflate în stare de degradare, și până la ajutorarea sporadică (și la o primă privire istorică neașteptată) a comunităților evreiești ș.a.m.d. Scepticismul inițial al lui Hackmann cu privire la chestiunea minelor, ușor de înțeles, și acceptarea de la sine înțeleasă a furnizării gratuite a materialelor pentru o mică sinagogă de sat de către episcopul Repta schițează o altă fațetă a acestei transformări, care trece dincolo de aspectele pur economice, și care se află mai aproape de aspectul conștiinței provinciale, despre care vom mai discuta.

Amintita legătură în acțiune urma să se evidențieze în mod clar în chestiunea politicii privind despăgubirile urbariale ca o consecință a anului 1848. Într-o privire structurală, dominanța economică singulară a Fondului prin intermediul proprietății sale funciare enorme (și prin posibilitatea unei intervenții statale până la nivelul local, care era legată de aceasta) a favorizat o asemenea reformă. Acest lucru poate fi dovedit printr-o privire asupra provinciei învecinate Galiția-Lodomeria, unde punerea în aplicare a despăgubirilor urbariale s-a prelungit timp de câteva decenii datorită drepturilor de posesiune și proprietate atât de fragmentate. Fondul, în calitate de cel mai însemnat proprietar funciar din Bucovina, a oferit statului și în domeniul social modalități de a pune în prac- 
tică reformele față de proprietarii funciari privați, realizabile dealtfel numai împotriva puternicei rezistențe a acestora, sau de a exercita, prin intermediul Fondului, cel puțin o presiune suficientă pentru punerea în mișcare a schimbărilor. În acest caz concret, această politică a Vienei prin intermediul pârghiei reprezentate de fond, a înlesnit întărirea comunităților politice existente din 1849 în Austria vis-a-vis de domeniile stăpânilor funciari. În afară de aceasta, Fondul religionar din Bucovina a primit în anul 1875 o Direcțiune a bunurilor pentru îmbunătățirea structurii organizatorice interne, care, alături de organele statului, episcop și consistoriu a reprezentat încă un organ decizional. Prin adaptările ulterioare succesive, aceasta a devenit o structură administrativă stabilă și relativ eficientă, care a promovat în mod esențial dezvoltarea economică a Fondului și a provinciei, avînd un ritm susținut până în 1914.

Resursele administrate de instituția Fondului religionar au fost investite de către stat în mod iscusit în proiecte de construcții. Acestea au fost atât în beneficiul Bisericii ortodoxe, cât și în interesul degrevării bugetelor provincial și central, pe cel din urmă în mod semnificativ. Construirea catedralei, a reședinței metropolitane, a administrației domeniilor și dotarea Universității Francisc Iosif din Cernăuți sunt doar câteva din cele mai reprezentative exemple ale acestei politici economice și structurale puse în aplicare prin intermediul Fondului și cu ajutorul mijloacelor acestuia. Tocmai în domeniul economic, și mai mult pe tărâmul politicii, s-a arătat prin acestea strânsa împletire a Fondului religionar cu domeniul învățământului din provincie. Aceasta se întindea de la școlile primare și până la universitate.

După anul 1918, situația economică a Regatului României era la început caracterizată de voința de reformă, însă multe dintre inițiative nu au putut fi realizate nici de departe într-o manieră planificată. Astfel, procesul complicat al reformei agrare s-a prelungit până la al Doilea Război Mondial. Bucovina era - precum în general celelalte teritorii "neoacquisita « ale Regatului - în mod proporțional mai puternic afectată de aceste măsuri ca Vechiul Regat. Acest lucru se poate explica nu în ultimul rând prin situația mai avantajoasă din punct de vedere structural a Bucovinei, ca de exemplu prin existența unor cadastre și cărți funciare, dar și prin cea a Fondului religionar. Tocmai această constatare se referă într-o măsură deosebită la bunurile Fondului și în mod comparativ mai puțin la acele bunuri ale altor mari proprietari funciari ai Bucovinei. Oricum, nici aici nu au putut fi atinse scopurile stabilite de către stat în chestiunea reîmpărțirii pământului.

Similar cu perioada dinainte de 1918, statul, acum în forma guvernului de la București, s-a folosit de posibilitățile Fondului de a dirija economia în regiune și - ceea ce era nou - și dincolo de aceasta. Această imagine se poate confirma în alte locuri, de exemplu la construcția noului palat românesc de cultură din Cernăuți. În alte privințe, linia continuității este, de asemenea, evidentă. Inițiativele statale privind reforma agrară, 
indiferent dacă au survenit înainte de anul de cotitură 1918 sau după aceea, trebuiau întotdeauna să se confrunte cu o reacție din partea domeniilor funciare (smanorial reaction`), care în majoritatea cazurilor era orientată contra ideii de reformă sau cel puțin încerca să o slăbească respectiv să o frâneze. ${ }^{19}$ Prin intermediul instituției care era Fondul religionar, care în mod concomitent era proprietar funciar, dar avea și prin structura sa o puternică relație cu Viena (respectiv Bucureștiul), devenea posibilă o evadare parțială din acest constrângător conflict de interese, în beneficiul statului (și al regiunii). Din perspectiva metodică, se pot evidenția dealtfel tocmai acele forțe de forfecare de deasupra acestei instituții, care au crescut în Bucovina din coliziunea diferitelor concepte privind societatea.

Economia deosebit de puternic reglementată din partea statului odată cu începutul războiului în 1939/40 a înrăutățit din nou situația Fondului religionar oricum afectat din punct de vedere economic. Astfel, această criză existențială a afectat un fond labil din punct de vedere economic de mai mult decât un deceniu. Deficiențele structurale, a căror rezolvare a fost amânată, precum și constantul amestec politic în chestiunile interne ale instituției au ajuns acum să-și producă efectele. Mai mult, intervențiile statale lipsite de echivoc în cerințele privind livrările precum și determinarea prețurilor produselor și serviciilor din Fondul religionar au grevat asupra acestuia și au accelerat slăbirea sa tot mai puternică din punct de vedere economic.

În cadrul chestiunii naționale, raportarea valorilor s-a translatat după anul 1918 de la Viena la București. Acest lucru se poate întrevedea, cu anumite întârzieri, și în domeniul economic. Fenomenul granițelor-fantomă ${ }^{20}$ se poate urmări, în această chestiune, în mod clar în Bucovina după anul 1918. În conflictul personal dintre Iancu Flondor și Ion Nistor - respectiv pe planul bisericesc lupta mitropolitului pentru autonomie bisericească față de București, aceste așteptări diferite și atât de îndepărtate una de cealaltă au determinat în cele din urmă o slăbire a Fondului și Bisericii provinciei. Ambele instituții au fost dezamăgite în strădaniile lor de către un stat național centralist care devenea din ce în ce mai rigid și pierdea tot mai mult adeziunea la fundamentele democratice. Atât Biserica cât și Fondul religionar nu au putut să se eschiveze din fața unei politizări treptate, cu toate consecințele economice și sociale ale acesteia. Credibilitatea instituțională, ca un factor fundamental de stabilitate atît pentru fond cât și pentru Biserică a avut din acest motiv de suferit în mod durabil. Slăbit de lupta politică, Fondul ca instituție a pierdut din flexibilitatea și capacitatea sa de cooperare (factorul dinamic). Rolul acestuia caracteristic, de mediator al intereselor social-politice în Bucovina, s-a estompat prin

19 Vezi GIORdano 2003, Vielfalt, 126.

20 Vezi MÜLLER 2015, Geschichtsregionen; aici pe baza exemplului Transilvaniei. 
aceasta tot mai mult. ${ }^{21}$ În timpul dictaturii militare și al anilor războiului, cu o scurtă perioadă de întrerupere prin efortul mitropolitului Visarion, neîncununat în cele din urmă de succes, procesul deprivării Fondului de drepturile de decizie s-a accelerat din nou. Această evoluție urma să-și atingă un ultim punct culminant odată cu ieșirea României din război respectiv cu ocuparea ei de către Armata Roșie. Înființarea societății sovieto-române pentru prelucrarea lemnului `Sovromlemn`și contractele forțate pe care le implica activitatea acesteia au marcat de acum încolo punctul exproprierii faptice a Fondului religionar dar și a Bisericii, precum și deprivarea definitivă de drepturi a gremiilor proprii de administrare a acestora. Dizolvarea Fondului religionar româno-ortodox din Bucovina în anul 1949 de către Republica Populară Română a avut astfel, în mare parte, doar un caracter formal.

Peste mai mult de 150 de ani, Fondul religionar a avut un rol modelator dintr-o poziție centrală atât al dezvoltării economice cât și al celei sociale a Bucovinei, într-o măsură deosebită începând cu mijlocul secolului al XIX-lea. În aceasta, componente și caracteristici ale acestei instituții au arătat de-a lungul timpului - în ciuda vicisitudinilor apărute - o persistență surprinzătoare. Realizările Fondului în ceea ce privește funcția de călăuzire a >depășit ‘ în însemnătatea sa la început misiunea sa pură în aducerea unei ordini, conferită la fondarea acestuia de către stat. În măsura în care Fondul religionar a început să preia valori ale statului respectiv, a încercat să aducă acestea la un numitor comun cu propriile concepții, și, mai mult, s-a deschis în fața discursului politic general în chestiunile naționale, credibilitatea instituțională s-a supus unui proces al permanentei justificări, atât față de Biserică ca și întreg, a reprezentanților acesteia, cât și față de credincioși, de conaționali sau față de stat. Fondul religionar a alunecat, împreună cu structurarea sa internă și valorile vehiculate de către aceasta, într-o criză durabilă doar în momentul în care parametrii contextului statal au început să se schimbe în mod semnificativ după anul 1918. Pretinsa convergență de după sfârșitul Războiului Mondial a valorilor naționale cu statul român nou și mărit, care fusese solicitată doar de către o parte a actorilor din interiorul Bisericii și a Fondului, care, bineînțeles s-a supus de la cumpăna dintre secole într-o măsură crescândă discursului public privitor la aceasta, a devenit de acum înainte un semn prevestitor cu privire la propria existență. Atât autonomia cât și spațiile de manevră ale instituției s-au strâmtorat văzând cu ochii în sistemul politic al Regatului, care era cu totul altfel structurat. O parte esențială a misiunii Fondului ca reper de orientare se afla totuși în legătură cu geneza și cotidianul unei conștiințe regionale precum și cu concepția privind o anume libertate de decizie și

21 Pentru aceste două indicații amicale, oferite cu ocazia Workshop-ului de la Innsbruck din 27-28 noiembrie 2014 le datorez mulțumiri profesorului univ. extraordinar Dr. Harald Heppner și conferențiarului Dr. Norbert Spannenberger. 
de acțiune. Cu privire la ordine și orientare, atât existența instituției Fondului religionar cât și continuitatea sa erau de aceea legate în modul cel mai strâns prin intermediul unei interacțiuni funcționale și de pe poziții aproape egale cu dezvoltarea statului.

\section{Буковинський Релігійний фонд: безперервна Аіяльність інституції?}

У цій розвідці про діяльність Буковинського (Греко-)Православного Релігійного фонду здійснено спробу проаналізувати (виходячи із засадничих для нашої праці міркувань Бленкнера та Реберга щодо досліджень інституцій) і в методичному плані скерувати фокус на три рівні розгляду проблеми: інституціалізацію; саму інституцію та її дійових осіб; інституційні механізми. Взято до уваги також чинник часу, виражений у формі інституційних змін; у випадку з Релігійним фондом вони відбувалися найпізніше з середини XIX століття у полі напруги провідних політичних ідей від понаднаціонально-загальнодержавних до національно-ірредентичних. На підставі цього сформульовано чотири взаємопов'язані тези: про заснування Релігійного фонду та його завдання; про інституційні зміни та національне питання; про інституційні зміни та регіональну модернізацію; а також про стійкість інституційних структур у довгому історичному триванні. Стосовно конкретної інституції, а саме Православного Релігійного фонду, що перебуває у центрі нашого дослідження, слід зауважити, що виразне розмежування його від православної Церкви на Буковині виявилося можливим чи доцільним далеко не в усіх сферах. Причиною цього $є$ бодай вже самі інституційно-персональні пов'язання осіб єпископа, окремих членів консисторії та власне діяльності Фонду, а також церковних органів, що і контролювали його, і водночас самі перебували під його впливом. Тому межі обох інституцій іноді є розмитими, їх не завжди вдається виразно провести.

Підсумкова дискусія покликана у скороченому вигляді представити здобуті висновки. Тому резюме окремих розділів не будуть повторюватися і деталізуватися, а стосуватимуться лише істотних пунктів окреслених на початку тез.

Процес інституціалізації Буковинського Релігійного фонду, тобто поступовий перехід від органу, що спершу головним чином здійснював нормативну діяльність, до інституції, яка активно формувала простір та суспільство, з погляду історичних наук тісно пов'язаний - через фактор часу - 3 питанням про мірило успіху просвітницьких реформ, впроваджуваних Йосифом II. ${ }^{22} 3$ погляду соціологічних досліджень, знову-таки, кожна існуюча інституція черпає свою легітимність головним чином з власної часової сталості та іноді також із прив'язкою до

22 MerkeR 1989, Aufklärung, 13; Bendel \& Spannenberger 2015, Aufklärung. 
місцевості (ssense of place $).{ }^{23}$ Оце останнє в нашому конкретному випадку, мабуть, варто розширити до поняття «простору» (sspace). Що випливає з поєднання цих двох перспектив для Буковинського Релігійного фонду?

Засновані на ідеях Просвітництва, реформи цісаря надзвичайно сильно позначилися на периферійній стосовно до віденського центру імперії Буковині, як це вже в іншому місці було доведено і у випадку загальної розбудови господарки цієї провінції, що згодом стане окремим коронним краєм австрійської монархії. ${ }^{24}$

Безпосередню діяльність Православного Релігійного фонду, насамперед у самому регіоні, можна докладно простежити аж до XIX століття, а опісля діяльність пов'язаних із ним інституцій аж до остаточної ліквідації 1948 року. Відтак у довготривалій перспективі Релігійний фонд Буковини безумовно належить до «вдалих» реформ цісаря Йосифа II. У плані регуляції життя духовенства, створенні консисторії для православної Церкви в провінції та заснуванні Православного Релігійного фонду зустрілися дві провідні тенденції реформ кінця XVIII століття: спроба територіальної консолідації держави назовні та реорганізації православної (крайової) Церкви як частини державного структурування управління - всередині монархії. Обидва кроки вирішальним чином готували підгрунтя для появи крайової свідомості, регіональної ідентичності Буковини, чи то пак їі мешканців (з сильною прив'язкою до австрійської загальнодержавної ідеї). Таким чином Релігійний фонд становив у тому числі осердя нормативного, організаційного «облаштування» провінції. Згодом він сприяв виникненню і пришвидшував формування регіональної ідентичності «Буковини» - простору, який до того часу історично під такою назвою не існував (власне колишньої Верхньої Молдавії). Відтак на прикладі Релігійного фонду можна чітко розпізнати тривале домінування тотожності власного орієнтаційного взірця Фонду як інституції та орієнтаційного взірця, заданого державою.

Натомість відносини та взаємовпливи інституційних змін і національного питання видаються у випадку Православного Релігійного фонду Буковини надзвичайно складними, а тому посідають у викладі центральне місце. Їм були притаманні постійні, з приходом кожного нового єпископа по-новому сформульовані бачення внутрішньо-церковної ієрархії. Стосунок до держави, натомість, без якихось помітних відхилень тримався переважно лояльної лінії, яка, щоправда, із завершенням Першої Світової війни зазнала гвалтовного розвороту. Виходячи з цього до Релігійного фонду Буковини цілком влучно можна застосувати окреслення «імперської інституції». Тим-то найновіші дослідження про інсти-

23 LOWNDES 1996, Varieties, 182.

24 SCHARR 2010, Landschaft. 
туції Центральної та Східної Європи перед Першою світовою війною особливо підкреслюють цей іманентний зв'язок між інституційною та правовою модернізацією. Щоправда, характер цієї пов'язаності позначений передусім «потребами імперської держави» і значно меншою мірою потребами національної держави. Це зазвичай пояснюють пізнішим в порівнянні із Західною Європою переходом «від імперської до національної системи». ${ }^{25}$ Із таким твердженням загалом можна погодитися стосовно до цисляйтанської частини Габсбурзької монархії, водночас - i це виразно доводять результати цього дослідження - при цьому не варто недооцінювати кумулятивний період національного розвитку в навіть іще 1914/18 pр. безсумнівно чинних та дієвих імперських рамках. Відтак немає істотної суперечності і в інституції досліджуваного тут Релігійного фонду. До розпаду Габсбурзької монархії він, з одного боку, обстоював інтереси імперії, тобто цілком працював на потреби держави, як вона цього від нього й вимагала. Він і сам представляв ці потреби та інтереси, однак, з іншого боку, водночас у власній структурі переживав почасти дуже запеклі дискусії та зсуви у бік націоналізації. Однак допіру поза межами імперського контексту, в румунській державі після 1918 року, радикальна національна позиції почала задавати тон всередині інституції. Щоправда, тепер потужно форсований з Бухаресту процес націоналізації торував шлях поступової втрати можливості внутрішнього управління фондом. Унаслідок поступового позбавлення влади його дійових осіб та інстанцій Релігійний фонд Буковини дедалі більше ставав політичною іграшкою - значно більше, ніж це було помисленно перед Світовою війною.

На початках цих тенденцій, в еру єпископа Євгенія Гакмана, його єпископство виявило аж дві провідні та доволі амбівалентні за своїм вираженням грані. 3 одного боку, в той час можна достерегти процес поступової інституціалізації. Фонд крок за кроком відходив від свого первинного завдання - лише розпоряджатися церковним майном - i дедалі більше виступав гравцем на політично-суспільній сцені коронного краю. Водночас - і це друга грань - починаючи 31848 року годі було не почути національних вимог, навіть якщо вони серед переважно сільського населення Буковини й не набули аж такого поширення. Консерватори, надзвичайно лояльні до держави та династії церковні ієрархи на кшталт Гакмана, займали підкреслено дистанційовану позицію щодо національних прагнень. Саме в дискусії щодо створення спільної православної єпархії усіх румунів всередині Габсбурзької монархії (ще до Австро-Угорської угоди 1867 року) ця позиція відкрито виявилася у цілком протилежному баченні проблем Андрія Шагуни, з одного боку, та Гакмана, з другого. І це при тому, що вимога церковного конгресу, як їі ставив Шагуна, аж

25 Siegrist \& Troebst 2012, Einführung, 322. 
ніяк не мала на меті посутню націоналізацію, цілком очевидно вона постала в контексті утисків румунського населення, в тому числі і в побуті, з боку суворого угорського домінування в Семигороді. Гакман, натомість, вважав, що таке розширення бази внутрішнього церковного співуправління матиме наслідком неприпустиме обмеження дотеперішньої легітимної ієрархії його церкви. Його формулювання, начебто тепер вівці будуть керувати пастухом, було хоч і перебільшене, зате ненавмисне поціляло в саму суть помітно пришвидшених інституційних змін.

До того ж, суголосно загальній політичній динаміці Габсбурзької монархії, на змінах Релігійного фонду дедалі більше почала позначатися й національна компонента. Вона, щоправда, при докладнішому розгляді виявляється вкрай гетерогенним утворенням. Скажімо, вирішальне для політичного дискурсу на Буковині до великої реформи виборчого права 1907 року угрупування великих землевласників в процесі залучення мирян до православної церкви краю переслідувало передусім власні інтереси, а не обов'язково тієї національної групи, яку вони начебто представляли. Єпископству Сильвестра Мораріу-Андрієвича, хоча воно й не слідувало безпосередньо за Гакмановим, однак під кожним оглядом надзвичайно позначилося на православній Церкві та її Релігійному фонді, притаманні дві потенційно суперечливі тенденції. В той час як Гакман, виходячи з власного розуміння цієї посади, вимагав від священиків обов'язкового та беззастережного послуху щодо єпископа і взагалі не погоджувався із так чи інак сформульованою розширеною співучастю вірян, то Сильвестр Мораріу-Андрієвич якраз через цю базу свідомо звертався до, на його думку, провідного національного елемента православної Церкви краю та їі Фонду - румунського. Ще священиком Мораріу-Андрієвич кількакратно порушував лояльність щодо свого єпископа. Тож після призначення його єпископом попервах суто внутрішньо-церковний дискурс щодо власного ладу і порядку управління Релігійним Фондом, з одного боку, дедалі відкривався до площини політичної публічності. Проте стимульована в такий спосіб націоналізація церковних дебатів мала, з другого боку, наслідком також і те, що діячі рангу єпископа хоч і розпалювали дискурс навколо національного спрямування єпархії та Фонду, однак їхня спроможність скеровувати цей дискурс була вже доволі обмежена. Таким чином Церква і Фонд вийшли на політичну площину, ставши воднораз однією з провідних арен у складному дискурсивному плетиві національних інтересів між румунами та русинами коронного краю. Політика імперії та краю посідали значно помітніше, ніж колись, місце і в особовому складі обох інституцій, і в їхній діяльності. Через участь деяких діячів виникали пов'язання і з крайовим урядом та університетом, передусім православним богословським факультетом, те саме можна сказати і про кафедри філології та історії. Навіть із тодішньої перспективи майже неможливо вже було провести виразне 
розмежування між різними причетними до цього дискурсивного поля коронного краю, поза Церквою та Релігійним фондом, інституціями.

3 боку окремих політичних течій краю відбувалося цілеспрямоване змішування соціальних та національних інтересів, внаслідок чого відбувалася поступова мобілізація сільських прошарків населення на користь сучасних масових партій. Релігійний фонд був змушений займати тут просто-таки гібридну позицію: з одного боку, поміщика та великого землевласника, з другого - розпорядника начебто історично легітимізованої національно-культурної спадщини румунів з величезним економічним потенціалом та, відповідно, вимогою використовувати його як політичний капітал, щоправда, лише для власної нації. Дійові особи і всередині Фонду, і поза ним, ледве чи могли триматися якоїсь єдиної зв'язної лінії аргументації, вони радше були змушені ситуативно достосовувати свої позиції - обставина, що не надто сприятливо позначилася на кадровій та інституційній вірогідності цієї установи в очах і так уже політично сприйнятливої громадськості. А відтак - із перспективи підсумкового розгляду - процеси інституційних перетворень та національні питання всередині Релігійного фонду віддзеркалюють не лише значну частину дискурсів, що визначали цей коронний край задовго перед 1914 роком; вони й самі з різною інтенсивністю становили рушійні сили цих дискурсів.

Утім, процеси інституційних перетворень Православного Релігійного фонду не містяться лише у щойно згадане національне питання коронного краю та його розвиток. У щільному взаємозв'язку перебували також регіональна (економічна) модернізація Буковини та Фонд. Загалом можна стверджувати, що Релігійний Фонд та його дедалі більші засоби та можливості у різний спосіб істотно спричинилися до покращання економічної структури коронного краю. Спектр цього впливу сягав від не зовсім добровільного перейняття підупалих шахт у Якобенах аж до поодиноких (та з перспективи нашого знання історії на перший погляд радше неочікуваних) випадків фінансової підтримки єврейських громад тощо. Цілком зрозумілий початковий скепсис Гакмана щодо шахт та самоочевидна згода єпископа Репти безкоштовно надати будівельні матеріали для маленької сільської синагоги окреслюють, натомість, іншу грань цих перемін, яка виходить далеко поза суто економічні межі, а радше наближені до аспекту розвитку свідомості краю, про який іще докладніше йтиметься.

Згаданий взаємозв'язок чітко виявиться в політиці звільнення земельної власності від реального обтяження в рамках аграрної реформи як наслідок 1848 року. 3 точки зору структури загальне економічне домінування Фонду сприяло такій реформі завдяки володінню велетенськими земельними угіддями (та пов'язаними з цим можливостями безпосереднього державного втручання аж до місцевого 
рівня). Це підтверджує приклад сусіднього коронного краю Галичини і Володимиpiї, де впровадження звільнення земельної власності десятиліттями відкладалося у зв'язку з надзвичайно подрібненими майновими правами та правами на володіння. Фонд як найважливіший землевласник Буковини надавав державі також і в соціальному відношенні змогу втілювати реформи супроти приватних землевласників, які поза тим чинили неабиякий спротив, чи принаймні створювати через Фонд достатній тиск для змін. В конкретному випадку ця політика Відня, використовуючи Фонд як важіль, сприяла посиленню політичних громад, запроваджених в Австрії 31849 року, супроти поміщицьких угідь. До того ж, 1875 року Релігійний фонд Буковини для покращання внутрішньої структури організації отримав власну Дирекцію угідь, яка стала ще одним - поряд з державними установами, єпископом та консисторією - органом прийняття рішень. Внаслідок пізніших поступових адаптацій вона перетворилася на стабільну та порівняно ефективну адміністративну структуру, яка аж до 1914 року вирішальною мірою сприяла помітному економічному розвитку самого Фонду та всього коронного краю.

Ресурси, отримані через господарську діяльність Релігійного фонду, держава спромоглася вміло інвестувати в будівельні проекти. Вони пішли на користь православної Церкви, неабияк розвантажували і крайовий, і центральний бюджет. Будівництво кафедрального собору, митрополичої резиденції, Управління угідь Фонду та створення університету Франца Йозефа в Чернівцях - це лише найпоказовіші приклади цієї господарчої та структурної політики через Фонд і самого Фонду. Саме на господарчому полі, більше ніж на політичному, виявилося тісне переплетення Релігійного фонду з освітнім ландшафтом коронного краю - від народних шкіл до університету.

Після 1918 року для економічної ситуації Королівства Румунського загалом спочатку було притаманне прагнення реформ, однак багато намірів навіть близько не могли бути здійснені в запланованих обсягах. Складний процес аграрних реформ розтягнувся аж до Другої світової війни. Буковини - як i, зрештою, всіх Neoacquisita королівства - ці заходи Вони торкнулися навіть більше, ніж за давнього цісарства. Це не останньою чергою можна пояснити структурно сприятливішою диспозицією Буковини - скажімо, наявністю кадастрових та земельних книг, але власне теж і Релігійного фонду. Це особливо стосувалося угідь Фонду, меншою мірою угідь інших великих землевласників Буковини. Проте навіть тут врешті-решт так і не вдалося досягти поставленої державою мети: перерозподілу землі.

Подібно до того, як це було до 1918 року, держава - тепер уже в особі бухарестського уряду - послуговувалася можливостями Фонду чинити економічний вплив на регіон i - а ось це вже було новим - поза його межами. Цю ситуацію можна підтвердити і в інших контекстах, скажімо, на прикладі будівництва нового 
румунського палацу культури в Чернівцях. Прагнення до тяглості виявляється і в іншому відношенні. Всі державні спроби аграрної реформи - чи до 1918 року, чи то пізніше - неминуче мусили рахуватися з реакцією землевласників (>manorial reaction`), яка здебільшого суперечила реформістським намірам або принаймні намагалася їх послабити чи пригальмувати. ${ }^{26}$ Інституція Релігійного фонду, яка, щоправда, й сама виступала землевласником, проте окрім того, через свою структуру, була сильно прив'язана до Відня (Бухареста), давала можливість державі (так само як і регіону) вирватися з цього гальмівного конфлікту інтересів. До того ж, з методичної перспективи, саме на прикладі цієї інституції можна показати ті напруги, що виникли із зіткнення різних суспільних концепцій на Буковині.

3 початком війни 1939-1940 з боку держави здійснюються надзвичайно сильні регулятивні втручання в економіку, це ще погіршило і так уже надщерблену фінансову ситуацію Релігійного фонду. При цьому загальна екзистенційна криза позначилася на і без того вже понад десятиліття економічно нестабільному Фонді. Не усунуті своєчасно структурні вади та постійні політичні втручання у внутрішні справи інституції не залишилися без наслідків. До того ж, недвозначні державні інтервенції у таких питаннях, як ціноутворення на продукти та послуги Релігійного фонду, також зробили своє діло, прискоривши його економічне послаблення.

В рамках національного питання ціннісна точка відліку після 1918 року пересунулася з Відня до Бухаресту. Із деяким запізненням ця ситуація перекинулася і на економічну сферу. Феномен «фантомних кордонів» ${ }^{27}$ можна у цьому відношенні чітко простежити на Буковині після 1918. В особистому конфлікті між Янку Флондором та Іоном Ністором - або ж, на церковному рівні, у намаганнях митрополита обстояти автономію Церкви супроти Бухареста - ці два розбіжні очікування призвели до послаблення Фонду та крайової Церкви. Обидві інституції були розчаровані прагненнями дедалі неповороткішої, заскорузлішої централістської національної держави, яка стрімко відходила від основних демократичних настанов. Ні Церкві, ні Фонду не вдалося у міжвоєнний період уникнути повзучої політизації з усіма ії економічними та соціальними наслідками. Від цього систематично потерпала інституційна вірогідність, цей засадничий статичний чинник $\mathrm{i}$ для Фонду, і для Церкви. Виснажений політичною боротьбою, Фонд як інституція, до того ж, втратив свою гнучкість та здатності до співпраці (динамічний чинник). Через це він дедалі втрачав притаманний йому ще від часів заснування характер медіатора соціо-політичних колективних інтересів на Буковині. ${ }^{28}$ В роки королів-

26 CM. GIORDANO 2003, Vielfalt, 126.

27 MÜLLER 2015, Geschichtsregionen; тут на прикладі Трансільванії.

28 Моя щира подяка за ці дві вказівки на джерела пану професору Гаральду Геппнеру та пану 
ської диктатури та війни, перерваних коротким періодом урешті безуспішних зусиль митрополита Вісаріона, процес втрати політичної та економічної самостійності Фонду знову набрав на силі. Свого останнього апогею ця тенденція сягнула з виходом Румунії з війни та окупацією Буковини Червоною армією. Створення спільного радянсько-румунського деревообробного підприємства «Sovromlemn» та пов'язані з цим примусові замовлення стали моментом відліку фактичної конфіскації Релігійного фонду та Церкви і остаточного позбавлення прав його органів самоуправління. Ліквідація Румунського Православного фонду Буковини Народною Республікою Румунія в 1949 році було вже радше суто формальним актом.

Понад 150 років Релігійний фонд був одним із центральних чинників економічного та суспільного розвитку Буковини - особливо з середини XIX століття. При цьому для окремих відділів та властивостей цієї інституції - попри всі суперечності та несприятливі обставини - впродовж усього цього часу властивою була дивовижна сталість. Орієнтаційні здобутки Фонду значно перевершили у своєму значенні призначені йому державою в момент заснування завдання суто «впорядкування». Тією мірою, як Релігійний фонд почав перебирати вартості держави, чи намагався узгодити їх із власними уявленнями, відкрившись при цьому в національних питаннях політичному дискурсу, його інституційна вірогідність улягала процесу постійного виправдовування, чи то супроти Церкви як цілості, чи то їі представників, вірян, національних спільнот чи держави. Однак у справжню затяжну кризу Релігійний фонд із притаманною йому самобутністю $\mathrm{i}$ несеними через неї вартостями потрапив допіру тоді, коли після 1918 почали суттєво мінятися параметри державного контексту. Гадана тотожність національних вартостей із новою, більшою румунською державою начебто досягнута після завершення Світової війни, що їі досі вимагала лише частина дійових осіб у Церкві та Фонді, який, втім, ще від зламу сторіч дедалі більше відкривався до публічного дискурсу з цих питань, несподівано обернулася тепер вироком для власного існування. Автономія та простір дії інституції помітно звужувалися у докорінно інакше структурованій політичній системі Королівства. Однак, істотна частина орієнтаційних досягнень Фонду була пов'язана з виникненням та буднями регіональної свідомості та уявленням про певну свободу дій та рішень. Відтак з огляду на порядок та орієнтацію і саме існування інституції Релігійний фонд, і його тяглість через добре налагоджене порозуміння на правах більш-менш рівноправних партнерів були якнайтіснішим чином пов'язані з розвитком держави.

доценту Норберту Шпанненбергу під час Майстер-класу «Innsbrucker Workshop» 27-28 листопада 2014 p. 


\section{Verzeichnis ungedruckter Quellen ${ }^{1}$}

Einzelbestände größeren Umfanges, etwa Gesetzestexte oder Protokolle und Ähnliches, die in die Arbeit Eingang gefunden haben, werden hier mit ihrer Sammelbezeichnung angeführt und am gegebenen Ort im Fließtext bei den Anmerkungen über die Kurzzitation des übergeordneten Bestandes ausführlich erwähnt. Ansonsten erfolgt hier lediglich eine Aufgliederung der gesichteten Archivalien nach den jeweiligen Hauptpositionen, ohne nähere Angaben zu deren Inhalt.

\section{Österreichisches Staatsarchiv Wien (ÖSTA)}

Allgemeines Verwaltungsarchiv (AVA)

Min. d. Innern Präs. Akten, Teil 1 A45 Landesfürstl. Behörden Bukowina (1848-1899)

Landwirtschaft Landeskultur Ackerbauministerium Separatkonvolute 299

Unterricht und Kultus

Kultus AK akath. gr-or. K(arton) 1, K 2, K 6, K 10

Kultus NK akath. gr.-or. K 22-26, K 28, K 30

Unterrichtsministerium Allgemein Reihe Akten 1185 Sign. 5 C-F

Finanz- und Hofkammerarchiv (FHKA)

NHK Domänenakten (Indexbände) oo6-099

Geistl. Domänenakten K 695, K 696 Religionsfonds

Domänen Staatsgüterbeschreibungen Galizien u. Bukowina 948.1-3, K 948

Domänen Staatsgüterbeschreibungen 958.345;958.35

Allg. Domänenakten

K 1830 Galizische u. Bukowinaer Staats- u. Fondsgüter Fasz. 10

K 963 Generelle Angelegenheiten

FHKA Finanzmin. Präs. Beilagen ad Zl. 19483; ad Zl. 21304-1854; ad Zl. 554-1845

(= FHKA, Kartensammlung Z436=A236)

FHKA Sonderbestände Sammlungen u. Selekte

Katastralschätzung 257, Bezirk Kimpolung 1882

1 Die verwendeten Aktenbestände werden in den einzelnen Kapiteln vollständig aufgeführt, gedruckte Quellen sind in das Literaturverzeichnis eingearbeitet. 
Karten- und Plansammlung Pd153

Kriegsarchiv (KA)

KVIIH 127-3

NFA 11. Korps 1426 (1916)

Haus-/Hof- und Staatsarchiv (HHSTA)

AB XI/17 Protokolle u. Indices der Kabinettskanzlei, Bd. 27-34

Archiv Folliot-Crenneville 24 Nr. 172-179

Faßbender Akten Plan VI, Karton 2-6

Findbehelf 316 XI/15 Repertorium, Fasz. 9 (12, 14, 18-19); Fasz. 10 (23-25, 29-30, $32-$

34, 39-40); Fasz. 11 (62, 79); Fasz. 12 (95)

Index Staatskanzlei 1783 ; Provinzen Bukowina alt 1

Index Staatspräsidium MF 094, 098, 103, 104

Kab. d. Min. XIV/395, 1. Teil, K 665 P.A.I.

Kaiser Franz Akten 147 (alt 150)

MdÄ Zeitungsarchiv 161-8

SB Familienarchiv Taaffe 39

SB Nachlass Wilhelm Möller 1 (alt 1), Chronik des Weltkrieges 1914-1918

StAbt Russland III 61-4

Staatskanzlei Türkei II, Karton 114 (1797), Karton $135(1804)^{2}$

\section{Rumänische Akademie der Wissenschaften Bukarest}

Biblioteca Academiei Române, Cabinetul de manuscrise (RAW)

A2703 (a-d) Fondul Bisericesc

A3339 (Puiu)

S47A/XXI 7.XI.1918 (Telegram Flondor - Onciul)

A1663 Min. Domenii (Photoalbum)

Biblioteca Academiei Române, Documente Istorice ${ }^{3}$

MDLXVIII (1568), nr. 1-164, MDLXXIII (1573), nr. 1-167

2 Den freundlichen Hinweis verdanke ich Prof. C. Feneșan, Bukarest; Schreiben vom 19.XI.2018.

3 Detto; Die Dokumente enthalten vorwiegend Unterlagen zur sogen. Mustazza-Affäre (s. Kapitel 4) und der kaiserlichen Agentie in Jassy. 


\section{Rumänisches Nationalarchiv}

Arhivele Naționale ale României București (ANR-B)

Consiliul Aulic de Război (Hofkriegsrat Wien)

VI-40-1781; VI-48-1781; XIV-4-1783; XIV-17-1783; XII-2/2a-1783; XIII-

39-1783; XIV-22-1784; XIV-60-1784; XIV-60-1784; XIV-67-1784; XVI-4-1784;

XVII-12-1784

Fonds 469 Ministrul Agriculturii și Domeniilor, Direcția Funciară, dos. 20, 23, 25, 39, 46, 52 [Județul Câmpolung]; dos. 28, 29 [Judeţul Rădăuţi]

Fonds 473 Ministrul Agriculturii și Domeniilor, Direcţia Bunuri (Ardeal/Bucovina) 1838-1945

Fonds 480 Ministrul Agriculturii şi Domeniilor, Comitetul Agrar dos. 13-1922, 2-1923, 15-1923, 7-1924, 6-1925, 5-1929 [Judeţul Câmpolung]; 6-1923, 26-1923, 3-1924, 1-1926, 2-1929 [Județul Cernăuţi]; 19-1924 [Judeţul Storojineţ]

Fonds 726 Casa Regală Oficiale Vol II 1914-1946

Fonds 727

Fonds 728

Fonds 1336

Fonds 1337

Oficiale Vol III 1904-1947

Fonds 2576 Oficiale Vol IV 1927-1947 Regele Carol II Regele Ferdinand Diverse 1/1915, 9/1937; 8/1939; 9/1941; 38/1945; $40 / 1945 ; 22 / 1947$

Fonds 823 Visarion Puiu 10/1936-1940;249/1945;237/1936; 44/1935; 248/1946

Fonds 945 Iancu Flondor 9/1898-1913; 11/1909-1919;31/-;23/1918; 16/1918-1919; 19/1918

Fonds 1486 Ministerul Agriculturii şi Domeniilor, Direcţia Cadastru (1864-1948) dos. 90, 91, 138, 177, 237

Fonds 2334 Comisia operativa pentru lichidărea bunurilor din Vest 1950/51

Fonds 2719 Ministrul Cultelor şi Artelor 1921-1932 $100 / 1921 ; 106 / 1921 ; 108 / 1921 ; 177 / 1921 ; 11 / 1924 ; 132 / 1925$; $138 / 1928 ; 112 / 1929 ; 135 / 1931$

Fonds 2720 Ministrul Cultelor şi Artelor 1933-1944 71/1933; 72/1933; 81/1936; 89/1937; 90/1937; 91/1937; 118/1943; 4/1940; 84/1944; 204/1944

Fonds 3039 Consiliul de Miniștri 1881-1972 110/1367-1947 (V. Puiu); 71/1300-1947 (Religionsfonds) 
Fonds 3117 Colecţia Consiliul de Miniștri 1919ff.

13 o.J. (Inspektionsbericht Hofrat Reichmann Bukowina 1804)

Arhivele Naționale ale României - Direcția Județeană Suceava (ANR-S)

Inventarul 271 - Colecţia Planuri

2-?; 14-1826; 11-1889; 13-1902; 7-1912; 16-1944

Inventarul 292 - Mitropolia Bucovinei (1781-1950)

Inventarul 296 - Mitropolia Bucovinei Secția diverse (1782-1936)

$54-1784$; 56-1784; 74-1785; 110-1787; 284-1785; 220-1805; 818-1830; 823-1844;

$1004-1848$; $1001-1849$; $1050-1850$; $1251-1851$; $1936-1851$; $1352-1856$; $1383-$ $1858 ; 1810-1882 ; 1836-1883 ; 1839-1883 ; 1847-1884$

Inventarul 35 - Administraţia Fondului bisericesc ortodox Român al Bucovinei Vol. I (1858-1942): 1-1871; 4-1925; 18-1930; 4-1931; 14-1937; 29-1938; 59-1939; 2-4/1940; 6-1940; 11-1940; 15-1940; 73-74/1940; 160-161/1940; 163-1940; 164$168 / 1940 ; 171-172 / 1940 ; 508-1940 ; 1-2 / 1941 ; 23-1941 ; 135-1941 ; 142-1941$; 241-1941; 474-1941; 561-1941；1-1942；33-1942；74-75/1941；111-1942；256$1941 ; 258-289 / 1941 ; 260-265 / 1941 ; 279-1941 ; 282-1941 ; 284-285 / 1941 ; 78-1942$

Vol. II (1943-1950) : 195-1943; 197-1943; 210-1943; 4-6/1944; 8-1944; 10-11/1944; $52-53 / 1944 ; 75-1944 ; 123-1944 ; 126-128 / 1944 ; 132-1944 ; 222-1945 ; 227-1945$; 232-1945; 234-1945; 237-1945; 239-1945; 2-4/1946; 6; 27-1946; 104-1946; 178 $1946 ; 72-1947 ; 6-1948 ; 18-1948 ; 45-1948 ; 158-159 / 1948 ; 1-1949 ; 1-3 / 1950$

\section{Staatliches Archiv der Oblast' Černivci (Ukraine) ${ }^{4}$}

Аержавний архів Чернівецької області (DACZ)

Signaturschlüssel z.B. 320/1/25

Die erste Zahl (320) verweist auf den jeweiligen Fonds, die zweite (1) auf das Findbuch (Opis'/russ. опись, ukr. опис). Fallweise bestehen die Findbücher der größeren Fonds aus mehreren Einheiten (T1, T2, etc.). In den Findbüchern bzw. Inventaren sind die einzelnen Akten - die jeweils dritte Zahl (25) - in Form kurzer Regesten mit der Angabe von Extremaldaten (in der Regel der jüngste und der älteste Eintrag) aufgenommen.

$1 \quad$ Bukowiner Kreisamt (1786-1853)

4 DerschaWniJ 2006, зібрання. 
2 Bukowiner Landesausschuß (1861-1918)

3 Bukowinaer Landes-Regierung (1854-1918)

6/1 Biroul prezidenţial al ministrului-delegat al Bucovinei, Cernăuţi (1918-1920)

14/1 Inspectoratul General administrativ regional, Cernăuţi (1920-1936)

26/1 Rezidenţul regal al Ţinutului Suceava, Cernăuţi (1938-1940)

298 k.k. Grundsteuer-Evidenzhaltung (1820-1918)

319 Direcția generală a cultelor, Cernăuţi (1918-1927)

/1 (1918-1928);/2 (1918-1926);/3 (1920-1927)

320 Bukowinaer gr.-orient. bischöfliches Konsistorium (1792-1940, 1941-1944)

$/ 1 / \mathrm{T}_{1}(1787-1940)$

$/ 1 / \mathrm{T}_{2}(1783-1940)$

126 - Normalien für die Einrichtung der gr--or. Eparchie der Bukowina angelegt durch Kameral-Konsistoralrat und Reichsrathsabgeordneten Andriewicz Wien, 7.IV.1870.

/2/T1 (1814-1940)

$/ 2 / \mathrm{T}_{2}(1815-1940)$

/57 Regulament pentru aplicarea dispoziţiunilor art. 39-43 din legea pentru organizarea bisericii ortodoxe române, care privesc «Fondul Bisericesc ort. rom. al Bucovinei", 1925.

/3/T1 (1786-1940)

/3/T2 (1703-1940)

$14(1762-1940)$

/5-6 (1784-1939)

321 k.k. Direktion der Güter des Bukowinaer gr.-orient. Religionsfondes in Czernowitz (1787-1940, 1941-1944)

1026 k.k. Galizische Statthalterei (Angelegenheiten der Bukowina) (1775-1861)

\section{Universitätsarchiv Graz, Nachlass R.F. KaindI}

Die Bestände stammen vermutlich aus dem Nachlass von F.A. Wickenhauser und wurden von R.F. Kaindl übernommen bzw. mit seiner Umsiedlung nach Graz dorthin verbracht. ${ }^{5}$ In den Kartons Nr. 4 und 5 finden sich u.a. folgende für den Religionsfonds und die Bukowina relevante Archivalien:

\section{Karton 4}

- Organisation der Werkscolonien als Gutsgebiete (1859ff.).

5 SCharR 2016, Ansichten. 
- An die Buccoviner Staatsgüter interimal Direction (1787).

- Ausweiß jener Ortschaften und Plätze wo deutsche Umsiedler gleich jetzt und wie viele untergebracht werden können (1787).

- Protocoll Welches in Folge hoher Domainen und Salinen Administrations Verordnung vom 23ten July 1820 Nr. 7206 mit der Lipowaner Gemeinde Klimoutz über ihre grundschuldigkeiten aufgenommen worden ist (etc.).

- Billance Um wie viel die Propination in der R. Fonds Herrschaft Fratautz bei einer neuerlichen Steuerpachtung pro 792. gegen den [?] Pachtschilling gestiegen oder gefallen...

- Buccoviner tabu. Extract. Uiber die bey der Kammeral.Herrschaft Zuczka gehörigen Ortschaften, alt Zuczka und Zuczka, Baila Lenkoutz, Mahala und Kotul Ostritza.

- Nr. 792 Zirkular ex 799 (Graben nach Erz und Mineralien).

- Jahrs-Billanze. Uiber das Steigen und Fallen der Gefällseinnahmen, und Ausgaben, bei der Religionsfonds Herrschaft Fratautz, zwischen den Militär Jahren 1789 und 1790.

- Auszug Über den Flachen Innhalt, den Grund Ertrag, der dem Religions Fond gehörigen Grundstende Pajaner Stampi nach Weisung des Ausmaaß und Fassions Buch.

- Haupt Contract. Welcher unter heut zu Ende gesetzten dato zwischen der k.k. St. Illier Rel. Fonds Herrschaft und nachstehenden Partheyen folgender massen geschloßen und Verabrecht worden.

- Prottocoll. Welches mit der Gemeinde Fontina Alba über die weitere Reluierung der unterthänigen Schuldigkeiten dann der Urbarial Giebigkeiten und des Zehends von dem Rustical Grundbesitze aufzunehmen worden ist.

- Präsidialmeinung (1804) Gesuch Lipowaner Gemeinde zu Warnitza.

- An den königl. Gubernialrath Staatsgüteradministrator und Robotabolizionshofkommissär in Galizien Herrn Mathäus von Ainser, Lemberg (1788).

- Erträgnis Ausweis der zur Verpachtung nach der Katastral Schätzung vom Jahre 1837 bestimmten Gründe.

Karton 5

- Verzeichniß deren in denen 3. landesfürstlichen Städten Czernovicz, Suczava und Sereth beij Aufhebung der Klöster eingezogenen und dermalen dem Relligions Fond zugehörigen Häußern und leeren Hofstätten (1787).

- Auszug aus dem Pfarrbuch des Millescheuzer Pastorats Bukowiner Kreises. Kurze Beschreibung von der Buccowina ( 1810).

- Tabelarische Uibersicht der landwirthschaftlichen Verhältnisse der gr. n. un. Religionsfonds Domaine Kotzman /Kuczurmare \& St. Onufri (1862). 


\section{Abbildungsverzeichnis}

Tabellen

Tab. 1 - Grundbesitzverteilung in der Bukowina um 1780. 62

Tab. 2 - Religionsfondsgüter in der Chotyner Raya 1791. 75

Tab. 3 - Religionsfondsgüter im Fürstentum Moldau 1799. 76

Tab. 4 - Verwaltungsstruktur und Dörfer der Staatsgüter in der Bukowina 1801. 83

Tab. 5 - Güter des gr.-orient. Religionsfonds und Cameralgüter [...] 1856. 100

Tab. 6 - Grundsteuerleistung der Religionsfondsherrschaften. 111

Tab. 7 - Personalschema der Güterdirektion nach dem Statut von 1869. 147

Tab. 8 - Forstverwaltung und Forstpersonal der Religionsfondsgüter 1869. 148

Tab. 9 - Zusammensetzung des Konsistoriums 1899-1913. 206

Tab. 10 - Domänen und Güter des Religionsfonds am Vorabend des Krieges. 220

Tab. 11 - Kirchenhierarchie der gr.-orient. Erzdiözese Bukowina Mai 1919. 260

Tab. 12 - Ausgaben des Religionsfonds 1930-1940. 294

Tab. 13 - Forstwirtschaftsbezirke des Religionsfonds 1938/1940. 300

Tab. 14 - Betriebsstätten der Bergwerke Jakobeny 1865/1880. 326

\section{Abbildungen}

Abb. 1 - Religionsfonds als Institution. 27

Abb. 2 - Auszug aller [...] denen Klöstern eigenthümlich zugehörigen Ortschaften. 72

Abb. 3-5 - Geographische Karte der [...] Cameral-Religions- und Schulen-Fonds-Güter in der Bukovina (um 1805). 73

Abb. 6 - Karte der in der Moldau gelegenen Religions-Fonds-Güter (um 1802). 82

Abb. 7 - Karte (um 1802), Detail. 83

Abb. 8 - Uibersichts Karte Cameral und Fonds Domaenen 1855. 106

Abb. 9 - Uibersichts Karte Religions Fond Herrschaften 1856. 107

Abb. 10 - Uibersichts Karte Czernowitzer Ober-Forstamts-Bezirk 1856. 108

Abb. 11 - Besitzer der Bauparzellen Religionsfonds nach Katastralgemeinden 1854. 109

Abb. 12/13 - Oppositionelle Kritik an Hackmann. 129

Abb. 14 - Zuständigkeit in der rumänischen Frage. 130

Abb. 15 - Residenz des Bischofs der Bukowina in Czernowitz. 139

Abb. 16 - Halbplastik von E. Hackmann. 151 
Abb. 17 - Bronzestatue für E. Hackmann. 151

Abb. 18 - Dositheus Cherescul. 153

Abb. 19 - Archimandrit Theoctist Blazewicz. 153

Abb. 20 - Morariu-Andriewicz als Erzbischof und Metropolit. 156

Abb. 21 - Czuperkowicz als Erzbischof und Metropolit. 174

Abb. 22-24-Memorandum der Jungruthenen an den Erzbischof 1899. 182

Abb. 25 - Foaia ordinăciunilor ... Verordnungsblatt der Erzdiözese. 190

Abb. 26 - Bukowiner gr.-orient. Kirchenfrage, schematische Darstellung. 194

Abb. 27 - Mitropolitul Bucovinei şi Dalmaţiei Dr. Vladimir de Repta. 195

Abb. 28 - Das 1902 eingeweihte Denkmal für das 41. Infanterieregiment. 196

Abb. 29/30 - Amtslokalität der Güterverwaltung in Czernowitz. 216

Abb. 31 - Agrar- und forstwirtschaftliche Zonen der Bukowina. 221

Abb. 32 - Cernăuţi Universitatea. Ansichtspostkarte der Zwischenkriegszeit. 225

Abb. 33 - Cernăuţi. Reședinţa Mitropolitană. Ansichtspostkarte der Zwischenkriegszeit.

226

Abb. 34 - Budgetvoranschläge des Religionsfonds für die Jahre 1864-1913. 227

Abb. 35-Geldertrags-Verhältnisse des Religionsfonds 1874-1898. 228

Abb. 36 - Kaiser Jubiläumsausstellung Wien 1898, Pavillon der Bukowina. 239

Abb. 37 - Exposiţia Naţională 1906. București. Casă tărăneasca din Bucovina. 239

Abb. 38 - Das neugeweihte Erzbischof Repta-Schutzhaus. 244

Abb. 39 - Rărău cu casa de adăpost »Mitropolitul Visarion«. Ansichtspostkarte. 244

Abb. 40 - Rumänien vom Dnister bis zur Theiss ... im Fondsalltag. 247

Abb. 41 - Demission Ianco Flondors 1919. 253

Abb. 42 - Briefcouvert, Sonderstempel und -briefmarke zur 75-Jahr-Feier 1993. 255

Abb. 43/44 - Kontinuitäten einer Epochengrenze. 258

Abb. 45 - Schematische Darstellung 1925. 263

Abb. 46/47 - Tafelplan und Gästeliste des Metropoliten 1922. $265 \mathrm{f}$.

Abb. 48 - Eparchialversammlung der Bukowina, Dezember 1931. 269

Abb. 49 - Schematische Darstellung 1936. 275

Abb. 50 - Unterschriften von Gläubigen aus der Gemeinde Borăuţi in Kyrillisch. 276

Abb. 51 - Der Metropolit als >oberster Herr $\prec .278$

Abb. 52 - Metropolit Puiu 1942. 281

Abb. 53 - Metropolit Puiu beim Verlassen der Kathedrale in Czernowitz 1938. 281

Abb. 54 - Dienstabzeichen (Nr. 4891) eines Jägers der Domeniile Bucovina. 285

Abb. 55 - Der Kulturpalast als monumentales Werk rumänischer Architektur. 296

Abb. 56 - Das Gebäude des vormaligen rumänischen Kulturpalastes heute. 296

Abb. 57 - Der Kulturpalast kurz nach der Wiedereroberung der Nordbukowina. 297

Abb. 58 - Forstwirtschaftsbezirke des Religionsfonds. 301 
Abb. 59 - Religionsfondsbesitz in der Bukowina 1939. 302

Abb. 60 - Grund Ris Von der Gegend bey dem Dorf Jacobina, 1782. 309

Abb. 61 -Eisenberg und Hüttenwerke zu Jakobeny in der Bukkowina nach 1810. 313

Abb. 62 - Jakobeny, Ausschnitt Franziszeischer Kataster 1856. 313

Abb. 63 - Die Erzlagerstätten der südlichen Bukowina, um 1899. 317

Abb. 64 - Jakobeny an der Goldenen Bistritza. Illustration aus dem Kronprinzenwerk. 318

Abb. 65 - Jakobeny um 1856, Detail Franziszeischer Kataster. 313

Abb. 66 - Struktur und Lage des Bergbaugebietes Jakobeny vor dem Ersten Weltkrieg. 323

Abb. 67 - Die Ruine der ehemaligen Manzschen Gießereihalle in Jakobeny. 325

Abb. 68 - Dorna-Watra Totalansicht. Ansichtspostkarte vor 1914. 331

Abb. 69 - Gruß aus Bad Dorna. Ansichtspostkarte vor 1914. 332

Abb. 70 - Noroc Bun!, Bergarbeiterspruch in Jakobeny. 336

Abb. 71 - Aufbereitungsanlagen und Abraumhalden von Ciocanești 2013. 336

Abb. 72 - Vatra Dornei. Izvorul `Unire`. Ansichtspostkarte der Zwischenkriegszeit. 337 Abb. 73 - Stiftungstafel über der Quelle der heutigen Izvorul Sentinela. 337 


\section{Abkürzungsverzeichnis}

\begin{tabular}{|c|c|}
\hline AFBis & Administraţia Fondului bisericesc ortodox român din Bucovina \\
\hline Anm. & Anmerkung \\
\hline ANR & Arhivele Naţionale ale României (Rumänisches Nationalarchiv) \\
\hline B & București \\
\hline CAR & Consiliul Aulic de Razboi (Hofkriegsrat Wien) \\
\hline FMAD & Fond Ministerul Agriculturii şi Domeniilor \\
\hline CA & Comitetul Agrar \\
\hline MAD & Ministru al Agriculturii și Domeniilor București \\
\hline $\mathrm{S}$ & Direcţia Județeană Suceava \\
\hline DACZ & $\begin{array}{l}\text { Державний архів Чернівецької області (Staatliches Archiv der Oblast' } \\
\text { Černivci, Ukraine) }\end{array}$ \\
\hline FBis & Fondul bisericesc ortodox român din Bucovina \\
\hline fl. & Gulden (Florentiner) \\
\hline galiz. & galizisch \\
\hline gr.-orient. & griechisch-orientalisch \\
\hline GVBl. & Gesetz- \& Verordnungsblatt \\
\hline HKR & Hofkriegsrat (rum. Consiliul Aulic de Război) \\
\hline $\mathrm{K}$ & $\begin{array}{l}\text { Kronen. Die Umrechnung von Kronen (als Reichswährung seit 1892) auf } \\
\text { Gulden erfolgte im Verhältnis } 2: 1 \text {. }\end{array}$ \\
\hline Mtz. & Meterzentner, Gewichtsmaß; entspricht $100 \mathrm{~kg}$ \\
\hline o.D. & ohne Datum \\
\hline ÖNB & Österreichische Nationalbibliothek Wien \\
\hline FKB & Fideikommiss \\
\hline KS & Kartensammlung \\
\hline ÖSTA & Österreichisches Staatsarchiv Wien \\
\hline HHSTA & Haus-/Hof- und Staatsarchiv \\
\hline AVA & Allgemeines Verwaltungsarchiv \\
\hline KA & Kriegsarchiv \\
\hline RAW & $\begin{array}{l}\text { Biblioteca Academiei Române, Cabinetul de manuscrise (Rumänische } \\
\text { Akademie der Wissenschaften, Handschriftenabteilung, Bukarest) }\end{array}$ \\
\hline StenoProt & $\begin{array}{l}\text { Stenographische Protokolle über die Sitzungen des Abgeordnetenhauses } \\
\text { des österreichischen Reichsrates }\end{array}$ \\
\hline UdSSR & Union der Sozialistischen Sowjetrepubliken \\
\hline $\mathrm{x}$ & Kreuzer \\
\hline
\end{tabular}




\section{Literaturverzeichnis}

\section{Gedruckte Quellen}

Kursiv gesetzt sind die Namen von Zeitungen; alle Internetzugriffe zuletzt 10.4.2019.

A

Ackerbauministerium (Hg.) (1893-1907): Jahrbuch der Staats- und FondsgüterVerwaltung, Band 1-6, Wien.

ACKerbauministerium (Hg.) (1897): Verwaltung und Wirtschaft in den Forsten des Bukowinaer griechisch-orientalischen Religionsfondes. Auf dem Hintergrund einer allgemeinen Culturskizze des Landes mit Benützung officieller Daten beleuchtet von einem Fachmanne, Wien.

Ackerbauministerium (Hg.) (1907): Die Holzproduktion Österreichs mit besonderer Berücksichtigung der Staats- und Fondsforste, Innsbruck.

Anonymus (1812): Die Berg- und Hüttenwerke zu Jakobeny und Mariensee am Silberberge in Kirlibaba in der Bukowina. In: Vaterländische Blätter für den österreichischen Kaiserstaat (Wien) 5, Nr. 41, 245f., 20.V.1812, Beiträge zur Kenntnis der Bergwerke in den k.k. Erbstaaten.

Anonymus (1829) : Пастирске Посланіє Митрополита Мораря 3 поводу сегорічних великодних сьвят Его румунизторскі змаганя Супротив Православних Русинів на Буковинї. Начертав Не уніят, вле таки православний Сьвященник (= Передрук 3 «Буковини»), Чернівцї.

ANONYMUS (1841-1914): Schematismus der griechisch-orientalischen Bukowiner Dioecese, Czernowitz.

Anonymus (1857): Poczet Szlachty Galicyjskiéj i bukowińskiéj, Lwow. Online: [http:// books.google.com.ua/books?id=uMMaAAAAYAAJ\&printsec=frontcover\&source= gbs_ge_summary_r\&cad $=0 \# \mathrm{v}=$ onepage $\& \mathrm{q} \& \mathrm{f}=$ true].

ANoNymus (1862): Hauptbericht der Handels- und Gewerbekammer für das Herzogthum Bucovina nebst der topographisch statistischen Darstellung des Kammerbezirkes mit Schluss des Jahres 1861, Czernowitz.

ANONYMUs (1864): Aufruf an die hohe Staatsverwaltung in der hierarchischen und Organisationsfrage der griechisch-orientalischen Kirche in der Bukowina, Czernowitz.

ANONYMUs (1864-1881): Voranschlag des griechisch nicht-unirten Religions-Fondes für die 14monatliche Finanzperiode, Czernowitz. 
ANonymus (1867): Acte oficioase pentru fondaria Mitropoliei greco-orientale pentru Romanii din Transilvania Ungaria şi Banat, Klausenburg.

Anonymus (1870): Katalog der Ausstellung land- und forstwirtschaftlicher Producte, gewerblicher und kunstgewerblicher Erzeugnisse, Czernowitz.

Anonymus (1872): Orts-Repertorium des Herzogthums Bukowina. Auf Grundlage der Volkszählung vom 31. Dezember 1869, Czernowitz.

Anonymus (1872): Hauptbericht und Statistik für die Periode vom Jahre 1862-1871, Lemberg.

Anonymus (1873): Bergwesen. Zur Montanstatistik. In: Mittheilungen des k.k. Ackerbauministeriums Wien 10, III. Jg., 8-12.

Anonymus (1874-1918): Gesetz- und Verordnungsblatt für das Herzogthum Bukowina, Czernowitz.

ANONYmus (1875): Voranschlag des griechisch-orientalischen Religionsfondes in der Bukowina für das Solarjahr 1875, Czernowitz.

ANONYMus (1881): Voranschlag des Bukowinaer griechisch-orientalischen Religionsfondes für das Jahr 1881, Czernowitz.

ANONYMUs (1882-1910): Voranschlag der Kurrentgebarung des Bukowinaer gr.-ort. Religionsfondes für das Jahr (...) Czernowitz.

ANONYMUs (1885): Voranschlag des Bukowinaer griechisch-orientalischen Religionsfondes für das Jahr 1885, Czernowitz.

ANONYMUs (1891): Apologie der orthodoxen gr.-orientalischen Kirche der Bukowina Nr. I und II beleuchtet von einem griech.-kath. Seelsorger in der Bukowina, Wien.

Anonymus (1900): Dienst-Instruktion und Wirkungskreis für die k.k. Direction der Güter des Bukowinaer gr.-or. Religionsfondes in Czernowitz, Wien.

Anonymus (1903): Die Affaire Dr. Janku v. Flondor von dem landtäglichen Mißbilligungsausschusse, Czernowitz (Beilage zum Bukowinaer Journal Nr. 323).

Anonymus (1903): Die Flondoraffaire im Bukowinaer Landtage. Nach den stenographischen Protokollen (Verlag Bukowinaer Post), Czernowitz.

ANONYMUs (1904): Militärisch-statistische Feldelaborate Ostgalizien und Bukowina. I., II. und III. Teil mit 14 Kartogrammen, Wien (ÖSTA-KA-KVIIh78-271a).

ANONYMUs (1905): Voranschlag der Kurrentgebahrung des Bukowinaer griechischorientalischen Religionsfondes für das Jahr 1905, Czernowitz.

ANONymus (1908): Denkschrift anlässlich des 25jährigen Bestandes der Aktiengesellschaft »Bukowinaer Lokalbahnen«, Czernowitz.

Anonymus (1909): Dienstinstruktion und Wirkungskreis für die k.k. Direktion der Güter des Bukowinaer gr.-or. Religionsfondes in Czernowitz, Czernowitz.

Anonymus (1910): Voranschlag der Kurrentgebahrung des Bukowinaer griechischorientalischen Religionsfondes für das Jahr 1910, Czernowitz. 
Anonymus (1931): Bugetul Fondului Bisericesc 22.XII.1930. In: Revista Pădurilor Fond. Bisericesc ort. rom. al Bucovinei Anul 1, No. 1/2, (Ian-Fev. 1931), Rădăuţi.

Anonymus (ca. 1902): Die Entwickelung des Eisenbahnnetzes der Bukowinaer Lokalbahnen, Wien.

Anonymus (Hg.) (2000 u. 2001): Cel mai vechiu cod silvic românesc Orândueala de pădure pentru Bucovina dată de împăratul Iosif al II-lea în 1786. In: Bucovina Forestieră Anul VIII (2), 61-73 (Teil I); IX (1-2), 75-87 (Teil II).

B-C

BANDHAUER-SchöFFMANN Irene (2004): Entzug und Restitution im Bereich der Katholischen Kirche (= Veröffentlichungen der Österreichischen Historikerkommission. Vermögensentzug während der NS-Zeit sowie Rückstellung und Entschädigungen seit 1945 in Österreich 22/1), Wien u.a.

BRUSANOWSKI Paul (2011): Rumänisch-orthodoxe Kirchenordnungen (1786-2008). Siebenbürgen-Bukowina-Rumänien (= Schriften zur Landeskunde Siebenbürgens 33, Hg. von K.W. Schwarz \& U.A. Wien), Köln.

Bukowinaer Landtag (Hg.) (1866): Stenographisches Protokoll der XVI. Sitzung der IV. Session des Bukowinaer Landtages, Czernowitz, 247-251 (Antrag Abgeordneter Hormuzaki v. 8. Feb. 1866), 336-338 (Antrag Hormuzaki Bericht 15.II.1866).

Bukowinaer Landtag (Hg.) (1892/93): Stenographische Protokolle des Bukowinaer Landtages der ersten Session der achten Wahlperiode, Czernowitz, 294-301 (Antrag Abgeordneter Pihuliak 2.V.1893), 553-560 (Antrag Pihuliak Bericht 20.V.1893).

Calinescu Myron M. (Hg.) (1887): Normalien der Bucovinaer gr.or. Diöcese von 1777-1886, I. Band, Czernowitz.

Cantemir Dimitrie (1771): Beschreibung der Moldau, Faksimiledruck der Originalausgabe (1973), Bukarest.

Czuperkowitz Miron \& Andreas Pralle (1848): Bittschrift des ... Deputierte der Freisassen-Gemeinden ... an ksl. königliche Majestät übergeben im Juli 1844, Wien.

D-H

Derschawnij Комiтет Державний Комітет Архівів України (Нg.) (2006): Apхівні зібрання України. Путівники. Державний архів Чернівецької області. Путівник. Том 1, фонди дорадянського періоду, Чернівці-Київ.

Direktion der Güter des Buk. gr.-or. Religionsfondes (1908): Programm für die in den Jahren 1908 bis 1917 in den Forsten und Domänen des Bukowiner gr.-or. Religionsfondes durchzuführenden Bauinvestitionen, Czernowitz.

DrĂCEA Ioan Coșei \& V.N. STINGHe (Hg.?) (nach 1932): Raport de expertiză asupra 
fondului religionar din Bucovina, unveröffentl. Typoskript, Universitätsbibliothek Černivci (9oCI24 - 107328).

Ficker Adolf (Hg.) (1854): Darstellung der Landwirtschaft und Montan-Industrie des Herzogthumes Bukowina mit vorzüglicher Rücksichtnahme auf die Jahre $1851 \mathrm{u}$. 1852. In: Mittheilungen aus dem Gebiete der Statistik 3/1.

Gesetz- und Verordnungsblatt für das Herzogthum Bukowina, Jahrgang 1870, IX. Stück, 16. April 1870, Organisationsstatut für die Administration der Güter des Bukowinaer griech.-orient. Religionsfondes.

Gesetz- und Verordnungsblatt für das Herzogthum Bukowina, Jahrgang 1874, XXI. Stück, 29.VIII.1874, Verordnung des Ackerbau-Ministeriums v. 29.VII.1874, Z. 8717-520, mittelst welcher provisorische Bestimmungen über die Verwaltung der Montanwerke des griech.-orient. Religionsfondes in der Bukowina erlassen werden.

Gesetz- und Verordnungsblatt für das Herzogthum Bukowina, Jahrgang 1894, III. Stück, 28.II.1894, Verordnung des Ackerbau-Ministeriums v. 23.II.1894, mittelst welcher an Stelle der provisorischen Bestimmungen über die Verwaltung der Montanwerke des griech.-orient. Religionsfondes im Grund der allerhöchsten Entschließung v. 5.I.1894 nachstehende Bestimmungen erlassen werden.

Hacman Eugenie (1862): Adresa catra Excelentia si Preasantia Sa Domnul Episcop all Bucovinei. Eugeniu Hacman membru casei de sus (...) in causa scolei reale infiintiande in Cernauți de’n fundul religiunariu, Cernauţi.

HACQUET Balthasar (1791): Hacquet's neueste physikalisch-politische Reisen in den Jahren 1788, 89 und 90 durch die Dacischen und Sarmatischen oder Nordlichen Karpathen, Zweyter Theil, Nürnberg (online zugänglich über www.literature.at).

HAKMANN Eugen (1864/1899): Sendschreiben des Bukowinaer gr. or. Bischofs Eugen an die Unterfertiger der Petition dto Czernowitz, den 6. October 1864, respective an die Verfasser der Flugschrift ,Einigkeitsruf an die griechisch-orientalische Provinzialkirche der Bukowina in der Organisationsfrage. Czernowitz 1864' (= Nationale und kirchliche Bestrebungen der Rumänen in der Bukowina 1848-1865 in einem Sendschreiben dargestellt, Hg. v. Dr. Stefan Smal-Stocki), Czernowitz.

Handels-Ministerium (Hg.) (1854): Mittheilungen aus dem Gebiete der Statistik, III. Jahrgang, I. Heft. Darstellung der Landwirthschaft und Montanindustrie des Herzogthums Bukowina mit vorzüglicher Rücksichtnahme auf die Jahre 1851 und 1852, Wien.

HaUser Michael Leopold (1988/89): Das Manz'sche Silberbergwerk am Fuße des Fluturikaberges in Kirlibaba-Mariensee, links der Goldenen Bistritz. In: Der Südostdeutsche - Buchenlanddeutsche Zeitung Jg. 39 (1988) Nr. 10, 7; Nr. 11, 3; Nr. 12, 3; Jg. 40 (1989) Nr. 1, 7; Nr. 2, 3; Nr. 3, 6. 
Hormuzaki George, Eugen Stircza, Alexander von Hormuzaki (1870): Denkschrift an Se. Excellenz den Herrn Minister für Cultus und Unterricht Carl Edlen von Stremayr zur Erläuterung der Majestätsadresse um Bewilligung eines constituierenden Kirchenkongresses zur Verwirklichung der Autonomie der gr.-orient. Landeskirche der Bucovina, Wien.

K-R

KLETEČKA, Thomas (Bearb.) (2002): Die Ministerratsprotokolle Österreichs und der Österreichisch-Ungarischen Monarchie 1848-1918. Ser. 1, Die Protokolle des Österreichischen Ministerrates 1848-1867, Abt. 2, Das Ministerium Schwarzenberg 1, 5. Dezember 1848 - 7. Jänner 1850 , Wien.

KLeteČKA, Thomas (Bearb.) (2005): Die Ministerratsprotokolle Österreichs und der Österreichisch-Ungarischen Monarchie 1848-1918. Ser. 1, Die Protokolle des Österreichischen Ministerrates 1848-1867, Abt. 2, Das Ministerium Schwarzenberg 2, 8. Jänner 1850 - 30. April 1850, Wien.

Kirileanu Gheorghe Teodorescu (Hg.) (2001): Orinduala de pădure pentru Bucovina data de împăratorul Josif al II-lea in 1786. Primul cod silvic Românesc, Suceava.

KonsistoriUm gr.-or. (1884): Fóia ordinăciunilor. Consistoriului archipiscopescie în afacerile Archidiecesei ort.-orient. a Bucuvinei, Cernăuţi.

Kropatscheк Josef (1784-1790): Handbuch aller unter der Regierung Kaiser Joseph II. ergangenen Verordnungen und Gesetze, 18 Bände, Wien.

Landesamt Statistisches (Hg.) (1913): Die Ergebnisse der Volks- und Viehzählung v. 31.XII.1910 im Herzogtume Bukowina nach den Angaben der k.k. statistischen Zentral-Kommission in Wien (= XVII. Heft der Mitteilungen des statistischen Landesamtes des Herzogtums Bukowina), Czernowitz.

Legea Nr. 295 pentru Organziarea Bis. ort. R. In: Revista Pădurea și viaţa 2 (2010), $10 f$. MAAss Ferdinand (1951-1961): Der Josephinismus. Quellen zu seiner Geschichte in Österreich 1760-1850, 5 Bände (= Fontes Rerum Austriacarum II/71-75), Wien.

MARTINOwICZ Isidor et al. (1895): Majestätsgesuch des bukowinaer griechisch-orientalischen Curatclerus um Erhöhung der Dotation desselben aus dem bukowinaer gr.-or. Religionsfonde. Allerhöchsten Ortes unterbreitet am 19. (31.) Januar 1895, Czernowitz.

Ministerium f. Cultus \& Unterricht (Hg.) (1871): Gesetzliche Bestimmungen über die Errichtung, Verwaltung und Verwendung der Religionsfonde der im Reichsrathe vertretenen Königreiche und Länder, veröffentlicht im Auftrage des k.k. Ministers für Cultus und Unterricht, Wien.

Ministerul Agriculturii (Hg.) (1921): Lege pentru reforma agrară din Bucovina (Publicată în Monitorul Oficial No. 93 din 30 Iulie 1921), București. 
Mitropolia Bucovinei (Hg.) (1936): Decret-Lege. Pentru organizarea şi funcţionarea Fondului Bisericesc ortodox Român al Mitropoliei Bucovinei. Din 4 Noemvrie 1937 cu modificările din 16 Martie 1938. Republicat în Monitorul Oficial Nr 72 din 2 Aprilie 1938, București.

MorARIU-ANDRIEvicz Silvester (1885): Apologie der orthodoxen griechisch-orientalischen Kirche der Bukowina (I), Czernowitz.

MoRARIU-ANDRIEviCz Silvester (1890): Apologie der orthodoxen griechisch-orientalischen Kirche der Bukowina (II), Czernowitz.

Pope A Nicolae (1879): Vechea Metropolie ortodosă română a Transilvaniei, suprimarea și retaurarea ei, Sibiu.

Romstorfer Carl \& Hubert Wiglitzky (Hg.) (1886): Vergleichende graphische Statistik in ihrer Anwendung auf das Herzogthum Bukowina und das österreichische Staatsgebiet, Wien.

\section{S-Z}

SIEGHART Rudolf (1915): Zolltrennung und Zolleinheit. Die Geschichte der österreichisch-ungarischen Zwischenzoll-Linie. Nach den Akten dargestellt, Wien.

Statistische Central-Commission k.k. (Hg.) (1871): Tafeln zur Statistik der Österreichischen Monarchie N.F. V. Band. Die Jahre 1860-1865 umfassend, Wien.

STYRCZA Emanule et al. (1864): Einigkeitsruf an die griechisch-orientalische Provincialkirche der Bucowina in der hierarchischen und Organisationsfrage, Czernowitz.

STÖger Michael (1832): Uebersicht des ersten Regulierungs-Plans für das Kirchenwesen der nicht unierten Griechen in der Bukowina. In: Österr. Archiv für Geschichte, Erdbeschreibung, Staatenkunde, Kunst und Kultur 23, Wien.

Tit TEL Ignac (1913): Schematismus und Statistik des Großgrundbesitzes im Königreiche Galizien mit Lodomerien und dem Herzogtume Krakau, dann dem Herzogtume Bukowina. Mit einer agronomischen und Eisenbahnkarte, Prag.

Verein (1852-1886): Mitteilungen des Vereins für Landescultur und Landeskunde im Herzogthume Bukowina, Czernowitz.

WAGneR Rudolf (Hg.) (1979): Die Reisetagebücher des österreichischen Kaisers Franz I in die Bukowina (1817 und 1823) (= Schriftenreihe der Landsmannschaft der Buchenlanddeutschen e. V.), München.

ZaCHAR Anton (1904): Die direkten Steuern im Herzogthume Bukowina in den Jahren 1898 bis 1902 (= Mittheilungen des statistischen Landesamtes des Herzogthums Bukowina X), Czernowitz.

ZaChar Anton (Hg.) (1902): Der Grundbesitz im Herzogthume Bukowina nach der Stellung der Besitzer und nach Grössenclassen des Besitzes, bearbeitet vom statisti- 
schen Landesamte des Herzogthums Bukowina I. Theil (= Mittheilungen des statistischen Landesamtes des Herzogthumes Bukowina IX), Czernowitz.

\section{Karten}

Kursiv gesetzt sind die Originalbezeichnungen der Karten (in Klammer stehen ggf. die Siglen des jew. Archivstandortes).

Adler F. (1784): Auszug aller in dem kk Buccoviner district befindilchen und denen Klöstern eigenthümlich zugehörigen Ortschaften. Extrahiert von F. Adler Oberlieutenant vom 2. Wallach:Graentz-Infanterie:Regiment, M 1:345.600, 1 gez. Blatt (ÖSTAKA KS B/IX/C556).

ANonymus (1779): Karte von der Bukowina in welcher die von der Grenz-Kommission festgesetzte Hauptgrenzlinie angezeigt und beschrieben ist, $\mathrm{M}$ 1:175.000, 4 gez. Blätter (ÖSTA-KA-KS BIXa427).

Anonymus (um 1800): Geographische Karte der gesammten Cameral-Religions und Schulen-Fonds-Güter in der Bukovina, M 1:288.000 (ÖNB-Wien ALB Port 207.9 Kar; ACo4647282B).

ANONymus (um 1802): Geographische Karte der in der Moldau gelegenen Buccoviner Religions-Fonds-Güter (ÖSTA-HHSTA Lade V/4).

Anonymus (um 1805): Geographische Karte der gesammten Cameral-Religions und Schulen-Fonds-Güter in der Bukovina (ÖNB-Wien ALB 673.1.Kar; AC04595393B).

BodyNSKi Maximilian \& Jaroslaw MichaILowsкi (1878): Statistische Karte Galiziens und der Bukowina die allgemein politisch-administrativen, die Communications-die Bodenkultur und insbesondere die Industrieverhältnisse umfassend. Nach den neuesten officiellen Erhebungen im Jahre 1878, M 1:288.000, 10 lith. Blätter (ÖSTA-KA-KS BIX C561-10).

Rumpler Helmut \& Martin Seger (Hg.) (2010): Die Gesellschaft der Habsburgermonarchie im Kartenbild. Verwaltungs-, Sozial- und Infrastrukturen. Nach dem Zensus von 1910 (= Die Habsburgermonarchie 1848-1918 IX, Soziale Strukturen 2), Wien. 


\section{Literatur}

Alle Internetzugriffe zuletzt 10.4.2019.

A

Abrudan Mircea-Gheorghe (2015): Ortodoxie și Luteranism în Transilvania între Revoluția paşoptistă şi Marea Unire. Evoluţie istorică şi relaţii confesionale, ClujNapoca.

ADANIR Fikret (2011): Commentary. Challenging Religion's Supranational Character in a Period of International Competition. In: Leonhard \& Hirschhausen (Hg.), Empires, 385-389.

Aкademischer Senat (Hg.) (1900): Die k.k. Franz-Josephs-Universität in Czernowitz im ersten Vierteljahrhundert ihres Bestandes, Festschrift, Czernowitz.

Alex A Doina (1996): Ion Nistor. The Politician /Omul Politic. In: Codrul Cosminului 2 (1996), 275-297.

AlexA Doina (2000): Ion Nistor, dimensiunile personalităţii politice și culturale, Rădăuţi.

Alexandru Felicia (2006): Church-State Relations in Post Communist Romania. Real Deprivatization or the way back to Byzantine Symphonia. In: Journal of Political Science 2, 57-69.

Altrichter Helmut et al. (Hg.) (2006): Gegen Erinnerung. Geschichte als politisches Argument im Transformationsprozess Ost-, Ostmittel- und Südosteuropas (= Schriften des Historischen Kollegs, Kolloquien 61), München.

Alvirescu Gavril (?) (1929): Probleme Bucovinene. Discurs rostit la discuţia adresei de răspuns la Mesajul Tronului in ședința camerei deputăţilor din 22 ianuarie 1929, București.

Alvirescu Gavril (?) (1937): Urgia fiscal și Problema Fondului Bisericesc din Bucovina. Discurs rostit în ședinţele din 17 și 18 martie 1937 ale adunari deputaţilor la discuţia generală a bugetului general al statului, București.

Anderson Benedict (2005): Die Erfindung der Nation. Zur Karriere eines erfolgreichen Konzepts, Frankfurt-New York.

Anonymus (1868): Die Eisenindustrie und die Montanwerke in der Bukowina. In: Czernowitzer Zeitung Nr. 23, 24, 27, 30, 32 (1868-1869).

Anonymus (1881): Die gegenwärtige Lage des rusticalen Grundbesitzes in der Bukowina. In: Mittheilungen des Vereines für Landescultur im Herzogthume Bukowina, Nr. 1-2 (VIII. Jg.), 6-8; Nr. 3, 15-17; Nr. 4-5, $25-26$.

Anonymus (1886): Die land- und forstwirthschaftliche Ausstellung in Czernowitz im 
Jahre 1886. In: Mittheilungen des Vereines für Landescultur im Herzogthume Bukowina, Nr. 8,9 u. 10 (XIII. Jg.), 25-26; 58-80.

ANoNymus (1889): Biografia lui Constantinu Morariu Andrieviciu fostu profesoru ord. de teologia morala la institutulu teologicu din Cernauţiu scrisa la Unu adîncu stimatoriu a dînsului, Gherla.

Anonymus (1906): Beitrag zur kirchlichen Frage in der Bukowina, Czernowitz.

Anonymus (1906): Die gr.-or. Kirchenfrage in der Bukowina und die Jungruthenen.

Kritische Beleuchtung der Broschüre »Beitrag zur kirchlichen Frage in der Bukowina.

Zwei zeitgemäße Artikel vom Reichsratsabgeordneten Hierotheus Pihuliak und einem griech.-or. Ruthenischen Priester«, von einem gr.-or. rumänischen Priester, Czernowitz.

ANONYMUS (1906): Privire scurtă asupra desvoltă lor pe terenul cultural și economic de la încorporarea Bucovinei la monarhia Austro-Ungară 1775 până la 1906, Cernăuț.

ANonymus (1911): Русини а «волоска віра». Написав Руский православний панотець. Друге, доповнене виданє. 3 образками (= Видавництво полїт. тов. «Руска Рада» /3 друкариї тов. «Руска Рада», під зарядом Івана Захарка), Чернивцї.

Anonymus (1936): Was Manz einst leistete. In: Czernowitzer Deutsche Tagespost, 28.VI.1936.

ANonymus (ca. 1902): Die Entwicklung des Eisenbahnnetzes der Bukowiner Lokalbahnen, Wien.

AnONymus (2017): Romsilva a castigat definitiv un proces cu Fondul Bisericesc Ortodox Roman al Bucovinei, iar $\mathbf{1 6 6 . 8 1 3}$ hectare de fond forestier raman in proprietatea statului [http://adevarul.ro/news/eveniment/romsilva-castigat-definitiv-procesfondul-bisericesc-ortodox-roman-bucovinei-166813-hectare-fond-forestier-ramanproprietatea-statului-1_58 b3f4b75ab6550cb8dc6dd1/index.html] Publikationsdarum 27.II.2017.

ANONymus (2014): Fondul Bisericesc al Bucovinei pierde la ICCJ procesul prin care revendica 166.000 ha de pădure. [https://www.mediafax.ro/social/fondul-biseri cesc-al-bucovinei-pierde-la-iccj-procesul-prin-care-revendica-166-000-ha-de-pa dure-13658781] Publikationsdatum 27.XI.2014.

Aretin Karl Otmar Freiherr v. (1985): Der Josephinismus und das Problem des katholischen aufgeklärten Absolutismus. In: Plaschka et al. (Hg.), Österreich, 509-524.

Arhiepiscopa Sucevei şi Rădăuţilor (Hg.) (2008): Fondul Bisericesc Ortodox Român al Bucovinei, Suceava.

Arhiepiscopa Sucevei și Rădăuţilor (Hg.) (2010): Fondul Bisericesc. Documente de proprietate, fapte de refuzare și de tergiversare a retrocedării Fondului expunere pe scurt, Suceava [http://www.arhiepiscopiasucevei.ro/fondul-bisericesc2/\#more-502]. 
Asво́тн Gottfried von (1894): Die Religionsfondsherrschaft Radautz, Hg. von J. Polek, Czernowitz.

AssmanN Aleida (1999): Erinnerungsräume. Formen und Wandlungen des kulturellen Gedächtnisses, München.

Assmann Aleida ( $\left.{ }^{4} 2009 / 1991\right)$ : Erinnerungsräume. Formen und Wandlungen des kulturellen Gedächtnisses, München.

Atanasiu Mihai-Bogdan, Mircea-Cristian Ghenghea (Hg.) (2010): Pro Bucovina. Repere istorice și naţionale, București.

B

BĂLAN Teodor (1923): Suprimarea Mișcărilor Naţionale din Bucovina pe timpul Războiului Mondial 1914-1918, Cernăuţi.

BĂLAN Teodor (1932): Serbarea dela Putna 1871, Cernăuți. (Extr. din vol. Șaptezeci de ani dela infiinţarea societaţii pentru cultura şi literature română in Bucovina, 18621932).

BĂLAN Teodor (2002): Din arhiva istoricului Teodor Bălan. Conflictul pentru Tricolor. Un capitol din istoria politică a Bucovinei 1898-1904. In: Glasul Bucovinei 3-4/2002, 121-153.

BĂNICĂ Mirel (2007): Biserica Ortodoxă Româ, stat și societate în anii '30, București.

BARBU Daniel \& Cristian PREDA (2006): Building the State from the Roof Down. Varieties of Romanian Liberal Nationalism. In: Iván Zoltán Dénes (Hg.), Liberty and the search for Identity. Liberal Nationalisms and the Legacy of Empires, 367-397.

Barton Peter F. (Hg.) (1981): Im Zeichen der Toleranz. Aufsätze zur Toleranzgesetzgebung des 18. Jahrhunderts in den Reichen Joseph II., ihren Voraussetzungen und ihren Folgen (= Studien und Texte zur Kirchengeschichte und Geschichte, Zweite Reihe, Band VIII), Wien.

BARWINSKYJ Alexander (1915): Österreich-Ungarn und das ukrainische Problem. Beiträge zur politischen Lage, München.

BECK Erich (1963): Bukowina. Land zwischen Orient und Okzident, Freilassing.

BEIDTEL Ignaz (1849): Untersuchungen über die kirchlichen Zustände in den kais. österr. Staaten, die Art ihrer Entstehung und die in Ansehung dieser Zustände wünschenswerten Reformen, Wien.

Beidtel Ignaz (1896/98): Geschichte der österreichischen Staatsverwaltung 17101848 , Innsbruck.

BEJAN Dionisie (1906): Români din Bucovina, Cernăuţi.

Bejinaru Petru (2004): Familia Isopescu in mișcarea naţionala din Bucovina (= Enciclopedia Bucovinei în Studii şi Monografii 11), Rădăuţi. 
BÉLAND Daniel \& Robert H. Cox (2011): Introduction - Ideas and Politics. In: dies. (Hg.), Ideas and Politics in Social Science Research, Oxford-New York, 1-27.

BÉLAND Daniel (2009): Ideas, Institutions, and policy change. In: Journal of European Public Policy 16/5, 701-718.

Beller Steven (2001): Kraus's Firework. State Consciousness raising in the 1908 Jubilee Parade in Vienna and the Problem of Austrian Identity. In: Maria Bucur \& Nancy M. Wingfield (Hg.), Staging, 46-71.

BenEdiKt Ernst M. (1947): Kaiser Joseph II. 1741-1790. Mit Benützung ungedruckter Quellen, Wien.

Bendel Rainer \& Norbert Spannenberger (Hg.) (2015): Katholische Aufklärung und Josephinismus. Rezeptionsformen in Ostmittel- und Südosteuropa (= Forschungen zur Kirchen- und Kulturgeschichte Ostdeutschlands 48), Köln-Weimar-Wien.

BEREND Iván T. \& György RÁ KKI (1985): Ungarn, Rumänien, Bulgarien, Serbien und Montenegro 1850-1914. In: Wolfram Fischer (Hg.), Europäische Wirtschafts- und Sozialgeschichte von der Mitte des 19. Jh. bis zum I. Weltkrieg (= Handbücher der europäischen Wirtschafts- und Sozialgeschichte 5), Stuttgart.

BERGER Johannes (1996): Was behauptet die Modernisierungstheorie wirklich und was wird ihr nur unterstellt? In: Leviathan 1, 45-62.

Berger Johannes (Hg.) (1986): Die Moderne. Kontinuitäten und Zäsuren (= Soziale Welt, Sonderband 4), Göttingen.

Berger Johannes (Hg.) (1986): Die Moderne. Kontinuitäten und Zäsuren, Göttingen.

Berindei Dan et al. (Hg.) (1973): Der Bauer Mittel- und Osteuropas im sozioökonomischen Wandel des 18 . und 19. Jahrhunderts. Beiträge zu seiner Lage und deren Widerspiegelung in der zeitgenössischen Publizistik und Literatur, Wien.

Bernhauer Elfriede (1989): Kirche und Josephinismus in Tirol, Dissertation Universität Innsbruck, 2 Bände, Innsbruck.

BERNSDORF Wilhelm (Hg.) (1969): Wörterbuch der Soziologie, Stuttgart.

Beust Constantin Freiherr von (1873): Die Montanwerke des griech.-orient. Religionsfonds in der Bukowina. In: Mittheilungen des k.k. Ackerbau-Ministeriums 3/11, Wien, $17 f$.

BIDERMANN Hermann Ignaz ( $\left.{ }^{2} 1876\right)$ : Die Bukowina unter österreichischer Verwaltung 1775-1875, Lemberg.

Biнl Wolfdieter et al. (1985): Czernowitz im Ersten Weltkrieg. Aus dem Tagebuche des k.k. Landgerichtsrates Dr. Alfons Regius. In: Österreichische Osthefte 27/2, 115-213. Biнl Wolfdieter (1980): Die Ruthenen. In: Helmut Rumpler \& Peter Urbanitsch (Hg.), Die Habsburgermonarchie 1848-1918 III/1, Die Völker des Reiches, Wien, 555-584. Binder Beate, Wolfgang Kaschuba \& Peter Niedermüller (Hg.) (2001): Inszenie- 
rungen des Nationalen. Geschichte, Kultur und die Politik der Identitäten am Ende des 20. Jahrhunderts (= Alltag \& Kultur 7), Berlin.

BINDER Dieter (1999): Religionsfonds. In: Walter Kasper (Hg.), Lexikon für Theologie und Kirche, Freiburg u.a., Band 8, Spalte 1049.

Bıroul de presă al Arhiepiscopiei Sucevei şi Rădăuţilor (Hg.) (2017): Comunicat de presă - Arhiepiscopia Sucevei și Rădăuţilor, Suceava, [https://www.agerpres.ro/co municate/2017/02/28/comunicat-de-presa-arhiepiscopia-sucevei-si-radautilor18-11-28] Publikationsdatum 28.II.2017.

Bit TNER Ludwig (Hg.) (1937): Inventare österreichischer staatlicher Archive, V. Inventare des Wiener Haus-, Hof- und Staatsarchivs 5. Gesamtinventar des Wiener HHSTA 2. Band, Wien.

BLÄNKNER Reinhard \& Bernhard Jussen (Hg.) (1998): Institutionen und Ereignis. Über historische Praktiken und Vorstellungen gesellschaftlichen Ordnens, Göttingen.

BLÄNKNER Reinhard (1994): Überlegungen zum Verhältnis von Geschichtswissenschaft und Theorie politischer Institutionen. In: Göhler (Hg.), Eigenart, 85-122.

Blessing Werner K. (1982): Staat und Kirche in der Gesellschaft (= Kritische Studien zur Geschichtswissenschaft 51), Göttingen.

BLUM Jerome (1948): Noble Landowners and agriculture in Austria 1815-1848. A study in the origins of peasant emancipation of 1848 (= John Hopkins University Studies in historical an political science 65/2), Baltimore.

Bocşan Nicolae et al. (Hg.) (2005): Andrei Şaguna. Corespondenţa I/1, Cluj-Napoca.

Bodna riuc Dumitru et al. (1980): Suceava (= Județele Patriei), București.

Böнм August (1897): „Durch die Bukowina«. Eine Reiseskizze zur Excursion des österreichischen Reichsforstvereines in der Bukowina im Juni 1897, Czernowitz. Die Bukowina - Vergangenheit und Gegenwart. Eine Veröffentlichung des Österreichischen Ost- und Südosteuropa-Instituts

Bois Lucian (2014): Primul Război Mondial. Controverse, paradoxuri, reinterpretări, București.

Bojor Ion et al. (1979): Suceava. Ghid turistic al Judeţului, București.

BojNicic Ivan v. (1985) : Der Adel von Galizien, Lodomerien und der Bukowina (begonnen von Friedrich Heyer von Rosenfeld, fortgesetzt und beendet von Ivan Bojnicic), Neustadt a.d. Aisch.

Boldt Hans (2003): Otto Brunner und die deutsche Verfassungsgeschichte. In: KarlEgon Löhne (Hg.), Historismus in den Kulturwissenschaften, Tübingen, 193-206.

Bolovan Ioan (2000): Transilvania între Revoluţia de la 1848 şi Unirea din 1918 (= Bibliotheca Rerum Transsylvanae XXV), Cluj-Napoca.

BoRNHOLDT Andreas (1986): Modernisierung und Integration in den östlichen Rand- 
gebieten (Provinzen) Österreichs und Preußens (1772-1809), Dissertation Universität Bochum, Bochum.

Botuschans'кy ј Ботушаньский B. M. et al. (Hg.) (1998): Буковина. Історичний нарис, Чернівці.

Botuschans'кy Ботушанський В. М. \& О. В. (2002): Розвиток сільської кооперації на Буковині у 80-х рр. XIX - на початку XX ст., Чернівці.

Botuschans'кү Ботушанський В. М. (2000) : Сільське господарство Буковини (друга половина XIX - поч. XX ст.), Чернівці.

Botuschans'ку Ботушанський B. M. et al. (2005): Буковина в контексті європейських міжнародних відносин (з давніх часів до середини ХХ ст.), Чернівці.

BotuSCHANS'кY - Ботушанський Василь (2011): Православний реліїгний фонд Буковини (1786-1918рр.). Соціально-економічнй аспект. In: Кафедра історії україни питання історіі україни. Збірник наукових прац 14, Чернівці.

BRĂTIANU Ion I. C. (1928): Unirea Bucovinei 28 Noemvrie 1918. Studiu și documente de Ion Nistor, București.

Brega Petru (1995): Structura Proprietăţii Fondului Forestier din Judeţul Suceava înainte de anul 1948 şi starea arboretelor ca urmar a modului diferit de gospodărire. In: Bucovina Forestieră Anul III (2), 1-8.

BRUCKMÜLLER Ernst (1977): Landwirtschaftliche Organisationen und gesellschaftliche Modernisierung (= Geschichte und Sozialkunde 1), Salzburg.

BRUCKмÜLLER Ernst (2002/2003): Geschichte der österreichischen Land- und Forstwirtschaft im 20. Jahrhundert, 2 Bände, Wien.

BRUCKMÜlLER Ernst (2010): Bäuerliche Mobilisierung und nationale Frage in der Habsburgermonarchie. Zur Genese und Struktur von politischen Organisationen der Bauern. In: Schultz/Harre (Hg.), Bauerngesellschaften, 71-86.

BRUCKMÜLleR Ernst (2010): Landwirtschaftliche Arbeitswelten und ländliche Sozialstrukturen. In: Helmut Rumpler \& Peter Urbanitsch (Hg.), Von der feudal-argrarischen zur bürgerlich-industriellen Gesellschaft. Lebens- und Arbeitswelten in der industriellen Revolution (= Die Habsburgermonarchie 1848-1918 IX, Soziale Strukturen 1/1), Wien, 251-322.

Bruckmüller Ernst, Ernst Langthaler \& Josef Redl (Hg.) (2004): Agrargeschichte schreiben. Traditionen und Innovationen im internationalen Vergleich (= Jahrbuch der Geschichte des ländlichen Raumes 2004), Innsbruck u.a.

BRÜNING Alfons (2003) : Orthodoxie als Element ukrainischer nationaler Identität. In: Thomas Bremer (Hg.), Religion und Nation. Die Situation der Kirchen in der Ukraine (=Schriften zur Geistesgeschichte des östlichen Europas 27), Wiesbaden, 11-23.

Brunner Otto (1922): Österreich und Walachei während des Türkenkrieges 16831699, Wien(?). 
BRUNNER Otto ( $\left.{ }^{4} 1959\right)$ : Land und Herrschaft. Grundfragen der territorialen Verfassungsgeschichte Österreichs im Mittelalter, Wien.

Brunner Otto ( $\left.{ }^{2} 1968\right)$ : Neue Wege der Verfassungs- und Sozialgeschichte, Göttingen.

BRUnNer Sebastian (1874): Joseph II. Charakteristik seines Lebens, seiner Regierung und seiner Kirchenreform, mit Benutzung archivalischer Quellen, Freiburg i. B.

Brunsson Nils (1989): The Organization of Hypocrisy. Talk, Decisions, and Actions in Organizations, John Wiley \& Sons Inc.

Brusanowski Paul (2006) : Polemica dintre episcopii Hacman și Şaguna cu privire la organizarea cononică a Bisericii Ortodoxe din Imperiul austriac. In: Revista Teologică 88 N.F. 16, Nr. 4, 91-129.

Brusanowski Paul (2007): Reforma Constituţională din Biserica Ortodoxă a Transilvaniei între 1850-1925, Cluj.

Brusanowski Paul (2010): Autonomia și constituționalismul în dezbaterile privind unificarea Bisericii Ortodoxe Române (1919-1925), Cluj.

BRUsat Ti Alois (1958): Die Staatsgüterveräußerungen in der Zeit von 1780-1848. Eine wirtschaftsgeschichtliche Untersuchung zum Problem des österreichischen Liberalismus. In: Mitteilungen des Österreichischen Staatsarchivs 11, 252-274.

Bucur Maria \& Nancy M. Wingfield (Hg.) (2001): Staging the Past. The Politics of Commemoration in Habsburg Central Europe, 1848 to the Present, West LafayetteIndiana.

Bucur Maria (2001): Birth of a Nation. Commemoration of December 1, 1918 and National Identity in Twentieth-Century Romania. In: Bucur \& Wingfield (Hg.), Past, 286-328.

BuD Alexandru-Bogdan (2015): Limitele loialităţii dinastice. Iosif al II-lea și românii din Transilvania în epoca Modernă, Cluj-Napoca.

Bude Heinz (2003): Das Altern von Institutionen. In: Joachim Fischer \& Hans Joas (Hg.), Kunst, Macht und Institution. Karl-Siegbert Rehberg zum 6o. Geburtstag, Frankfurt a. Main-New York, 221-230.

BüHL Walter L. ( $\left.{ }^{4} 2007\right)$ : Schlagwort `Institution`. In: Lexikon zur Soziologie, Wiesbaden, 299.

Buкowez - Буковец Инна А. (1978): Антинародная деятельность правослвной церкви в северной Буковине и борба прогрессивных сыл края против социально-экономического и политического гнета духовенства 1774-1918 (Автореферат), Львов.

BULGARU Valeriu (2003/1968): Reforma agrară din 1921 fundemente economice, Timișoara.

Büsch Otto \& Michael Erbe (Hg.) (1983): Otto Hinze und die moderne Geschichts- 
wissenschaft. Ein Tagungsbericht (= Einzelveröffentlichungen der Historischen Kommission zu Berlin 38), Berlin.

Buszко Józef (1978): Zum Wandel der Gesellschaftsstruktur in Galizien und in der Bukowina (= ÖAW, phil.-hist. Klasse, Sitzungsberichte 343), Wien.

Busz ко Józef (1984): Die inneren Verhältnisse in Galizien und in der Bukowina. In: Harry Kühnel (Red.), Das Zeitalter Kaiser Franz Josephs I. 1848-1880, Band 2 (= Von der Revolution zur Gründerzeit 1848-1880, Ausstellung Schloss Grafenegg 19.V. bis 28.X.1984), Wien, 282-286.

Buszко Józef (1985): Theresianisch-josephinische Agrar- und Bauernpolitik in Galizien und ihre Folgen. In: Richard G. Plaschka (Hg.), Österreich im Europa der Aufklärung. Kontinuität und Zäsur in Europa zur Zeit Maria Theresias und Josephs II. (= Internationales Symposium in Wien 20.-23.X.1980, Band 1), Wien, 67-86.

\section{C}

CÂndeA Romulus (1909): Românii și rutenii în Biserica gr.or. din Bucovina. În: Revista Teologica III/2, o.S.

CÂNDEA Romulus (1924): Mitropolitul Vladimir Repta, Cernăuți.

CAPoccia Giovanni \& Daniel Ziblatt (2010): The Historical Turn in Democratization Studies. A New Research Agenda for Europe and Beyond. In: Comparative Political Studies 43, 931-968.

CĂPREANU Ioan (1995): Bucovina, istorie și cultura româneasca 1775-1918, Iaşi.

CĂRUNTU Mihai-Aurel (2004): Bucovina în al doilea război mondial, Iaşi.

CATARgi Georg v. (Hg.) (1899): Die Bukowina, eine allgemeine Heimatkunde verfasst anläßlich des 5ojährigen Regierungsjubiläums d. k.k. Gendarmerie des Landes-Gendarmerie-Commandos Nr. 13, Czernowitz (zweisprachige Neuauflage 2004 Чернівці).

Cenuușu Mihai-Ştefan (1982): Documente. Contribuţii la istoricul exploatării sari la sfârșitul secolului al XVIII-lea și în prima jumătate a secolului al XIX-lea în Bucovina. In: Anuarul Muzeului Județean (Suceava) IX, 377-392.

CEAUșu Mihai-Ștefan (1993): Aspecte juridice ale instituirii administraţiei habsburgice în Bucovina. In: Anuarul Institutului de Istorie A.D. Xenopol 30, 397-402.

Ceaușu Mihai-Ștefan (1995): Vasile Balş - un iosefinist bucovinean. In: Nicolae Bocşan, Nicolae Edroiu \& Pompiliu Teodor (Hg.), Dr. Prodan. Puterea modelului, Cluj-Napoca, 132-142.

Ceaușu Mihai-Ștefan (1996): Politica iosefinistă de reformare a bisericii ortodoxe din Bucovina. In: Anuarul Institutului de Istorie A.D. Xenopol 33, 147-158.

Ceaușu Mihai-Ştefan (1998): Bucovina habsburgica de la anexare la Congresul de la Viena. Iosefinism și postiosefinism 1774-1815 (= Biblioteca istorica 4), Iaşi. 
Céauşu Mihai-Ştefan (1998): Bucovina Habsburgică. De la Anexare la Congresul de la Viena, Iași.

Ceaușu Mihai-Ștefan (2000): Der Landtag der Bukowina. In: Helmut Rumpler \& Peter Urbanitsch (Hg.), Die Habsburgermonarchie 1848-1918 VII/2, Verfassung und Parlamentarismus, Wien, 2171-2198.

CeAușu Mihai-Ștefan (2004): Parlamentarism, partide și elită politica in Bucovina habsburgica. Contribuţii la istoria parlamentarismului în spaţiul central-est european, Iași.

CeAuşu Mihai-Ştefan (2008): Die josephinischen Reformen in der Bukowina. In: Schmale et al. (Hg.), Josephinismus, 55-64.

Ceauşu Mihai-Ştefan (2008): Un iluminist Bucovinean Boierul Vasile Balş (17561832), Iaşi.

Ceredarec Nicolae (1983): Exploatarea minelor de cupru de la Fundu Moldovei în timpul stăpînirii austriece (1805-1918). In: Anuarul Muzeului Județean (Suceava) $10,853-856$.

Cerman Markus (2004): Agrardualismus in Europa? Geschichtsschreibung über Gutsherrschaft und ländliche Gesellschaft in Mittel- und Osteuropa. In: Bruckmüller et al. (Hg.), Agrargeschichte, 12-29.

Chioveanu Mihai (2010): Istorici și politica în România interbelică. In: Ovidiu Pecican (Hg.), România interbelică. Istorie şi istoriografie, Cluj-Napoca, 141-162.

CLARK Roland (2012): Nationalism and Orthodoxy. Nichifor Crainic and the political culture of the extreme right in 1930 Romania. In: Nationalities Papers 40/1 (Jan.), 107-126.

CLARK Roland (2012): Orthodoxy and nation-building. Nichifor Crainic and religious nationalism in 1920s Romania. In: Nationalities Papers 40/4 (July), 525-543.

Сiobanu Petre (1993): Fundul Bisericesc Ortodox Român din Bucovina (1783-1948). Prezentare Generală. În: Bucovina Forestieră I/1-2, 5-17.

CLIPA Sorin-Toader (2006): Fondul bisericesc al Bucovinei şi lichidarea lui (19481949), Suceava.

CocA Calistrat (1891): Istoria Bisericeasca pentru clasele superioarale şcoalelor scundare şi alte institute mai înalte de cultură, Cernăuţi.

Cocuz Ioan (2003): Partidele politice româneşti din Bucovina 1862-1914, Suceava.

Cohen Gary B. (1998): Neither Absolutism nor Anarchy. New Narratives on Society and Government in Late Imperial Austria. In: Austrian History Yearbook XXIX/1, 37-61.

Cojocaru Alexie (2010): Două Fotografii-Document din Arhiva Mănăstirii Putna. În: Atanasiu \& Ghenghea (Hg.), Bucovina, 195-199. 
Corbea-Hoişı́ Andrei (1994): La Culture juive germanophone de Bucovine et de Czernowitz. In: Revue Germanique Internationale 1 (1994), 165-181.

Corbea-Hoișie Andrei (1996): Urbane Kohabitation in Czernowitz als Modell einer gespannten Multikulturalität. In: Neohelicon XXIII/1, 77-93.

CorbeA-Hoişı́ Andrei (2005): Czernowitz 1892. Die snationale' Wende in der Bukowiner Innenpolitik aus Wiener Sicht. In: Maner (Hg.), Grenzregionen, 89-101.

Corbea-Hoișie Andrei (2010): Czernowitz 1892. Die imagologische Projektion einer Epochenschwelle. In: Wladimir Fischer et al. (Hg.), Räume und Grenzen in Österreich-Ungarn 1867-1918. Kulturwissenschaftliche Annäherungen (= Kultur-Herrschaft-Differenz 11, Hg. v. Moritz Csáky et al.), 35-46.

Corbea-Hoișie Andrei (2012): „Wie die Juden Gewalt schreien«: Aurel Onciul und die antisemitische Wende in der Bukowiner Öffentlichkeit nach 1907. In: East Central Europe 39, 1-48.

Corbea-Hoișıe Andrei, Ion Lihaciu \& Markus Winkler (Hg.) (2012): Prolegomene la un dicţionar al presei de limbă Germană din Bucovina istorica (1848-1940), Iaşi.

Cosgrove Denis \& Stephen Daniels (2002): The iconography of landscape (= Cambridge Studies in Historical Geography 9), Cambridge.

Constantinescu Gheorghe (1939): Averile Bisericești din Bucovina (Hg. Mitropolia Bucovinei, Administraţia Fondului Bisericesc, Editura Mitropoliei Bucovinei), CERnăuţi.

CotLARCIUC Nectarie (1932): Împumutul fondului bisericesc al Bucovinei (Cuvântare Rostiţă in Şedinţa dela 10 Octomvrie 1932 a Senatului), București.

Cotlarciuc Nico (1904): Ceva despre reforma patronatului bisericei din Bucovina, Cernăuţi.

Cotla RCIUC Nico (1907): Stifterrecht und Kirchenpatronat im Fürstentum Moldau und in der Bukowina. Eine historisch-dogmatische Studie zum morgenländischen Kirchenrecht (= Kirchenrechtliche Abhandlungen 47), Stuttgart, Nachdruck 1965.

Covalcruc Dumitru (2013): Consemnaţiile din 1784 şi 1785 ale clerului bucovinean. In: Ţara Fagilor, Almanah Cultural-Literar XXI-XXII (2012/13), Cernăuţi-Târgu Mureş, 18-40.

CsÁ KY Moritz (2013) : Einführende Überlegungen. Moderne-Peripherie-Mehrdeutigkeiten. In: Elisabeth Haid et al. (Hg.), Galizien. Peripherie der Moderne - Moderne der Peripherie (= Tagungen zur Ostmitteleuropaforschung 31), Marburg, 11-30.

Čučко Чучко Михаил К. (2014): Православная церковь на Буковине во время первой мировой войны (I). In: Русин № 3 (37), 85-108; (II) № 4 (38), 7-29.

Čučко Чучко Михайло К. (2015): У горнилі випробувань: Православна Церква на Буковині в 1914-1919 pр, Чернівці. 
Czada Roland (1995): Institutionelle Theorien in der Politik. In: Dieter Nohlen et al. (Hg.), Lexikon der Politik I, München, 205-213.

Czech Franz (1931): Rezumat asupra gospodăriei silvice în pădurile Fondului bisericesc ort. rom. al Bucovinei. In: Codrii Bucovinei I/7-9, 10-26.

D

DAN Demeter (1899): Die Lippowaner. In: Österreich-Ungarn in Wort und Bild, Band Bukowina, Wien, 282-295

DAN Dimitri (1908): Împăratul nostru Francisc Iosif I (1848-1908). Scriere festivă pentru tinerimea școlară, Editura fondului religionar greco-oriental al Bucovinei, Viena.

DAN Dimitrie (1925): Rolul preotimei Bucovinene în mentionierea românismului dela robirea (1775) la desrobirea Bucovinei (15.11.1918). Un adaos la istoria bisericii române, Cernăuţi.

DAN Dimitru (1919): Fondul religionar gr.or. din Bucovina. Deslușire istorica pentru poporul român. Suplement la `Gazeta Ţăranului<, Cernăuţi.

DAszkiewicz Silvester (1892): Die Lage der gr.-or. Ruthenen in der Bukowinaer Erzdiözese, Czernowitz.

DAuss Markus \& Karl-Siegbert Rehberg (2009): Gebaute Raumsymbolik. Die Architektur der Gesellschaft aus Sicht der Institutionenanalyse. In: Fischer \& Delitz (Hg.), Architektur, 109-119.

Denarowski Calr (1868): Die Mineralquellen in Dorna-Watra und Pojana-Negri in der Bukowina (Braumüller's Badebibliothek), Wien.

Deletant Dennis (2004): România sub regimul comunist (Decembrie 1947 - Decembrie 1989). In: Mihai Bărbulescu et al., Istoria României, Bucureşti, 407-481.

Denesczuk Wolodemar (1972): Rechtliche Stellung der Ukrainer (Ruthenen) in der Bukowina von 1774-1918, Dissertation Universität Innsbruck, Innsbruck.

Dickson Peter G.M. (1993): Joseph II's Reshaping of the Austrian Church. In: The Historical Journal 36/1, 89-114.

Dimıtrovici Silviu (1922): Istoricul și organizarea Pădurilor Fondului Bisericesc Ortodox-Român din Bucovina, Cernăuţi.

Dimitrovici Silviu (1932): Paşcovici Nicolae. Memoriu. In: Codrii Bucovinei II/Ian., 13-25.

Dimitrovici Silviu (1934): Baile din Vatra-Dornei, Puciosu-Iacobeni și Dorna Candrenilor. Situaţia lor actuală și noui propuneri pentru o mai-bună valorificare în viitor. În: Codrii Bucovinei IV, 33-40.

Dinklage Karl (1973): Die landwirtschaftliche Entwicklung. In: Adam Wandruszka \& Peter Urbanitsch (Hg.), Die Habsburgermonarchie 1848-1918 I, Die wirtschaftliche Entwicklung (Hg. v. Alois Brusatti), Wien, 403-461. 
DiPPER Christof (1987): Otto Brunner aus der Sicht der frühneuzeitlichen Historiographie. In: Annali dell'Istituto storico italo-germanico in Trento 13, 73-96.

Dовоş Filaret (1928): Zeci ani de viața agricolă în Bucovina. In: Ioan Nistor (Hg.), Zeci ani, 151-177.

DoBRINCU Dorin \& Constantin Iordachi (Hg.) (2005): Ţărănimea și puterea. Procesul de colectivizare a agriculturii în România (1949-1962), București.

DoвRŽANs'кYJ Добржанський, О. (1999): Національний рух українців Буковини другої половини 19 - початку 20 ст, Чернівці.

DовRŽANs'KY Oleksandr (2000): Czernowitz und die Ukrainer. In: Harald Heppner (Hg.), Czernowitz. Die Geschichte einer ungewöhnlichen Stadt, 45-61.

Dordet T Alexander (1916): Die Ordnung zwischen Kirche und Staat. Ein historischsystematischer Grundriß, Innsbruck.

Döring Jörg \& Tristan Thielmann (Hg.) (2008): Spatial Turn. Das Raumparadigma in den Kultur- und Sozialwissenschaften, Bielefeld.

Droвesch Werner (2003): Grundherrschaft und Bauer auf dem Weg zur Grundentlastung. Die >Agrarrevolution ` in den innerösterreichischen Ländern (= Aus Forschung und Kunst 35), Klagenfurt.

Droвеsch Werner (2006): Vereine und Interessensverbände auf überregionaler (cisleithanischer) Ebene. In: Helmut Rumpler \& Peter Urbanitsch (Hg.), Die Habsburgermonarchie 1848-1918 VIII, Politische Öffentlichkeit und Zivilgesellschaft, Wien, 1029-1132.

Droвesch Werner et al. (Hg.)(2007): Mensch, Staat und Kirchen. Zwischen Alpen und Adria 1848-1938, Wien u.a.

Droвеsсн Werner (2013): Mitteleuropäische Agrarverfassung(en), Agrarrevolution und Industrielle Revolution. In: ders. (Hg.), Kärnten am Übergang von der Agrarzur Industriegesellschaft. Fallstudien zur Lage und Leistung der Landwirtschaft auf der Datengrundlage des Franziszeischen Katasters (1823-1844), Klagenfurt, 15-19.

Drunen van Jeroen (2015): 'A Sanguine Bunch،. Regional Identification in Habsburg Bukovina 1774-1919 (= Pegasus Oost-Europese Studies 24), Amsterdam.

Dumbrava Vasile (2006): Warum Geschichte immer wieder neu betrachtet werden muß. Die Republik Moldova und der Umgang mit der Vergangenheit. In: Altrichter et al. (Hg.), Erinnerung, 261-275.

Durandin Catherine (1998): Istoria Românilor (= Colecţia Oglinzi Paralele 4), Iași.

Durкнеiм Emile (1992/1930): Über soziale Arbeitsteilung. Studie über die Organisation höherer Gesellschaften, Frankfurt a. M.

Dutcza K Basil (1910): Die Gestaltung der Gutsterritorien in der Bukowina. Eine gemeinderechtliche Abhandlung, Czernowitz. 
DutCzAK Basil (1912): Über den Geschäftsführungsanspruch des Bukowiner gr.-or. Religionsfondes. Eine gemeinderechtliche Erörterung, Czernowitz.

Duţu Alexandru (1993): Der Josephinismus. Zivilisatorischer Prozeß und rumänische kulturelle Tradition. In: Reinalter (Hg.) (1993), Josephinismus, 121-135.

E

EсоNомU Radu (2011): Unirea Bucovinei 1918, Cernăuţi.

ELlis Steven (2002): Empires and States in European Perspective (= Clioh's Workshop II/VI), Pisa.

Eminescu Mihai (1996): La Bucovina, Suceava.

EngeL-Janosi Friedrich (1967): The Church and the Nationalities in the Habsburg Monarchy. In: Austrian History Yearbook III/3, 67-82.

EndRes Max (1905/1922): Handbuch der Forstpolitik mit besonderer Berücksichtigung der Gesetzgebung und Statistik, Berlin.

\section{$\mathrm{F}$}

FEJTö François (1956): Joseph II. Kaiser und Revolutionär, Stuttgart.

Fellner Thomas, Heinrich Kretschmayr \& Friedrich Walter (1907-1970): Die österreichische Zentralverwaltung, 2. Abteilung, Von der Vereinigung der österreichischen und böhmischen Hofkanzlei bis zur Errichtung der Ministerialverfassung (1749-1848); 3. Abteilung, Von der Märzrevolution 1848 bis zur Dezemberverfassung 1867 , Wien.

Ficker Adolf \& Alois Alth (1853): Bericht über eine im Sommer 1852 durch die Vereinsmitglieder Dr. Ficker und Dr. Alth unternommene wissenschaftliche Reise durch die Bukowina. In: Mittheilungen des Vereins für Landescultur und Landeskunde im Herzogthume Bukowina 1, 76-96.

Fillafer Franz Leander \& Thomas Wallnig (Hg.) (2016): Josephinismus zwischen den Regimen. Eduard Winter, Fritz Valjavec und die zentraleuropäischen Historiographien im 20. Jahrhundert (= Schriftenreihe der Österreichischen Gesellschaft zur Erforschung des 18. Jahrhunderts 17), Wien-Köln-Weimar.

Fillafer Franz Leander (2016): Das Elend der Kategorien. Aufklärung und Josephinismus in der zentraleuropäischen Historiographie 1918-1945. In: Fillafer \& Wallnig (Hg.), Josephinismus, 51-101.

Fischer Eduard (1935): Krieg ohne Heer. Meine Verteidigung der Bukowina gegen die Russen, Wien.

Fischer Joachim \& Heike Delitz (Hg.) (2009): Die Architektur der Gesellschaft, Bielefeld. 
FLORIN Abraham (2009): Colectivizarea agriculturii în România. Un process de transformare societală. In: Arhivele Totalitarismului 3-4, 151-164.

FLÜGEL Axel (1996): Chancen der Regionalgeschichte. In: Edwin Dillmann (Hg.), Regionales Prisma der Vergangenheit. Perspektiven der modernen Regionalgeschichte (Saarlandbibliothek 11), St. Ingbert, 25-46.

FoDor Ligia-Maria (2014): Învățămâtul secundar în Bucovina (1861-1918), București.

Franz Hermann (1908): Studien zur kirchlichen Reform Joseph II., mit besonderer Berücksichtigung des vorderösterreichischen Breisgaus, Freiburg i. B.

\section{G}

GAFIŢA Vlad (2003): Aspecte ale activităţii politice a lui Iancu Flondor (a doua jumătate a secolului al XIX-lea și inceputul secolului al XX-lea). In: Codrul Cosminului 8-9 (2002/03), 53-76.

GAFIŢA Vlad (2004): Consideraţii privind attitudenea lui Iancu Flondor faţă de clasele sociale din Bucovina (sfârşitul secolului al XIX-lea și începutul secolului al XX-lea). In: Codrul Cosminului X (2004), 225-230.

Gafiţa Vlad (2008): Les Débuts de l’Activité Politique de Iancu Flondor au service du Movement National des Roumains de la Bucovine. In: Codrul Cosminului 12 (2008), 133-156.

GAfu Cristina \& Mihaela Nubert-CheţAN (2009): The institutions within the IstroRomanian Community (Croatia) and their role in the process of moulding collective identity. În: Buletinul Universităţii Petrol-Gaze din Ploiești LXI/2, 109-112.

GĂInA Vasile (1907): Arhiepiscopul și Mitropolitul Dr. Silvestru Morariu-Andrievici. Schiţa biografică, Cernăuţi.

GÂRBU Ştefan (1931): Originea și istoricul Fondului Bis., ort. rom. al Bucovinei. În: Codrii Bucovinei I/7-9, 5-10.

GÂRBU Ştefan (1936): Problemă Reorganizării administraţiei Fondului Bisericesc ort. Rom din Bucovina. În: Codrii Bucovinei Anul V-VI (1935/36), 1-16.

GidDENS Anthony (1988): Die Konstitution der Gesellschaft. Grundzüge einer Theorie der Strukturierung, Frankfurt a. M.

Giordano Christian (2003): Interpendente Vielfalt. Die historischen Regionen Europas. In: Wieser Enzyklopädie des Europäischen Ostens 11, Europa und die Grenzen im Kopf, Klagenfurt, 113-135.

Goehlert J. Vinc. (1863): Die Lipowaner (sic!) in der Bukowina. In: Sitzungsbericht XLI der Akademie in Wien, phil.-hist. Classe (41), Februarheft, 478-488.

Göderle Wolfgang (2016): Zensus und Ethnizität. Zur Herstellung von Wissen über soziale Wirklichkeiten im Habsburgerreich zwischen 1848 und 1910, Göttingen.

GöHLER Gerhard (1994): Politische Institutionen und ihr Kontext. Begriffliche und 
konzeptionelle Überlegungen zur Theorie politischer Institutionen. In: Göhler (Hg.), Eigenart 19-46.

GöHLER Gerhard (Hg.) (1994): Die Eigenart der Institutionen. Zum Profil politischer Institutionentheorie, Baden-Baden.

GöHLER Gerhard (Hg.) (1997): Institutionenwandel, Leviathan-Sonderheft 16, Opladen.

Good David F. (1986): Der wirtschaftliche Aufstieg des Habsburgerreiches 1750-1914 (= Forschungen zur Geschichte des Donauraumes 7), Wien.

Gözsy Zoltán (2014): Konsolidierung der Kircheninstitution in Südtransdanubien nach der Osmanenzeit. In: Norbert Spannenberger \& Szabolcs Varga (Hg.), Ein Raum im Wandel. Die osmanisch-habsburgische Grenzregion vom 16. bis zum 18. Jahrhundert, Stuttgart, 197-213.

Grigorovici Radu (Hg.) (1998): Bucovina în primele descrieri geografice, istorice, economice și demografice. Ediţie bilinguă îngrijită, cu introduceri, postfețe, note și comentarii, prefaţă de D. Vatamaniuc (= Encyclopedia Bucovinei în studii și Monografii 2), București.

Gross Karl $\left({ }^{8} 1922 / 1894\right)$ : Lehrbuch des katholischen Kirchenrechts, Wien.

GrÜNBERG Karl (1899): Die Grundentlastung. In: Kast et al. (Hg.), Geschichte 1/1, Wien, 1-80.

GRÜNBERG Karl (1901): Studien zur österreichischen Agrargeschichte, Leipzig.

GUTTENBERg Adolf (1897): Bericht über die Exkursion des Reichsforstvereins und die 42. Wanderversammlung desselben in Czernowitz, Wien. In: Österreichische Vierteljahresschrift für Forstwesen N.F. XV. (ganze Folge XLVII), Wien, 246-323.

GutTenberg Adolf (1897/2001): Raport asupra excursiei Asociaţiei Silviculturiolor din Austria în Bucovina și a 41-a adunare generală, ținută la Cernăuți (13-21 iunie 1897). In: Bucovina Forestieră IX/1-2, 54-74.

GutTenberg Adolf (1902): Die Holzpreise in Österreich in den Jahren 1848-1898, Wien.

GuZMAN Eugen (1901): Die Forstwirtschaft und ihre Industrien. In: Kast et al. (Hg.) (1901), Geschichte, 81-232.

$\mathrm{H}$

HaAs Hanns \& Ewald Liebl (2007): Politik vor Ort. Sinngebung in ländlichen und kleinstädtischen Lebenswelten. In: dies. (Hg.), Politik vor Ort (= Jahrbuch f. d. Geschichte des ländlichen Raumes 4), 9-30.

HAAs Hanns \& Peter MäHNER (2000): Ethnikum und Nation in der dörflichen Lebenswelt des deutsch-tschechischen Dorfes Baumöl/Podmoli. In: Zeitschrift für Kultur- 
und Bildungswissenschaften, Flensburger Univ.-Zeitschrift 10; Thema: Heimat und regionale Identität, $45-62$.

HaAs Hanns (1999): Ethnikum und Nation in der dörflichen Lebenswelt eines deutschtschechischen Dorfes. In: Vincenc Rajšp \& Ernst Bruckmüller (Hg.), Pravo-Zgodovina-Narod, Recht-Geschichte-Nation. In Memoriam Sergij Vilfan, Lubljana, 555588 [www.demokratiezentrum.org].

HАDвAWNik Oskar et al. (1986): Die Zipser der Bukowina (= Schriftenreihe der Raimund Friedrich Kaindl Gesellschaft), München.

HARre Angela (2009): Wege in die Moderne. Entwicklungsstrategien rumänischer Ökonomen im 19. und 20. Jahrhundert (= Studien zur Sozial- und Wirtschaftsgeschichte Ostmitteleuropas 18), Wiesbaden.

Hauptmann Peter (1963): Altrussischer Glaube (= Kirche im Osten, Monographiereihe 4), Göttingen.

Hausleitner Mariana (2000): Die Epochengrenze in der Bukowina als Fallbeispiel einer multiethnischen Region. In: Sundhaussen \& Torke (Hg.), Epochengrenze, 101119.

Hausleitner Mariana (2001): Die Rumänisierung der Bukowina. Die Durchsetzung des nationalstaatlichen Anspruchs Großrumäniens 1918-1944 (= Südosteuropäische Arbeiten 111), München.

Hausleitner Mariana (2002): Gegen die Zwangsrumänisierung. Die Kooperation von Bukowiner Deutschen, Juden und Ukrainern in der Zwischenkriegszeit. In: Werkstatt Geschichte 32, 31-43.

Hausleitner Mariana (2006): Deportationen als Mittel der Durchsetzung politischer Interessen in Südosteuropa bis 1944. In: Anuarul Institutului de Istorie "George Bariţ« din Cluj-Napoca, XLV Series Historica, 169-178.

Hausleitner Mariana (2009): Der Pakt, die Sowjetisierung und die Folgen. Bessarabien und die Nordbukowina 1940-41. In: Osteuropa 59/7-8, 203-218.

Hausleitner Mariana (2013): Fünf verschiedene Vereinshäuser in Czernowitz und ihre Entwicklung bis 1914. In: Peter Haslinger u.a. (Hg.), Heimstätten der Nation. Ostmitteleuropäische Vereins- und Gesellschaftshäuser im transnationalen Vergleich (= Tagungen zur Ostmitteleuropa-Forschung 32), Marburg, 89-112.

Hausleitner Mariana (2014): Historiker der Universität Czernowitz als Wissenschaftler und Politiker. Raimund Friedrich Kaindl und Ion Nistor. In: Markus Winkler (Hg.), Partizipation und Exklusion. Zur Habsburger Prägung von Sprache und Bildung in der Bukowina 1848-1918-1940 (= Veröffentlichungen des Instituts für deutsche Kultur und Geschichte Südosteuropas e.V. 132), München, 55-76.

Helfert Josef ( $\left.{ }^{2} 1825\right)$ : Von dem Kirchenvermögen, dem Religionsfonde, den Einkünften, Abgaben und Verlassenschaften geistlicher Personen, Prag. 
Helfert Josef $\left({ }^{3} 1846\right)$ : Handbuch des Kirchenrechts aus den gemeinen und österreichischen Quellen zusammengestellt, Prag.

Heinde Waltraud (1990): Bürokratie, Staat und Reform. Überlegungen zum Verhältnis von Bürokratie und Staat im aufgeklärten Absolutismus in Österreich. In: Moritz Csáky \& Anrea Lanzer (Hg.), Etatisation et bureaucratie. Staatswerdung und Bürokratie (= Beihefte zum Jahrbuch der Österreichischen Gesellschaft zur Erforschung des 18. Jahrhunderts 2), Wien. 39-48.

Heinen Armin \& Oliver Sснмітт (Hg.) (2013): Inszenierte Gegenmacht von rechts. Die »Legion Erzengel Michael« in Rumänien 1918-1938 (= Südosteuropäische Arbeiten 150), Regensburg.

Hess Ulrich (1996): Leipziger Regionalforschung im 21. Jahrhundert. In: Edwin Dillmann (Hg.), Regionales Prisma der Vergangenheit. Perspektiven der modernen Regionalgeschichte (Saarlandbibliothek 11), St. Ingbert, 47-65.

Hintze Otto (1911): Die Entstehung des modernen Staates. In: Vergangenheit und Gegenwart I, 58-69.

HirschHAUSEN Ulrike von (2009): From imperial inclusion to national exclusion. Citizenship in the Habsburg monarchy and in Austria 1867-1923. In: European Review of History $16 / 4,551-573$.

Historisches Seminar Univ. Hamburg (Hg.) (1963): Alteuropa und die Moderne Gesellschaft, Göttingen.

Hitchins Keith (1977): Orthodoxy and Nationality. Andrei Şaguna and the Rumanians of Transylvania, 1846-1873, Cambridge u.a.

Hitchins Keith (1980): Die Rumänen. In: Helmut Rumpler \& Peter Urbanitsch (Hg.), Die Habsburgermonarchie 1848-1918 III/1, Die Völker des Reiches, Wien, 585-625. Hıтchıns Keith (2004): Desăvârşirea Naţiunii Române. In: Mihai Bărbulescu et al. (Hg.), Istoria României, Bucureşti, 287-406.

Hock Carl \& Hermann Ignaz Bidermann (1879): Der österreichische Staatsrath (1760-1848). Eine geschichtliche Studie, Wien.

HoLzKnech T Georgine (1914): Ursprung und Herkunft der Reformideen Kaiser Josefs II. auf kirchlichem Gebiete (= Forschungen zur inneren Geschichte Österreichs 11), Innsbruck.

Hormuzachi Constantin (1913): Chestia delimitării dieceselor naţionale gr.-or. din Bucovina, Cernăuţi.

HormuZAKi Eudoxius (1861): Noth- und Hilferuf der Gemeinden des Mold.-Câmpolounger Okols in der Bukowina, dargelegt in einer aktenmässig begründeten Petition an Seine Majestät den Kaiser Franz Joseph I., mit 41 Beilagen, Wien.

HormuZA KI Konstantin (1900): Die Slavisierung der Bukowina im 19. Jahrhundert als 
Ausgangspunkt grosspolnischer Zukunftspolitik. Ethnographische und politische Betrachtungen von einem Bukowiner Rumänen, Wien.

HörTNAGL Friedrich (1950): Die Stellung der Religionsgesellschaften im österreichischen Kaiserstaate zur Zeit Maria-Theresias und Josef's II., Dissertation Universität Innsbruck, Innsbruck.

Huber Manfred (1973): Grundzüge der Geschichte Rumänien, Darmstadt.

Huss AREK Max v. (1909): Religionsfonds. In: Ernst Mischler \& Josef Ulbrich (Hg.), Österreichisches Staatswörterbuch. Handbuch des gesamten österreichischen Rechtes 4 (R-Z), 92-103.

Huţu Cătălin (2010): Bucovina. Adevăruri trecute sub tăcere (= Coleția Texte de Frontieră 47), Iași.

$\mathrm{I} / \mathrm{J}$

Iснім Radu (1994): Din Regulamentul de exploatarea pădurilor fondului bisericesc ortodox român din Bucovina. In: Bucovina Forestieră Anul II (2), 88f.

IorgA Nicolae (1905): Neamul Românesc în Bucovina, Bucureşti.

IoRgA Nicolae (1938): Românismul în trecutul Bucovinei, București.

IoRgA Nicolae (2011): Istoria Bisericii Române și vieţii religioase a românilor, București.

Irimescu Gavril (1981/82): Din istoria mineritului în Bucovina. In: Anuarul Muzeului Județean (Suceava) 8 (1981), 265-277; 9 (1982), 265-284.

IRIMESCU Gavril (1984/85): Dezvoltarea industriei miniere sucevene între anii 19451948. In: Anuarul Muzeului Județean (Suceava) 11/12, 247-260.

JACOBEscu Mihai (1995): Dr. Silvestru Morariu-Andreievici (1818-1895). In: Codrul Cosminului I (1995), 146-172.

JAREмTSCHUK - Яаремчук Сергій (2001): Нариси історії православної церкви на Буковині в Австрійський період (1775-1918pp.) [Skizzen der Geschichte der orthodoxen Kirche in der Bukowina während der österreichischen Periode (17751918)]. In: Світильник церковно-богословский журнал 9/2001, 170-209.

JAworksi Rudolf (1982): Nationalismus und Ökonomie als Problem der Geschichte Ostmitteleuropas im 19. und zu Beginn des 20. Jahrhunderts. In: Geschichte und Gesellschaft 8/2, 184-204.

Jetschgo Johannes et al. (Hg.) (2004): Österreichische Industriegeschichte 1848 bis 1955 (Band II). Die verpasste Chance, Wien.

JÁszI Oscar (1929): The Dissolution of the Habsburg Monarchy, Chicago.

JILGE Wilfried (2006): Nationale Geschichtspolitik während der Zeit der Perestroika in der Ukraine. In: Altrichter et al. (Hg.), Erinnerung, 99-128. 
Judson Pieter M. (2008): L'Autriche-Hongrie était-elle un empire? In: Annales. Histoire, Sciences Sociales 63e Année, 563-596.

JUMARĂ Dan (2005): Societăţile culturale acadmice românești din Bucovina în perioda Interbelică, Iaşi.

JURASKI Johann (1867): Die Manz'schen Berg- und Hüttenwerke in der Bukowina. In: Österreichische Zeitschrift für Berg- und Hüttenwesen XV. Jg., Nr. 19 (1867), 146149; Nr. 20, 156-160.

K

KAINDL Raimund Friedrich (1896): Das Entstehen und die Entwicklung der Lippowaner-Colonien in der Bukowina. Zumeist nach urkundlichen Materialien aus dem Nachlasse des Finanzrates a.D. F.A. Wickenhauser (= Archiv für österreichische Geschichte LXXXIII, II. Hälfte, Wien), 236-384 (als Separatdruck 3-152).

KAINDL Raimund Friedrich (1899): Die Bukowina in den Jahren 1848 und 1849. In: Österreichisch-Ungarische Revue. Monatsschrift f.d. gesammten Culturinteressen Österreich-Ungarns, 24. Bd., 221-230 u. 274-329.

KaINDL Raimund Friedrich (1900): Zuczka. Beiträge zur Geschichte des Bukowiner Religionsfonds. Aus dem Nachlasse v. F. A. Wickenhauser. In: Jahrbuch des Bukowiner Landes-Museums 8, 3-48.

KAINDL Raimund Friedrich (1902): Das Ansiedlungswesen in der Bukowina seit der Besitzergreifung durch Österreich (= Quellen und Forschungen zur Geschichte, Literatur und Sprache Österreichs 8), Innsbruck.

KAINDL Raimund Friedrich (2005/1908): Geschichte von Czernowitz, Czernowitz (zweisprachige Neuauflage Чернівці).

KaINDL Raimund Friedrich (1915): Die ethnographische Zusammensetzung der Bevölkerung der Bukowina. In: Petermanns Mitteilungen aus Justus Perthes' Geographischer Anstalt 61, 298-301.

KANN Robert A. (1950): The multinational empire. Nationalism and national reform in the Habsburg monarchy 1848 - 1918, 2 Bände, New York.

KA PPELER Andreas (2003): Der schwierige Weg zur Nation. Beiträge zur neueren Geschichte der Ukraine (= Wiener Archiv für die Geschichte des Slawentums und Osteuropas XX), Wien.

KAPs Klemens (2009): Peripherisierung der Ökonomie. Ethnisierung der Gesellschaft. Galizien zwischen äußerem und innerem Konkurrenzdruck (1856-1914). In: Doktoratskolleg Galizien (Hg.), Galizien Fragmente eines diskursiven Raumes, InnsbruckWien, 37-62.

KASER Michael \& Charles u. Edward Albert Radice (Hg.) (1985): The Economic History 
of Eastern Europe 1919-1975, Vol. 1, Economic Structure and performance between the two wars, Oxford.

KAst Michael von et al. (Hg.) (1899-1901): Geschichte der österreichischen Land- und Forstwirtschaft und ihrer Industrien 1848-1898, 4 Bände (= Festschrift zur Feier der am 2. December 1898 erfolgten fünfzigjährigen Wiederkehr der Thronbesteigung Sr. Majestät des Kaisers F. J. I.), Wien.

KiesLer Heinrich (1883): Der Streit um die in der Bukowina gelegenen Güter rumänischer Klöster, Czernowitz.

KING Jeremy (2001): The Nationalization of East Central Europe. Ethnicism, Ethnicity, and Beyond. In: Bucur \& Wingfield (Hg.), Past, 112-152.

KLAUBE Manfred (1984): Deutschböhmische Siedlungen im Karpatenraum (= Wissenschaftliche Beiträge zur Geschichte und Landeskunde Ostmitteleuropas 120), Marburg a. d. Lahn.

KLeinwäChter Friedrich (1895): Das Berg- und Hüttenwesen in der Bukowina, Czernowitz.

KLEINWÄCHTER Friedrich (1899): Bergbau und Hüttenwesen. In: Die österreichischungarische Monarchie in Wort und Bild (Kronprinzenwerk), Bukowina, Wien 502514.

Klueting Harm (Hg.) (1995): Der Josephinismus. Ausgewählte Quellen zur Geschichte der theresianisch-josephinischen Reformen, Darmstadt.

КовуLAnsкa Olga (2013): Valse Mélancholique. Ausgewählte Prosa. Herausgegeben und mit einem Nachwort von Petro Rychlo, Czernowitz.

Koloss A Tibor (1965): Statistische Untersuchung der sozialen Struktur der Agrarbevölkerung in den Ländern der österreichisch-ungarischen Monarchie. In: Die Agrarfrage in der österreichisch-ungarischen Monarchie 1900-1918. Mitteilungen auf der Konferenz der Geschichtswissenschaftler, Budapest, 4.-9. Mai 1965, Bukarest.

KovÁcs Elisabeth (1980): Was ist Josephinismus? In: Karl Gutkas et al. (Hg.), Österreich zur Zeit Kaiser Joseph II. Mitregent Kaiserin Maria Theresias, Kaiser und Landesfürst (Stift Melk 29.III.-2.XI.1980 Niederösterreichische Landesausstellung), Wien, 24-30.

KozAK Eugen (1921): Benennung der Bukowinaer ort.-or. Erzdiözese im Kirchenkongresse 1921, Czernowitz.

Krammer Michael (1999): Die Errichtung des russisch-orthodoxen altgläubigen Bistums von Bielokrinica in der Bukowina und die Auswirkungen auf das politische Verhältnis Österreichs mit Rußland. In: Alfred Stirnemann \& Gerhard Wilflinger (Hg.), Russland und Österreich (= Pro Oriente XXIII, Innsbruck-Wien), 87-94.

Krasuski Faustin R. v. (1907): Das Berg- und Hüttenwesen der Bukowina von seinen Anfängen an. In: Czernowitzer Allgemeine Zeitung Nr. 1013 v. 30.V.1907, 8; Nr. 1014 
v. 1.VI., 4; Nr. 1015 v. 2.VI., 4f.; Nr. 1016 v. 4.VI., 4; Nr. 1019 v. 7.VI., 3; Nr. 1020 v. 8.VI., 3; Nr. 1021 v. 9.VI., 4; Vortrag des k.k. Bergrates Faustin Ritter v. Krasuski im Bukowinaer akademischen technischen Vereine am 25.V.1907.

KRAUS Wolfgang (1999): Identität als Narration. Die narrative Konstruktion von Identitätsprojekten (= Colloquium vom 22. IV. 1999, FU Berlin) [http://web.fu-berlin.de/ postmoderne-psych/berichte $/ \mathrm{kraus} . \mathrm{htm}]$.

Kremnitzky Philipp (1868): Die v. Manz'schen Eisensteinbergbaue in der Bukowina. Eingesendete Mittheilungen. In: Verhandlungen der k.k. geologischen Reichsanstalt Wien 11, 241.

Ku BŮ Eduard, Torsten Lorenz, Uwe Müller \& Jiří Šouša (Hg.) (2013): Agrarismus und Agrareliten in Ostmitteleuropa, Berlin-Praha.

L

Lane Jan-Eric \& Svante O. Ersson (2000): The New Institutional Politics. Performance and Outcomes, London.

LANGEWIESCHE Dieter (1995): Nation, Nationalismus, Nationalstaat. Forschungsstand und Forschungsperspektiven. In: Neue Politische Literatur 40, 190-236.

LANGeWiesche Dieter (2006): Die Idee Nation als Handlungsorientierung. Kommentar. In: R. Lutz \& H.-E. Tenorth (Hg.), Ideen als gesellschaftliche Gestaltungskraft im Europa der Neuzeit. Beiträge für eine erneuerte Geistesgeschichte, München, 359368.

LANGEWiesche Dieter (2013): Das Jahrhundert Europas. Eine Annäherung in globalhistorischer Perspektive. In: Historische Zeitschrift 296, 29-48.

Lehners Jean-Paul (1996): Menschen über Grenzen - Grenzen über Menschen. Zu den Begriffen Region, Raum und Grenze am Beispiel des Saar-Lor-Lux-Raumes. In: Edwin Dillmann (Hg.), Regionales Prisma der Vergangenheit. Perspektiven der modernen Regionalgeschichte (Saarlandbibliothek 11), St. Ingbert, 67-86.

Leisching Peter ( $\left.{ }^{2} 1995\right)$ : Die römisch-katholische Kirche in Cisleithanien. In: Adam Wandruszka (Hg.), Die Habsburgermonarchie IV (Die Konfessionen), 1-247.

LeITNER Ulrich (2011): Imperium. Geschichte und Theorie eines politischen Systems, Frankfurt-New York.

Lemberg Hans (2005): Imperien und ihre Grenzregionen im Europa des 18. und 19. Jahrhunderts. Einige einführende Beobachtungen. In: Maner (Hg.), Grenzregionen, 25-36.

LEONHARD Jörn \& Ulrike v. Hirschhausen (22011): Empires und Nationalstaaten im 19. Jahrhundert, Göttingen.

LeONHARD Jörn \& Ulrike v. Hirschhausen (Hg.) (2011): Comparing Empires. Encounters and Transfers in the Long Nineteenth Century, Göttingen. 
LEONHARD Jörn (2012): Wie legitimieren sich multiethnische Empires im langen 19. Jahrhundert? In: Münkler \& Hausteiner (Hg.), Legitimation, 70-93.

LEONHARD Jörn (Hg.) (2011): Comparing Empires. Encounters and Transfers in the long 19th Century (= Schriftenreihe der FRIAS School of History 1), Göttingen.

Leustean Lucian N. (2007): «For the Glory of Romanians". Orthodoxy and Nationalism in Greater Romania, 1918-1945. In: Nationalities Papers 35/4 (Sept.), 717-742.

Leustean Lucian N. (2009): Orthodoxy and the Cold War. Religion and Political Power in Romania, 1947-1965, Macmillan Pub. Basingstoke.

Lieven Dominic (2001): Empire. The Russian Empire and Its Rivals, New Haven-London.

LiHaciu Ion (2012): Czernowitz 1848-1918. Das kulturelle Leben einer Provinzmetropole (= Bukowinastudien I), Kaiserslautern-Mehlingen.

LisnIC Ioan (2013): Î.P.S. Visarion Puiu, Mitropolit al Bucovinei (1935-1940) [http:// ortodox.md/i-p-s-visarion-puiu-mitropolit-al-bucovinei-1935-1940/].

LISNIC Ioan (2013): Reorganizarea Fondului Bisericesc al Bucovinei. (online Artikel, Logos Portalul Tineretului Ortodox din Republika Moldova, abgerufen 7.II.2014).

Loebel Arthur (1895): Die geschichtliche Entwicklung des Eisenbades Dorna. Nach archivalischen Studien. In: Österreichisch-Ungarische Badezeitung. Organ für Balneologie, Klimatologie und Hygiene, XXIV. Jg., Nr. 1-22 (28.IV.-22.IX.).

Loebel Arthur (1896): Geschichtliche Entwicklung des Eisenbades Dorna. Mit fünf Abbildungen, Wien-Leipzig.

Loebel Arthur (1899): Die Reconstructionsepoche des Eisenbades Dorna. Reminiscenzen mit Benützung amtlicher Quellen, Wien-Leipzig.

Loebel Arthur (1909): Dorner Dokumente aus dem Franzisko-Josephinischen Zeitalter, Wien.

Lorenz Torsten (2006): Genossenschaften und Nation-Building in Osteuropa 18501940. In: Dagmara Jajesniak et al. (Hg.), Soziale Konflikte und nationale Grenzen in Ostmitteleuropa, Berlin, 157-169.

LoRenz Torsten (Hg.) (2006): Cooperatives in Ethnic Conflicts. Eastern Europe in the 19 th and early 2oth Century, Berlin.

Lowndes Vivien (1996): Varieties of New Institutionalism. A critical Appraisal. In: Public Administration 72/2, 182-197.

Luce AC Ilie (2007): Discursurile lui Eudoxiu Hurmuzaki în dieta Bucovinei. Din viaţa parlamentară a Bucovinei în cea de a doua jumătate a secolului al XIX-lea, București.

LuceAc Ilie (2010): Biserici din Cernăuţi (Orașul Cernăuţi la 600 de ani). In: Atanasiu \& Ghenghea (Hg.), Bucovina, 89-124.

Luceac Ilie (2015): Eudoxiu (Doxaki) Hurmuzaki (1812-1874), Cernăuţi.

LUSTKANDL Wenzel (1881): Die josefinischen Ideen und ihr Erfolg, Wien. 
Lutz Raphael (2000): Recht und Ordnung. Herrschaft durch Verwaltung im 19. Jahrhundert, Frankfurt a. M.

$M$

MAAss Ferdinand (1951-61): Der Josephinismus. Quellen zu seiner Geschichte in Österreich 1760-1790 (= Fontes Rerum Austriacarum II/71-75), Wien.

MAČEK Jože (2002): Krainer Religionsfond (Kranjski verski sklad). Errichtung, Dotation und Wirkung in der Zeit von 1782 bis etwa 1810. In: Šelih (Hg.), Država, 415-432.

MAIOR Liviu (2006): Habsburgi şi Români. De la loialitatea dinastică la identitate naţională, București.

Maior Liviu (2016): Doi ani mai devreme. Ardeleni, Bucovineni și Basarabeni în Război 1914-1916, Cluj-Napoca.

MANER Hans-Christian (2001): Voraussetzungen der autoritären Monarchie in Rumänien. In: Erwin Oberländer (Hg.), Autoritäre Regime in Ostmittel- und Südosteuropa 1919-1944, Paderborn u.a., 431-469.

MANer Hans-Christian \& Norbert Spannenberger (2007): Konfessionelle Identität und Nationsbildung. Die griechisch-katholischen Kirchen in Ostmittel- und Südosteuropa im 19. u. 20. Jh. (= Forschungen zur Geschichte und Kultur des östlichen Mitteleuropa 25), Stuttgart.

Maner Hans-Christian (Hg.) (2005): Grenzregionen der Habsburgermonarchie im 18. und 19. Jahrhundert. Ihre Bedeutung und Funktion aus der Perspektive Wiens, Münster u.a.

Maner Hans-Christian (2007): Multikonfessionalität und neue Staatlichkeit. Orthodoxe, griechisch-katholische und römisch-katholische Kirche in Siebenbürgen und Altrumänien zwischen den Weltkriegen (1918-1940) (= Forschungen zur Geschichte und Kultur des östlichen Mitteleuropas 29), Stuttgart.

Manolache Eusebi (2014): Fondul Bisericesc Ortodox Român al Bucovinei pierde definitiv procesul în care revendica 166.000 de pădure (joi, 27 Nov 2014, 20:55 / Justiţie) [https://www.agerpres.ro/justitie/2014/11/27/fondul-bisericesc-ortodoxroman-al-bucovinei-pierde-definitiv-procesul-in-care-revendica-166-0oo-de-pa dure-20-55-12].

Marcean Mihai (2002): Pădurile Sucevei și calamităţile din perioada 1945-2002. In: Bucovina Forestieră. Revistă de silvicultură și stiinţele mediului X, 1/2, 59-73.

Mareci Harieta \& Ştefan Purici (2007): Under Pressure for Change. Nation State Building and Identity Mutations in Modern Romania. In : Steven G. Ellis \& Lud'a Klusáková (Hg.), Imagining Frontiers. Contesting Identities (Thematic Work Group 5, Frontiers and Identities II), Pisa, 175-187. 
Martynowicz Emil (1885): Badeort Dornawatra. Historische Fragmente. In: Bukowinaer Rundschau Nr. 127 v. 17.V.1885, 4f.; Nr. 128 v. 21.V.1885, 4 f.

Matis Herbert \& Karl Bachinger (1973): Österreichs industrielle Entwicklung. In: Adam Wandruszka \& Peter Urbanitsch (Hg.), Die Habsburgermonarchie 1848-1918 I, Die wirtschaftliche Entwicklung (Hg. v. Alois Brusatti), Wien, 403-461, Wien, 105232.

Mazoнl Brigitte (2014): ‘Equality among Nationalities and the Peoples (Volksstämme) of the Habsburg Empire. In: Kelly L. Grotke \& Markus J. Prutsch (Hg.), Constitutionalism, Legitimacy, and Power. Nineteenth Century Experiences, Oxford 163-187.

Maurer Andrea \& Michael Schmid (Hg.) (2002): Neuer Institutionalismus. Zur soziologischen Erklärung von Organisation, Moral und Vertrauen, Frankfurt a. M.

Maurer Michael (1999): Kirche, Staat und Gesellschaft im 17. und 18. Jahrhundert (= Enzyklopädie Dt. Geschichte 51), München.

Merker Nicolao (1982): Die Aufklärung in Deutschland, München.

Merton Robert K. (1940): Bureaucratic Structure and Personality. In: Social Forces (May 1940), Vol. 18, 560-568.

Michelson Paul E. (2010): Ion I. Nistor and the Development of Romanian Historiography in Bucovina to the Union of 1918. In: Codrul Cosminului XVI/1 (2010), 59-81.

Michelson Paul E. (2011): Ion I. Nistor in Romanian Politics, Scholarship, and Culture, 1919-1933. In: Codrul Cosminului XVII/1 (2011), 117-148.

MıнA Constantin (2010): Biserica şi elitele intelectuale interbelice (= Colecţia Academica 78), Iași.

MıнAI Constantin $\left({ }^{2} 2014\right)$ : Biserica și elitele intelectuale interbelice (= Studii culturale şi media), Iaşi.

Mikulicz Andreas (1875): Kulturzustände im Herzogthume Bukowina 1775 und 1875, Czernowitz.

Milasch (Milaš) Nikodem (1885): Das Synodal-Statut der gr--orthodoxen Metropolie der Bukowina und Dalmatiens. In: Archiv für katholisches Kirchenrecht 53, 251-263.

Mittelmann Hermann (2001/1907): Illustrierter Führer durch die Bukowina, Wien (Reprint).

Mitrofanov von, Paul (1910): Joseph II. Seine politische und kulturelle Tätigkeit, Wien.

Mitropolia Bucovinei (Hg.) (1937): Fapte și Gânduri pentru Biserica Bucovinei, București.

Mitropolia Bucovinei (Hg.) (1939): Administraţia Fondului Bisericesc, Cernăuţi. 
Mitropolia Bucovinei (Hg.) (1942/1943): Lucrările Adunarii Eparhiale a arhipiscopiei Cernăuților din sesiunea ordinară a anului 1941, Cernăuți.

Moldovan Svetlana (2004): Obščina russkih-lipovan. Spravočnik, București.

MorariU Aurel (1914): Bucovina 1774-1914 (= Biblioteca Bucovina 11-16), București.

Mor ARIU Aurel (1937): Intru apărarea Mitropoliei a Facultăţii noastre teologice și a Fondului bisericesc ort. rom. al Bucovinei. Intervenţiune parlamentară în ședinţa Adunării Deputăţilor din 19 Martie 1937, Cernăuţi.

Morariu Constantin (1881): Culturhistorische und ethnographische Skizzen über die Rumänen der Bukowina. 1. Teil aus der Romänischen Revue (Resicza/Reșiţa-Wien).

MorARIU Constantin (1893): Păţi din istoria Românilor bucovinene scrise în limbă poporală (Broșura I) (Abriss der Geschichte der Rumaenen in Bucovina), Cernăuț. MoRDWINOW - Мордвинов Владимир (1874): Православная церковь в Буковине, Санкт-Петербург.

MoroșAN Nicolae (2005): Lupta culturală a românilor din Bucovina pentru realizarea unității naţionale reflectată în >Revista Politică ‘şi >Gazeta Bucovinei<, Suceava.

MoschaRIWs'кIJ - Можарівський Володимир (2006): Православная церква на Буковинію. Доба Митрополлій (сер. XIX - I пол. XX. ст.ст.), Чернівці.

Mosser Alois (1995): Das Habsburgerreich als Wirtschaftsraum unter besonderer Berücksichtigung der östlichen Karpatengebiete. In: Slawinski (Hg.), Bukowina, 53-72.

Müller Dietmar \& Angela Harre (2011): Agrarismus als Dritter Weg zwischen Faschismus und Kommunismus sowie zwischen Kapitalismus und Kollektivismus. In: dies. (Hg.), Transforming Rural Societies (= Jahrbuch für Geschichte des ländlichen Raumes 2010), 7-13 (14-22).

Müller Dietmar (2001): Agrarpopulismus in Rumänien. Programmatik und Regierungspraxis der Bauernpartei und der Nationalbäuerlichen Partei Rumäniens in der Zwischenkriegszeit (= Rumänien-Studien 1), St. Augustin.

Müller Dietmar (2006): Die Zwischenkriegszeit. Politisches System und Staatsbürgerschaft. In: Thede Kahl et al. (Hg.), Rumänien, 279-296.

Müller Dietmar (2007): Die Gouvernementalität des Bodeneigentums im östlichen Europa. In: Hannes Siegrist (Hg.), Entgrenzung des Eigentums in modernen Gesellschaften, Leipzig, 112-129.

Müller Dietmar (2009): Landreformen, Property rights und ethnische Minderheiten. Ideen- und Institutionengeschichte nachholender Modernisierung und Staatsbildung in Rumänien und Jugoslawien 1918-1948. In: Karl-Peter Krauss (Hg.), Agrarreformen und ethnodemographische Veränderungen. Südosteuropa vom ausgehenden 18. Jh. bis in die Gegenwart, Stuttgart, 207-234.

MüLlER Dietmar (2010): Vorarbeiten zu einer Begriffs- und Kulturgeschichte des Ei- 
gentums in Rumänien, 1746 bis 2009. In: Vasile Dumbrava (Hg.), Geschichte politisch-sozialer Begriffe in Rumänien und Moldova, Leipzig, 184-214.

MüLlER Dietmar (2012): Bodeneigentum und Institutionenwandel in Ostmittel- und Südosteuropa 1918-1945-1989. In: Zeitschrift für Ostmitteleuropaforschung 61/3, 332-355.

MülLER Dietmar (2014): Rechtstransfer - Institutionen - Rechtskultur. Historiografie und Hypothesen. In: Wim van Meurs \& Dietmar Müller (Hg.), Institutionen und Kultur in Südosteuropa (= Südosteuropa Jahrbuch 39), München, 119-162.

Müller Dietmar (2015): Geschichtsregionen und Phantomgrenzen. In: Béatrice v. Hirschhausen, Hannes Grandits, Claudia Kraft, Dietmar Müller \& Thomas Serrier (Hg.), Phantomgrenzen. Räume und Akteure in der Zeit neu denken (= Phantomgrenzen im östlichen Europa 1), Göttingen, 57-83.

MülLER Uwe (2014): ’Nachzügler` im Industrialisierungsprozess und `Semiperipherie` in einer sich globalisierenden Ökonomie? Transnationale Verflechtungen in der ostmitteleuropäischen Wirtschaft des 19. Jahrhunderts. In: Jahrbuch für Wirtschaftsgeschichte - Economic History Yearbook 55/1, 9-32.

MüNKLER Herfried \& Eva Maria Hausteiner (Hg.) (2012): Die Legitimation von Imperien. Strategien und Motive im 19. und 20. Jahrhundert, Frankfurt u. New York.

MüNKLER Herfried (2011): Was leisten Imperien? In: Zeitschrift für Weltgeschichte $11 / 2,5-10$.

Murgescu Bogdan (2003): The Romanian Historiography in the 1990's. In: Romanian Journal of Political Science 1, 1-21.

Murgescu Bogdan (2006): Die rumänischen Länder in der frühen Neuzeit. In: Thede Kahl, Michael Metzeltin \& Mihai-Răzvan Ungureanu (Hg.), Rumänien, Wien u.a., 221-236.

Murgescu Bogdan (2006): Geschichte im Transformationsprozess. Rumänien. Politische und institutionelle Rahmenbedingungen nach der Wende. In: Altrichter et al. (Hg.), Erinnerung, 237-259.

Murgescu Bogdan (2010): The Social Fabric of Agrarian Political Success in Early Twentieth Century East Central Europe. A structural comparison of Stjepan Radić, Antonín Švehla, Alexander Stamobijski and Ion Mihalache. In: Schultz \& Harre (Hg.), Bauerngesellschaften, 121-134.

Murgescu Bogdan (2010): România și Europa. Acumularea decalajelor economice (1500-2010), București.

Murgescu Bogdan (2015): Agriculture and landownership in the economic history of twentieth-century Romania. In: Siegrist \& Müller (Hg.), Property, 48-61. 
N

NASke Carl (1908): Manganerzbau in der Bukowina. In: Stahl und Eisen. Zeitschrift für das deutsche Hüttenwesen (Düsseldorf) 28, 543-547.

Neculiţ A Voronca Elena (1894): Casa naţională. Conferință ţinuta în 9 Decemvrie 1894 în folosul fondului pentru clădirea unui palat naţional, Cernăuţi.

Németh Thomas M. (2010): Autonome Orthodoxe Gemeinden in Cisleithanien. In: C. G. Fürst \& R. Potz (Hg.), Autonomie in den Ostkirchen (= Kanon 21), Hennef, 82-102.

Németh Thomas M. (2012): Josef von Zhishman (1820-1894) und die Orthodoxie in der Donaumonarchie, Freistadt.

Neșciuc Eugen E. (Hg.) (1893): Istoricul bisericii ort. or. din Bucovina (1775-1893). Seriere festivă la serbarea iubileului de 50 de ani de preoție a Înalt Prea Sfânţitului Archiepiscop al Cernăuţului și Mitropolit al Bucovinei și Dalmaţiei Dr. Silvestru Morariu Andrievici, Cernăuţ.

Neşıuc E. (Hg.) (1893): Istoria biserici ort.or. din Bucovina (1775-1893), Cernăuţi.

Niedermüller Peter (1997): Zeit, Geschichte, Vergangenheit. Zur kulturellen Logik des Nationalismus im Postsozialismus. In: Historische Anthropologie 5, 245-267.

NisToR Ioan (1920): Regulamentul la legea pentru reformă agrară în Bucovina cu textul român și traducerea în limba germană, Cernăuți.

Nistor Ioan (1928): Zece ani de la unire Bucovinei 1918-1928, București.

Nistor Ioan (1997/1934): Problema ucraineana în lumina istoriei prezentare Gheorghe Buzatu. Ediţie îngrijită de Ştefan Purici, Rădăuţi.

Nistor Ion (1912): O pagină din istoria bisericii bucovinene Episcopul Herescu. In: Gazeta Mazililor și Răzeșilor Bucovinei 12 (Cernăuţi), 200-202.

Nistor Ion (1916): Un capitol din viaţa culturală a Românilor din Bucovina 17741857. Discurs rostit la 21 Maiu (3 iunie) 1916 în ședinţă solemnă de I. Nistor cu răspuns de N. Iorga (= Academia Română. Discursuri de Recepţiune XLIV), București, 3-70.

Nistor Ion (1919): Der Nationale Kampf in der Bukowina mit besonderer Berücksichtigung der Rumänen und Ruthenen, mit einer ethnographischen Karte der Bukowina, Bucureşti.

Nistor Ion (1921): Istoria fondului bisericesc din Bucovina (= Biblioteca Glasul Bucovinei 5), Cernăuţi.

Nis ToR Ion (1932): Şase ani de autonomie bisericească. Discurs rostit în şedinţa Adunari Eparhiale din 30 Decemvrie 1931, Cernăuţi.

Nistor Ion (1940): Die Vereinigung der Bukowina mit Rumänien, București.

Nistor Ion (2001/1915): Romanii şi Ruteni în Bucovina, Bucureşti. 
Nis'ToR Ion (2003/1916): Istoria Bisericii din Bucovina și a rostului ei naţional-cultural în viaţa Românilor Bucovineni, Rădăuţi.

Nistor Ion (2010/1928): Unirea Bucovinei 28 Noiembrie 1918. Studii și documente, Cluj-Napoca.

Nolte Hans-Heinrich (1980): Zur Stellung Osteuropas im internationalen System der frühen Neuzeit. Außenhandel und Sozialgeschichte bei der Bestimmung der Regionen. In: Jahrbücher für Geschichte Osteuropas N.F. 28/2, 161-197.

Nolte Hans-Heinrich (2005): Weltgeschichte. Imperien, Religionen und Systeme 15.19. Jahrhundert, Wien u.a.

Nolte Hans-Heinrich (2009): Die letzte Chance der Imperien. Österreich-Ungarn, Russland, Osmanisches Reich und Preußen-Deutschland. In: Michael Mann (Hg.), Die Welt im 19. Jahrhundert, 244-274.

Nolte Hans-Heinrich (2013): Zentren und Peripherien (Verein für Geschichte des Weltsystems. Zweigstelle Hannover der dt. Gesellschaft für Osteuropakunde). In: HNet Reviews Juli 2013.

NorTH Douglass (1991): Institutions, institutional change and economic performance, Cambridge.

0

Offe Claus (2003): Kann man Institutionen konstruieren? Überlegungen zum Institutionenwandel und zum institutional design. In: Joachim Fischer \& Hans Joas (Hg.), Kunst, Macht und Institution. Studien zur Philosphischen Antrophologie, soziologischen Theorie und Kultursoziologie der Moderne, Frankfurt-New York, 173-184.

OgRIs Werner (1981): Joseph II. Staats- und Rechtsreformen. In: Barton (Hg.), Zeichen, 109-151.

Onciul Aurel C. von (1999): Aurel Ritter von Onciul und der nationale Ausgleich in der österreichischen Bukowina. Eine wissenschaftliche Dokumentation, Nürnberg.

Onciul Aurel von (1907): Reden des Aurel Onciul, gehalten im Bukowiner Landtage am 1. und 7. Okt. 1907. Zur Parzellierung der Religionsfondsdomänen. Zur Proprination. Zum Budget, Czernowitz.

ONCIUL Isidor von (1890/1891): Fondul Religionariu gr.or. al Bucovinei. In: Candela 9 (1890) und 10 (1891).

ONCIUL Isidor von (1891): Fondul religionar gr. or. al Bucovinei. Substratul, formarea desvoltarea și starea lui de faţă, Cernăuţi.

ONciul Isidor von (1899): Der griechisch-orientalische Religionsfonds. In: Die österreichisch-ungarische Monarchie in Wort und Bild, Bukowina, Wien, 154-174.

ONCIUL Isidor von (1905): Zur griechisch-orientalischen Kirchenfrage (Sonderausgabe 
a.d. Bukowiner Post Nr. 1714, 19.I., 1f.; Nr. 1715, 22.I., 1f.; Nr. 1717, 26.I., 1f.; Nr. 1718, 29.I., 1ff.; Nr. 1721, 5.II., 2f.; Nr. 1724, 12.II., 3).

Onciulescu Dimitrie (1939): O încercare de catolizare a Bucovinei (cu anexe documentare) (Extras din revista teolog. ’Candela‘ anul L 1939), Cernăuţi.

Opletal Josef (1913): Das forstliche Transportwesen im Dienstbereiche der k.k. Direktion der Güter des Bukowinaer griechisch-orientalischen Religionsfondes in Czernowitz, 2 Bände, Wien.

Osatschuк S. D. et al. Сергій Д. Осачук, Володимир M. Заполовський, Василь Ф. Холодницький (2004): "Додому в Райх«. Переселення німців з Північної Буковини 1940 року. Матеріали, свідчення, документи, Чернівці.

Osterhammel Jürgen (2002): Expansion und Imperium. In: Peter Burschel et al. (Hg.), Historische Anstöße (= Festschrift für Wolfgang Reinhard zum 65. Geburtstag), Berlin, 371-392.

Osterhammel Jürgen (2009): Die Verwandlung der Welt. Eine Geschichte des 19. Jahrhunderts, München.

Oтruba Gustav (1985): Staatshaushalt und Staatsschuld unter Maria-Theresia und Joseph II. In: Plaschka et al (Hg.), Österreich, 197-249.

OZIRny Ј Озїрний (1903): Положене русинів на Буковинї, Львів.

Özkirimli Umut (2000): Theories of Nationalism. A critical introduction, Basingstoke.

P

PaArha mmer Hans (Hg.) (1989): Kirchliches Finanzwesen in Österreich, Thaur.

PACHоLкIv Savatoslav (2002): Emanzipation durch Bildung. Entwicklung und gesellschaftliche Rolle der ukrainischen Intelligenz im habsburgischen Galizien (18901914) (= Schriftenreihe des österreichischen Ost- und Südosteuropa-Instituts 27), Wien.

PĂCURARIU M. (1989): Istoria Bisericii Ortodoxe Române, București.

РАномі Mircea (1998): Biserici și schituri ortodoxe românești din ţinutul Cernăuţi. Din istoria bisericii ortodoxe române din nordul Moldovei (= Enciclopedia Bucovinei în Studii și Monografii 4), Suceava.

PAPUC Liviu (2010): Un an din viaţa lui Ion Grămadă (August 1914 - August 1915). In: Atanasiu \& Ghenghea (Hg.), Bucovina, 159-194.

PAşCovicı Nicolae (1932): Situaţia inginerilor silvici de la Fondul Bisericesc. In: Codrii Bucovinei II, Ian. 1932, 25-27.

PAșcovici Nicolae (1936): Contribuţiuni la Reorganizarea ocoalelor silvici din administraţia Fondului Bis. ort. rom. din Bucovina. In: Codrii Bucovinei Anul V-VI (1935/36), 26-31.

PAscu Stefan (1980): Siebenbürgen und die Bukowina im Rahmen des Habsburger- 
reiches. Geographische, öknomische und ethno-demographische Grundlagen. In: Adam Wandruszka \& Peter Urbanitsch (Hg.), Die Habsburgermonarchie 18481918 III, Die Völker des Reiches, Wien, 1339-1351.

PAvelescu Mihai (1985): Mineritul in zona Dornelor. In: Tribuna. Săptămînal de Cultură (Cluj), Anul 30 (1986), Nr. 21, 22.V., 8.

Perrow Charles (1961): The Analysis of Goals in Complex Organisations. In: American Sociological Review 26/6 (Dec. 1961), 854-866.

Perrow Charles ( $\left.{ }^{2} 1979\right)$ : Complex Organizations. A Critical Essay, New York.

Pinuliak Hyrotheus \& Anonymus (1906): Beitrag zur kirchlichen Frage in der Bukowina, Czernowitz.

PinUliak Hyrotheus (1913): Der Kirchenstreit in der Bukowina. In: Reichspost Nr. 501, 23.X.1913, 5 .

Pinuliak Hyrotheus (1914): Die Kirchenfrage in der Bukowina (Separatdruck der Bukowinaer Post), Czernowitz.

PINGgÉRA Karl (2003): Ein Jahrhundert Ostkirchenkunde. Aufstieg und Niedergang einer Disziplin. In: Osteuropa 63/2-3, 103-117.

PlaschKa Richard G. et al. (Hg.) (1985): Österreich im Europa der Aufklärung. Kontinuität und Zäsur in Europa zur Zeit Maria-Theresias und Josephs II., Band 1, Wien.

PLöchl Willibald (1972): Die orthodoxe Kirche in der habsburgischen Donaumonarchie (1526-1918). In: Balkan Studies 13, 17-30.

Podraza Antoni (2001): Die Agrarfrage in Galizien und die Bauernbefreiung 1848. In: Helmut Reinalter (Hg.), Die europäische Revolution 1848/49 in Polen und Österreich und ihre Folgen, Frankfurt a. M.

PoLEK Johann (1893): General Splény's Beschreibung der Bukowina, Czernowitz.

PoleK Johann (1894): Die Anfänge des k.k. Staatsgestütes Radautz. In: Jahrbuch des Bukowiner Landesmuseums 2, Czernowitz, 35-114.

PoLeK Johann (1895): Joseph's II. Reisen nach Galizien und der Bukowina und ihre Bedeutung für letztere Provinz. In: Jahrbuch des Bukowiner Landesmuseums 3, Czernowitz, 25-140.

Polek Johann (1896): Die Lippowaner in der Bukowina. I. Geschichte ihrer Ansiedlung. In: Jahrbuch des Bukowiner Landesmuseums 4, Czernowitz, 46-130.

Polek Johann (Hg.) (1897): Topographische Beschreibung der Bukowina mit militärischen Anmerkungen von Major Friedrich von Mieg. In: Jahrbuch des Bukowiner Landesmuseums 5, Czernowitz, 3-38.

Polek Johann (1904): Die Ausbreitung des Protestantismus in der Bukowina. In: Jahrbuch der Gesellschaft für die Geschichte des Protestantismus in Österreich 25, 364374.

Polek Johann (Hg.) (1908): Die Bukowina zu Anfang des Jahres 1801 in alphabetischer 
Darstellung. Nach einer amtlichen Denkschrift (Sonderabdruck a. d. Jahrbüchern des Bukowiner Landesmuseums 15), Czernowitz.

Роцјалко Полянко Олег (2001): Нарис з історії православноії церкви на Буковині, Чернівці.

Popovicı Eusebiu (1912) : Navala rutenilor venetici asupra Bisericii noastre românești din Bucovina, Cernăuți.

Popovici Euseb (1891): Offener Brief an den Verfasser der Broschüre "Apologie der ortodoxen griechisch-orientalischen Kirche der Bucovina «, Nr. I und II, Czernowitz. Popowicz (Popovici) Eusebius (1913): Zur gr.-or. Kirchenfrage. In: Czernowitzer Allgemeine Zeitung Nr. 3322, 30.XI.1913, 1-3.

PoRumbescu Iraclie (1891): Zur administrativen Organisierung der gr.-or. Kirche in der Bucovina, Czernowitz.

PrAGHER Willy (2007): Brechungen. Rumänische Bildräume 1924-1944, Ostfildern.

Prelicz Ernst (1912): Das Salzbergwerk in Kaczyka. In: Deutscher Kalender für die Bukowina 10, Czernowitz, 101-103.

Prelicz Viktor (1904): Geschichte des Bukowiner Bergbaues. In: Deutscher Kalender für die Bukowina 2, Czernowitz, 84-93.

Procopovici Alexe (1943): La 25 de ani dela Unirea Bucovinei. In: Transilvania 74/11-12, 832-847.

Prokороwiтsch Erich (1959): Das Ende der österreichischen Herrschaft in der Bukowina (= Buchreihe der Südostdeutschen Historischen Kommission 2), München.

Рвокорошітsсн Erich (1965): Die rumänische Nationalbewegung in der Bukowina und der Dako-Romanismus (= Studien zur Geschichte der österreichisch-ungarischen Monarchie III), Graz-Köln.

Proкschi Rudolf (2007): Die orthodoxe(n) Kirche(n) in Cisleithanien. In: Drobesch et al. (Hg.), Mensch, 77-90.

Puiu Visarion (2014/1944): Însemnări din viaţa mea, Iaşi.

Pumnul Arun (1865): Privire raepede preste doue sute șese-deci și șepte de'n proprietaețile așá numite Moșiile mînaestiresci, de’n carile s'a format maerețul Fund Relegiunariu all Biséricei dreptcredincioase raesaeritene de’n Bucovina faecuta dupae adeverințe autintice pre’n Arun Pumnul Professoriu de limba și literatura rumînae la gimnasiul plenariu de’n Cernaeuţi, Cernaeuţi.

PuRICi Ștefan (1998): Mișcarea Naţionala româneasca în Bucovina între anii 17751861 (= Enciclopedia Bucovinei în Studie și Monografii 3), Suceava.

PURICI Ştefan (2001): Elitele sociale din Bucovina (sfârşitul secolului al XVIII-lea prima jumătate a secolului al XIX-lea). In: Codrul Cosminului seria noua nr. 6-7 (16-17), 197-212. 
PURICI Ştefan (2004): Iancu Flondor (1865-1924). O Viaţă în Slujba Dreptăţii. In: Codrul Cosminului X (2004), 259-270.

PUșCARIU Ilarion (1900): Metropolia Românilor ortodocşi din Ungaria și Transilvania, Sibiu.

Rychlo Petro \& Oleg Liubriwsky (Hg.) (2007): Literaturstadt Czernowitz. Autoren, Texte, Bilder, Czernowitz, 150.

\section{R}

Radics Paul von (1890): Die Reisen Kaiser Joseph II. und ihre Bedeutung für Österreich-Ungarn, besonders vom volkswirtschaftlichen Standpunkt. In: Österreichischungarische Revue N.F. 8, 241-268.

RAJŠP Vincenc (2002): Die Religionsfonds auf dem Gebiet des heutigen Slowenien und der Ankauf der Wälder in Oberkrain durch den Krainer Religionsfond. In: Šelih (Hg.), Država, 433-442.

Rauchensteiner Manfried (2013): Der Erste Weltkrieg und das Ende der Habsburgermonarchie, Wien u.a.

Regele Oskar (1949): Der österreichische Hofkriegsrat 1556-1848 (= Mitteilungen des Österreichischen Staatsarchivs, Ergänzungsband 1,1), Wien.

Rенв E RG Karl-Siegbert (1994): Institutionen als symbolische Ordnungen. Leitfragen und Grundkategorien zur Theorie und Analyse institutioneller Mechanismen. In: Göhler (Hg.) (1994), Eigenart, 47-84.

REHBERg Karl-Siegbert (2001) : Weltrepräsentanz und Verkörperung. Institutionelle Analyse und Symboltheorien. Eine Einführung in systematischer Absicht. In: Gert Melville (Hg.), Institutionalität und Symbolisierung. Verstetigungen kultureller Ordnungsmuster in Vergangenheit und Gegenwart, Köln u.a., 3-52.

REH BERG Karl-Siegbert (2002): Institutionen, Kognitionen und Symbole. Institutionen als symbolische Verkörperungen. Kultursoziologische Anmerkungen zu einem handlungstheoretischen Forschungsprogramm. In: Maurer \& Schmid (Hg.), Institutionalismus, 39-56.

Reifer Manfred (1947): Dr. Mayer Ebner. Ein jüdisches Leben, Tel Aviv.

Reinalter Helmut (2008): Josephinismus als aufgeklärter Absolutismus - ein Forschungsproblem? Gesellschaftlicher Strukturwandel und theresianisch-josephinische Reformen. In: Schmale, Zedinger \& Mondot (Hg.), Josephinismus, 19-33.

Reinalter Helmut (2010) : 1790. Tod Joseph II. Aufklärung und Josephinismus. In: Martin Scheutz \& Arno Strohmeyer (Hg.), Von Lier nach Brüssel. Schlüsseljahre österreichischer Geschichte (1496-1995), Wien, 153-165.

Reinalter Helmut (2011): Joseph II. Reformer auf dem Kaiserthron, München.

Reinalter Helmut (Hg.) (1993): Der Josephinismus. Bedeutung, Einflüsse und Wir- 
kungen (= Schriftenreihe der Intern. Forschungsstelle Demokrat. Bewegungen in Mitteleuropa 1770-1850, 9), Frankfurt a. M. u.a.

ReINHARDT Rudolf (1966): Zur Kirchenreform in Österreich unter Maria-Theresia. In: Zeitschrift für Kirchengeschichte 77, 105-119.

ReLi Simeon (1928): Politica religioasă a Habsburgilor faţă de Biserica ortodoxăromână în sec. al XIX-lea (În lumina unor acte şi documente inedited din Arhiva Casei şi curtii imperial din Viena) (= Extras din Codrul Cosminului IV 1927, Buletinul Institutul de Istorie și Limbă dela Universitatea din Cernăuţi), Cernăuţi.

ReLI Simeon (1928): Propaganda catolică austriacă împotriva bisericii ort.-române din Bucovina. Trecera la unie a sătenilor români din Boian (după acte şi documente) (= Extras din Candela Anul XXXVIII, 1927 Nr. 6-9), Czernowitz-Cernăuţi.

ReLi Simeon (1930): Raiaua Hotinului în timpul ocupaţiei austriace și legăturile ei bisericești cu Episcopia Bucovinei (1788-1792) (= Contribuție la istoria Episcopiei Hotinului) (= Extras din revista teol.bis. `Candela‘, Anul XLI/1-3, 1930), Cernăuţi.

RELI Simeon (1931): Din viaţă religioasă şi bisericească a Sucevii în secolele XVII-XIX, Cernăuți.

ReLI Simeon (1935): Mitropolitul Silvestru Morariu ca pedagog social religios al Bucovinei (= Extras din Revista de pedagogie 1935), Cernăuţi.

ReLI Simeon (1942): Istoria vieţii bisericești a Românilor, 2 Bände, Cernăuți.

ReptA Репта Владимір (1908) Лист пастырскій. Должности христіанина поступати не лишь взглядом розуму, но и седца и воле, Черновце.

REPTA Vladimir (1908): Epistola pastorală a Arhiepiscopului şi Mitropolitului v.d.R. despre datoria creștinului a înaintă nu numai în privinţa minţiii, ci şi a inimei și a voii, Cernăuţi.

Riehl Anton \& Rainer von Reinöhl (1881): Kaiser Joseph II. als Reformator auf kirchlichem Gebiete, Wien.

Rieser Herbert (1963): Der Geist des Josephinismus und sein Fortleben. Der Kampf der Kirche um ihre Freiheit, Wien.

Rit TER Sebastian (1954): Die kirchliche Vermögensverwaltung in Österreich, Salzburg. Romstorfer Karl A. (1904): Die Eröffnung der in der gr.or. Klosterkirche Putna befindlichen Fürstengräber im Jahre 1856 (= Sonderabdruck a. d. Jahrbuch des Bukowiner Landesmuseums), Czernowitz.

Roshwald A. (2001): Ethnic Nationalism and the Fall of Empires. Central Europe, Russia and the Middle East, 1914-1923, London-New York.

Rumpler Helmut (1966): Das Völkermanifest Kaiser Karls vom 16. Oktober 1918. Letzter Versuch zur Rettung des Habsburgerreiches (Österreich Archiv), Wien.

Rumpler Helmut \& Kurt ScharR (Hg.) (2015): Der Franziszeische Kataster im Kronland Bukowina. Czernowitzer Kreis (1817-1865), Wien u.a. 
Rumpler Helmut (1964) : Politik und Kirchenunion in der Habsburgermonarchie. In: Österreichische Osthefte 6/4, 302-320.

Rumpler Helmut (2007): Kirche und Staat in Österreich im 19. Jahrhundert. In: Drobesch et al. (Hg.), Mensch, 127-139.

$\mathrm{S}$

ŞAGUNA Andrei (1849): Promemoria über das historische Recht der nationalen Kirchen Autonomie der Romanen morgenländischer Kirche in den k.k. Kronländern der österreichischen Monarchie, Wien.

ŞAGUNA Andrei (1862): Geschichte der griechisch-orientalischen Kirche in Oestreich:

Bruchstücke aus der allgemeinen Kirchengeschichte des Andreas von Schaguna, Hermannstadt.

SAlomon Flavius (2006): Das Europa der Nationalstaaten versus das Europa der Minderheiten. Bemerkungen am Rande eines schicksalhaften Misserfolgs. In: Aldřich Tůma \& Jiři Jindra (Hg.), Czechoslovakia and Romania in the Versailles System, Prag, $116-130$.

SANDGRUBER Roman (1978): Österreichische Agrarstatistik 1750-1918 (= Materialien zur Wirtschafts- und Sozialgeschichte 2), Wien.

ŞANDRU Dumitru (1975): Reforma agrară din 1921 în România, București.

SÂRBU Georgi (1931) : Reflexiuni asupra administraţiei Fondului Bisericesc ort. rom. din Bucovina în trecut și în prezent, Cernăuţi.

SATco Emil (2004): Enciclopedia Bucovinei, 2 Bände, Suceava.

Schaguna Andreas Baron de (1863): Anthorismus oder berichtigende Erörterung über die Broschüre "Die Wünsche des rechtgläubigen Klerus aus der Bukowina in Betreff der kanonischen Organisierung der Diöcese und ihrer hierarchischen Stellung im Organismus der orthodox-orientalischen Kirche in Österreich. Ins Deutsche übersetzt von mehreren ortodoxen Christen romanischer Nationalität aus der Bukowina, Hermannstadt.

Schaguna Andreas Freiherr von (1860): Denkschrift, wodurch die Bitte der Romanen des orientalischen Glaubens in Oesterreich um Herstellung ihrer Metropolie aus dem Gesichtspunkte der Kirchensatzungen beleuchtet wird. Dem k.k. Ministerium für Cultus und Unterricht überreicht 1851, Hermannstadt (Das Exemplar ist in der Österreichischen Nationalbibliothek nicht nachgewiesen, liegt jedoch im Staatsarchiv in Wien vor: ÖSTA-AVA Kultus NK akat gr. or. Karton 6).

SCHARBERT Frideric (2000/1935): Problemă exploatărilor și a regenerărilor în pădurile Fondului Bisericesc Ortodox Român al Bucovinei. In: Bucovina Forestieră Anul $\mathrm{VIII} / 2,52-60$.

SCHARR Kurt (2007): Die innere Verwaltungsentwicklung der Bukowina 1775-1918 - 
Beharrlichkeit alter und Heranwachsen neuer politischer Strukturen. In: Jahrbücher für Geschichte Osteuropas 55/2, 178-209.

SCHARR Kurt (2007): Österreichische Archivalien in der Ukraine (Galizien und der Bukowina). Ein Bericht. In: Mitteilungen des Österreichischen Staatsarchivs 52, 331347.

SCHARR Kurt (2010) : "Die Landschaft Bukowina«. Das Werden einer Region an der Peripherie 1774-1918, Wien.

Scharr Kurt (2011): Czernowitz im Bild. Stadtentwicklung im Spiegel der Katastralmappen von 1820 und 1854 . In: Rumpler \& Scharr, Kataster, 39-54.

SCHARR Kurt (2011): Der griechisch-orientalische Religionsfonds in der Bukowina.

Kulturkampf und Nationalitäten im Spiegel einer Institution. In: Andres Kappeler (Hg.), Die Ukraine. Prozesse der Nationsbildung, Köln u.a., 255-268.

SCHARR Kurt (2013): Der griechisch-orientalische Religionsfonds der Bukowina als regionaler Modernisierungsfaktor. Das Beispiel Jakobeny. In: Österreich in Geschichte und Literatur mit Geographie (Themenheft Historische Regionen der östlichen Habsburgermonarchie - ein Vergleich) 57/3, 287-303.

SCHARR Kurt (2014): Fondul religionar greco-oriental din Bucovina - Bătălie Culturală şi conctruct naţional în lumina unei instituţii. In: Anuarul Institutului de Istorie „George Barițiu « din Cluj-Napoca /Yearbook of the »George Bariţiu « Institute of History of Cluj-Napoca LIII Series Historica, 227-239.

SCHARR Kurt (2014): The Habsburg Cadastral Registration System in the Context of Modernization. In: Siegrist \& Müller (Hg.), Property, 100-116.

ScharR Kurt (2016): Im Anderen das Eigene. Die außenpolitischen Ereignisse der Jahre 1905 und 1907 in der Czernowitzer Allgemeinen Zeitung. In: Jahrbücher für Geschichte Osteuropas 64, 199-227.

SCHARR Kurt (2016): Ansichten eines Unverstandenen? Der Historiker Raimund F. Kaindl (1866-1930). In: Alois Kernbauer (Hg.), Wissenschafts- und Universitätsgeschichtsforschung am Archiv. Österreichisches Universitätsarchivkolloquium 14. und 15. April 2015, Beiträge (= Publikationen aus dem Archiv der Universität Graz 45), Graz, 124-148.

Scha RR Kurt (Hg.) (2004): Die Karpaten. Balthasar Hacquet und das »vergessene" Gebirge in Europa, Innsbruck.

Schatткоvsкy Ralph, Sergij Osatschuк \& Bernadetta Wójtowicz-Huber (2009) : Kirche und Nation. Westpreußen, Galizien und die Bukowina zwischen Völkerfrühling und Erstem Weltkrieg, Hamburg.

Scнif F Walter (1898): Österreichs Agrarpolitik seit der Grundentlastung, Tübingen.

Schif F Walter (1899): Die Regulierung und Ablösung der Wald- und Weide-Servituten. In: KAst et al. (Hg.), Geschichte 1/1, 81-134. 
Schindler Ilse (1998): Zur Bedeutung der »Raths-Departements« des Hofkriegsrates: Das Departement "G« im Jahre 1795 und die Verwaltung Galizien, der Bukowina und der polnischen Wojwodschaften (= Dissertationen Universität Wien N. F. 45), Wien.

Schindle R Karl (1885): Die Forste der in Verwaltung des k.k. Ackerbau-Ministeriums stehenden Staats- und Fondsgüter, Hg. vom k.k. Ackerbau-Ministerium I. Theil, Wien.

Schindler Karl (1889): Die Forste der in Verwaltung des k.k. Ackerbau-Ministeriums stehenden Staats- und Fondsgüter, Hg. vom k.k. Ackerbau-Ministerium II. Theil, Wien.

Schindling Anton (1997): Aspekte des »Josephinismus». Aufklärung und frühjosephinische Reformen in Österreich. Ein Essay zu dem klassischen Werk Eduard Winters. In: Erich DonNERT (Hg.), Europa in der Frühen Neuzeit (= Festschrift f. Gunter Mühlpfordt zum 75. Geburtstag; Aufbruch zur Moderne 3), Weimar u.a., 683-690.

Schlichting Alfred (1883): Die ruthenische Kalenderfrage in Ost-Galzien. In: Archiv für katholisches Kirchenrecht 49, 416-420.

Schmale Wolfgang, Renate Zedinger \& Jean Mondot (Hg.) (2008): Josephinismus. Eine Bilanz, Bochum.

SснміD Ferdinand (1894): Die Vermögensgebahrung der katholischen und der griechisch-orientalischen Kirche in den im Reichsrate vertretenen Königreichen und Ländern im Jahre 1890. In: Statistische Monatsschrift 20, 225-278.

Schneider Johann (2005): Der Hermannstädter Metropolit Andrei von Şaguna. Reform und Erneuerung der orthodoxen Kirche in Siebenbürgen und Ungarn nach 1848 (= Studia Transylvanica 32), Köln u.a.

Schneider Ute \& Raphael Lutz (Hg.) (2008): Dimensionen der Moderne (= Festschrift für Christof Dipper), Frankfurt a. M. u.a.

Schорғ Franz Joseph (1835): Die Landwirtschaft in den deutschen, böhmischen und galizischen Provinzen des österreichischen Kaiserstaates. In ihrer gesetzlichen Verfassung dargestellt für Behörden und Landwirthe, Wien, 3 Bände.

Schuller zu Schrattenhofen Hermann v. (1899): Geschichtliche Darstellung der Besteuerung der Land- und Forstwirtschaft. In: KAst et al. (Hg.), Geschichte, 1/2, Wien, 935-1028.

Schultz Helga \& Angela Harre (Hg.) (2010): Bauerngesellschaften auf dem Weg in die Moderne. Agrarismus in Ostmitteleuropa 1880 bis 1960 (= Studien zur Sozialund Wirtschaftsgeschichte Ostmitteleuropas 9), Wiesbaden.

Schulze-Wessel Martin (1998): Religion - Gesellschaft - Nation. Anmerkungen zu Arbeitsfeldern und Perspektiven moderner Religionsgeschichte. In: Nordost-Archiv 7 (Konfession und Nationalismus in Ostmitteleuropa), 353-364. 
Schulze-Wessel Martin (Hg.) (2006) : Nationalisierung der Religion und Sakralisierung der Nation im östlichen Europa, Stuttgart.

Schwarz Karl W. (2007): Das Verhältnis von Staat und Kirche in Österreich. In: Zeitschrift für evangelisches Kirchenrecht 52/3, 464-494.

Sсотт Richard W. (2014): Institutions and Organisations. Ideas, Interests and Identity, Stanford.

SEIfERT Eckhart (1973): Paul Joseph Riegger (1705-1775). Ein Beitrag zur theoretischen Grundlegung des josephinischen Staatskirchenrechts (= Schriften zur Rechtsgeschichte 5), Berlin.

ŠELIH Alenka (Hg.) (2002): Država in cerkev (= Razprave. Slovenska Akademija Znanosti in Umetnosti, Razred za Zgodovinske in Družbene Vede 19), Ljubljana.

SELznick Philip (1948): Foundations of the Theory of Organization. In: American Sociological Review (Feb. 48), 13/1, 25-35.

SELznICK Philip (1951): Institutional Vulnerability in Mass Society. In: American Journal of Sociology 56/4, 320-331.

Selznick Philip (1957): Leadership in Administration, a sociological interpretation, New York.

Selznick Philip (1996): Institutionalization »Old « and »New». In: Administrative Science Quaterly 41 (June 1996), 270-277.

ŞESAN Valerian (1920): Proiect de unificare a Organizației Bisericii autocefale Ortodoxe din România întregită, Cernăuţi.

ŞEsAn Valerian (1928): Zece ani dela unirea Bucovinei cu Patria-Mamă pe terenul bisericesc. In: Nistor, Zece ani, 78-115.

Sfarghiu Vasile (2003): File din existența fondului bisericesc ortodox al Bucovinei, Câmpulung Moldovenesc.

Siegrist Hannes \& Stefan Troe в s т (2012): Einführung. Institutionenwandel und Rechtstransfer im östlichen Europa des 20. Jahrhunderts. In: Zeitschrift für Ostmitteleuropa-Forschung 61/3, 321-331.

SiEgrist Hannes (2007): Die Propertisierung von Gesellschaft und Kultur. Konstruktion und Institutionalisierung des Eigentums in der Moderne. In: Comparativ 16/5-6 (2006) (= Entgrenzung des Eigentums in modernen Gesellschaften und Rechtskulturen), 9-52.

Siegrist Hannes \& Dietmar Müller (Hg.) (2014): Property in East-Central Europe. Notions, Institutions, and Practices of Landownership in the Twentieth Century, Oxford-New York.

Simiginowicz-Staufe Ludwig (1884): Die Völkergruppen der Bukowina, Czernowitz. 
Simiginowitz-Staufe Ludwig A. (1866): Die Lippowaner in der Bukowina. In: Westermanns Monatshefte (Illustrirte Deutsche Monatshefte) 9, 652-656.

SîRBU Ciprian-Marius (2012): Episcopii Râmnicului și viaţa politică românească în perioada. In: Buridava. Studii și Materiale 10, 162-187.

Sковејко Hanna (2007): Griechisch-katholische Kirche und Multikonfessionalität in der Bukowina Ende des 19. und Anfang des 20. Jh. In: Maner \& Spannenberger (Hg.), Identität, 103-111.

Slawinski Ilona \& Joseph P. Strelka (Hg.) (1995): Die Bukowina. Vergangenheit und Gegenwart, Berlin-Frankfurt a. M. u.a.

Sölch Josef (1911/12): Tschernowitz. In: Deutsche Rundschau für Geographie 34/8, $365-369$.

Sommeregger Franz (1912): Die Wege und Ziele der österreichischen Agrarpolitik seit der Grundentlastung, Wien.

Spannenberger Norbert \& Hans-Christian Maner (2007): Konfessionelle Identität und Nationsbildung. Die griechisch-katholischen Kirchen in Ostmittel- und Südosteuropa im 19. und 20. Jahrhundert (= Forschungen zur Geschichte und Kultur des östlichen Mitteleuropa 25), Stuttgart.

SPAUN Johann Ritter von (1907): Die griechisch-orientalische Kirchenfrage in der Bukowina. Separatdruck aus der Zeitschrift `Das Österreichische Verwaltungsarchiv IV, 336-381.

Sta в B Nicolai (2011): Rumänische Kultur, Orthodoxie und der Westen. Der Diskurs um die nationale Identität in Rumänien aus der Zwischenkriegszeit (= Erfurter Studien zur Kulturgeschichte des orthodoxen Christentums 5), Frankfurt a. M. u.a.

STAN Maria (2009): Andrei Şaguna and the Organic Statute, Dissertation Universität Wien, Wien.

ŞTEFANELLI Teodor von (1911): Istoricul luptei pentru drept in ţinutul Campulungului Moldovenesc. Discurs rostit la 21 Maiu (3 iunie) 1911 de T.V.Șt. cu răspuns de D. Onciul (= Academia Română Discursuri de Recepţiune XXXVII), București.

ŞTefanelli Teodor von (1912): Chestiunea Bisericească in Bucovina (Extras din Revista »Ţară-Nouă« Nr. 7 și 8 dela 15 Aprilie - 15 Maiu 1912), Bucureşti.

ŞTEFANOVICI Olga (1996): Documente inedite din archiva personală a istoricului Ion Nistor. In: Suceava. Anuarul Muzeului Naţional al Bucovinei, anul XXII-XXIII (1995-1996), 434-452.

Steinacker Harold (1934): Die geschichtlichen Voraussetzungen des österreichischen Nationalitätenproblems und seine Entwicklung bis 1867. In: Karl Gottfried Hugelmann (Hg.), Das Nationalitätenrecht des alten Österreich, Wien-Leipzig, 1-76.

Steinbach Peter (1985): Territorial- oder Regionalgeschichte. Wege der modernen 
Landesgeschichte. Ein Vergleich der »Blätter für deutsche Landesgeschichte und des "Jahrbuchs für Regionalgeschichte«. In: Geschichte und Gesellschaft 11/4, 528-540.

Steiner Andreas Christian (2012): Die territoriale Entwicklung der Verwaltung und der Gerichtsbarkeit in den Königreichen Galizien und Lodomerien von 1848-1918, Diplomarbeit Universität Graz, Graz.

STICKLER Matthias (2012): „Die Habsburgermonarchie 1848-1918«. Ein Jahrhundertwerk auf der Zielgeraden. In: Historische Zeitschrift 295/3, 690-719.

Stimmer Gernot (1997): Eliten in Österreich 1848-1970, Wien-Köln-Graz.

Stincнсомве Arthur L. (1968): Demography of Organizations. In: American Journal of Sociology 74/3, 221-229.

Stinchсомве Arthur L. (1997): On the Virtues of the old Institutionalism. In: Annual Review of Sociology 23/1, 1-19.

Stollberg-Rilinger Barbara (Hg.) (2005): Was heißt Kulturgeschichte des Politischen? (= Zeitschrift für Historische Forschung, Beiheft 35 ).

Stourzh Gerald (1995): Der nationale Ausgleich in der Bukowina 1909/1910. In: Slawinski \& STrelka (Hg.), Bukowina, 35-52.

Stourzh Gerald (2011): The Ethnicizing of Politics and "National Indifference" in Late Imperial Austria. In: ders. (Hg.), Der Umfang der österreichischen Geschichte. Ausgewählte Studien 1990-2010, Wien u.a., 283-323.

Strohmeyer Arno (2014): Das Habsburgische Reich. Grundelemente und Bewertungen. In: Michael Gehler \& Rober Rollinger (Hg.), Imperien und Reiche in der Weltgeschichte. Epochenübergreifende und globalhistorische Vergleiche 2, Wiesbaden, 1027-1049.

STYRCA E. et al. (1864): Anruf an die hohe Staatsverwaltung in der hierarchischen und Organisationsfrage der griechisch-orientalischen Kirche in der Bukowina, Czernowitz.

SuввотIN Nikolaj I. (1899/1886): История так называемого Австрийского, или Белокриницкого священства. Вып.1, Москва.

Sundhaussen Holm \& Hans-Joachim Torke (Hg.) (2000): 1917-1918 als Epochengrenze? (= Multidisziplinäre Veröffentlichungen Osteuropa-Institut der Freien Universität Berlin 8), Wiesbaden.

Sundhaussen Holm (1993): Die "Modernisierung « der Balkanländer in vorsozialistischer Zeit: Ein Missverständnis und seine Folgen. In: Ilina Gregori \& Angelika Schaser (Hg.), Rumänien im Umbruch. Chancen und Probleme der osteuropäischen Integration, Bochum, 23-34.

Sundhaussen Holm (2000): Von der Multiethnizität zum Nationalstaat. Der Zerfall "Kakaniens « und die staatliche Neuordnung im Donauraum am Ende des Ersten Weltkrieges. In: Sundhaussen \& Torke (Hg.), Epochengrenze, 79-100. 
Sundhaussen Holm (2009): Von der Befreiung zur Marginalisierung der Bauern. Zwei Jahrhunderte Agrarreform in Südosteuropa. In: Karl-Peter Kraus (Hg.), Agrarreform und ethnodemographische Veränderungen vom ausgehenden 18 . Jh. bis in die Gegenwart, Stuttgart.

SuPPAN Arnold (2005): Herrschaft und Beherrschte in kontinentalen europäischen Imperien im Vergleich, 1700-1920 (Einleitung zu einer Projektskizze). In: Staletí objevů, diplomacie a válek. Sborník k 60. narozeninám profesora Aleše Skřivana (= Studia Historica LV), Praha, 87-104.

Suttner Ernst-Christoph (1978): Beiträge zur Kirchengeschichte der Rumänen, Wien-München.

Sut Tner Ernst-Christoph (1981): Die Toleranzgesetzgebung Joseph II. und die Orthodoxie im Habsburgerreich. In: BARTON (Hg.), Zeichen, 93-100.

Suttner Ernst-Christoph (1989): Staat aus orthodoxer Sicht. In: Servitium Pietatis (= Festschrift für Hans Hermann Kardinal Groër zum 7o. Geburtstag, Hg. v. A. Coreth \& J. Fux), Maria Roggendorf, 330-348.

Sut twer Ernst-Christoph (2007): Staaten und Kirche in der Völkerwelt des östlichen Europa. Entwicklungen der Neuzeit (= Studia Oecumenica Friburgensia 49), Fribourg.

Sut Tner Ernst-Christoph (2009): Kirche und Theologie bie den Rumänen von der Christianisierung bis zum 20. Jahrhundert (= Studia Oecumenica Friburgensia 52), Fribourg.

SzÜcs Jenö (1990): Die drei Regionen Europas, Frankfurt a. M.

T

TACкE Veronika (2010): Organisationssoziologie. In: Georg Kneer \& Markus Schroer (Hg.), Handbuch Spezielle Soziologien, Wiesbaden, 341-359.

TÂrzıU Dumitru Romulus (2010): Fețe Bisericești `Poftesc «la Bunul Public, Bunul Poporului Român. In: Revista Pădurea și viaţa 1, 49-55.

Ther Philipp (2003): Sprachliche, kulturelle und ethnische "Zwischenräume« als Zugang zu einer transnationalen Geschichte Europas. In: ders. \& Holm Sundhaussen (Hg.), Regionale Bewegungen und Regionalismen in europäischen Zwischenräumen seit der Mitte des 19. Jh., Marburg.

Tıмu Dumitru (1936): Dezastrul din administraţia fondului bisericesc ort. Rom. Din Bucovina (Interpelare desvoltată în şedinţa senatului din 16 Decemvrie 1932, publicată după M.OF. Nr. 13 din 28 Decemvrie 1932, partea III), București.

Tismaneanu Vladimir (2003): Stalinism for all Seasons, Berkeley.

Tом A Iorgu G. (1927): Fondul bisericesc orthodox român al Bucovinei în lumina legislaţiunii românești (= Retipărire după revista >Progresulk), Cernăuţi. 
Tom Ass Mark K. (2012): Religious Identity, Informal Institutions, and the Nation-States of the Near East. In: Journal of Economic Issues XLVI/3, 705-727.

TrAşCĂ Ottmar (2013): Doppelte Loyalität. Die deutsche Minderheit Rumäniens 19331940. In: Mathias Beer \& Stefan Dyroff (Hg.), Politische Strategien nationaler Minderheiten in der Zwischenkriegszeit (= Buchreihe der Kommission für Geschichte und Kultur der Deutschen in Südosteuropa 42), 211-239.

Trоввsт Stefan (2006): „Wie sind Transnistrier!«. Geschichtspolitik im Ostteil Moldovas. In: Altrichter et al. (Hg.), Erinnerung, 278-302.

TuRCZYNSKI Emanuel (1967): The national movement in the Greek orthodox church in the Habsburg Monarchy. In: Austrian History Yearbook III/3, Houston, 83-128.

TurCZynski Emanuel (1972): Gestaltenwandel und Trägerschichten der Aufklärung in Ost- und Südosteuropa. In: Erna Lesky et al. (Hg.), Die Aufklärung in Ost- und Südosteuropa. Aufsätze, Vorträge, Dokumentationen, Wien u.a., 23-49.

TuRCZYNSKI Emanuel (1976): Konfession und Nation. Zur Frühgeschichte der serbischen und rumänischen Nationsbildung (= Bochumer Historische Studien 11), Düsseldorf.

TurCZynski Emanuel (1993): Geschichte der Bukowina in der Neuzeit. Zur Sozialund Kulturgeschichte einer mitteleuropäisch geprägten Landschaft (= Studien der Forschungsstelle Ostmitteleuropa an der Universität Dortmund 14), Wiesbaden.

TuRCZYNSKI Emanuel ( $\left.{ }^{2} 1995\right)$ : Orthodoxe und Unierte. In: Adam Wandruszka (Hg.), Die Habsburgermonarchie 1848-1918 IV, Die Konfessionen, 399-478.

TuRCZYNSKI Emanuel (1996): Die kirchlichen Verhältnisse in der Bukowina als Modell einer konfliktökonomischen Integration. In: Gerhard Wilflinger \& Alfred Stirnemann (Hg.), Religion und Kirchen im Alten Österreich (= Pro Oriente XVIII), Innsbruck-Wien, 99-106.

TuRCZYNSKI Emanuel (2002): Longue durée. Kulturen und Lebensformen in Czernowitz. In: Jahrbücher für Geschichte und Kultur Südosteuropas 3, 107-115.

TurCZYNSKi Emanuel (2006): Vereine, Interessensverbände und Parteien in der Bukowina. In: Helmut Rumpler \& Peter Urbanitsch (Hg.), Die Habsburgermonarchie 1848-1918 VIII/1, Politische Öffentlichkeit und Zivilgesellschaft, Wien, 859-908.

Turnrock David (2006): The Economy of East Central Europe 1815-1989. Stages of Transformation in a peripheral region, London-New York.

U-W

UMLAUfT Friedrich (1897): Die Österreichisch-Ungarische Monarchie. Geographischstatistisches Handbuch, Wien u.a.

Ungureanu Constantin (2003): Bucovina în Perioada Stăpânirii Austriece 1774-1918, Chişinău. 
VALEnciuc Dumitru (2001): Ierarhi Bucovinei, Suceava.

Valenciuc Dumitru (2004): Visarion Puiu, Mitropolit al Bucovinei (1935-1944) un martir al Demnităţii Ortodoxe. In: Analele Bucovinei XI/1, 41-82.

VAlenciuc Dumitru (2010): Fondul Bisericesc ortodox Român din Buccovina. Probleme controversate, Câmpolung.

VALENCiUC, Ioan-Paul (2011): Preoțimea ortodoxă din Bucovina în timpul ocupaţiei Habsburgice (1775-1918), Teză de doctorat, Cluj-Napoca.

VALJAVEC Fritz ( $\left.{ }^{2} 1945\right)$ : Der Josephinismus. Zur geistigen Entwicklung Österreichs im achtzehnten und neunzehnten Jahrhundert, Wien.

VAN Meurs Wim (1999): Land Reform in Romania - A never ending story. In: SouthEast Europe Review for Labour and Social Affairs 2, 109-122.

VAN Meurs Wim \& Dietmar Müller (2014): Institutionen und Kultur in Südosteuropa. Ein Plädoyer für eine Erweiterung der Institutionenforschung. In : dies. (Hg.), Institutionen und Kultur in Südosteuropa (= Südosteuropa-Jahrbuch 39), BerlinMünchen-Washington, 7-17.

VÁRI András (2013): Ländliche Genossenschaften in der Habsburgermonarchie zwischen lokaler Eigeninitiative und Mitwirkung der Elite. In: Kubů et al. (Hg.), Agrarismus, 255-298.

VASILE Cristian (2005): Biserica Ortodoxă Română în primul deceniu comunist, București.

Vatamaniuc Dimitru (2006): Bucovina între occident şi orient. Studii şi documente. Prefaţă de acad. Ştefan Ştefănescu, București.

Vering Friedrich H. (1883): Zur Organisation der gr.-or. Kirche in Oesterreich-Ungarn. In: Archiv für katholisches Kirchenrecht 49 (Freiburg i. B.), 152-155.

VERING Friedrich H. $\left({ }^{3} 1893\right)$ : Lehrbuch des katholischen, orientalischen und protestantischen Kirchenrechts, Freiburg i.B.

Vilfan Sergij (1973): Die Agrarsozialpolitik von Maria Theresia bis Kudlich. In: Dan Berindei et al. (Hg.), Der Bauer Mittel- und Osteuropas im sozio-ökonomischen Wandel des 18. und 19. Jahrhunderts, Wien, 1-52.

VocelKa Karl (2001): Glanz und Untergang der höfischen Welt. Repräsentation, Reform und Reaktion im habsburgischen Vielvölkerstaat (Österreichische Geschichte 1699-1815), Wien.

Vog T Martin (2008): Die Erneuerung des Staates. Gedanken zur aufgehaltenen Modernisierung in der verspäteten ersten deutschen Republik. In: Ute Schneider \& Lutz Raphael (Hg.), Dimensionen der Moderne (Festschrift für Christof Dipper), Frankfurt a. M. u.a., 511-527.

Voivtschi Alexie (1919): Der bukowinaer ort. or. Religionsfond, dessen Entstehung und Verwaltung, Czernowitz. 
Voloșciuc Aurel (1932): [Krise der Waldwirtschaft in Europa]. Darea de scamăma asupra Adunării generale extraordinare a Societăţii inginerilor silvice din Ad-ţia Fondului bisericesc ort.-rom. al Bucovinei din 23 Ianuarie 1932. In: Codrii Bucovinei Revista Pădurilor Anul II/1 (Jan.), 7.

Vововет̧ Vasile (1997): Unele consideraţii cu privire la aplicarea legii Nr. 18/1991 în silvicultură raportate la prevederile condului silvic. In: Bucovina Forestieră Anul $\mathrm{V} / 1-2,36-39$.

Voroвет̧ Vasile (1999): Fondul Bisericesc și pădurile din Bucovina (1783-1918). In: Bucovina Forestieră Anul VII/1-2, 40-45.

VoroвсHIEvici Eugenie /Voroв Kevyc Jevgenij (1893): Privire Scurtă istorică-statistică asupra arhidiecezei ort. or. a Bucovinei și Dalmaţiei, Czernowitz.

VulPIUs Ricarda (2001): Ukrainische Nation und zwei Konfessionen. Der Klerus und die ukrainische Frage 1861-1921. In: Jahrbücher für Geschichte Osteuropas 49, 240256.

WANDRUSZKa Adam \& Peter Urbanitsch (Hg.) (21995): Die Habsburgermonarchie 1848-1918 IV, Die Konfessionen, Wien.

Weber Max (1922): Wirtschaft und Gesellschaft. Grundriß der Sozialökonomik, Tübingen.

WeHLer Hans-Ulrich (1996): Bibliographie zum Nationalismus. Arbeitsgruppe Nationalismusforschung, Bielefeld.

WeINZIERL-Fischer Erika (1960): Die österreichischen Konkordate von 1855 und 1933, Wien.

WEISs Karl (1923): Die staats- und volkswirtschaftliche Bedeutung der Religionsfonde österreichischen Ursprungs, Dissertation Universität Erlangen, Erlangen.

Welsch Sophie A. (1986): The Bukovina-Germans during the Habsburg Period. Settlement, Ethnic Interaction, Contributions. In: Immigrants and Minorities 5/1 (March), 73-106.

WELzK Stephan (1982): Nationalkapitalismus versus Weltmarktintegration? Rumänien 1830-1944, Saarbrücken.

Wickenhauser Franz Adolf (1890): Molda oder Beiträge zur Geschichte der Moldau und Bukowina IV, Geschichte des Bistums Radautz und des Klosters Groß-Skitt, Czernowitz.

Wischermann Clemens \& Anne Nieberding (2004): Die institutionelle Revolution. Eine Einführung in die deutsche Wirtschaftsgeschichte des 19. und 20. Jahrhunderts, Stuttgart.

Wit tLin Józef (1980/1937): Das Salz der Erde (Roman), Leipzig-Weimar.

Wolfsgruber Cölestin (1909): Kirchengeschichte Österreich-Ungarns. Mit einer Kirchenkarte von Österreich-Ungarn, Wien-Leipzig. 


\section{$\mathrm{X}-\mathrm{Z}$}

Z ACH Krista \& Cornelius ZACH (Hg.) (2004): Modernisierung auf Raten in Rumänien. Anspruch, Umsetzung, Wirkung (= Veröffentlichungen des Instituts für deutsche Kultur und Geschichte Südosteuropas 90), München.

$\mathrm{Z}_{\mathrm{ACH}}$ Krista (2009): Vergangenheitsbezug und Identitätskonstruktion in rumänischen Geschichtsnarrativen im europäischen Vergleich. In: Flavius Salomon, Krista Zach \& Juliana Brandt (Hg.), Vorbild Europa und die Modernisierung in Mittel- und Südosteuropa (= Geschichte, Forschung und Wissenschaft 29), Münster, 271-295.

Zachar Anton (1899): Der Boden der Bukowina und dessen Benutzung. Darstellung der Culturgattungen und Bodenreinerträge, sowie des Verhältnisses des Bodens zu Bevölkerung und zum Viehstande (= Mittheilungen des statistischen Landesamtes des Herzogthums Bukowina VII), Czernowitz.

ZaChar Anton et al. (1901): Die Entwickelung der Land- und Forstwirtschaft und ihrer Industrien sowie der Jagd und Fischerei im Herzogthume der Bukowina seit dem Jahre 1848 unter besonderer Berücksichtigung des Wirtschaftsbetriebes auf den Gütern des Bukowiner griechisch-orientalischen Religionsfonds. In: KAst et al. (Hg.), Geschichte, Supplementband, 41-247.

ZaChar Anton et al. (Hg.) (1902): Der Grundbesitz im Herzogthume Bukowina nach der Stellung der Besitzer und nach Grössenclassen des Besitzes, bearbeitet vom stat. Landesamte des Herzogthums Bukowina, I. Theil (= Mittheilungen des statistischen Landesamtes des Herzogthums Bukowina IX), Czernowitz.

Zaharovschi Victor (1909): Die Habsburger und die Rumänen. Eine historische Skizze, Czernowitz.

ZApolovs'кı Заполовський Володимир M. (2003): Буковина в останній війні Австро-Угорщини 1914-1918, Чернівці.

Zeene Andreas, Franz Helderich \& Josef Gruntzel (Hg.) ( $\left.{ }^{6} 1919\right)$ : Österreichische Vaterlandskunde für die oberste Klasse der Mittelschulen, Wien.

ZENKer Ernst V. (1909): Kirche und Staat unter besonderer Berücksichtigung der Verhältnisse in Österreich, Wien u. Leipzig.

ZePharovitsch V. von (1854): Mitteilungen über den Bergwerksdistrikt der Bukowina. In: Jahrbuch der k.k. geologischen Reichsanstalt Wien 4, 219-223.

Zieglauer Ferdinand von (1893-1904): Geschichtliche Bilder aus der Bukowina zur Zeit der österreichischen Militärverwaltung. Nach Quellen des k. u. k. Kriegsarchivs und der Archive im k.k. Ministerium des Inneren und des Unterrichts, 12 Bände, Czernowitz.

(1893): Dargestellt am Spiegel der Denkschriften des commandierenden Generals Freiherrn von Enzenberg.

(1895): Zweite Bilderreihe. Die Jahre 1780 und 1781. 
(1896): Dritte Bilderreihe. Die Jahre 1782 und 1783.

(1897): Vierte Bilderreihe. Die Jahre 1783 und 1784.

(1898): Fünfte Bilderreihe. Die Jahre 1784 und 1785.

(1899): Sechste Bilderreihe. Die Jahre 1785 und 1786.

(1900): Siebente Bilderreihe. Die Jahre 1785 und 1786.

(1901): Achte Bilderreihe. Das Jahr 1786.

(1902): Neunte Bilderreihe. Das Jahr 1786.

(1904): Zehnte Bilderreihe. Nachträge und Ergänzungen 1777-1786.

Zu в Iulia-Elena (2015): Traducerile legislaţiei austriece în Bucovina habsburgică (17751918), Iași. 


\section{Personenregister}

Im Register wurden auch Namensnennungen in den Fußnoten berücksichtigt, um u.a. das Auffinden der Literaturverweise im Text zu erleichtern.

Abrudan Mircea-Gheorghe 119, 123

Adanir Fikret 128

Adler F. $60,62-72$

Alesani Hieronymus Freiherrn von 166,169

Alth Alois 92

Alvirescu Gavril (?) 270

Amadei Rudolf Graf 90, 96, 135

Antonescu Ion 279f., 283, 288

Aretin Karl Otmar Freiherr v. 37, 39, 42

Bachinger Karl 314

Balan Teodor 184ff., 208, 272

Balsch Basilius 45, 47, 48ff., 55, 58f.,74, 80, 87

Bandhauer-Schöffmann Irene 40

Banică Mirel 257

Barbu Daniel 30

Beck Erich 325, 335

Bejan Demeter Ritter von 211

Bejan Dionisie (Dionys) 186f., 206, 259, $325 \mathrm{f}$.

Beland Daniel 2of., 24

Beller Steven 24

Bendel Rainer 34, 36, 152, 341, 348, 355, 363

Bendella Theophil 152, 158, 164, 166, 224, 320f., $328 \mathrm{f}$.

Benedikt Ernst 42

Berger Johannes 25

Bernhauer Elfriede 35, 41

Bernsdorf Wilhelm 18

Beust Constantin Freiherr von $308 \mathrm{f}$.

Bidermann Hermann Ignaz 38, 40, 49, 56

Bihl Wolfdieter 176

Binder Dieter 40

Bittner Franz 243

Blänkner Reinhard 27, 340, 348, 355

Blazewicz Theoctist 152f., 378

Bocșan Nicolae 119, 126, 132
Bodnariuc Dumitru 335

Böhm August 234

Boia Lucian $248 \mathrm{f}$.

Bojoi Ion 335

Boldt Hans 22

Bolovan Ioan 122

Bourguignon Friedrich 178, 185ff., 331

Brătianu Ion 254, 261, 264, 270

Bruckmüller Ernst 23, 90, 93

Brunner Otto 22, 39, 43

Brunner Sebastian 39

Brunsson Nils $19 f$.

Brusanowski Paul 50, 59, 126, 132, 156, 256, 261

Brusatti Alois 103

Bud Alexandru-Bogdan 35

Bude Heinz 30

Bühl Walter 22

Bulgaru Valeriu 290, 293f.

Büsch Otto 22

Buzila Ipolit 285

Calinescu Myron 59, 186f., 200f., 204, 206

Callimachi Gavril 46

Candea Romulus 194, 205, 212

Cantemir Dimitrie 44

Capoccia Giovanni 21

Carol II. (König von Rumänien) 271, 277-280, 373

Catargi Georg v. 92, 102, 314, 317, 322, 327

Ceaușu Mihai-Ștefan 45, 48, 51, 54, 55, 58, 88, 130 , 176,185

Ceredarec Nicolae 312

Cherescul (Herescul) Dositheus 50, 152, 153, 378

Chioveanu Mihai 255

Ciobanu Petre 268, 286

Clipa Sorin-Toader 260, 278f., 283, 286

Coca Calistrat 222 
Cohen Gary B. 212

Constantinescu Gheorghe 277f., 280

Corbea-Hoișie Andrei 169, 171, 177, 179, 184, $196,198,212$

Cotlarciuc Nectarie (geb. Nicolae) 265, 267, 269, 271

Cox Robert H. 2of.

Čučko Чучко Михаил К. 208, 210

Cuza Ioan 125, 133

Czada Roland 23

Czuperkowicz Arkadius (geb. Alexander) 7, 164, 173-176, 181, 183, 185, 187f., 19of., 193, 206

Dan Dimitri 222

Daszkiewicz Silvester 170

Dauss Markus $23 \mathrm{f}$.

Deletant Dennis 286

Denarowski Carl 329

Dickson Peter G.M. 36

Dimitrovici Silviu 261

Dinklage Karl 91

Dipper Christof 22

Doboş Filaret 292

Dobržans'kyj Oleksandr 176

Dori Popovici 261

Döring Jörg 22

Drobesch Werner 91, 112

Drunen van Jeroen 172, 203, 254f.

Durkheim Emile 19f.

Dutczak Basil 231

Economu Radu 254, 259, 293

Endletsberger Theodor 320

Endres Max 227

Enzenberg Karl Freiherr von 45-48, 50-53, 55f., $58,61,307$

Erbe Michael 22

Ersson Svante 23

Fejtö François 35

Ficker Adolf 58

Fillafer Franz Leander $35 \mathrm{f}$.

Fischer Eduard 208, 248

Flondor Iancu 125, 181, 185f., 196, 204, 249-255, 259f., 264f., 269.f, 293, 295, 346, 353, 361, 372f., 378

Florin Abraham 293

Fodor Ligia-Maria 218

Franz Hermann 35, 4off.

Franz II./I. 78, 87, 311ff., 315, 372

Franz Joseph I. 116, 173f., 213, 258

Friedenthal Felix Pino von 320

Gafiţa Vlad 191, 250, 254

Gafu Cristina 23

Găina Vasile 154, 16of., 167f., 401

Garbu Ştefan 242

Giddens Anthony 22

Giordano Christian 346, 353, 361, 369

Göderle Wolfgang 167

Goga Octavian 261, 261

Göhler Gerhard 2of., 31

Good David F. 89 f.

Gramada Ilie 285

Grămåă Ion 209

Grigorovici Radu 46, 48, 307, 308

Gross Karl 4of.

Groza Petru 280, 284f.

Grünberg Karl 89-92, 94f., 97

Grüne Niels 11, 20

Gutkas Karl 36

Guzman Eugen 98f., 101ff., 215f., 228ff., 233, 240, 242,327

Hackmann Eugen 7, 29f., 97, 115-129, $132 \mathrm{f}$., 135-140, 142-146, 15off., 155-159, 161-165, $172,213,215,217,224,320,342 \mathrm{ff}$., 35 off., $357 \mathrm{ff}$., $377 f$.

Hacquet Balthasar 47f., 308, 328

Hadbawnik Oskar 311

Halip Metelius 201, 206

Hammer Albin 143

Hanicki Gheorghe 186, 201, 206

Harre Angela 30, 171

Hausleitner Mariana 211, 246, 250, 252, 254, 261, $264,275,282,298$

Heindl Waltraud 37

Helfert Josef $39 f f$.

Heppner Harald 11, 347, 354, 362 
Herbert Baron von 78

Hinze Otto 22

Hirschhausen Ulrike von 26

Hitchins Keith 120, 122f., 176, 185, 289

Hock Carl 38, 40

Holzknecht Georgine 38

Hormuzachi (Hormuzaki) Constantin 205

Hormuzaki Alexander 125, 186

Hormuzaki Eudoxius 125,150

Hormuzaki George 125, 128, 133-136, 140, $159 f$.

Hörtnagl Friedrich 39

Huber Manfred 290

Hussarek Max v. $38-42$

Huţu Cătălin 304

Iorga Nicolae 44, 5of., 53ff., 132, 175, 186, 212 , 251f., 255, 263

Irimescu Gavril 322, 334

Jacobescu Mihai 152

Jászi Oscar (Oszkár) 248f.

Jeremijczuk Dionys 177f., 180, 202

Jetschgo Johannes 315

Joseph II./Josef II. 13, 28, 33-40, 43f., 45, 51-54, $56,58,61,88,114,122,135,145,207,227,340$, 348

Juraski Johann 316

Juravlea Dumitru 285

Kaindl Raimund Friedrich 52, 55, 58, 6of., 63, 65, 86f., 92, 101, 104, 139, 316, 375

Kalinczuk Johann $157 \mathrm{f}$.

Kappeler Andres 179

Kaps Klemens 25

Kaunitz-Rietberg Wenzel Anton von 48f., 53

Kirileanu Gheorghe Teodorescu 230

Klaube Manfred 311

Kleinwächter Friedrich 314, 318, $322 \mathrm{f}$.

Kletečka, Thomas $141 \mathrm{f}$.

Klueting Harm $38 \mathrm{f}$.

Kobylanska Olga 236

Kochanowsky Anton 320

Kolossa Tibor 93

Körber Ernest von 197

Kostin Alexander von 125, 128, 133, 136
Kovács Elisabeth 34,37

Kozak Eugen 177

Krasuski Faustin Ritter von 310ff., 322, 324, 327,

337

Krauß Franz Freiherr von 171

Kropatschek Josef 38

Lane Jan-Eric 23

Leisching Peter 35

Lemberg Hans 25

Lesky Erna 26

Leustean Lucian N. 285

Lezzeny Baron von 6 of.

Lisnic Ioan 258

Liubkiwskyj Oleg 9

Loebel Arthur 328-331

Lowndes Vivien 2off., 340, 349, 355, 364

Luceac Ilie 119, 125

Maček Jože 38

Maior Liviu 122, 248

Manastyrski Artemon 186, 201, 205-208, 210

Maner Hans-Christian 256f., 264, 274

Manolache Eusebi 14

Manz Anton von Mariensee 105, 142f., 149, 191, 232, 310-316, 319, 324, 329, 338

Marcean Mihai 14

Marcu Vasile 264

Mareci Harieta 30

Maria Theresia 34, 37f.

Martynowicz Emil $328 \mathrm{f}$.

Matei Dumitru 285

Matis Herbert 314

Maurer Andrea 20

Maurer Michael 34

Merker Nicolao 341, 348, 355, 363

Merton Robert K. 26

Michelson Paul E. 255

Mieg Friedrich von 47

Mihai Constantin 257, 264

Mihai I. (König von Rumänien) 284

Mikulicz Andreas 233

Milasch (Milaš) Nikodem 183

Mittelmann Hermann 332

Möller Wilhelm 372 
Morariu Aurel 185, 189, 261, 268, 274

Morariu Constantin 168, 260

Morariu-Andriewicz Silvester 7, 29, 119, 142, 151-156, 158, 160-173, 175ff., 183, 187, 206, $256,343,351,358,378$

Moroșan Nicolae 177

Müller Dietmar 18, 24, 89, 250, 269, 289ff., 346, $354,361,369$

Murgescu Bogdan 43, 246, 290

Mustazza Theodor von 71, 78ff., 87, 138, 372

Myrbach Franz von 136, $143 \mathrm{ff}$.

\section{Nandriş Grigore 295}

Naske Carl 322, 324

Németh Thomas M. 11, 116, 119, 128, 134f., 137

Neșciuc Eugen E. 57, 87, 142, 152f., 156, $167 \mathrm{f}$.

Nikolaj Alexandrowitsch 208

Nikolajewitsch Alexej 208

Nistor Ioan 50, 55f., 118, 129, 160, 174f., 183, 241f., 248-256, 259-265, 267-274, 276-280, 287, 292f., 295, 346, 353, 361

North Douglass $20 \mathrm{f}$.

Nubert-Chețan Mihaela 23

Offe Claus 24

Ogris Werner 34,37

Onciul Aurel C. von 178, 19off., 196, 198f., 203, $210,213,218,327,372$

Onciul Isidor von 55f., 96f., 132, 145, 147, 322

Opletal Josef 229

Osatschuk Sergij 298

Osterhammel Jürgen 25

Otruba Gustav 45

Pace Anton Graf 169, 171

Pacholkiv Savatoslav 23

Pahomi Mircea 55

Papuc Liviu 209

Pardðu Irimia 285

Pașcovici Nicolae 270

Pauli Franz 79ff.

Perrow Charles 19, 21

Petrino Otto Baron 143, 167

Petrowicz Jakob Ritter von $143 \mathrm{f}$.
Pihuliak Hierotheus $178-183,188,196-201,205$, 235

Plöchl Willibald 173

Polek Johann 46-49, 52ff., 86, $307 f$.

Ponta Victor 14

Popea Nicolae 132

Popovici Euseb(ius) 167, 181, 205

Popowicz Constantin 144, 158, 199f., 260

Pragher Willy 297

Pramberger Hugo $143 \mathrm{ff}$.

Preda Cristian 30

Prelicz Viktor 310ff.

Prodan Wasile 16of.

Prokopowitsch Erich 175, 181, 209f., 248

Prokschi Rudolf 44

Puiu Visarion 245, 258, 265, 271-274, 276-282, 354, 372 f., 378

Pumnul Arun 55f., 66, 100

Purici Ștefan 30, 25of., 254

Rajšp Vincenc 35,40

Rauchensteiner Manfried 249

Regele Oskar 22

Regner von Bleyleben Oktavian $212 \mathrm{f}$.

Rehberg Karl-Siegbert 19-25, 340, 348, 355

Reifer Manfred 255

Reinalter Helmut 34f., 37

Reinhardt Rudolf 38

Reinöhl Rainer von 42

Reis Effendi 78

Reli Simeon 153f., 211

Repta Wladimir von 7, 29, 173, 175f., 183, 186f., $193 \mathrm{ff}$., 197ff., 202ff., 206-211, 213ff., 222, 240, 243ff., 251, 258-262, 264f., 267, 274, 287, 344, $352,359,361,378$

Riegger Paul Joseph 39

Riehl Anton 42

Rieser Herbert 39

Ritter Sebastian 37, 40

Romstorfer Karl A. 310

Rosenkranz Moses 9

Rumpler Helmut 52, 89, 91, 94, 249, 290

Rychlo Petro 9 
Şaguna Andrei/Schaguna Andreas von 30,

119-128, 132f., 162, 342, 350, 357

Sandgruber Roman 90, 232, 235, 237

Şandru Dumitru 289f., $292 \mathrm{ff}$.

Sandru George 260

Sarbu Georgi 26of., 267f., 292, 335

Sârbu Georgi 26of., 267f., 292, 335

Satco Emil 119, 152, 176, 178, 186, 267, 282

Scharr Kurt 3, 25ff., 43f., 48, 53, 57, 62, 71, 81, 87,

$89,91,94,100,118,122,151,167,216,225 f$.,

239, 244, 255, 265, 285, 290, 307f., 315, 336, 341,

$349,356,364,375$

Schiff Walter 94f., 97, 99

Schindler Ilse 23

Schindler Karl 99f., 215

Schindling Anton 34f., 37, 42

Schmid Michael 20

Schneider Johann 117, 123, 127

Schönbach Anton 129ff., 158, 162f., 320

Schulze-Wessel Martin 117, 121

Schwarz Karl W. 40

Scott Richard W. 22

Seger Martin 89

Seifert Eckhart 39

Selznick Philip 18ff., 30

Şesan Valerian 256, 260, 265

Sieghart Rudolf 312

Siegrist Hannes 24, 342, 349, 357, 365

Simedrea Tit 282

Skedl Arthur 184, 187

Smal-Stockyj Stephan 118, 176, 178, 180

Sölch Josef 89

Spannenberger Norbert 11, 34, 36, 341, 347f.,

354f., 362f., 391, 402, 410, 424f.

Spaun Johann Ritter von 192f., 203

Splény Gabriel Freiherr von Miháldy 45, 47f., 307

Staab Nicolai 257

Stan Maria 119

Ștefanelli Teodor von $204 f$.

Ştefanovici Olga 279

Stephanowicz Kajetan 231-234, 237

Stinchcombe Arthur L. 21, 31

Stöger Michael 86

Straucher Benno 196, 235

Styrcza Emanule 123, $125 \mathrm{ff}$.
Sundhaussen Holm 25, 249, 403, 426f.

Suppan Arnold 25

Suttner Ernst-Christoph $44 \mathrm{f}$.

Taaffe Eduard Graf von 155, 170, 372

Tacke Veronika 19

Theodorowna Alexandra 208

Theodorowna Maria 208

Thielmann Tristan 22

Timu Dimitru 268, 271, 273

Tismaneanu Vladimir 286

Tittel Ignac 215, 220, 232

Toma Iorgu G. 268

Troebst Stefan 24, 342, 349, 357, 365

Turcan Victor 285

Turczynski Emanuel 44, 117, 122, 124, 154, 176

Tyminski Titus 210

Umlauft Friedrich 89

Ungureanu Constantin 167

Valenciuc Dumitru 258, 261, 264, 271f., 282

Valenciuc, Ioan-Paul 110, 250

Valjavec Fritz 34f., 37f., 42, 44

Meurs van Wim 18, 24, 293

Vasile Cristian 285

Vilfan Sergij 89, 112

Voda Cuza 261

Vogt Martin 23

Voloșciuc Aurel 268

Vorobchievici Eugenie/ Vorobkevyc Jevgeni 154

Vorobchievici Ipolit 210, 260, 265, 267

Wagner Rudolf 311f., 315

Wallnig Thomas 36

Walter Bruno $321 \mathrm{f}$.

Wassilko Nikolai Ritter von 125, 176f., 181ff., 185 ,

187f., 196-199, 201, 211

Wassilko Victor Baron 211

Wassilko-Serecki Georg Baron 194, 196, 232

Weber Max 18f., 26

Welsch Sophie A. 311

Wickenhauser Franz Adolf 49, 51-56, 58, 61, 77, 375

Wiglitzky Hubert 310 
Winkler Markus 4, 11

Wittlin Jozef 209

Wlachowicz Daniel 54

Zachar Anton 91, 93, 96, 318

Zapolovs'kij Заполовський Володимир М. 207
Zeehe Andreas 89

Zenker Ernst V. 39

Zhishman Josef von 116, 119, 128, 134ff., 142

Ziblatt Daniel 21

Zieglauer Ferdinand von 45-50, 55, 137

Zurkanowicz Johann 158, 164f. 


\section{Synoptische Ortsnamenkonkordanz}

Die Aufstellung der Ortsnamen wie Toponyme orientiert sich methodisch an der bereits 2010 erschienen Arbeit über die Landschaft Bukowina. Das soll mithin die Verbindung beider Monographien erleichtern. Den Nennungen von Toponymen (d.h. Orts- und fallweise auch Flurnamen) bis zum Ende der österreichischen Periode im Jahr 1918 liegt die Schreibweise der letzten Volkszählung von 1910 zugrunde. Mit 1918 werden zumeist die rumänischen Entsprechungen aus den amtlichen Kartenwerken herangezogen, sowie analog dazu zur Verortung der Siedlungen in der Nordbukowina nach 1939/44 und 1991 die russischen bzw. ukrainischen. Wurden hingegen abweichende Ortsnamen aus bestimmten Quellen für Tabellen etc. übernommen, so ist dies eigens in den Fußnoten angemerkt.

Die kyrillischen Toponyme wurden in ihrer jeweils aktuellen Form transkribiert, ihnen folgt die Schreibweise im Ukrainischen (bzw. Russischen), danach steht die Rumänische (das gilt v.a. für die Zwischenkriegszeit) und zuletzt findet sich (was die historische Bukowina betrifft) die "Österreichische« bis 1918 gültige Schreibweise nach der Volkszählung von 1910. Sind die ukrainische (in Transkription) und die österreichische Schreibweise identisch, steht vor dem Landeskürzel (=). Die Landeskürzel orientieren sich nach den gültigen Autokennzeichen, also >RO ‘ für die Republik Rumänien. Für jene Orte, die erst nach 1918 zur Bukowina hinzukamen, gibt es keine österreichischen Entsprechungen. Das wird mit (-) markiert. Eine eventuelle österreichisch-rumänische Schreibgleichheit ist mit $\left.{ }^{*}\right)$, eine rumänisch-ukrainische/russische mit (\#) hervorgehoben; diese werden daher auch nicht wiederholt. International übliche Bezeichnungen wie Lemberg, Czernowitz oder Bukarest sind als Exonyme beibehalten worden. Historische Regionen sind kursiv gesetzt und werden keinem Staat zugeordnet.

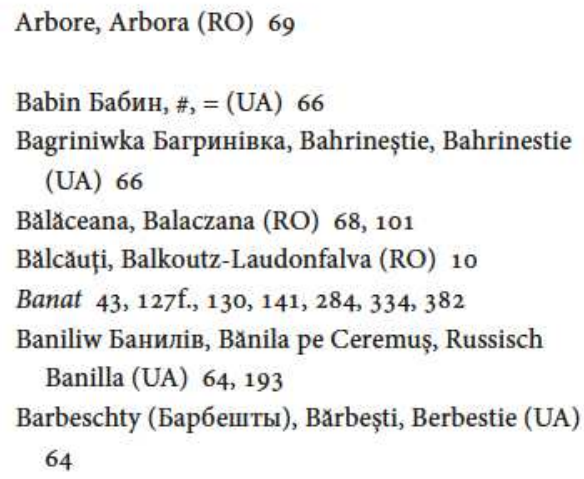

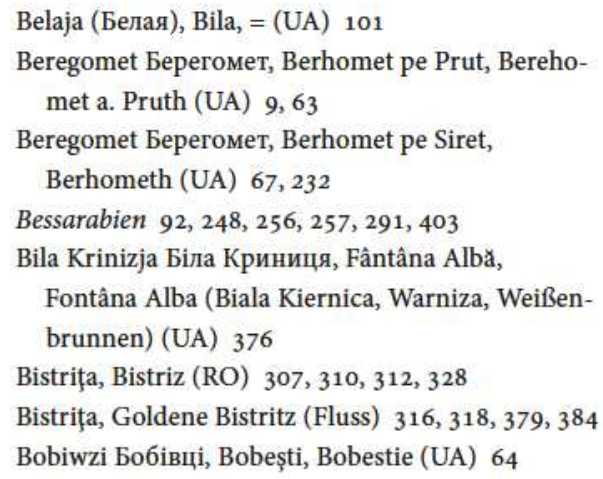


Bojantschuk Боянчук, Boianceni, Bojanczuk (UA) 65

Boriwzi Борівці, Borăuţi, Boroutz (UA) 66, 276

Botoşani (RO) 76

Breaza, Breaza (RO) 103, 300

Brest (Брест), Brest-Litowsk (BY) 124

Bridok Брідок, Vadul-Nistrului?, Brodok (UA) 84, 96,104

Brodina 220, 300, 303

Broskiwzi Stari Старі Бросківці, Broscăuţii Vechi, Alt Broschkoutz (UA) 63

Bucșoaia, Bukschoja (RO) 312

București, Bukarest (RO) 14, 16, 27, 31f., 115, $207,212,214,223,238 f f ., 246,249-257,259$, 261f., 264, 269ff., 276, 279f., 282-287, 289-293, 295, 298f., 303, 331, 334f., 342, 345f., 357, $360 f$., $372 f$., $378,380,383,385 f$., $388,390,392 f$., $397 f f$., 401f., 404f., 407, 409ff., 413f., 416, 421, 425, 427, 429

Buda Буда, * , = (UA) 84, 100,

Budenez Буденець, Budeniț, Budenitz (UA) 67

Bukschoja s. Bucșoaia (RO) 312

Burdei (Бурдей), Bordei, Burdey (UA) 104

\section{Căbești bei Kostinzi 87}

Cacica, Kaczika/Kaczyka(RO) 148

Câmpolung Moldovenesc, Moldauisch Kimpolung (RO) $173,290,292,294,304,310,373,424 f$., 428

Cârlibaba, Kirlibaba, Mariensee-Kirlibaba/Ludwigsdorf (od. Lajosfalva) (RO) 103f., 299, 308, 311f., 314ff., 326, 381, 384

Cernăuţi s. Czernowitz 160, 165, 225f., 262, 267, $272,275,280,283,290 f ., 294 f f ., 298 f f ., 303,334$, $360,373,375,378,384 f$., $389 f$., $395-398$, 400 ff., 404, 409, 411, 414-417, 419ff., 424, 427

Chișinău (MD) 428

Chliwischtsche Хлівище, Clivești, Chliwestie (UA) $63,65,83$

Chotin Хотин, \#, Hotin (UA) 75, 153, 257, 271f., $282,291,294,420$

Chotyner Raya 71, 75, 377

Chreschtschatik Хрещатик, Crișceatec, Kryszcatek (UA) 66
Ciocanești, Czokanestie (RO) 69, 85, 103, 148, $312,336,379$

Ciprian Porumbescu, Stupka (RO) 70

Cisleithanien 29, 91, 93, 150, 212, 215, 230, 246, $310,408,413,418$

Climauți, Klimoutz (RO) 101, 376

Clit, Glitt (RO) 148

Cluj-Napoca (dt. Klausenburg, ung. Koloszvar) (RO) 16, 129f., 132, 155, 209, 392, 394ff., 403, $410,414,422,428$

Czernowitz (ukr. Tscherniwzi/Чернивці, rum. Cernauți, russ. Tschernowzi/Черновцы) (UA) -

Dalmatien $89,116,120,152 f$., $173 f$., $183,194,208$, $226,237,411$

Dawydowzy (Давыдовцы), Davidești, Dawidestie (UA) $52,65,104,220$

Deutschland 391, 411, 415

Dichtinez Дихтенець, Dihteniţ, Dichtenitz (UA) 64

Dimka Димка, Trestiana, */Dymka (UA) 67

Dnister (Fluss) 52, 100, 237, 246f., 378

Dobriniwzi Добринівці, Dobronăuţi, Dobronoutz (UA) 65,77

Dorna Candrenilor, Dorna Candreni/Kandreny (RO) $85,103,299,312$,

Dornești, Dornestie (RO) 69

Dorohoi (RO) 76, 291, 294

Doroschiwzi Дорошівці, Dorosăuţ, Doroschoutz (UA) 66

Dowgopillja Довгопілля, Câmpulung pe Ceremuș, Dolhopole/Russ. Kimpolong (UA) 64

Dragomirna (RO) 54f., 66, 70, 84, 101, 110, 152, 210, 217

Dratschinzi Драчинці, Drăcinet,, Draczynetz (UA) 64

Dubowzi Дубівці, Dabăụi, Duboutz (UA) 63

Eisenau s. Prisaca Dornei (RO) $103,315,324 \mathrm{ff}$.

Eisenthal s. Iacobeni 293, 297-300, 305, 333ff., 359,398

Enns (Fluss) 40

Falticeni (RO) 76 
Frankfurt 127, 307, 388, 394, 399, 401, 408f., 411, $413,415,417,419,423,425,427,429$

Frasin, Frassin (RO) 69f. 102, 148, 220, 299, 312

Frătăuţi (Noi), Fratautz (RO) 56, 68, 73, 86f., 102, $104,220,299,376$

Fürstenthal s. Voivodeasa $103,148,220$

Galaţi (RO) 77,271

Galizien-Lodomerien 25, 45, 57, 92, 114, 124, 140, $172,183,307,318,344$

Gawrilowzy Гавриловцы, Gavrilești, Hawrylestie (UA) $63,65,84$

Gliboka Глибока, Hliboca, Hliboka (UA) 67

Glinizja Глиниця, Hliniţa, Hlinitza (UA) 64

Goretscha Гореча, Horecea Liuzii/Mănastirea Horecea, Horecza (Manastioarea od. Vorstadt)

(UA) 62,132

Gorizia/Nova Gorica, Görz (I/SLO) 40

Goroschiwzi Горошовци, Horosăuţi, Horoschoutz (UA) 65

Gradisca, Gradiska (I) 40

Gura Humorului, Gurahumora (RO) 69, 85, 102, $148,291,298 \mathrm{f} ., 312$

Gura Putnei, Karlsberg (RO) 102, 220, 311

Hadikfalva bei Dorneşti 102

Humora (Kloster) (RO) $68-71,85$

Humoreni, Ludihumora (RO) 68, 84, 102

Iacobeștie, Jakobestie /Fogodisten (RO) 67

Iași, Jassy (RO) 46, 48ff., 53, 61, 69ff., 77f., 8of.,

$87,254,257,271,282,293,303,329,372,395 \mathrm{ff}$., $399,405 f$., 411, 418, 432

Iaslovați, Jaslowetz (RO) 69, 84, 102

Ilișești, Illischestie (RO) $299 \mathrm{f}$.

Innsbruck (A) 11, 20, 259, 347, 354, 362, 370, 382, 39of., 393, 398f., 404-407, 422, 428

Ischiwzi Цૈжівці, Igești, Idzestie (UA) 67

Ispas, Icnac, \#, = (UA) 64

Istanbul, Konstantinopel, Stambul (TY) 44, 71, 78,81

Ițcani, Itzkany (RO) 70, 84, 87, 101

Iwankiwzi Іванківці, Ivançuţi, Iwankoutz (UA)

63
Iwano-Frankiwsk Івано-Франківск, Stanislau

(UA) 210

Jablunizja Яблуниця, Iablonița, Jablonitza 64, 240 Jakobeni s. Jacobeni 25, 112, 143, 149, 293, 297 , 299f., 306, 308, 316, 333ff., 398

Jordaneschti Йорданешти, Iordanești, Jordanestie (UA) 67,104

Jurkiwzi Юрківці, Iurcăuti, Jurkoutz (UA) 65

Kabestie bei Kostinz 64

Kadubiwzi Кадубівці, Cadobești, Kadobestie (UA) 63

Kalitschanka Калічанка, Calicianca, Kaliczanka (UA) 218

Kalnowzy, (Кальновцы), Călinești pe Derelui, Kalinestie (UA) 64

Kamjana Кам'яна, Camena, Kamena (UA) 62

Karaptschiw Карапчів, Carapciu pe Ceremuş, Karapcziu 64, 67

Kiew (UA) 43, 118, 151, 271, 280

Kiseliw Киселів, Chisălău, Kisseleu (UA) 63

Kizman Кіцмань, Chiţmani/Cosmeni, Kotzman

(UA) 52, 56, 65, 83f., 100f., 104, 106, 111, 119, $148,186,201 \mathrm{f}$, 210, 220, 376

Klokutschka Клокучка, Clocucica, Klokuczka (UA) 218

Kolomija Коломия, -, Kolomea (UA) 56

Komariwzi Комарівці, Comarești, Komarestie (UA) $67,70,125$

Koritne Коритне, Vilaucea, Willawcze (UA) 64 Korowija Коровія, Corovia, Korowia (UA) 62, 100 Kortschiwzi Корчівці, Corcești, Korczestie (UA) 66,104

Kostinzi Костинці, Costești, Kostestie (UA) 64

Kostrischiwka Кострижівка, Luca, Luka (UA) 87 , 259

Krasnoilsk Красноїльськ, Crasna Ilschi, KrasnaIlski/Krasna Putna/Krasna (UA) 67, 104f., 148

Kremnica, Kremnitz (SK) 408

Kulewzi (Кулевцы), Culauţi, Kuleutz (UA) 66

Kupka Купка, Cupca, $=($ UA) $67,104,148$

Kut (Кут), Cotul Bainschi, Kotul Bainsky (UA) $103 \mathrm{f}$. 
Lechutscheny (Лехучены), Lehacenii-Tăutului, Lehuczeny-Teutului (UA) 63

Lemberg (ukr. Lviv/Львів, poln Lvóv, russ. Lvov/ Львов) (UA) 25, 47, 51, 57, 76, 79f., 83, 87, 92, $105,110,138,140,152,157,167,172,204,218$, 229, 307, 308, 314, 316, 318, 376, 382, 391

Lenkiwzi Ленківці, Lenţești, Lenkoutz (UA) 63, 84,101

Lipoveni, Lipoweni (RO) 70

Liteni, Litteny/Liteni (RO) 71

Lucăcești, Lukaczestie (RO) 103

Lukawzi Лукавці, Lucavațul de Jos/de Sus pe Siret, Lukawetz a. Sereth (UA) 67,125

Lukowizja Луковиця, Lucaviţa, Lukawitza (UA) 62 Luschani Лужани, Lujeni, Lużan (UA) 63

Magala Магала, Mahala, * (UA) 62, 84, 376

Malij Kutschuriw Малий Кучурів, Cuciurul Mic, Kuczurmik (UA) 65

Maljatinzy (Малятинцы), Malatineţi, Malatynetz (UA) 65

Mamaeschti (Мамаешты), Mămaeștii Noi, NeuMamajestie (UA) 84, 104, 148, 240

Mamaiwzi Мамаївці, Mămăștii Vechi, Alt-Mamajestie (UA) $63,84,104,119,148,158,240$

Mamorniza (Маморница), Mamorniţa, Mamornitza (UA) 62

Mănastioara, St. Onuphri (RO) 60

Maramureş (Marmarosch, Maramuresch) 282

Marginea, Mardzina (RO) $84,102,148,220,300$

Marinitschi Мариничі, Măriniceni, Marenicze (UA) 64

Michajliwka Михайлівка, Mihuceni, Mihuczeny (UA) 66

Miliewe Міліэве, Milie, Millie (UA) 64

Milișăuţi, Milleschoutz (RO) 69, 85, 87, 102

Mitocu Dragomirnei, Mitok-Dragomirna/Mitoka

Dragomirna (RO) 70, 84, 101, 152, 210

Moldovița, Russisch Moldawitza (RO) 299f., 303, 312

Moldowa, Moldau (Fluss) 312

Molnizja Молниця, Molniţa, Molnitza - (UA) 67

Molodija Молодія, Mologhia vel Plaiul Cosminu-

lui, Molodia (UA) 62,100

Moskau (RU) 118, 151
Musorowka (Мусоровка), Mosoreni, Mossorówka (UA) 66

Mytkow (Мытков), Mitcău, Mitkeu (UA) 66, 104

Neamţ (RO) $77,280,282$

Nepolokiwzi Неполовівці, Nepolocăuţi, Nepolokoutz (UA) 63

Nischni Petriwzi Нижні Петрівці, Pðtrăuţii de Jos pe Siret, Petroutz a./ (UA) 67

Nischni Staniwzi Нижні Станівці, Stăneștii de Jos pe Ceremuș, Unter-Stanestie a./ (UA) 64, 66

Nou Solonețu, Neu Solonetz (RO) 68, 102

Nowa Krasnoschora Нова Красношора, Crăsnișoara Nouð, Neu-Hütte (UA) 104

Nowa Schadowa Нова Жадова, Jadova Noua, Neu Żadowa a. Sereth, (UA) 67

Nowa Schutschka Нова Жучка, Jucica Nouð, NeuZuczka (UA) 101

Nowi Wowtschinez Нови Вовчинець, Volcineţii Noi, Wolczynetz (UA) 66

Nowoselizjа Новоселиця, Noua Suliţă, Nowoselitza (Stroiești d. jos) (UA) 77

Onut Онут, \#, Onuth (UA) 66

Oprischeni Опришени, Oprișeni, Oprischeny (UA) 67,101

Orschiwzi Opшівці, Orasşeni, Oroscheny (UA) 63,76

Oschichlibi Ошихліви, Osehlib, Oschechlib (UA) 65

Ostrizja Остриця, Cotul-Ostriţei, Kotul Ostritza (links d. Pruts) (UA) 84, 100f., 292, 376

Paltinoasa, Paltinossa (RO) 102

Panka Панка, Panca, $=($ UA) 67

Pătrauți, Petroutz (RO) 55, 70, 84, 101, 148, 300

Petritschanka (Петричанка), Petriceni, Petriczanka (UA) 104

Pjadikiwzi П’ядиківці, Piedecăuţi, Piedykoutz (UA) 63

Ploska Плоска, Plosca, $=($ UA) 64, 220

Pogoriliwka Погорілівка, Pohorlauți, Pohorloutz (UA) 65

Poiana Stampei, Pojana Stampi (RO) 149,312 
Pojorâta, Pożoritta (RO) $85,103,148,299 f ., 312$, 314f., 322, 324, 326

Polen 129, 160, 167, 334, 417

Prag (CZ) 209f., 222, 241, 386, 403f., 421

Priliptsche (Прилипче), Prelipcea, Prelipcze (UA) 66

Priworoki Привороки, Prevoroche, Preworokie (UA) 66

Prut Прут, Pruth (Fluss) 52, 86, 237, 303

Putila Путила, \#, Putilla (UA) 64, 186, 201

Putna, Putno (RO) 50, 54f., 62, 66-69, 76, 103 , $110,132,173,217,220,300,303,390,396,420$

Råăuti, Radautz (RO) $13,46,48-51,56,60 . f, 68$, $76,79 f ., 86,100,102,106,111,137,143 \mathrm{f}$., 153 , $163,168,181,183,193,210,220,222,260 f ., 267$, $282,290,294,304,373,383,388 \mathrm{ff}$., 392, 414, 417,430

Rarău (Berg) (RO) 243f., 378

Repuschiwzi Репуживці, Răpujineți, Repużynetz (UA) 66

Rewakowzy (Реваковцы), Revăcauti, Rewakoutz (UA) 63

Rewno Ревно, Revna pe Prut, Rewna (UA) 299 f. Ridkiwzi Рідківці, Rarancea, Rarancze (UA) 63 , 232

Roman (RO) 219, 271, 329,

Roptscha Ропча, Ropcea, Ropcze (UA) 67

Roscha Poшa, Roșa, Rosch (UA) 62, 218

Rostoki Розтоки, Rastoace, = (UA) 65

Russland 141, 208, 252, 280, 307, 372, 407, 415

Sadgora Садгора, Sadagura (inkl. Rohozna), Sadagóra (UA) 63,78

Sadowa Садова, \#, Sadova (UA) 52, 69, 85, 103

Sadubriwka Задубрівка, Zadobreni, Zadobrowka (UA) 65

Salischtschiki Заліщики, Zaleschiki, Zallesczyki (UA) 44

Samostja Замостя, Zamostea, Zamostie/Zamosce (UA) $64,84,87$

Samuschin Самушин, Sămușeni, Samuszyn (UA) 66

Sastawna Заставна, Zastavna, Zastawna (UA) 66 Satu Mare, Satulmare (RO) 69, 87, 102, 220
Schepit Шепiт, Șipotele Sucevei, Schipot (UA) 103

Schipinzi Шипинці, Șipeniţ, Schipenitz 63

Schischkiwzi Шишківці, Șișcăți, Schischkoutz (UA) 66

Schpetki (Шпетки), Sălasseni?, Szpetki (UA) 64

Schubranez Шубранець, Șubraneți, Schubranetz (UA) 65

Seleniw Зеленів, Zeleneu, * (UA) 64

Selennij Gaj Зелений Гай, Seliștea?/Gogolina, Gogulina (Stroiești d. s.), Zelennij Ga (UA) 63

Seljatin Селятин, Seletin, * (UA) $64,103,220,300$ Sf. Ilie, St. Illie (RO) 52, 56, 68ff., 84, 86, 101, 106, 111,376

Siebenbürgen (rum. Transilvania/Ardeal, dt. Transsilvanien, ung. Erdely) 35, 43, 119f., $122 \mathrm{ff} ., 127 \mathrm{f}$., 134f., 150, 155, 162, 248ff., 256, 269, 294, 306ff., $343,346,373,382$ f., $388,392,394,410,416,418$, 423

Siret, Sereth (RO) $68,100,110,218,376$

Slatina (RO) $63,66,71$

Sloboda Baniliw Слобода-Банилів, Slobozia Bănilei, Slobodzia-Banilla (UA) 64,

Sloboda Komariwzi Слобода Комарівці, Slobozia Comareștilor, Komarestie-Slobodzia (UA) 125

Sloboda Redkiwzi Слобода Редківці, SloboziaRarancea, Rarance-Slobodzia (UA) 63

Slobodka (Слободка), Slobozia-Berlinților, Slobodzia-Berlince (UA) 67,101

Slowenien 419

Solca, Solka (RO) $299 \mathrm{f}$.

Sremski Karlovci (dt. Karlowitz) (YU) 54, 58, 116, 12of., 123, 126ff., 164, 213

St. Petersburg, Petersburg, Petrograd, Leningrad (RU) 203

Stara Krasnoschora Стара Красношора, Crăsnişoara Veche, Alt Hütte 104

Stara Schadowa Стара Жадова, Jadowa Vechi, Żadowa (UA) 67

Stara Schutschka Стара Жучка, Jucica Veche, AltZuczka (UA) 63, 101

Starij Wowtschinez Стариі Вовчинець, Volcineț, Wolczynetz (UA 66

Stawtschani Ставчани, Stauceni, Stawczan (UA) $65,76,83$

Stebni Стебні, \#, Stebne (UA) 64 
Stertsche (Стерче), Prisaca?, Slobodzia Styrcze

(UA) $67,101,125$

Storoschinez Сторожинець, Storojineţ,

Storożynetz (UA) 290, 294, 373

Stulpicani, Stulpikany (RO) $267,299,312$

Suceava, Suczawa (RO) 11, 13f., 50, 54, 70, 100, $103,110,152,218,248,284,290,294,298,304$, 313f., 319, 324, 329f., 335, 374f., 380, 385, 389, 392f., 395f., 400, 405, 412, 416, 418, 421, 425 , 428

Sucevița, Suczawitza (RO) $54,68,75,84,102,217$, 220, 235

Suchowerchiw Суховерхів, Suhoverca, Suchowerchów (UA) 52, 65, 83, 104, 220

Sutscheweni Сучевени, Suceveni, Suczaweny (UA) 104

Swenjatschin Звенячин, Zvineace, Zwiniacze (UA) 66

Terebletsche Тереблече, Tereblecea-Nouă, Deutsch u. Rumänisch Tereblestie (UA) $67,87,101,148$

Teschen, Český Těšin (CZ), Cieszyn (PL) 145, 314, 324,327

Ţibeni, Istensegits (RO) 101

Tihuța, Borgo (Pass) (RO) 308, 310

Timișoara, Temesvar (RO) 394

Tirol (A) 93, 243, 391

Toporiwzi Toпорівці, Toporauţi, Toporoutz (UA) 63,148

Towtri Товтри, Tauteni, Toutry (UA) 63

Transleithanien 29

Tschagor Чarop, Ceahor, Czahor (UA) 62, 100, 152, 154f., 240

Tschernyj Potok (Чёрный Поток), Pârâul-Negru, Czarnypotok (UA) 66

Tschorniwka Чорнівка, Cernauca, Czernawka (UA) 65

Tschudej Чудей, Ciudei, Czudyn (UA) 67, 104, $299 f$.

Tschunkiw Чуньків, Cincău, Czinkeu (UA) 66

Ukraine $14,27,176,374,380,393,398 f ., 403$, 405f., $421 f$.

Ungarn 40, 113, 127f., 134, 171, 184, 213, 307, $390 f ., 397 f ., 406,415,419,423,429 f$.
Ust-Putila (Усть-Путила), Gura Putilei, Uście Putilla (UA) 64

Valea Putnei, Waleputna (RO) 85, 103

Vama, Wama (RO) 69f., 85, 103, 111, 148, 299f., 312,324

Vatra Dornei, Dorna Vatra (RO) $8,17,54,69$, $85,103,112,148,209,240,279,282 \mathrm{ff}$., $292 \mathrm{f}$., 295, 298ff. 303, 306f., 309, 311ff., 315, 317, 319, 321ff., 325, 327-339, 379, 398, 409, 410

Vatra Moldoviței, Watra Moldawitza, Freudenthal (RO) $69,85,103,315,320,324,326$

Vicovu de Jos, Oberwikow (RO) 300

Vicovu de Sus, Unterwikow (RO) 299

Vorarlberg (A) 40, 184, 232, 240

Vorniceni, Josephfalva/Joseffalva/Tolova (RO) 76 , 103

Voroneţ, Woronetz (RO) $53,55,69,71,85,102$, 291,312

Walachei 43, 394

Walja Kusmina Валя-Кузьмина, Valea-Cosminului, Franzthal (UA) 148, 227, 388, 401, 405, 411, $418 \mathrm{f}$.

Waljawa Валява, Valeva, Walawa (UA) 65

Waschkiwzi Вашківці, Vașcăuţi pe Ceremuș, Waschkoutz (UA) 65

Wasiliw Василів, Vasilau, Wassileu (UA) 66

Waslowiwzi Васловівці, Vaşsłauţi, Wasloutz (UA) 65,116

Welikij Kutschuriw Великий Кучурів, Cuciurul Mare, Kuczurmare (UA) $299 f$.

Welikoselje (Великоселье), Pilipăuți, - (UA) 77

Werbiwzi Вербівці, Verbauți, Werboutz (UA) 65

Wikno Вікно, Ocna, Okna (UA) 66

Wischnizja Вижниця, Vijniţa, Wiżnitz (UA) 64, 201

Witiliwka Витилівка, Vintileanca, Witelówka (UA) $65,83,104$

Woloka Волока, Voloca pe Derelui, $=(\mathrm{UA}) 62,64$, 100,148

Zuren Цурень, Țureni, Zurin (UA) 62,230 
Im Zuge der Josephinischen Reformen kam es zur Auflösung von Klöstern und zur grundlegenden Umgestaltung kirchlichen Eigentums. Kurt Scharr analysiert den Bukowiner Religionsfonds in seiner Bedeutung für die Gestaltung, Entwicklung und Nationalisierung der Region sowohl als Teil der Habsburgermonarchie als auch Großrumäniens. Darüber hinaus bietet diese Monografie einen überraschend neuen Einblick in ein vernachlässigtes Forschungsfeld, weit über die Region hinaus.

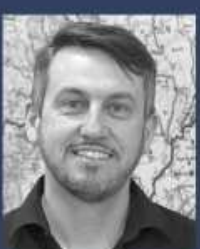

Kurt Scharr ist Universitätsprofessor für Österreichische Geschichte an der Leopold-Franzens-Universität Innsbruck. 